The Impact of Customer Relationship Management (CRM) Technology on Business-to-Business Customer Relationships

\author{
By \\ James Edward Richard \\ A thesis \\ submitted to Victoria University of Wellington \\ in fulfillment of the requirements for the degree of \\ Doctor of Philosophy \\ in Marketing
}

Victoria University of Wellington

August 2008 


\begin{abstract}
Recent academic and practitioner studies suggest that Customer Relationship Management (CRM) provides improved business opportunity, yet has received mixed performance reviews in the extant literature. This research explored the relationship between CRM technology adoption, market orientation and relationship marketing, and the subsequent impact on business relationships and relationship performance.

A conceptual model was developed based on the literature and information obtained through one-to-one in-depth interviews. The model incorporated key relationship constructs; trust, commitment and communications quality, and investigated the impact of CRM technology adoption on these constructs and relationship performance. In addition the firm's market and technology orientation was considered as critical antecedents to the adoption of CRM technology. The research incorporated a twophased, cross-sectional design. The first research phase was exploratory, utilising oneon-one in-depth interviews with key informants. The objective was to explore the conceptualised CRM technology adoption - customer relationship model for robustness and realism. These findings were used to refine the CRM technology adoption customer relationship model and the measurement instrument before proceeding with the explanatory phase of the study.
\end{abstract}

The explanatory phase of the research consisted of an instrument development stage - creating, testing and finalising the research instrument, followed by a quantitative study of medium and large business in the manufacturing, services and wholesale industries in New Zealand. The objective of this stage of the research was to test and validate the CRM technology adoption - customer relationship model and measurement instruments. Measures of CRM technology adoption were collected from the supplier firms, while measures of relationship strength and relationship performance were collected separately from the customer perspective.

The benefits for practitioners include methods to improved relationship and business performance from CRM technology implementation. The key benefit for academia is the development of a conceptual model linking CRM technology to RM, and providing insights into the synergies available from technology. 


\section{ACKNOWLEDGEMENTS}

I would like to express my sincere gratitude to all those who supported me with this project. First and foremost I would like to dedicate this thesis to my wife, Claire, for her patience and never-ending support. When I was down she was there to pick me back up, when I needed a smile she gave it to me, when I was sad she made me laugh, and when I needed to share, she was there to share it with.

I also wish to thank my supervisors, Professor Peter Thirkell and Professor Sid Huff, for the time, effort and advice freely given to me throughout the project. Through them I have learned much and will forever be in their debt for their support and patience.

Throughout the project there were a variety of people who played different roles to support me, to those I need to give a special thanks - Val Lindsay, Nick Ashill, Ashish Sinha, James Wiley, Jacqui Fitzgerald, the Critical Thinking in Marketing seminar group (Nicole, Jayne, Janine, Kate, Aaron and Nick), and many others too numerous to name. I would also like to thank Victoria University of Wellington, the Faculty of Commerce and Administration, and the School of Marketing \& International Business for their financial support of this research.

Finally, to my parents, Nada and Lawrence, I owe both of them sincere thanks, for providing me the environment and opportunity to experiment, learn and grow at my own pace. 


\section{TABLE OF CONTENTS}

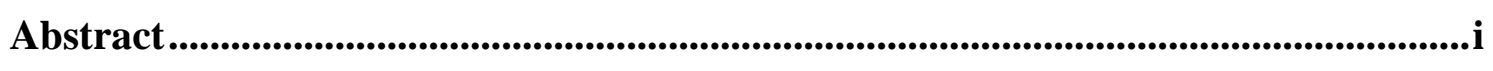

Acknowledgements....................................................................................................................ii

List of Tables ............................................................................................................................viii

List of Figures................................................................................................................................

CHAPTER 1. Introduction........................................................................................1

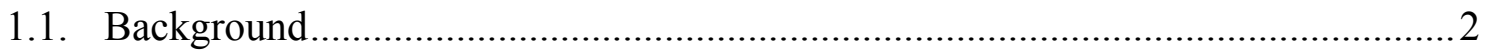

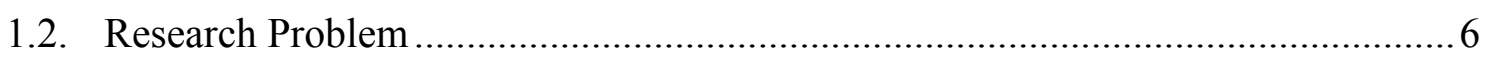

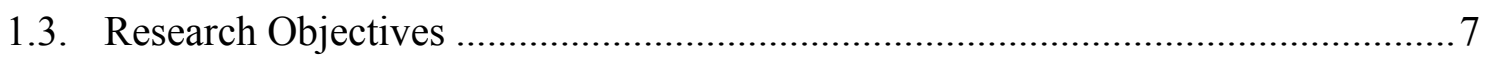

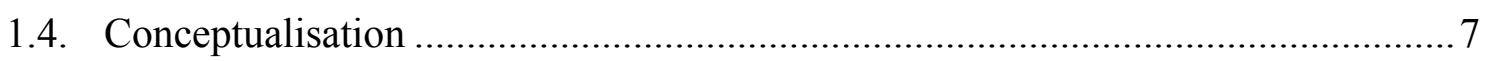

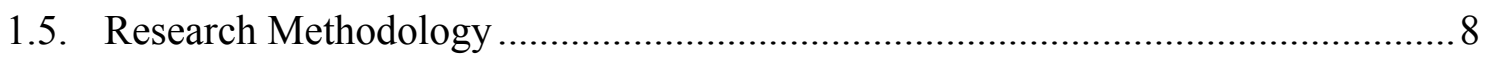

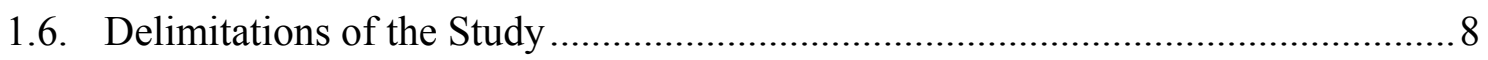

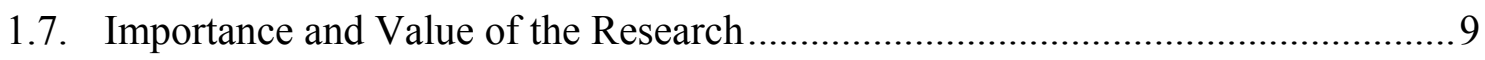

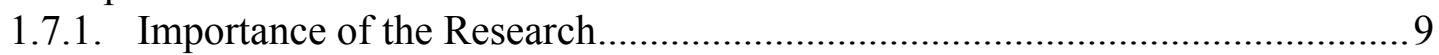

1.7.2. Value of the Research for Academics.......................................................... 10

1.7.3. Value of the Research for Practitioners ........................................................ 10

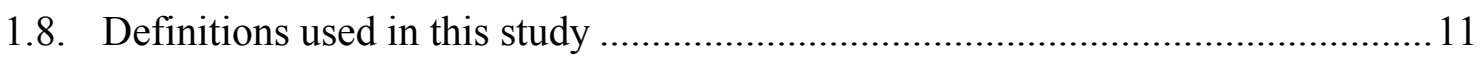

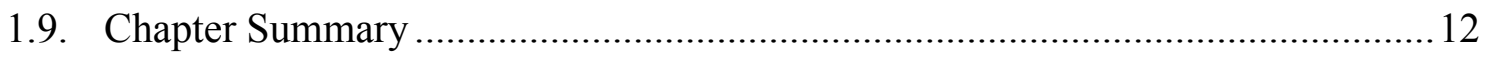

CHAPTER 2. Literature Review ...............................................................14

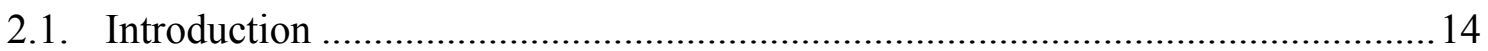

2.2. Relationship between Information Technology and Marketing ............................16

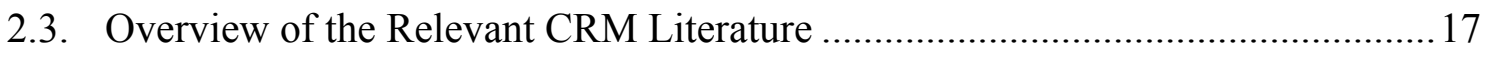

2.4. Evolution of Relationship Marketing ………………………………………...19

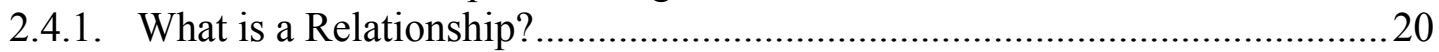

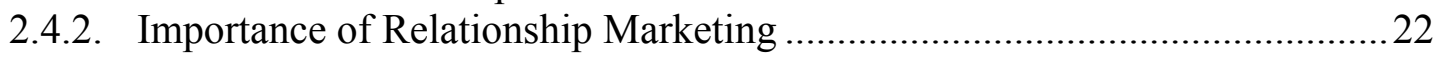

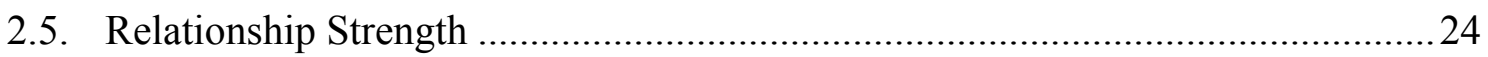

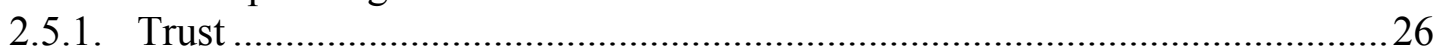

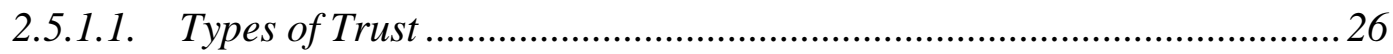

2.5.1.2. Findings from Trust Research .......................................................... 28

2.5.2. Commitment...................................................................................

2.5.2.1. Defining Commitment......................................................................... 31

2.5.2.2. Findings from Commitment Research ....................................................32

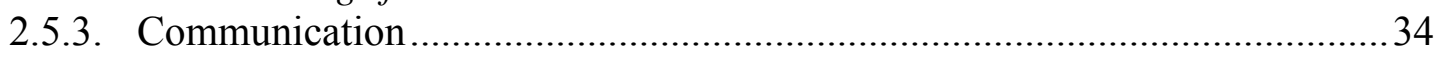

2.5.3.1. Defining Communication in the Context of Relationships ........................34

2.5.3.2. Findings from Communication Research.................................................35

2.5.4. Other Characteristics of Relationship Marketing............................................38

2.5.4.1. Customer Satisfaction........................................................................ 38

2.5.4.2. Cooperation ....................................................................................... 39

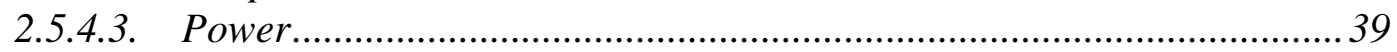

2.5.4.4. Performance of Duties......................................................................... 40

2.5.4.5. Dependency .................................................................................... 41

2.5.4.6. Duration....................................................................................... 


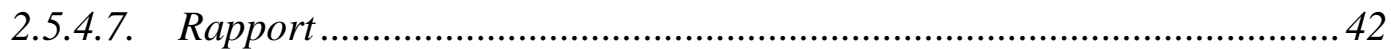

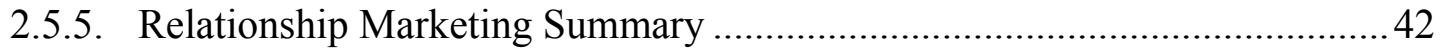

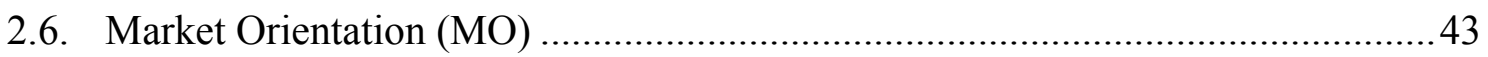

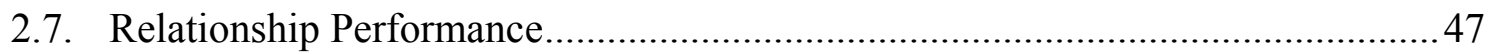

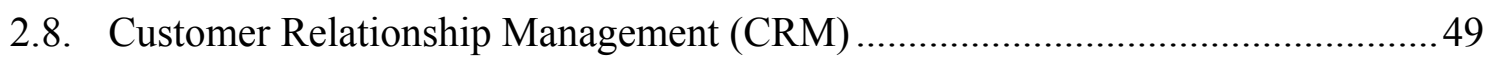

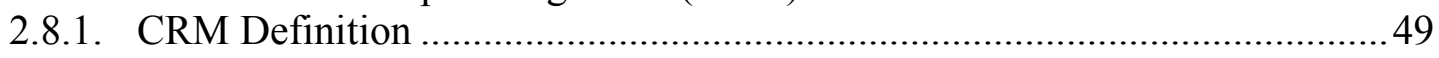

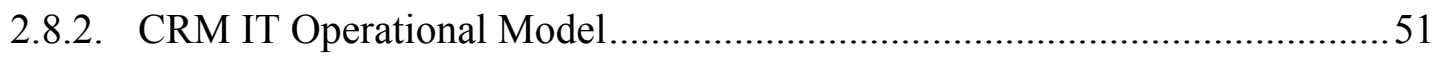

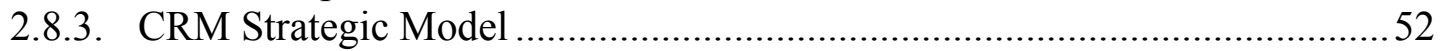

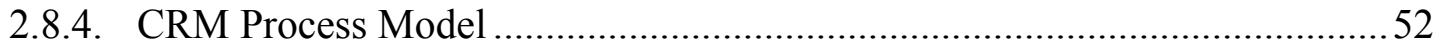

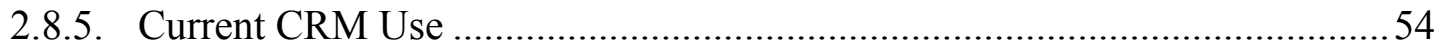

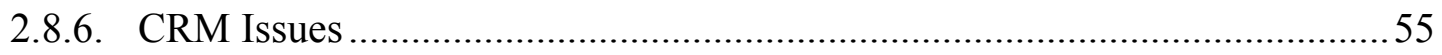

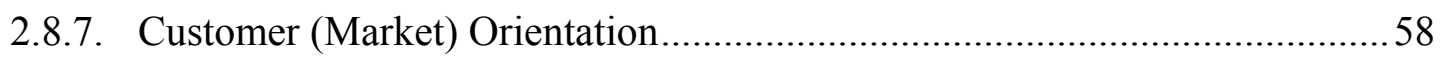

2.8.8. Information Technology Management.......................................................59

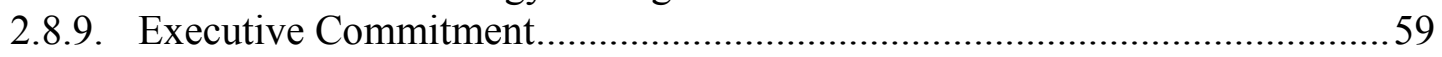

2.8.10. Integration of People, Process and Technology ...........................................6 60

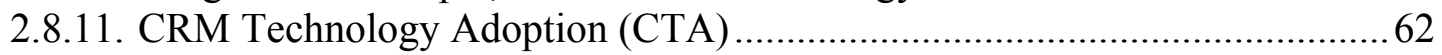

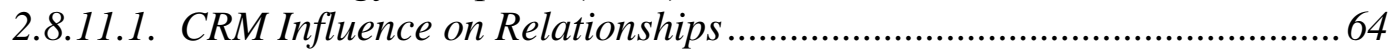

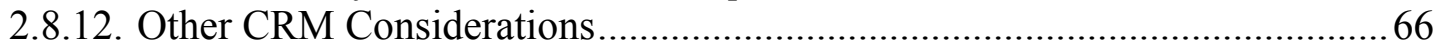

2.9. Customer Relationship Orientation and Customer Expectations .........................67

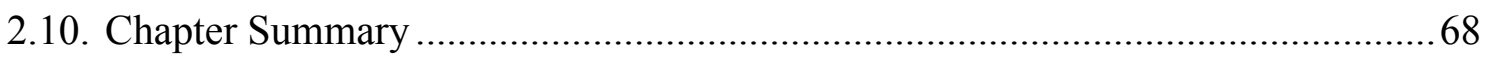

CHAPTER 3. Research Model and Hypotheses...................................................... 72

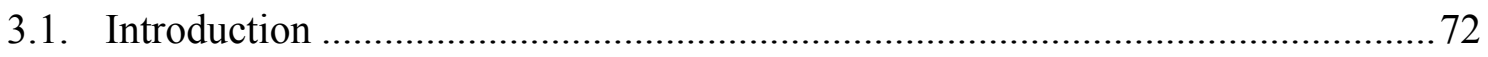

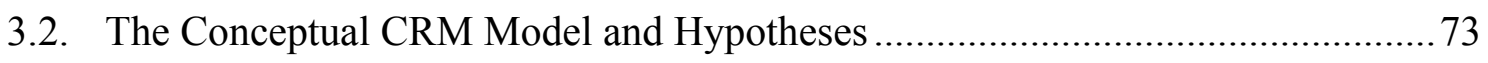

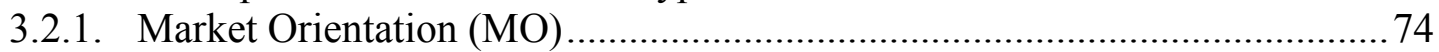

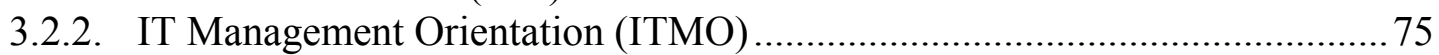

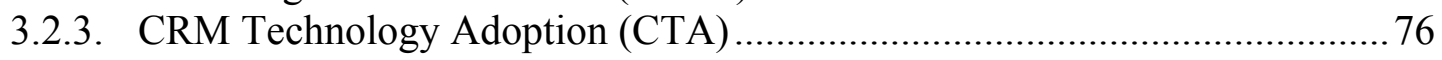

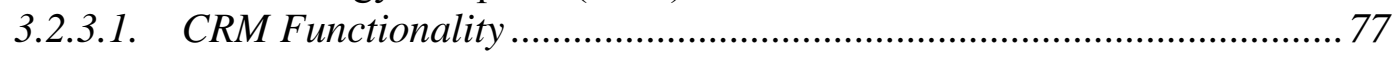

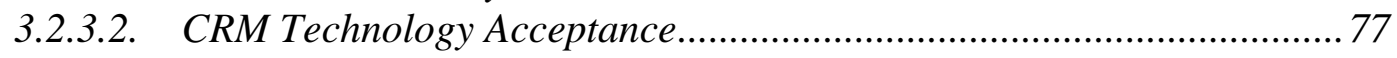

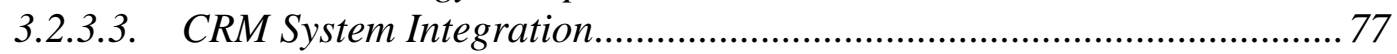

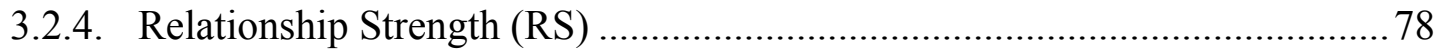

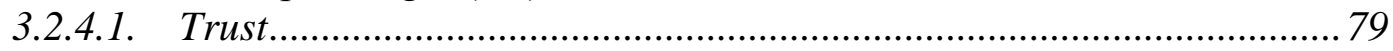

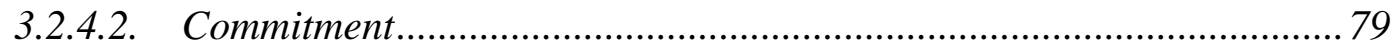

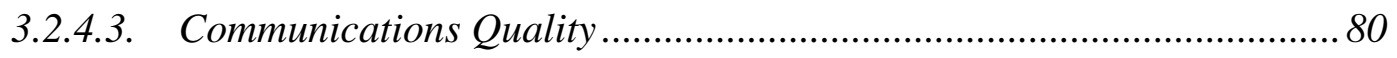

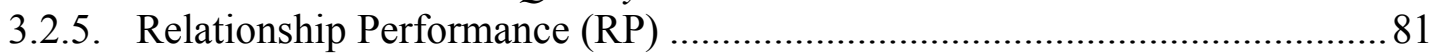

3.2.6. Moderator and Control Factors (secondary hypotheses) ............................. 82

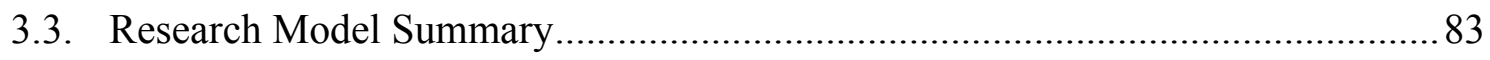

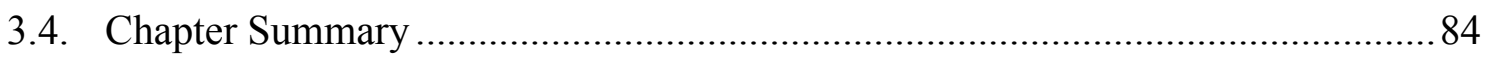

CHAPTER 4. Research Methodology .............................................................................8 85

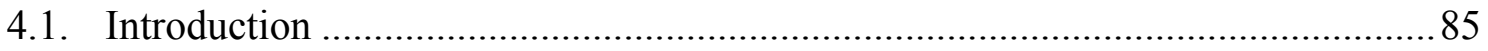

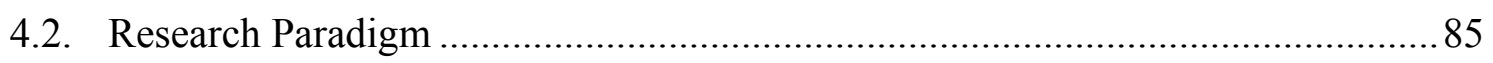

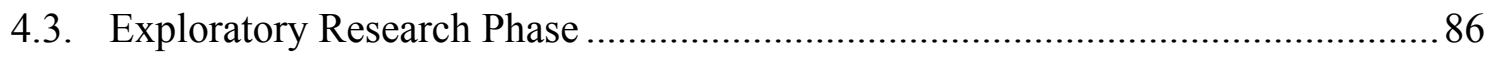

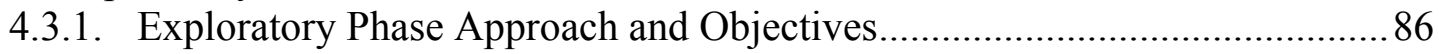

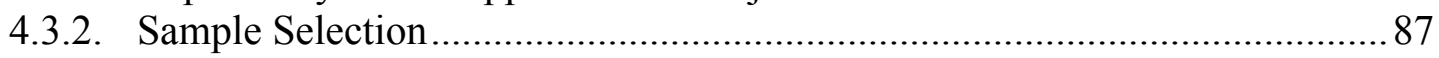

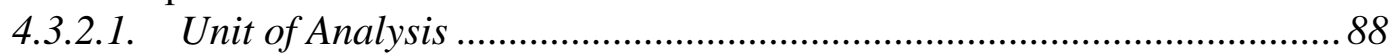

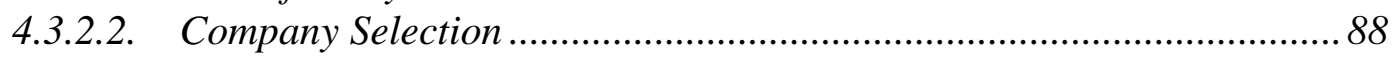

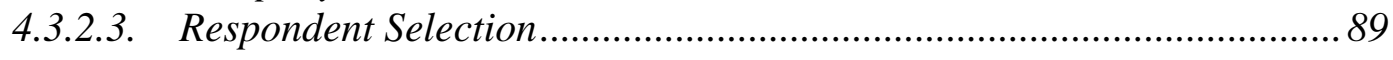




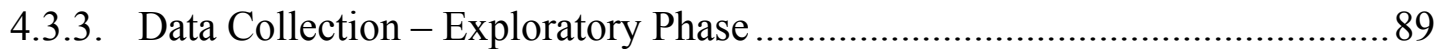

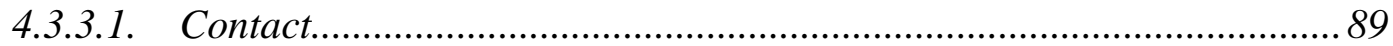

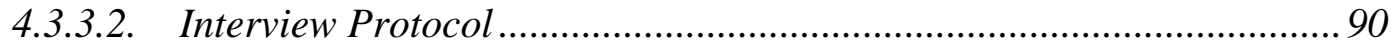

4.3.4. Participation Rate and Respondent Profile ................................................. 90

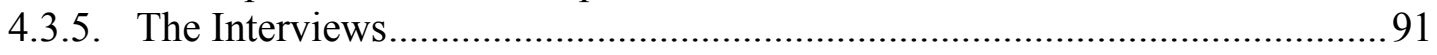

4.3.6. Exploratory Data Analysis Procedure ........................................................ 91

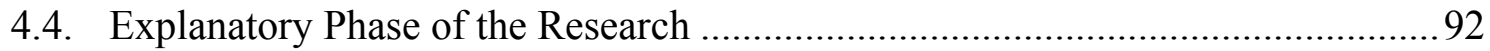

4.4.1. Explanatory Phase Approach and Objectives ............................................ 92

4.4.2. Overview of Research Design................................................................. 93

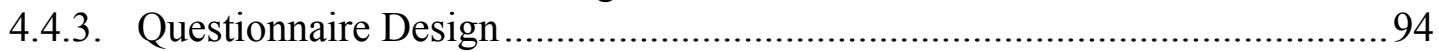

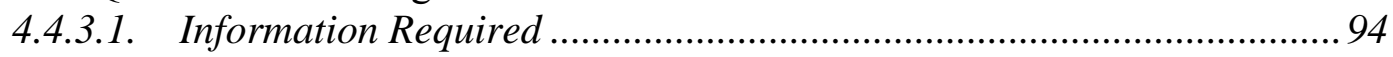

4.4.3.2. Type of Questionnaire and Method of Administration ........................... 95

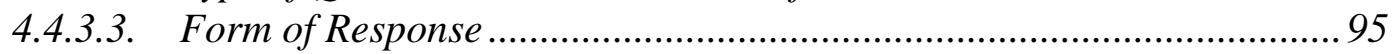

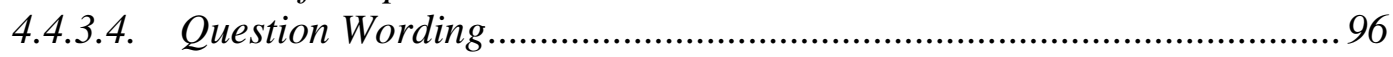

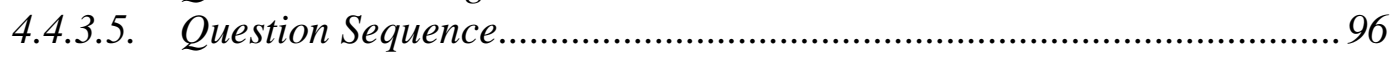

4.4.3.6. Physical Aspects of the Questionnaire ................................................ 96

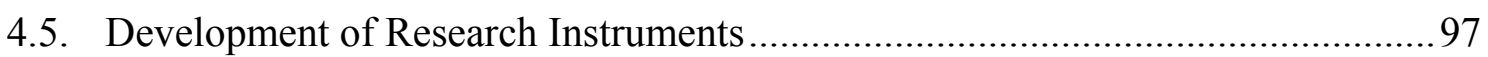

4.5.1. Overview of Research Instrument Development .......................................97

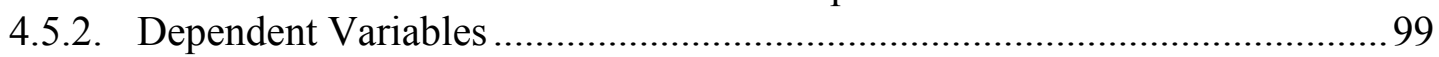

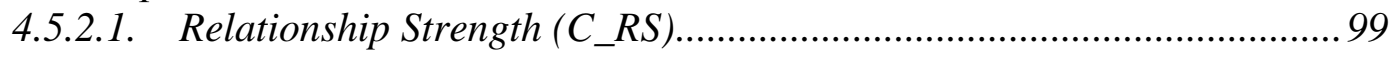

4.5.2.1.1. Measurement of Trust (C_RT) ............................................ 100

4.5.2.1.2. Measurement of Commitment (C_CMT)..................................100

4.5.2.1.3. Measurement of Communications Quality (C_CQ) .................. 101

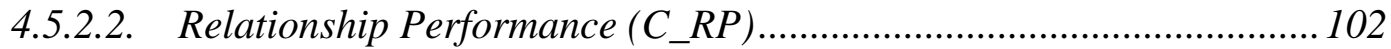

4.5.2.2.1. Measurement of Perceived Performance (C_PR) ..................... 102

4.5.2.2.2. Measurement of Relationship Satisfaction (C_RSA) .................102

4.5.2.2.3. Measurement of Loyalty (C_LY).......................................... 103

4.5.2.2.4. Measurement of Customer Retention (C_RN) ......................... 103

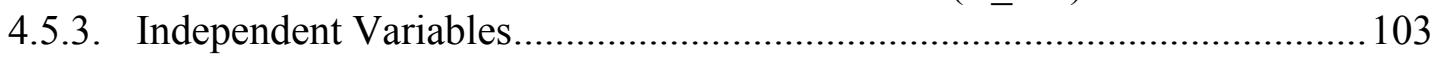

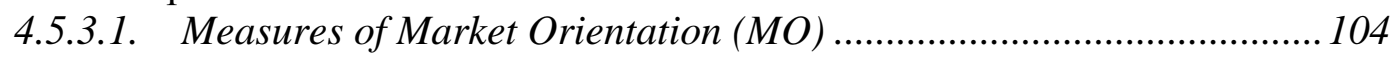

4.5.3.2. Measures of IT Management Orientation (ITMO)............................... 104

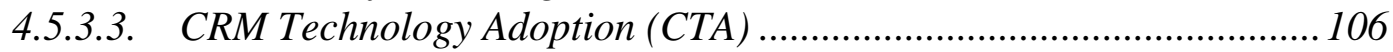

4.5.3.3.1. Measurement of CRM Functionality (CFN) ............................ 107

4.5.3.3.2. Measurement of CRM Technology Acceptance (CRA) ............ 109

4.5.3.3.3. Measurement of CRM System Integration (CSI)...................... 111

4.5.4. Moderator and Control Variables ............................................................. 112

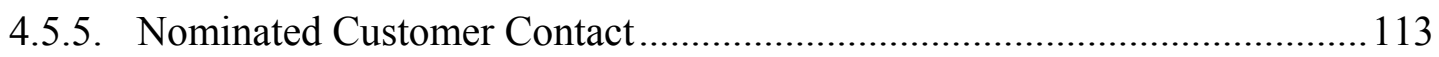

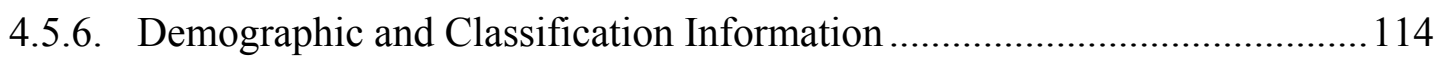

4.5.7. Data Collection for Instrument Refinement and Verification....................... 114

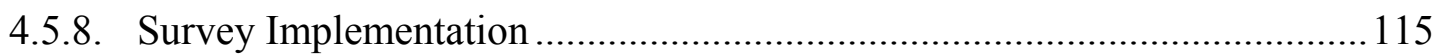

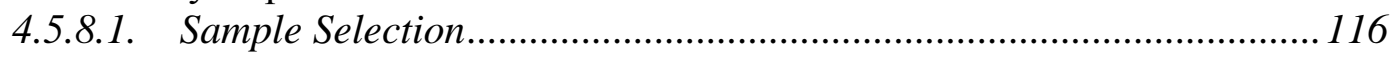

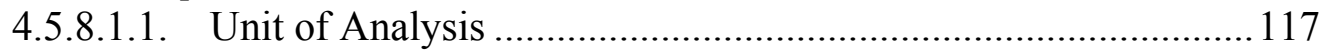

4.5.8.1.2. Company and Respondent Selection........................................ 117

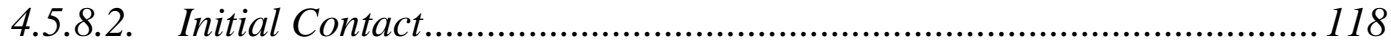

4.5.8.3. Cover Letter and Mail-out .............................................................. 118

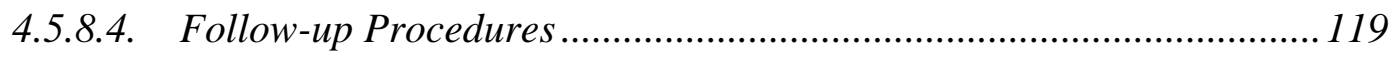

4.6. Data Analysis and Hypothesis-testing Procedures ............................................. 119

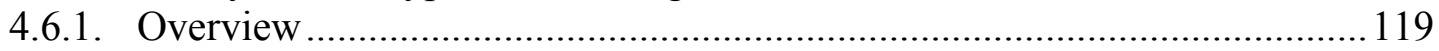

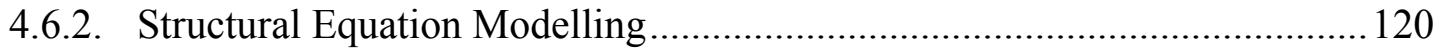

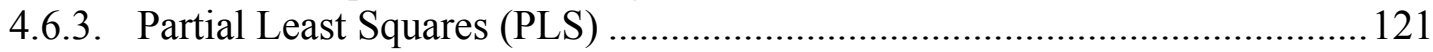


4.6.3.1. Confirmatory Factor Analysis (CFA) ................................................. 123

4.6.4. Exploratory Factor Analysis (EFA) …................................................... 123

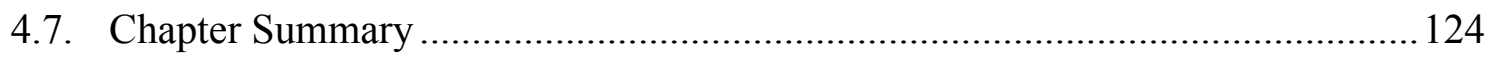

CHAPTER 5. Data Analysis and Results....................................................125

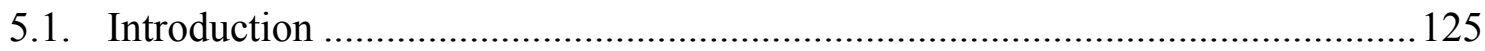

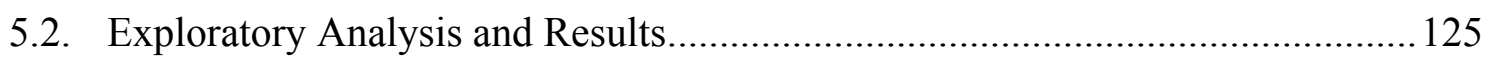

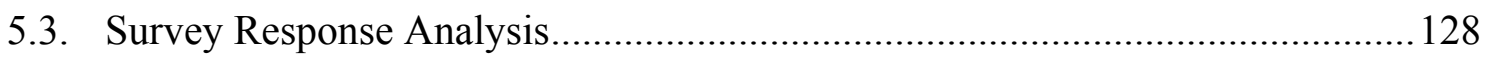

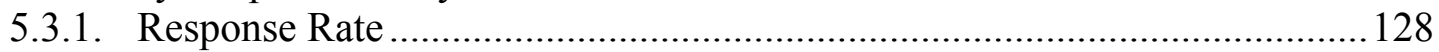

5.3.2. Respondent and Demographic Profiles.................................................. 131

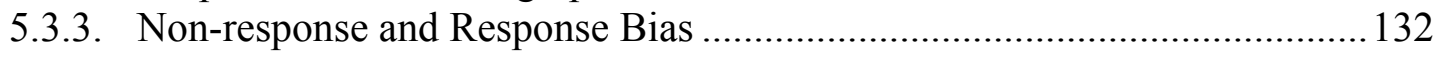

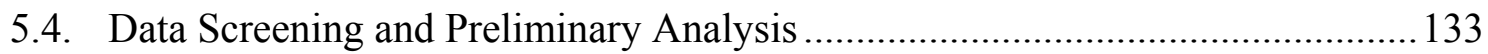

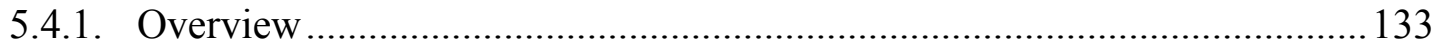

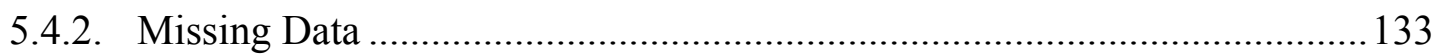

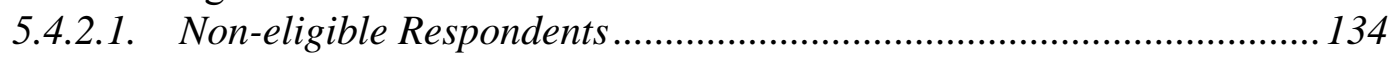

5.4.2.2. “Do not know” Response - IT Management Orientation section........134

5.4.3. Assumptions Underlying Statistical Procedures ........................................ 135

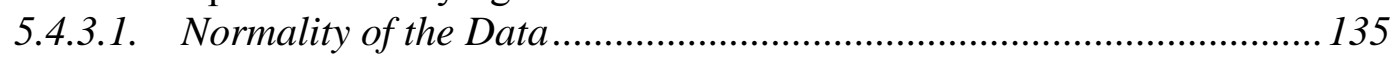

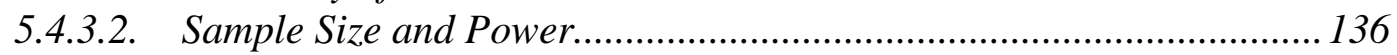

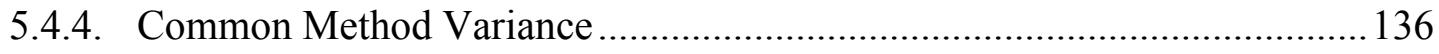

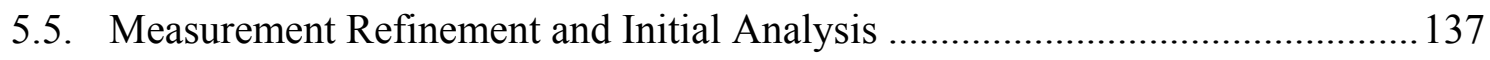

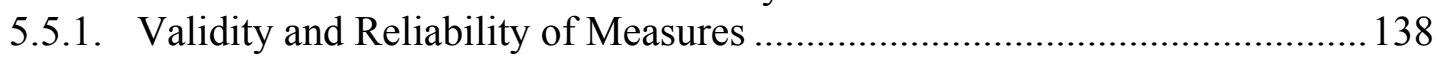

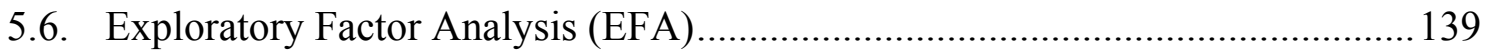

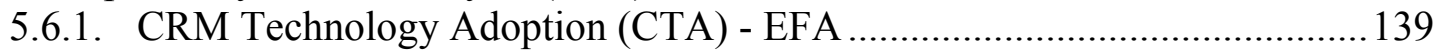

5.6.1.1. Final CTA 2-Factor Construct .........................................................141

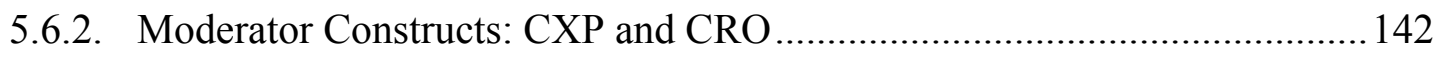

5.7. Confirmatory Factor Analysis and Measurement Model .................................. 144

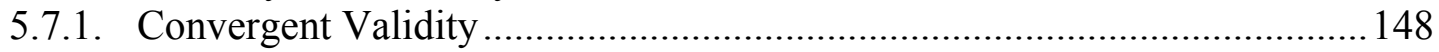

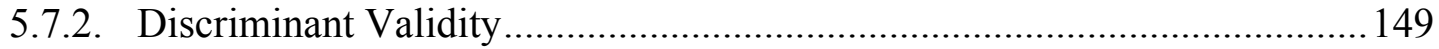

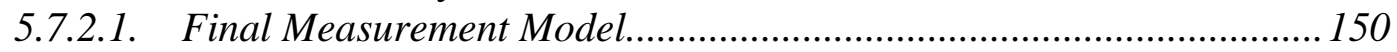

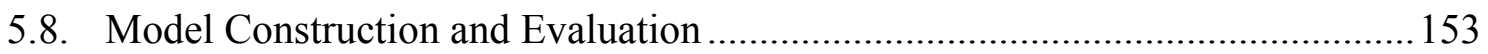

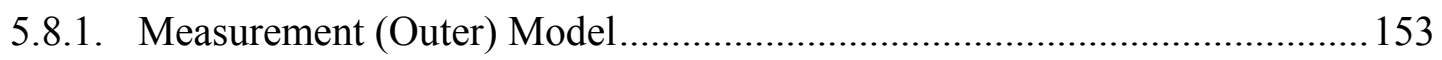

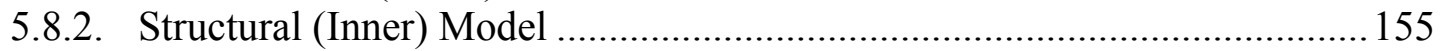

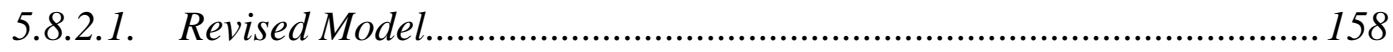

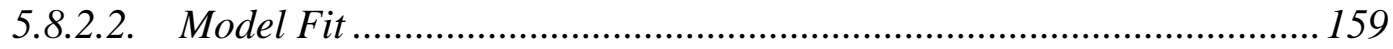

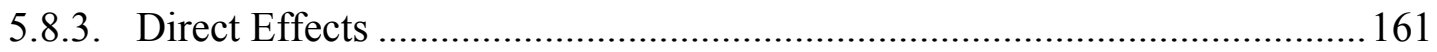

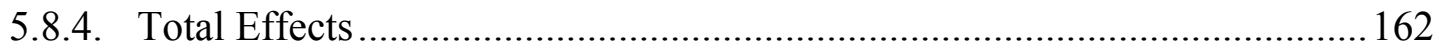

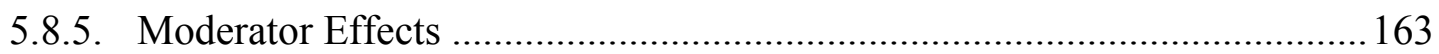

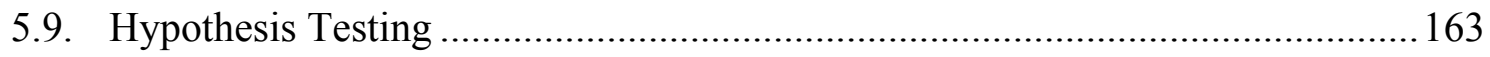

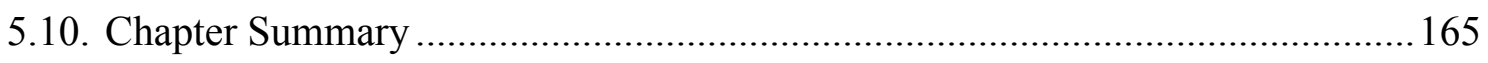

CHAPTER 6. Discussion and Conclusions ..................................................167

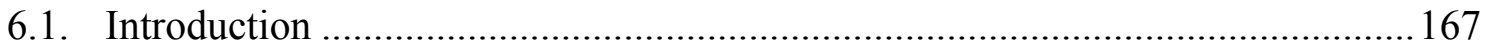

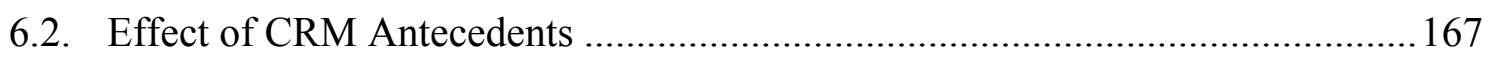

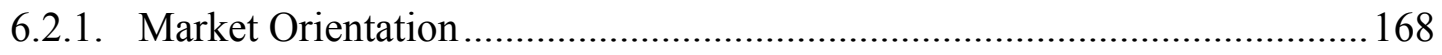

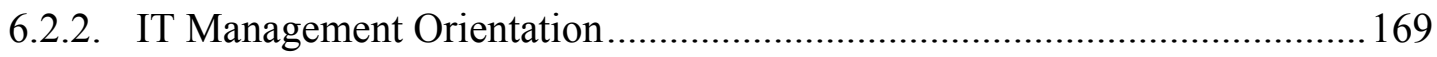

6.3. Effects of CTA on Relationship Strength and Relationship Performance ........... 170 


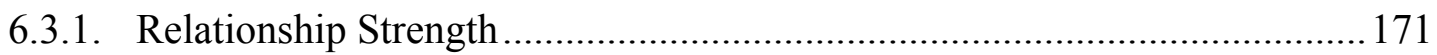

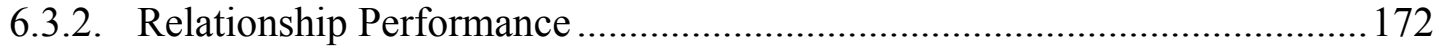

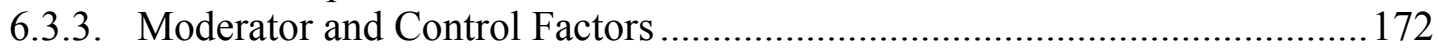

6.4. Research Implications and Contributions .......................................................... 174

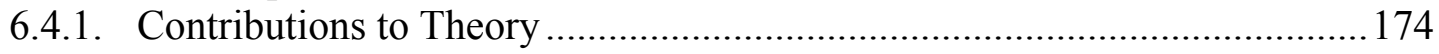

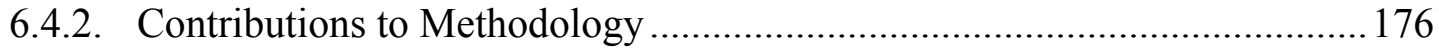

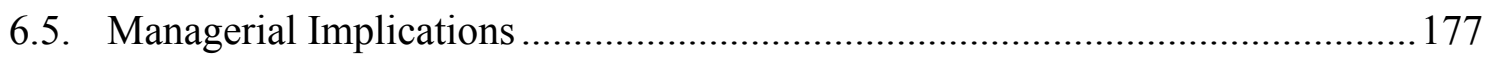

6.5.1. CRM Technology Adoption..................................................................... 178

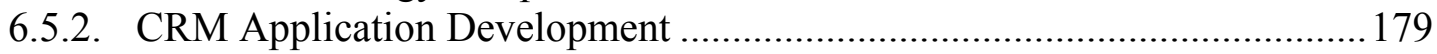

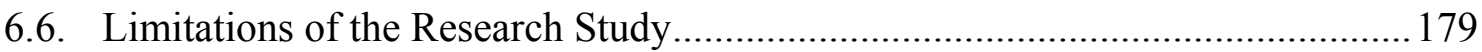

6.7. Directions for Further Research ……........................................................... 180

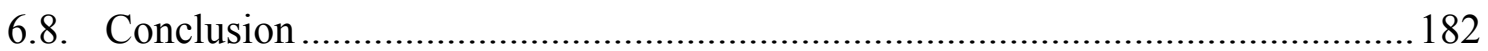

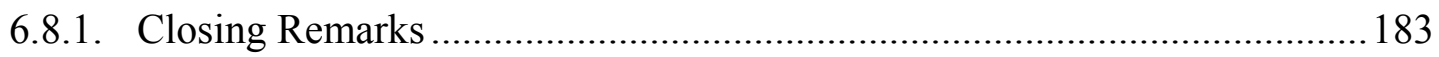

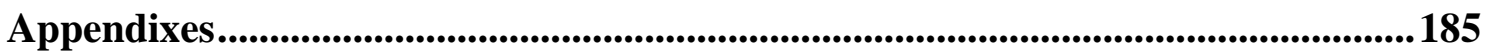

Appendix A1: Interview Protocols and Contact Summary Forms................................. 185

Appendix A2: Interview Data Display Summaries..................................................... 198

Appendix A3: Scale Construction....………………………………………………...2213

Appendix A4: Copies of Survey Questionnaires …………………………………...2216

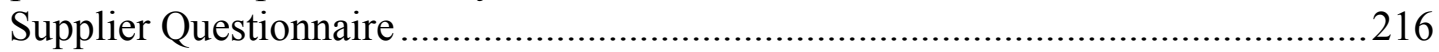

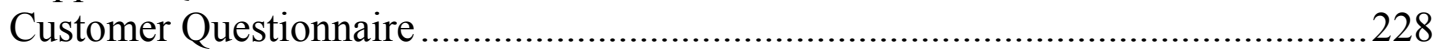

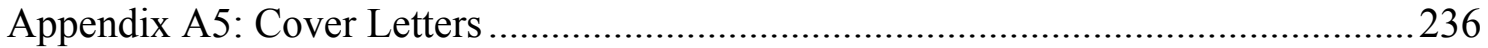

Personalised Supplier Cover Letter ........................................................................236

Generic Customer Cover Letter ……………………………………………......237

Personalised Customer Cover Letter...................................................................238

Appendix A6: Summary of Supplier Respondent Demographic Information...............239

Appendix A7: Test for Non-response Bias ……………………………………….....2 242

Appendix A8: Analysis of Supplier "Do Not Know" Answers .....................................2245

Appendix A9: Survey Data Distribution...................................................................247

Appendix A10: Measurement Item Loading on Composite Indicator Scales ..............251

References ........................................................................................................................ 252 


\section{LIST OF TABLES}

Table 2.1: Associations between Factors Found to Influence Key Constructs of Relationship Strength ....................................................................24

Table 2.2: Relationship Quality and Relationship Strength Research Summary ...........25

Table 2.3: Trust Facets and Typology of Sampled Trust Research ............................... 30

Table 2.4: Market Orientation Dimensions Measured in Research ...............................43

Table 4.1: Supplier CRM System Profile ................................................................ 90

Table 4.2: Supplier and Customer Respondent Profile (Exploratory Phase).................. 91

Table 4.3: Instrument Development Sources for the Three Major Supplier Constructs. 98

Table 4.4: Customer Instrument Development Sources for the Two Major Dependent

Constructs and Sub-constructs ................................................................. 98

Table 4.5: Relationship Strength Constructs and Sub-construct Details Used in the Current Study .....

Table 4.6: Relationship Performance Sub-constructs Used in the Current Study ........ 102

Table 4.7: Major Supplier Construct and Sub-construct Details Used in the Current Study ....

Table 4.8: CRM Technology Adoption Sub-construct Details Used in the Current Study 106

Table 4.9: Target Enterprise (ANZSIC) by Employee Count....................................... 117

Table 5.1a: Supplier Response Profiles from Initial Contact $(\mathrm{n}=1,639) \ldots \ldots \ldots \ldots \ldots \ldots \ldots . . . .128$

Table 5.1b: Supplier Response Profiles from Questionnaires Sent $(\mathrm{n}=526)$............... 129

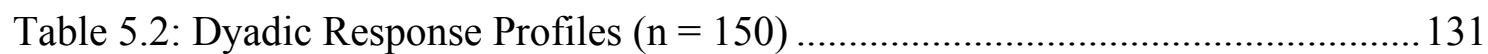

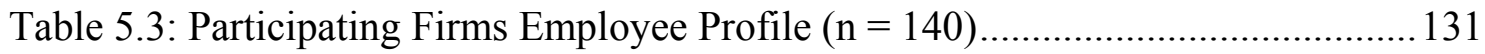

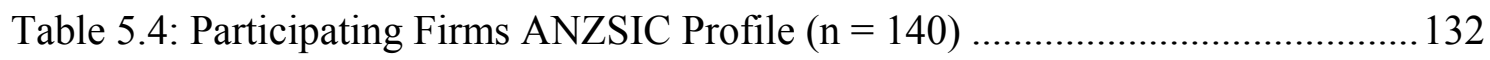

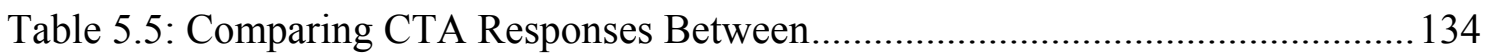

Table 5.6: Supplier and Customer RS and RP Correlations $(n=113)$.......................... 137

Table 5.7: Initial CTA Conceptual Factors, Constructs and Measurement Items ........ 140

Table 5.8: CTA Two-factor Varimax Rotated Results ................................................ 141

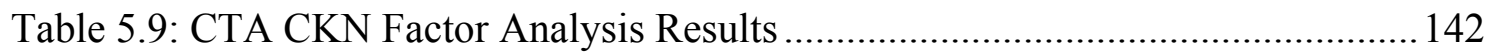

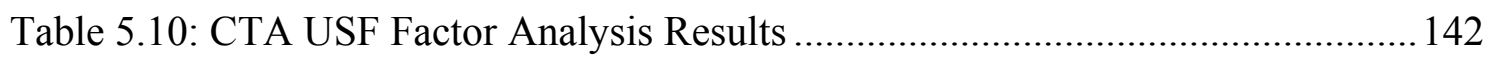

Table 5.11: CRO and CXP Two-factor Varimax Rotated Results................................. 144

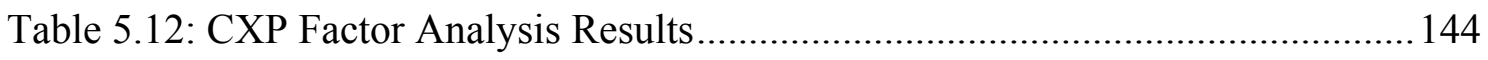

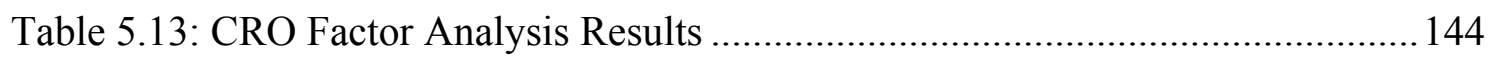

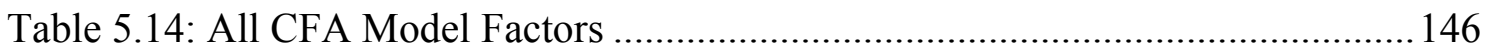

Table 5.15: Items Deleted Due to Loadings Less than 0.60 on Any Single Construct

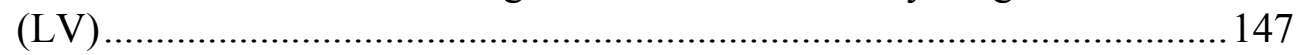

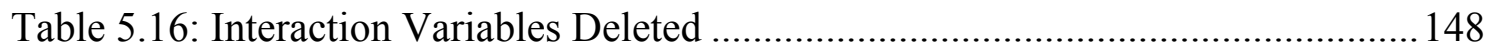

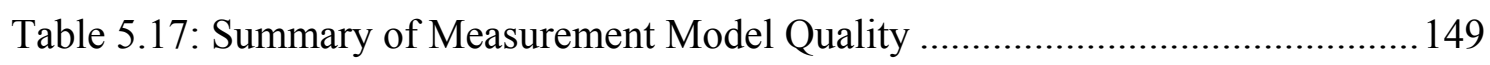

Table 5.18: Discriminant Validity Results Using AVE Approach .............................. 151

Table 5.19: Final Measurement Model Items, Loadings and Significance Values ....... 152 
Table 5.20: Constructs, Items and Composite Indicators

Table 5.21: Composite Indicator Measurement Model Quality Results.

Table 5.22: Composite Indicator Scales Discriminant Validity Using AVE Method .. 156

Table 5.23: Inner Model Path Coefficients and Significance Level ............................. 157

Table 5.24: Revised Structural (Inner) Model Results ................................................159

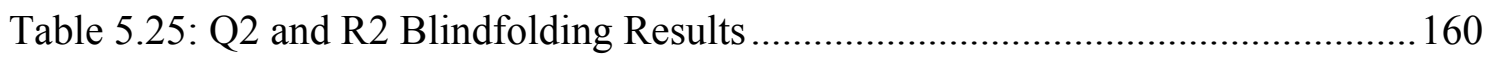

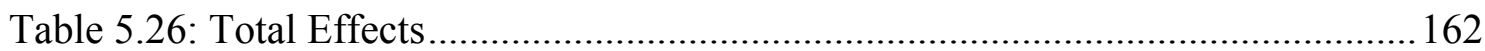

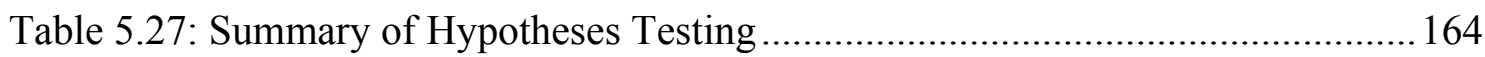

Table A2.1: Interview Questionnaire Summary ....................................................... 198

Table A2.2: Summary of CRM Technical Functionality Provided ..............................2 210

Table A2.3: Summary of CRM Functionality Implemented .....................................2 210

Table A2.4: CRM Integration Rating and Relationship Impact ................................211

Table A2.5: Market Orientation Influence on CRM Technology Adoption..................211

Table A2.6: IT Management Orientation Influence on CRM Adoption.......................212

Table A3.1: Supplier Questionnaire Construction ....................................................2 213

Table A3.2: Customer Questionnaire Construction ...................................................2. 215

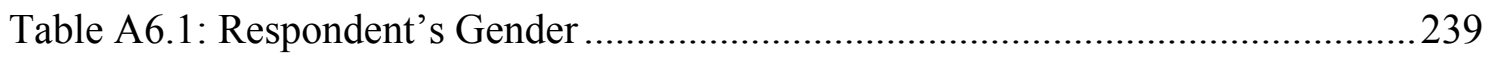

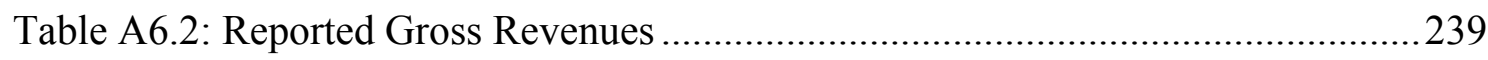

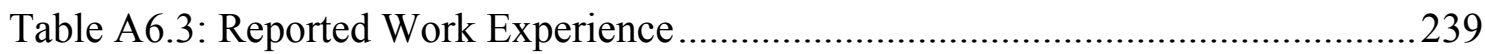

Table A6.4: Reported Education Level.................................................................2239

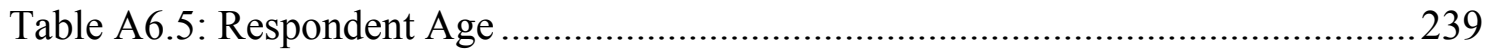

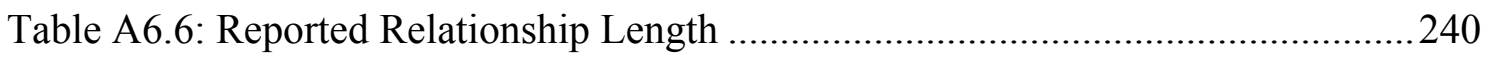

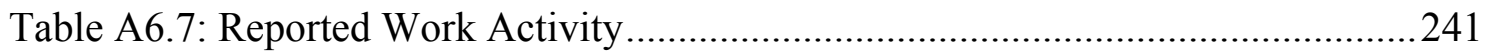

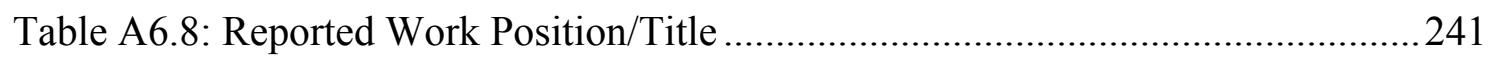

Table A7.1: Late Supplier Respondent Demographic Statistics ...................................2242

Table A7.2: Late Supplier Respondent CTA Response Statistics ................................242

Table A7.3: Comparing Late Supplier Respondent Demographics.............................243

Table A7.4: Comparing Late Supplier Respondent CTA Responses $(n=113)$...........244

Table A8.1: Supplier 'Do Not Know' Response Statistics $(n=150)$...........................245

Table A8.2: Comparing Supplier 'Do Not Know' Respondent CTA Construct

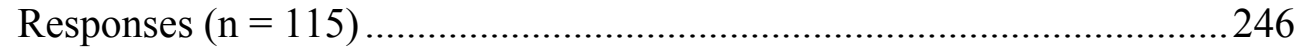

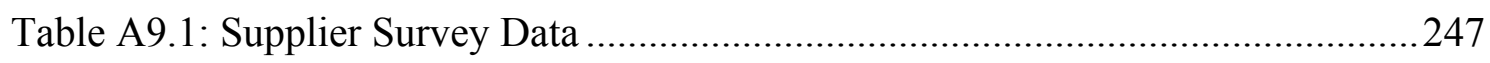

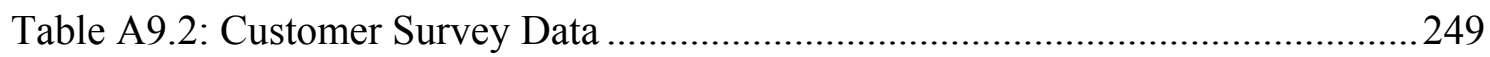




\section{LIST OF FIGURES}

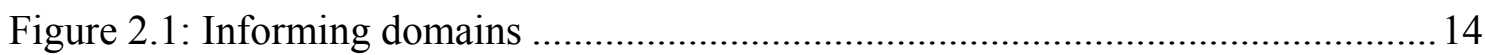

Figure 2.2: Overview of the evolution of information systems/technology with respect

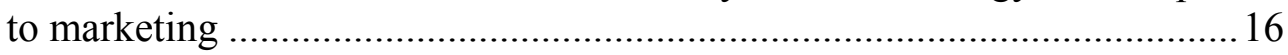

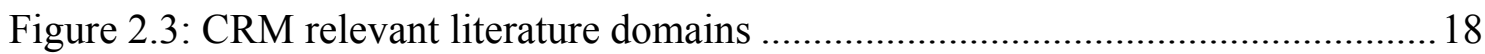

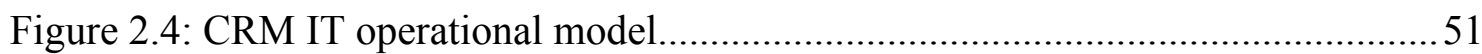

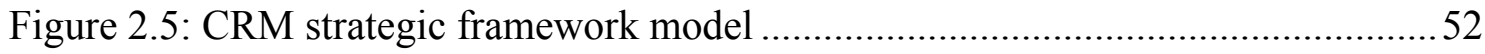

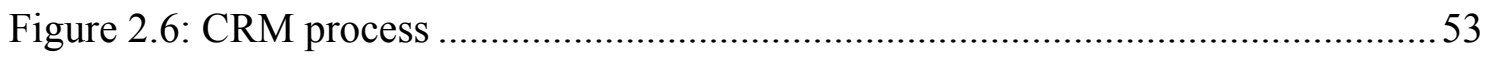

Figure 3.1: CRM technology adoption - relationship conceptual model ....................... 73

Figure 3.2: CRM technology adoption - customer relationship research model and

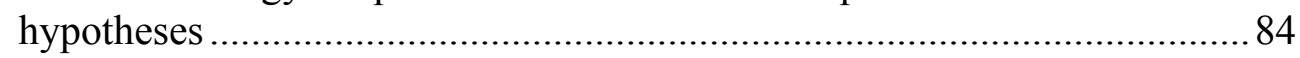

Figure 4.1: Unit of analysis: Supplier - Customer dyad............................................ 88

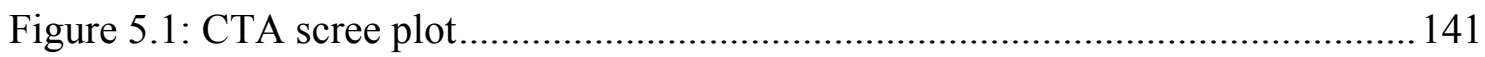

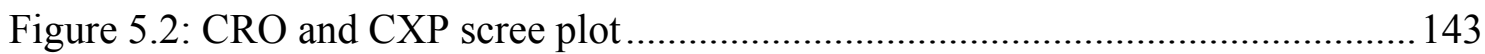

Figure 5.3: Original measurement model used for confirmatory factor analysis ......... 145

Figure 5.4: Composite scale measurement model.................................................... 153

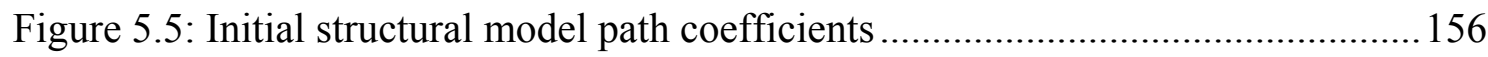

Figure 5.6: Revised structural model with path coefficients..................................... 158 


\section{CHAPTER 1. Introduction}

With advances in technology, the proliferation of the Internet, and the emphasis on one-to-one marketing techniques, customer relationship management (CRM) has become a key focus of marketing (Palmatier, Gopalakrishna, \& Houston, 2006; Payne $\&$ Frow, 2005). Predicated on the views that (a) strong customer relationships are important contributors to customer loyalty which leads in turn to corporate profitability and (b) information technology contributes to building strong customer relationships, CRM technology development and enterprise implementations have expanded at a phenomenal rate (Chalmeta, 2006; Zablah, Bellenger, \& Johnston, 2004). IDC (2004) predicted that worldwide CRM applications market would reach US\$11.4 billion in revenues by 2008, compared to US\$200 million in 1994, representing phenomenal growth in CRM over the time period. Paradoxically, at the same time as investment has increased, customer satisfaction ratings have continued to fall (Sweat \& Hibbard, 1999).

Customer focus and relationship management have become fundamental marketing and business philosophies for many companies seeking competitive advantage. Establishing, maintaining and enhancing customer relationships have always been an important aspect of business. However, over the last few years there has been a significant increase in CRM related research (Kamakura et al., 2005; Ngai, 2005). Although CRM is considered by many academics to be a business philosophy closely related to relationship marketing, it is the link with technology that is particularly of interest. Marketing academics have begun to explore and understand the linkage between CRM technology, relationship marketing and business relationships as providing opportunities for sustainable competitive advantage.

Improvements in technology enable businesses to implement CRM systems that can create practical mass customization marketing programs, based on one-to-one marketing techniques. This linkage between marketing and technology is viewed by some academics as providing the opportunity to establish, cultivate and maintain long term, mutually beneficial interactions with large numbers of customers in a cost-effective manner (Peppers, Rogers, \& Dorf, 1999; Reinartz \& Kumar, 2000). By collecting past customer transaction information, demographics, psychographics, media and channel preferences, marketers hope to create personalized product and service offerings that 
capture customer share, build customer loyalty and enhance profit (Niraj, Gupta, \& Narasimhan, 2001; Venkatesan \& Kumar, 2004; Verhoef, 2003). CRM systems are seen by some as an integral component of the information technology required to support and improve the business "front-office" and the customer relationship experience (Ling \& Yen, 2001; Nguyen, Sherif, \& Newby, 2007).

Despite these technological advances and high levels of investment CRM faces serious difficulties and implementation failures (Arnold, 2002; Davids, 1999; Doherty \& Lockett, 2007; Ragowsky \& Somers, 2002). CRM projects suffer from high failure rates, resulting from a range of problems which include lack of corporate customer focus, management commitment, change management, and people, technology and process issues (Kale, 2004; Raman \& Pashupati, 2004). It has been estimated that 55 $80 \%$ of all CRM projects fail to produce results (Bush, Moore, \& Rocco, 2005; Seligman, 2002). A survey of 1,500 companies found that $91 \%$ of businesses plan to or have deployed CRM technology, yet $41 \%$ of the firms with CRM projects were experiencing significant problems (The Data Warehousing Institute, 2000). Davis (2002) reported that many CRM implementations fail to meet fundamental business goals; up to $70 \%$ of companies do not realize any benefit from CRM projects. Rigby, Reichheld and Schefter (2002a) found that twenty percent of senior executives reported that CRM initiatives had failed to deliver profitable growth. In some cases these initiatives had been viewed to in fact have damaged existing customer relationships. Such negative outcomes impact an organization's ability to meet customer expectations, build strong relationships and improve performance.

Despite the ongoing implementation problems to date, many academics and practitioners continue to believe that CRM technology offers the potential for substantial benefits to corporations through improved customer relationships, customer retention, satisfaction and enhanced profitability (Bohling et al., 2006; Payne \& Frow, 2005). The challenge many enterprises face is realising the considerable advantage brought about by leveraging CRM technology and relationship marketing effectively (Chalmeta, 2006; Ngai, 2005).

\subsection{Background}

Motivation for this thesis is driven by two trends in the marketing and information technology (IT) environment. First, the growing requirement and acceptance in business 
for marketing and IT to work closely together to deliver value to the organisation and the customer (Ling \& Yen, 2001; Nakata \& Zhu, 2006; Rust \& Espinoza, 2006). Second, the growing importance of market orientation, and relationship marketing in particular, as an effective organisational business strategy (Kohli \& Jaworski, 1990; Peppers \& Rogers, 1993). With the rapid development of the Internet,e-commerce and self-service customer support, there are increased expectations from customers for improved, personalised service and immediacy (Beckett, Hewer, \& Howcroft, 2000; M. L. Roberts, 2003). This has prompted marketing practitioners to use technology to capture and use customer information in order to better meet customer demands (Álvarez, Martín, \& Casielles, 2007; Peters \& Fletcher, 2004b; Rust \& Chung, 2006).

Customer relationships are considered superior to transactional exchange in their ability to create sustainable competitive advantage and superior business performance (Day, 2003). As a consequence, due to the impacts of globalisation and mass customisation, there is an increased focus on IT to provide applications and infrastructure in support of appropriate business-to-business customer relationships (Day, 2000; Day \& Montgomery, 1999; Kotler, 1989; O'Malley \& Tynan, 2000; Reinartz, Krafft, \& Hoyer, 2004; J. S. Thomas, Blattberg, \& Fox, 2004). The marketing, management, IT, and practitioner literature make numerous references to CRM's impact on business orientation and performance (Almquist, Heaton, \& Hall, 2002; Goodhue, Wixom, \& Watson, 2002; Palmatier et al., 2006; Rigby \& Ledingham, 2004). Yet the increased adoption of CRM systems to help manage customer information and knowledge is perceived by some practitioners and researchers as not delivering proven business value (IDC, 2004; Raman \& Pashupati, 2004). Business-to-business (also known as B2B and industrial buyer-seller) relationships have generally been the focus of relationship marketing research because $\mathrm{B} 2 \mathrm{~B}$ relationships are considered more regular, formal, constructive, and intense (Kong \& Mayo, 1993; Peterson, 1995). Business interactions, and B2B relational exchanges in particular, progress over a period of time, from initial introduction through contractual negotiations and delivery of promises, reflecting an ongoing process (K. Roberts, Varki, \& Brodie, 2003). As well, $\mathrm{B} 2 \mathrm{~B}$ relationships are considered to be based on rational behaviour and mutual acceptance of reciprocity with a strong likelihood of shared benefits and burdens (Dwyer, Schurr, \& Oh, 1987), whereas consumer buyer behaviour is more emotional, less routine or regular, and largely non-negotiable (Stern, 1997). B2B relationships are 
closer, more intense, regular and interactive than consumer (B2C) relationships (Kong \& Mayo, 1993). The key difference between the two is the necessity and value of the B2B exchanges; there are dependencies and the potential for competitive advantage, as well as social and attitudinal dimensions from the buyer's perspective (Palmer, 2007; Sheth \& Parvatiyar, 2000). For these reasons B2B relationships are the focus of this study.

Close links between the marketing and IT departments are viewed by some as a prerequisite for the successful implementation of CRM (Ling \& Yen, 2001). However as a consequence of different success criteria, the marketing, management and IT disciplines have their own separate and distinct views of what constitutes successful CRM implementation (Bose, 2002; B. A. Corner, 2002; Crosby \& Johnson, 2001; Lemon, White, \& Winer, 2002; Reinartz et al., 2004). For example, measures of IT success include system and information quality, use (i.e., task-technology fit), and user satisfaction (DeLone \& McLean, 1992, 2003; Goodhue, 1995). Whereas marketing success is predominately measured through business performance (Kamakura, Mittal, Rosa, \& Mazzon, 2002), increasing profits (Reinartz \& Kumar, 2000), capturing additional customers, implementing marketing programs (Verhoef, 2003), improving market share and delivering the right product (Kotler, 2003; Moorman \& Rust, 1999). Differences in CRM technology adoption and outcomes may also reflect the firm's information technology management and market orientation (Karimi, Somers, \& Gupta, 2001).

$\mathrm{CRM}$ is not therefore easy to define, as it holds different meanings for different people. This will be discussed further in Chapter 2. Some researchers consider customer relationship management (CRM) a business strategy (Day, 2003), while others view CRM as an organisational culture, focused on creating quality (profitable) relationships with customers (Ngai, 2005; Romano \& Fjermestad, 2003). Still others believe that $\mathrm{CRM}$ is a technology which provides a comprehensive, reliable and integrated view of customers, delivering seamless personalised service through all customer touchpoints (Zikmund, McLeod, \& Gilbert, 2003). The use of technology generally, as an aid to marketing (Shoemaker, 2001; Speier \& Venkatesh, 2002), along with the value of CRM specifically to relationship and business performance, have been examined with mixed results (Croteau \& Li, 2003; Stefanou, Sarmaniotis, \& Stafyla, 2003). However, the research does seem clear in indicating that the firm's initial customer focus and 
orientation may be a key antecedent to CRM success (Wright, Stone, \& Abbott, 2002). The ability of a firm to understand and use technology appropriately raises an additional set of issues and may also contribute to the mixed reviews in the literature of the value of CRM technology (Karimi et al., 2001).

Underlying the growing acceptance and adoption of CRM in business are the concepts of market orientation and relationship marketing. Market orientation is a business philosophy that focuses the firm's resources on gathering, collecting, analysing, disseminating and responding to customer and competitor information in order to provide superior customer value (Kerin, Berkowitz, Hartley, \& Rudelius, 2003; Mitussis, O'Malley, \& Patterson, 2006; Pelham, 1997). Relationship marketing builds from a market orientation approach and encompasses the concept of establishing, maintaining, enhancing and commercialising customer relationships in order to achieve mutual objectives (Grönroos, 1990). Both market orientation and relationship marketing have been the subject of significant amounts of research (Adamson, Chan, \& Handford, 2003; Grönroos, 1995; Gummesson, 1994a; Kohli, Jaworski, \& Kumar, 1993; Narver \& Slater, 1990). The majority of these marketing studies have indicated a positive effect of market orientation and marketing relationships on business performance (Crosby \& Stephens, 1987).

Relationship marketing researchers have focused on what constitutes B2B relationships - how they are created, enhanced and sustained - in an effort to understand relationships between customers and vendors (J. C. Anderson \& Narus, 1990; Dwyer et al., 1987). Key dimensions of relationships include trust, commitment and communications, although a range of other factors also influences the development and maintenance of relationships (Morgan \& Hunt, 1994). CRM itself is viewed by some researchers as a practical application of relationship marketing (Gummesson, 2004). Yet the linkage between CRM and these key dimensions of customer relationships is tenuous due to the lack of empirical research (Gummesson, 2004; Reinartz et al., 2004). It appears from the extant literature that marketing practitioners predominantly use CRM technology to capture and manipulate customer data in order to prioritise and target profitable customers through integrated marketing programmes rather than to focus on developing and maintaining relationships (Goodhue et al., 2002; Romano, 2000). 
The literature is not explicit that CRM technology implementation has been fully detailed or understood by organisations, let alone in a New Zealand context (Ngai, 2005; Raman \& Pashupati, 2004). CRM involves IT to a significant degree, yet little research exists on the design, use or success of systems to support CRM from the marketing perspective (Reinartz et al., 2004). Introducing CRM is a major IT and management undertaking for any organisation; key variables have not yet been clearly identified, nor do current theories fully explain the behaviour of stakeholders or organisations following CRM implementation (Chalmeta, 2006; Hughes, 2002; Ling \& Yen, 2001). The limited number of CRM-specific empirical studies and theories available today needs to be expanded and the subject explored further (Goodhue et al., 2002; Romano, 2000).

CRM research is still considered by many researchers as limited in scope and depth, reflected in the lack of empirical and generalisable research (Gummesson, 2004; H.-W. Kim, Lee, \& Pan, 2002; Reinartz et al., 2004; Romano \& Fjermestad, 2003; Stefanou et al., 2003). Much of the IT-related research is focused on the functional aspects of implementation and there continues to be a call for additional research in order to understand, explain and benefit from the CRM phenomenon (Doherty \& Lockett, 2007; Payne \& Frow, 2006; Reinartz et al., 2004; Romano, 2000). The fundamental research problem these issues and trends evoke is outlined below.

\subsection{Research Problem}

The fundamental problem is the exceptionally poor business performance from CRM implementations (Raman \& Pashupati, 2004). Prior marketing and IT research indicates that CRM applications are not uniformly delivering anticipated business improvements (Reinartz et al., 2004), and that the problem may stem from factors such as lack of customer orientation (Rigby et al., 2002a), IT management practice (Karimi et al., 2001) and issues around people, process and technology (Ling \& Yen, 2001). Furthermore the available IT and marketing research indicates that customers may be suspicious of CRM implementations (Bhattacherjee, 2002; Hoffman, Novak, \& Peralta, 1999) and that CRM applications may not actually assist in the creation or maintenance of customer relationships (Peters \& Fletcher, 2004a). One of the issues leading to confusion in the research is the lack of an agreed CRM definition of what constitutes CRM and how the outcomes are determined and measured. This leads us to the research question: 
What is the impact of CRM technology adoption on B2B customer relationships?

\subsection{Research Objectives}

The objectives of this research are to:

- Determine whether CRM technology adoption has a positive effect on business-to-business relationships and the extent of that impact,

- Determine whether the supplier firm's market orientation and technology orientation has a positive effect on CRM technology adoption and the extent of that impact,

- Contribute to the current marketing and IT literature on CRM technology and relationship marketing,

- Inform CRM practitioners engaged in CRM implementation and software development.

\subsection{Conceptualisation}

Based on an extensive review of the market orientation, relationship marketing and IT literature it is proposed that CRM technology adoption has a strong positive effect on customer relationship development and maintenance. In addition the firm's initial market orientation and IT management orientation is considered to positively affect the successful adoption of CRM technology within the firm. A brief description of the key constructs and variables follow, a more detailed discussion of the model constructs and sub-constructs can be found in Chapter 3 .

The market orientation (MO) of the firm and IT management orientation (ITMO) (i.e., IT management practices) of the firm are considered to have positive effects on CRM technology adoption. Based on the existing literature MO is viewed as positively influencing the strength of the customer relationship. The CRM technology adoption (CTA) construct is positively linked to customer relationship strength and relationship performance. The dependent variables are relationship strength, and relationship performance. Relationship strength is also considered to positively affect relationship performance.

The conceptualisation of the CRM technology adoption - customer relationship (CTA - CR) linkage is used to address how CRM technology adoption affects the 
ability of firms to create, enhance, and sustain customer relationships in terms of the impact of CRM technology on key relationship constructs and relationship performance. Each linkage between the key constructs will be framed as a specific hypothesis, to be tested with the research data. The justification for, and wording of, each specific hypothesis is provided in Chapter 3.

\subsection{Research Methodology}

In order to accomplish the stated objectives, a conceptual model was developed, tested and validated using instruments designed to measure CRM technology adoption, relationship strength, relationship performance and potential interrelationships. A two phase, cross-sectional design was used for this study (Creswell, 2003). The first phase was exploratory using a multiple case design as described by Miles and Huberman (1994), and Yin (2003) to: (a) better understand the CRM technology - B2B relationship phenomenon, (b) further verify and refine the conceptual model, (c) inform the scale development and (d) inform the interpretation of the survey results. Key informants from medium and large New Zealand businesses were invited to participate in one-on-one interviews to discuss CRM technology impact on B2B relationships. In separate interviews customer contacts, provided by the firms, were interviewed for their perspective on the B2B relationships. Insights gained from these interviews were used to refine the research model, and to confirm and adjust the hypotheses. In phase two survey instruments were developed and pre-tested in order to proceed with the explanatory phase of the study. Once the conceptual model and research instruments were finalised and verified a mail survey was implemented so as to empirically test the explanatory capabilities of the conceptual model, across a number of different businesses and industries within New Zealand.

The results of the survey were analysed using exploratory factor analysis (EFA) with SPSS. The partial least squares technique of structural equation modelling was used to confirm the measurement model and test the hypotheses.

\subsection{Delimitations of the Study}

The domain of relationships and related constructs extends into psychology, social science, and organisational behaviour, including various aspects of marketing, business, and IT (Kingshott, 2004; K. Roberts et al., 2003). The intent of this study is to better understand and attempt to explain the impact of CRM technology adoption on 
relationships in the context of business-to-business (B2B) since the existence and importance of B2B relationship dynamics are well structured, documented and supported in the literature (e.g., Grönroos, 1989).

Business relationships and relationship dynamics are complex and consist of a number of dimensions (Fontenot \& Wilson, 1997). Ongoing research efforts continue to identify additional business relationship elements, antecedents and influencing factors (Palmatier et al., 2006; Palmatier, Scheer, Houston, Evans, \& Gopalakrishna, 2007). In the development of quality relationships trust, commitment and communications quality play a significant role. These three attributes are considered by many RM researchers as fundamental to relationship building (e.g., Medlin, Aurifeille, \& Quester, 2005; Morgan $\&$ Hunt, 1994). For this reason the study centres in particular on the relationship attributes of trust, commitment and communications quality. It is beyond the scope of this research to investigate the potential effects of CRM on the myriad of additional relationship attributes.

\subsection{Importance and Value of the Research}

\subsubsection{Importance of the Research}

The importance of CRM research is emphasised by the continued academic and practitioner focus on relationship marketing (RM), and CRM in particular. The Industrial Marketing Management (IMM) journal devoted a special issue to relationship management titled "Transactions, Relationships or Both: Impact of Customer Strategies on Firm Performance" in November 2003. They also prepared a special issue on customer relationship management in August 2004. The Journal of Customer Behaviour produced a special issue on CRM in the spring of 2004. In addition the Journal of Marketing published a Special Issue on CRM in October 2005. However the Journal of Marketing Management's (JMM) July 1997 special issue on Relationship Marketing did not include any articles referencing CRM specifically, indicating CRM was not viewed as a marketing focus at that time.

The Marketing Science Institute (MSI), founded in 1961, leads the way in developing rigorous and relevant knowledge by bringing together marketing scholars and corporate executives. They provide funding, an open environment for, and access to leading-edge marketing knowledge. MSI is widely acknowledged as a leader for marketing research prioritisation for both practitioners and academics. The MSI, in their 
research priorities for 2004 - 2006 and again for 2007 - 2009, identified customer management as a key community of interest, and managing customers as a top tier priority topic. The MSI community awards top tier research priorities to those areas deemed most deserving of intensive research. Implementing and assessing the impact of CRM has been prioritised as one of the top six topics most important to the Customer Management community. This follows from MSI's 2002 - 2004 research priorities where CRM, and managing customer relations, were identified as two of the top five topics of interest for research.

\subsubsection{Value of the Research for Academics}

A key contribution is a fuller exploration of the linkage between CRM and contemporary relationship marketing theory. Existing literature implies a relationship between CRM and RM (e.g., Gummesson, 2004; Mitussis et al., 2006), but there is little published empirical CRM research in this area. In addition it is important to further expand, explore and explain the links between RM theories and CRM application.

The primary contribution of this research is the conceptualisation and empirical testing of CRM technology impacts on B2B relationships, and the operationalisation and measurement of CRM technology adoption within firms. Developing a measure of the impact of CRM adoption on $\mathrm{B} 2 \mathrm{~B}$ relationships provides an empirical method for academics to better understand and predict the relationship between CRM and RM. Measuring CRM technology adoption provides the ability to determine whether more intense CRM technology adoption leads to better customer relationships and improved relationship performance.

\subsubsection{Value of the Research for Practitioners}

Application developers, marketing and IT practitioners benefit from better understanding the factors that affect relationships that can be created and maintained through CRM technologies. In particular, CRM vendors benefit from understanding how CRM technology adoption affects customer relationships, and how key attributes around $\mathrm{B} 2 \mathrm{~B}$ relationships may be developed and better supported by CRM applications.

Marketing and IT practitioners ought to benefit from a better understanding of the relationship between CRM adoption (i.e., type of CRM technology, integration and acceptance), and customer relationship performance. This enhanced understanding should assist management decision-making when evaluating CRM technology. An 
empirical method to study the effect of CRM technology adoption on customers' outcomes may provide additional insight for CRM applications and strategies. CRM applications can be developed that are beneficial to relationship building in particular and marketing more generally.

\subsection{Definitions used in this study}

Commitment

\section{Communication}

Customer CRM

Expectation (CXP)

\section{Customer \\ Relationship \\ Management (CRM)}

CRM technology

\section{Customer \\ Relationship \\ Orientation (CRO)}

\section{Customer \\ Satisfaction (CS)}

Data warehousing

(DW)

Dyads

Enterprise Resource Planning (ERP)
The desire and willingness to make short-term sacrifices (if necessary) in order to develop a confident and stable exchange relationship between partners.

The formal or informal sharing of meaningful and timely information between firms.

The customers' expectations from a supplier's adoption of CRM technology which may influence how customers perceive the relationship and the relationship performance Considered as a potential relationship moderator.

CRM is a customer-centric business focus shaped by the market orientation (MO) of the firm and implemented through IT. CRM includes the process of identifying, accepting and building appropriate mutually beneficial relationships with each customer (i.e., RM) through the use of technology in order to maximise value for each party.

A sub-set of CRM, focused on the technology and technology applications used to support CRM implementation.

The customer's preference for a business relationship based on the customer's desire and appreciation of relationships. Considered as a potential moderator of customer perceived relationship strength and relationship performance.

A customer's cumulative satisfaction or overall contentment with a company, product or service.

An electronic repository of an organization's data to facilitate retrieval, reporting and analysis.

A supplier - customer pair, in this study used as the basis for data collection and analysis.

Business support system that maintains the data needed for a variety of business functions such as Manufacturing, Supply Chain Management, Financials, Projects, Human Resources and Customer Relationship Management 
Information

Technology (IT)

Knowledge

Management (KM)

Market Orientation (MO)

Market Turbulence (MT)

Relationship

Marketing (RM)

Relationship

Strength (RS)

\section{Relationship \\ Performance (RP)}

\section{Technology \\ Turbulence (TT)}

Trust
The study, design, development, implementation, support or management of computer-based information technology, particularly software applications and computer hardware.

No common definition, but comprises a range of organisational practices to identify, create, represent, distribute and enable adoption of what it knows, and how it knows it.

Comprises of three key activities with respect to customers and competitors: collecting, analysing and disseminating market intelligence

Relative stability or volatility of a firm's customer composition and preferences, as well as the rate of that change within the industry

Attracting, maintaining and enhancing customer relationships.

Encompasses the dimensions of trust, commitment and communications quality expressed by the customer, and reflecting the influence of MO and CTA within the supplier firm.

Captures outcomes of the relationship through measures of customer satisfaction, customer retention, and customer loyalty.

The rate of business technology innovation, as well as product innovation, in the industry

Confidence in an exchange partner based on contractual, competence and goodwill trust.

\subsection{Chapter Summary}

A brief discussion of the motivation for the research, research problem description, research model, and the theoretical and practical justifications was presented. An overview of the conceptual model, methodology and initial delimitations of the research were outlined. This thesis consists of five additional chapters. Chapter 2 presents the literature review focused around market orientation, relationship marketing, and customer relationship marketing from the perspectives of marketing and IT. Chapter 3 further develops the research model and hypotheses. Chapter 4 provides the details of the specific methodologies for each phase of the study, while Chapter 5 presents the results of the data analysis. Chapter 6 reviews the outcomes of the study and outlines the 
discussion and conclusions, including limitations and areas for future research. Appendices and references follow Chapter 6. 


\section{CHAPTER 2. Literature Review}

\subsection{Introduction}

Given the multidisciplinary nature of CRM research it is important to review the literature from the pertinent disciplines that structure this investigation. This chapter reviews the major streams of literature in the marketing and information technology (IT) domains which relate to CRM, summarises the main research approaches and findings, and identifies gaps in the research. In order to establish the theoretical foundations of this research the chapter begins by looking at the relationship between IT and marketing (Section 2.2). Figure 2.1 represents a schematic view of the scope of the literature review. A miniature version of Figure 2.1 will be used through this chapter to help guide the reader through the literature review.

The literature domain of each sub-section will be highlighted by a darker colour. Section 2.3 provides an overview of the relevant CRM literature within the marketing, IT and management domains. Section 2.4 then examines the evolution and foundation of relationship marketing $(\mathrm{RM})$ within the marketing discipline, while Section 2.5 provides a comprehensive literature review of how relationship strength has been measured. Section 2.6 explores the market orientation (MO) literature, and Section 2.7

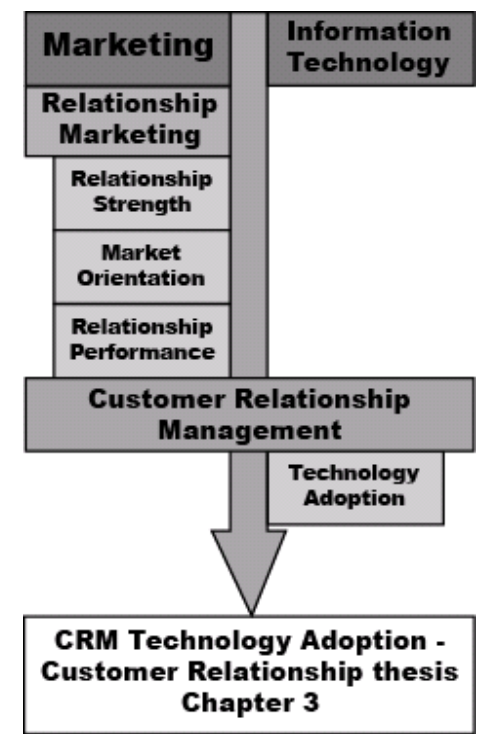

Figure 2.1: Informing domains extends the review into an examination of the relationship performance literature. Section 2.8 brings together the material drawn from both the marketing and IT domains into an overall discussion of the CRM literature. Specific customer perspectives not generally investigated in relationship research, but relevant to the topic, are discussed in Section 2.9. The chapter finishes by summarising the research gaps and opportunities.

The marketing discipline is fundamentally concerned with understanding customer needs and requirements; delivering value to customers resulting in high levels of customer satisfaction; pursuing long-term relationships with customers; and providing positive customer experiences when dealing with the firm (Jayachandran, Sharma, Kaufman, \& Raman, 2005; Moorman \& Rust, 1999; Webster, 1992). An underlying 
premise is that relationship marketing provides value for the firm and is an essential element of the marketing concept (Grönroos, 1989; Morgan \& Hunt, 1994; Reichheld, 1996). Businesses engaged in relationship marketing create and develop profitable exchange relationships with customers over time. This implies that long-term relationships with customers are better than short-term transactional exchanges, particularly in the B2B environment (Berry, 1983; Grönroos, 1990; Raman \& Pashupati, 2004).

Information technology is concerned with the use, design, development, implementation and support of computer-based information systems. This includes the secure collection, storage, protection, transmission and retrieval of information (Turban, McLean, \& Wetherbe, 2003). IT attempts to provide both strategic and operational value to businesses (DeJarnett, Laskey, \& Trainor, 2004; J. C. Henderson \& Venkatraman, 1999; Leek, Turnbull, \& Naude, 2003; Zinkhan, Joachimsthaler, \& Kinnear, 1987). It is concerned with the use and adoption of technology (e.g., Compeau, Higgins, \& Huff, 1999; F. D. Davis, 1989), critical aspects of technology implementation (Brown \& Vessey, 2003; Natovich, 2002; Nguyen et al., 2007), and the strategic role of IT within businesses (Chan, Huff, Barclay, \& Copeland, 1997; Enns, Huff, \& Higgins, 2003; Johnston \& Carrico, 1988; Tallon, Kraemer, \& Gurbaxani, 2000). IT provides the specific technology to implement one-to-one CRM applications and techniques on a large scale which are of benefit to firms, individuals and customers (Greenberg, 2002; Romano \& Fjermestad, 2003).

The relationship marketing ( $\mathrm{RM})$ and technology adoption literatures contribute to the theoretical foundation for CRM research, and CRM can be viewed as a practical implementation of RM theory, with emphasis on one-to-one marketing techniques enabled through technology (Buttle, 2004; F. D. Davis, 1989; Doherty \& Lockett, 2007; Gummesson, 2004; Ryals \& Knox, 2001). The focus of this research is to understand and model the impact of CRM technology adoption on B2B relationships. Settling on a working definition of CRM is not straightforward, and will be discussed at length in this chapter, as a prelude to the development of the formal research model. 


\subsection{Relationship between Information Technology and Marketing}

Marketing's association with and utilisation of IT began around the mid 1960s when the likely impact of massive data-processing capabilities on business practice was first considered (E. Y. Li, McLeod, \& Rogers, 2001). Figure 2.2 presents a brief overview of

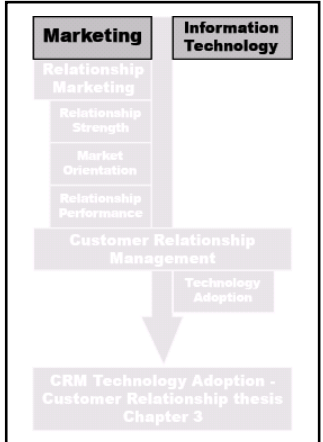
the IT evolution with respect to marketing. Considered as purely a business support function in the early days, IT has evolved through simple, routine number crunching and data processing applications into a strategic contributor to contemporary business (O'Brien, 2004; Talvinen, 1995). Kotler (1966; 1970) was among the first to see the likely benefits of IT use in marketing including real-time information management of customer and competitor information, enhanced analytical capabilities and sophisticated decision support systems (DSS), anticipating the growth and early adoption of marketing information systems (MkIS) (E. Y. Li et al., 2001). Marketing's need to provide comprehensive support for senior management decision-making, and group working processes (such as electronic meetings), provided drivers for the early utilisation of executive information systems (EIS) and group support systems (GSS) (Easton, Easton, \& Belch, 2003; Fjermestad \& Hiltz, 2000; Hess, Rubin, \& West, 2004). During the 1980s marketing practitioners began utilising Supply Chain Management (SCM) applications to help solve problems related to supply and distribution (Heckmann, Shorten, \& Engel, 2003; Turban, McLean et al., 2003).

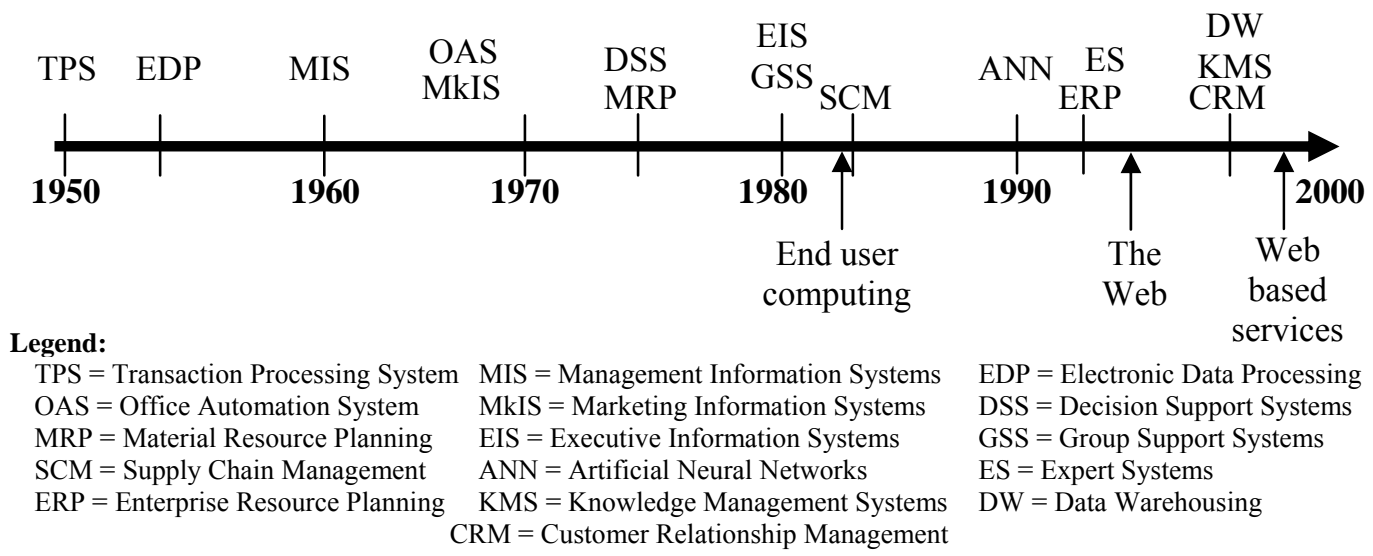

Figure 2.2: Overview of the evolution of information systems/technology with respect to marketing

Marketing has continued to take advantage of IT capabilities with artificial neural networks (ANN) and expert systems (ES) applications used extensively in marketing to 
help analyse and supplement customer self-service centres and web-based service initiatives (Boone \& Roehm, 2002; Fish \& Segall, 2004; S. Li, Davies, Edwards, Kinman, \& Duan, 2002; Moghrabi \& Eid, 1998; O'Brien, 2004; R. W. Stone \& Good, 1995; Turban, McLean et al., 2003; Venugopal \& Baets, 1994). Enterprise Resource Planning (ERP) provides integrated real-time solutions across all business processes, allowing companies to focus on their internal processes to improve efficiencies, quality and profitability (Turban, Rainer, \& Potter, 2003). Data warehousing (DW) is considered a critical component of CRM - sometimes termed the CRM engine - while data mining is the process of extracting information from data warehouses, looking for previously unknown information, for use by applications such as CRM (Greenberg, 2002; Nairn, 2002; Turban, Rainer et al., 2003; Wells \& Hess, 2002).

Notwithstanding the extensive history, the IT and marketing relationship can be strained due to such factors as organisational cultural disparity between IT and marketing, differing key performance indicators (both implicit and explicit), and misaligned perceptions of system usability (I. Corner \& Hinton, 2002). Despite the difficulties, there continues to be a need for IT and marketing departments to actively work together to develop comprehensive and integrated business strategies, support management decision making, create sustainable competitive advantage, and generate real-time market research applications (Demirdjian, 2003; Ling \& Yen, 2001). As technologies continue to converge over time, their need will become even greater.

\subsection{Overview of the Relevant CRM Literature}

CRM applications are relatively new to the business world, conceived in the 1980s, but only attaining marketing prominence in the late 1990s primarily due to advances in information technology, data management systems, improved analytics, enhanced communications, systems integration and the rapid adoption of the Internet (Berry, 1995; Bose, 2002; Greenberg, 2002). The adoption of such technologies provides efficiencies for business change initiated by customer demand for customised, personal service. By collecting past customer transaction information, demographics, psychographics, media and channel preferences marketers hope to create personalised product and service offers that capture customer share, build customer loyalty and enhance profit over time (Kotler, 2003; Ling \& Yen, 2001; Reichheld, 1996). 
There is considerable overlap in business orientation and implementation issues between the CRM marketing, management and IT literature domains. However there are distinct differences in the focus of CRM research between the domains. Figure 2.3 is provided to put this study into perspective based on existing bodies of literature. The management literature is primarily concerned with organisational issues surrounding CRM business strategy development and implementation, and the critical success factors important to the successful adoption of a CRM business strategy. These organisational issues may also include the firm's market orientation and relationship marketing approach. Research of CRM as a business strategy is not the focus of this study and hence the management literature will not be exhaustively reviewed. For the most part the CRM IT literature has focused on critical success factors involved in CRM system (technological) implementation. As shown in Figure 2.3 the identified IT issues do overlap with both management and marketing domains. The CRM specific marketing literature is limited, and focuses to varying degrees on aspects of CRM including critical success factors, business strategy, market orientation and relationship marketing.

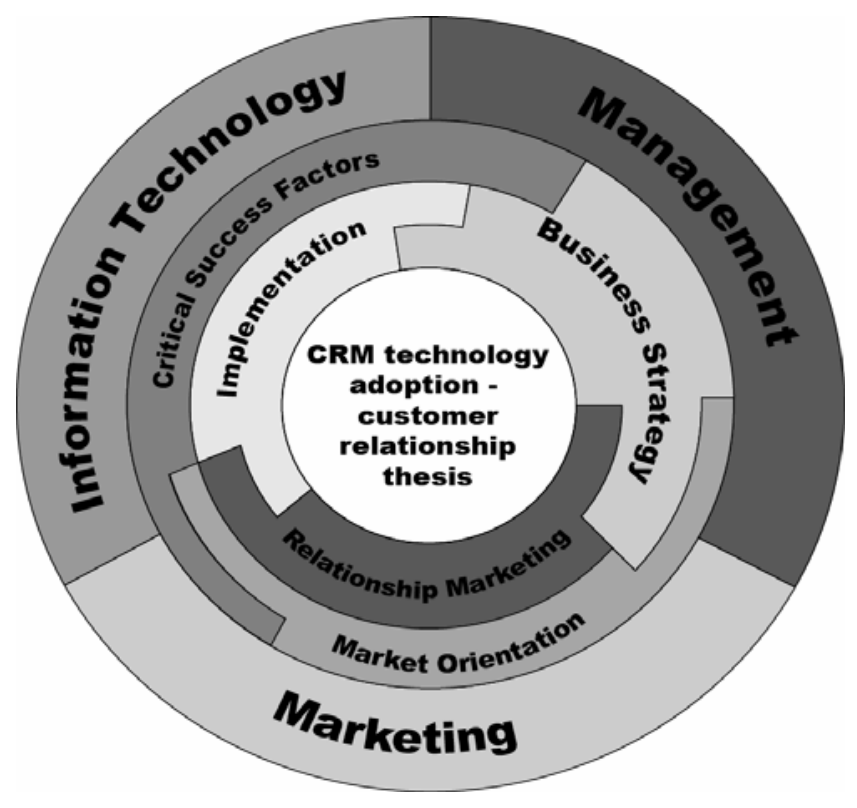

Figure 2.3: CRM relevant literature domains

Relationship marketing is a growing area of active interest and research, and CRM research is becoming more prominent in the marketing, management and IT research domains (Ngai, 2005). CRM research specifically has only come to the fore over the last decade or so, whereas relationship marketing has been practiced and researched for some time (Cassels, 1936; Grönroos, 1994b). Even here, a broad-based interest in 
relationship marketing beyond a primarily Scandinavian focus has only emerged over the last fifteen years or so. Some authors have advocated that CRM was born from relationship marketing and is simply the practical application of long standing relationship marketing principles which have existed since the dawn of business itself (Gummesson, 2004; Ryals \& Knox, 2001). As a specific area of enquiry however, CRM research is still quite new within the marketing discipline.

CRM research has maintained its distinctiveness from other marketing research areas such as RM and market orientation (MO), possibly due to the variety of research domains (i.e., Marketing, Management, and Information Technology), fragmented research focus (i.e., relationship marketing, management strategy, systems implementation), initial technology focus of CRM (e.g., technology fad), or perceived lack of a theoretical foundation (Helfert, Ritter, \& Walter, 2002). The separate trajectories of RM and CRM research have given rise to significant gaps in the research literature which are assessed further below (Mitussis et al., 2006).

\subsection{Evolution of Relationship Marketing}

As early as 1948 Alderson and Cox discussed the impact of ecological studies on marketing theory acknowledging market relationships "as provid[ing] one starting point for a theory of the relationships of individual retailers or clusters and their customers" (p. 147). Following from this Morgan and Hunt (1994) suggested an

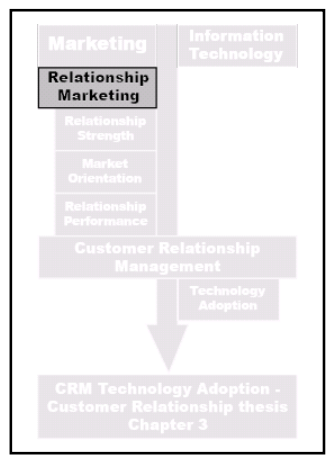
all-encompassing RM definition: "Relationship marketing refers to all marketing activities directed toward establishing, developing, and maintaining successful relational exchanges" (p. 22). Some argued that this went too far and eliminated the need for a separate definition of marketing itself (Peterson, 1995).

Since the mid-1970s contemporary studies of relationship marketing have been driven from what has been referred to as the Nordic School of Services, and the IMP Group in particular (Grönroos, 1995; Gummesson, 1994a). However it was not until 1983 that Berry (1983, p. 26) formally introduced "relationship marketing" into the academic marketing literature as "attracting, maintaining and - in multi-service organizations - enhancing customer relationships". Mainstream marketing from the late fifties through to the late eighties focused primarily upon the study and utilisation of the marketing mix (the 4Ps) (Vargo \& Lusch, 2004). Over the intervening years the 
evolution and definition of RM has been somewhat convoluted (Bitner, 1995), with many RM researchers tending to use one of four dominate theoretical perspectives to investigate and understand interorganisational relationships: a) commitment-trust, b) dependency, c) transaction cost economics, and d) relational norms (Palmatier, Dant, \& Grewal, 2007). The commitment-trust perspective is best exemplified in Morgan and Hunt's (1994) work. The exchange dependence structure viewpoint, whereby the interdependency of a partner determines the desire to maintain a relationship, takes into consideration power, willingness to compromise and opportunism (Ganesan, 1994; K. Kim \& Frazier, 1997; N. Kumar, Scheer, \& Steenkamp, 1995). The concepts of relationship specific investments (RSI), and opportunistic seller behaviour highlights transaction cost economics. Because RSIs represent sunk assets in a relationship, sellers are less likely to act opportunistically and hence, there is a greater expectation of partnership continuity (Rindfleisch \& Heide, 1997; J. B. Smith \& Barclay, 1997). Relational norms provide the fourth substantial theoretical perspective and often emerges with the commitment-trust viewpoint to explain the positive influence of relationship marketing (Gundlach, Achrol, \& Mentzer, 1995; Siguaw, Simpson, \& Baker, 1998). This perspective assumes that transactions are undertaken within the context and norms of a stable ongoing relationship and that a set of common contract norms exist (Cannon, Achrol, \& Gundlach, 2000; Heide \& John, 1992; Kaufmann \& Dant, 1992).

More recently however a number of authors propose that an emphasis on the $4 \mathrm{P}$ marketing mix is no longer the dominant marketing logic and that RM may be a more appropriate "new" paradigm for marketing thought, theory and practice (Dwyer et al., 1987; Grönroos, 1989, 1990; Gummesson, 1994b; Kotler, 1992; Vargo \& Lusch, 2004). With a strengthened focus upon RM, the CRM linkage becomes clear: "CRM provides management with the opportunity to implement relationship marketing on a companywide basis" (Ryals \& Knox, 2001, p. 535). Or as Zablah, Bellenger, and Johnston (2004, p. 480) state "relationship marketing is often cited as the philosophical basis of CRM ....[and] some perceive them to be so similar as to not warrant a distinction in the literature".

\subsubsection{What is a Relationship?}

A number of perspectives on and definitions of what constitutes a business relationship exist in the literature (Grönroos, 1990; Harker, 1999). Database marketing 
(Tapp, 2005), direct marketing (Pearson, 1994), one-to-one marketing (Peppers et al., 1999), key account management (Burnett, 2001), and building and maintaining customer networks (Shani \& Chalasani, 1992) have all been used to denote and describe business relationships (typically known as relationship marketing or RM within the marketing field itself). Some marketers consider a relationship to begin when customer information is collected and used in a database, or when any form of exchange of goods or services takes place. Grönroos (1990, p. 6) more fully described establishing, maintaining and enhancing customer relationships from the service provider's perspective: “1) establishing a relationship involves giving promises; 2) maintaining a relationship is based on fulfilment of promises; and finally, 3) enhancing a relationship means that a new set of promises are given with the fulfilment of earlier promises as a prerequisite.” Relationships can be complex and are considered as a point along a transactional-relational continuum, with one extreme including ongoing, long-term business and social interactions, and the other end-point viewed as simple one-time single transactions (Grönroos, 1994a, 1995). Two main types of relationships exist in the business literature; business-to-business (B2B) and business-to-consumer (B2C).

Much of the marketing research has focused on what constitutes B2B relationships, attempting to understand the elements of business relationships; in particular the dynamics of relationship formation, growth, maintenance and termination (Dwyer et al., 1987; Fontenot \& Wilson, 1997; Morgan \& Hunt, 1994). There is a long history of research specifically examining industrial (B2B) buyer-seller relationships (J. C. Anderson, 1995; Baxter \& Matear, 2004; Cannon \& Homburg, 2001; Dwyer et al., 1987; Ganesan, 1994; Krapfel, Salmond, \& Spekman, 1991; Levitt, 1983; Narayandas \& Rangan, 2004; Nielson, 1998; Shapiro, 1974; Wilson, 1995). Grönroos (2000, p. 32) argued that there is still not enough research emphasis on trying to understand "What is a relationship?" or "When do we know a relationship has developed?" - but the amount of research attention focused on this area has increased markedly over recent years, and Grönroos overstates the dearth of work in the area.

Harker (1999) undertook a substantial literature review and uncovered 26 definitions of RM currently used in the RM research literature. Although these different conceptualisations make it difficult to communicate a shared understanding of RM theory and development, commonalities have emerged. For example, trust and commitment are consistently highlighted as elements central to proper relationship 
development and enhancement (Morgan \& Hunt, 1994; O'Malley \& Tynan, 2000). Harker (1999, p. 16) offered an RM definition based on the results and key conceptualisations from his study:

An organisation engaged in proactively creating, developing and maintaining committed, interactive and profitable exchanges with selected customers [partners] overtime $[s i c]$ is engaged in relationship marketing.

Grönroos (1996, p. 7) suggested that:

'Relationship marketing is to identify and establish, maintain, and enhance relationships with customers and other stakeholders, at a profit, so that the objectives of all parties involved are met;' and 'this is done by a mutual exchange and fulfilment of promises'.

Ironically marketers on the supplier side appear to be the ones deciding when a relationship exists (without consultation with customers) and hence many definitions of RM in the contemporary literature lack a customer perspective (Grönroos, 2000). Grönroos attempted to address this issue with a customer oriented definition: "A relationship has developed when a customer perceives that a mutual way of thinking exists between customer and supplier or service provider" (p. 33). The "mutual way of thinking" in his definition referred to mutual commitment, loyalty, interaction and communications.

In summary, business relationships are complex exchanges between two parties and a relationship may exist anywhere along a continuum - from purely transactional (i.e., no relationship) to fully relational (i.e., embedded partnership and collaborative), yet necessarily mutually exclusive (Coviello, Brodie, Danaher, \& Johnston, 2002; Gummesson, 2004). It is important to recognise that customers play an important and valued role in the initiation, development and maintenance of relationships. Therefore utilising a definition involving the customer as a central participant is inherently appealing as a basis for B2B relationship research (Grönroos, 1996, 2000).

\subsubsection{Importance of Relationship Marketing}

$\mathrm{RM}$ is considered by some academics as the new marketing paradigm, as relevant for manufacturing as it is for products and services (Grönroos, 1989, 1996; Gummesson, 1994a; Vargo \& Lusch, 2004). RM theory postulates that benefits to the firm accrue in the form of protecting the customer base, by creating product differentiation and barriers to switching, and improving profits (Dwyer et al., 1987; Low, 1996; Reichheld $\&$ Sasser, 1990). Berry (1995) suggested that customers find RM attractive because of 
its potential to reduce risk, increase recognition and impart prestige. An added benefit to both parties is the opportunity for the supplier to understand more about customer requirements thereby gaining the ability to customise and tailor solutions to customer needs.

Highlighting the importance of RM, Kalwani and Narayandas (1983; 1995) conducted a cross-sectional and longitudinal study based on 76 firms, pair-matched for SIC codes, market served and level of sales. They compared two groups, long-term relationship group with the transactional group, along three dimensions Net Sales, Inventory Turnover ratio and ROI over two separate periods $1986-87$ and $1990-91$. They concluded that long-term relationships provide a long-term competitive advantage without giving up profitability. Perhaps more importantly the benefits of understanding and delivering to customer requirements went beyond simple manufacturing efficiency gains but also led to higher profitability.

The most common factors viewed as reflecting the value of RM and influencing relationship development, maintenance and strength include:

1. Trust (J. C. Anderson \& Narus, 1990; Crosby, Evans, \& Cowles, 1990; Friman, Garling, Millett, Mattsson, \& Johnston, 2002),

2. Commitment (Morgan \& Hunt, 1994; Verhoef, 2003),

3. Communication (J. C. Anderson \& Narus, 1990),

4. Satisfaction (Crosby et al., 1990; Selnes, 1998),

5. Power (Iacobucci \& Ostrom, 1996; Narayandas \& Rangan, 2004)

6. Cooperation (J. C. Anderson \& Narus, 1990; Selnes, 1998) and

7. Performance (Gruen, Summers, \& Acito, 2000; Helfert et al., 2002; Lemon et al., 2002)

Although a number of other variables, such as duration, conflict, competence and dependence/independence, have also been investigated with respect to relationship marketing, these studies generally find in turn some direct or indirect link to trust, commitment or communications (Aijo, 1996; J. C. Anderson \& Narus, 1990; Berry, 1995; Ganesan, 1994; Grönroos, 1994a; Gummesson, 1994a; Leuthesser \& Kohli, 1995; Lewin \& Johnston, 1997; O'Malley \& Tynan, 2000; Ravald \& Grönroos, 1996; Sirdeshmukh, Singh, \& Sabol, 2002). These studies demonstrate the importance of trust, commitment and communications quality to relationship initiation and development. Table 2.1 lists some of the antecedents found to influence the trust, commitment and 


\section{Table 2.1: Associations between Antecedents Found to Influence Key Constructs of Relationship Strength}

\begin{tabular}{|c|c|c|}
\hline Antecedent & Construct & Relationship Outcomes \\
\hline $\begin{array}{l}\text { - Experience (Dwyer et al., 1987) } \\
\text { - Competence (Sirdeshmukh et al., 2002) } \\
\text { - Organisational characteristics; Individual } \\
\text { characteristics (Moorman, Deshpandé, \& } \\
\text { Zaltman, 1993) } \\
\text { - Shared values; Cooperation; } \\
\text { Communication; Opportunistic behaviour } \\
\text { (-ve); Investment (Morgan \& Hunt, 1994) } \\
\text { - Performance (Narayandas \& Rangan, } \\
\text { 2004) } \\
\text { - Satisfaction (Verhoef, 2003) } \\
\text { - Use of power (-ve) (Iacobucci \& Ostrom, } \\
\text { 1996) } \\
\text { - Duration (-ve) (Doney \& Cannon, 1997) }\end{array}$ & TRUST & $\begin{array}{l}\text { - Enhanced relationship (Selnes, 1998) } \\
\text { - Functional conflict resolution; Less } \\
\text { uncertainty; Increased commitment } \\
\text { (Morgan \& Hunt, 1994) } \\
\text { - Improved performance (N. Sharma \& } \\
\text { Patterson, 1999) } \\
\text { - Higher satisfaction; Increased } \\
\text { cooperation (J. C. Anderson \& Narus, } \\
\text { 1990) }\end{array}$ \\
\hline $\begin{array}{l}\text { - Communication; Trust; Cooperation; } \\
\text { Investment (Morgan \& Hunt, 1994) } \\
\text { - Performance (Narayandas \& Rangan, } \\
\text { 2004) } \\
\text { - (J. C. Anderson \& Narus, 1990) } \\
\text { - Satisfaction; Price (Verhoef, 2003) } \\
\text { - Dependency (Ganesan, 1994) } \\
\text { - Loyalty (Garbarino \& Johnson, 1999) }\end{array}$ & COMMITMENT & $\begin{array}{l}\text { - Increased cooperation; Increased } \\
\text { acquiescence; Increased continuity; } \\
\text { Additional investment (Morgan \& } \\
\text { Hunt, 1994) } \\
\text { - Increased satisfaction (Verhoef, 2003) } \\
\text { - Improved performance (Narayandas } \\
\text { \& Rangan, 2004) } \\
\text { - Increased loyalty (Garbarino \& } \\
\text { Johnson, 1999) }\end{array}$ \\
\hline $\begin{array}{l}\text { - Initial; Frequency (Leuthesser \& Kohli, } \\
\text { 1995) } \\
\text { - Open (Selnes, 1998) } \\
\text { - Meaningful; Timely (Lewin \& Johnston, } \\
\text { 1997) }\end{array}$ & $\begin{array}{l}\text { COMMUNICATIONS } \\
\text { QUALITY }\end{array}$ & $\begin{array}{l}\text { - Increased trust; Increased } \\
\text { commitment (Morgan \& Hunt, 1994) }\end{array}$ \\
\hline
\end{tabular}

communications constructs in the relationship marketing research and the effect on relationship outcomes. This table highlights and further demonstrates the potential complexity of relationship research. Of all the factors investigated trust, commitment and communications have been most commonly identified as a pre-requisite or primary factor affecting relationship development and performance. With few reservations, this set of antecedents and constructs is similar for both business customers and consumers (Coviello \& Brodie, 2001; O'Malley \& Tynan, 2000).

\subsection{Relationship Strength}

One of the roles of marketing is to establish, maintain and develop relationships with customers. The strength (or quality) of business relationships between suppliers and customers has been investigated and measured in a variety of ways (Hausman, 2001; Morgan \& Hunt, 1994; Odekerken-Schroder, De Wulf, \&

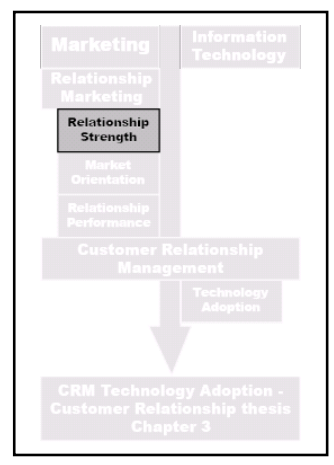
Schumacher, 2003). The general consensus is that strong relationships provide substantial benefits to both parties (Ravald \& Grönroos, 1996). Although "there is no consensus on which dimensions make up relationship quality...[d]iscussions of 
relationship quality often emphasize the importance of trust, satisfaction, and commitment" (Dorsch, Swanson, \& Kelley, 1998, p. 130). Relationship strength has been shown to vary significantly between firms depending on the level of the individual sub-constructs, such as trust, commitment and shared norms (Hausman, 2001).

Wong and Sohal (2002) attempted to measure relationship quality directly using a single-item scale, with trust and commitment as antecedents of relationship strength. However, as shown in Table 2.2, marketing and IT researchers have generally considered relationship quality and relationship strength as a single multidimensional construct. These dimensions have included trust (Crosby et al., 1990; K. Roberts et al., 2003; Wong \& Sohal, 2002), commitment (Lages et al., 2005; Wong \& Sohal, 2002), conflict (Lang \& Colgate, 2003), social bonds (Lang \& Colgate, 2003), communications quality (Lages et al., 2005), customer satisfaction (Dorsch et al., 1998) and information flow (Lages et al., 2005).

Other researchers have developed models of relationship quality based on linking service quality, customer satisfaction, relationship strength, relationship longevity and relationship profitability (Storbacka et al., 1994). Given that relationship quality and relationship strength have been researched as synonymous constructs, only relationship

Table 2.2 Relationship Quality and Relationship Strength Research Summary

\begin{tabular}{|c|c|c|c|}
\hline Study & $\begin{array}{l}\text { Relationship quality } \\
\text { /strength measure }\end{array}$ & Outcomes & Context \\
\hline $\begin{array}{l}\text { Crosby et al. (1990) } \\
\text { (Marketing) }\end{array}$ & $\begin{array}{l}\text { Trust and satisfaction } \\
\text { (performance)(with salesperson) }\end{array}$ & $\begin{array}{l}\text { Anticipation of future } \\
\text { interaction and sales } \\
\text { effectiveness }\end{array}$ & $\begin{array}{l}\text { U.S. Insurance industry } \\
\text { - whole life. Personal } \\
\text { relationships }\end{array}$ \\
\hline $\begin{array}{l}\text { Storbacka, Strandvik, \& } \\
\text { Grönroos (1994) } \\
\text { (Management) }\end{array}$ & $\begin{array}{l}\text { Service quality, customer } \\
\text { satisfaction, commitment, bonds }\end{array}$ & $\begin{array}{l}\text { Relationship strength, customer } \\
\text { profitability }\end{array}$ & Conceptual \\
\hline $\begin{array}{l}\text { Dorsch et al. (1998) } \\
\text { (Marketing) }\end{array}$ & $\begin{array}{l}\text { Trust, satisfaction, commitment, } \\
\text { opportunism, customer } \\
\text { orientation, ethical profile }\end{array}$ & $\begin{array}{l}\text { Association between } \\
\text { relationship quality and vendor } \\
\text { status }\end{array}$ & $\begin{array}{l}\text { U.S. Purchasing } \\
\text { executives }\end{array}$ \\
\hline $\begin{array}{l}\text { Hausman (2001) } \\
\text { (Marketing) }\end{array}$ & $\begin{array}{l}\text { Trust, commitment, } \\
\text { relationalism }\end{array}$ & $\begin{array}{l}\text { Perceived performance, } \\
\text { relationship satisfaction and } \\
\text { continuance }\end{array}$ & $\begin{array}{l}\text { US Hospital supply } \\
\text { chain }\end{array}$ \\
\hline $\begin{array}{l}\text { Wong and Sohal (2002) } \\
\text { (Marketing) }\end{array}$ & $\begin{array}{l}\text { Single-item scale, trust and } \\
\text { commitment as antecedents }\end{array}$ & $\begin{array}{l}\text { Salesperson trust impacts } \\
\text { overall RQ. Commitment is } \\
\text { significant influence. }\end{array}$ & $\begin{array}{l}\text { Retail shoppers - } \\
\text { Australia }\end{array}$ \\
\hline $\begin{array}{l}\text { Lang and Colgate (2003) } \\
\text { (Marketing) }\end{array}$ & $\begin{array}{l}\text { Antecedents = commitment, } \\
\text { trust, satisfaction, social } \\
\text { bonding, conflict }\end{array}$ & $\begin{array}{l}\text { Customer IT expectation and } \\
\text { use influences RQ. Social } \\
\text { bonding not significant. }\end{array}$ & $\begin{array}{l}\text { Banking industry - } \\
\text { New Zealand }\end{array}$ \\
\hline $\begin{array}{l}\text { K. Roberts et al. (2003) } \\
\text { (Marketing) }\end{array}$ & $\begin{array}{l}\text { Trust (credibility and } \\
\text { benevolence), commitment, } \\
\text { satisfaction, conflict }\end{array}$ & Significantly influences loyalty & Consumers \\
\hline $\begin{array}{l}\text { Lages et al. (2005) } \\
\text { (Management) }\end{array}$ & $\begin{array}{l}\text { Information sharing, } \\
\text { communication quality, long- } \\
\text { term relationship orientation, } \\
\text { satisfaction }\end{array}$ & $\begin{array}{l}\text { Quality of relationship has a } \\
\text { positive impact on export } \\
\text { performance }\end{array}$ & U.K. Export market \\
\hline
\end{tabular}


strength will be discussed further (e.g., Lages et al., 2005; Palmatier, Scheer et al., 2007; Storbacka et al., 1994). A number of specific dimensions of relationship strength from the literature are now reviewed.

\subsubsection{Trust}

Trust has been conceptualised in the literature as having "confidence in an exchange partner's reliability and integrity" (Morgan \& Hunt, 1994, p. 23), or alternatively as “a willingness to rely on an exchange partner in whom one has confidence" (Moorman et al., 1993, p. 82). Trust is considered by some IT researchers to be based on integrity, credibility and competence (Bhattacherjee, 2002). Other researchers believe trust is built through forthright and frequent two-way communications (Lewin \& Johnston, 1997; Selnes, 1998).

Numerous studies have argued that trust is the foundation of RM (Doney \& Cannon, 1997; Duncan \& Moriarty, 1998; Dwyer et al., 1987; Fontenot \& Wilson, 1997; Geyskens, Steenkamp, \& Kumar, 1998; Lewin \& Johnston, 1997; Narayandas \& Rangan, 2004; Ravald \& Grönroos, 1996). Trust is a primary and fundamental requirement for successful relationship development (Berry, 1995; Grönroos, 1996; Medlin et al., 2005), and relationship maintenance (J. C. Anderson \& Narus, 1990; Harker, 1999). In addition trust provides the basis for loyalty, relationship enhancement (i.e., decreased perception of risk), and yet is mediated by customer perceived value of the relationship (i.e., perceived net benefits) (Morgan \& Hunt, 1994; Selnes, 1998; Sirdeshmukh et al., 2002). Trust has been conceptualised both as a dimension (E. Anderson, Lodish, \& Weitz, 1987; Crosby et al., 1990), and an antecedent, of relationship strength (J. C. Anderson \& Narus, 1990; Mohr \& Nevin, 1990).

\subsubsection{Types of Trust}

Trust itself is considered multi-dimensional and cannot be researched or measured successfully in a unidimensional manner (Doney \& Cannon, 1997; Ganesan, 1994; Geyskens et al., 1998; Pressey \& Mathews, 2004).

Blois (1999) reviewed a number of relevant B2B marketing studies on trust and was concerned with the lack of clarity surrounding the conceptualisation of trust, and the different features of trust not represented in the marketing research literature (e.g., trust and reliance; blanket trust; reciprocity; trust and trustworthiness; and organisational trust). McKnight and Chervany $(1996 ; 2000)$ proposed a four component 
interdisciplinary model of trust that included disposition to trust, institution-based trust, trusting beliefs, and trusting intention. They suggested that the elements of the trusting belief component included competence, benevolence, integrity and predictability. Other researchers have similarly found trust, and trust development, to include competence (Bhattacherjee, 2002; E. Kim \& Tadisina, 2003; Pressey \& Mathews, 2004), benevolence (Bhattacherjee, 2002; Doney \& Cannon, 1997; E. Kim \& Tadisina, 2003; Pressey \& Mathews, 2004), and credibility (Bhattacherjee, 2002; Doney \& Cannon, 1997; Ganesan, 1994).

Sako (1992) proposed a typology of trust for management of buyer-supplier relations incorporating contractual trust, goodwill trust and competence trust. Contractual trust is based upon mutually agreed obligations, expectations, ethical standards, formality, and structure. That is, both parties believe, share and uphold similar ethical and moral standards of business; keeping and delivering on promises (Garbarino \& Johnson, 1999). This includes the expectations of payment, use and security of confidential material, and basic honesty. Opportunism, as well as complete dependence on legal penalties, indicates a lack of contractual trust, while oral agreements indicate increased levels of contractual trust.

Goodwill trust captures such attributes as shared normative values, fairness, confidentiality, dependability, discreteness and benevolence (Gounaris, 2005). This type of trust reflects a form "of open commitment to each other ...[and] the willingness to do more than is formally expected" (Sako, 1992, p. 38). There are no explicit promises or professional standards to be met. Rather, there is the understanding that either party can take the initiative to exploit new opportunities without taking unfair advantage of the other. Goodwill trust increases the vulnerability of each party to be in the other's debt. Bhattacherjee (2002), in his study of trust in online firms, identified that benevolence (goodwill) trust is a significant element of trust with the inherent belief that each party will act in a manner that is in the best interest of the relationship.

Competence trust is grounded in the belief that the partner has the ability, technical knowledge, expertise and capability (including managerial) to perform their role (Moorman et al., 1993; Sako, 1992). It is similar to the concept of ability trust (Bhattacherjee, 2002), and is "a pre-requisite for the viability of any repeated transactions" (Sako, 1992, p. 43). 


\subsubsection{Findings from Trust Research}

Using a multi-format self-administered questionnaire, Moorman, Deshpandé, and Zaltman (1993) found that 15 interpersonal and organisational factors significantly affected users' trust. Complementing the traditional psychological approach to trust research by incorporating sociological theory, they found that individual user characteristics were not key factors. The other parties' perceived integrity, willingness to reduce uncertainty, confidentiality, expertise, sincerity, tactfulness, timeliness, and congeniality all significantly affected trust. Degree of formalisation was the only organisational structure found to affect trust. Other factors significantly affecting trust included the perceived power of the provider's organisation, the provider's perceived organisational culture, the reporting structure, and the firm's propensity for project customisation.

From 212 usable questionnaires returned from a wide variety of industries, Pressey and Mathews (2004), investigating patterns of UK supplier trust in long-term B2B relationships, found that at any point in time, any of the three trusting behaviours contractual, goodwill or competence trust - may be in evidence, however goodwill and contractual trust did not co-exist within the same relationship. They also found that competence trust (the ability of the other party to perform their assigned role) was not only relied on by both parties, but may be a fundamental requirement for trust to exist. Furthermore trust may not necessarily progress from low levels of trust to higher levels of trust in a linear fashion over time, but may change based on situations and events.

Anderson and Weitz (1989), studied 690 dyadic relationships between independent manufacturing sales representatives and their principals. They found that more trusting relationships occurred with older relationships, and trust was enhanced by two-way communication, perceived congruent goals and between parties that provided mutual support. Lower levels of trust were found with parties that had poor reputations, and relationships involving asymmetrical power balance. The authors also found that older relationships required less communication, that communication helped build trust, while trust facilitated effective communication. However, Doney and Cannon's (1997) study of 210 US industrial manufacturing firms found no significant link between relationship duration and trust.

Ganesan (1994), studying 124 US retailer buyers and 52 sellers, using a mailed questionnaire, found that retailer and vendor commitment was mediated by trust 
primarily because trust reduced perceived future risk. In his study only the credibility dimension of trust was a key predictor. Transaction specific investments (TSI) were found to increase a firm's perception of trustworthiness and helped create mutual dependency and signalled commitment. Suppliers' trust in retailers increased when performance outcomes were satisfactory, whereas retailers valued the supplier's reputation more.

IT researchers have developed "initial trust" measurement instruments to help understand how trust first comes about or is initiated. Bhattacherjee (2002) investigated three dimensions of initial trust: ability (competence and knowledge), integrity (principles, conduct and fairness), and benevolence (willingness to do good). The author concluded that, since (potential) customers transfer sensitive information (i.e., e-mail address, credit card information, personal information and preferences) to online firms, initial trust is important to the development of online relationships. Kim and Tadisina (2003) also developed a self-administered questionnaire to measure initial trust within an e-commerce environment. Competence and goodwill were again found to be significant factors impacting the development of initial trust. Within the context of business and technology, people may trust firms similar to how they trust people (Doney \& Cannon, 1997), but people do not necessarily trust technology the same way (Friedman, Khan, \& Howe, 2000). Roberts (2003) offered the perspective that a lack of trust is a primary obstacle to e-commerce and by implication e-interaction. Customer concerns over privacy and data use may influence a customer's willingness to participate in information exchange and this may impact the buyer-seller perception of technology and CRM adoption within supplier firms (Coupey, 2005; Peters \& Fletcher, 2004b).

Trust is an important and necessary attribute for a strong and robust relationship and contributes to relationship performance and has been shown to be mediated by variables such as: performance (J. C. Anderson \& Narus, 1990; Narayandas \& Rangan, 2004), shared values (Morgan \& Hunt, 1994), perceived value add (Sirdeshmukh et al., 2002), and customer satisfaction (Leuthesser \& Kohli, 1995; Selnes, 1998).

Table 2.3 provides a summary from a number of studies indicating that the three types of trust proposed by Sako (1992), contractual, competence and goodwill trust, provide acceptable dimensions with which to classify and investigate trust within the 
Table 2.3: Trust Facets and Typology of Sampled Trust Research

\begin{tabular}{|c|c|c|}
\hline Study & Key trust facets studied & Typology (Sako 1992) \\
\hline Dwyer, Schurr, and Oh (1987) & Expertise; reliability; co-operation & Competence \\
\hline Anderson and Narus (1990) & $\begin{array}{l}\text { Benevolence; other party will take action resulting in } \\
\text { positive outcomes for both }\end{array}$ & Goodwill \\
\hline E. Anderson and Weitz, (1989) & $\begin{array}{l}\text { Fairness; benevolence; Long-term orientation; confidence in } \\
\text { other; needs will be fulfilled }\end{array}$ & Contractual, Goodwill \\
\hline $\begin{array}{l}\text { Moorman, Deshpandé, and } \\
\text { Zaltman (1993) }\end{array}$ & $\begin{array}{l}\text { Integrity; expertise; intention; requires some aspect of } \\
\text { vulnerability and uncertainty }\end{array}$ & $\begin{array}{l}\text { Contractual, } \\
\text { Competence, Goodwill }\end{array}$ \\
\hline Ganesan (1994) & Credibility; benevolence & Contractual, Goodwill \\
\hline Morgan and Hunt (1994) & Integrity; competence; benevolence & $\begin{array}{l}\text { Contractual, } \\
\text { Competence, Goodwill }\end{array}$ \\
\hline Ravald and Grönroos (1996) & Will deliver on commitments & Contractual \\
\hline Doney \& Cannon (1997) & $\begin{array}{l}\text { Calculative; Predictive; Capability; Intentionality, } \\
\text { Transference }\end{array}$ & $\begin{array}{l}\text { Contractual, } \\
\text { Competence, Goodwill }\end{array}$ \\
\hline Smith and Barclay (1997) & $\begin{array}{l}\text { Affective - character, role competence, judgment, motive; } \\
\text { Trusting behaviour - investment, forbearance; } \\
\text { Communication }\end{array}$ & $\begin{array}{l}\text { Contractual, } \\
\text { Competence, Goodwill }\end{array}$ \\
\hline $\begin{array}{l}\text { Geyskens, Steenkamp and } \\
\text { Kumar (1998) }\end{array}$ & $\begin{array}{l}\text { Compatibility \& fairness; communications, behaviour, } \\
\text { support, economic outcomes }\end{array}$ & $\begin{array}{l}\text { Contractual, } \\
\text { Competence, Goodwill }\end{array}$ \\
\hline Selnes (1998) & Competence & Competence \\
\hline Garbarino and Johnson (1999) & Confidence; reliability & Competence \\
\hline Grayson and Ambler (1999) & Competence; benevolence & Competence, Goodwill \\
\hline $\begin{array}{l}\text { Helfert, Ritter, and Walter } \\
(2002)\end{array}$ & Benevolence; honesty; competence & $\begin{array}{l}\text { Contractual, } \\
\text { Competence, Goodwill }\end{array}$ \\
\hline $\begin{array}{l}\text { Sirdeshmukh, Singh and Sabol } \\
(2002)\end{array}$ & $\begin{array}{l}\text { Execution; consistency; skills; abilities; knowledge; fair, } \\
\text { altruistic; problem-solving }\end{array}$ & $\begin{array}{l}\text { Contractual, } \\
\text { Competence, Goodwill }\end{array}$ \\
\hline E. Kim and Tadisina (2003) & $\begin{array}{l}\text { Measured initial trust based on competence and goodwill } \\
\text { measures of trust. (e-business) }\end{array}$ & Competence, Goodwill \\
\hline Narayandas and Rangan (2004) & $\begin{array}{l}\text { Promises made and kept by individuals; performance outside } \\
\text { terms of contract; commitment }\end{array}$ & $\begin{array}{l}\text { Contractual, } \\
\text { Competence, Goodwill }\end{array}$ \\
\hline Pressey and Mathews (2004) & $\begin{array}{l}\text { Fair; benevolent; confidential; technical knowledge, } \\
\text { expertise, performance, expectations, mechanisms, formality }\end{array}$ & $\begin{array}{l}\text { Contractual, } \\
\text { Competence, Goodwill }\end{array}$ \\
\hline Gounaris (2005) & Goodwill; moral order & Contractual, Goodwill \\
\hline
\end{tabular}

RM domain. However few studies have investigated and published the effect of CRM technology adoption on trust within B2B relationships.

Studies investigating CRM technology and trust include Payton and Zahay (2005) who found a lack of intra organisational trust between marketing and IT departments. In addition they found that CRM application users did not always trust the quality of the data available in the shared database. J. W. Kim, Choi, Qualls and Park (2004) found that the relationship strength between manufacturers and retailers, measured through satisfaction, trust and commitment, improved when CRM delivered increased customer satisfaction, customer relationship quality and customer loyalty. The limited CRM specific published research on supplier - customer trust represents a research gap. 


\subsubsection{Commitment}

Commitment is considered within the marketing literature as a significant factor necessary for the creation, building and maintenance of relationships (Duncan $\&$ Moriarty, 1998; Dwyer et al., 1987; Fontenot \& Wilson, 1997; Geyskens et al., 1998; O'Malley \& Tynan, 1997). The impact and critical nature of commitment on relationships have origins in social exchange theory, organisational, buyer, and services marketing literatures (Morgan \& Hunt, 1994).

\subsubsection{Defining Commitment}

Commitment typically has been defined as "a channel member's intention to continue the relationship" (Geyskens, Steenkamp, Scheer, \& Kumar, 1996, p. 304). Anderson and Weitz (1992, p. 19) defined commitment to a business relationship between two parties as the "desire to develop a stable relationship, a willingness to make short-term sacrifices to maintain the relationship, and a confidence in the stability of the relationship" [italics in original]. It has also been defined as an exchange relationship between partners "so important as to warrant maximum effort at maintaining it" (Morgan \& Hunt, 1994, p. 23) and an "enduring desire to maintain a valued relationship" (Moorman, Zaltman, \& Deshpandé, 1992, p. 316).

Although a few researchers consider commitment to be a complex multidimensional construct not easily understood or studied unidimensionally (Gruen et al., 2000; Gundlach et al., 1995; Medlin, 2003), Geyskens et al. (1996) and Gounaris (2005) postulated that motivation for commitment consists of two independent, yet not mutually exclusive, constructs - affective commitment and calculative commitment. Affective commitment reflects the desire to continue a relationship because of a psychological attachment, kinship or bond. There is an element of loyalty and belonging in the relationship (Gounaris, 2005). Calculative commitment, on the other hand, is based purely on cost - benefit analysis, separate and distinct from the relationship context. This type of commitment manifests itself in the perceived need to maintain the relationship due to the calculated investment and/or termination costs of leaving the relationship. A normative form of commitment is considered to create a moral (or reciprocal) obligation between two parties based on benefits received (J. P. Meyer, Allen, \& Topolnytsky, 1998). The majority of the existing buyer-seller commitment research has focused only on the affective form of commitment (e.g., E. Anderson \& 
Weitz, 1992; N. Kumar et al., 1995; Moorman et al., 1992; Morgan \& Hunt, 1994; Wilson, 1995).

\subsubsection{Findings from Commitment Research}

Morgan and Hunt (1994) found that commitment can be a demonstration of loyalty, whereby, for example, a supplier commits superior resources (vis-à-vis the competition) in order to maintain and enhance an existing relationship (Ganesan, 1994). Verhoef (2003) found that commitment is an antecedent both to customer retention and customer share development. Other empirical studies of commitment indicate a strong relationship between perceived commitment of both parties and their ability to overcome difficulties (conflict) in order to achieve mutual gain (Lewin \& Johnston, 1997; Narayandas \& Rangan, 2004). However Gruen, Summers and Acito’s (2000) empirical study of commitment using life insurance agents $(n=2,545)$ concluded that commitment did not mediate future intention to purchase nor did it lead to retention. The authors believed that the non-significant results may have been influenced by the nature of the insurance industry, the use of aggregation in place of individual measures of commitment, and the attempt to link commitment to actual retention behaviour. Interestingly another insurance industry study undertaken by MacKenzi, Podsakoff, and Ahearne (1998) produced similar results providing additional support to Gruen et al's interpretation.

Morgan and Hunt's (1994) seminal study of commitment and trust concluded that commitment and trust are the primary mediating factors contributing to successful RM. They developed a questionnaire adapting a variety of existing measurement instruments and tested 13 hypotheses with a sample of 204 members of the National Tire Dealers and Retreaders Association (NTDRA), using correlations and structural equation modelling (LISTREL VII). They proposed establishing clear communications for information, such as performance evaluations, market information, forecasts and expectations, to help develop, sustain and improve trust and commitment between exchange partners.

Gundlach et al. (1995) investigated exchange relationships from the buyer and seller perspective, one of only two such studies (Medlin, 2003). The authors considered a three-component commitment model consisting of (a) input - the level of resources, (b) attitudinal - intention, and (c) temporal - consistency over time. The results indicated 
that the credibility and level of input "reinforce and escalate commitment over time" (Gundlach et al., 1995, p. 90), while intention (attitudinal component) is not a clear predictor of commitment over time.

Narayandas and Rangan (2004) investigated relationships using grounded theory methodology in three industrial buyer-seller settings. They found that trust affects commitment and performance, and although individual trust is a precursor to development of commitment, interorganisational commitment does not foster interpersonal trust.

Gounaris (2005) collected data from 127 questionnaires mailed to companies in Athens, Greece. As part of this research the author investigated the effect of affective and calculative commitment on relationship maintenance and relationship investment. He found that higher levels of trust led to increased affective commitment, and that there was a causal relationship between trust and commitment in which trust precedes commitment. In addition Gounaris supported the findings from Geyskens et al. (1996) that the affective bond between the buyer-seller is important to relationship maintenance and leads to further relationship investment and enhancement. Furthermore the Gounaris study demonstrated that calculative commitment and affective commitment result in significantly different behavioural intentions. The study suggested that as the level of trust increases in the relationship, calculative commitment decreases. This supported an earlier study which found that "trust can lead even highly interdependent firms to focus less on calculative motivations and emphasize the desire to maintain the relationship because of identification with and attachment to the partner" (Geyskens et al., 1996, p. 314). Calculative commitment on the other hand appeared to have a negative impact on the intention to maintain relationships and increase investment.

In summary, commitment is considered essential for relationship success and affects relationship performance (Gounaris, 2005; Helfert et al., 2002; Morgan \& Hunt, 1994). The underlying motivation for relationship commitment is important in order to better understand, investigate and predict ongoing relationship performance (Gounaris, 2005). Although there is a lack of empirical studies focusing on affective and calculative commitment, the distinction appears to provide a useful typology to study relationship commitment (Gounaris, 2005). Few studies have attempted to link CRM technology adoption and customer commitment (Park \& Kim, 2003). The effect of CRM 
technology adoption on commitment and relationship performance is not well understood and represents a gap in the relevant research literature.

\subsubsection{Communication}

Communication is used to initiate and build relationships; mediate ideas, thoughts and feelings, transfer information, solve problems and simply connect people (Bordia, 1997; Rix, Buss, \& Herford, 2001). The area of communications research is vast and sometimes confusing, encompassing the transfer of meaning, as well as the transfer of data, and the use of channels of communication (e.g., technology mediated communication (TMC)) (Eunson, 2005; Rogers \& Albritton, 1995). The abundance of communication channels available today increases the volume of information, as well as the quantity of information transferred (Rogers \& Albritton, 1995). However this does not necessarily improve the quality of communication and understanding, and instead may culminate in Priestley's paradox (Eunson, 2005). Priestley's paradox proposes that quantity of communications (especially through TMC) may actually diminish communication quality, rather than enhance it. Similar paradoxical findings have been demonstrated in studies of the impact of technology on interpersonal relationships (McQuillen, 2003).

\subsubsection{Defining Communication in the Context of Relationships}

Neither communication nor communication quality appears to have single unified definitions in the RM literature (Mohr \& Nevin, 1990). Communication has been "defined broadly as the formal as well as informal sharing of meaningful and timely information between firms ... [focused] on the efficacy of information exchange rather than the quantity or amount, and ... inherently taps past communications" (J. C. Anderson \& Narus, 1990, p. 44). This form of communication definition has been used extensively in the RM literature (J. C. Anderson \& Narus, 1984; Lewin \& Johnston, 1997; Morgan \& Hunt, 1994; N. Sharma \& Patterson, 1999).

Communication effectiveness has been defined as the sharing of meaningful and timely information, with timeliness having an impact on perceived communication quality, satisfaction and trust (Moorman et al., 1993; N. Sharma \& Patterson, 1999). Communication openness has been used to reflect the formal and informal sharing of plans, goals, expectations, motives and evaluation criteria (E. Anderson \& Weitz, 1989; J. C. Anderson \& Narus, 1984; J. B. Smith \& Barclay, 1997). Some view 
communications as the "glue" which holds relationships together (Mohr \& Nevin, 1990), and that relationships would be impossible without good communication (Duncan \& Moriarty, 1998), while others simply conclude that "communication is the exchange of information between supplier and customer" requiring an open dialog to maintain the relationship and trust (Selnes, 1998, p. 310).

Communication quality is reflected in the effectiveness (i.e., effectiveness of the media used) and efficiency (i.e., message clarity) of the communication (Shelby, 1998). Frequency of communication is also considered an element of quality. The perception exists that more frequent communication is better, yet an inappropriately high frequency of communications may become annoying, negatively impacting the value and quality of the communication (Mohr \& Sohi, 1995).

\subsubsection{Findings from Communication Research}

Duncan and Moriarty (1998) argued that business relationships are impossible without communication, and that trust and commitment are simply products of effective communication. The authors suggested that the interactive nature of communication can build or diminish relationships, and therefore proposed a "communications-based relationship marketing model" focused on communication theory. Common elements between marketing and communication include; relationship exchange between stakeholders, feedback (interactivity), and information (messages). Sharma and Patterson (1999) analysed 201 mail survey questionnaires (23 percent response rate) from financial services customers in Australia and provided support for Duncan and Moriarty's conceptualisation. Their results demonstrated that communication effectiveness, "the formal and informal sharing of meaningful and timely information between a client and advisor in an empathetic manner", significantly and positively impacted relationship commitment and trust (N. Sharma \& Patterson, 1999, p. 158). Empathetic communication involves listening and providing appropriate feedback to customers which can be used to develop emotional and social bonds, and a sense of closeness and comfort in the relationship. A strong empathetic bond can be advantageous in a relationship when problems arise (N. Sharma \& Patterson, 1999).

Communication is not only a precursor to relationship commitment and trust (Lewin \& Johnston, 1997; Morgan \& Hunt, 1994), but is essential to the nurturing process and long-term orientation of relationships (Geyskens et al., 1998). Smith and Barclay (1997) 
studying Canadian sales representatives from two multinational computer companies and their customers, using matched responses from 105 questionnaires, found that trusting characteristics and/or motives led to more open communication. More importantly however bilateral communication of needs, issues and priorities was what helped create meaningful relationships; not simply communication by itself (Dwyer et al., 1987). Cultivating an interactive, open and frequent communication environment focusing on valuable information - expectations, market information, and partnership performance - delivered in a forthright manner helps develop, sustain and hold the relationship together (Berry, 1995). The case study evidence provided by Lewin and Johnston (1997) supports the view that accurate, open, timely communication is key to relationship building. They found that the candid sharing of important confidential information is an important dimension to relationship maintenance. The authors noted that normal suppliers (i.e., those focused on transactional exchanges) were not viewed, or communicated with, in the same manner as long-term relationship suppliers.

Selnes (1998) found that communication had a significant influence on trust and customer satisfaction, contributing to the enhancement of the relationship and the propensity to re-purchase (i.e., continue the relationship). A mail survey study of 102 industrial companies ( $46 \%$ response rate) in the US B2B environment demonstrated that buyers can be satisfied with technology-mediated communication (TMC) (MacDonald $\&$ Smith, 2004). TMC demonstrated a positive effect on future purchase intention and trust (Zeithaml, Berry, \& Parasuraman, 1996). At the same time the trust and commitment relationship factors mediated the effect of TMC satisfaction on future purchase intention. Yet the increase in CRM initiated TMC (i.e., Call centres and Internet) may delay or inhibit trust and relationship development (Wilson \& Vlosky, 1998); creating a level of delayed or fragile trust, whereby parties may be more prone to defect due to "social deindividuation" (Bos, Olson, Gergle, Olson, \& Wright, 2002). That is, in the absence of a face-to-face relationship there may manifest a lack of otherawareness that can decrease behavioural inhibitions making it easy for individuals to “opt-out" of relationships (Bordia, 1997).

Leuthesser and Kohli (1995) investigated the effect of RM on customer satisfaction and share of business by looking at the communication between customers and suppliers. They focused on three types of behaviours identified from the literature: type of information conveyed, frequency and richness (i.e., face-to-face) of the interactions 
and organisational involvement. The sample consisted of 800 randomly chosen National Association of Purchasing Management members, obtaining a 59.3\% response rate $(\mathrm{n}=$ 454). The results indicated that the type of interaction as well as the interaction frequency had a significant effect on customer satisfaction. Frequency of interaction appeared to be more important for trust-building at the beginning of a relationship. Contrary to the authors' hypothesis, there was a significant relationship between frequency of interaction and products with low customer importance. This was interpreted as buyers paying relatively more attention to quality of interaction when the product itself was less important.

Mohr and Sohi (1995) suggested that communication quality is a function of completeness, credibility, accuracy, timeliness and adequacy of communication flows. Their study consisted of 125 returned questionnaires (22 percent response rate) from a U.S. national sample of computer dealers. They found that only frequency of communication flow was significantly related to perceived quality of communication. Bidirectionality (i.e., feedback) and formality (i.e., formal or informal communication) had no significant impact on perceived communication quality, while bidirectionality did significantly affect communication satisfaction, as did communication frequency.

These studies highlight that correct initiating behaviour and quality of communication is important in relationship development and maintenance (Leuthesser \& Kohli, 1995; Mohr \& Spekman, 1994). In contrast Chong and Dick’s (2004) empirical IT focused study of the influence of predictable and timely communication on cognition-based trust (rational and action based trust) in a virtual environment did not find a significant relationship. They argued this may be due, in part, to the methodology; a limited sample size, single site, and sample demographics.

In summary, RM researchers view communication effectiveness and quality as important factors in relationship development, maintenance and performance (J. C. Anderson \& Narus, 1984, 1990; Berry, 1995; Dwyer et al., 1987; Fontenot \& Wilson, 1997; Morgan \& Hunt, 1994; Selnes, 1998), if not the key factor (Duncan \& Moriarty, 1998), significantly affecting the initiation and development of trust and commitment directly (Geyskens et al., 1998). Key dimensions of communication quality appear to include timeliness, frequency, openness and accuracy. Communication enhances the relationship, and influences trust and commitment (J. C. Anderson \& Narus, 1990; Lewin \& Johnston, 1997; Morgan \& Hunt, 1994; Selnes, 1998). However the empirical 
research investigating the affects of CRM technology adoption on communication quality and effectiveness within a business relationship environment is sparse and general in nature. Park and Kim (2003), from their single case study analysis, conclude that CRM relationship activities benefit from appropriate, frequent and active communication between the company and the customer. The general importance of communication, the potential impact of technology-mediated communication in relationships, and the lack of specific CRM communications research indicates an important research gap.

\subsubsection{Other Characteristics of Relationship Marketing}

A number of additional factors with regards to relationship marketing have been examined in the extant literature. However the evidence for inclusion of these additional factors in this study is not compelling and in some cases the results have been found to be contradictory. Other than customer satisfaction (which is used in the relationship performance measure to be discussed later), these factors are not subsequently incorporated into the conceptual model under study. They are however briefly discussed here for completeness.

\subsubsection{Customer Satisfaction}

Customer satisfaction has been widely researched with respect to relationship marketing, yet defined in a number of different ways (Crosby \& Stephens, 1987; Leuthesser \& Kohli, 1995; Reynolds \& Beatty, 1999; Selnes, 1998; Yeung, Ging, \& Ennew, 2002). One definition popular with current researchers focuses on cumulative satisfaction or overall contentment rather than transaction-specific satisfaction (Andaleeb, 1996; E. W. Anderson, Fornell, \& Rust, 1997; Garbarino \& Johnson, 1999). However, the nature and measurement of customer satisfaction has been debated, with satisfaction found to be related to and difficult to discriminate from other positive emotions (e.g., happiness, joy, and enjoyment) (Bagozzi, Gopinath, \& Nyer, 1999; Oliver, 1993). Studies have established positive relationships between customer satisfaction and price equity (Verhoef, Franses, \& Hoekstra, 2001); loyalty (Oliver, 1999); trust and satisfaction (Selnes, 1998); satisfaction, trust and commitment (Garbarino \& Johnson, 1999); usage level and satisfaction (Bolton \& Lemon, 1999); as well as satisfaction and profitability (E. W. Anderson, Fornell, \& Lehmann, 1994). In most cases satisfaction has been shown to be a complex factor, affecting some outcomes 
more than others, although customer satisfaction and performance outcomes have been shown to be predominantly linear in nature; customer satisfaction increases as performance improves (E. W. Anderson et al., 1994; Yeung et al., 2002). Although satisfaction may not constitute a "unique, fundamental construct in and of itself" (Bagozzi et al., 1999, p. 201), the cumulative perspective of customer satisfaction has been considered and found to be significant both as a dependent and independent variable in a number of studies (Ganesan, 1994; Leuthesser \& Kohli, 1995).

\subsubsection{Cooperation}

Cooperation between firms has been defined as actions taken in order to achieve mutually beneficial outcomes between the firms or independent singular outcomes with the expectation of reciprocation over time (J. C. Anderson \& Narus, 1990; Lewin \& Johnston, 1997). Trust, competitive strategy and dependency are generally considered a precursor to cooperation (A. J. Campbell, 1998). Anderson and Narus (1990), using social exchange theory and communications as the backdrop, found that firms meeting or exceeding performance objectives through cooperation with other firms (partners) cultivate trust and satisfaction (cf. Lewin \& Johnston, 1997). They concluded that cooperation is an antecedent not a consequence of trust, whereas Morgan and Hunt (1994) found that commitment and trust leads to cooperation. This suggests that the relationship between cooperation, trust and commitment is an iterative process requiring a frank, honest and open exchange of information between the parties (J. C. Anderson \& Narus, 1990; Lewin \& Johnston, 1997; Selnes, 1998). However cooperation is not always based on trust or interdependency. Young and Wilkinson (1989) showed that in certain instances cooperation is coerced by the more powerful member and justified by the desired outcomes. Overall it was concluded that cooperation tended to overlap and link strongly to trust and commitment, and that its inclusion as a distinct construct would not add significant insight or explanatory power beyond those two constructs.

\subsubsection{Power}

Power, dependency and trust are intertwined to the extent that firms perceived to be powerful can be more trusting, while those perceived less powerful are less trusting of partners (Young \& Wilkinson, 1989). Similarly, those firms most dependent are generally more receptive to the stronger firms overtures and suggestions (J. C. Anderson $\&$ Narus, 1990). The judicious exercise of power (acknowledged and accepted by the 
other party), can help create a mutually beneficial relationship (Dwyer et al., 1987; Morgan \& Hunt, 1994). However asymmetric power tends to leads to conflict, and subsequent loss of trust and commitment, while mutual dependency leads to less conflict (Morgan \& Hunt, 1994; Young \& Wilkinson, 1989). Asymmetric power may be transient in nature (strongly favourable to the more powerful firm initially), yet over time, given increased trust and commitment, culminate in lower risk, erode, or transfer to the other party (Narayandas \& Rangan, 2004). Iacobucci and Ostrom (1996) found that good individual to individual relationships are generally balanced, symmetrical and pleasant in nature. They suggested therefore that firms should concentrate on creating the perception of a power balance in order to improve customer relationships. Given the nature of the study (the effect of CRM technology adoption) and the strong interaction between power and trust, the evidence for inclusion of power as a separate construct in this study was not considered sufficient.

\subsubsection{Performance of Duties}

How each party performs, or is perceived to perform their duties (within and outside the contract), affects the development, trust enhancement, and commitment within the relationship (Narayandas \& Rangan, 2004). In particular, performing above the partner's expectations, leads to trust and satisfaction with the partnership (J. C. Anderson \& Narus, 1990). Bolton (1998) modelled the effect of expected value on the duration of the relationship, postulating that cumulative satisfaction anchors the customers expectations. She found that a performance (service) 'pluses and minuses' balance sheet is taken into account with the cumulative effect of satisfaction being positively related to performance over time (i.e., service continuation). Lemon, White, and Winer (2002) investigated actual customer "service" purchase versus intention to buy. Their results also demonstrated that customers incorporate an adaptive expectations approach to repurchase services, that is, customers consider not only past and current business performance measures of service but also project future expectations and benefits of performance into their decision-making of retaining or changing service providers. The Gruen et al. (2000) study found that performance of the supplier positively affected customer participation and retention in professional associations, without necessarily being mediated by commitment. Given the inclusion of Sako's (1992) competence trust construct, the performance of duty construct is considered redundant for this study. 


\subsubsection{Dependency}

Dependency within a relationship relates to the relative power and therefore the extent one party depends on (or must trust) the other party (J. C. Anderson \& Narus, 1990). Some believe the development of interdependency is antecedent to a successful relationship (Lendrum, 2003). However, increasing interdependence asymmetry can decrease trust and commitment while increasing interfirm conflict. In addition Kumar, Scheer, and Steenkamp (1995) demonstrated that relationships with greater total interdependence exhibit higher trust, stronger commitment, and lower conflict than relationships with lower interdependence, although perceived mutual benefit may moderate feelings of asymmetrical dependence (Lewin \& Johnston, 1997). Similarly Geyskens et al. (1996) found evidence that interdependence enhances commitment, but that the type of commitment will depend on trust.

However, Dwyer et al. (1987, p. 24) considered relationship development simply "a process of ever-expanding interdependency between buyer and seller." Furthermore they suggested that any form of prolonged dependency (i.e., delayed payment or scheduled delivery) initiates a relationship (expected or not), since an element of trust and cooperation exists. Initially one firm within the relationship will be more dependent on the other, but this dependency asymmetry can be offset over time based on performance (within and outside contractual obligations), trust and commitment (Narayandas \& Rangan, 2004). Due to the complex interactions between dependency, trust, power, performance and commitment, there was no compelling rationale to include dependency as a separate construct in this study.

\subsubsection{Duration}

Duration of the relationship is thought to affect the ongoing relationship dynamics including trust, commitment and satisfaction (Gruen et al., 2000). Reynolds and Beatty (1999) found that long-term satisfied customers perceive additional social benefits and are more loyal to sales people as well as to the firm itself. Other studies however have found a negative correlation to ongoing relationship development, explained by growing too accustomed to each other, not challenging each other, or not initiating new innovations (Doney \& Cannon, 1997; Helfert et al., 2002). Due to the contradictory results the duration construct was not included in this study. 


\subsubsection{Rapport}

Rapport or the chemistry between customer and supplier has been shown to aid the development of trust between buyers and salespeople, as well as positively affect the ongoing relationship dynamics between individuals and firms (Doney \& Cannon, 1997). The construct has been characterised as the quality of a relationship, enjoyable interactions between participants, mutual trust, or simply 'clicking' with another person (Bernieri, Gillis, Davis, \& Grahe, 1996; Gfeller, Lynn, \& Pribble, 1987; Gremler \& Gwinner, 2000; Puccinelli, Tickle-Degnen, \& Rosenthal, 2003). Irrespective of the definition, marketing researchers have recognised the value of establishing rapport consistent with Gremler and Gwinner (2000) (DeWitt \& Brady, 2003; Gremler \& Gwinner, 1998). Due to the lack of a clear definition of the rapport construct, and the similarity between rapport measures reported in the literature and the relationship strength and relationship quality constructs in the current study, rapport was not included as a separate construct in this research.

\subsubsection{Relationship Marketing Summary}

Relationship marketing is considered an essential element of the current B2B marketing mix. "The primary impetus behind the concept of relationship marketing is to foster a long-term relationship and thereby create repeat purchases" (Yau et al., 2000, p. 1112). Although a number of B2B relationship factors were reviewed, trust, commitment and communications are considered primary factors important to the development and maintenance of business relationships (Morgan \& Hunt, 1994). Overall, the RM literature highlights the importance of incorporating these three factors in any $\mathrm{B} 2 \mathrm{~B}$ relationship research.

As noted above, relationship marketing is considered an important element of contemporary marketing, yet little CRM specific research has been published investigating the effect of CRM technology adoption on relationship marketing measures. However the extent and relative importance of relationship marketing within a firm, as well as the customer relationships themselves, may depend on the firm's level of market orientation. 


\subsection{Market Orientation (MO)}

Although the term "market orientation" has been defined in a number of ways (Kohli \& Jaworski, 1990), several empirical studies share the conclusion that market orientation (MO) has a positive effect on business performance (Deshpandé, Farley, \& Webster Jr., 1993; Moorman \& Rust, 1999; Narver \& Slater, 1990). In particular, Cano, Carrillat and Jaramillo (2004) identified, through

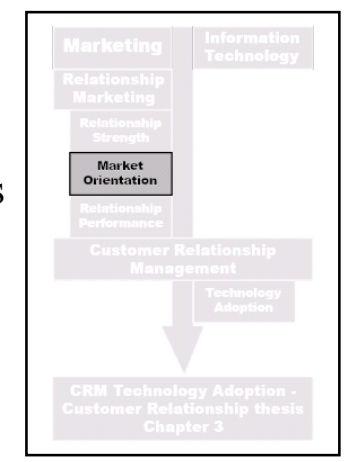
meta-analysis, that MO plays an important role in business performance and long-term success, explaining approximately 12 percent of variance in business performance.

Market orientation has been defined as:

The generation of appropriate market intelligence pertaining to current and future customer needs, and the relative abilities of competitive entities to satisfy these needs; the integration and dissemination of such intelligence across departments; and the coordinated design and execution of the organization's strategic response to market opportunities (Deng \& Dart, 1994, p. 726).

Table 2.4 summarises dimensions of MO researched from selected key marketing and customer orientation studies since 1982. Customer orientation refers to a firm's

Table 2.4: Market Orientation Dimensions Measured in Research

\begin{tabular}{|c|c|c|c|c|c|c|c|c|}
\hline & SOCo & & & & & & & RMO \\
\hline Factors & $\begin{array}{l}\text { Saxe and Weitz } \\
\text { (1982) }\end{array}$ & $\begin{array}{l}\text { Narver and } \\
\text { Slater (1990) }\end{array}$ & $\begin{array}{c}\text { Kohli, Jaworski } \\
\text { and Kumar } \\
\text { (1993) }\end{array}$ & $\begin{array}{c}\text { Deshpandé, Farley } \\
\text { and Webster, Jr } \\
\text { (1993) }\end{array}$ & $\begin{array}{l}\text { Deng and Dart } \\
\text { (1994) }\end{array}$ & $\begin{array}{c}\text { Gray, Matear, } \\
\text { Boshoff and } \\
\text { Matheson (1998) }\end{array}$ & $\begin{array}{l}\text { Helfert, Ritter } \\
\text { and Walter } \\
(2002)\end{array}$ & $\begin{array}{c}\text { Yau, McFetridge, } \\
\text { Chow, Lee, Sin and } \\
\text { Tse (2000) }\end{array}$ \\
\hline $\begin{array}{l}\text { Customer } \\
\text { orientation }\end{array}$ & $\mathrm{x}$ & $\mathrm{x}$ & $\mathrm{x}$ & $\mathrm{x}$ & $\mathrm{x}$ & $\mathrm{x}$ & $\mathrm{x}$ & \\
\hline $\begin{array}{l}\text { Competitor } \\
\text { orientation }\end{array}$ & & $\mathrm{x}$ & & $\mathrm{x}$ & $\mathrm{x}$ & $\mathrm{x}$ & $\mathrm{x}$ & \\
\hline $\begin{array}{l}\text { Interfunctional } \\
\text { coordination }\end{array}$ & & $\mathrm{x}$ & $\mathrm{x}$ & & $\mathrm{x}$ & $\mathrm{x}$ & $\mathrm{x}$ & \\
\hline Profit emphasis & & $\mathrm{X}$ & & & $\mathrm{X}$ & $\mathrm{x}$ & & \\
\hline Long-term focus & & $\mathrm{x}$ & & & & & & \\
\hline Responsiveness & & & $\mathrm{x}$ & & & $\mathrm{x}$ & & \\
\hline Bonding & & & & & & & & $\mathrm{X}$ \\
\hline Empathy & & & & & & & & $\mathrm{X}$ \\
\hline Reciprocity & & & & & & & & $\mathrm{X}$ \\
\hline Trust & & & & & & & & $\mathrm{x}$ \\
\hline
\end{tabular}

focus on the customer, for example, the ability to sense and respond to customer needs, and can be defined as: understanding and meeting the customer's ongoing needs, addressing customer satisfaction, continuously creating customer value, providing after sales support and demonstrating customer commitment. Competitor orientation represents a firm's focus on competitor activity, the ongoing collecting and dissemination of competitor information throughout the business, the firm's responsiveness to competitor information and the firm's ability to respond. Interfunctional coordination conveys the firm's ability to synchronise, coordinate and 
leverage the creation and delivery of superior customer value between and within departments. Profit emphasis reflects a firm's focus on profit as an objective measure of performance, while long-term focus is the ability to take a long-term view of the business environment and objectives. Responsiveness refers to action taken in response to information collected and disseminated within the organisation. Bonding reflects shared goals and close relationships between supplier and buyer. Empathy is the ability to view and understand each party's perspective and reciprocity allows each party to make allowances for favours given and received, understanding that the favour will eventually be returned. Trust, in this context, refers to personal (goodwill) trust as the basis for the relationship (Sako, 1992; Yau et al., 2000). These definitions are commonly used to varying degrees in MO research (Kohli \& Jaworski, 1990; Kohli et al., 1993; Narver \& Slater, 1990; Pelham, 1997).

Saxe and Weitz (1982) developed the Selling Orientation - Customer Orientation (SOCO) scale, a 24-item paper-and-pencil instrument, in order to measure, "the degree to which a salesperson engages in customer-oriented selling... directed toward providing customer satisfaction and establishing mutually beneficial, long-term relationships" (p. 343). Although the SOCO instrument has been used successfully in identifying the customer orientation of sales people in a number of industries and is thought to reflect the firm's orientation, it has not been validated or generally used as a measure for a firm's market orientation (Periatt, LeMay, \& Chakrabarty, 2004; R. W. Thomas, Soutar, \& Ryan, 2001).

The MKTOR (Narver \& Slater, 1990), MARKOR (Kohli et al., 1993) market orientation scales and their derivatives (e.g., Deng \& Dart, 1994; Gray, Matear, Boshoff, \& Matheson, 1998; Pelham, 1997) are currently the most commonly used instruments to measure MO. These scales have been used to help explain variance in business performance through a firm's embedded market philosophy and implementation activities. There are four fundamental dimensions or attributes that most researchers agree comprise MO: (a) customer orientation, (b) competitor orientation, (c) interfunctional coordination, and (d) profit orientation (e.g., Kohli \& Jaworski, 1990; Kohli et al., 1993; Narver \& Slater, 1990; Pelham, 1997). The MKTOR instrument was originally constructed as a 15-item scale, using 7-point Likert-type scales. It focused on (a) customer orientation, (b) competitor orientation and (c) interfunctional coordination as observable behaviours around sustainable competitive advantage and creation of 
customer value (Narver \& Slater, 1990). The MO score is the simple average from the three behavioural score components. Following the scale development and testing, Narver and Slater (1990) examined the MO construct against business performance. The results indicated that "market orientation is strongly related to profitability and business performance [and that] ... commodity business[es] with the greatest market orientation have substantial control over their markets" (Narver \& Slater, 1990, p. 32). In addition their study supported the Kohli and Jaworski (1990) concept of MO as a continuum and concluded that MO is "relevant in every business environment" (Narver \& Slater, 1990, p. 33).

Kohli, Jaworski, and Kumar's (1993) criticism of Narver and Slater's MKTOR instrument was that it (a) is too narrowly focused on customers and competition, (b) does not recognise the impact of speed of market intelligence gathering and dissemination, and (c) includes items not specific to market orientation. The subsequently developed MARKOR instrument provided additional validity to the MO construct (Kohli et al., 1993). However in another study investigating the antecedents and consequences of MO, Jaworski and Kohli (1993, p. 64) found a "linkage between a market orientation and performance", but could not substantiate a relationship between MO and market share.

Pelham's (1997) MO study of 160 small U.S. industrial firms supported an indirect relationship between MO and profitability, mediated by firm effectiveness and sales growth. In addition he found that MO impacted business performance more than any of the other variables considered in the study; industry structure, and strategy (low cost and differentiation). Varela and del Río (2003) investigated the Spanish food, timber and chemical sectors using the simplified 20 item version of the MARKOR scale (Kohli et al., 1993). Their results indicated that timeliness of information collection and dissemination are important elements of a MO firm, as is senior management's cultural orientation and commitment to MO. In the Noble, Sinha and Kumar (2002) study, analysing shareholder letters in US based mass merchandising company annual reports over a period of years, performance was found to be positively influenced by sales orientation, while production orientation and customer orientation were not significantly related to performance assessment by senior executives. Narver and Slater (1990) inferred that market orientation requires long-term attention, and that short-term profitability should not be a primary focus of MO. 
Gray et al. (1998) believed that responsiveness to competitor action (timeliness) and customer requirements is a necessary attribute of market orientation, while Helfert et al's (2002) empirical study indicated that market orientation, leading to resource availability, is an antecedent to successful relationship performance. Studies have demonstrated superior performance of $\mathrm{MO}$ in not-for-profit organisations (Cano et al., 2004). On the other hand resource availability (or operational market orientation) may simply reflect commitment (Morgan \& Hunt, 1994).

Yau et al. (2000) believed that the existing MO instruments did not focus enough on the customer relationship nor capture the effect or impact of relationships on business performance. Therefore they developed a relationship marketing orientation (RMO) instrument, consisting of four components; bonding (four items), empathy (three items), reciprocity (three items) and trust (four items). They found the RMO construct exhibited a significant, and more dominant, impact on business performance than did market orientation as measured by the Narver and Slater (1990) MKTOR instrument. However the RMO instrument only measured relationship and performance, and did not take into account the broader MO perspective such as information collection and competition.

Market orientation "represents the foundation of high-quality marketing practice" (Kohli et al., 1993, p. 467) and has been shown to positively influence customer satisfaction which in turn leads to customer retention and increased profitability (Sanzo, Santos, Vázquez, \& Álvarez, 2003; Singh \& Ranchod, 2004; Storbacka et al., 1994). Although MO is widely viewed as the current basis of marketing philosophy (Hunt \& Morgan, 1995; McNamara, 1972; Sanzo et al., 2003; Varela \& del Río, 2003), Gray et al. (1998) noted that relatively few studies have attempted to generalise the results across multiple industries and that there is more to be learned by using the $\mathrm{MO}$ construct across a range of industries. Other studies suggest that a dyadic approach to MO research may be beneficial since companies may be unable to accurately self-report their customer orientation, implying it is the customer's perception of a firm's market orientation that is related to performance (Deshpandé et al., 1993; S. Henderson, 1998). Within the CRM context MO is best defined around the parameters central to CRM systems and applications and proposed by a number of researchers, which are: focus on customers, data collection, data analysis, responsiveness and dissemination of information (Deng \& Dart, 1994; Kohli et al., 1993; Narver \& Slater, 1990). The majority of definitions consider MO an adequate indicator of the level of market 
philosophy that guides the firm's behaviour towards its customers (Day, 1994; Slater \& Narver, 1995) and may play a key role in the successful adoption of CRM technology (Goodhue et al., 2002). This point is discussed and expanded on further in Section 2.8 Customer Relationship Management.

\subsection{Relationship Performance}

In contrast to business performance measures, such as financial (i.e., ROI) and customer-centric measures (i.e., customer satisfaction and retention) (e.g., Appiah-Adu \& Singh, 1999), relationship performance considers the overall relationship behaviour and reflects customer satisfaction, loyalty, brand

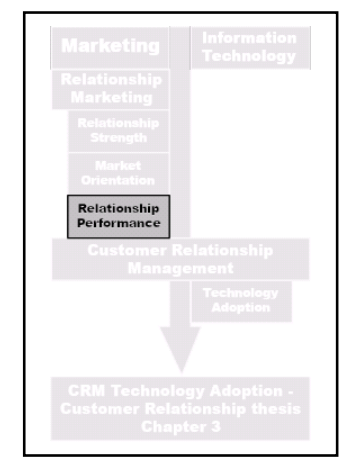
awareness and overall performance compared to competitors, in addition to relationship outcomes (Gray, Matear, \& Matheson, 2002; J. W. Kim et al., 2004). Sales growth and market share have been used as performance measures when investigating trust and relationships across international borders (Aulakh, Kotabe, \& Sahay, 1996).

Relationship performance has been successfully investigated in Chinese supplier firms using subjective measures of commitment and profitability (Wilkinson \& Wiley, 2000)

The different parties within a relationship may have diverse perspectives of the value and performance of the existing relationship yet few studies have attempted to measure relationship performance from both sides of the relationship dyad (Medlin, 2003). K. Kim (2000) investigated the impact of power, trust and commitment within the US industrial machinery industry on the solidarity of relationships between suppliers and distributors. The dependent variable was dyadic solidarity - no other dependent variable was tested or compared. Solidarity referred to the perceived unity, common goals and positive relationships between the matched suppliers and distributors. The matched responses $(n=67)$ to the questionnaire instrument, worded differently for supplier or distributor, indicated that coercive influence is less likely in a relationship built on trust, and commitment may not be sufficient to maintain a mutually beneficial relationship. The author concluded that the dyadic analysis approach is an appropriate method to investigate perceived and actual, firm and relationship performance.

Lages, Lages and Lages (2005) developed a relationship multidimensional scale comprised of: (a) amount of information sharing, (b) communication quality, (c) longterm orientation, and (d) satisfaction with the relationship. The authors found that the 
perception of the relationship between exporter and importer in the UK export industry had a positive affect on export performance as measured through financial performance, strategic performance and satisfaction with the export venture. Other researchers have suggested that under certain circumstances satisfaction with business performance may outweigh a lack of trust within the relationship and that more research needs to be conducted on performance and satisfaction (Geyskens, Steenkamp, \& Kumar, 1999).

Jayachandran et al.(2005) measured customer relationship performance through the firm's self-assessment of customer satisfaction and customer retention and found that CRM technology use had a moderating effect on the association between relational information processes (i.e., information capture, information integration, use and access) and relationship performance. Their sample consisted of 172 key informants (marketing, sales or customer service executives) from a variety of industries. Of the 172 responses however only 48 firms had implemented CRM technology. The Reinartz, Krafft, and Hoyer (2004) study on the other hand indicated that CRM technology use did not appear to significantly and positively effect financial performance. Their study was conducted in the Austrian, German and Swiss financial, hospitality, online retail and power utility consumer markets, using both primary and secondary data sources. The sample consisted of 211 usable responses from executives responsible for CRM operations. One explanation for the different results presented by Jayachandran et al. is that the CRM technology effect may materialise "more easily and earlier on intermediate process measures" (p. 190) than on financial performance outcomes.

The relationship research literature indicates that, depending on the objectives of the research, it may be important to collect both economic and non-economic measures separately and from both the supplier and customer perspectives (Geyskens \& Steenkamp, 2000; Geyskens et al., 1999; Medlin, 2003). These studies also indicate that the source (i.e., objective or subjective) and type of business performance (i.e., financial or non-financial) data is an important consideration and should reflect the purpose of the study undertaken. The scarcity of research investigating the effect of CRM technology adoption on customer relationship performance appears to be a significant research gap and could enrich the relationship marketing literature. 


\subsection{Customer Relationship Management (CRM)}

Although the basis of CRM has been around since 1956 (e.g., the segmentation of discrete customer groups), it is only within the last 6 to 10 years that CRM has created a significant impact in the business world (Nairn, 2002). The management focus on relationship marketing (specifically one-to-one marketing techniques) (Peppers \& Rogers, 1993; Peppers et al., 1999) and

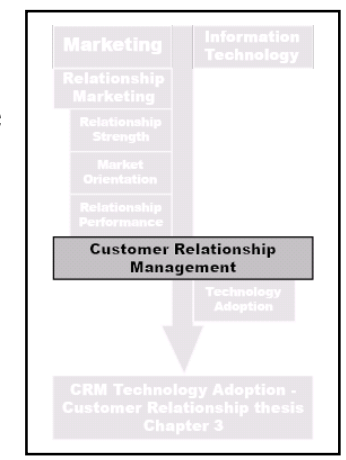
market orientation (focused on collecting, analysing and disseminating large quantities of customer data) helped create the opportunity for CRM technology. The rapid growth of CRM can be attributed to: (a) fierce business competition for valuable customers, (b) the economics of customer retention (i.e., life-time value) and (c) technology advances (Buttle, 2004; Goodhue et al., 2002; Karimi et al., 2001; Ling \& Yen, 2001; Winer, 2001).

CRM has been described from a number of different perspectives including functional, technical and managerial aspects (Doherty \& Lockett, 2007; Ngai, 2005; Sathish, Pan, \& Raman, 2002; Wright et al., 2002). From a management perspective, due to the inherent focus on the customer, CRM is viewed as an important business strategy and philosophy (e.g., Almquist et al., 2002; Beckett-Camarata, Camarata, \& Barker, 1998; Chang, Yen, Young, \& Ku, 2002). Marketing academics view "CRM [as] a concept that adds [practical] value to the meaning of customer orientation" (Wright et al., 2002, p. 340), helps operationalise MO and provides marketing value (e.g., Aspinall, Nancarrow, \& Stone, 2001; Reinartz \& Kumar, 2002; Rheault \& Sheridan, 2002; Ryals, 2005; Srivastava, Shervani, \& Fahey, 1999); while IT researchers appear primarily interested in the technological and implementation aspects of CRM (e.g., Chalmeta, 2006; Cooper, Watson, Wixom, \& Goodhue, 2000; Gefen \& Ridings, 2002; Romano \& Fjermestad, 2001; Wells \& Hess, 2002).

\subsubsection{CRM Definition}

Rigby et al. (2002a) state that most executives cannot readily define CRM, and Greenberg (2002) quotes ten different definitions provided by leading CRM software development business CEOs. Early definitions of CRM focused on the acquisition and long-term retention of customers (Ling \& Yen, 2001; The Data Warehousing Institute, 2000; Wyner, 1999). CRM as a business strategy is another common definition: "CRM 
is an approach or business strategy which provides seamless integration of every area of business that touches the customer" (Sathish et al., 2002, p. 545). Others have defined CRM in terms of the opportunity for profit maximisation, as in attracting and retaining “economically valuable" customers while getting rid of "economically invaluable" ones (Pan \& Lee, 2003; Romano, 2000; Romano \& Fjermestad, 2001). A number of studies take a more integrative and holistic approach to CRM, attempting to define CRM jointly through its relationship with technology and as a business strategy (Bose, 2002; Buttle, 2004; Dibb, 2001; Goodhue et al., 2002; J. Kim, Suh, \& Hwang, 2003; Sathish et al., 2002; The Data Warehousing Institute, 2000). This type of definition moves us closer to capturing the dual aspects of CRM that need to be given consideration when assessing the success or otherwise of actual CRM implementations. Each aspect considered on its own is likely to yield an incomplete picture. Vendor (e.g., Oracle, PeopleSoft, SAP, and Siebel) and practitioner magazine (e.g., destinationCRM.com, CRM Magazine, and CRM Today) definitions focus on the profit potential of CRM technology implementation. For example: “CRM...is a company-wide business strategy designed to reduce costs and increase profitability by solidifying customer loyalty" (destinationCRM, 2002).

CRM technology has also been viewed as providing the "glue" that integrates "front office" (i.e., sales, support and marketing) and "back office" (i.e., ERP and/or order fulfilment) applications for sales and marketing, via tools for detailed analysis and modelling, along with the technology infrastructure to seamlessly provide a single cohesive and comprehensive customer-facing unit (Buttle, 2004; I. J. Chen \& Popovich, 2003). The contemporary view of CRM is defined more around using technology and IT to help manage the relationship with customers. In general, CRM technology defining characteristics and elements found within the extant literature generally focus around the use of IT to: (a) acquire and retain long-term customers, (b) create a (long-term) business strategy, (c) help implement CRM processes, and (d) increase profit (over time).

This study adopts the more holistic CRM approach, reflecting the intent of Gummesson (2004), and Ling and Yen (2001) regarding CRM as a customer-centric business focus, shaped by the market orientation (MO) of the firm and implemented through IT. In particular CRM includes the process of identifying, accepting and 
building appropriate mutually beneficial relationships with each customer (i.e., RM) through the use of technology in order to maximise value for each party.

\subsubsection{CRM IT Operational Model}

At the most rudimentary level CRM functionality consists of contact manager software that captures, stores and retrieves customer information in a stand-alone configuration (e.g., Microsoft Outlook - Contact application) (Zikmund et al., 2003). At the other end of the scale, CRM consists of a number of complex, integrated IT components including data warehouses, data marts, analytical tools and applications used to capture and analyse customer information from a variety of inbound touchpoints, and provides integration to outbound touchpoints (e.g., MySAP and Oracle) (Turban, McLean et al., 2003). The most highly sophisticated systems integrate other functional areas of the business (e.g., incorporates ERP) (Greenberg, 2002; O'Brien, 2004).

There are three main categories of CRM that can be implemented separately, phased in, or integrated from the beginning - analytical, operational, and collaborative CRM. Figure 2.4, adapted from the 2000 TDWI Study (The Data Warehousing Institute, 2000)

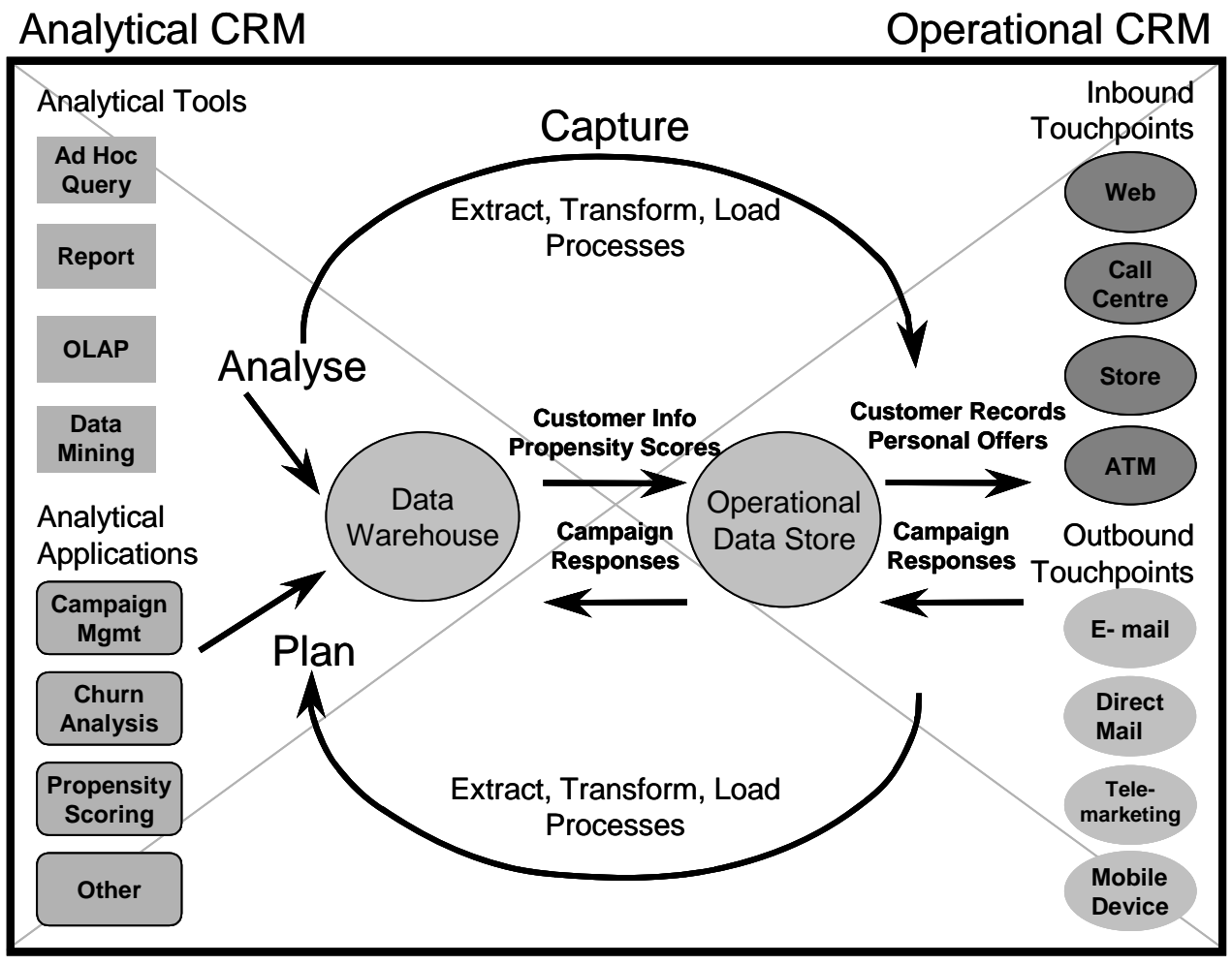

Figure 2.4: CRM IT operational model

Source: Adapted from The Data Warehousing Institute (2000). 
shows the architecture and relationships between the various components in an analytical and operational CRM implementation. Another CRM variant - portal-based CRM creates common Internet based gateways for customers, partners and employees utilising user-specific access to vendor-customer information incorporating analytical, operational and collaborative CRM applications (O'Brien, 2004; Turban, McLean et al., 2003).

\subsubsection{CRM Strategic Model}

The CRM strategic framework is based on the view that effective and successful $\mathrm{CRM}$ is the result of coordinated cross-functional processes and activities within organisations (Payne \& Frow, 2004, 2005, 2006). The five business processes (strategy development, value creation, information management, multi-channel integration and assessment of performance) work together in harmony to provide the greatest value to shareholders and customers. Figure 2.5 illustrates the relationship between the various business process, emphasising the iterative and interactive nature of CRM.

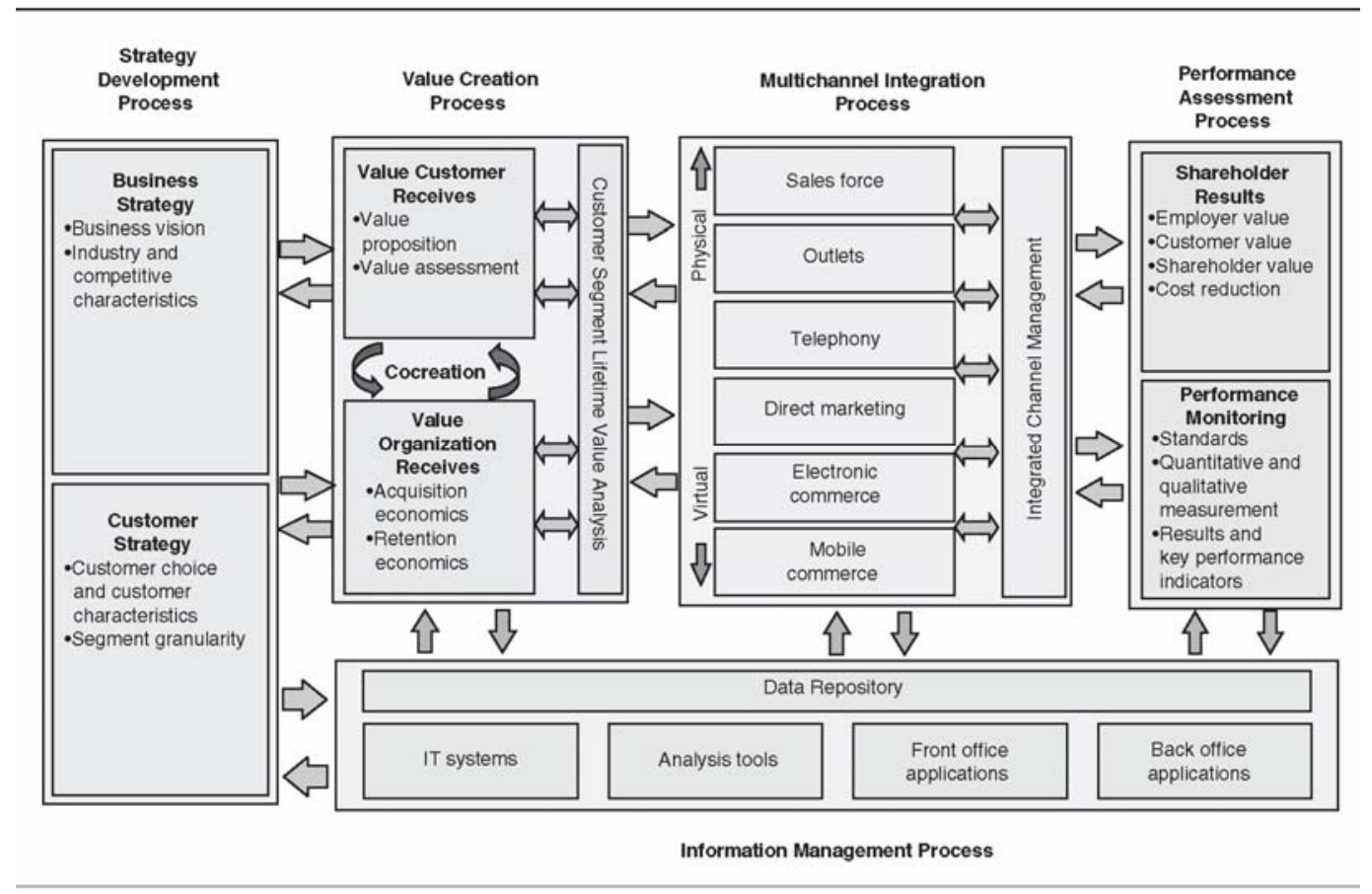

Figure 2.5: CRM strategic framework model

Source: Payne \& Frow (2005)

\subsubsection{CRM Process Model}

This section describes a traditional CRM process and highlights the potential disconnect between the CRM process and a relationship marketing approach. CRM 
systems are an integral component of the information technology growth to support and improve the business "front office" and the customer relationship (O'Brien, 2004; Turban, McLean et al., 2003). CRM technology is an IT application that consists of three basic subsystems - a collection (input) component, a data base component, and a delivery system (Goodhue et al., 2002; Zikmund et al., 2003). Other components may include (but are not limited to) analysis tools and campaign management tools (Ling \& Yen, 2001; The Data Warehousing Institute, 2000). Some research literature differentiates between CRM and e-CRM (electronic CRM) (e.g., Fjermestad \& Romano, 2003; Romano, 2000), while others view e-CRM as an extension of CRM technology into the e-commerce realm, rather than a different application or system (Greenberg, 2002; Turban, McLean et al., 2003).

Figure 2.6 depicts a process model of CRM, which involves (a) collecting customer information on an ongoing basis, (b) using that knowledge to manage customer contact through such activities as marketing campaigns and direct sales promotions, (c) developing business and marketing strategies, (d) developing marketing programmes, and (e) measuring success, while refining and enhancing the customer database (M. L. Roberts, 2003; Zablah et al., 2004). The underlying assumption for the model is that the firm conducts ongoing information collection, refines, enhances and applies the information appropriately. Knowledge about the customer is collected, stored and made available to customer contact personnel. As customer information is analysed, new information is created, stored, transferred and marketing programs created and enacted. Feedback is obtained from the marketplace, customer data is updated and refined, new information is created and new programmes created. This CRM process is iterative and

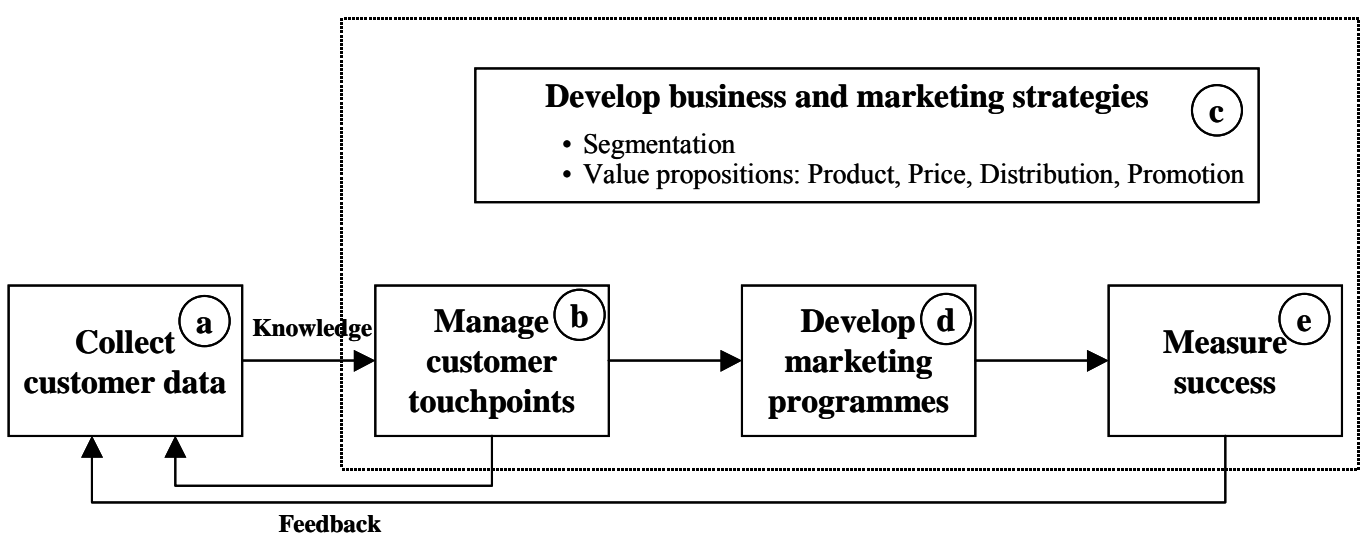

Figure 2.6: CRM process model

Source: Adapted from M. L. Roberts (2003) 
ongoing, and has similarities with knowledge management systems (KMS) (e.g., Alavi \& Leidner, 2001; Shoemaker, 2001; Zablah et al., 2004).

The model is similar to the underlying characteristics of market orientation discussed previously, in that an MO firm is characterised by (a) continuous (near real-time) customer data collection, (b) collecting competitor capabilities information, (c) sharing information across departments and (d) using the information to create customer value (Kerin et al., 2003; Kohli et al., 1993; Narver \& Slater, 1990). However, the problems with this process model include no direct linkages into the other areas of the organisation (e.g., operations, finance and IT), and the fact that it is company focused, not customer driven (cf. Kapoulas, Ellis, \& Murphy, 2004). This traditional marketing product focus, creating value propositions based on the 4P marketing mix model (i.e., process $\mathrm{c}$ in Figure 2.6), highlights a research gap. The traditional CRM process does not adequately take into account the wider perspectives of relationship value and the potential impact of the firm's MO discussed earlier (Grönroos, 1990).

\subsubsection{Current CRM Use}

Today CRM is used primarily by sales, sales support and customer service staff (including call centres and telemarketers) to portray a unified and coordinated point or points of contact to customers. It is also used as a marketing tool to segment and target customers, help develop marketing/sales programmes for targeted customers, and aid in keeping track of customer activities (Ling \& Yen, 2001; Shoemaker, 2001; Speier \& Venkatesh, 2002).

CRM requires the IT, and sales and marketing departments to work closely together if the benefits of CRM are to be properly realised. Yet this has not always been the case (Ryals \& Knox, 2001; Yu, 2001). In addition CRM, by definition, and consistent with an underlying MO philosophy, collects, stores and utilises detailed customer information and hence is potentially a major potential contributor to organisational knowledge and knowledge management (Alavi \& Leidner, 2001; Davenport \& Klahr, 1998; Kerin et al., 2003; Richard, 2003; Zablah et al., 2004).

From the practitioner perspective, CRM technology adds value to the business by: (a) making it easy for customers to do business, (b) focusing on the end-customer for products and services, (c) redesigning customer-facing business processes from the endcustomer's point of view, (d) designing a comprehensive, evolving electronic business 
architecture, and (e) fostering customer loyalty (Turban, Rainer et al., 2003). CRM systems also have the potential to become an integral component of "business fulfilment," adding customer value by integrating all the business components - from sales through distribution (fulfilment) to invoicing and even receivables (Markowitz, 2002).

However, as discussed in detail below, CRM system implementation has received mixed reviews in both the academic (e.g., Karimi et al., 2001; Ling \& Yen, 2001; Speier \& Venkatesh, 2002) and popular literature (e.g., Arnold, 2002; Casselman, 2003; Le Pla, 2002; Markowitz, 2002). The CRM industry suffers from "overpromising and underdelivering" says Craig Conway, PeopleSoft Chief Executive and President, hence CRM is seen as inadequately meeting today's business needs let alone meeting their potential for strategic business value (Markowitz, 2002).

\subsubsection{CRM Issues}

Although CRM is in some important respects consistent with marketing theory (Abbott, Stone, \& Buttle, 2001; Kotler, 2003; Ling \& Yen, 2001), makes good business sense (Buttle, 2004; Greenberg, 2002; Zikmund et al., 2003) and is available today from a variety of suppliers (Turban, McLean et al., 2003), it has continued to face serious difficulties and implementation failures (Adebanjo, 2003; Arnold, 2002; Davids, 1999; Nairn, 2002; O'Brien, 2004; Raman \& Pashupati, 2004; Rheault \& Sheridan, 2002; Turban, McLean et al., 2003). A number of popular business magazines (Le Pla, 2002; Markowitz, 2002), as well as commercial research groups (IDC, 2002) have published scathing reviews on the implementation of CRM technology, focusing on the lack of commercial benefits gained from substantial CRM investment. Successful CRM technology implementation and adoption requires visible, concentrated and long-term senior management buy-in and significant organisational change if its full benefits are to be realised (Bohling et al., 2006; Casselman, 2003; Fleischer, 2002; Ling \& Yen, 2001; $\mathrm{Yu}, 2001)$.

The underlying expectation of CRM technology is to deliver customer loyalty and enhanced corporate profitability, however the META Group states that " $55 \%$ of all CRM projects don't produce results" (R. Davis, 2002; Seligman, 2002). A survey of 1,500 companies found that $91 \%$ of businesses plan or have deployed CRM solutions, however $41 \%$ of the firms with CRM projects were experiencing serious 
implementation problems (The Data Warehousing Institute, 2000). R. Davis (2002) stated that up to $70 \%$ of companies had not realised any benefit from CRM technology implementation or failed to meet basic company goals, such as ROI. This may in part reflect the difficulty in identifying and matching the appropriate CRM investments and returns (Ang \& Buttle, 2002). Other studies indicate that $20 \%$ of senior executives reported that CRM initiatives had failed to deliver profitable growth and in some cases had even damaged existing customer relationships (Rigby et al., 2002a). In response CRM vendors have undertaken new development, focusing on adding additional features, benefits and value (Songini, 2002).

CRM "success" is not well defined in the IT or marketing literature. This can in part be attributed to the difficulty in agreeing on a CRM definition, as well as the different approaches to CRM research. The IT research focuses primarily on conceptualising and understanding CRM system implementation issues (e.g., Brown \& Vessey, 2003; Goodhue et al., 2002; Plakoyiannaki \& Tzokas, 2002), critical success factors (e.g., Bose, 2002; H.-W. Kim et al., 2002; Romano, 2000), and improving the use and adoption of CRM (Ahn, Kim, \& Han, 2003). Other researchers have defined CRM success around the dimensions of systems quality, information quality and user satisfaction, following and adapting the DeLone and McLean IS Success Model (DeLone \& McLean, 1992, 2003; H.-W. Kim et al., 2002). Brown and Vessey (2003, p. 66) defined the IT perspective of CRM implementation success most appropriately and succinctly as: "an up-and-running system with agreed-upon requirements delivered within schedule and budget." There have been relatively few empirical studies attempting to link CRM success directly with business performance or relationship performance metrics such as market share and retention (e.g., Croteau \& Li, 2003; J. W. Kim et al., 2004).

This is in contrast to the marketing research, which has primarily been focused on the impact of CRM on customer relationship measures (e.g., Day, 2000; Garbarino \& Johnson, 1999; Lemon et al., 2002; Reinartz \& Kumar, 2003). This does not imply that marketing researchers have ignored the potential business performance aspects of CRM, and they have found for example that CRM technology tends to positively influence business performance and customer satisfaction measures (e.g., Gummesson, 2004; Raman \& Pashupati, 2004; Reinartz et al., 2004; Srinivasan \& Moorman, 2005). 
CRM marketing research attempts to link success more directly to business performance measures, while also investigating the interaction of RM implementation and IT efficiencies (e.g., Gummesson, 2004; Lemon et al., 2002; Peppard, 2000; Reinartz et al., 2004). The management literature appears to have a more general view of CRM "success" focusing on how to use CRM as a change catalyst to stimulate business growth (Rigby \& Ledingham, 2004; Seybold, 2001) or support customer oriented business strategies (Reinartz \& Kumar, 2002; Winer, 2001; Zeithaml, Rust, \& Lemon, 2001). The extant literature suggests that CRM "success" is predicated on: successful CRM system implementation (Brown \& Vessey, 2003; Ling \& Yen, 2001), CRM's ability to support the customer facing aspects of an MO business approach (Gummesson, 2004; Raman \& Pashupati, 2004), and improving economic performance (Reinartz et al., 2004).

It is evident that the poor results reported for CRM implementation can be partly explained by the conflicting CRM models and related research. Some of the issues related to measures of CRM success include the inability to a) isolate, test and examine CRM technology factors apart from CRM strategic, organisational and business factors; b) correctly isolate and separate CRM investment; and c) identify and measure the dependent variable(s)(e.g., loyalty, retention or profitability) (Ang \& Buttle, 2006; J. Kim et al., 2003; Reinartz et al., 2004). CRM research has tended to emphasise increased profitability, performance improvements and customer retention with little or no focus on measuring relationship development (Aspinall et al., 2001; Hirschowitz, 2001). The limited reports of CRM accomplishment have generally focused on project management success, improved data quality, management leadership and strategic readiness for CRM implementation (Bohling et al., 2006; Bose, 2002; Kennedy, Kelleher, \& Quigley, 2006; Nguyen et al., 2007; Yu, 2001). Others consider the basis of CRM evaluation and success as a customer intimacy issue and that customers should be able to see some improvement in relationship measures from a successful CRM technology implementation (e.g., Payne, 2006).

The CRM implementation challenges have been compared to the early days of ERP implementation, implying that it may only be a matter of time before the factors which make CRM technology successful are understood and measurable benefits are more fully realised (Brown \& Vessey, 2003; Sheng, 2002; Woodcock \& Starkey, 2001; Yu, 2001). The majority of CRM IT research, although focused on what needs to take place 
within an organisation to implement CRM successfully (Chalmeta, 2006; Nguyen et al., 2007) does parallel the business philosophy and MO aspects discussed earlier. Some of the critical factors in CRM implementation, discussed in detail in the next few sections, include: a customer oriented culture; the IT management approach; executive commitment, and the integration of people, process and technology.

\subsubsection{Customer (Market) Orientation}

Both the marketing and IT literatures agree that a customer-centric focus (market orientation) is considered an essential theoretical foundation for CRM success (Davids, 1999; Ling \& Yen, 2001; Lloyd, Scullin, Allora, \& Fjermestad, 2001; Plakoyiannaki \& Tzokas, 2002) and this is supported by case study research from both domains (Abbott et al., 2001; Goodhue et al., 2002; Wright et al., 2002). The case study research, primarily carried out in the U.S.A. and the U.K., emphasises that relationship marketing needs to be accepted as the core strategy across the company and highlights the importance of customer relationships at all levels of the organisation, with customer loyalty a high priority.

Fundamental to CRM strategy development and success, from a marketing outlook, is the need to embrace ongoing relationships with customers (Abbott et al., 2001). Reviews of existing CRM implementations, from both marketing and IT perspectives, highlight the need to develop customer focused business strategies before attempting to implement CRM (Lloyd et al., 2001; Rigby et al., 2002a). In addition the IT literature suggests, for CRM to deliver optimum benefit, this marketing focus must be a business strategy accepted throughout the firm (Ling \& Yen, 2001). Furthermore, marketing research indicates that CRM adds value to the concept of customer orientation. Wright et al. (2002) examined how CRM has altered traditional marketing views. They concluded that CRM technology is only an enabler, while CRM itself is an attitude that must be cultivated in people, processes and management in order for "CRM" to be fully successful. Firms identified as not marketing or customer focused were found to be slow to adopt CRM (Abbott et al., 2001).

The customer centric philosophy that the IT literature discusses is similar to the market orientation concept found in the marketing literature, which highlights a research gap between the two research domains. That is, although the importance of a customeroriented business philosophy has been cited as critical to CRM technology 
implementation success, little empirical research is available in the extant literature linking MO to CRM technology implementation.

\subsubsection{Information Technology Management}

CRM technology implementation success may simply be the result of IT management practices. IT management sophistication describes the level of IT maturity within the firm (Karimi et al., 2001; Stefanou et al., 2003). In an empirical study investigating the role of IT steering committees and IT maturity Karimi, Bhattacherjee, Gupta and Somers (2000) found that IT management sophistication within a firm can be characterised by the degree, complexity and level of IT planning, control, organisation and integration.

A company's IT maturity refers to the focus and capability of the firm to involve (a) top-down planning process linking IT strategy to business requirements, (b) broad distribution of application technology transfer, and (c) effective exploitation of IT through technology integration (Johnston \& Carrico, 1988; Karimi, Gupta, \& Somers, 1996a, 1996b). Karimi et al. (2001), investigating the impact of IT management and leadership on CRM implementation developed a questionnaire to measure IT management sophistication and IT leadership with respect to CRM technology adoption, along with IT's potential for impact on marketing and operations. The authors identified IT-leader firms as having an above average potential for IT to positively impact marketing and operations. IT-enabled customer focused firms have the same potential to impact marketing, but not operations. IT-enabled operations firms have the same potential, as the IT-leader firms, to impact operations but not marketing. The ITlaggard firms have less than average potential for their CRM technology implementation to impact marketing and operations. The results indicated that IT management practices within a firm have significant implications for CRM technology adoption and success, but the authors did not compare the results against existing marketing management practices or the potential effect on customer relationships.

\subsubsection{Executive Commitment}

The IT literature indicates that senior level champions are necessary for IT systems' adoption and success, and CRM is no exception (Beath, 1991; Bose, 2002; Howell \& Higgins, 1990; H.-W. Kim et al., 2002; J. Lee \& Runge, 2001; Ling \& Yen, 2001; Mirchandani \& Motwani, 2001; Palvia \& Chervany, 1995). CRM adoption needs to be 
demonstrated throughout the organisation in order to obtain management and employee buy-in, create or maintain a customer-oriented culture and embrace a culture of change (Fjermestad \& Romano, 2003; Hansotia, 2002; Plakoyiannaki \& Tzokas, 2002). Clear communication and resource commitment from senior management facilitates IT system deployment (Gefen \& Ridings, 2002), and acceptance within organisations; "commitment was needed from people at the top of the company" in order to make CRM "happen” (Abbott et al., 2001, p. 28).

Based on their studies of ERP projects over the last 10 years, Brown and Vessey (2003) found that top management must be "engaged in the project, not just involved" (p. 66) to achieve CRM system implementation success. Croteau and Li (2003) found, in their study of 57 large Canadian firms, significant relationships between senior management support and CRM impact, and also between knowledge management capabilities and RM impact. However the level of sponsorship required varied depending on the organisational level (i.e., departmental or corporate-wide) and sophistication (i.e., personal contact management or enterprise-wide integration) of the CRM system implemented (Gallivan, 2001; Goodhue et al., 2002). The focus, engagement and leadership from senior management plays an essential role in establishing and maintaining customer orientation, reducing resistance, and improving usability - all critical to CRM implementation success (Kennedy et al., 2006; Locander, Hamilton, Ladik, \& Stuart, 2002; Markus, 1983).

The executive commitment factor reinforces the importance of IT management practices and the market orientation of the business firm in the adoption and successful implementation of CRM technology.

\subsubsection{Integration of People, Process and Technology}

Taking an integrative and balanced approach to people, process and technology is important. Speier and Venkatesh (2002) explored the role of the sales person in sustaining CRM practices since adoption is required to support CRM. Their premise was that sales force automation (SFA) provides salespeople with tools which enhance their knowledge of customers, providing the ability to generate better and more timely alternatives and decisions, improving customer relationships and hence productivity. Using a theoretical lens of technical diffusion and identity theory they studied two organisations in which SFA had been rejected in order to ascertain why SFA had failed. 
They concluded that forcing technology sales tools onto an unprepared sales force might create significant conflict within sales people, to the extent that some become disgruntled and voluntarily leave the company. In a similar vein, Bush, Moore and Rocco (2005) found that sales force buy-in, to both the technology and any organisational change, was critical to the successful adoption of CRM.

Sathish, Pan, and Raman (2002) defined a CRM organisation as one that successfully implements a business strategy providing seamless customer touch points through integration of people, process and technology. Plakoyiannaki and Tzokas' (2002) proposed a building block approach to CRM encompassing people, process and technology: (a) create a customer oriented corporate view, (b) focus on customer value creation, (c) collect and transform data to gain customer insight, (d) introduce a knowledge management process for knowledge creation and dissemination, (e) segment markets and prepare profitable customer portfolios, (f) continually define, develop and deliver value propositions, $(\mathrm{g})$ enhance the value proposition through innovative use of campaign and channel management, and (h) measure performance to help decisionmaking. Implementing CRM is thought to not only require significant business process changes, but also is considered a catalyst for business process re-engineering (Hansotia, 2002). A critical element of CRM deployment is understanding existing business processes before CRM is actually deployed (Buttle, 2004).

The impetus for CRM technology infrastructure efforts often comes from the IT group because IT professionals see not only the opportunities for enterprise wide systems, but also difficulties caused by non-standardized infrastructures (Goodhue et al., 2002). However Ling and Yen (2001) theoretically analysed CRM technology implementations and concluded that CRM technology success for firms arises from the successful and innovative utilisation of customer information formed around the effective collaboration of IT and marketing. Although the literature recognises the potential impact of IT to provide the basis for a sustainable competitive advantage (Bharadwaj, Varadarajan, \& Fahy, 1993), it is imperative that IT and marketing departments work closely together on CRM system implementation (Ling \& Yen, 2001; Yu, 2001).

Ling and Yen (2001) proposed a methodology for CRM implementation and suggested firm's need to resolve legacy systems issues and stand-alone product related processes and systems in order to: (a) become customer centric, (b) capture customer 
interactions, (c) exploit knowledge, (d) maximise efficiency from technology, and (e) build flexibility. They suggested that customer profitability analysis, focusing on generic loyalty programs, implementing new IT systems and/or organising around customer segments would not automatically bring success to CRM implementation. They concluded that successful CRM implementation and adoption is not the sole responsibility of the marketing department but is a corporate wide ongoing practice.

Shoemaker (2001) viewed CRM technology as linking available IT applications to a firm's ability to develop market-relating capability. CRM (the customer-facing system) is used to create partnerships and relationships with customers at all touch points. She concluded that CRM, ERP and KM all play a role in the marketing capability of a firm. That is, Enterprise Resource Planning (ERP) provides the internal processes and efficiencies to fulfil customer needs, while Knowledge management Systems (KMS) create, synthesise and disseminate customer knowledge to the advantage of both the customer and the firm. Each system places different demands on management, sales, marketing and IT, and develops different customer expectations.

The people, process and technology focus provides additional support for a more holistic view of CRM technology implementation. Understanding and modifying existing business practices, utilising customer information, and integrating existing IT and manual business systems to provide value to users and customers reinforce the adoption of CRM technology. The impact of people, process and technology on CRM technology adoption has not been specifically investigated with respect to customer relationships.

\subsubsection{CRM Technology Adoption (CTA)}

Technology adoption reflects the willingness of users to accept and use IT technology positively in their environment (F. D. Davis, 1989). Although not specific to CRM technology adoption, the technology acceptance model (TAM) has been widely used to investigate and measure the acceptance of computer technology and

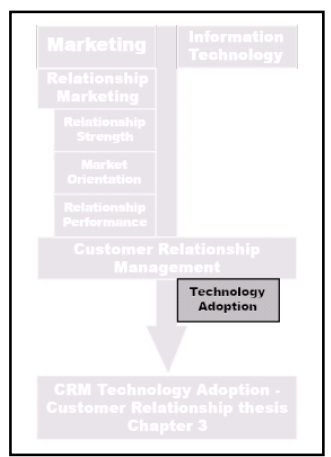
applications within firms (Dishaw \& Strong, 1999; Klopping \& McKinney, 2004; Venkatesh \& Davis, 1996). The TAM is comprised of five key constructs; perceived usefulness, perceived ease of use, attitude toward using, intention to use and actual usage, which are considered key antecedents to technology acceptance (F. D. Davis, 
Bagozzi, \& Warshaw, 1989; Venkatesh \& Davis, 2000). Although there is evidence that user acceptance is important and necessary for CRM technology adoption within a firm, there has been relatively little CRM specific research published in this area (Speier \& Venkatesh, 2002). Wu and Wu (2005), using a modified TAM questionnaire with CIOs as respondents, found among other results, that a user's attitude to use CRM depends on the perceived usefulness and not on ease of use, and that the relative advantage of using CRM technology can predict attitudes to use CRM. In addition trust and perceived ease of use in the online world are intertwined and have been found to be positively related to the use of e-vendor web sites (Gefen, Karahanna, \& Straub, 2003).

CRM technology offers the opportunity to add customer value (and perceived usefulness) through the knowledge management capabilities (Massey, Montoya-Weiss, \& Holcom, 2001; Rowley, 2002; Zablah et al., 2004). Payne and Frow (2005; 2006) view value creation as part of the process involved in a comprehensive CRM strategy. They consider three elements as central to value creation: (a) what value the firm can provide to customers, (b) what value the firm can receive from customers, and (c) managing the value exchange.

Choosing functionality and integrating CRM technology with existing systems presents two of the most difficult and expensive undertakings and has led to perceived CRM failure and user discontent (Brown \& Vessey, 2003; Goodhue et al., 2002; Ling \& Yen, 2001). Raman and Pashupati (2004) asked respondents to identify their CRM system functionality. They found that CRM users categorised functionality as: Sales Force Automation (60.4\%), Collaborative Communication (37\%), Marketing Automation (33.3\%), and Customer Service Functions (25.9\%). In addition, four areas of CRM analytics were identified by the respondents: forecast customer preferences (33\%), evaluate channel performance $(28 \%)$, track customer loyalty $(25 \%)$, and calculate retention rates $(19 \%)$. The measurement technique the authors used allowed respondents to describe the use of CRM technology within their firm; however this technique was limited by the respondents' understanding of technology, their ability to communicate that functionality, and the researcher's interpretation of the respondent's written meaning of the CRM functionality.

Stefanou et al. (2003), in their CRM investigation of large Greek organisations, also collected information regarding the type of IT and CRM systems used. Only descriptive statistics were supplied, with 53.4 percent of the respondents reporting implementing 
ERP systems, 21.9 percent using non-ERP systems and 24.7 percent employing customised or in-house systems. Of concern is that nearly 50 percent of the respondents did not answer this question, possibly reflecting their lack of specific IT system knowledge. Neither study (Raman \& Pashupati, 2004; Stefanou et al., 2003) reported system functionality or integration as a potential independent variable linked to relationship quality or performance. Although there were indications that the level of CRM technology employed did reflect the level of customer-centricity within the firm, it was not related to customer-centric initiatives, such as customer satisfaction research (Stefanou et al., 2003).

The extent of CRM systems integration throughout the organisation has been raised as a potential source of concern for CRM adoption and success (e.g., Ling \& Yen, 2001; Zeng, Wen, \& Yen, 2003). Meyer and Kolbe (2005) identified a number of CRM technology integration layers (social, process, technical and organisational) and characteristics (resource collaboration or communication interaction), and suggested that successful CRM integration included inter-departmental and inter-organisational activities, spanning strategy, processes and systems within and outside the company.

Technology acceptance, functionality and integration, as outlined herein, appear to provide a sound basis from which to investigate CRM technology adoption and the effect on customer relationships.

\subsubsection{CRM Influence on Relationships}

Conceptually CRM technology adoption should enhance the ability for firms to influence and contribute positively to the antecedents and factors affecting trust, commitment and communication quality while helping to initiate, develop and sustain customer relationships (Berry, 1995; Kapoulas et al., 2004; Ling \& Yen, 2001; Mitussis et al., 2006; Too, Souchon, \& Thirkell, 2001). Peters and Fletcher (2004b) demonstrated that by introducing CRM technology responsibly and respecting data privacy issues, customers are more willing to provide additional, detailed and pertinent information to suppliers, which in turn permits suppliers to better satisfy and communicate with customers - gaining their trust and commitment (although this may not always be the case (Croteau \& Li, 2003)). This "better" information and trusting relationship culminates in improved overall performance for the firm, as indicated by business performance and relationship performance metrics (Croteau \& Li, 2003; Karimi et al., 
2001). Mithas, Krishnan and Fornell (2005), in their cross-sectional study of U.S. firms, found a positive effect between CRM technology use and customer knowledge and customer satisfaction. The J. W. Kim et al. (2004) study of 263 Korean appliance manufacturers and retailers found that CRM adoption does improve manufacturerretailer relationship quality in terms of sales effectiveness, relationship strength and marketing efficiency.

Lang and Colgate (2003) demonstrated that customers' expectation and perception of IT significantly influenced their perception of relationship quality in the banking industry. The authors collected questionnaire data from 1,346 New Zealanders $(55.5 \%$ response rate) focused on identifying IT gaps, that is, the difference between a customer's preferred usage of various IT mediums and what is available to them in the banking industry. A positive IT gap meant customers prefer to use more IT for business interaction, while a negative IT gap meant the customer would prefer to use less IT. The results showed that IT had a significant impact on relationships. Trust, satisfaction and conflict showed the most sensitivity to the IT gap, while commitment and social bonding were less so. Lang and Colgate concluded that customers with any perception of an IT gap view their relationship as weaker than those who are satisfied with the level of IT use. Furthermore, understanding how customers want to use IT to interact, and making it as easy as possible to do so, can enhance relationships. Karimi, Somers and Gupta (2001) identified that CRM systems can play a major role improving customer service (customer satisfaction and customer retention). They suggested that further research can be directed at examining integration of CRM technologies, how to use IT to delight, engage, entertain and energize the customer and create a personalised experience for customers. But again there was little mention how CRM technology can help relationships.

Other studies have found that the use of CRM technology and data base applications can build stronger relationship through cross-selling and up-selling (Kamakura, Ramaswami, \& Srivastava, 1991; Kamakura, Wedel, de Rosa, \& Mazzon, 2003). However, Cass and Lauer (2002) examined relationships in the light of CRM technology and concluded that firms manage customers through CRM according to the firm's plan - not the customer's plan. The whole customer (e.g., background, history and experiences) is not recognised through CRM technology, only pertinent transactional attributes (i.e., a reductionist view of the data and the customer) are 
recognised, collected, analysed and dealt with, which may not reflect the actual customer as a person, nor necessarily lead to a mutually valued relationship. Cochran (2004) extended this view further and concluded that if companies did not provide real, tangible customer benefits information sharing will stop and only transactional relationships will persist. Sathish et al. (2002) suggested that considerable research is still required in order to fully understand the CRM phenomenon, but do not mention relationship development or maintenance.

\subsubsection{Other CRM Considerations}

In commercialising CRM applications little focus has been placed on existing RM theory and CRM's potential to develop stronger ties to relationship building at a fundamental level. For example, the CRM business process (refer to Figure 2.6) employs product, price, place (distribution) and promotion as fundamental elements of the business and marketing strategies, yet the current marketing literature views the 4Ps as insufficient to create, develop, sustain or enhance relationships (Grönroos, 1994a; Gummesson, 2002; Vargo \& Lusch, 2004). Although Winer (2001) identified the need for a relationship component within his seven component CRM evaluation framework, he did not expand upon the necessary elements, techniques or applications to achieve or measure this component. Romano (2000) and Romano and Fjermestad (2001) do not specifically include a relationship component in their five areas for future CRM IT research:

1. Markets, consisting of participants, resource allocation, transactions and communications,

2. Business models, involving logistics, communication channels, intermediation, branding and portals and/or hubs

3. Knowledge management (KM), including repositories, ownership, transformation, KM process, and people management

4. Technology, for example user interface, media (voice/video) and virtual reality

5. Human factors including accessibility, usability, privacy, trust, behaviours, and attitudes.

CRM and customer support involves a high degree of data and information management involving a balance between human and computer-based knowledge (Davenport \& Klahr, 1998). Knowledge management capabilities within the 
organisation was found to be one of two key factors affecting CRM impact (Croteau \& Li, 2003); while Shoemaker's (2001) work indicated an opportunity for IT and marketing departments to work together to build knowledge management systems alongside CRM systems to help develop sustainable competitive advantage.

In spite of the recognised high CRM technology implementation failure rate (e.g., Adebanjo, 2003; Fjermestad \& Romano, 2003; Rheault \& Sheridan, 2002), the literature does indicate that CRM technology may provide long-term benefits for business and customers (Bohling et al., 2006; Gummesson, 2004; M. Meyer \& Kolbe, 2005). However two underlying research gaps are apparent: (a) a lack of common CRM knowledge and understanding between technology (IT departments), users (Sales and Marketing departments), and senior management vision and direction; and (b) the lack of focus on the linkage between CRM technology adoption and customer relationships (Ling \& Yen, 2001; Shoemaker, 2001).

\subsection{Customer Relationship Orientation and Customer Expectations}

A B2B relationship consists of two willing parties using relationship components such as mutual trust and commitment to initiate and maintain their relation (Gounaris, 2005; Yau et al., 2000). Yet the relationship process may not be completely reciprocal between the buyer and the seller; in any specific instance sellers may want a relationship while customers may prefer single transactions (Grönroos, 1991). Although there are models that identify the unique perspective of customers in an exchange, few studies have empirically investigated the effect of the customer's orientation toward B2B relationships (Pels, Coviello, \& Brodie, 2000).

The customer's orientation towards initiating and continuing a relationship has an effect on the development of the relationship, and has been shown to moderate the impact of relationship investment and the subsequent outcomes (De Wulf, OdekerkenSchroder, \& Iacobucci, 2001; Palmatier et al., 2006; Peters \& Fletcher, 2004b). Ganesan (1994) found that the customer's relationship orientation played an important part in the development and continuation of relationships. For example, some customers considered short-term relationships advantageous and would pursue short-term gains (i.e., price reduction). Peters and Fletcher (2004b, p. 61) investigated "the relationship orientation exhibited by the respondent towards a company nominated by them [the respondent]" by measuring the customer's trust and commitment, on a seven-item 
instrument. The sample consisted of 108 (22\% response rate) questionnaires completed by customers who had received direct mail within the prior two days. The authors were interested in whether the customer's relationship orientation toward their nominated firm had any bearing on their: (a) information privacy concerns, (b) trust of the use of data collected by firms, and (c) receptivity to direct marketing. The findings suggested that the customer's relationship orientation may be positively influenced by responsible data use. Another study, using a series of four focus groups to investigate customer attitudes toward RM in the financial services industry, found that some customers "did not embrace RM themselves because of an overriding wish to limit and control the boundaries of the relationship" (Kapoulas et al., 2004, p. 41). Furthermore "several ecustomers [bold in original] did not appreciate (nor desire) FSIs' [financial service firms'] attempts to move towards RM, whereas others favoured these latest moves" ( $p$. 39).

In addition customers having a positive relationship orientation may be more inclined to view relationship performance positively, or alternatively imprint specific expectations as to what that relationship should entail (Garbarino \& Johnson, 1999). A case study of an industrial chemical manufacturer found that customers do form additional expectations from a relationship after CRM technology is adopted by the manufacturer (Richard, Thirkell, \& Huff, 2007). There was an expectation that CRM technology-enabled suppliers would understand and deal with customer issues better (e.g., reducing frequency of late deliveries, running out of stock, and improving supply chain management) and that suppliers would have a better overall understanding of the customers' business and therefore better meet the customer's specific needs. Customers also perceived more frequent and productive customer-supplier meetings.

The effect of a customer relationship orientation may moderate the relationship between suppliers and customers in a B2B environment. Similarly customers may develop expectations from a supplier's adoption of CRM technology, which may moderate certain aspects of the relationship performance.

\subsection{Chapter Summary}

The CRM research to date has focused on CRM technology implementation issues, identifying critical CRM success factors (process, management and stakeholders), and highlighting CRM benefit for sales, marketing and the firm (but rarely extended to the 
customer, (cf. Kapoulas et al., 2004)). Market orientation (MO), relationship marketing $(\mathrm{RM})$ and customer relationship management (CRM) are important concepts in current marketing theory and practice. Factors found in the IT and marketing literature that reputably affect CRM adoption and success include:

1. Market orientation (Abbott et al., 2001; Davids, 1999; French, 2001; Goodhue et al., 2002; Ling \& Yen, 2001; Lloyd et al., 2001; Plakoyiannaki \& Tzokas, 2002; Reinartz et al., 2004; Rigby et al., 2002a),

2. IT management orientation (Karimi et al., 2000; Karimi et al., 2001)

3. The ability to build customer relationships (Fournier, Dobscha, \& Mick, 1998; Pan \& Lee, 2003; Rigby et al., 2002a).

4. People, process and technology issues, including CRM acceptance (Lloyd et al., 2001; Speier \& Venkatesh, 2002).

The decision to implement CRM technology can be a change catalyst for business reengineering while refocusing the business on contemporary metrics such as customer lifetime value, retention rate, and customer satisfaction (Goodhue et al., 2002; Shoemaker, 2001). Common themes found in the CRM marketing and IT literatures include the impact of market orientation and the relationship between people, process, and technology. CRM research is also increasing in the areas of customer acquisition, development and retention (Kamakura et al., 2005; Ngai, 2005).

Fundamentally, CRM technology adoption is viewed by both IT and marketing academics and researchers, and portrayed by vendors and academics, as a practical approach to RM (Greenberg, 2002; Gummesson, 2004; Turban, McLean et al., 2003). However there are few empirical studies linking MO, CRM and RM (Tuominen, Rajala, \& Möller, 2004). Additional empirical research linking CRM and market orientation is required in order to help focus the different perspectives and consolidate the current conceptualisations and theory (Helfert et al., 2002).

The level of IT management practices, reflecting the influence of IT management on business practices within a firm, has been shown to effect CRM performance outcomes with respect to customer satisfaction measures (Karimi et al., 2001). However the specific influence of such IT management practices on the adoption of CRM technology within the firm has not been fully investigated. 
There are few CRM studies specifically investigating the impact of CRM functionality adopted or level of CRM system integration within the firm. Although some studies describe the CRM functional components in place at the time of the study (e.g., Abbott et al., 2001; Brown \& Vessey, 2003; Goodhue et al., 2002), most do not. Stefanou et al. (2003) and Raman and Pashupati (2004) are two studies that do identify and collect CRM functionality and integration data from respondents, but give limited discussion to the impact. Another study found that the extent of CRM technology adopted (based on a hypothesised CRM process measured through formative indicators) did not have a significant impact on economic performance (Reinartz et al., 2004). However the impact of the extent of CRM acceptance within a firm on relationship strength and performance (i.e., customer satisfaction, loyalty and retention) has not been adequately investigated or detailed (Raman \& Pashupati, 2004; Stefanou et al., 2003). Other than the more technical issues necessary for CRM technology adoption and success, knowledge utilisation has also been shown to be important to the adoption and success of CRM (i.e., a reflection of CRM usefulness) (Bose \& Sugumaran, 2003; F. D. Davis, 1989).

Little empirical CRM-related research has been undertaken in the areas of initiation, development and sustaining customer relationships. It takes two for a relationship and the customer needs to view the proposal for a relationship and its outcomes positively as well (Fournier et al., 1998). Trust, commitment and communication between the parties have consistently been shown to help create, nurture and enhance customer relationships (Cochran, 2004; Duncan \& Moriarty, 1998; Jutla, Craig, \& Bodorik, 2001; Morgan \& Hunt, 1994; Rosenbaum \& Huang, 2002), and are fundamental for successful RM and CRM. Communication and trust are interlinked; good communications supports trust building, and trust facilitates two-way, open communications (E. Anderson \& Weitz, 1989). Relationships flourish when there is a symmetry, or balance, between the core trust, commitment, and communication relational elements (Lewin \& Johnston, 1997). These core relationship constructs have also been found to help predict relationship performance (Hausman, 2001; Wilson, 1995). Enhanced relationship performance represents outcomes that are efficient, productive and effective, and lead to cooperative behaviour between customers, individuals or partners (Berry, 1983; Morgan \& Hunt, 1994). 
CRM technology is viewed by some as a RM enabler with the ability to help create "relationships" (Almquist et al., 2002; Bose, 2002; Buttle, 2004; Doherty \& Lockett, 2007; Ling \& Yen, 2001; Zablah et al., 2004). Without technology RM implementation is expensive and time consuming but technological advances provide the ability for efficiency gains (Berry, 1995; Goodhue et al., 2002). Tracking, customising, integrating, communicating, minimising errors, augmenting core services and personalising can be implemented quickly and cost effectively through technology (Berry, 1995).

To help overcome Sheth's (2002) concern that the IT focused CRM sales and marketing automation may marginalise marketing and diffuse customer focus, additional marketing and IT cross-discipline research is necessary. It is important for academics, researchers, practitioners and application developers to better understand, not only the impact of CRM technology adoption on relationship and business performance, but also the impact on relationship building since relationships are now considered key to customer retention, customer satisfaction and marketing success. Trust, commitment and communications have been heavily researched with respect to relationships, yet research gaps exist in the area of RM, CRM and relationship performance.

The gaps evident in the extant research include: (a) the discontinuity of CRM related research between the IT and marketing domains; (b) the role of market orientation and IT management orientation in the acceptance, adoption and subsequent success of CRM technology within the firm; (c) the impact of the degree of CRM technology adoption on creation, maintenance and enhancement of B2B customer relationships, and (d) the lack of empirical research linking CRM technology adoption with RM theory and practice (Stefanou et al., 2003). The lack of generalisable research in these areas may be a factor contributing to the high perceived CRM "failures" being cited in the literature. The question not answered is: What is the impact of CRM technology adoption on B2B customer relationships and relationship performance?

The next chapter addresses these gaps in the research by presenting and developing the research model more fully in order to investigate the CRM phenomenon and its affects on B2B relationship strength and performance. 


\section{CHAPTER 3. Research Model and Hypotheses}

\subsection{Introduction}

Chapter 2 provided the literature review and background to the current research and the research model. This chapter formally introduces the conceptual model, outlines the relationships between RM and CRM, the significant research gaps, and presents the research model and hypotheses to be tested.

Relationship marketing (RM) is considered an emerging dominant marketing theory and CRM is an example of a RM application (Gummesson, 2004; Vargo \& Lusch, 2004). However, as Gummesson states in his commentary on Vargo and Lusch's 2004 article discussing technology and marketing, "it has been observed how relationship marketing principles, transformed into customer relationship management software (eCRM), partially get lost by the neglect of human aspects" (Day et al., 2004, p. 21). This apparent disconnect between CRM technology adoption and RM, as well as the gap in knowledge and understanding between CRM application and RM theory is important for academics and practitioners (Helfert et al., 2002). The value and impact of CRM technology adoption on relationship strength and relationship performance requires better understanding and clarification. The research gap linking CRM technology adoption with the relationship side of RM is the focus of this study.

CRM technology and applications has evolved (and continues to evolve) primarily through IT capability and pragmatic business requirements, while the marketing and IT research literature has focused on uncovering and analysing the technical and more general managerial aspects of CRM (Ngai, 2005). There appears to be little published research focused directly on the antecedents and relationship factors that effect the creation and improvement of business relationships through CRM technology. In addition, the linkage between market orientation, IT management orientation and CRM technology adoption needs to be better understood. Understanding these gaps and the CRM application drivers will have implications for the managerial, technical implementation and application development dimensions of CRM technology. 


\subsection{The Conceptual CRM Model and Hypotheses}

Central to the proposed CRM technology adoption - customer relationship (CTA $\mathrm{CR}$ ) model is the view that CRM technology plays a role in B2B relationships.

Although there are few empirical studies in the research literature regarding CRM technology adoption and the effect on relationship strength, there is the implicit belief that CRM technology should positively affect relationships and provide tangible results (Buttle, 2004; Payne \& Frow, 2006). A review of the extant relationship performance literature led to the choice of the key measures. The basic premise is that the customer perspective has been under researched, and that a successful CRM system should provide value to the customer side as well as the supplier side.

One measure of customer relationship success is the strength and performance of the partnership (J. W. Kim et al., 2004). Characteristics of CRM technology that may impact relationship strength and relationship performance include the adoption level of CRM technology within the firm, and the ability to provide timely, accurate and credible information through all customer touchpoints in a seamless and integrated manner (Ngai, 2005; Zikmund et al., 2003). The ability to provide rich multi-media, electronic and interactive communication to customers is another inherent advantage of CRM technology (Geissler, 2001; MacDonald \& Smith, 2004). In addition investing in CRM technology may signal supplier commitment to customers and thus be considered a specific investment in the business relationship (Ganesan, 1994; Rokkan, Heide, \& Wathne, 2003).

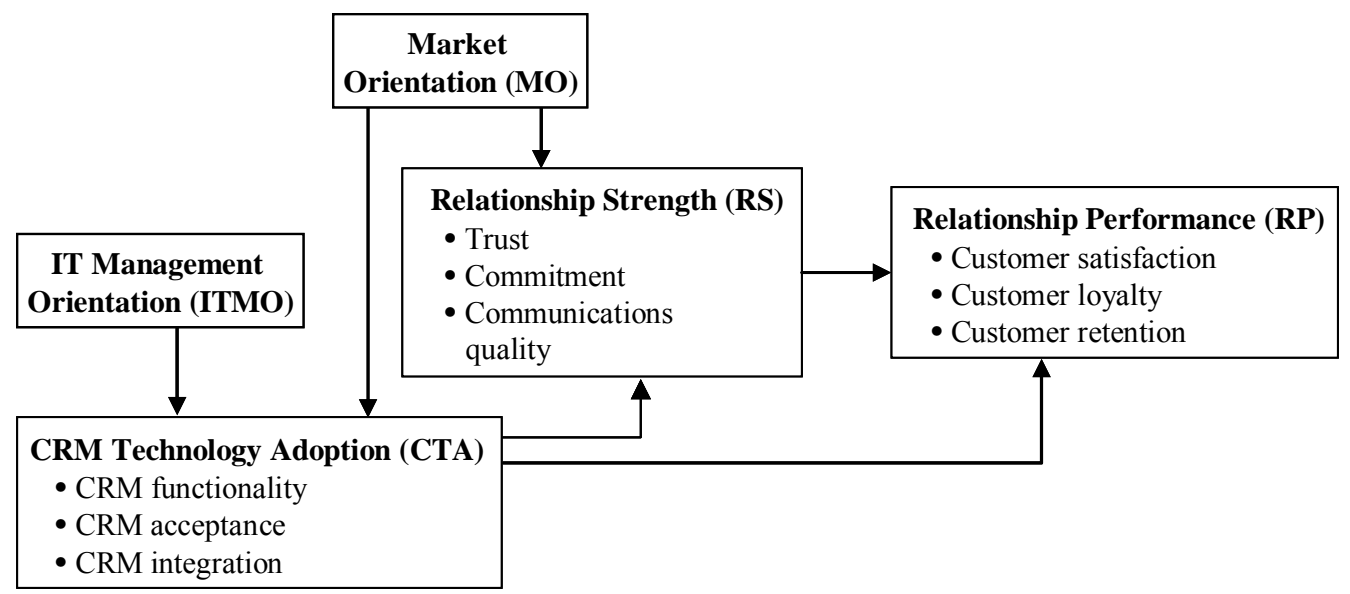

Figure 3.1: CRM technology adoption - customer relationship conceptual model 
Each component of the conceptual CTA - CR model in Figure 3.1 will now be discussed in detail.

\subsubsection{Market Orientation (MO)}

The extant literature suggests that market orientation (MO) positively affects CRM adoption and customer relationships (Farrelly \& Quester, 2003; Ling \& Yen, 2001; Sanzo et al., 2003). Market orientation reflects a company culture focused on the customer (Day, 1994; Kirca, Jayachandran, \& Bearden, 2005; Noble et al., 2002). In a highly market-orientated firm there is continuous and ongoing information collection and internal dissemination of customer and competitor data (Deng \& Dart, 1994; Kohli \& Jaworski, 1990). The orientation (culture) of the firm is considered to play a major role in the successful adoption, implementation and acceptance of CRM technology (Raman, Wittmann, \& Rauseo, 2006; van Bentum \& Stone, 2005). A number of marketing and IT researchers have highlighted that preparing the organisation with the right business and management culture and processes is paramount for the successful implementation of CRM technologies (J.-S. Chen \& Ching, 2004; Goodhue et al., 2002; M. L. Roberts, Liu, \& Hazard, 2005). "The presence of a customer-centric organizational culture makes the introduction of a CRM strategy much less threatening to the company's people” (Buttle, 2004, p. 45). As Rigby et al. (2002a, p. 103) state, "installing CRM technology before creating a customer-focused organization is perhaps the most dangerous pitfall."

Facets of the firm's culture, particularly market orientation, have been demonstrated through case study to positively affect CRM implementation and performance results (Abbott et al., 2001; Goodhue et al., 2002). It is postulated therefore that the firm's existing MO will have an effect on employee adoption of CRM technology, as well as the perception of relationship strength when CRM technology is implemented. This leads to the following two hypotheses:

$H_{1}$ : The greater the level of market orientation of the firm the greater the CRM technology adoption within the firm

$\mathrm{H}_{2}$ : The greater the level of market orientation of the firm the greater the overall relationship strength between the firm and the customer. 


\subsubsection{IT Management Orientation (ITMO)}

A firm's IT management orientation, reflecting the level of IT management practices, planning, organisation and control, has been demonstrated to influence the acceptance and adoption of information technology solutions (Karimi et al., 1996a; Karimi et al., 2001; Sabherwal \& Kirs, 1994). The IT management responsibility has changed substantially over the years necessitating a broadening of skills in operations, strategy and management in order to understand the potential impact of IT on business (Applegate \& Elam, 1992). IT executives now play a key role in business strategy development, identifying IT value for functional areas, and working closely with other senior managers to implement IT business solutions (Enns et al., 2003; Feeny, Edwards, \& Simpson, 1992; Stephens, Ledbetter, Mitra, \& Ford, 1992). This more strategic IT function necessitates both business nuance and IT sophistication in order for the IT executive to be effective (Enns et al., 2003; Sabherwal \& Kirs, 1994). In addition, IT management within the organisation can play a major role with respect to what type of CRM technology and functionality is purchased, implemented and supported (F. D. Davis, 1989; Ling \& Yen, 2001; Ngai, 2005; Romano \& Fjermestad, 2001).

The firm's IT management sophistication and IT leadership position may reflect the technical orientation of the firm as well as the relative importance placed on the decision to implement CRM technology. IT management practices have been shown to affect the organisation's ability to utilise technology in support of marketing (Karimi et al., 2001). In particular, firms that have strong IT leadership and demonstrate IT management sophistication through technology use benefit more from technology (Karimi et al., 1996a). In the context of this study IT management orientation is considered to influence the functionality (analytical, operational, collaborative), user acceptance, and level of integration (departmental or enterprise-wide) of the CRM technology solution (Karimi et al., 2001; Ling \& Yen, 2001). Hence IT management orientation is expected to play an important role in the implementation, utilisation and adoption of CRM within the organisation (Karimi et al., 2001). This factor is reflected in the IT management orientation (ITMO) construct and leads to the following hypothesis:

$H_{3}$ : The greater the level of IT management orientation of the firm, the greater the CRM technology adoption. 


\subsubsection{CRM Technology Adoption (CTA)}

Implementing CRM technology within a firm is thought to positively affect the initiation and development of relationships (Berry, 1995; Ling \& Yen, 2001). However an organisation can implement a wide variety of CRM applications and systems (Abbott et al., 2001; Buttle, 2004; Computerworld, 2004; Goodhue et al., 2002). And although it is possible to determine whether a firm has CRM technology or not, the type, extent, sophistication, user acceptance, and integration of the CRM technology implementation within a firm is important to the effectiveness and utilisation (Karimi et al., 2001; Raman \& Pashupati, 2004; Speier \& Venkatesh, 2002; Stefanou et al., 2003). Although there may be strategic business reasons for CRM technology implementation, the purpose of the CRM technology adoption scale is not to address this aspect, but rather to focus on the technology adopted by the user of the CRM system.

A CTA scale is proposed in order to establish a standardised method of measuring the degree of CRM technology adoption within a firm. CRM systems are rarely explicitly defined operationally in the research literature, making it difficult to compare studies and results (cf. Raman \& Pashupati, 2004). The academic and practitioner literature reports of implemented CRM technology range from databases, call centres, data analysis tools, e-mail, Internet and group support systems (i.e., Lotus Notes) to sophisticated SAP systems (Abbott et al., 2001; Computerworld, 2004). There is a need for a standardised CRM technology adoption scale reflecting:

1. Functionality (i.e., type of CRM technology) (Gefen \& Ridings, 2002; Karimi et al., 2001; Ling \& Yen, 2001),

2. The acceptance level (and extent of use) within the firm (F. D. Davis, 1989; Gefen \& Ridings, 2002; Goodhue \& Thompson, 1995; Speier \& Venkatesh, 2002), and

3. The level of integration with existing organisational IT systems and processes (Buttle, 2004; Ling \& Yen, 2001).

Based on the theoretical foundation that CRM is a special application of RM, the extent of CTA technology adoption is proposed to be positively linked to both relationship strength and relationship performance (Gummesson, 2004). 


\subsubsection{CRM Functionality}

CRM functionality refers to the CRM applications introduced into the firm. CRM applications and systems encompass a wide range of products and services from a variety of suppliers (Computerworld, 2004).

Other than the Raman and Pashupati (2004) paper few other studies have focused on CRM functionality and the potential effect on outcomes. Due to the wide variety of CRM applications and functionality available, a CRM technology continuum is conceptually appropriate in order to determine where a firm "sits" relative to other firms. At the extremes of this continuum are "contact manager" applications (e.g., Microsoft "Outlook") at one end, and CRM enterprise suites, highly sophisticated client/server applications, offering 360 degree views of the customer (e.g., MySAP, Siebel, PeopleSoft) at the other (Buttle, 2004; Greenberg, 2002; Turban, McLean et al., 2003; Zikmund et al., 2003).

\subsubsection{CRM Technology Acceptance}

User acceptance relates to the habitual use of the technology, as part of the job function to achieve results (F. D. Davis et al., 1989). The desired results in the case of CRM technology can be described as collecting customer information, accessing, and using that customer information on a regular basis to complete the job requirements ( $\mathrm{J}$. W. Kim et al., 2004). User acceptance can also be influenced by a number of factors including perceived ease of use, attitude toward the system, and usefulness (F. D. Davis et al., 1989; Frambach, 1993). As Speier and Venkatesh (2002) demonstrated user acceptance is necessary for CRM technology to be successfully adopted within the firm. Perceived use and usefulness of CRM technology within an organisation reflects the user's utilisation of the CRM applications and technology. Due to the nature of the CTA construct, the higher the level of CRM technology acceptance within the firm the more likely perceived and measurable benefits will accrue to both users and customers.

\subsubsection{CRM System Integration}

The implementation of an enterprise wide CRM system is not generally a "turnkey" solution, due to idiosyncratic business processes, procedures and customer interfaces (Gefen \& Ridings, 2002). However purchasing and implementing stand-alone CRM software such as ACT! requires little integration on a PC or in a small business 
environment and is relatively simple. Organisations implementing CRM technology may incorporate any combination of operational, analytical and/or collaborative CRM, in any number of variations (e.g., ACT!, 2004; Epiphany, 2004; Microsoft, 2004; Oracle, 2004; PeopleSoft, 2003; SAP, 2004; SAS, 2004; Siebel, 2004).

A number of researchers have indicated the importance of system integration as a critical success factor of CRM technology implementation (Bull, 2003; Goodhue et al., 2002; M. Meyer \& Kolbe, 2005; Plakoyiannaki \& Tzokas, 2002). There are two aspects of systems integration that are pertinent to CRM technology adoption: first, integration into existing legacy systems and organisational applications; and second, integration across other functional customer touchpoints (Buttle, 2004; Payne \& Frow, 2006). The ability to link the CRM system to finance, operations, distribution, and human resources provides additional value to users, and potentially to customers: customer queries and complaints can be handled more professionally with credible, accurate and timely information.

Similarly, integrating call centres, e-mail and websites through CRM technology provides the opportunity for seamless and transparent customer touchpoints. The extent of CRM integration within the firm should manifest itself in the customer's perceived relationship strength and performance and leads to the following two hypotheses:

$\mathrm{H}_{4}$ : The greater the level of CRM technology adoption within a firm the greater the overall relationship strength with customers.

$H_{5}$ : The greater the level of CRM technology adoption within a firm the greater the relationship performance.

\subsubsection{Relationship Strength (RS)}

Although there are no strict definitions of relationship strength (RS) in the literature, RS has been considered a higher-order construct by most relationship researchers in both the business-to-consumer and business-to-business environments (Lages et al., 2005). For example, a number of studies have defined RS as consisting of a variety of dimensions including trust, commitment, communication quality, information sharing, conflict, long-term relationship orientation, satisfaction, opportunism and customer orientation (Crosby et al., 1990; Dorsch et al., 1998; Lages et al., 2005; Lang \& Colgate, 2003; Storbacka et al., 1994; Wong \& Sohal, 2002). Trust and commitment are central to most evaluations of relationships and can not be easily discarded (K. Roberts et al., 
2003). Similarly communication is generally considered a key antecedent or driver of relationships and relationship quality (Duncan \& Moriarty, 1998; Lages et al., 2005; Morgan \& Hunt, 1994). More importantly, CRM technology provides the potential for extensive, frequent and bidirectional communication beyond traditional communications media (i.e., telephony and postal service). Hence the communication aspect is considered an important aspect of RS within the CRM context. The other factors noted above have been shown to be dimensions of RS in specific circumstances. For example, information sharing in UK export industry (Lages et al., 2005) or conflict in consumer services (K. Roberts et al., 2003). Relationship strength in this study encompasses the dimensions of trust, commitment and communications quality expressed by the customer, and reflecting the influence of MO and CTA within the supplier firm. In addition it is proposed, based on prior research, that relationship strength is positively related to relationship performance (Lages et al., 2005).

\subsubsection{Trust}

It is not uncommon to define trust narrowly based on the theory being tested and the paradigm being used (McKnight \& Chervany, 1996). Trust has been defined, used and studied extensively in the area of relationship initiation, development and maintenance (Berry, 1995; Morgan \& Hunt, 1994). Elements of trust are considered to play a significant role in the initiation, development and maintenance of relationships and are central to the concept of RS (K. Roberts et al., 2003). Trust is just as important in the online environment, affecting customer's perceptions and willingness to participate and establish relationships with suppliers online (Gefen et al., 2003; E. Kim \& Tadisina, 2003; Pennington, Wilcox, \& Grover, 2004; Rosenbaum \& Huang, 2002). Since CRM technology incorporates aspects of the online environment, the RS trust factor may be affected by CRM technology adoption.

The trust typology proposed by Sako (1992) incorporating contractual trust, competence trust and goodwill trust, is used to define trust in this study.

\subsubsection{Commitment}

Commitment is considered necessary for relationship continuation, an antecedent to customer retention, and to positively affect relationships (Helfert et al., 2002; Morgan \& Hunt, 1994; Verhoef, 2003). However not all studies have demonstrated that commitment leads to customer retention (Gruen et al., 2000). Antecedents to 
commitment include forming a psychological attachment or affective commitment, deploying superior resources compared to the competition, and working together to provide customer preferred solutions (Garbarino \& Johnson, 1999; Lewin \& Johnston, 1997). From this perspective the affective and calculative classifications of commitment provide a useful typology to study relationship commitment (Gounaris, 2005).

CRM technology adoption may be considered as committing resources toward the relationship in the form of a transaction specific investment (TSI) (J. W. Kim et al., 2004). Some TSIs has been demonstrated to improve relationships between retailers and suppliers by indicating commitment to customers (Ganesan, 1994). However the nature and perceived benefit of the TSI may dictate whether there is any improvement in relationship quality (J. W. Kim et al., 2004). The adoption of CRM technology by a supplier may be viewed as an instrumental component, or affirmative action, demonstrating customer commitment - that is, by collecting and utilising customer data to develop value congruence. Offering leading edge technology, like CRM, in order to provide superior customer solutions exhibits greater resource deployment. In addition CRM technology implementation may be interpreted as attempting to form affective bonds, through acknowledging the values and goals of customers (Gundlach et al., 1995).

\subsubsection{Communications Quality}

Some researchers consider communication as the basis for relationships or even as the foundation of a marketing model (Duncan \& Moriarty, 1998; Lewin \& Johnston, 1997). Effective quality communication aids relationship initiation and building, and is brought about through timeliness, frequency, accuracy, completeness and credibility (Mohr \& Sohi, 1995; Mohr \& Spekman, 1994). Timeliness of the information has been shown to be important in relationship building in that the more timely the information the greater the trust (Moorman et al., 1993). Mohr and Sohi (1995) also demonstrated that frequency (and feedback) were viewed as positive attributes of quality communication, while formal and informal sharing of meaningful and timely information has been shown to significantly contribute to relationship commitment and trust (J. C. Anderson \& Narus, 1990; N. Sharma \& Patterson, 1999).

CRM technology is considered by many as possessing the potential to develop improved bilateral communication (interactions) with customers, and implement one-to- 
one marketing techniques to a broad customer base (Dibb, 2001; Gummesson, 2004; Ling \& Yen, 2001; Winer, 2001; Yu, 2001). Therefore the adoption of CRM technology by a firm has the potential to improve the communications quality between the firm and the customer within a relationship.

As Sharma and Patterson (1999, p. 163) state "regular communications can help develop a sense of closeness and ease in the relationship, and be instrumental in building emotional and social bonds, thus making the relationship more resistant to the occasional problems that inevitably develop from time to time."

This study views communication quality as a construct based on attributes such as communication frequency, openness, formality, and bidirectionality.

\subsubsection{Relationship Performance (RP)}

Financial business performance will not be addressed directly in this study for two reasons. First, Lages, Lages and Lages (2005) have already demonstrated that relationship strength has a positive effect on business performance. Second, traditional marketing metrics (i.e., market share) and business performance measures (i.e., sales growth) may not be appropriate to evaluate relationships and CRM (Payne \& Frow, 2005). For example, an increase in market share (objective measure) may develop from new marketing and sales initiatives, not necessarily from the adoption of CRM technology. Similarly "objective" profitability measures would not demonstrate whether profitability was improved by enhanced business relationships or merely from the acquisition of a new major customer. As Parvatiyar and Sheth (2000, p. 24) indicate "if the purpose of a particular relationship marketing effort is to enhance distribution efficiencies by reducing overall distribution cost, measuring the program's impact on revenue growth and share of customer's business may not be appropriate". Although a balanced scorecard approach has been used to measure RM performance, other measures such as relationship satisfaction and loyalty have also been successfully utilised (Parvatiyar \& Sheth, 2000; Reichheld \& Sasser, 1990). Therefore relationship measures were favoured over more "objective" market- or financial-based measures (Bharadwaj et al., 1993).

Compared to relationship strength, relationship performance considers the overall relationship behaviour and reflects the ongoing quality of the relationship and encompasses customer satisfaction in addition to relationship performance (J. W. Kim 
et al., 2004). That is, one may trust the other party to behave in a certain manner, be committed to purchase from them due to price, and even communicate frequently, but yet not be a satisfied or loyal customer. Improvement in RP is considered a driver of CRM technology implementation in business, yet there are few CRM specific quantitative studies that investigate this linkage (Firth, 2001; J. W. Kim et al., 2004; Reinartz et al., 2004; Zeithaml et al., 2001). Relationship performance captures outcomes of the relationship through measures of customer satisfaction (Farrell \& Oczkowski, 2002; Guo, 2002; Stefanou et al., 2003; Verhoef, 2003; Webster, 2000), customer retention (Croteau \& Li, 2003; Jutla et al., 2001; J. W. Kim et al., 2004) and customer loyalty (Matear, Osborne, Garrett, \& Gray, 2002; Sanzo et al., 2003; Webb, Webster, \& Krepapa, 2000). Relationship performance is measured separately as a consequence of relationship strength (Hausman, 2001), and leads to the following hypothesis:

$H_{6}$ : The greater the level of relationship strength the greater the relationship performance.

\subsubsection{Moderator and Control Factors (secondary hypotheses)}

A customer's preference for a relationship has been found to influence the desire and appreciation of relationships (Kapoulas et al., 2004; Peters \& Fletcher, 2004b). Hence customer relationship orientation (CRO) was included as a potential moderator of customer perceived relationship strength and relationship performance. Similarly, customers have been shown to form expectations from a supplier's adoption of technology which may influence how customers perceive the relationship and the relationship performance (Garbarino \& Johnson, 1999; Richard et al., 2007). Therefore customer CRM expectations (CXP) were also included as potential relationship moderators.

$H_{7}$ : The greater the level of customer relationship orientation the greater the CRM technology adoption effect on (a) relationship strength and (b) relationship performance.

$H_{8}$ : The greater the level of customer CRM expectation the greater the CRM technology adoption effect on (a) relationship strength and (b) relationship performance. 
Market turbulence (MT) and technological turbulence (TT) within the business environment have been shown to interact significantly with key variables in marketing studies investigating MO and business performance (Pelham, 1999; Pulendran, Speed, \& Widing, 2003), although not in all cases (Jaworski \& Kohli, 1993; Subramanian \& Gopalakrishna, 2001). Market turbulence reflects the relative stability or volatility of a firm's customer composition and preferences, as well as the rate of that change within the industry (Kohli \& Jaworski, 1990). For example, a firm whose customers have rapidly changing preferences may require a higher level of market orientation (i.e., need to be more in tune with customer needs) in order to succeed. Technology turbulence refers to the rate of business technology innovation, as well as product innovation, in the industry (Appiah-Adu, 1997; Kohli \& Jaworski, 1990). Firms competing in a extremely technology turbulent industry may not require as high a level of market orientation to succeed since early technology adoption is highly valued by customers in these industries (Appiah-Adu, 1997). Since market orientation (MO) and IT management orientation (ITMO) were considered antecedent variables, MT and TT were included as potential moderator factors in the research model. This leads to the following hypotheses:

$H_{9}$ : The greater the level of market turbulence the stronger the market orientation effect on CRM technology adoption.

$H_{10}$ : The greater the level of technology turbulence the stronger the (a) market orientation effect on CRM technology adoption, and (b) the IT management orientation effect on CRM technology adoption.

\subsection{Research Model Summary}

The initial CRM technology adoption - customer relationship (CTA - CR) research model, Figure 3.2, summarises the hypothesised linkages between the proposed constructs under investigation in this study. The hypothesised positive impact of a supplier firm's market orientation (MO) $\left(\mathrm{H}_{1}\right)$ and IT management orientation (ITMO) $\left(\mathrm{H}_{3}\right)$ on CTA are considered. Central to the model acceptance is the hypothesised positive effect of CRM technology adoption (CTA) on customer perceived relationship strength $(\mathrm{RS})\left(\mathrm{H}_{4}\right)$ and relationship performance $(\mathrm{RP})\left(\mathrm{H}_{5}\right)$. The two variables, customer relationship orientation $\left(\mathrm{H}_{7 a}\right.$ and $\left.\mathrm{H}_{7 b}\right)$ and customer CRM expectations, $\left(\mathrm{H}_{8 a}\right.$ and $\left.\mathrm{H}_{8 b}\right)$ believed to moderate CTA's effect on RS and RP are also considered and tested. 


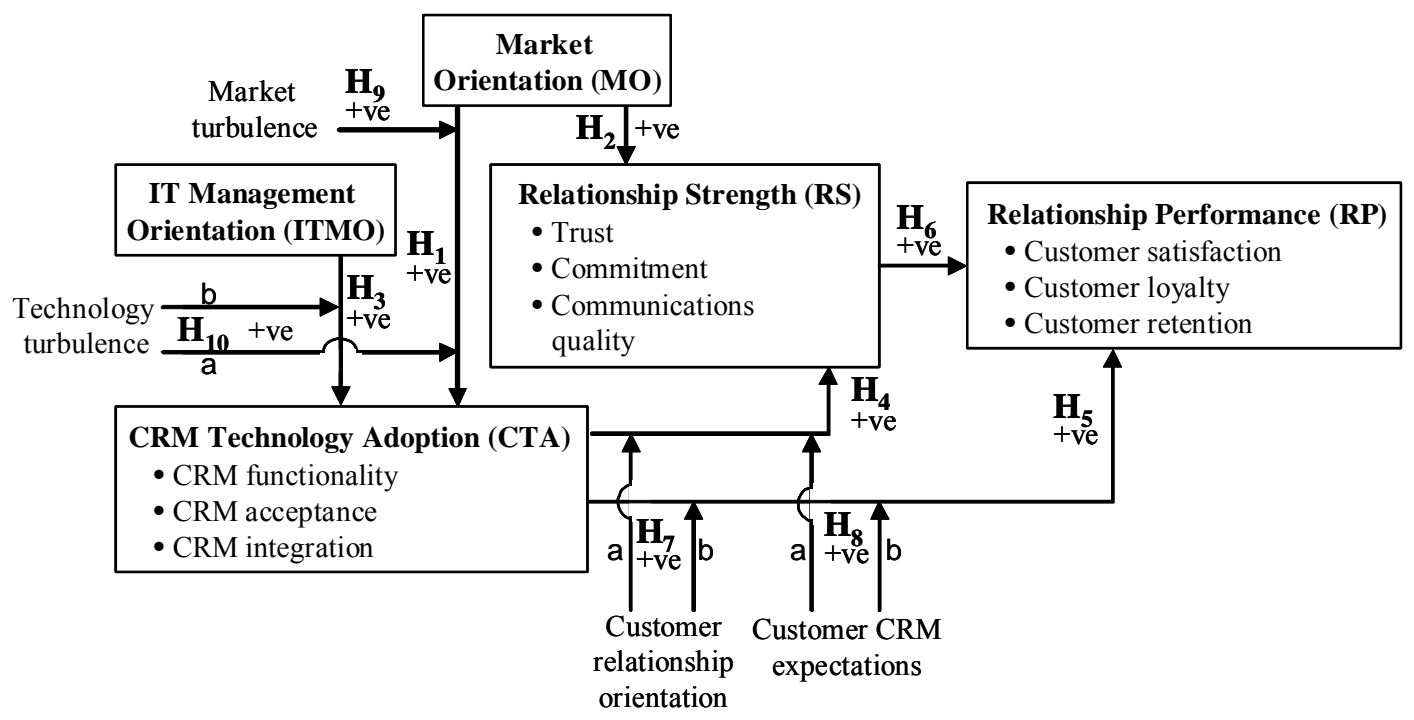

Figure 3.2: CRM technology adoption - customer relationship research model and hypotheses

In addition the research model considers the moderating effect of market turbulence $\left(\mathrm{H}_{9}\right)$ and technology turbulence $\left(\mathrm{H}_{10 a}\right)$ on the effect of market orientation on CTA. The hypothesised moderating effect of technology turbulence on IT management orientation on CTA is also considered $\left(\mathrm{H}_{10 b}\right)$. The direct effect of market orientation on relationship strength is also tested $\left(\mathrm{H}_{2}\right)$, as is the direct effect of relationship strength on relationship performance $\left(\mathrm{H}_{6}\right)$.

\subsection{Chapter Summary}

This chapter described the proposed research model under investigation in this study. The need for a CRM technology adoption measure and constructs for operationalisation was discussed. Each of the five major model components were discussed with respect to the linkages between each construct and ten hypotheses were proposed for testing. The study investigates the relationship between CRM technology adoption and key relationship constructs. Chapter 4 now discusses the research methodology that will be used to carry out the research to answer the research question. 


\section{CHAPTER 4. Research Methodology}

\subsection{Introduction}

Following the development of the research model and hypotheses in Chapter 3, the purpose of this chapter is to discuss the methods used for refining, validating and testing the model. The chapter begins with an overview of the general research paradigms and approaches utilised in the research, followed by a description of the exploratory and explanatory research phases of the study. The procedures adopted for sample selection, data collection and data analysis are also discussed.

\subsection{Research Paradigm}

A research paradigm underlies the researcher's basic beliefs of inquiry, it is "a set of linked assumptions about the world which is shared by a community of scientists investigating that world" (Deshpandé, 1983, p. 101) and acts as "a criterion for choosing problems that ... can be assumed to have solutions" (Kuhn, 1996, p. 37). The nature of the positivist paradigm is that there is a single reality that exists, objectively measurable, inherently understandable and outcome oriented. A post-modernist paradigm (e.g., constructivism, interpretivist, or participatory) considers reality as a social construct, interpreted by people based on their participation in events (Lincoln \& Guba, 2000). The interpretivist paradigms tend to deeply explore, richly describe, and holistically understand the phenomenon in detail, while the positivist paradigm forms the basis of scientific tradition and, although not limited to, underlies most experimental and quantitative research methods (Deshpandé, 1983; Gummesson, 2003; Hirschman, 1986; Lincoln \& Guba, 2000; Marsden \& Littler, 1996). A post-positivist paradigm is not as extreme as the positivist view, in that it accepts an imperfect reality which is mostly perceivable and understandable, providing outcomes and research findings that are probably true (Hunt, 1990; Lincoln \& Guba, 2000; Shrivastava \& Kale, 2003).

Choosing a research method is generally based on (a) the researcher's view of reality (ontology), since this influences the choice of research methodology (Chung \& Alagaratnam, 2001; Hirschman, 1986); and then (b) the requirements stemming from the central research question and the objectives of the research (Stake, 1994, 2000; Yin, 2003). CRM research in the marketing and IT domains have utilised both qualitative research methods for theory building (e.g., Abbott et al., 2001; Goodhue et al., 2002; 
Kapoulas et al., 2004; Wells \& Hess, 2002), and quantitative methods for theory testing (e.g., Croteau \& Li, 2003; Karimi et al., 2001; Peters \& Fletcher, 2004b; Reinartz et al., 2004; Rosenbaum \& Huang, 2002). The CRM phenomenon under study includes both subjective and objective aspects of business outcomes (John \& Reve, 1982). That is, the study includes objective measures as well as subjective perceptions of the people who form relationships within the B2B context (Medlin, 2003). The post-modernist paradigms are more subjective in nature, with constructed meaning or interpretation having more value than measurement and hence are not generally considered appropriate for survey or experimental research (Perry, Riege, \& Brown, 1999). The post-positivist paradigm is suitable for both qualitative and quantitative research and is the perspective adopted by the researcher in this study (Chung \& Alagaratnam, 2001; Lincoln \& Guba, 2000).

In consideration of the objectives of the study and the phenomenon itself, a postpositivist paradigm is appropriate (Hunt, 1990; Perry, 1998). Next the research methodology is discussed, consisting of an exploratory phase and an explanatory phase.

\subsection{Exploratory Research Phase}

The exploratory phase of the research was conducted using the qualitative methodology described by Creswell (1998; 2003) and Yin (2003). This phase is used to explore and better understand how managers and customers perceive the specific business relationships, aspects and issues emanating from CRM technology implementation within organisations (Denzin \& Lincoln, 2000).

\subsubsection{Exploratory Phase Approach and Objectives}

Qualitative research "help[s] the researcher to understand the potential survey respondents' general perspective on the issues, frame of reference, way of thinking, and typical vocabulary" (Alreck \& Settle, 2004, p. 386), thereby providing a detailed and rich understanding of the CTA - CR phenomenon. A dyadic multiple case design was chosen since it is considered superior to single-case design, in that it provides additional data points, more generalisable results, and more convincing conclusions (Yin, 2003). Multiple-case design has been used successfully by a number of CRM researchers (e.g., Abbott et al., 2001; Goodhue et al., 2002). 
The scope of the qualitative phase is limited to refining the conceptual model, informing scale development and aiding interpretation of the subsequent quantitative research results. The purpose and objectives of the exploratory phase are to:

1. Determine if support exists for the proposed CRM technology acceptance customer relationship (CTA - CR) model,

2. Explore and validate the proposed variables in the model, specifically the impact of CRM technology adoption on business relationships,

3. Gain additional insight into the motivation, attitudes and emotions influencing CRM technology adoption,

4. Identify relevant existing or previously unidentified variables (Creswell, 1998, 2003),

5. Ascertain practitioner familiarity with specific terms and expressions in the survey questionnaires (Hair, Bush, \& Ortinau, 2003), and

6. Provide detailed contextual data so as to better interpret the research instrument data and results (Creswell, 2003).

The data obtained in this phase were used to help shape the conceptual model and develop appropriate scales before proceeding to the explanatory phase of the research (DeVellis, 2003; Rossiter, 2002; Spector, 1992; Stake, 1995).

\subsubsection{Sample Selection}

Since CRM technology adoption diversity was desirable, a maximum variation and purposeful sampling strategy was incorporated, where cases are selected on their potential contribution to theory and the demands of the research objective, in order to identify firms with different types of CRM systems (Aaker, Kumar, \& Day, 2004; Eisenhardt, 1989; T. W. Lee, 1999; Narayandas \& Rangan, 2004). Participating supplier firms were requested to nominate customers to interview, and it was considered more efficient and cost effective if firms and customers were in proximity to the interviewer, therefore convenience sampling was also included as part of the sampling strategy (Miles \& Huberman, 1994). 


\subsubsection{Unit of Analysis}

The unit of analysis, depicted in Figure 4.1, is the Supplier - Customer (business) dyad. Each supplier response was matched with the corresponding customer response.

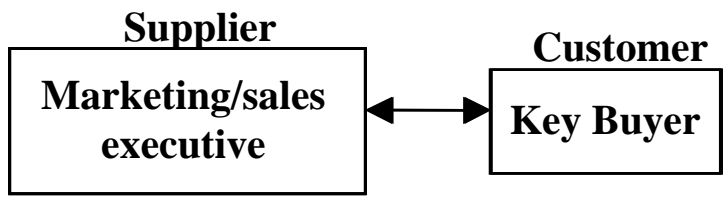

Figure 4.1: Unit of analysis: Supplier - Customer dyad

\subsubsection{Company Selection}

In order for a case site to provide rich and relevant data representing the CRM technology phenomenon, specific criteria were developed as suggested by Creswell (2003) and Stake (1995).

The minimum criteria included having: (a) CRM technology implemented, (b) at least one of internal sales, marketing, or customer service departments, (c) an accessible senior executive (or equivalent) with regular customer contact, (d) a willingness to participate in dyadic research by providing customer relationship data, and (e) at least one accessible and willing customer. These criteria ensured that participating firms were able and willing to participate, and could provide valuable and relevant information.

The New Zealand Kompass database ${ }^{1}$ and word-of-mouth (judgmental "snowball" sampling) was used to find organisations to interview (Aaker et al., 2004; Miles \& Huberman, 1994). The Kompass database is available on CD, updated bi-annually and provides New Zealand business information including information on 17,000 business head offices, accounting for $80 \%$ of the New Zealand economy's output, and 43,000 executive names and contact details (Kompass New Zealand, 2007). Excluded from the supplier firm sampling frame were government, hospitals, libraries and non-profit organisations, since they were unlikely to be able to provide adequate or appropriate business performance information in response to the interview questions.

Financial services and the service industry in general are more likely to involve IT in their strategic business and marketing activities (Bharadwaj et al., 1993; Christiaanse \& Venkatraman, 2002; Colgate, 1998; Johnston \& Carrico, 1988). However RM may be a

\footnotetext{
${ }^{1}$ The business database was a commercially available April 2006 CD product provided by Kompass New Zealand.
} 
more dominant and important marketing mechanism in the manufacturing sector (Yau et al., 2000). Since relatively few CRM marketing studies have investigated multiple industries, a broadly representative sample of businesses was sought in order to aid generalisability (Croteau \& Li, 2003; Raman \& Pashupati, 2004; Reinartz et al., 2004). Ten firms meeting the criteria were chosen from the Wellington, New Zealand area.

\subsubsection{Respondent Selection}

The selection of participants was driven by the theoretical framework identified from the CRM and RM literature (Miles \& Huberman, 1994). Given that CRM usage, and day-to-day relationship building and maintenance is generally within the domain of sales and marketing, the study focused on participants from this functional area within the supplier firm (Abbott et al., 2001; Speier \& Venkatesh, 2002). In-depth interviews were conducted with a single senior management informant, responsible for customer relationships on a day-to-day basis, because (a) they are more likely to use CRM technology if it exists within the firm, (b) they tend to be more involved in the overall customer sales and marketing process, and (c) they would be familiar with their organisation's culture and IT strategy (Menon, Bharadwaj, Adidam, \& Edison, 1999; Moorman \& Miner, 1997). Although the use of multiple respondents is preferred to help overcome potential response bias and gain multiple perspectives (triangulation) (Creswell, 2003; T. W. Lee, 1999; Yin, 2003), it was considered too problematic to find knowledgeable second respondents in small and medium-sized (SME) businesses (Reinartz et al., 2004).

The nominated customers were recommended by supplier participants, knowledgeable in the business relationship and regularly conducted business with the customer. Keeping in mind the cost and time constraints, the research question, and the objectives for the exploratory stage of the research, single respondents, one from each supplier firm and one from each customer firm, were deemed appropriate.

\subsubsection{Data Collection - Exploratory Phase}

\subsubsection{Contact}

To increase acceptance, the most senior manager in each targeted organisation was contacted by telephone and asked to nominate the most appropriate sales or marketing person in their organisation to participate (Jobber \& O'Reilly, 1998). Each nominated 
person was contacted, agreed to a 60 -minute interview and provided one customer contact potentially willing to participate in the study. The nominated customers were telephoned independently by the researcher to set up interviews, unless otherwise suggested by the supplier firm, in which case the researcher contacted the nominated customer after the supplier firm had gained the customer's approval. Initial interview durations with the nominated customers were set for one hour.

\subsubsection{Interview Protocol}

Interview protocols were developed, as recommended by Yin (2003), one for the supplier interviews and one for the customer interviews, and used to guide each interview (Miles \& Huberman, 1994). These protocols ensured all the essential and necessary information regarding the proposed research model and associated research questions were collected and recorded. The customer protocol did not include any questions regarding CRM technology implementation. In addition to the protocols, a contact summary form, and interview follow-up forms were developed and used for data recording and later analysis (Stake, 1995).

A separate telephone interview protocol was developed (Fontana \& Frey, 1994), and subsequently used for one customer telephone interview. The protocols and forms are provided in Appendix A1.

\subsubsection{Participation Rate and Respondent Profile}

Eleven companies were contacted and ten agreed to participate. The firm choosing not to participate stated a lack of time and interest. Eisenhardt (1989), and Miles and Huberman (1994) consider ten to be a sufficient number for exploratory case research. More important is the information richness derived from the cases rather than the

Table 4.1: Supplier Industry and CRM System Profile

\begin{tabular}{lll}
\hline Firm & Industry & CRM System \\
\hline TecCo & Computer Services & ACT! \\
RecCo & Recruitment Services & Custom database \\
MarCo & Marketing Services & Inhouse build \\
FinCo & Finance & Custom build \\
TelCo & Telecommunications & Vantive FOCiS \\
BMSCo & Wholesale Trade & ACT! \\
DocCo & Document Services & CoWeb \\
ComCo & Telecommunications & Salesforce.com \\
CompCo & Computer Services & Siebel \\
BankCo & Finance & Certegy \\
\hline
\end{tabular}


sample size (Perry, 1998), and the sample cases provided a rich medium for analysis.

The supplier profiles shown in Table 4.1 indicate that these companies encompass a broad range of industries and utilise a variety of IT systems and solutions to provide CRM applications. Table 4.2 provides the respondent and firm profiles, indicating a good spread across the categories of small ( 2 - 20 employees), medium (50 - 190 employees) and large businesses (300+ employees).

Table 4.2: Supplier and Customer Respondent Profile (Exploratory Phase)

\begin{tabular}{l|l|c|l|c}
\hline Firm & R & ANZSIC & Informant title / position & Size \\
\hline TecCo & S & L7834 & Owner & Small \\
\hline MgtCo & C & L7855 & Owner & Small \\
\hline RecCo & S & L7861 & Account executive & Medium \\
\hline GovDp & C & M8112 & HR manager & Large \\
\hline MarCo & S & L7853 & Account manager & Small \\
\hline InsCo & C & K7422 & General manager - Marketing & Medium \\
\hline FinCo & S & K7340 & Manager - Investor Services & Small \\
\hline FinAd & C & K7340 & Owner - Investment advisor & Small \\
\hline TelCo & S & J7120 & Account manager & Large \\
\hline PropCo & C & L7712 & General Manager IT & Medium \\
\hline BMSCo & S & F4539 & Owner & Small \\
\hline SupCo & C & F4539 & Services manager & Small \\
\hline DocCo & S & L7832 & Strategic account manager & Medium \\
\hline EdGvCo & C & M8112 & Sales manager & Medium \\
\hline ComCo & S & J7120 & Corporate account manager & Large \\
\hline UniCo & C & N8431 & E-communications supervisor & Large \\
\hline CompCo & S & L7834 & Client Relations Executive & Medium \\
\hline HlthCo & C & K7421 & Commercial and business manager & Large \\
\hline BankCo & S & K7321 & General manager credit cards & Medium \\
\hline NpoCo & C & Q9629 & IT manager & Small \\
\hline Note R $=$ Respondent S $=$ Supplier firm C = Customer firm &
\end{tabular}

Note: $\mathrm{R}=$ Respondent; $\mathrm{S}=$ Supplier firm; $\mathrm{C}=$ Customer firm

\subsubsection{The Interviews}

The supplier firm interviews were conducted at the participating firms' offices in all cases. The customer interviews were also conducted at their places of business, except for two, one conducted over the telephone and the other conducted offsite. All interviewees agreed to be tape-recorded and were given the opportunity to review the written transcripts; in addition notes were taken during the interviews.

\subsubsection{Exploratory Data Analysis Procedure}

Miles and Huberman (1994, p. 10) stipulate that qualitative data analysis progress through parallel and simultaneous processes of "data reduction, data display, and conclusion drawing/verification." To this end each interview transcript was analysed 
through selection, summarising, and abstracting the data in order to uncover key themes and constructs from the text segments (Ryan \& Bernard, 2000). The conclusions and verifying process involves a continuous process of "noting regularities, patterns, explanations, possible configurations, causal flows, and propositions" (Miles \& Huberman, p. 11). Similarities and differences in perceptions of the relationship between the firm and the customer were identified and organised to simplify and understand the complex information. Leximancer 2.21 software was used to help structure and analyse the interview data (A. E. Smith, 2005; A. E. Smith \& Humphreys, 2006).

Yin (2003) advocates cross-case synthesis for multiple case studies since cross-case analysis provides the possibility of replication and generalisation compared to single within-case analysis. Cross-case analysis was conducted by comparing and contrasting case-by-case, word tables and feature arrays in order to aggregate and examine common themes and findings shared by the participating companies, first separately by supplier and customer, and then combined (Eisenhardt, 1989; Miles \& Huberman, 1994; Mohrman, Gibson, \& Mohrman Jr., 2001; Yin, 2003). Since one of the primary purposes of the research was the development and validation of a generalised CTA CR model, cross-case analysis was favoured over within-case analysis.

The results were compared to the research model and the extant literature in order to refine the CTA - CR model and help select items for the questionnaire. Appendix A2 provides a summary of the interviews, used to inform the scale development and subsequent interpretation of the survey results from the explanatory phase. Next, the methodology employed in the explanatory research phase is discussed.

\subsection{Explanatory Phase of the Research}

\subsubsection{Explanatory Phase Approach and Objectives}

This phase of the research tested and validated the research model, to thereby establish theory for better understanding and predicting the effects of the CRM phenomenon (Sekaran, 2003). First, an overview of the research design is presented, followed by questionnaire design, development of the research instruments, the survey implementation methodology, data screening and preliminary analysis, and finally the data analysis and hypothesis testing procedures. 


\subsubsection{Overview of Research Design}

Given the potential difficulty in identifying and gaining access to businesses contemplating CRM technology adoption, a cross-sectional study was determined more appropriate than a longitudinal study. Longitudinal studies provide the ability to observe and test parameters over time with the same individuals or organisation. The advantage of longitudinal study is that complex variables and interactions that evolve over time (i.e., relationships) can be identified and causal linkages established more readily (Bowen \& Wiersema, 1999). Hence cross-sectional research limits causal inference since timing effects may not be understood or captured (MacCallum \& Austin, 2000; Pinsonneault \& Kraemer, 1993). A cross-sectional design for this study was justified however due to cost and resource constraints, and because the study's primary purpose was to validate the proposed CTA - CR model, not to identify changes in relationships over time due to CRM technology adoption (King, 2001; Pinsonneault \& Kraemer, 1993; Scandura \& Williams, 2000).

In addition, since a number of CRM technology adoption construct measures were to be developed, a research design that facilitated measurement development was required (Churchill \& Brown, 2004). Measurement development is highly dependent on respondents that are representative of the population for which the scale is intended (Alreck \& Settle, 2004), since "sample non-representativeness can severely harm a scale development effort" (DeVellis, 2003, p. 90). Sample representativeness was obtained through an appropriate random selection procedure described in detail later in the Sample Selection section.

Although personal interviews are preferable for research dealing with relationships, the time and cost required to identify and interview a large, diverse sample of companies and customers made personal interviewing unfeasible (Aaker et al., 2004; Alreck \& Settle, 2004). Telephone interviewing was also dismissed due to the length and detail of the measuring instrument (136 items for the supplier survey) (Aaker et al., 2004; Hair et al., 2003; Jobber, Allen, \& Oakland, 1985). Internet surveys are becoming more popular, but suffer from a number of issues including (Couper, Kapteya, Schonlau, \& Winter, 2007; Ranchhod \& Zhou, 2001; Simsek \& Veiga, 2001):

1. Sampling representativeness, and low response rate, due to user variability in e-mail use, Internet availability and familiarity,

2. Lack of professional image and design, 
3. Perceived lack of anonymity, and confidentiality.

Direct mail surveys provide a number of advantages: relatively low cost, access to widely dispersed samples, minimal resource requirements, and allows time for thoughtful answers or consultation (Aaker et al., 2004; Hair et al., 2003). The anonymity provided by mail surveys may also help overcome any sensitivity surrounding the relationship between the two parties (supplier - customer) (Churchill \& Iacobucci, 2005). Another advantage of the mail survey in the current research is that the supplier firm also received the customer questionnaire to forward $\mathrm{on}^{2}$. This allowed the supplier firm to review and become comfortable with the questions their customers were being asked to answer. Limitations of mail surveys include the possibilities of low response rate, non-response bias and a loss of control once the survey is in the postal system (Aaker et al., 2004). Satisfactory response rates can be hard to forecast and difficult to obtain, however there are techniques and guidelines to help improve response rates (Dillman, 2000; Dillman, Sinclair, \& Clark, 1993; Jobber, 1986; Jobber \& O'Reilly, 1996, 1998), and non-response bias can be estimated (Armstrong \& Overton, 1977; Assael \& Keon, 1982).

\subsubsection{Questionnaire Design}

There are two primary objectives of questionnaire design related to data quality: first, to reduce non-response, and second, reduce or avoid measurement error (Alreck \& Settle, 2004; Churchill \& Peter, 1984; Dillman, 1998, 2000; Fink, 1995; Hair et al., 2003; McDaniel \& Gates, 2005). In addition to the methods proposed by Dillman (1998; 2000), the nine-step procedure for developing a questionnaire, proposed by Churchill and Iacobucci (2005) guided the questionnaire design in this study.

\subsubsection{Information Required}

The research objectives, the CTA - CR model and subsequent hypotheses determined the information required from the research instruments. Five types of information were sought from the supplier firm; (a) market orientation, (b) IT management orientation, (c) CRM technology adopted (function, user acceptance and integration with other systems), (d) environmental characteristics (technology and marketing turbulence), and (e) personal and organisational demographic classifying

\footnotetext{
${ }^{2}$ The majority of firms preferred to review the customer questionnaire before agreeing to nominate or send out the customer survey; only five firms freely nominated a customer and provided contact details during the original telephone conversation.
} 
information (gender, age, work experience, education, business industry, organisation size, length of relationship with nominated customer, and respondent title). In addition, relationship strength (trust, commitment, communications), and relationship performance (perceived performance, satisfaction, loyalty and retention) data were collected from the supplier respondents. Five types of customer information were similarly sought: (a) relationship strength, (b) relationship performance, (c) environmental characteristics, (d) customer characteristics (CRM expectations, relationship orientation), and (e) personal and organisational demographic classifying information. Appendix A3 provides the item construction details included in the two questionnaires.

\subsubsection{Type of Questionnaire and Method of Administration}

Since there was no reason to disguise the rationale or motivation of the study, and standardisation of questions and responses was necessary for comparison purposes to enable statistical analysis of the results, a structured-undisguised, self-administered questionnaire was selected (Alreck \& Settle, 2004; Churchill \& Iacobucci, 2005; Netemeyer, Bearden, \& Sharma, 2003). Given that the questionnaire was mailed to supplier firms, with the majority of customer questionnaires forwarded on by the supplier firm, the self-administered questionnaire was an appropriate method of administration (McDaniel \& Gates, 2005).

\subsubsection{Form of Response}

Rating scales are commonly used in social science research to measure latent (unobservable) constructs (Alreck \& Settle, 2004; Netemeyer et al., 2003). All constructs in the measuring instrument used seven-point Likert-type scales, except for one semantic differential scale dealing with communications and a checklist (rankingtype scale) for one aspect of CRM system integration. Although a five-point scale is considered adequate, a seven-point scale provides a finer level of detail and does not place undue cognitive burden on the respondent (Lissitz \& Green, 1975; Miller, 1956; Preston \& Colman, 2000). In addition seven appears to be optimal for information processing purposes and scale reliability (Churchill \& Peter, 1984; Cox, 1980; Green \& Rao, 1970; Peter, 1979).

The majority of the scales were treated as interval, with demographic information fundamentally considered as nominal (DeVellis, 2003; Kirk-Smith, 1998; Nunnally, 
1959; Nunnally \& Bernstein, 1994; F. S. Roberts, 1994; Suppes \& Zinnes, 1963; Traylor, 1983).

\subsubsection{Question Wording}

The literature on survey research methodology provides excellent guidelines for composing the questions (Alreck \& Settle, 2004; Churchill \& Iacobucci, 2005; Dillman, 2000; E. Lee, Hu, \& Toh, 2004). Questionnaire items from previously published and validated questionnaires on information systems (Karimi et al., 1996a; Karimi et al., 2001; Venkatesh \& Davis, 2000; Venkatesh, Davis, Morris, \& Davis, 2003), marketing management (Avlonitis \& Panagopoulos, 2005; Jayachandran et al., 2005), market orientation (Pelham \& Wilson, 1996), trust (Ganesan, 1994), commitment (Gounaris, 2005; N. Kumar et al., 1995), communication (Z. G. Li \& Dant, 1997; Mohr \& Sohi, 1995), business relationship (Andaleeb, 1996; Z. G. Li \& Dant, 1997), loyalty (Zeithaml et al., 1996), retention (Sin, Tse, Yau, Lee, \& Chow, 2002), and technology and marketing turbulence (Jaworski \& Kohli, 1993; Moorman \& Miner, 1997) were adapted to the context of this study.

\subsubsection{Question Sequence}

The sequence of the questions, or even the order of two or more questions, may have a significant effect on the answers provided in a survey (Tourangeau, Rips, \& Rasinski, 2000). Dillman (2000) and other researchers (Aaker et al., 2004; Churchill \& Iacobucci, 2005; Parasuraman, Grewal, \& Krishnan, 2004) provide guidelines to help order the question sequence appropriately. Applying the guidelines involved dividing the supplier questionnaire into eight sections, and the customer questionnaire into four sections. Details of the questionnaire construction can be found in Appendix A3.

\subsubsection{Physical Aspects of the Questionnaire}

The perception of questionnaire importance is reflected in its presentation, design and layout; the respondent's first impression is a lasting one (Churchill \& Iacobucci, 2005; Jobber, 1989; Mayer \& Piper, 1982; Sanchez, 1992), even “[t]he format, spacing, and positioning of questions can have a significant effect on the results" (Malhotra, 1999, p. 312). Following Dillman's (1978; 2000) recommendations, and to make the questionnaire appear shorter and less dense, the supplier questionnaire was formatted into a user friendly six page double-sided standard size A4 booklet. The 136 items in the 
supplier survey were distributed across 11 sides of paper ${ }^{3}$. The customer questionnaire was similarly formatted into a four page double-sided booklet, with the 72 items distributed across six sides of paper.

Each questionnaire had a reference number hand written on the top right hand corner of the cover page to facilitate the matching of supplier and customer questionnaire returns. There is an argument that respondents may decline to participate or provide different answers if they believe they can be identified, although recent research is inconclusive as to the effect of anonymity on mail surveys (Jobber, 1986; Jobber \& Saunders, 1993; Malhotra, 1999; Michaelidou \& Dibb, 2006). Confidentiality, however, was promised in the cover letter and reinforced at the appropriate sections in the questionnaire.

Following the pre-test the final questionnaire was professionally printed in colour and stapled in booklet form by the Victoria University of Wellington printing department.

\subsection{Development of Research Instruments}

Following the exploratory phase, the construction and validation of the final research instrument was undertaken. Two versions of the final instrument were prepared - one version to be administered to the supplier firms (subtitled 'Supplier Questionnaire'), another version for the customer firms (subtitled 'Customer Questionnaire'). The supplier questionnaire consisted of scales to measure all of the previously outlined constructs - market orientation (MO), IT management orientation (ITMO), CRM technology adoption (CTA), relationship strength (RS), and relationship performance (RP) - including environmental moderating variables. The customer questionnaire included only the two specific construct measurement scales - RS, RP - and the environmental moderating variables. However, as additional control variables, the customer instrument also measured the customer's CRM expectations (CXP) and their relationship orientation $(\mathrm{CRO})$.

\subsubsection{Overview of Research Instrument Development}

Development of the two research instruments used in the explanatory phase of the study utilised existing scales and measures wherever possible (Menon et al., 1999;

\footnotetext{
${ }^{3}$ In both cases the questionnaire cover page did not contain any questions; the customer questionnaire included page 7 intentionally blank.
} 
Sudman \& Bradburn, 1982). The recommendations for scale construction provided by Churchill (1979), DeVellis (2003), Netemeyer et al. (2003), and Nunnally and Bernstein (1994) were used to guide the instrument development.

Few instruments have been published for the purpose of empirically investigating the relationship between RM, CRM and business performance. A number of instruments have been developed in separate studies to investigate and measure the degree of market orientation, IT management orientation, and technology application adoption, as shown in Table 4.3. Existing scales were combined and modified (by adding and deleting specific items) to create scales for the three primary supplier based constructs; MO, ITMO and CTA.

\section{Table 4.3: Instrument Development Sources for the Three Major Supplier Constructs and Sub-constructs}

\begin{tabular}{|c|c|c|c|}
\hline Construct & Sub-constructs & Primary Source of initial scales & Items \\
\hline $\begin{array}{l}\text { Market } \\
\text { Orientation }\end{array}$ & Market Orientation & Pelham and Wilson (1996) & 10 \\
\hline $\begin{array}{l}\text { IT } \\
\text { Management } \\
\text { Orientation }\end{array}$ & $\begin{array}{l}\text { IT Management control } \\
\text { IT Organisation maturity } \\
\text { IT Integration maturity }\end{array}$ & $\begin{array}{l}\text { Karimi, Gupta, \& Somers (1996a), Karimi et } \\
\text { al. (2001) }\end{array}$ & 14 \\
\hline \multirow{3}{*}{$\begin{array}{l}\text { CRM } \\
\text { Technology } \\
\text { Adoption }\end{array}$} & Acceptance & $\begin{array}{l}\text { Avlonitis \& Panagopoulos (2005); } \\
\text { Venkatesh \& Davis (2000); Venkatesh, } \\
\text { Davis, Morris, \& Davis (2003) }\end{array}$ & 19 \\
\hline & Functionality (NEW) & Jayachandran et al. (2005) & 20 \\
\hline & Integration (NEW) & Venkatesh, Davis, Morris, \& Davis (2003) & 13 \\
\hline
\end{tabular}

Table 4.4 shows the sources for the scale development of the two dependent variables, C_RS and C_RP (the customer based constructs) used in the questionnaire. The newly created scales provided fourteen sub-constructs used in the structural

Table 4.4: Customer Instrument Development Sources for the Two Major Dependent Constructs and Sub-constructs

\begin{tabular}{|c|c|c|c|}
\hline Construct & Sub-constructs & Primary source of initial scales & Items \\
\hline \multirow{3}{*}{$\begin{array}{l}\text { Relationship } \\
\text { Strength }\end{array}$} & Trust & Doney and Cannon (1997) & 7 \\
\hline & Commitment & $\begin{array}{l}\text { Gounaris (2005); N. Kumar et al. (1995); } \\
\text { Mohr, Fisher, and Nevin (1996) }\end{array}$ & 15 \\
\hline & Communications quality & Li and Dant (1997); Mohr and Sohi (1995) & 9 \\
\hline \multirow{5}{*}{$\begin{array}{l}\text { Relationship } \\
\text { Performance }\end{array}$} & Perceived performance & Li and Dant (1997) & 3 \\
\hline & Relationship satisfaction & Andaleeb (1996) & 3 \\
\hline & Customer loyalty & $\begin{array}{l}\text { Zeithaml, Berry, \& Parasuraman (1993; } \\
\text { 1996) }\end{array}$ & 3 \\
\hline & Customer retention & Sin, Tse, Yau, Lee, \& Chow (2002) & 5 \\
\hline & & & 45 \\
\hline
\end{tabular}


equation model (Netemeyer et al., 2003; Sudman \& Bradburn, 1982).

Appendix A3 details the alignment of the questionnaire items with the respective constructs. A CRM technology adoption (CTA) scale was developed since no adequate instrument currently exists in the published literature. It was created by combining two new measures, CRM functionality and CRM system integration, together with an existing measure of technology acceptance (TAM) (F. D. Davis, 1989). Additional items were added to the existing technology acceptance scale based on the research objectives and insights gained from the exploratory interviews. Wherever possible multi-item measures were adapted or developed in order to help reduce measurement error (Nunnally \& Bernstein, 1994). The development of the individual scales is described in the following sections.

\subsubsection{Dependent Variables}

Relationship strength (C_RS) was chosen as the primary dependent variable in this study; relationship performance (C_RP) as a secondary dependent variable. The customer C_RS and C_RP scales were developed within the context of this study utilising wording to reflect the customer's perspective (i.e., interchanging supplier and customer in the statements as appropriate). The letter and number along side each item represents the section and line item in the respective questionnaire, see Appendix A4 for copies of the two questionnaires.

\subsubsection{Relationship Strength (C_RS)}

The customer questionnaire measured relationship strength (C_RS) through measures of trust, commitment and communications quality. Table 4.5 depicts the three key constructs and seven sub-constructs used in this study to define C_RS.

\section{Table 4.5: Relationship Strength Constructs and Sub-} constructs Used in the Current Study

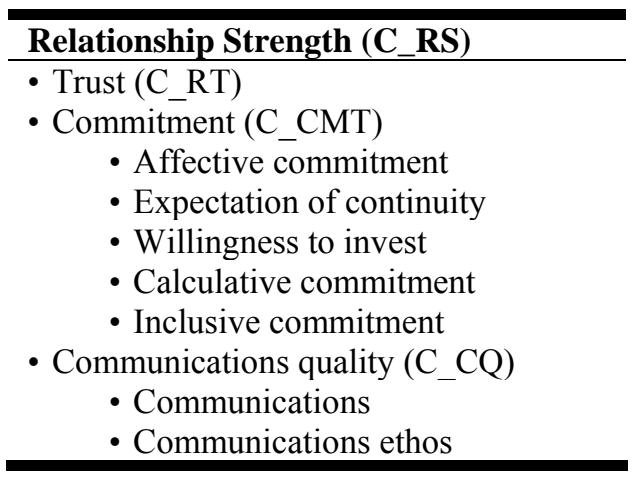




\subsection{Measurement of Trust (C_RT)}

The seven-point Likert scale developed by Doney and Cannon (1997) was adapted and used to measure the customer's perception of trust with the supplier $(\overline{\mathrm{x}}=5.30, \mathrm{SD}=$ $1.20, \alpha=0.94$; as reported in the original study). Unless otherwise noted, the sevenpoint Likert response scale used in the current study ranged from "Strongly Disagree" to Strongly Agree". The eight items used to measure trust in the customer questionnaire:

A2: This supplier keeps promises it makes to our firm.

A3: This supplier is not always honest with us.

A4: We believe the information that this vendor provides us

A5: This supplier is genuinely concerned that our business succeeds.

A6: When making important decisions, this supplier considers our welfare as well as its own.

A7: We trust this supplier keeps our best interests in mind.

A8: This supplier is trustworthy.

A9: We find it necessary to be cautious with this supplier.

\subsection{Measurement of Commitment (C_CMT)}

The N. Kumar, Scheer, \& Steenkamp (1995) nine-item, seven-point Likert-type scale measures a firm's affective commitment (C_AFC), propensity for relationship continuation (C_EOC), and willingness to invest (C_WTI) $(\alpha=0.82)$. The results of the in-depth interviews did not support the inclusion of a normative component of commitment. The scale items as adapted for this study are listed below:

A10: Even if we could, we would not drop the supplier because we like being associated with them.

A11: We want to remain a member of the supplier's network because we genuinely enjoy our relationship with them.

A12: Our positive feelings towards the supplier are a major reason we continue working with them.

A13: We expect our relationship with the supplier to continue for a long time.

A14: The renewal of our relationship with the supplier is virtually automatic.

A15: It is unlikely our firm will still be doing business with this supplier in two years.

A16: If the supplier requested it, we would be willing to make further investment in supporting the supplier's line.

A17: We are willing to put more effort and investment in building our business in the supplier's product. 
A18: In the future we will work to link our firm with the supplier's in the customer's mind.

Calculative commitment (C_CLC) was measured adapting the Gounaris (2005) measurement scale $(\alpha=0.87)$ :

A19: It would be difficult to break this relationship.

A20: There are no worthwhile alternative suppliers.

A21: There is a high cost to change suppliers.

The customer questionnaire also included three items to measure inclusive commitment (C_ICT) (a general commitment to the supplier) adapted from the Mohr, Fisher, and Nevin (1996) scale $(\alpha=0.80)$ :

A22: We are very committed to carrying this supplier's products.

A23: We would like to discontinue this supplier's products.

A24: We have a minimal commitment to this supplier.

\subsection{Measurement of Communications Quality (C_CQ)}

Communications was measured by adapting Li and Dant's (1997) four-item, fivepoint Likert-type scale ( $\alpha=0.83$ ), while communications ethos was measured using Mohr and Sohi's (1995) five-item, five point semantic differential scale $(\alpha=0.92)$.

The customer questionnaire communication scale $\left(\mathrm{C} \_\mathrm{CM}\right)$ consisted of the following four items:

A25: We keep each other informed about events that affect each other.

A26: We often exchange information informally.

A27: We often exchange information beyond what is required by our formal agreements.

A28: We provide each other with information that may be of help.

The customer questionnaire communication ethos scale (C_CME) consisted of the following five semantic-differential items. The response scale consisted of a seven-point scale (1 to 7$)$ :

Please indicate the nature of your communication with this supplier:

A29: Untimely- Timely

A30: Inaccurate - Accurate

A31: Inadequate-Adequate

A32: Incomplete- Complete

A33: Not credible - Credible 


\subsubsection{Relationship Performance (C_RP)}

Overall customer perceived relationship performance (C_RP) was measured independent of the C_RS measurement. For this study the C_RP scale was based on the work of Jutla, Craig, and Bodorik (2001) and Li and Dant (1997) and comprised of four sub-constructs: perceived performance, relationship satisfaction, loyalty intention and customer retention (see Table 4.6). Thirteen items were used to measure the four subconstructs from the customer perspective.

\section{Table 4.6: Relationship Performance Sub-constructs Used in the Current Study}

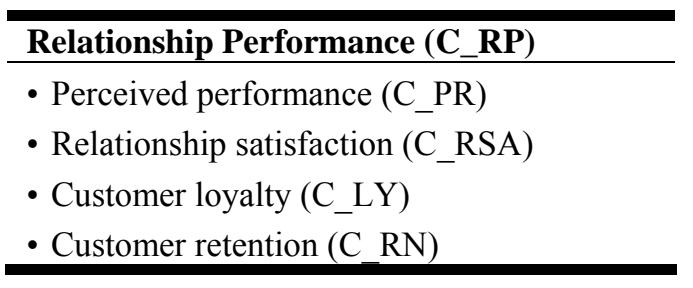

\subsection{Measurement of Perceived Performance (C_PR)}

The perceived performance scale was adapted from Li \& Dant's (1997) three item five-point Likert-type scale $(\alpha=0.90)$, based on input provided from the exploratory interviews:

B1: Our relationship with them has been productive.

B2: The time and effort we spent in the relationship with them has been worthwhile.

B3: The relationship with them has been satisfactory.

\subsection{Measurement of Relationship Satisfaction (C_RSA)}

The relationship satisfaction scale used in this study was adapted from Andaleeb's (1996) three-item, seven-point Likert-type manufacturer-distributor relationship satisfaction scale $(\alpha=0.95)$; one additional item (A1) relating to perceived strength of the overall business relationship was added. The customer relationship satisfaction scale therefore included four items:

A1: Our business relationship with [name of supplier firm] is strong.

B4: The relationship between my company and this supplier reflects a happy situation.

B5: The relationship between the two companies is very positive.

B6: My company is very satisfied with this supplier. 


\subsection{Measurement of Loyalty (C_LY)}

Loyalty was measured by adapting Zeithaml, Berry and Parasuraman's (1996) fiveitem, seven-point Likert-type organisational loyalty scale. The customer loyalty scale consisted of four items:

B7: I say positive things about this supplier to others.

B8: I encourage others to do business with this supplier.

B9: I would recommend this supplier to someone who seeks my advice.

B10: I expect to do more business with this supplier in the next few years.

\subsection{Measurement of Customer Retention (C_RN)}

A customer may continue to re-purchase products and services from a specific supplier, but that does not necessarily imply the customer is loyal. The customer retention scale consisted of one item (B11) based on the Zeithaml, Berry and Parasuraman (1996) scale, one item (B13) from the Gounaris (2005) scale and one new item (B12):

B11: I consider this supplier our first choice to buy from.

B12: We continue to purchase from this supplier more so than from other suppliers.

B13: We are looking for alternative suppliers.

\subsubsection{Independent Variables}

Table 4.7 shows the three independent variables used in this study: market orientation (MO), IT management orientation (ITMO), and CRM technology adoption (CTA) (CTA is both a dependent and independent variable in the CTA - CR model). This portion of the survey instrument was only administered to the supplier firms; the customer survey did not include these items.

Table 4.7: Major Supplier Construct and Sub-construct Details Used in the Current Study

\footnotetext{
- Market orientation (MO)

- IT management orientation (ITMO)

- IT management planning

- IT management control

- IT organisation

- IT integration

- CRM technology adoption (CTA)
} 


\subsubsection{Measures of Market Orientation (MO)}

Pelham and Wilson's (1996) nine-item, five-point Likert-type market orientation scale $(\alpha=0.92)$, based on Narver and Slater's (1990) MO operationalisation, was adapted to measure MO. Ten items on the supplier questionnaire, listed below, comprised the measure for MO:

C1: All our functions (not just marketing and sales) are responsive to serving target markets.

C2: All our functions are integrated in serving target markets.

C3: Our firm's strategy for competitive advantage is based on a thorough understanding of our customer needs.

C4: All our managers understand how the entire business can contribute to creating customer value.

C5: Information on customers, marketing success, and marketing failures is communicated across the firm.

C6: If a major competitor were to launch an intensive campaign targeted at our customers, we would implement a response immediately.

C7: Our firm's market strategies are to a great extent driven by our understanding of possibilities for creating value for customers.

C8: Our firm responds quickly to negative customer satisfaction wherever it may occur in the organisation.

C9: Senior managers frequently discuss competitive strengths and weaknesses.

C10: We frequently leverage targeted opportunities to take advantage of competitor's weaknesses.

\subsubsection{Measures of IT Management Orientation (ITMO)}

Karimi et al. (2001) developed an instrument to measure the level of IT management sophistication through 20 items reflecting IT Planning (IMP) (6 items, $\alpha=0.88$ ), IT management control (IMC) (6 items, $\alpha=0.86$ ), IT organisation (IMO) (4 items, $\alpha=$ 0.80 ) and IT integration (IMI) (4 items, $\alpha=0.78$ ) (Karimi et al., 2000; Karimi et al., 1996a). The nature of the ITMO construct focused on management practices, rather than technical IT issues, therefore it was anticipated that informed executives should be able to answer the questions posed in the questionnaire (Churchill \& Iacobucci, 2005). However, in order to make this section less threatening a separate 'Do not know' (DNK) category was added to the Likert seven-point scale. Although adding this category may increase the percentage of DNK answers, the amount of guessing should 
also decrease (Sudman \& Bradburn, 1982). Karimi et al.'s (2001) original study surveyed IT executives in the financial services industry, therefore the survey instrument was adapted for sales and marketing executives in this study by ensuring appropriate context (e.g., replacing 'Our IT' with 'Our firm's IT'), key aspects were not changed (Sudman \& Bradburn, 1982).

B1: Our firm's IT projects support the business objectives and strategies of our company.

B2: Our IT group continuously examines the innovative opportunities IT can provide for our competitive advantage.

B3: Our IT group is well informed on the current use of IT by other firms in our industry.

B4: Our IT group is well informed on the potential use of IT by other firms in our industry.

B5: Our IT group has an adequate picture of the coverage and quality of our IT systems.

B6: Our firm is content with how our IT project priorities are set.

B7: In our organisation, the responsibility and authority for IT direction and development are clear.

B8: In our organisation, the responsibility and authority for IT operations are clear.

B9: Our firm is confident that IT project proposals are properly appraised.

B10: Our IT group constantly monitors the performance of IT functions.

B11: Our IT group is clear about its goals and responsibilities.

B12: Our IT group is clear about its performance criteria.

B13: In our organisation, user ideas are given due attention in IT planning and implementation.

B14: Our IT specialists understand our business and the firm.

B15: The structure of our IT group is appropriate for our organisation.

B16: The IT specialist-user relations in our firm are constructive.

B17: In our firm, top management perceives that future exploitation of IT is of strategic importance.

B18: There is a top-down planning process for linking information systems strategy to business needs.

B19: Some IT development resource is positioned within the business unit.

B20: The introduction of, or experimentation with, new technologies takes place at the business unit level, under business unit control. 


\subsubsection{CRM Technology Adoption (CTA)}

One purpose of the current study was to develop a CRM technology adoption (CTA) scale that can be used by academics and practitioners to help understand the type and extent of CRM technology implemented in firms and to differentiate between CRM technology adoption within firms. The scale is based on CRM attributes, functions, applications and characteristics obtained from (a) previous research (Jayachandran et al., 2005; Stefanou et al., 2003), (b) conceptualisations from the literature (Buttle, 2004; Freeland, 2003; Kincaid, 2003; V. Kumar \& Reinartz, 2006), and (c) vendor literature and product descriptions (e.g., Oracle, 2004; SAP, 2004).

Based on the literature and findings from the exploratory phase of this study, CTA is conceptualised as a higher order construct with three independent scales as depicted in Table 4.8; measuring CRM functionality (e.g., type of CRM technology implemented) (Raman \& Pashupati, 2004), CRM technology acceptance within the firm by the users (F. D. Davis et al., 1989), and CRM system integration reflecting the level of integration into the business processes and legacy systems (Ling \& Yen, 2001).

\section{Table 4.8: CRM Technology Adoption Sub-construct Details Used in the Current Study}

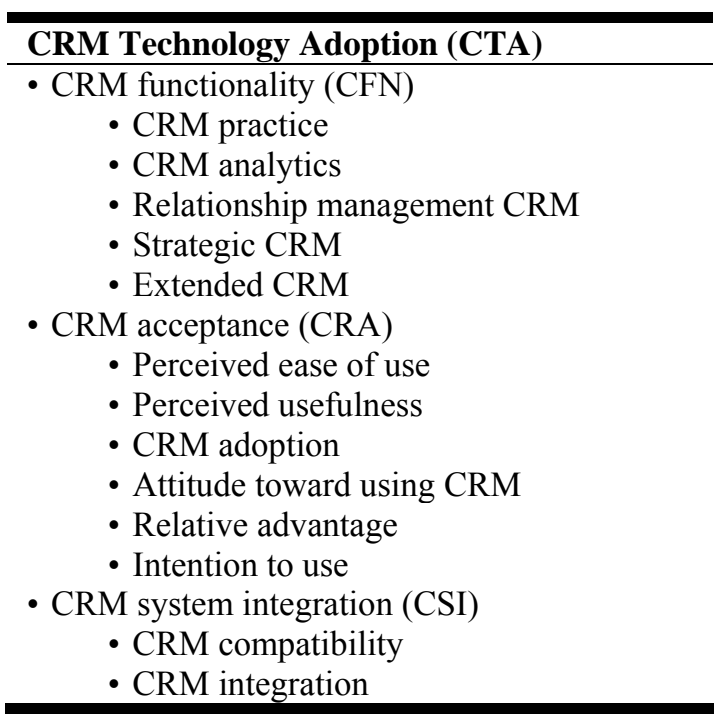

The quote below provides an example of the insight gained from the detailed interview data and used in the development of this portion of the survey:

[CRM technology is] primarily around accounts, or organisations and management. Contact management, sales opportunity right through the whole cycle, from awareness to an issue or problem, the whole cycle, basically right through to 
closing it. Forecasting, activity tracking, tracking events, keeping track of meetings, presentations, workshops, [CRM technology is] a repository for customer information, and reports. Those sorts of things can be tied to the CRM system. Organisation charts. It's not used here for service; it is used for marketing, although I don't personally use it for marketing. Though marketing people use it worldwide it's not used in a service kind of way at all. There's no integration. Computer Company, Client Relations Executive (Supplier - CRM user)

Note: Where different Likert scale anchor points are used in this section of the questionnaire, they are italicized and shown in parentheses after the item.

\subsection{Measurement of CRM Functionality (CFN)}

CRM functionality has not been previously reported in published work as a key variable (or antecedent) in the adoption or success of CRM technology (Raman \& Pashupati, 2004; Stefanou et al., 2003). A new scale to measure CRM functionality was based on the extant literature and feedback from the exploratory research interviews (Greenberg, 2002; V. Kumar \& Reinartz, 2006; Payne, 2006; Payne \& Frow, 2005). This new CRM functionality scale consisted of five dimensions; CRM Practice, CRM Analytics, Relationship Management CRM, Strategic CRM and Extended CRM.

\section{$\underline{\text { CRM Practice (CPR) }}$}

CRM practice relates to functional aspects of the actual tools and applications within the firm used by the respondent and correspond to the operational aspects of CRM (Buttle, 2004). The four items listed below focused on sales tools, contact centre process, customer support process and functional linkages to measure this construct (Buttle, 2004; Goodhue et al., 2002).

A2: The sales force tools available to me are (The seven-point Likert-type scale for this item was anchored with: Manual - Fully automated)

A3: Our customer contact centre processes are (Manual - Fully automated)

A4: Our customer support and service processes are (Manual - Fully automated)

A5: All of our systems (e.g., Finance, Sales, and Operations) are linked and talk to each other. (Not at all - Fully linked)

\section{CRM Analytics (CAN)}

CRM analytics "involves the capture, storage, organization, analysis, interpretation and use of data created from the operational side of the business" (Payne, 2006, p. 23). The measurement of the construct investigates what information sources, types of 
analysis and analysis tools are available to the respondent and how automated these functions are (Buttle, 2004; Goodhue et al., 2002). Three items - availability of customer information, data analysis, and analysis tools - were used to measure this construct:

A6: Customer information sources available to me are primarily (Manual card files Online profiles)

A7: The customer analyses available to me give (No insights - Detailed insights)

A8: The analysis tools that we use are (Manual - Fully automated)

\section{$\underline{\text { Relationship Management CRM (RMC) }}$}

A central CRM concept is the ability for businesses to better manage customer relationships, leading to improved customer metrics (Mithas et al., 2005; Reinartz et al., 2004). The six items used to measure this construct dealt with the extent to which the CRM technology in place provided assistance to maintain customer relationships, customer information from customer contact points, a single view of the customer, a single source of customer information, Internet access to customer and product information, database updates.

A1: To what extent does your information technology help you maintain relationships with your customers? (Not at all - To a great extent)

A9: Our customer contact points provide me with (No customer information Complete customer information)

A10: Our processes provide me with a single view of the customer. (No single view Complete 360 view)

A11: To what extent is a single source for all customer information available? (No single source - Single source)

A12: To what extent is the Internet / Intranet used to help find customer and product information? (Not at all - All the time)

A13: To what extent is our customer database(s) updated? (Infrequently - In real time)

\section{$\underline{\text { Strategic CRM (STC) }}$}

Retention, dissemination and strategic use of customer and competitor information within the firm were used to reflect the strategic CRM construct (Payne \& Frow, 2005). Four items in the supplier questionnaire attempted to measure the extent each supplier firm engaged in knowledge retention, utilising customer knowledge for decisionmaking, dissemination of customer and competitor information within the firm. 
A14: To what extent is customer knowledge retained? (No knowledge retained - All knowledge retained)

A15: To what extent does customer knowledge support decision-making? (No supportExtensive support)

A16: To what extent is customer information disseminated throughout the firm? (No information disseminated - Information widely disseminated)

A17: To what extent is competitor information disseminated throughout the firm? (No information disseminated - Information widely disseminated)

\section{Extended CRM (EXC)}

The Extended CRM construct investigates the customer value creation aspects of the firm. Payne and Frow $(2005 ; 2006)$ identified that a comprehensive strategic framework for CRM should include the ability to create superior value with and for customers. Four items attempted to measure this construct. Two of the items gauged the extent to which the firm focused on product-based versus customer-based value. Another item explored to what extent the business dealings were transactional or relationship focused and the final item inquired to what extent the value propositions were broad based or tailored to each customer.

A18: To what extent does your firm focus on product-based value creation? (Not at all Completely product-based)

A19: To what extent does your firm focus on customer-based value creation? (Not at all - Completely customer-based)

A20: Business dealings with our customers are (Transactional focused - Relationship focused)

A21: Our customer value propositions are (Broadbased - Tailored to each customer)

\subsection{Measurement of CRM Technology Acceptance (CRA)}

Since simply implementing CRM technology within the supplier firm would not necessarily mean that it was being used, it was considered important for CRM technology acceptance to form one of the dimensions of the overall CRM technology adoption construct. Based on the extant literature six constructs have been found to impact CRM technology acceptance; Perceived Ease of Use, Perceived Usefulness, CRM adoption, Attitude toward using CRM, Relative Advantage and Intention to Use. The scales used to measure these constructs are now discussed. 


\section{$\underline{\text { Perceived Ease of Use (PEU) }}$}

To measure PEU four items were adapted from Venkatesh and Davis (2000) ( $\alpha=$ 0.86). One new item - "I use CRM in my job", based on the Venkatesh et al. (2003) study - was added.

A22 I use CRM in my job. (The seven-point Likert-type scale for this item consisted of: Never; Once a month; Once a fortnight; Weekly; Twice a week; Daily; Hourly)

A23 My interaction with CRM is clear and understandable.

A24 Interacting with CRM does not require a lot of my mental effort.

A25 I find CRM easy to use.

A26 I find it easy to get CRM to do what I want it to do.

\section{$\underline{\text { Perceived Usefulness (PU) }}$}

Four items were adapted from the Venkatesh and Davis (2000) instrument ( $\alpha=0.86)$ to measure the PU construct in this study:

A27 Using CRM improves my performance in my job.

A28 Using CRM in my job increases my productivity.

A29 Using CRM enhances my effectiveness in my job.

A30 I find CRM to be useful in my job.

\section{$\underline{\text { CRM Adoption (CAD) }}$}

The CRM adoption construct, in the current study, was measured using two items adapted from the Avlonitis and Panagopoulo (2005) study $(\alpha=0.75)$ :

A31 Compared to my peers, I consider myself a frequent user of CRM.

A37 I have fully accepted CRM in my daily work.

\section{Attitude toward using CRM (ATU)}

The four items used to measure attitude toward using CRM were adapted from Venkatesh, Davis, Morris and Davis (2003) ( $\alpha=0.86)$ :

A32 CRM technology makes work more interesting.

A33 Working with CRM is fun.

A34 I like working with CRM technology.

A40 Using CRM is a good idea.

\section{$\underline{\text { Relative Advantage (RAD) }}$}

Two items were adopted from Venkatesh, Davis, Morris, and Davis (2003) to measure relative advantage: 
A35 Inputting CRM data is time consuming.

A36 CRM makes my job easier.

\section{Intention to Use (ITU)}

People have a clear distinction between intention and estimation (forecasting) of future behaviour (Sheppard, Hartwick, \& Warshaw, 1988). Two items were adapted from the Venkatesh et al. (2003) scale ( $\alpha=0.84)$ to measure ITU:

A41 I intend to use CRM in the next 6 months.

A42 I predict I will use CRM in the next 6 months.

\subsection{Measurement of CRM System Integration (CSI)}

"IT's importance as a source of SCA [sustainable competitive advantage] stems from its potential to impact the transformation of a service firm's value chain... sometimes completely changing the basis of competition" (Bharadwaj et al., 1993, p. 93). For example the advantage of CRM technology to collect, store, process and provide faster communication of relevant information between departments and functional areas enables organisation to respond faster to customer needs. Stefanou et al. (2003) proposed a conceptual CRM development model, consisting of an $\mathrm{x}$-axis denoting CRM integration stages (sophistication and integration of CRM technology use in the firm), and a y-axis relating to IT sophistication level (CRM integration into existing IT applications and services, and sophistication of customer information capture and use). However no valid or reliable instrument has been reported measuring the level of CRM technology integration or sophistication on either axis within a firm. Although a number of studies report that CRM technology integration is necessary for successful implementation and adoption of CRM technology (Zeng et al., 2003), it appears that few studies have yet empirically investigated or reported the impact of the level of CRM technology integration within a firm (Stefanou et al., 2003). The two dimensions of the CSI sub-construct are outlined below.

\section{$\underline{\text { CRM Compatibility (CCM) }}$}

A two-item scale was developed, based on Moore and Benbasat's (1991) work, to measure CRM compatibility with other IT systems and processes within the organisation (Ling \& Yen, 2001; Nunnally \& Bernstein, 1994).

A38 CRM is not compatible with other systems or applications I use.

A39 CRM is used throughout the enterprise. 


\section{$\underline{\text { CRM Integration (CRI) }}$}

An index of ten items, ranging from simple, stand-alone, single user applications (e.g., Contact Management) to complex, sophisticated, enterprise-wide, fully integrated, ERP systems (e.g., MySAP) was developed to measure the extent of CRM technology business integration within the firm (Buttle, 2004; Greenberg, 2002; Turban, McLean et al., 2003; Zikmund et al., 2003). This index is similar in nature to the measure used by Jayachandran et al. (2005) in their measure of CRM technology. The checklist was constructed to capture specific CRM linkages to other functional business areas and systems within the supplier firm. This conceptualisation was based on the accumulated work by Dyché (2002), Greenberg (2002), Kincaid (2003), Payne (2006) as well as the offerings of CRM system developers and suppliers (ACT!, 2004; Computerworld, 2004; Microsoft, 2004; Oracle, 2005; SAP, 2006; SAS, 2004; Siebel, 2004). Adding up the number of checked links produced a dummy variable, CRI_LINKS, which was used to indicate the level of CRM technology business integration within the firm.

A44: What other information systems is your CRM system linked to?

$\square$ Stand-alone, not connected to any other business system

\section{OR}

Linked to (please tick all that apply):

$\square$ Sales
$\square$ Customer Service
$\square$ Marketing
$\square$ Accounts Receivable
$\square$ Finance

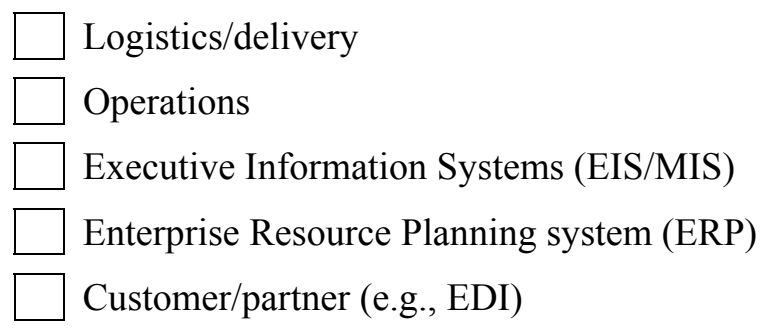

\subsubsection{Moderator and Control Variables}

Measures of customer CRM expectations (CXP) and customer relationship orientation (CRO) constructs were included in the customer instrument. Based on the exploratory research, a three-item construct was developed to examine the customer perceived expectations of CRM technology when adopted by the supplier firm. The items stated:

C10: My supplier will be able to deliver the right product when I need it.

C11: My supplier will not allow me to run out of inventory.

C12: My supplier better understands my requirements and needs. 
The CRO measure was also developed based on information extracted from the exploratory research and included three items:

C13: I think long-term relationships are good.

C14: If I had to choose I would choose a long-term relationship.

C15: Business relationships provide additional value to my firm.

Market turbulence (MT) and technological turbulence (TT) interaction with the key variables were measured in both questionnaires. The Jaworski and Kohli (1993) fiveitem, five point Likert-type scale was adapted and used to measure market turbulence ( $\alpha$ $=0.68)$.

G7/C5: In our kind of business, customers' product preferences change quite a bit over time.

G8/C6: Our customers tend to look for new products all the time.

G9/C7: We are witnessing demand for our products and services from customers who never bought them before.

G10/C8: New customers tend to have product-related needs that are different from those of our existing customers.

G11/C9: The nature of the market has changed significantly over the last few years.

Technology turbulence was measured using an adaptation of the Jaworski and Kohli (1993) four-item, five point Likert-type scale $(\alpha=0.88)$.

$\mathrm{G} 3 / \mathrm{C} 1$ : The technology in our industry is changing rapidly.

G4/C2: Technology changes provide big opportunities in our industry.

G5/C3: Many new product ideas have been made possible through technological breakthroughs in our industry.

G6/C4: Technological developments in our industry are rather minor.

\subsubsection{Nominated Customer Contact}

Mid-way through the supplier questionnaire (Section D), preceding the sections on relationship strength and relationship performance, supplier respondents were asked to nominate a customer, including the company name, contact person and phone number, email and/or address. This customer information was necessary in order to send out the customer surveys and follow up customer participation. The respondents were informed that this information would remain confidential. In addition the respondent was asked to indicate on a seven-point Likert scale the strength of the business relationship with the customer. 
In order to control for potential bias caused by the nominated customer selection ( $\mathrm{J}$. C. Anderson \& Narus, 1984; K. Kim, 2000; Rokkan et al., 2003), the statement requesting the information included the following: "If you have not already done so, please provide customer contact details for either your third or your fourth most important customer.”

\subsubsection{Demographic and Classification Information}

Section $\mathrm{H}$ requested background information of the respondent and the firm, including (a) gender, (b) industry, (c) annual gross revenue, (d) number of employees in the firm, (e) length of relationship with the nominated customer, (f) full-time work experience, (g) education level, (h) age and (i) position or title. These respondent profiles were collected partly to determine sample representativeness and response bias, and partly to determine whether some of these factors might comprise important covariates in later analysis. The last page of the questionnaire provided space to note any additional thoughts or comments on the issues raised and an opportunity to request a summary of the results.

\subsubsection{Data Collection for Instrument Refinement and Verification}

A pre-test was conducted with five CRM sales and marketing users, also considered CRM experts, and five academic colleagues from Victoria University of Wellington. Ten specifically chosen experts was deemed a sufficient number for a pre-test (Moorman et al., 1993; Spector, 1992). The questionnaire was reviewed by each of them to ensure adequate understanding, comprehensibility, face validity, and reliability of measures employed. The pre-test respondents focused primarily on content validity (the extent to which the items reflect the constructs), questionnaire response formats (appropriateness of item statements and scale points) and instructions (DeVellis, 2003; Diamantopoulos, Reynolds, \& Schlegelmilch, 1994; Netemeyer et al., 2003). The respondents found that the questionnaires were easy to complete, easy to understand and generally were able to be completed within the suggested timeframe ( 25 minutes for the supplier questionnaire and 10 minutes for the customer questionnaire). The pre-test indicated that respondents were comfortable with the seven-point Likert scale format. Based on the feedback several modifications were incorporated into the questionnaires. Two questions were deleted, the wording of certain scale items was modified, extensive section explanations were removed, and the instructions were simplified and clarified. 
Rearrangement of some questions was undertaken to improve the flow and sequencing of the questionnaire. In particular the first questions were revised to make them more salient and appealing, since, as Dillman (2000, p. 92) emphasises "no single question is more crucial than the first one" and may influence whether the questionnaire will be completed or discarded. A definition of CRM technology was added to the front cover; and the inside front cover and second page included a succinct definition of CRM technology highlighted in bold typeface, to ensure there was a common definition readily available in the sections relating to CRM.

\subsubsection{Survey Implementation}

Survey implementation should attempt to: (a) reduce the respondent response burden, (b) provide appropriate incentive to participate, and (c) build trust in the researcherrespondent interaction (Dillman, 1978). Therefore a modified Total Design Method (TDM) was used to guide the survey implementation, in order to improve data quality, and optimise the response rate (Dillman, 2000).

There are a number of reasons respondents may not participate in mail surveys, including time constraints, too many questionnaires, questionnaire length, and complexity (Baldauf, Reisinger, \& Moncrief, 1999; Huber \& Power, 1985). Organisational respondents may be prohibited from providing detailed or confidential information due to sensitivity issues surrounding the CRM implementation (Hair et al., 2003). Poor business relationship or confidentiality issues with customers may make asking for their customer participation problematic. In addition informants may submit inaccurate data since the linkage between self-reported attitude and behaviour is tenuous (Kirk-Smith, 1998). To help overcome non-participation by potential respondents, respondents were offered a summary of the completed study as a tangible benefit of their participation, confidentiality of the study was emphasised, the university connection was highlighted and the participant's process streamlined as much as possible (Gendall, Hoek, \& Esslemont, 1995).

Although incentives, in general, are considered advantageous in generating higher response rates (Dillman, 2000; Jobber, Mirza, \& Wee, 1991; Jobber, Saunders, \& Mitchell, 2004), the current study was guided by Jobber and Saunders (1993) who found that the influence of incentives in a B2B context may be offset by simply making 
additional quality contacts, and effective telephone and mail follow-up. Therefore the following steps were implemented:

1. Firms were contacted by telephone to verify current contact details. If there was no answer, or the appropriate person was busy or not available, the call was noted in the Call Back Log and two additional call attempts were made. On the third call a message was left briefly outlining the purpose of the call and asking for the contact person to call the researcher back.

2. A personal request was made to each $\mathrm{CEO} / \mathrm{MD} / \mathrm{Sales} /$ Marketing manager to participate.

3. A cover letter and questionnaire( $\mathrm{s}$ ) were mailed to the appropriate informant with detailed information regarding purpose, due dates, benefits to their organisation, and researcher's contact details.

4. Self-addressed, free-post return envelope(s) were included in the mail-out (Jobber \& O'Reilly, 1998).

5. Each firm was followed-up through the post and through telephone calls.

\subsubsection{Sample Selection}

Less than 20 employees is considered small business, while greater than 100 employees is considered large business in New Zealand (Locke, 2004; Statistics New Zealand, 2005). Small business are less likely to adopt extensive IT, due to their lack of readiness, little peer pressure and perceived benefit (Iacovou, Benbasat, \& Dexter, 1995; J. Lee, 2004). Therefore companies with twenty or more employees were selected for the study. Based on New Zealand business census data this employee cut-off point represents 4,669 enterprises (see Table 4.9), 2.8\% of the total enterprises in New Zealand (Statistics New Zealand, 2005).

The ANZSIC (Australian New Zealand Standard Industry Classification) divisions targeted for this research were Manufacturing (Division C), Wholesaling (Division F), and Services (Divisions J, K and L), shown in Table 4.9. Educational institutions, government bodies, hospitals and libraries were excluded since they are non-profit oriented and are less likely to utilise CRM practices.

A list of New Zealand companies in the manufacturing, wholesale and services industries was compiled from the Kompass (April 2006) database. The subset of New Zealand-based firms with contact details identified from the Kompass database and 
Table 4.9: Target Enterprise (ANZSIC) by Employee Count

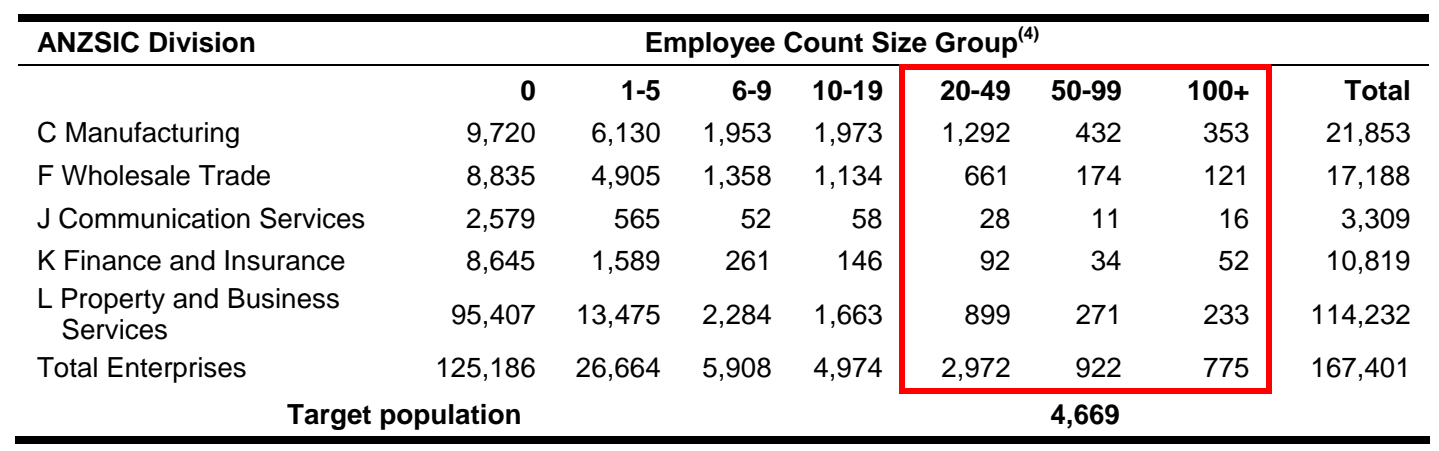

Source: Statistics New Zealand (2005)

meeting the ANZSIC and business criteria was 3,414. From this list 1,689 randomly selected companies were contacted by telephone in order to identify the appropriate person, gain agreement to participate, collect customer contact details and validate contact details in the database. This study employed a purposeful heterogeneous mix of industries in order to provide a greater opportunity to generalise the results (John \& Reve, 1982).

\subsection{Unit of Analysis}

The unit of analysis is the same as described in the exploratory phase: the supplier customer dyad. This type of dyadic relationship unit of analysis has been investigated previously by Medlin (2003), Gundlach, Achrol and Mentzer (1995) and K. Kim (2000).

\subsection{Company and Respondent Selection}

Well-informed and knowledgeable executives make good informants, providing as accurate and sound information as those collected from multiple sources (Menon et al., 1999; Zahra \& Covin, 1993). There has been some controversy regarding single informant responses, however, studies have shown that key informants can supply reliable data given their role provides them with the required information and they are willing to participate (D. T. Campbell, 1955; John \& Reve, 1982; K. Kim, 2000). However, "when dependent and independent variable data are collected from a single informant, common-method bias can be a potential problem" (Menon et al., 1999) ${ }^{4}$. Keeping in mind the research question, as to whether CRM technology adoption impacts business relationships and relationship performance, the lack of empirical

\footnotetext{
${ }^{4}$ Measures used to address common-method bias are discussed in detail in Chapter 5.
} 
dyadic research, and the requirement for matched customer data, a dual respondent approach - from the supplier and from the customer - was deemed appropriate. It was imperative that at least one customer be matched to each firm, agreed to participate in the study and returned a completed questionnaire.

J. C. Anderson and Narus (1990), in their study of working partnerships between manufacturers and distributors, found the collection of dyadic data difficult and problematic. One of the primary issues was that the first or second highest selling distributors had very uniform working relationships with the manufacturers - providing little variation. To overcome this issue, researchers asked the distributors to "specify as their manufacturer partner the firm that supplied the fourth-highest-selling product line and accounted for at least $5 \%$ of their total sales... or... third-highest-selling product line, and so on" (p. 46). K. Kim (2000), and Rokkan, Heide, and Wathne (2003), have used similar selection criteria to overcome potential respondent selection bias in their distributor-supplier dyad research. Following the approach taken by these earlier researchers, each potential supplier participant in the present study was asked to provide the contact details for a customer that they feel are representative of their "third or fourth most important" customer, and who may be willing to participate.

\subsubsection{Initial Contact}

Each CEO, marketing manager or sales manager was initially contacted by telephone to establish the identity of a key person responsible for customer relationships, determine survey eligibility, confirm details and gain respondent agreement to participate in the survey (Dillman, 2000; Jobber \& O'Reilly, 1998; Schlegelmilch \& Diamantopoulos, 1991). Appropriate survey questionnaire packages were sent to the contact person at the supplier firm, and also to the customer contact person if available, for the collection of data from the participating supplier firms and customers.

\subsubsection{Cover Letter and Mail-out}

Three different cover letters were necessary in order to provide an appropriate letter for each type of recipient (supplier firm, unknown customer, known customer). In the cases where the customer contact details were given over the telephone during the initial contact (known customer), a personalised customer cover letter was produced. The majority of supplier firms only provided the customer contact details once they had received both questionnaires, and forwarded the customer questionnaire themselves 
(unknown customer). In this case the customer questionnaire package consisted of a generic customer cover letter. The body of the cover letter was similar in all three cases, see Appendix A5.

\subsubsection{Follow-up Procedures}

Follow-up procedures were especially important in this study since the methodology depended on completed survey responses from both the supplier and customer firms. Due to the potentially sensitive nature of the survey, dealing with interfirm and personal relationships, and the criticality of the customer to also return a survey, a follow-up procedure was standardised for this study. The follow-up procedure included a postcard mailer to the supplier firm after three weeks, followed by a telephone call two weeks later (Reinartz et al., 2004). During the telephone follow-up process two telephone attempts were made before a message was left which invited the potential participant to contact the researcher.

A follow-up process for nominated customers included a telephone call one week after receiving the completed supplier questionnaire. Customers continued to receive telephone follow-up until they returned a completed survey, promised to complete the survey, declined to participate or after three unsuccessful attempts. The overall followup process continued until the number of matched surveys (dyads) met the minimum sample size requirements and was considered sufficient by the researcher ${ }^{5}$.

Non-deliverable surveys were not considered a problem since (a) the database was developed using the latest Kompass CDROM (April 2006), (b) addresses and contact details were verified on the initial telephone contact, and (c) any returned surveys were re-verified with the original contact person, re-addressed and re-mailed. However one supplier followed-up did report that the survey was mailed back, but was never received by the researcher.

\subsection{Data Analysis and Hypothesis-testing Procedures}

\subsubsection{Overview}

Data was collected separately from both the supplier and the customer, and the returned surveys matched and coded. Data summaries using SPSS, factor analysis and

\footnotetext{
${ }^{5}$ The minimum sample size requirements are discussed in the following PLS section and again in Chapter 5 .
} 
structural equation modelling (SEM) was used to analyse the data, validate the measurement model and test the hypotheses.

\subsubsection{Structural Equation Modelling}

Structural equation modelling (SEM) has a long history and is widely used in a number of disciplines, including marketing (Chau, 1997; Maruyama, 1998) and information systems (Rivard \& Huff, 1988). SEM is a powerful second generation multivariate technique for analysing results that may have a number of variables, allowing the assessment of measurement properties and theoretical (structural) relationships, including unobservable latent variables with multiple relationships, simultaneously within the same analysis (Chin, 1998a, 2000). SEM uses a combination of multiple regression, factor analysis and path analysis techniques to simultaneously estimate measurement of, and the relationships between, a number of theoretically related constructs (latent variables) (Hoyle, 1995; Kelloway, 1998; Kline, 2005; Maruyama, 1998; Schumacker \& Lomax, 2004).

SEM provides advantages over other multivariate analysis techniques. For example analysis of variance (ANOVA) and regression models assume error free measurement of the dependent variable and separate measurement models (Bagozzi, 1977). In contrast SEM determines measurement error, and tests measurement and structural models simultaneously. The SEM iterative analysis process allows the testing of complex and large-scale models in a systematic and comprehensive manner (Gefen, Straub, \& Boudreau, 2000; Wilcox, 1998).

There are two fundamental SEM techniques; covariance based and principal component based. Covariance-based SEM assumes data to be multivariate normal, meeting the requirements of univariate normality, linearity, homoscedasticity, nonmulticollinearity, scaled relative variance, and requires fairly large sample sizes (e.g., samples of 250 or more) (Hair, Black, Babin, Andersen, \& Tatham, 2006; Kline, 2005; Schumacker \& Lomax, 2004). Data distributions departing from these assumptions may not produce valid SEM results. Hence covariance-based SEM has difficulty coping with relatively small sample sizes when examining large numbers of interactions, non-linear relationships between variables and constructs, multicollinearity and heteroscedasticity (Gefen et al., 2000). Covariance-based SEM has also been shown to exhibit serious flaws when not applied properly with respect to: (a) data characteristics, (b) reliability 
and validity, (c) evaluating model fit, (d) model respecification, and (e) equivalent models (Shook, Ketchen, Hult, \& Kacmar, 2004).

Although SEM's strength is the ability to estimate both the measures of a latent variable, and a number of interrelated variables simultaneously, while allowing dependent variables in one equation to become independent variables in others, "[s]tructural equation modelling is inherently a confirmatory technique" (Kelloway, 1998, p. 7). SEM relies on theory in order to specify a model for testing.

Model specification includes two distinct components (a) a measurement model and (b) a structural model (Hoyle, 1995; Kline, 2005). Within the SEM analysis, confirmatory factor analysis is employed to validate the items (indicators) explicitly measuring the individual latent variables. The structural model on the other hand formally describes the causal relationship between the latent variables to be estimated and tested (Hoyle, 1995).

\subsubsection{Partial Least Squares (PLS)}

Partial least squares (PLS) is a specific variance-based (principal components) second generation SEM analysis technique that is appropriate for testing complex structural models with multiple constructs where latent variables (theoretical constructs), non-normal data, small sample size and multicollinearity exist (Fornell \& Bookstein, 1982; Fornell \& Cha, 1994; Hulland, 1999; Wold, 1985). Although the covariance-based methods (e.g., LISREL) has dominated the marketing literature PLS provides some unique advantages (Fornell \& Bookstein, 1982; Fornell \& Cha, 1994; Wold, 1982). Since PLS is conducted as a series of interdependent ordinary least squares (OLS) regressions, PLS does not (a) require large sample sizes, (b) assume any specified multivariate distribution, or (c) demand observation independence (Fornell \& Bookstein, 1982; Fornell \& Cha, 1994). Some researchers consider it to be a complementary alternative to the covariance-based SEM technique (Chin, 1995; Hair et al., 2006).

Social science data does not always meet the stringent requirements of multivariate normality, interval scaling or sample sizes required by covariance-based SEM techniques (Fornell \& Bookstein, 1982). PLS uses an estimation procedure that only involves a part of the model in each step; measurement models are estimated separately construct by construct (block by block). Hence PLS only needs enough cases to estimate 
the largest number of parameters for any one structural equation (Fornell \& Cha, 1994). Chin (2000) suggests a minimum sample size of 30 cases or ten times the construct with the greatest number of structural paths going into it. The research model, discussed in Chapter 3 and evaluated in Chapter 5, indicates that the largest number of structural paths going into the CTA construct is four; therefore the minimum sample size required by PLS to evaluate the model is 40 dyads.

The aim of "PLS is to maximize variance explained" (Chin, 1995, p. 6) from observed or unobserved variables, whereas covariance-based SEM techniques (i.e., LISREL) attempt to account for observed covariance and provide the best fit to a theoretical covariance matrix (Fornell \& Bookstein, 1982; Fornell \& Cha, 1994). Hence covariance SEM techniques are better suited for theory testing while PLS is better suited for explaining complex relationships (Fornell \& Bookstein, 1982; Fornell, Lorange, \& Roos, 1990; Tobias, 1995). PLS iteratively minimises all residual variances until the parameter estimates stabilize. In particular PLS considers all path coefficients simultaneously, allowing analysis of direct, indirect and spurious relationships, and estimates the individual item weightings within the theoretical model rather than in isolation, (Birkinshaw, Morrison, \& Hulland, 1995). PLS is most useful for exploratory research with little previous developed theory, many and complex variable interactions, and non-normal data distributions. PLS avoids indeterminacy (where factor scores cannot be calculated) and the occurrence of multiple solutions, both issues with covariance-based SEM techniques, by utilising component scores and explicitly defining the unobservable latent variables (Cool, Dierickx, \& Jemison, 1989; Lastovicka \& Thamodaran, 1991).

The social science disciplines where PLS has been used includes, information systems (e.g., Compeau \& Higgins, 1995; Hwang, 2005; Karimi, Somers, \& Gupta, 2004; Rivard \& Huff, 1988; Wixom \& Watson, 2001), strategic management (e.g., Birkinshaw et al., 1995; Cool et al., 1989; Delios \& Beamish, 1999; Johansson \& Yip, 1994), organisational behaviour (e.g., Howell \& Higgins, 1990) and marketing (e.g., Arnett, Laverie, \& Meiers, 2003; Ashill, Carruthers, \& Krisjanous, 2005, 2006; Barclay, 1991; Grégoire \& Fisher, 2006; Klemz, Boshoff, \& Mazibuko, 2006; O'Cass, 2002; J. B. Smith \& Barclay, 1997; Zinkhan et al., 1987).

PLS is considered particularly appropriate for this research since (a) the focus is theory development rather than theory testing, (b) the proposed CRM technology 
adoption - customer relationship model conceptualisation is complex with latent variables constructs taking on both dependent and independent roles simultaneously, (c) there are a smaller number of cases than would be required were a covariance-matching method used, and (d) the data distribution is non-normal.

In practice SEM is conducted with computer software utilising a covariance-based (e.g., LISREL, EQS and AMOS) or component-based (e.g., PLS-Graph and SmartPLS) approach (Bentler, 2005; Byrne, 2001, 2006; Chin, 1998a; Joereskog \& Soerbom, 1982; Ringle, Wende, \& Will, 2005). SmartPLS version 2.0 M3 was chosen to conduct the PLS analysis (Ringle et al., 2005).

\subsubsection{Confirmatory Factor Analysis (CFA)}

Confirmatory factor analysis (CFA) is generally used to assist in the confirmation and validation of the unidimensionality of constructs used in a survey. Although there are differences of opinion among researchers regarding acceptable criteria, minimum factor component loadings of 0.70 or higher are normally considered significant for CFA purposes and are adopted in this study (Hair et al., 2006; Nunnally \& Bernstein, 1994).

\subsubsection{Exploratory Factor Analysis (EFA)}

Factor analysis is a series of procedures primarily used for data reduction and summarisation. The relationships between large numbers of interrelated variables are examined and underlying factors are extracted based on correlation groupings. Factor analysis is also used to identify smaller sets of uncorrelated variables to be used in subsequent multivariate analysis (Malhotra, 2007).

Exploratory factor analysis (EFA) is used as a first step to identify and validate factor groupings reflecting underlying theoretical constructs. Since PLS is dependent to some extent on theory to guide the model development and construction, it is not appropriate for EFA. EFA considers the correlated factor loadings of all items related to a construct (and / or series of sub-constructs) simultaneously to determine appropriate independent factor components (Nunnally \& Bernstein, 1994). To aid interpretation, factor loadings can also be rotated (e.g., varimax) in order to produce orthogonal or "clean" loadings on independent components. In this study, minimum factor component loadings of 0.60 or higher are considered significant for EFA purposes, while factors exhibiting crossloadings of 0.45 and above should be considered for deletion (Hair et al., 2006). 


\subsection{Chapter Summary}

This chapter outlined the research method to be used in this study. The research is divided into two phases. The exploratory phase of the research used a multiple-case design method in order to better understand the CRM technology adoption - customer relationship (CTA - CR) phenomenon within the business-to-business environment. The results from this phase were used in finalising the conceptual model and design of the research instrument. Instrument development utilised existing scales and measures wherever possible, however since measures did not exist for some constructs (e.g., CTA, CRO and CXP), scales were developed and tested specifically for this study. Two different instruments were developed - one for the supplier firm (independent variables), another for the customer (dependent variables).

The explanatory phase of the research consisted of a mail survey, the data subsequently used to validate the CTA - CR model and test the hypotheses. This involved distributing and collecting survey questionnaires from 1,689 New Zealand business firms in the manufacturing, communications, services and wholesale industries. The customer survey questionnaire was delivered to customers nominated by the participating supplier firms. Each participating supplier firm response was matched with the customer response to form a dyad. The unit of analysis in this study is the supplier - customer dyad relationship. Structural equation modelling (SEM) and other data analysis techniques were discussed. Due to the complexity of the CTA - CR model with latent variables taking on both dependent and independent roles, a small sample size, and non-normal data distributions, partial least squares (PLS) data analysis was selected to test the research hypotheses. 


\section{CHAPTER 5. Data Analysis and Results}

\subsection{Introduction}

The purpose of this chapter is to reflect briefly upon the contribution of the qualitative (exploratory) phase, and present a full analysis of the relevant data collected from the quantitative (explanatory) phase of the research. The chapter presents key insights from the exploratory research, as well as the results from the questionnaire survey, including the multivariate analysis techniques undertaken, and the results of the hypotheses testing.

\subsection{Exploratory Analysis and Results}

The ten supplier and customer interviews from the exploratory phase were analysed using the guidelines provided by Miles and Huberman (1994) and Yin (2003). Detailed summaries of the qualitative data analysis can be found in Appendix A2. Where available representative quotes from the interview data are presented to exemplify the results of the qualitative data analysis. The key insights gained include:

1. Overall support for the proposed CRM technology acceptance - customer relationship model. Both supplier and customer firm respondents agreed that CRM technology can play an important role in B2B relationships (see Appendix A2.1: Q14, Q22, Q25).

[I] t enables people who aren't good at relationships to at least have a reasonable level of performance.... it provides reminders of things they should be doing anyway, and consistency. HR Manager (Customer).

The most important word in CRM is relationships and CRM is to help that. Investor Services Manager (Supplier - CRM user).

2. Validation of the proposed variables and the impact of CRM technology adoption on business relationships. Supplier respondents indicated that the MO of the firm influenced CRM technology adoption (Appendix A2.5). Responses to the ITMO questions provided mixed responses from the supplier firms (Appendix A2.6), thereby providing support for its inclusion as a variable. The analysis results also corroborated the CTA, relationship strength and relationship performance constructs and sub-constructs (Appendix A2.1). 
Once again I think as a customer you don't know if someone is using a CRM system. You just don't know that. Your relationship with them might be absolutely brilliantly, they're timely, their information is good and that maybe coming out of the CRM system but you don't know that. Supply Company Services Manager (Customer).

We're very market orientated...[but]... No I think it's totally accidental that [the implementation of CRM technology] happened and I think it's probably the other way round. We have the CRM system and I guess we're all realising that it could have a potential effect if we used it properly. Telco Account Manager (Supplier - CRM user).

3. Important insights into the motivation, attitudes and emotions influencing CRM technology adoption were identified. For example (see Appendix A2.1 for details):

- CRM technology provides a form of business advantage; either around the use of technology to better capture and use information about the customer, or to aid in documentation, time management and business reporting. Some respondents were cynical toward management's reasons for adopting CRM technology.

CRM itself to me is a tool to foster the relationship or to continue [to do] the small things which you need to do to keep building a relationship. Owner, Management Company (Customer).

CRM is used to record my relationship, it's to record my services - I can win or lose business particularly if I have opposition involved, by not recording the information correctly and not having that information readily retrievable. Owner, Technical Services Company (Supplier - CRM user).

- Expectations of CRM technology users centred around sales support and knowledge (information) management,

I think the majority of people actually in the sales side of the organisation would actually think it's a really important tool for them to do the job, learn to carry out the day-to-day forecasts, and upkeep of their territory basically. Strategic Account manager (Supplier - CRM user).

- Benefits of CRM technology included a common repository available to any interested and authorised internal party, as well as the ability to identify customer and product trends, 
Related to the research side CRM provides you the ability to identify issues over geography, over time, and over a large number of stuff inside their head and of course different sorts of relationships where there can also be similar patterns going. HR Manager (Customer).

[CRM] enables a good handover of accounts from person to person. It enables virtual teams to function within accounts by being able to access information about that account on an as needed basis. It enable different people in the organisation to have a view of what's happening at an account level and a portfolio level and a regional level without having to keep reinventing the wheel. Corporate Account Manager (Supplier CRM user).

- CRM systems are considered more as a business tool or enabler, and not necessarily helpful initiating B2B relationships, except perhaps by providing good leads. Some respondents considered CRM technology to play a critical role in relationships. Others indicated far less involvement of CRM technology to influence relationship dimensions such as customer satisfaction and loyalty.

Putting information into a database enables an organisation to, research is a very general term, find out what makes a good relationship, which bits of the ingredients are having more of an impact upon the relationships. HR Manager (Customer).

I think the majority of people actually in the sales side of the organisation would actually think it's a really important tool for them to do the job.... Strategic Account Manager (Supplier CRM user).

I don't think it's that well received amongst the sales force. I think most people find it a bugbear. I think the management find it a bit of a bugbear. I think a lot of people have struggled to get to like it and get to understand it. Telco Account Manager (Supplier - CRM user).

4. Support for the existing variables used in the CTA - CR research model.

I think it's important because it's, it is about demonstrating, you know, a willingness or a desire to invest in the relationship, so commitment to me is around the resources being applied to the innovation.... Healthcare Commercial Manager (Customer).

So the communication you know I guess it's almost a, I don't know for want of a better term a high team issue there, if you can't communicate properly then there's going to be no trust. The commitment won't happen and none of them [relationship factors] will happen. IT General Manger (Customer). 
5. Confirmation that practitioners were familiar with specific CRM terms and expressions.

6. Detailed contextual data used to help interpret the research results. The insights and contextual information provided additional perspectives and support when interpreting the results from the survey data (explanatory phase) in Chapter 6.

The detailed analysis and results from the explanatory phase of the research is discussed next.

\subsection{Survey Response Analysis}

\subsubsection{Response Rate}

Although 1,689 firms were contacted, 50 were discarded after the initial telephone call since the firms did not meet the business selection criteria, as discussed in Chapter 4. In addition 'No Answer' and 'Busy' contacts were dropped from the contact list after three telephone attempts (Frey, 1983; Groves \& Lyberg, 1988). Tables 5.1a and 5.1b depict the details of the response rates obtained. Of the 526 supplier firms that agreed during the initial telephone call to participate in the survey (32.1\%), 167 supplier surveys were returned (10.2\% response rate), and 140 dyads collected, which constitutes an overall $8.5 \%$ response rate. Although these response rates appear low in comparison

Table 5.1a: Supplier Response Profiles from Initial Contact

$$
(\mathbf{n}=1,639)
$$

\begin{tabular}{rrcc}
\hline Overall Response (n= 1,639) & $\mathbf{N}$ & $\mathbf{\%}$ \\
\hline 1) & Initial agreement to participate (surveys sent to suppliers) & 526 & 32.1 \\
2) & Telephone message left (no call returned) & 469 & 28.6 \\
3) No answer, wrong number or no contact (telephone) & 135 & 8.2 \\
4) Supplier refusals following additional email information & 71 & 4.3 \\
5) Supplier refusals (initial telephone contact) & 438 & 26.7 \\
a. No time, too busy & 180 & 11.0 \\
b. Not interested & 71 & 4.3 \\
c. No appropriate person available & 59 & 3.6 \\
d. Refuse to involve customer & 32 & 2.0 \\
e. Not appropriate for this business & 27 & 1.7 \\
f. Does not do surveys & 25 & 1.5 \\
g. No reason given & 14 & 0.9 \\
h. No B2B customers & 10 & 0.6 \\
i. Already completed similar survey & 6 & 0.4 \\
j. Already completed too many surveys & 5 & 0.3 \\
k. Survey too long & 4 & 0.2 \\
l. $\quad$ Confidential information & 3 & 0.2 \\
m. Business closing & 2 & 0.1 \\
\hline
\end{tabular}




\section{Table 5.1b: Supplier Response Profiles from Questionnaires Sent $(n=526)$}

\begin{tabular}{|c|c|c|}
\hline Response from Questionnaires Sent $(n=526)$ & $\mathbf{N}$ & $\%$ \\
\hline 1. Supplier surveys returned & 167 & 10.2 \\
\hline No response (from questionnaire sent) & 205 & 12.5 \\
\hline 3. Supplier refusals (from questionnaire sent) & 154 & 9.4 \\
\hline a. No time, too busy & 61 & 3.7 \\
\hline b. No reason given & 30 & 1.8 \\
\hline c. Not appropriate for this business & 20 & 1.2 \\
\hline d. No appropriate person available & 16 & 1.0 \\
\hline e. Refuse to involve customer & 15 & 0.9 \\
\hline f. Not interested & 5 & 0.3 \\
\hline g. Survey too long & 4 & 0.2 \\
\hline h. Business closing & 2 & 0.1 \\
\hline i. Already completed similar survey & 1 & 0.1 \\
\hline
\end{tabular}

to traditional mail surveys (e.g., Jobber \& O'Reilly, 1996), the process of dyadic data collection requires multiple levels of agreement and participation from multiple firms (supplier and customer firms) and individuals within the firms.

Dyadic relationship survey research provides additional obstacles in obtaining initial agreement to participate and subsequent survey completion due to the inherent nature of the research (i.e., relationships) and the use of a sequential sampling approach (E. Anderson \& Weitz, 1992; J. C. Anderson \& Narus, 1990). In particular each supplier firm had to be contacted by telephone, agree to participate (not all contacted firms did finally participate) and nominate a customer firm. The customer firm then had to be contacted and also agree to participate and not all customer firms agreed to participate. However these results are similar to dyadic response rates obtained by K. Kim (2000). In that study $32.3 \%$ of firms initially agreed to participate and Kim obtained a $7.1 \%$ overall dyadic response rate.

Studies have shown that traditional telephone refusal rates for telephone interviews are between 20 - 28 percent (Frey, 1983). The results from this study compare favourably with $26.7 \%, 438$ in total, refusing to participate from the initial telephone call. Other studies have indicated the reasons for non-participation in surveys include disinterest, inconvenient timing, privacy concerns, and not a priority (Churchill \& Iacobucci, 2005; Frey, 1983). The telephone contacts refusing to take part in this survey provided similar reasons for their non-participation: lack of time, no interest in the survey, and no appropriate person available, accounting for the majority of reasons, see Tables 5.1a. A number of firms contacted refused to involve customers, a unique dyadic 
research reason for non-participation. Some initial telephone contacts were extremely negative and vocal regarding the potential use of their customers in relationship research. Others were obviously not comfortable in approaching their customers to participate in this type of survey regarding the status of their relationship, see Tables $5.1 \mathrm{a}$ and $5.1 \mathrm{~b}$ (47 stating outright they did not want to involve the customer).

There were also indications that the nature of the survey investigating B2B relationships was considered intrusive or sensitive. A large number of potential respondents who had reviewed additional email information or received the customer questionnaire to forward-on did not respond. The high number of non-respondents and refusals (430) may indicate a reluctance to involve their customer ${ }^{6}$, in which case the 'Refuse to involve customer' figure may understate the true reason for nonparticipation.

Given the known difficulty of gaining dyadic survey participation a number of tactics were employed to increase the response rate from the supplier firm (E. Anderson \& Weitz, 1992; K. Kim, 2000), including the use of a pre-notification telephone call to screen potential participants and request cooperation (Schlegelmilch \& Diamantopoulos, 1991); the use of Victoria University of Wellington official letterhead; the promise of confidentiality and personalisation; a copy of the results; a front cover coloured graphic to attract attention; use of closed-ended questions; a postage paid return envelope; and two reminders in the form of a follow-up postcard and a follow-up telephone call with a second questionnaire if necessary (Dillman, 2000; Jobber \& O'Reilly, 1996). The process followed to increase customer questionnaire returns depended on the return of the supplier questionnaire. Once the supplier questionnaire was returned the nominated customer contact details were available. If after two weeks following the return of the supplier questionnaire, the customer questionnaire had not been received, a telephone call was made to the customer to (a) ensure they had received the questionnaire, (b) answer any questions they may have, and (c) determine a return date for the questionnaire. If the nominated customer had not received the questionnaire from the supplier, a customer questionnaire was either posted or emailed directly to them. After three days the customer was called again to ensure they had received the questionnaire and would complete it.

\footnotetext{
${ }^{6}$ A total of 71 potential respondents receiving additional email information (see Table 5.1a) and 359 potential respondents receiving the customer questionnaire (see Table 5.1b) did not return the questionnaire.
} 
The dyadic response profile is shown in Table 5.2, 146 customer surveys were returned. One customer refused outright to complete the customer questionnaire, another customer stated they had mailed the survey back, but it was never received, and two customers refused due to time commitments. Two customers returned their survey but could not be matched to a supplier survey ${ }^{7}$. Therefore a total of 140 matched dyads formed the basis for the analysis. Although the response rate was lower than hoped for the sample frame was unique in that, unlike the majority of dyadic research published to date (e.g., John \& Reve, 1982), the focus was not specific to one industry (cf. J. C. Anderson \& Narus, 1984; Farrelly \& Quester, 2003; Medlin, 2003; Rokkan et al., 2003), and used only matched data (Deshpandé et al., 1993).

Table 5.2: Dyadic Response Profiles $(n=150)$

\begin{tabular}{lcc}
\hline Response & N & \% \\
\hline Usable supplier surveys & 150 & 9.2 \\
Customer surveys returned (from usable supplier surveys) & 146 & 97.3 \\
Completed matched questionnaires (dyads) & 140 & 93.3 \\
\hline
\end{tabular}

\subsubsection{Respondent and Demographic Profiles}

The respondent profiles, responding firms and participating customers are presented in Tables 5.3 and 5.4. The sample used in this study is broadly representative of the selected business population in New Zealand. Although the $100+$ employee firm size is over-represented with $28.3 \%$, this is most likely due to larger firms utilising CRM technology more than smaller firms, and therefore being more willing to participate in the survey (Iacovou et al., 1995). From the initial telephone contact it became apparent that smaller firms tended not to have CRM technology in place and therefore were less willing to participate in the survey. Larger firms tended be more familiar with CRM technology, and therefore were also more inclined to participate in the study, which

Table 5.3: Participating Firms Employee Profile $(n=140)$

\begin{tabular}{lcccc}
\hline & \multicolumn{4}{c}{ Employee Firm Size } \\
\hline Sample & $\mathbf{2 0 - 4 9}$ & $\mathbf{5 0 - 9 9}$ & $\mathbf{1 0 0 +}$ & Total \\
Percent & 53 & 28 & 32 & 140 \\
Sample Frame & $46.9 \%$ & $24.8 \%$ & $28.3 \%$ & \\
Percent & 2,965 & 943 & 766 & 4,669 \\
\hline
\end{tabular}

\footnotetext{
${ }^{7}$ The two suppliers were repeatedly contacted, but never returned their questionnaire.
} 
helps explain the over representation of Manufacturing (53.1\%), Communications $(3.5 \%)$ and Finance (7.1\%) shown in Table 5.4.

Table 5.4: Participating Firms ANZSIC Profile $(n=140)$

\begin{tabular}{lcccccc}
\hline & \multicolumn{6}{c}{ Australia New Zealand Standard Industry Classification } \\
& C - & F - & J - & K - & L - & \\
& Man & Trade & Comms & Finance & Services & Total \\
\hline Sample & 60 & 12 & 4 & 8 & 29 & 140 \\
Percent & $53.1 \%$ & $10.6 \%$ & $3.5 \%$ & $7.1 \%$ & $25.7 \%$ & \\
Sample Frame & 50 & 23 & 1 & 4 & 34 & 4,669 \\
Percent & $44.5 \%$ & $20.5 \%$ & $1.2 \%$ & $3.8 \%$ & $30.1 \%$ & \\
\hline
\end{tabular}

Respondents were represented by Business Executives (42.5\%), Sales (36.3\%), Marketing (16.8\%) and general business administrators (3.5\%). Females comprised $12.4 \%$ of the participants. The majority of respondents reported more than 16 years work experience, were older than 36 years, and had at least some tertiary education. The average length of the reported customer supplier relationship was 10.3 years. See Appendix A6 for additional demographic details.

\subsubsection{Non-response and Response Bias}

Non-respondents may differ systematically from respondents in attitude, motivation, behaviour, personality, demographics or psychographics - any or all of which may affect the study result (Churchill \& Brown, 2004; Malhotra, Hall, Shaw, \& Oppenheim, 2006). Non-response and response bias was tested, using t-tests to compare relationship length, work experience, number of employees, education level, age, gross revenues and industry segment.

Late respondents can be used to represent non-respondents since they would probably have not responded had they not been extensively followed up (Churchill \& Brown, 2004; Malhotra et al., 2006). Early and late respondents were compared using two-tailed t-test (Armstrong \& Overton, 1977; Brennan, Turnbull, \& Wilson, 2003; Heide \& John, 1992). There were no significant differences with respect to general demographics, other than late respondents had relationships spanning a greater number of years $(14.9$ years vs. 9.7 years $)(t=2.317, p<.022)$ and greater work experience $(t=$ $5.035, \mathrm{p}<.00)$.

Comparing late supplier respondents' responses to the early supplier responses on the basis of the two CTA sub-constructs used in the final analysis, Customer Knowledge $(\mathrm{CKN})$ and CRM Usefulness (USF), found no significant differences; $\mathrm{CKN}(\mathrm{t}=0.063, \mathrm{p}$ 
$<.95)$, and USF $(\mathrm{t}=1.274, \mathrm{p}<.21)$. Appendix A7 provides the non-response and response bias statistical analysis details. The overall results indicate no significant concerns regarding non-response bias in this study.

\subsection{Data Screening and Preliminary Analysis}

\subsubsection{Overview}

The extent to which the data meets psychometric assumptions was addressed before the appropriate data analysis techniques were employed, since some of the criteria (i.e., data distribution, and sample size) have direct bearing on the choice of analysis techniques and tests.

\subsubsection{Missing Data}

Missing data is a concern of most researchers and can affect empirical research (Malhotra, 1999). Sixty-nine returned supplier surveys (41.6\% of supplier surveys), and 55 (40.1\%) of the customer surveys returned had missing data. Respondents who returned surveys with missing data were contacted by telephone and offered the opportunity to complete the survey over the telephone or via email. In all cases the participant either had not understood the original question requirement and needed clarification, or had simply overlooked that portion of the survey. The most common item of missing data in the supplier surveys was the first item of Section A on the second page asking the extent of CRM use. Thirty-seven respondents overlooked this item on the survey, accounting for $53.6 \%$ of the number of surveys with missing data. It was concluded that respondents simply overlooked the 'extent of CRM use' item due to the physical position of this item on the page. For the balance of the surveys with missing data the missing data was evenly distributed across 41 items.

In the customer survey, the very first item in Section A was most often omitted; 46 respondents ( $83.6 \%$ of the surveys missing data) failed to answer this item. This item referred to the strength of the relationship with the nominating firm. It was concluded that due to the declarative statement itself and the relative position of the item on the page the respondents simply overlooked this item. In all situations the requirements were appropriately clarified and the surveys completed over the phone (or email). In five cases of missed data, specific sections of the supplier survey were emailed to the 
respondent and the surveys were completed electronically and returned. This follow-up process resulted in no missing data for the 140 matched surveys.

\subsubsection{Non-eligible Respondents}

Since the objective of the study was to investigate the effect of CRM technology adoption on customer relationships, response from suppliers who indicated they did not currently have or use CRM technology (or a CRM system) were discarded from further analysis. This resulted in the elimination of 25 dyads, leaving 115 dyads.

\subsubsection{2. "Do not know" Response - IT Management Orientation section}

As discussed in Chapter 4 the "Do not know" (DNK) option was included only in the IT management orientation (ITMO) section of 20 items. DNKs were anticipated in the ITMO section since it was considered that not all of the marketing and sales respondents would have the appropriate level of IT operational knowledge required to answer this series of questions (Durand \& Lambert, 1988). Although the use of DNKs creates additional problems for data analysis (Poe, Seeman, McLaughlin, Mehl, \& Dietz, 1988), DNKs are considered acceptable responses and should not be ignored (Leigh \& Martin, 1987). The number of respondents choosing at least one DNK response in the ITMO section was $16(10.7 \%)$.

In order to understand the effect of DNK responses in the ITMO section of the survey, the pattern of DNKs was analysed using SPSS Missing Value Analysis (MVA) and then the DNK's were treated as missing data. Based on MVA there was no overall discernable pattern to the DNK responses. DNK respondents were compared, using independent $\mathrm{t}$-tests, to the balance of the supplier respondents with respect to the two sub-constructs of the CRM technology adoption (CTA) variable (CKN and USF scales). Table 5.5 shows no significant difference between the two group's responses to the CTA items. Refer to Appendix A8 for details of the DNK analysis.

Table 5.5: Comparing CTA Responses Between "Do not know" and General Respondent ITMO Responses $(n=115)$

\begin{tabular}{lccc}
\hline \multicolumn{4}{c}{ t-test for Equality of Means } \\
Construct & t-value & df & Sig. (2-tailed) \\
\hline CKN & 1.612 & 113 & 0.110 \\
USF & -0.318 & 113 & 0.751 \\
\hline
\end{tabular}


Since the overall number of DNKs was relatively small, and restricted to the ITMO section only, in order to preserve the data properties to allow full analysis of the data, the DNK responses were treated as missing values and were substituted using series means. Two cases were deleted from subsequent analysis since they exhibited extremely high DNK responses in the ITMO section at 70\% and 100\% respectively. This left 113 dyads as the final number of cases for analysis.

\subsubsection{Assumptions Underlying Statistical Procedures}

\subsubsection{Normality of the Data}

Normality of the data was assessed using the Kolmogorov-Smirnov (KS) test, visual examination of normal probability plots, and by computing skewness and kurtosis measures (Carver $\&$ Nash, 2005). Skewness ratings of \pm 1 and kurtosis scores of \pm 2 are considered mild and fall within the 'normal' range, while scores outside of this range have the potential to restrict the data analysis and subsequent interpretation of results (Heck, 1998; Kline, 2005). Considering the relationship strength (RS) and relationship performance (RP) questions related to relationships with a current supplier, it was anticipated that customers would tend to respond more positively than negatively toward their supplier, resulting in a skewed data distribution on these specific items. As expected, the data distribution from a number of customer items relating to relationship strength and performance was highly skewed with corresponding high kurtosis. (The survey criteria did specify that supplier firms nominate their third or fourth most important customers in an attempt to reduce or neutralise this effect.) Six items from the supplier data regarding CRM technology adoption (CTA) also exhibited similar distribution concerns (see Appendix A9 for survey data distribution details).

When confronted with non-normal data distributions for factor analysis, attempts should be made to normalise the data in order to conduct appropriate and valid data analysis (Rummel, 1970). However, the result of data transformations, although facilitating data analysis, can restrict and alter subsequent interpretation of the results and therefore should not be conducted unnecessarily (Hair et al., 2006; Rummel, 1970). Although many multivariate analysis techniques are known to be robust with respect to data distributions, (i.e., some deviation from normality is acceptable) (Hau \& Marsh, 2004; Muthén \& Kaplan, 1985; S. Sharma, Durvasula, \& Dillon, 1989; Yanagihara \& Yuan, 2005), as a precaution the CTA principal components exploratory factor analysis 
was conducted twice, once using untransformed data, and a second time using transformed data. Both analysis approaches led to similar conclusions ${ }^{8}$, therefore only the untransformed data is reported in the exploratory factor analysis (EFA) results. Since PLS is not restricted or constrained by the distribution properties of the data, and for the sake of consistency with the factor analysis results, only the untransformed data was used to conduct the PLS analysis (Chin, 1995; Wold, 1985).

\subsubsection{Sample Size and Power}

Since little guidance is available from the SEM and PLS literature regarding statistical power, factor analysis criteria were adopted (Chin, 1998a). Hair et al. (2006) provide guidelines for identifying significant factor loadings for factor analysis dependent on sample size. Given a sample size of 113 cases, a factor loading of 0.55 or greater is considered significant, assuming a 0.05 significance level for a Type I error $(\alpha)$, and a power level of 80 percent (Cohen, 1992). (A Type I error is the probability of accepting a "false positive" as true.) For this study the more conservative 0.60 level was used as the minimum criterion for assessing factor loadings.

\subsubsection{Common Method Variance}

Common-method bias is recognised as a major source of measurement error and can have a substantial impact on observed relationships between the measured variables (Bagozzi \& Yi, 1991; Nunnally \& Bernstein, 1994). Although there are a number of sources of common method bias, including context and item characteristics, the use of the same respondent for independent and dependent measures is a common source and has been shown to produce significant artificial covariance (Podasakoff, MacKenzie, Lee, \& Podsakoff, 2003). Podasakoff et al. suggest a set of procedures to control for common method bias and recommend in the first instance that "predictor and criterion variables [can] be measured from different sources....Additional statistical remedies could be used but in our view are probably unnecessary in these instances" (p. 897). The use of supplier respondents for the dependent variables and customer respondents for the dependent variables helped reduce common method bias (Reinartz et al., 2004).

Another potential source of common method bias, related to the general measurement context specific to this dyadic research, is the existing relationship between supplier and customer. There was the possibility that suppliers colluded with

\footnotetext{
${ }^{8}$ A detailed comparison of the TD and UTD EFA methods and results are available on request.
} 
customers in order to present their relationship in a more favourable light. Survey research assumes random measurement error across informant questionnaire responses (Nunnally, 1959; Viswanathan, 2005). In order to test for this possibility a correlation matrix was generated comparing supplier RS and customer RS responses, and again for supplier RP and customer RP responses, see Table 5.6 (J. C. Anderson \& Narus, 1990). There was an expectation that the perception of the relationship would be similar between the two parties, but should not be in complete agreement. The a priori decision was that correlations between 0.00 and 0.40 would be an acceptable range of correlations, correlations beyond 0.70 would be suspect, while correlations between 0.40 and 0.70 would be subject to closer scrutiny. The results indicate no strong correlations between the relationship variables across the two respondent groups and therefore no apparent collusion on behalf of the two parties was evident.

Table 5.6: Supplier and Customer RS and RP Correlations $(n=113)$

\begin{tabular}{lc}
\hline Relationship variables & Correlation \\
\hline Supplier \& Customer RS trust & $\mathbf{0 . 2 0 5}$ \\
Supplier \& Customer RS commitment & $\mathbf{0 . 1 2 5}$ \\
Supplier \& Customer RS communication & $\mathbf{0 . 2 6 9}$ \\
Supplier \& Customer RP performance & $\mathbf{0 . 0 9 1}$ \\
Supplier \& Customer RP satisfaction & $\mathbf{0 . 2 8 0}$ \\
Supplier \& Customer RP loyalty & $\mathbf{0 . 1 8 2}$ \\
Supplier \& Customer RP retention & $\mathbf{0 . 0 5 1}$ \\
\hline
\end{tabular}

\subsection{Measurement Refinement and Initial Analysis}

Consistent with the recommendations found in the SEM and related literature a twostep model building approach was adopted (J. C. Anderson \& Gerbing, 1988; Hair et al., 2006; Schumacker \& Lomax, 2004). Step one involved EFA, for untested new scales, and confirmatory factor analysis (CFA), for pre-existing validated scales, to purify and validate the measures. The second step involved using PLS to build and test the structural model (Hair et al., 2006; Schumacker \& Lomax, 2004).

EFA was used to identify, reduce and validate the underlying factors (sub-constructs) of the CRM technology adoption (CTA) construct, the customer CRM expectations (CXP) and customer relationship orientation (CRO) modifier constructs (scales developed specifically for this study) (Gerbing \& Anderson, 1988; Malhotra, 2007; Proctor, 2005). The objective of the EFA was to prepare the data for subsequent multivariate analysis using PLS (Hair et al., 2006). CFA was used to confirm and 
reduce the number of factors from the remaining constructs (MO, ITMO, C_RS, and C_RP) and modifier constructs (TT and MT). SPSS 14.0 software was used to perform the EFA, while SmartPLS software was used to conduct the CFA (Falk \& Miller, 1992; Ringle et al., 2005).

To establish factorability a visual inspection of the correlation matrix was conducted to ensure a substantial number of correlations greater than 0.30, as well the Bartlett test of sphericity $(\mathrm{p}<.05)$, and the measure of sampling adequacy (MSA $>0.50)$ were examined (Hair et al., 2006). Criteria for the number of factors extracted included eigenvalues greater than 1 (latent root criteria), as well as factor conceptualisations based on theory, and scree plot analysis. Unrotated and rotated factor matrices were computed, factors loadings interpreted and factor models respecified as appropriate (Hair et al., 2006). Varimax (orthogonal) rotation was employed for interpretation of the factor matrices under investigation (Hair et al., 2006; Nunnally \& Bernstein, 1994).

Each variable within each factor matrix was examined for significance and crossloading. EFA variables found to have factor loadings of more than 0.45 across more than one factor were considered for deletion. Ideally variables load only on a single factor and have communality measures greater than 0.50 . Communality represents the total amount of variance the specific variable shares with all other variables included in the factor analysis. Communality values greater than 0.50 indicate a strong relationship between the items; and provide the basis for good explanatory value. Communality values less than 0.50 indicates other extraneous sources of variance impact the relationship more than or equal to the identified measurement item, leading to less than adequate explanatory value.

In summary, to retain individual items measuring specific constructs the items had to exhibit; (a) a communality greater than 0.50 , (b) a factor loading greater than 0.60 on a single factor and (c) for EFA, cross-loading less than 0.45 on any other factor.

\subsubsection{Validity and Reliability of Measures}

Content reliability considers whether the items actually measure the construct under consideration (Bagozzi, 1994a). Assessment of item reliability is conducted "by examining the loadings (or simple correlations) of the measures with their respective construct" (Hulland, 1999, p. 198). Convergent validity was examined through Cronbach's alpha and the Fornell and Larcker (1981) composite reliability (CR) 
measure (Hulland, 1999). Many authorities recommend a Cronbach's alpha loading benchmark of 0.70 (Nunnally \& Bernstein, 1994) however some propose a less conservative level of 0.60 (Hair et al., 2006). This internal consistency measure represents how well the items converge to measure the construct. Well-formed items measuring a single construct will exhibit higher Cronbach's alphas, while low internal consistency measures of a construct (e.g., below 0.60) may indicate poor construct definition or a multidimensional construct. In the latter case the construct should be split into separate unidimensional constructs with respective items, or items should be eliminated until only a one-dimensional construct remains (Hair et al., 2006).

Discriminant validity was assessed using the AVE procedure described in Fornell and Larcker (1981), where they suggest that the squared correlations (shared variance between a construct and its measures) be less than the average variance extracted (AVE) by the items measuring the constructs. The AVE is the "average variance shared between a construct and its measures... This measure should be greater than the variance shared between the construct and the other constructs in the model" (Hulland, 1999, p. 200).

\subsection{Exploratory Factor Analysis (EFA)}

Exploratory factor analysis (EFA) explores data from an atheoretical perspective, allowing the data to load on factors independent of theory or a priori assumptions (Gerbing \& Anderson, 1988; Ullman, 2006). Unlike CFA there is no fixed number of factors or loading assumptions. The item loadings and number of constructs are not predetermined through theoretical conceptualisation or previous empirical results (Hair et al., 2006). The following two sections describe the results of the EFA conducted on the items comprising the CTA, CRO and CXP constructs.

\subsubsection{CRM Technology Adoption (CTA) - EFA}

Since CTA is a new construct conceived specifically for this study, EFA and reliability analysis were used to assess the items measuring CTA. Table 5.7 lists all the CTA items used in the EFA. An inspection of the CTA correlation matrix indicated that (a) a number of correlations exceeded 0.30 , (b) the Bartlett test of sphericity $\left(\chi^{2}=\right.$ $3,227.548, \mathrm{p}<.000$ ) was significant, (c) the MSA $=0.818$ was adequate, and therefore factor analysis was appropriate. 
Table 5.7: Initial CTA Conceptual Factors, Constructs and Measurement Items

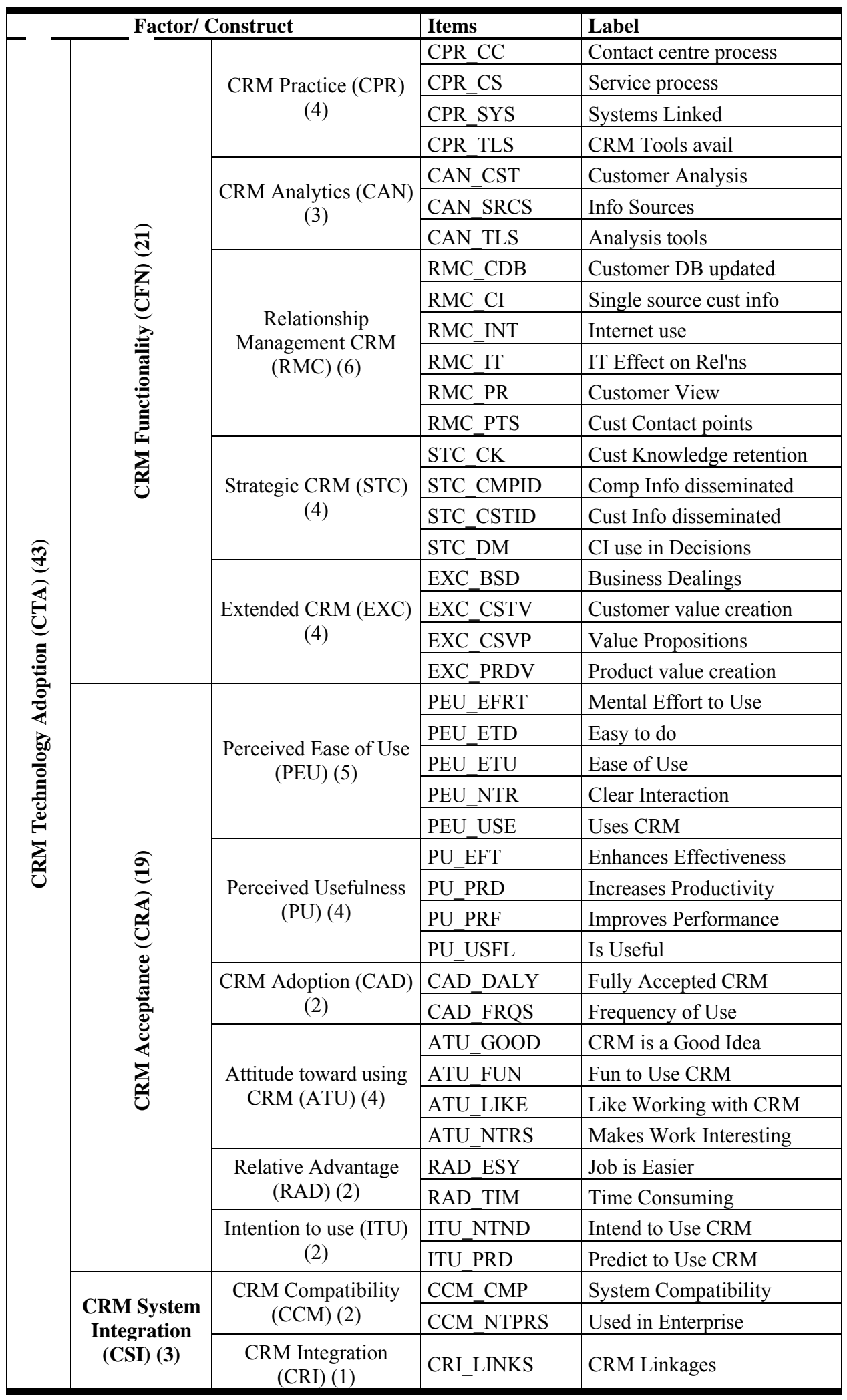

Under unrestricted EFA not all communalities met the 0.50 loading criteria, and there was considerable initial cross-loading making interpretation difficult. The scree plot indicated two factors as the most likely number of factors to extract (see Figure 5.1) 
explaining $68.5 \%$ of the variance. The factor model was respecified deleting variables that did not meet the loading criteria. The extraction of two factors was reasonable, based on a combination of the scree plot results, eigenvalues and latent variable conceptualisation.

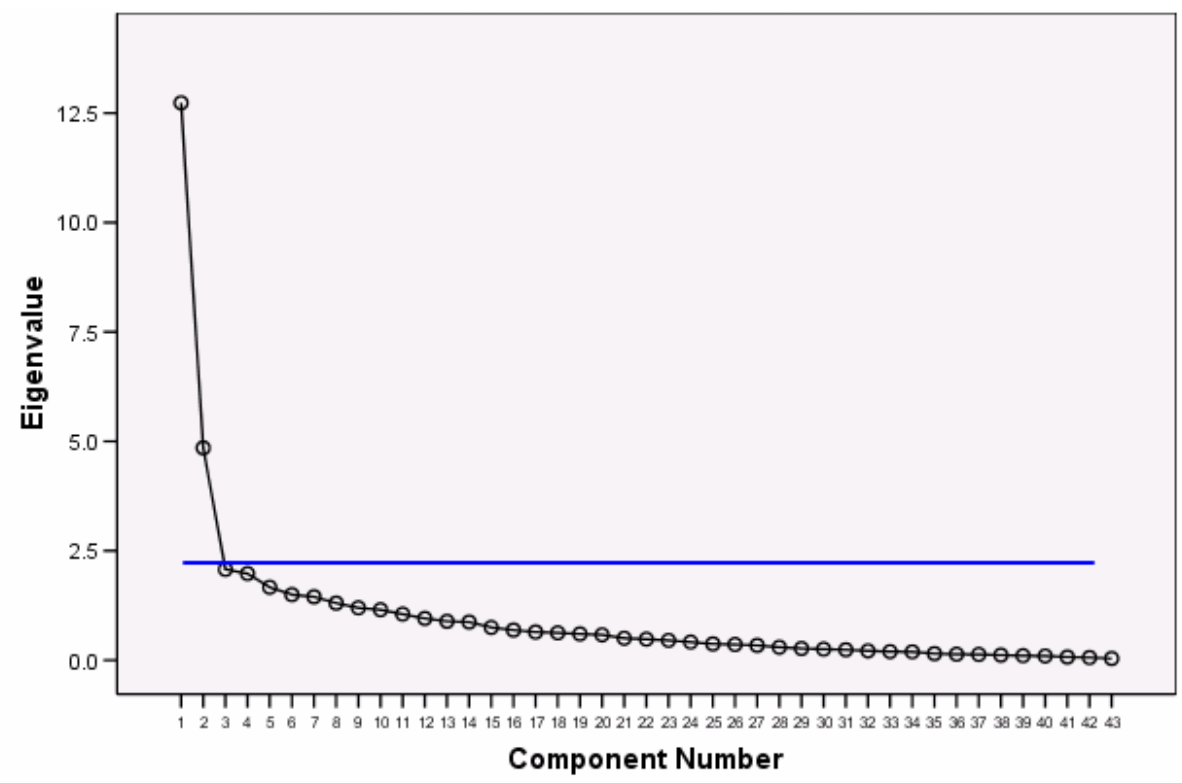

Figure 5.1: CTA scree plot

\subsubsection{Final CTA 2-Factor Construct}

Although the initial CTA conceptualisation consisted of a number of potential subconstructs, as indicated from the EFA, only two strong factors emerged from the exploratory factor analysis; see Table 5.8. Following varimax rotation, the final CTA items split into two factors labelled Customer Knowledge and CRM Usefulness. The

Table 5.8: CTA Two-factor Varimax Rotated Results

\begin{tabular}{lcc}
\hline \multicolumn{3}{c}{ Rotated Factor Matrix } \\
& \multicolumn{2}{c}{ Factors } \\
& USF & CKN \\
\hline CRM Tools avail & 0.161 & $\mathbf{0 . 7 0 5}$ \\
Customer Analysis & 0.102 & $\mathbf{0 . 8 0 9}$ \\
Cust Contact points & 0.153 & $\mathbf{0 . 7 6 5}$ \\
Customer View & 0.167 & $\mathbf{0 . 8 4 2}$ \\
Single source cust info & 0.031 & $\mathbf{0 . 7 9 2}$ \\
Improves Performance & $\mathbf{0 . 8 6 4}$ & 0.177 \\
Increases Productivity & $\mathbf{0 . 8 7 3}$ & 0.100 \\
Enhances Effectiveness & $\mathbf{0 . 8 9 6}$ & 0.147 \\
Is Useful & $\mathbf{0 . 8 7 5}$ & 0.130 \\
Job is Easier & $\mathbf{0 . 7 8 9}$ & 0.221 \\
Fully Accepted CRM & $\mathbf{0 . 7 2 9}$ & 0.267 \\
CRM is a Good Idea & $\mathbf{0 . 7 8 6}$ & -0.061 \\
\hline
\end{tabular}


first factor extracted, measured by seven items reflected the extent to which CRM technology is useful to the user and the job requirements and is termed CRM Usefulness (USF). The second factor, measured by five items, focused on the extent to which CRM technology helps accumulate and provide customer knowledge (CKN). Subsequent CFA showed that the average variance explained by the five $\mathrm{CKN}$ factors is $63.2 \%$, and $71.2 \%$, for the seven USF factors, both greater than the minimum $50 \%$ criteria. Tables 5.9 and 5.10 show that the communalities of the items are all greater than 0.50 , the

Table 5.9: CTA CKN Factor Analysis Results

\begin{tabular}{llcccc}
\hline Customer Knowledge (CKN) 5 items & Loading & Com* & $\begin{array}{c}\text { Cronbach's } \\
\text { Alpha }\end{array}$ & AVE\# \\
\hline CPR_TLS & CRM Tools avail & 0.723 & 0.523 & & \\
CAN_CST & Customer Analysis & 0.814 & 0.663 & & 63.15 \\
RMC_PTS & Cust Contact points & 0.788 & 0.622 & 0.847 & \\
RMC_PR & Customer View & 0.859 & 0.739 & & \\
RMC_CI & Single source cust info & 0.782 & 0.611 & & \\
\hline
\end{tabular}

Note. ${ }^{*}$ Com $=$ Communality; ${ }^{*}$ AVE $=$ Average Variance Explained

individual factor loadings are strong (all greater than 0.70), and the respective Cronbach's alphas exceeds the minimum criteria of 0.60 for exploratory analysis (Hair et al., 2006; Nunnally \& Bernstein, 1994). These two constructs and related items are used in further multivariate analysis and hypothesis testing using PLS.

Table 5.10: CTA USF Factor Analysis Results

\begin{tabular}{llcccc}
\hline CRM Usefulness (USF) 7 items & Loading & Com* & $\begin{array}{c}\text { Cronbach's } \\
\text { Alpha }\end{array}$ & AVE \\
\hline PU_PRF & Improves Performance & 0.883 & 0.780 & & \\
PU_PRD & Increases Productivity & 0.878 & 0.770 & & \\
PU_EFT & Enhances Effectiveness & 0.909 & 0.826 & & 71.24 \\
PU_USFL & Is Useful & 0.883 & 0.780 & 0.921 & \\
RAD_ESY & Job is Easier & 0.816 & 0.666 & & \\
CAD_DALY & Fully Accepted CRM & 0.767 & 0.588 & & \\
ATU_GOOD & CRM is a Good Idea & 0.760 & 0.577 & &
\end{tabular}

Note. ${ }^{*}$ Com $=$ Communality; ${ }^{*}$ AVE $=$ Average Variance Explained

\subsubsection{Moderator Constructs: CXP and CRO}

Customer CRM expectations (CXP) and customer relationship orientation (CRO) are new scales designed to measure moderator constructs within the CTA - CR model. In 
particular, as outlined in Chapter 4, both CXP and CRO have been conceptualised as potential moderators of the effect of CTA on relationship strength $\left(C_{-} R S\right)$ and relationship performance (C_RP). The data distributions of two of the CXP items and three of the CRO items were moderately skewed, while one CXP item and two CRO items exhibited moderate kurtosis. Since there was no significant difference between the transformed data and untransformed data in the factor analysis only the untransformed data results are presented. Both the Bartlett test of sphericity $\left(\chi^{2}=268.673, \mathrm{p}<.000\right)$ and the MSA at 0.746 results indicate that there are sufficient correlations among the variables to conduct a meaningful factor analysis. EFA identified two distinct factors, based on the scree plot and eigenvalues (see Figure 5.2), supporting the original CXP and CRO construct conceptualisation. Table 5.11 shows the factor loadings obtained from the varimax rotation. All loadings exceeded the minimum criteria of 0.60 for EFA (Hair et al., 2006).

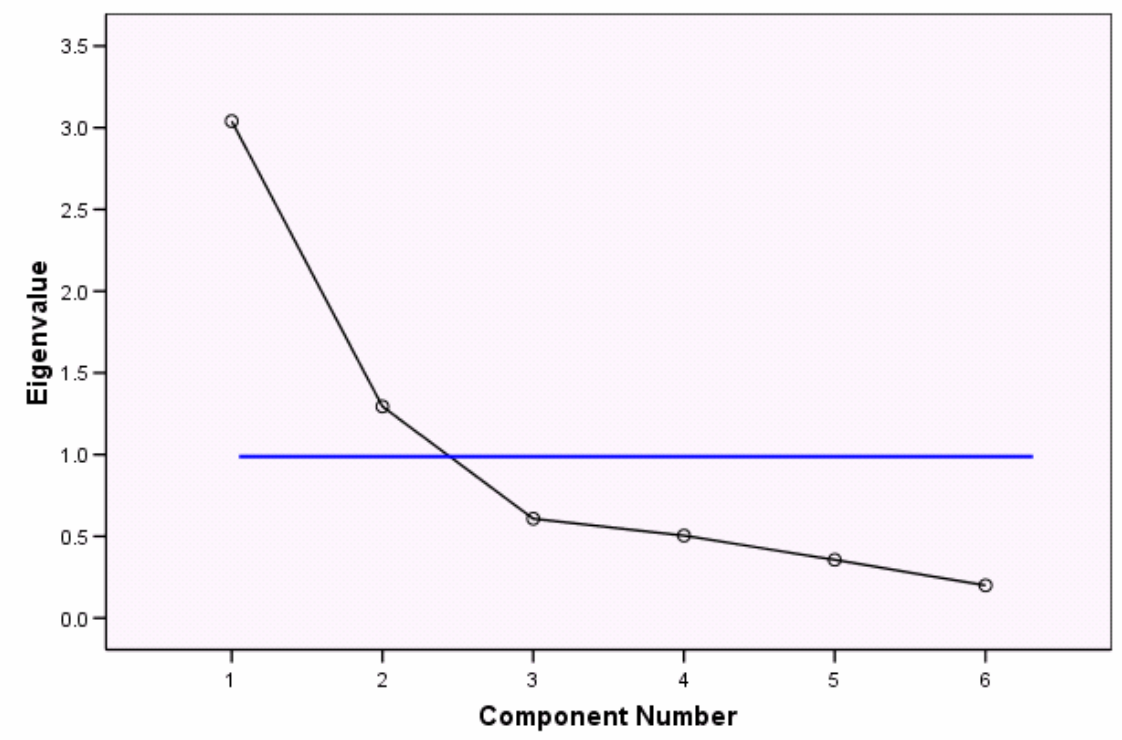

Figure 5.2: CRO and CXP scree plot

Summaries of the subsequent individual CFAs are shown in Table 5.12 for CXP and Table 5.13 for CRO. The communalities of all six items are all greater than 0.50 , the factor loadings are strong (all greater than 0.70), and both Cronbach's alphas exceeds the criteria of 0.60 for exploratory analysis (Hair et al., 2006; Nunnally \& Bernstein, 1994).

The average variance explained by the three CXP factors is $64.7 \%$, and for the three $\mathrm{CRO}$ factors it is $75.6 \%$, both greater than the minimum $50 \%$ criteria. The CRO and 
Table 5.11: CRO and CXP Two-factor Varimax Rotated Results

\begin{tabular}{lcc}
\hline \multicolumn{3}{c}{ Rotated Factor Matrix } \\
& \multicolumn{2}{c}{ Factors } \\
& CRO & CXP \\
\hline Deliver Right Product & 0.204 & $\mathbf{0 . 7 6 8}$ \\
Inventory Stock & -0.018 & $\mathbf{0 . 8 4 0}$ \\
Understand Requirements & 0.433 & $\mathbf{0 . 7 5 4}$ \\
Long term Rel'n are good & $\mathbf{0 . 8 9 0}$ & 0.126 \\
Relationship Preference & $\mathbf{0 . 8 9 8}$ & 0.069 \\
Value of Relationship & $\mathbf{0 . 7 2 0}$ & 0.352 \\
\hline
\end{tabular}

CXP moderator constructs will be used to investigate the interaction effects of these proposed moderator variables within the subsequent PLS analysis.

Table 5.12: CXP Factor Analysis Results

\begin{tabular}{llcccc}
\hline \multicolumn{2}{l}{ Customer CRM expectations (CXP) 3 items } & Loading & Com* & $\begin{array}{c}\text { Cronbach's } \\
\text { Alpha }\end{array}$ & AVE $^{\#}$ \\
\cline { 1 - 3 } C_EXP_PRD & Deliver Right Product & 0.807 & 0.651 & & \multirow{2}{*}{0.702} \\
C_EXP_INV & Inventory Stock & 0.749 & 0.561 & & \\
C_EXP_RQMT & Understand Requirements & 0.854 & 0.730 & & \\
\hline
\end{tabular}

Note. ${ }^{*}$ Com $=$ Communality; ${ }^{*}$ AVE $=$ Average Variance Explained

Table 5.13: CRO Factor Analysis Results

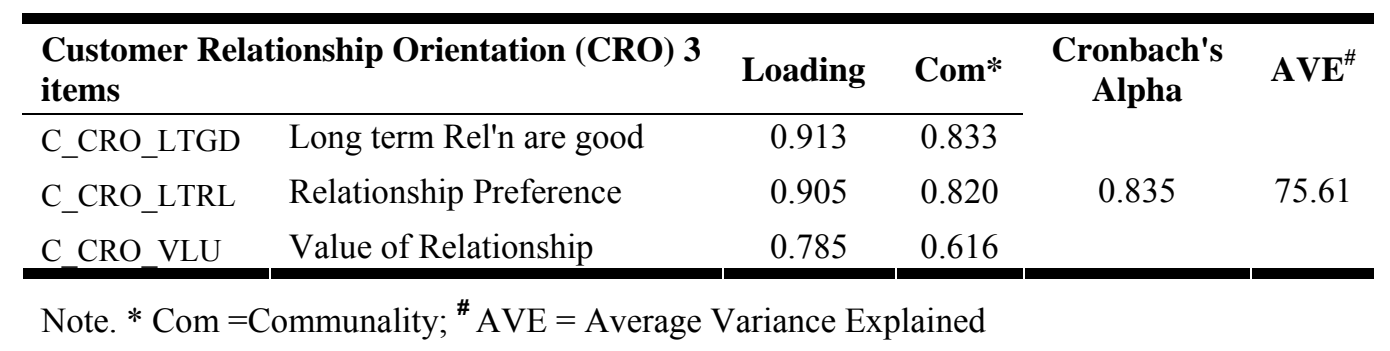

\subsection{Confirmatory Factor Analysis and Measurement Model}

SEM techniques such as PLS are used for CFA and the establishment of a correctly specified measurement model before evaluating the structural (theoretical) model (J. C. Anderson \& Gerbing, 1988; Bagozzi, 1994b; Falk \& Miller, 1992; Fornell \& Yi, 1992; Jöreskog, 1993). Figure 5.3 shows the original measurement model including all items related to each construct, as well as the new CTA sub-constructs (CKN and USF). The yellow boxes represent individual questionnaire items (measurement items), the blue circles are latent variables, and the rose coloured circles represent moderating 
Figure 5.3: Original measurement model used for confirmatory factor analysis

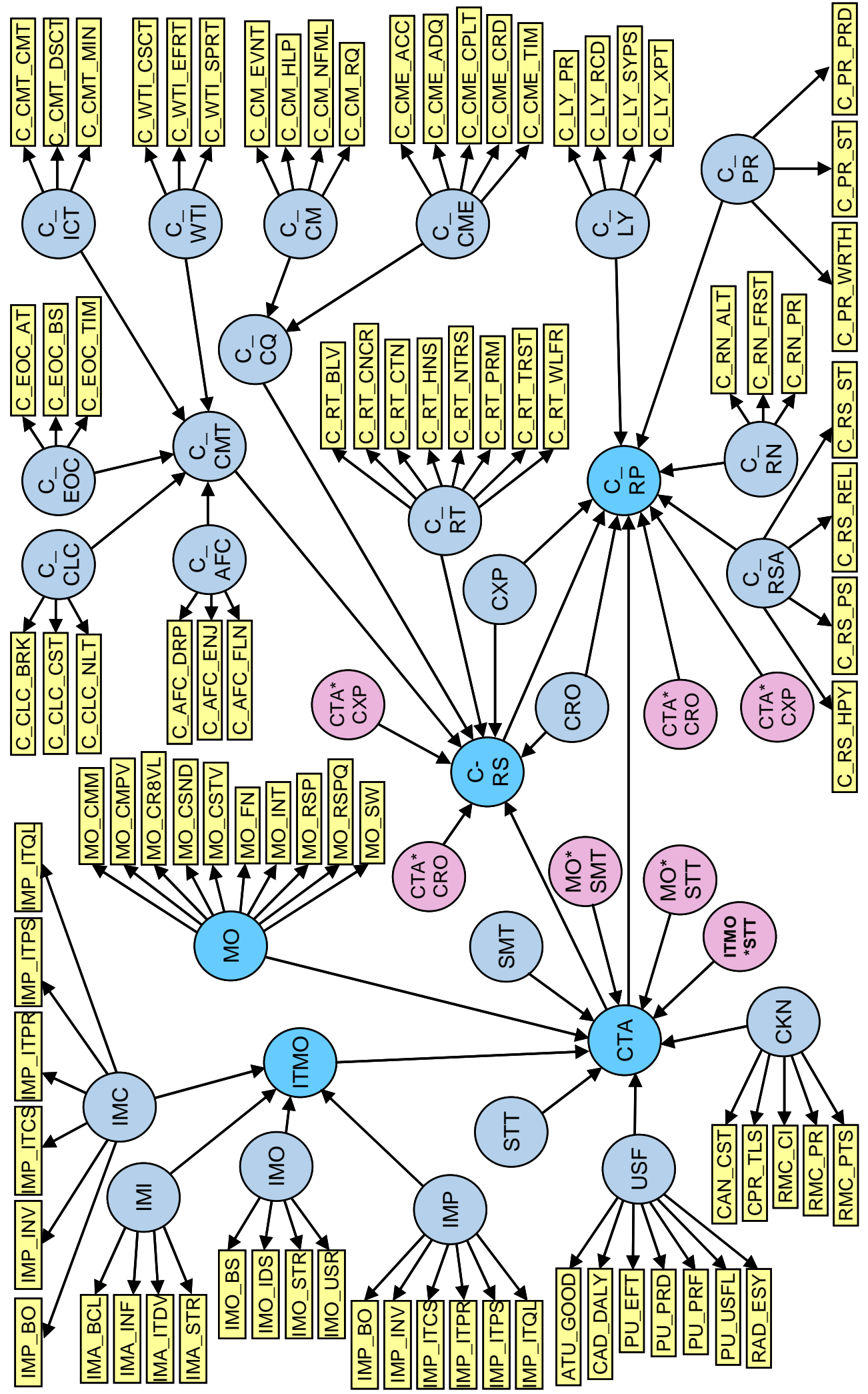

(interacting) variables. The dark blue circles represent the primary constructs under consideration in the research model. 
Table 5.14 lists each item, related sub-construct and construct considered in the CFA,

Table 5.14: All CFA Model Factors

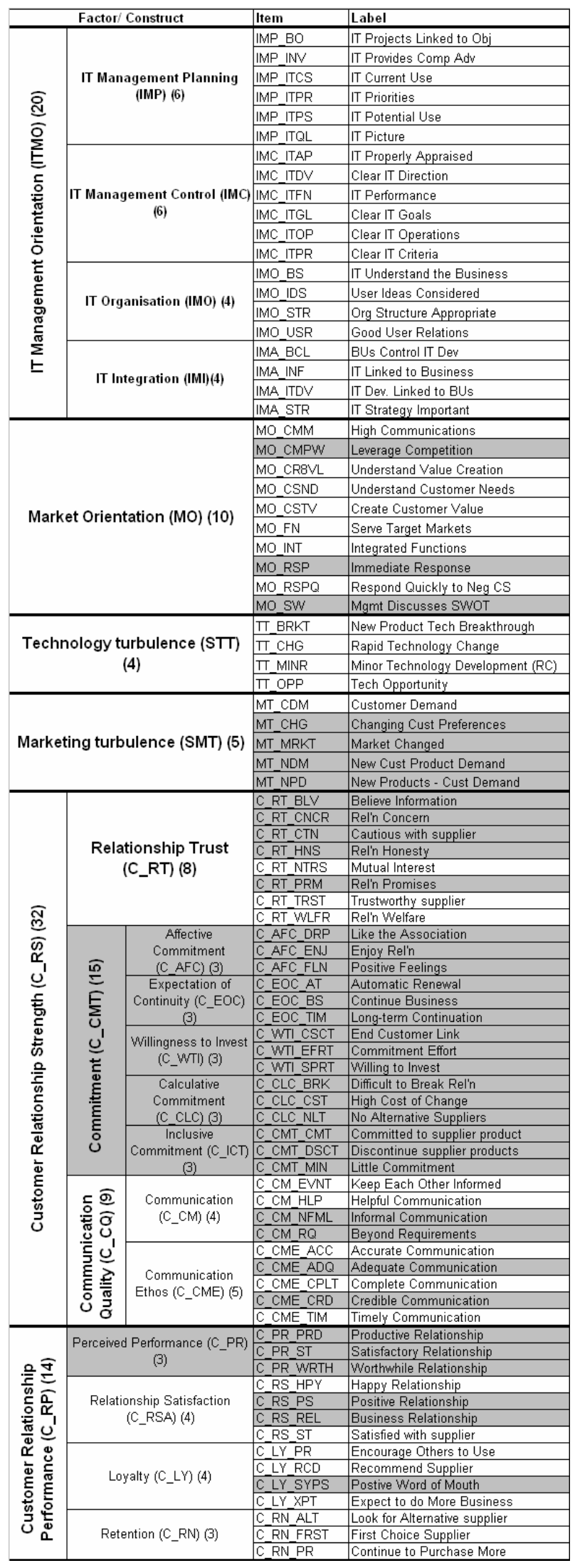

Note: The shaded area represents the items and constructs deleted from the original model to this point 
excluding the CTA sub-constructs. Each construct, sub-construct and item was examined using PLS CFA, including the CTA sub-constructs, in order to establish a valid and reliable measurement model. Item reliability was evaluated by examining PLS item loadings from the outer (measurement) model. Item loadings represent the correlation coefficients between the indicator and the latent variable (construct) (Fornell et al., 1990). In order to compare relative strength, all coefficients are expressed in standardised form. All of the measurement items were evaluated for loadings on their specific constructs. Although there is no hard and fast rule regarding factor loadings in PLS, a loading of 0.70 is an acknowledged level used for retention, although loadings greater than 0.60 are acceptable, especially when new items or scales are involved (Hulland, 1999; Hulland, Chow, \& Lam, 1996). Measurement items were generally deleted if loadings were less than 0.60 (Chin, 1998a; Fornell \& Larcker, 1981; Hair et al., 2006; Hulland, 1999; Nunnally \& Bernstein, 1994).

Table 5.15 shows the items deleted from the model due to loadings less than 0.60 on any single construct. In addition the SMT moderating variable was deleted since only one measurement item remained and the AVE remained below the 0.50 threshold, see Table 5.16. The measurement item criterion guidelines provided by Hair et al. (2006), which have been adopted in this study, suggest an appropriate AVE for measurement model items should equal or exceed 0.50. Anything less than 0.50 implies more variance is due to error than due to the construct itself. Items with minimal loadings and/or high cross-loadings for constructs with low AVE were systematically deleted from the model in attempts to improve the AVE. Constructs with AVE values less than 0.50 are candidates for deletion since they do not add much in the way of explanatory value.

Table 5.15: Items Deleted Due to Loadings Less than 0.60 on Any Single Construct (LV)

\begin{tabular}{lcc}
\hline \multicolumn{1}{c}{ Items } & Loading \\
\hline Leverage Competition & MO_CMPW & 0.544 \\
Immediate Response & MO_RSP & 0.568 \\
Mgmt Discusses SWOT & MO_SW & 0.590 \\
Changing Cust Preferences & MT_CHG & 0.356 \\
Market Changed & MT_MRKT & 0.398 \\
New Cust Product Demand & MT_NDM & 0.045 \\
New Products - Cust demand & MT_NPD & 0.327 \\
Rel'n Concern & C_RT_CNCR & 0.520 \\
High Cost of Change & C_CLC_CST & 0.480 \\
Satisfactory Relationship & C_PR_ST & 0.592 \\
\hline
\end{tabular}


The shaded areas in Table 5.14 indicate the items and constructs deleted from the original model to this point. The result being that the remaining 14 commitment items and the two remaining perceived performance items were deleted, along with 11 assorted other items across five constructs.

Table 5.16: Interaction Variables Deleted

\begin{tabular}{l|l|c|c|c}
\hline \multirow{2}{*}{ Interaction Variables } & \multicolumn{1}{c}{$\begin{array}{c}\text { AVE } \\
\text { Loading }\end{array}$} & \multicolumn{2}{|c}{ Path Coefficients } \\
\cline { 3 - 5 } CTA * CRO & $\begin{array}{l}\text { CRM Technology Adoption * } \\
\text { Customer Relationship Orientation } \\
\text { CRM Technology Adoption * }\end{array}$ & 0.288 & C_RP & C_RS \\
\hline CTA * CXP & $\begin{array}{l}\text { Customer Relationship Orientation } \\
\text { CRM Technology Adoption * } \\
\text { Customer CRM Expectations }\end{array}$ & 0.245 & 0.000 & 0.251 \\
CTA * CXP & $\begin{array}{l}\text { CRM Technology Adoption * } \\
\text { Customer CRM Expectations } \\
\text { Market Orientation * Market } \\
\text { Turbulence }\end{array}$ & 0.226 & 0.000 & -0.006 \\
\hline MO SMT & & 0.174 & -0.001 & -0.002 \\
\hline
\end{tabular}

Moderator (interaction) variables are assessed somewhat differently with PLS, since the moderator variables themselves are not under direct investigation. It is the interaction with the latent variable constructs that are the focal point of the analysis. The loadings of the interacting variables determine the significance of the moderator affects (Chin, Marcolin, \& Newsted, 1996). In this instance the moderator interacting variables in the measurement model, CTA*CRO, CTA*CXP and MO* SMT, were well below the AVE loading criteria of 0.50, as shown in Table 5.16. Since CRO and CXP consisted of only three measurement items, AVE could not be improved significantly by deleting items. Similarly only one measurement item remained for SMT and the path coefficients were minimal and non-significant. Therefore the CRO, CXP and SMT moderator (interaction) constructs were deleted from the model and the model respecified without these three moderator constructs (Chin et al., 1996). Once the minimum AVE criterion was achieved for each construct, the model was assessed for convergent validity.

\subsubsection{Convergent Validity}

Convergent validity was assessed using Cronbach's alpha and the composite reliability (CR) score (Fornell \& Larcker, 1981; Hulland, 1999). A benchmark of 0.70 was used as the minimum acceptable Cronbach's alpha (Hulland, 1999; Nunnally \& Bernstein, 1994). An acceptable CR is assessed similar to the Cronbach's alpha and a 


\section{Table 5.17: Summary of Measurement Model Quality - Convergent Validity}

\begin{tabular}{|c|c|c|c|c|c|c|}
\hline & & $\begin{array}{l}\text { Number } \\
\text { of items }\end{array}$ & AVE & $\begin{array}{l}\text { Composite } \\
\text { Reliability }\end{array}$ & $\begin{array}{c}\text { Cronbach's } \\
\text { Alpha }\end{array}$ & Communality \\
\hline $\mathrm{CKN}$ & Customer Knowledge & 3 & 0.686 & 0.8672 & 0.77 & 0.686 \\
\hline CTA & CRM technology adoption & 12 & 0.535 & 0.9152 & 0.89 & 0.535 \\
\hline C_CM & Customer communications & 2 & 0.842 & 0.9142 & 0.81 & 0.842 \\
\hline C_CME & Customer communications ethos & 3 & 0.770 & 0.9093 & 0.85 & 0.770 \\
\hline C_CQ & Communications quality & 5 & 0.624 & 0.8919 & 0.85 & 0.624 \\
\hline C_LY & Customer loyalty & 3 & 0.720 & 0.8853 & 0.81 & 0.720 \\
\hline C_RN & Customer retention & 3 & 0.651 & 0.8448 & 0.72 & 0.651 \\
\hline C_RP & $\begin{array}{l}\text { Customer relationship } \\
\text { performance }\end{array}$ & 8 & 0.538 & 0.9198 & 0.90 & 0.538 \\
\hline C_RS & Customer relationship strength & 8 & 0.559 & 0.9100 & 0.89 & 0.559 \\
\hline C_RSA & $\begin{array}{l}\text { Customer relationship } \\
\text { satisfaction }\end{array}$ & 2 & 0.870 & 0.9307 & 0.85 & 0.870 \\
\hline C_RT & Customer relationship trust & 3 & 0.746 & 0.8978 & 0.83 & 0.746 \\
\hline IMC & IT management control & 6 & 0.735 & 0.9433 & 0.93 & 0.735 \\
\hline IMI & IT management integration & 4 & 0.592 & 0.8528 & 0.77 & 0.592 \\
\hline IMO & IT management organisation & 4 & 0.779 & 0.9339 & 0.91 & 0.779 \\
\hline IMP & IT management planning & 6 & 0.584 & 0.8925 & 0.85 & 0.584 \\
\hline ITMO & IT management orientation & 20 & 0.521 & 0.9554 & 0.95 & 0.521 \\
\hline ITMO*STT & $\begin{array}{l}\text { IT management orientation * } \\
\text { Technology turbulence }\end{array}$ & 80 & 0.638 & 0.9930 & 0.99 & 0.638 \\
\hline $\mathrm{MO}$ & Market Orientation & 7 & 0.553 & 0.8961 & 0.87 & 0.553 \\
\hline MO*STT & $\begin{array}{l}\text { Market Orientation } * \\
\text { Technology turbulence }\end{array}$ & 28 & 0.696 & 0.9846 & 0.98 & 0.696 \\
\hline STT & Technology turbulence & 4 & 0.720 & 0.9112 & 0.87 & 0.720 \\
\hline USF & CRM usefulness & 7 & 0.712 & 0.9452 & 0.93 & 0.712 \\
\hline
\end{tabular}

value of 0.70 or greater is acceptable (J. B. Smith \& Barclay, 1997). As shown in Table 5.17 all constructs exhibited acceptable Cronbach's alpha and CR scores, with values greater than 0.70 . The AVE and communality result for each construct also exceeds the minimum criteria of 0.50 .

\subsubsection{Discriminant Validity}

Discriminant validity is achieved if an item correlates more highly with items measuring the same construct than with items measuring different constructs (Churchill, 1979). As a first step, all of the individual items were scrutinised for acceptable cross-loading on other constructs. Discriminant validity was assessed using the Fornell and Larcker (1981) AVE criterion shown in Table 5.18. The results identified a number of constructs exhibiting evidence of strong correlations with other constructs. This apparent lack of discriminant validity was anticipated due to the nature of a measurement model with second order constructs. Where first order constructs are unidimensional, this is not a 
serious concern (Bagozzi \& Heatherton, 1994; Gerbing \& Anderson, 1988). In particular:

1. CRM technology adoption (CTA) is expected to be highly correlated with CRM usefulness (USF), since USF is one of the dimensions of CTA.

2. Customer communications (C_CM) and customer communications ethos (C_CME) are expected to be highly correlated with customer communications quality (C_CQ) and customer relationship strength (C_RS), since they are both dimensions of both constructs.

3. C_CQ and customer relationship trust (C_RT) are expected to be highly correlated with C_RS, since they are both dimensions of C_RS. Customer loyalty (C_LY), customer retention (C_RN) and customer relationship satisfaction (C_RSA) are expected to be highly correlated with customer relationship performance (C_RP), since they are dimensions of C_RP.

4. IT management control (IMC), IT management integration (IMI), IT management organisation (IMO) and IT management planning (IMP) are expected to be highly correlated with IT management orientation (ITMO), since they are dimensions of ITMO.

Overall Table 5.18 confirms that discriminant validity is demonstrated in this model, in that unrelated constructs exhibit appropriately low correlations.

\subsubsection{Final Measurement Model}

The loadings and t-statistics for the fully assessed measurement model are shown in Table 5.19. All item loadings are greater than 0.60 with the majority of items exceeding 0.70 , are significant at the $\mathrm{p}<.001$ level, and demonstrate adequate convergent and discriminant validity. This measurement model is now ready to be used to assess the structural (theoretical) model and test the research hypotheses. 
Table 5.18: Discriminant Validity Results Using AVE Approach

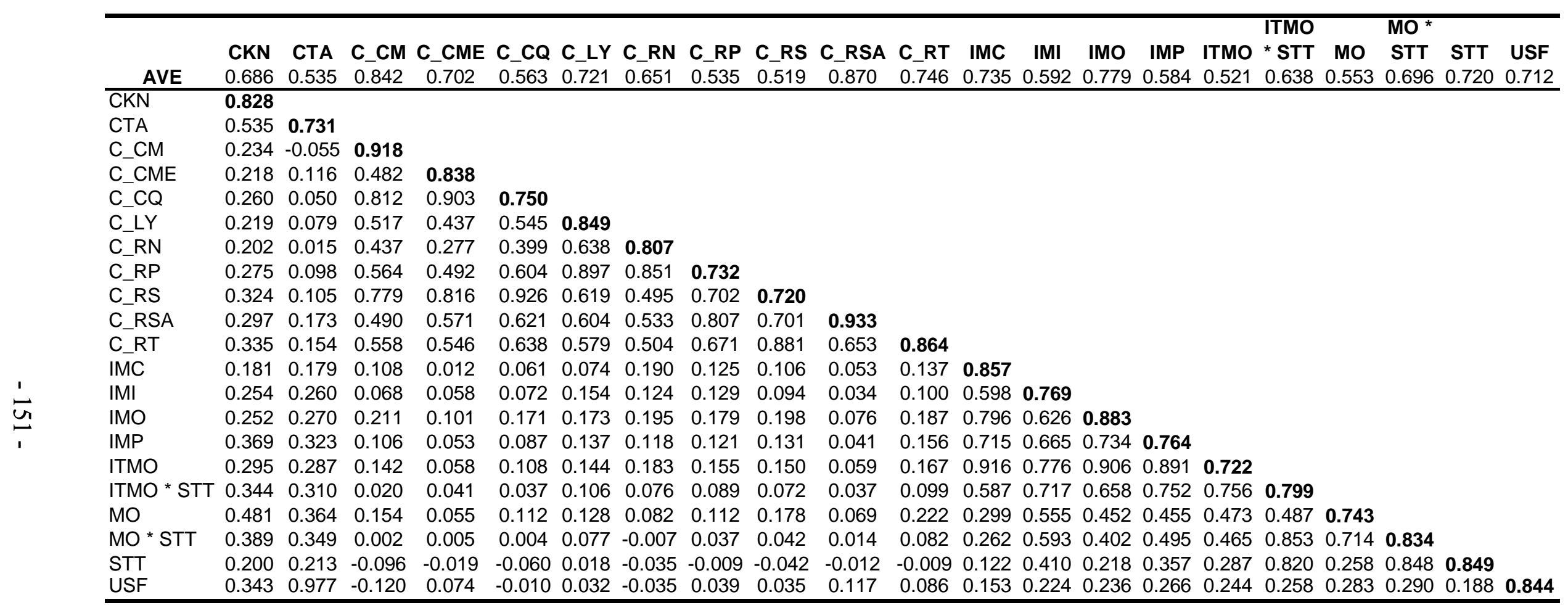

Note. CTA is expected to be highly correlated with USF, since USF is one of the dimensions of CTA.

C_CM and C_CME are expected to be highly correlated with C_CQ and C_RS, since both are dimensions of both constructs

$\mathrm{C}$ CQ and C RT are expected to be highly correlated with $\mathrm{C}$ RS, since both are dimensions of C RS

$\mathrm{C}_{-} \mathrm{LY}, \mathrm{C}_{-} \mathrm{RN}$ and $\mathrm{C}_{-} \mathrm{RSA}$ are expected to be highly correlated with $\mathrm{C}_{-} \mathrm{RP}$, since they are dimensions of C_RP

IMC, IMI, IMO and IMP are expected to be highly correlated with ITMO, since they are dimensions of ITMO

ITMO and STT are expected to be highly correlated with ITMO*STT and MO*STT, since they are an interactions of the two variables

Root AVE is shown along the diagonal 
Table 5.19: Final Measurement Model Items, Loadings and Significance Values

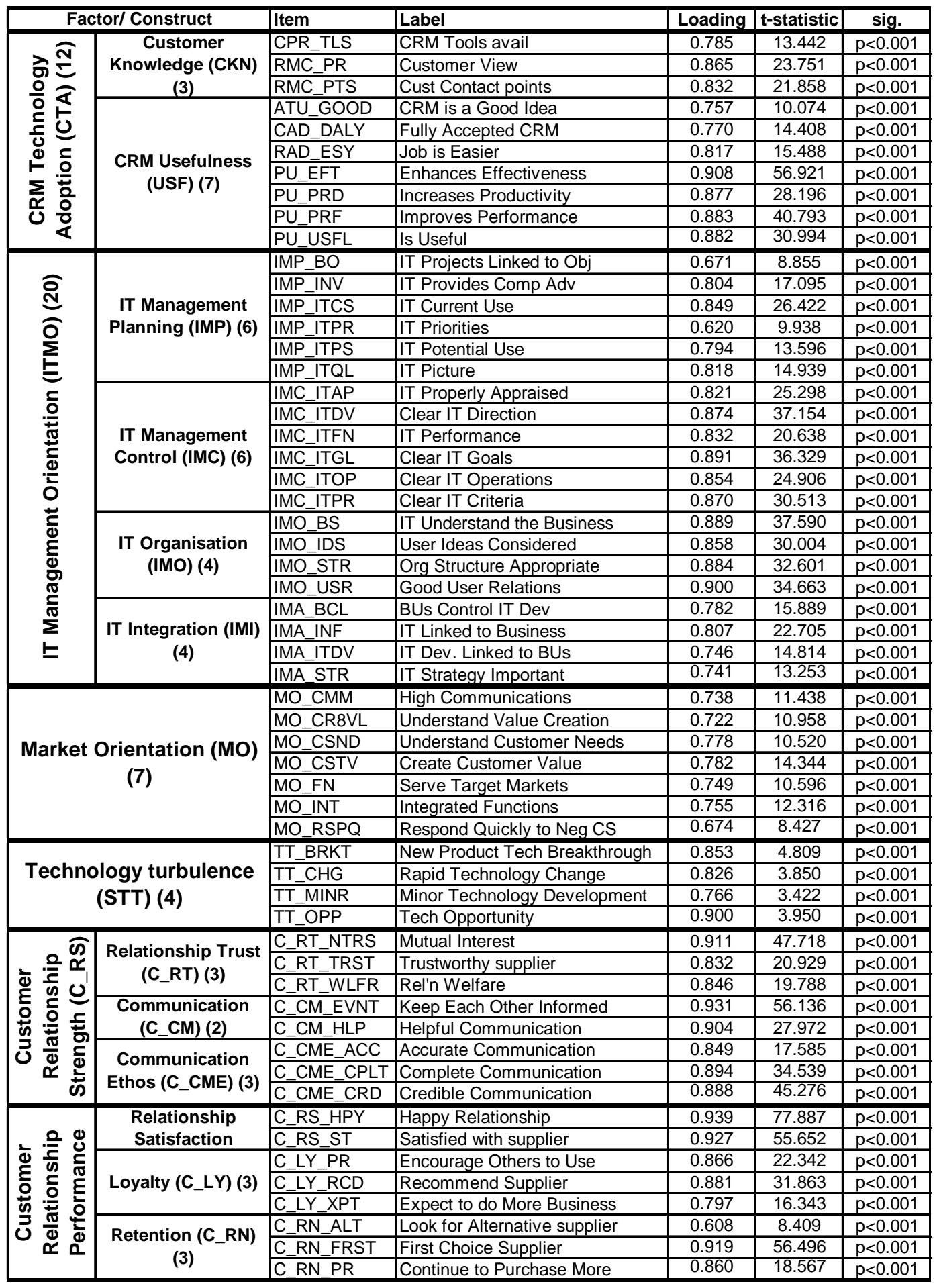




\subsection{Model Construction and Evaluation}

\subsubsection{Measurement (Outer) Model}

The measurement model used in the PLS analysis is shown in Figure 5.4. Chin (1998b) suggests three or four measurement indicators per construct, since using a high number of items (greater than five) per construct will not provide acceptable SEM results (Bagozzi \& Baumgartner, 1994). For constructs with more than five measurement items, Bagozzi and Baumgartner suggest "dividing the scale in half or thirds and use these sub-scales composites as multiple indicators of the construct".

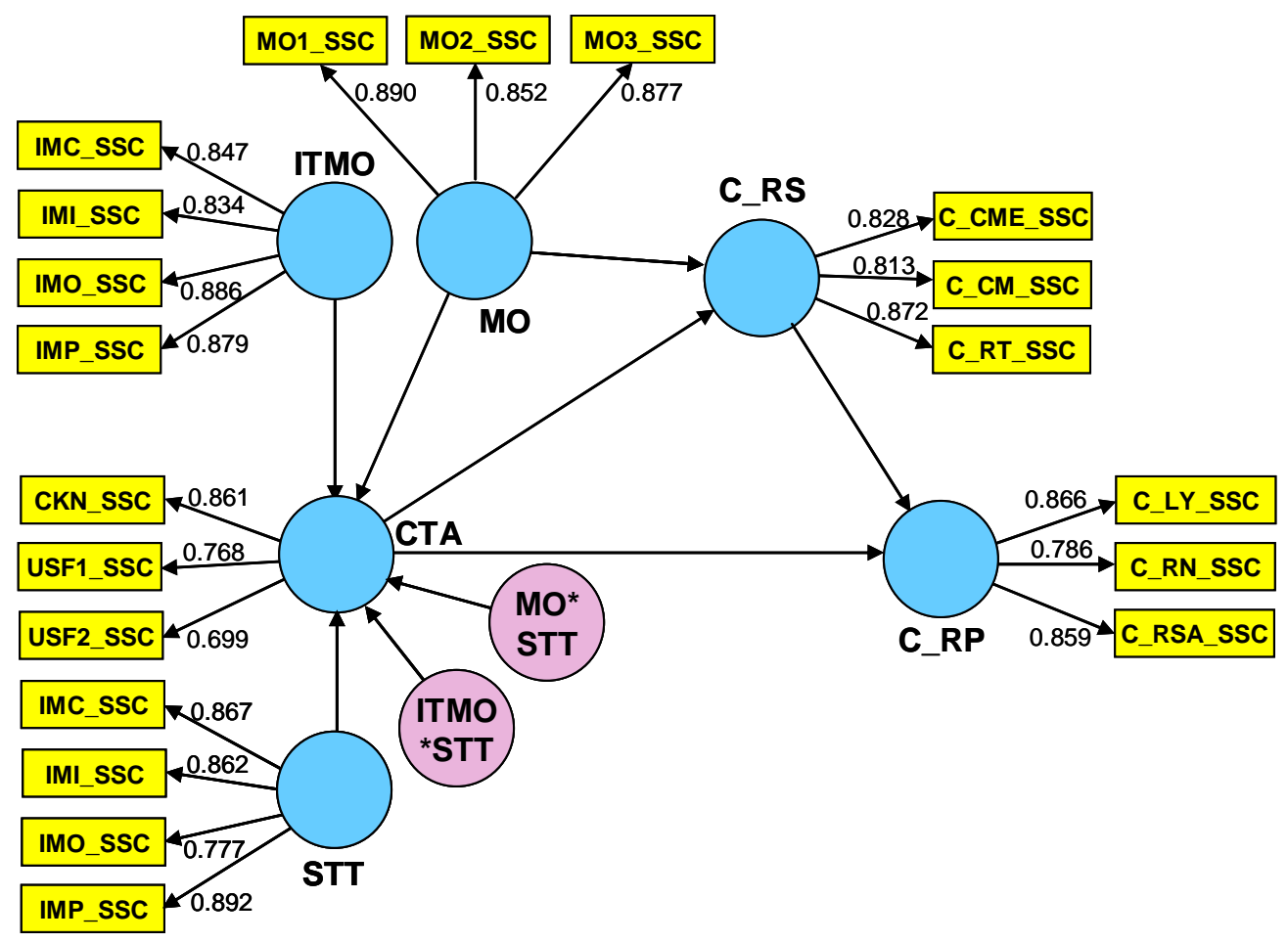

Figure 5.4: Composite scale measurement model

To achieve an acceptable number of indicators per construct, items measuring the same unidimensional construct were combined into a single composite indicator (Hair et al., 2006; Häubl, 1996). In the case of the USF construct, the seven individual measurement items were first split into two groups and then the individual items combined to form two composite indictors, USF1_SSC and USF2_SSC. Similarly the seven items measuring the MO construct were split and recombined into three groups of composite indicators, MO1_SSC, MO2_SSC and MO3_SSC (Bagozzi \& Heatherton, 1994). Table 5.20 specifies each of the individual items used to construct the composite indicators for each construct. 
Table 5.20: Constructs, Items and Composite Indicators

\begin{tabular}{|c|c|c|c|c|}
\hline Fac & torl Construct & Item & Label & Indicator \\
\hline & Customer & CPR_TLS & CRM Tools avail & \\
\hline के בี & Knowledge (CKN) & RMC_PR & Customer View & CKN_SSC \\
\hline 읒 & (3) & RMC_PTS & Cust Contact points & \\
\hline 은 & & ATU_GOOD & CRM is a Good Idea & \\
\hline$\frac{1}{0}$ & & CAD_DALY & Fully Accepted CRM & USF1_SSC \\
\hline$\Phi \underset{1}{0}$ & & RAD_ESY & Job is Easier & \\
\hline 5 을 & (USF) (7) & PU_EFT & Enhances Effectiveness & \\
\hline$\gtreqless \frac{2}{\alpha}$ & & PU_PRD & Increases Productivity & USF2 SSC \\
\hline 응 & & PU_PRF & Improves Performance & 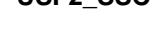 \\
\hline & & PU USFL & Is Useful & \\
\hline & & IMP_BO & IT Projects Linked to Obj & \\
\hline 옹 & & IMP_INV & IT Provides Comp Adv & \\
\hline & IT Management & IMP_ITCS & IT Current Use & \\
\hline 0 & Planning (IMP) (6) & IMP ITPR & IT Priorities & IIVIP_SSC \\
\hline$\sum$ & & IMP_ITPS & IT Potential Use & \\
\hline E & & IMP_ITQL & IT Picture & \\
\hline & & IMC_ITAP & IT Properly Appraised & \\
\hline 은 & & IMC_ITDV & Clear IT Direction & \\
\hline$\stackrel{\widetilde{\pi}}{ \pm}$ & IT Management & IMC_ITFN & IT Performance & \\
\hline$\frac{\mathrm{c}}{\mathrm{d}}$ & Control (IMC) (6) & IMC_ITGL & Clear IT Goals & IIVIC_ssc \\
\hline 'ำ & & IMC_ITOP & Clear IT Operations & \\
\hline & & IMC_ITPR & Clear IT Criteria & \\
\hline$\frac{\mathbf{c}}{9}$ & & IMO_BS & IT Understand the Business & \\
\hline ह્ & IT Organisation & IMO_IDS & User Ideas Considered & \\
\hline త్ర & (IMO) (4) & IMO_STR & Org Structure Appropriate & IIVIO_sce \\
\hline ฮูర & & IMO_USR & Good User Relations & \\
\hline స్ & & IMA_BCL & BUs Control IT Dev & \\
\hline$\Sigma$ & IT Integration (IMI) & IMA_INF & IT Linked to Business & IMI SSC \\
\hline ヒ & & IMA_ITDV & IT Dev. Linked to BUs & 1IVII_SSC \\
\hline & & IMA STR & IT Strategy Important & \\
\hline & & MO_CMM & High Communications & \\
\hline & & MO_CR8VL & Understand Value Creation & IVIU1_SSC \\
\hline Market & Orientation (MO) & MO_CSND & Understand Customer Needs & \\
\hline & (7) & MO_CSTV & Create Customer Value & IVU2_SSC \\
\hline & & MO_FN & Serve Target Markets & \\
\hline & & MO_INT & Integrated Functions & MO3_SSC \\
\hline & & MO RSPQ & Respond Quickly to Neg CS & \\
\hline & & TT_BRKT & New Product Tech Breakthrough & TT_BRKT \\
\hline Techno & logy turbulence & TT_CHG & Rapid Technology Change & TT_CHG \\
\hline & (STT) (4) & TT_MINR & Minor Technology Development & TT_MINR \\
\hline & & TT_OPP & Tech Opportunity & TT_OPP \\
\hline & & C_RT_NTRS & Mutual Interest & \\
\hline 을 뚠 & (C RT) (3) & C_RT_TRST & Trustworthy supplier & C_RT_SSC \\
\hline$\Phi \frac{c}{\dot{\omega}} u^{\prime}$ & & C_RT_WLFR & Rel'n Welfare & \\
\hline ำ 드 & Communication & C_CM_EVNT & Keep Each Other Informed & C CM SSC \\
\hline 車至至 & $\left(\mathrm{C} \_\mathrm{CM}\right)(2)$ & C_CM_HLP & Helpful Communication & C_CIVI_SSC \\
\hline $3 \frac{0}{0} \frac{1}{0}$ & & C_CME_ACC & Accurate Communication & \\
\hline $\boldsymbol{\alpha}$ & Ethos (C CME) (3) & C_CME_CPLT & Complete Communication & C_CME_SSC \\
\hline & & C CME CRD & Credible Communication & \\
\hline & Relationship & C_RS_HPY & Happy Relationship & C RSA SSC \\
\hline & Satisfaction & C_RS_ST & Satisfied with supplier & C_KSA_SOC \\
\hline 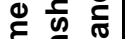 & & C_LY_PR & Encourage Others to Use & \\
\hline ธิ ร & Loyalty (C_LY) (3) & C_LY_RCD & Recommend Supplier & C_LY_SSC \\
\hline 苛 & & C_LY_XPT & Expect to do More Business & \\
\hline $3 \frac{0}{0} \frac{t}{0}$ & Retention (C_RN) & C_RN_ALT & Look for Alternative supplier & \\
\hline$\simeq \boldsymbol{\simeq}$ & (3) & C_RN_FRST & First Choice Supplier & C_RN_SSC \\
\hline & & C RN PR & Continue to Purchase More & \\
\hline
\end{tabular}

All composite indicators were then evaluated for convergent validity by assessing item reliability, Cronbach's alpha, composite reliability (CR) and average variance extracted (AVE). Unidimensionality, that indicators measuring a single construct are strongly related to each other, is a requirement and an underlying assumption in order to proceed with the creation of composite scales. Each indicator scale loads strongly with 
corresponding items on their respective constructs ${ }^{9}$. Unidimensional scales, as indicators themselves, can be embedded within a higher order construct within a structural model (e.g., second-order construct) (Gerbing \& Anderson, 1988). The unidimensionality of each sub-construct was previously assessed and reported through the PLS confirmatory factor analysis (CFA) refer to Tables 5.18 and 5.19. Before analysing the structural model, the measurement model, based on the composite scales, was re-verified. Reliability, the degree of internal consistency of each construct, was assessed using the AVE and communality criteria that values must exceed 0.50 to be retained. The composite reliability (CR) and Cronbach's alpha were assessed based on Nunnally and Bernstein's (1994) criteria of 0.70 (Hulland, 1999; J. B. Smith \& Barclay, 1997). The resultant measurement model quality shown in Table 5.21 demonstrates strong reliability and validity results.

\section{Table 5.21: Composite Indicator Measurement Model Quality Results}

\begin{tabular}{|c|c|c|c|c|c|c|}
\hline & & $\begin{array}{l}\text { Number } \\
\text { of items }\end{array}$ & AVE & $\begin{array}{l}\text { Composite } \\
\text { Reliability } \\
\end{array}$ & $\begin{array}{c}\text { Cronbach's } \\
\text { Alpha }\end{array}$ & Communality \\
\hline CTA & CRM technology adoption & 3 & 0.606 & 0.8209 & 0.73 & 0.606 \\
\hline C_RP & $\begin{array}{l}\text { Customer relationship } \\
\text { performance }\end{array}$ & 3 & 0.702 & 0.8759 & 0.79 & 0.702 \\
\hline C_RS & Customer relationship strength & 3 & 0.703 & 0.8763 & 0.79 & 0.703 \\
\hline ITMO & IT management orientation & 4 & 0.742 & 0.9201 & 0.89 & 0.742 \\
\hline $\mathrm{ITMO} * \mathrm{STT}$ & $\begin{array}{l}\text { IT management orientation * } \\
\text { Technology turbulence }\end{array}$ & 16 & 0.753 & 0.9799 & 0.98 & 0.753 \\
\hline MO & Market Orientation & 3 & 0.763 & 0.9060 & 0.85 & 0.763 \\
\hline $\mathrm{MO} * \mathrm{STT}$ & $\begin{array}{l}\text { Market Orientation * } \\
\text { Technology turbulence }\end{array}$ & 12 & 0.780 & 0.9769 & 0.97 & 0.780 \\
\hline STT & Technology turbulence & 4 & 0.723 & 0.9126 & 0.87 & 0.723 \\
\hline
\end{tabular}

Discriminant validity, the extent to which two conceptually similar constructs are distinct, was tested by reviewing the cross loadings, and calculating the discriminant validity (Fornell \& Larcker, 1981), see Table 5.22 for results. The off diagonal values are less than the on diagonal values (the square root of the AVE), indicating acceptable discriminant validity. The next step is to assess the structural model.

\subsubsection{Structural (Inner) Model}

The initial CTA - CR structural model was constructed based on the extant literature, conceptualisation and theory. Each linked path between the constructs represents an explicit research hypothesis to be tested. In this case there are ten hypotheses to be

\footnotetext{
${ }^{9}$ Individual indicator loading on the respective constructs can be found in Appendix A9.
} 


\section{Table 5.22: Composite Indicator Scales Discriminant Validity Using AVE Method}

\begin{tabular}{|c|c|c|c|c|c|c|c|c|c|}
\hline & & CTA & C_RP & C_RS & ITMO & $\begin{array}{l}\text { ITMO } \\
* \text { STT }\end{array}$ & MO & $\begin{array}{c}\text { MO } \\
* \\
\text { STT }\end{array}$ & STT \\
\hline & AVE & 0.606 & 0.702 & 0.703 & 0.742 & 0.753 & 0.763 & 0.780 & 0.723 \\
\hline CTA & CRM technology adoption & 0.779 & & & & & & & \\
\hline C_RP & $\begin{array}{l}\text { Customer relationship } \\
\text { performance }\end{array}$ & 0.233 & 0.838 & & & & & & \\
\hline C_RS & $\begin{array}{l}\text { Customer relationship } \\
\text { strength }\end{array}$ & 0.217 & 0.723 & 0.838 & & & & & \\
\hline ITMO & IT management orientation & 0.360 & 0.119 & 0.136 & 0.862 & & & & \\
\hline $\mathrm{ITMO} * \mathrm{STT}$ & $\begin{array}{l}\text { IT management orientation } \\
* \text { Technology turbulence }\end{array}$ & 0.365 & 0.077 & 0.063 & 0.798 & 0.868 & & & \\
\hline $\mathrm{MO}$ & Market Orientation & 0.483 & 0.085 & 0.164 & 0.505 & 0.491 & 0.873 & & \\
\hline $\mathrm{MO} * \mathrm{STT}$ & $\begin{array}{l}\text { Market Orientation * } \\
\text { Technology turbulence }\end{array}$ & 0.421 & 0.039 & 0.046 & 0.528 & 0.851 & 0.728 & 0.883 & \\
\hline STT & Technology turbulence & 0.234 & 0.008 & $0 . \overline{-}$ & 0.366 & 0.829 & 0.288 & 0.854 & 0.851 \\
\hline
\end{tabular}

Note. MO*STT highly correlated with STT is not unexpected, since it combines with STT. (square root of AVE in the diagonal)

examined. The initial PLS structural model including path coefficients, calculated tvalues, and variance explained $\left(\mathrm{R}^{2}\right)$ for each endogenous (dependent variable) construct is shown in Figure 5.5.

The path coefficients and calculated t-values from the bootstrap resampling

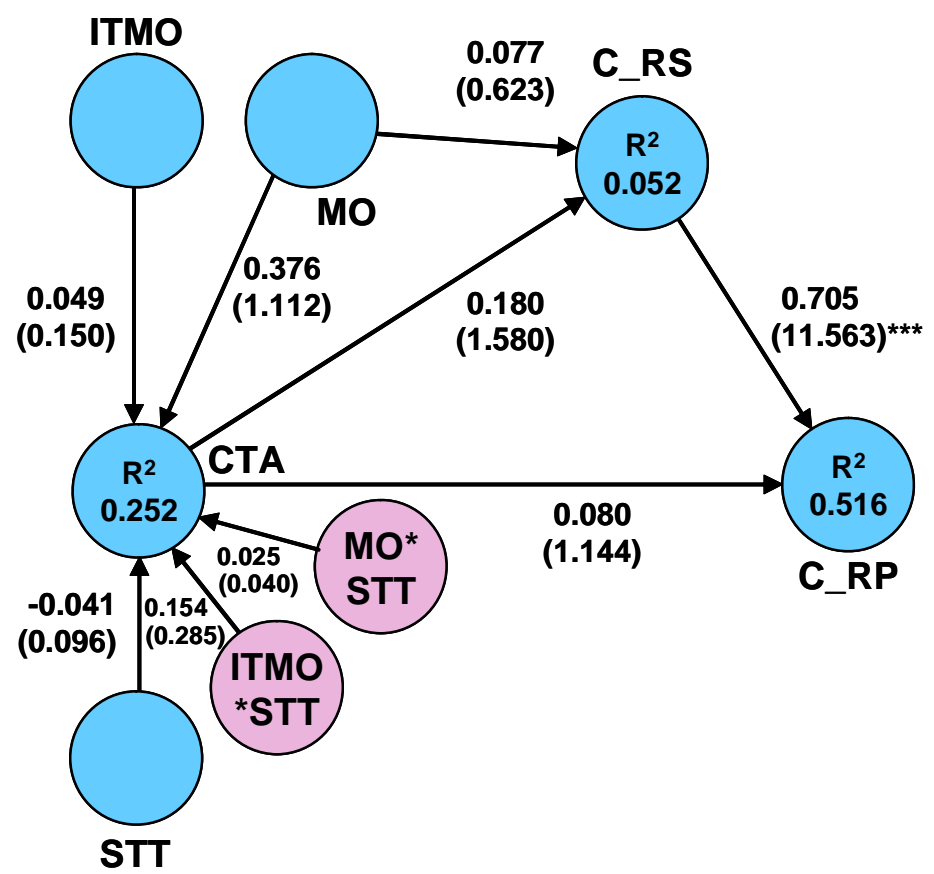

Note. t-statistics shown in parentheses, $* * * \mathrm{p}<.001, * \mathrm{p}<.10$ $\mathrm{R}^{2}$ shown within each endogenous construct

Figure 5.5: Initial structural model path coefficients 
procedure are summarised in Table 5.23. Bootstrapping is a resampling technique used to estimate a distribution's standard errors and confidence intervals for mean, median, correlation coefficient or regression (path) coefficient. Bootstrapping is not dependent on sample normality or sample size (Efron \& Gong, 1983).

Table 5.23: Inner Model Path Coefficients and Significance

\section{Level}

\begin{tabular}{|c|c|c|c|c|}
\hline & $\begin{array}{c}\text { Path } \\
\text { Coefficient }\end{array}$ & $\begin{array}{l}\text { Standard } \\
\text { Error }\end{array}$ & $\begin{array}{c}\mathbf{t} \\
\text { Statistic }\end{array}$ & $\begin{array}{c}\text { Sig. Level } \\
\text { 2-tailed }\end{array}$ \\
\hline $\mathrm{CTA} \rightarrow \mathrm{C} \_\mathrm{RP}$ & 0.080 & 0.070 & 1.144 & ns \\
\hline $\mathrm{CTA} \rightarrow \mathrm{C} \_\mathrm{RS}$ & 0.180 & 0.128 & 1.410 & ns \\
\hline C_RS $\rightarrow$ C_RP & 0.705 & 0.061 & 11.563 & $\mathrm{p}<.001$ \\
\hline ITMO $\rightarrow$ CTA & 0.049 & 0.329 & 0.150 & ns \\
\hline $\mathrm{ITMO} * \mathrm{STT} \rightarrow \mathrm{CTA}$ & 0.154 & 0.542 & 0.285 & ns \\
\hline $\mathrm{MO} \rightarrow \mathrm{CTA}$ & 0.376 & 0.338 & 1.112 & ns \\
\hline $\mathrm{MO} \rightarrow \mathrm{C} \_\mathrm{RS}$ & 0.077 & 0.123 & 0.623 & ns \\
\hline $\mathrm{MO} * \mathrm{STT} \rightarrow \mathrm{CTA}$ & 0.025 & 0.620 & 0.040 & ns \\
\hline $\mathrm{STT} \rightarrow \mathrm{CTA}$ & -0.041 & 0.429 & 0.096 & ns \\
\hline
\end{tabular}

The result of the bootstrapping indicated that the majority of path coefficients were not significant; the C_RS $\rightarrow$ C_RP path was the only significant path $(\mathrm{p}<.001)$. In any SEM modelling exercise there are a number of potential alternative, or equivalent, models that may fit the data. Therefore it is common to identify alternative models which may fit the data and theory better. The structural model was therefore respecified to improve parsimony and model fit (Fornell, 1982; Johansson \& Yip, 1994).

To proceed with the model respecification, paths with non-significant t-values were deleted one at a time, based on theoretical relevance, loading weights and t-statistic value (O'Loughlin \& Coenders, 2004). This led to removing the moderating variable paths in the first instance, since no specific effect was hypothesised (i.e., little theoretical relevance), and the loading weights were minimal $(\mathrm{MO} * \mathrm{STT}=0.025$, ITMO*STT $=0.154)$. The non-significance of technology turbulence $(\mathrm{STT})$ as moderating the effect of MO is consistent with a number of studies (Kohli et al., 1993). The potential effect of STT on ITMO has never been previously established, and the results from the current study indicate that technology turbulence does not moderate the effect of IT management orientation on CTA.

The MO $\rightarrow$ C_RS path coefficient was the next path deleted from the model. Although there are mixed views from the extant literature regarding the effect of MO on 
relationship marketing and performance, the market orientation - customer relationship strength path was originally included based primarily on the literature (Kohli \& Jaworski, 1990; Narver \& Slater, 1990). The non-significant path coefficient is somewhat surprising but not totally unexpected, since an underlying premise of the current CTA - CR model is that MO works through CTA. Hence this path is not considered critical to the fundamental CRM technology adoption - relationship model conceptualisation, and in fact provides some support for the inclusion of the CTA component of the model itself.

The third path deleted was the CTA $\rightarrow$ C_RP path coefficient. Although the CRM technology adoption - customer relationship performance path was part of the original theory conceptualisation, this result is also not completely unexpected. There are a large number of external variables, which are not part of this model, that affect relationship performance. That the direct effects of CTA on loyalty, retention and relationship satisfaction (the C_RP indicators), are minimal and not significant is conceptually and theoretically understandable. This result may be indicating that an overly simplistic approach to CRM technology adoption (e.g., implementing CRM technology in an attempt to simply improve customer loyalty) may not provide the best solution for success. The model was respecified and the bootstrap resampling procedure recalculated after each path deletion and the model quality re-assessed.

\subsubsection{Revised Model}

The revised structural model (see Figure 5.6) indicates that after the two path deletions a number of hypotheses are supported; refer to Table 5.24 for details. The

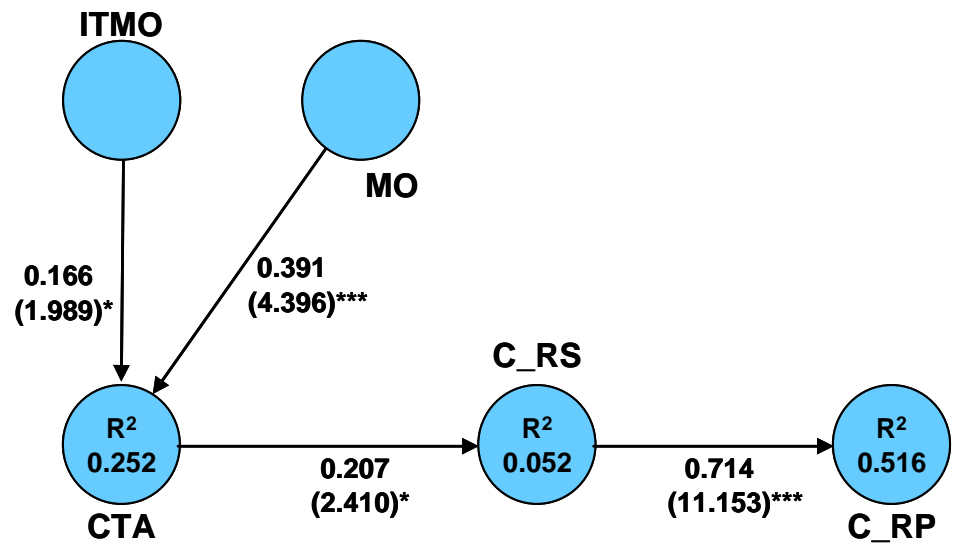

Note. t-statistics shown in parentheses, ${ }^{* * *} \mathrm{p}<.001, * \mathrm{p}<.10$

$\mathrm{R}^{2}$ shown within each endogenous construct

Figure 5.6: Revised structural model path coefficients 
Table 5.24: Revised Structural (Inner) Model Results

\begin{tabular}{lcccc}
\hline & $\begin{array}{c}\text { Path } \\
\text { Coefficient }\end{array}$ & $\begin{array}{c}\text { Standard } \\
\text { Error }\end{array}$ & $\begin{array}{c}\text { t } \\
\text { Statistic }\end{array}$ & $\begin{array}{c}\text { Sig. Level 2- } \\
\text { tailed }\end{array}$ \\
\hline CTA $\rightarrow$ C_RS & 0.207 & 0.086 & 2.410 & $\mathrm{p}<.05$ \\
C_RS $\rightarrow$ C_RP & 0.714 & 0.064 & 11.153 & $\mathrm{p}<.001$ \\
$\mathrm{MO} \rightarrow$ CTA & 0.391 & 0.089 & 4.396 & $\mathrm{p}<.001$ \\
$\mathrm{ITMO} \rightarrow$ CTA & 0.166 & 0.084 & 1.989 & $\mathrm{p}<.05$ \\
\hline
\end{tabular}

primary theoretical relationships in the CRM technology adoption- relationship model are significant. In particular the CTA $\rightarrow$ C_RS path coefficient is significant; indicating that customer relationship management technology adoption (CTA) does positively influence customer relationship strength (C_RS).

Path coefficients are interpreted equivalent to a standardised beta weight in a multiple regression model (Gopal, Bostrom, \& Chin, 1992). Standardised path coefficients ideally should be between 0.20 and 0.30 to be meaningful (Chin, 1998a; Meehl, 1990). Kline (2005) however provides the following guidelines for new research with little theoretical or empirical basis from which to judge path coefficient effects: path coefficients less than 0.10 indicate a 'small' effect, values around 0.30 a 'medium' effect and values greater than 0.50 a 'large' effect (Bollen, 1989; Cohen, 1988; Pedhazur, 1982).

The results of this structural model analysis indicate that CRM technology adoption (CTA) has a significant effect on customer relationship strength $\left(C_{-}\right.$RS $)(t=2.410, p<$ .05), market orientation (MO) has a significant effect on CRM technology adoption $(\mathrm{CTA})(\mathrm{t}=4.396, \mathrm{p}<.001)$, IT management orientation $($ ITMO) has a significant effect on CRM technology adoption $(\mathrm{CTA})(\mathrm{t}=1.989, \mathrm{p}<.05)$ and customer relationship strength (C_RS) has a significant effect on customer relationship performance (C_RP) (t $=11.153, \mathrm{p}<.001)$.

\subsubsection{2. $\quad$ Model Fit}

PLS models are not evaluated using traditional measures such as Chi-square $\left(\chi^{2}\right)$, goodness-of-fit (GFI), Root Mean Square Error of Approximation (RMSEA), or other variations of model fit indices (Bentler, 2005; Hu \& Bentler, 1995; Hulland et al., 1996; Kline, 2005; Schumacker \& Lomax, 2004). Instead, goodness of fit for PLS models is assessed using variance explained $\left(\mathrm{R}^{2}\right)$ and blindfolding techniques to determine predictive relevance $\left(Q^{2}\right)$ (Chin, 1995). The fit of the model was evaluated using the $R^{2}$ 
for dependent constructs and the Stone-Geisser $\mathrm{Q}^{2}$ for predictive relevance (Wold, 1982). Table 5.25 summarises the blindfolding results. The $\mathrm{R}^{2}$ value (variance explained by independent variables) is interpreted, similar to regression analysis, as the proportion of variation in the variable that is explained by its relationship with the variables believed to impact it. There are no strict criteria to assess $\mathrm{R}^{2}$, since "meaningfulness is specific to a given research area" and can vary significantly between researchers, domains and phenomenon (Pedhazur, 1982, p. 25). Nevertheless some authors do provide guidelines. Falk \& Miller (1992) suggest the $\mathrm{R}^{2}$ for endogenous variables should be greater than or equal to 0.10 to be meaningful. However Cohen (1992) provides a convenient statistical power analysis using effect-size indices and statistical test tables which indicate that given multiple regression, three independent variables, $\alpha$ $=0.01$, and a medium effect size, an $\mathrm{R}^{2}$ as small as 0.0196 is acceptable.

Table 5.25: Q2 and R2 Blindfolding Results

\begin{tabular}{|c|c|c|c|c|c|c|}
\hline & \multirow{2}{*}{ Construct } & \multirow{2}{*}{$\mathbf{R}^{2}$} & \multicolumn{2}{|c|}{ Omission distance $=7$} & \multicolumn{2}{|c|}{ Omission distance $=15$} \\
\hline & & & $\begin{array}{c}\text { Communality } \\
\mathbf{Q}^{2} \\
\end{array}$ & $\begin{array}{c}\text { Redundancy } \\
\mathbf{Q}^{2} \\
\end{array}$ & $\begin{array}{c}\text { Communality } \\
\mathbf{Q}^{2} \\
\end{array}$ & $\begin{array}{c}\text { Redundancy } \\
\mathbf{Q}^{2} \\
\end{array}$ \\
\hline CTA & CRM technology adoption & 0.2521 & 0.228 & 0.120 & 0.263 & 0.118 \\
\hline C_RP & Customer relationship performance & 0.5164 & 0.422 & 0.341 & 0.419 & 0.342 \\
\hline C_RS & Customer relationship strength & 0.0515 & 0.399 & 0.024 & 0.395 & 0.024 \\
\hline MO & Market Orientation & na & 0.498 & na & 0.496 & na \\
\hline ITMO & IT management orientation & na & 0.581 & na & 0.582 & na \\
\hline
\end{tabular}

In this model, customer relationship strength (C_RS) explains $51.6 \%$ of the variance of customer relationship performance (C_RP), while market orientation (MO) and IT management orientation (ITMO) explain $25.2 \%$ of the variance in CTA. CRM technology adoption (CTA) explains 5.2\% of the variance in C_RS and given the limited research in this area provides support for the overall model.

The $\mathrm{Q}^{2}$ measures how well the observed values are reproduced by the model and parameter estimates (Geisser, 1975; M. Stone, 1974). $Q^{2}$ estimates utilise a blindfolding technique in which a part of the data is omitted for a particular block of indicators and the model attempts to estimate the omitted part using the estimated parameters. This procedure is repeated as often as the omission distance until every data point has been omitted and estimated, producing a generalised cross-validation measure (Chin, 1998b). The omission distance sets the number of resample procedures to be completed before 
the jackknifed estimates of mean, standard deviation and standard error are calculated (Fornell \& Cha, 1994; Sambamurthy \& Chin, 1994).

There are two types of predictive relevance $\left(\mathrm{Q}^{2}\right)$ estimates. The cross-validated communality $\mathrm{Q}^{2}$ is produced by predicting the omitted data points through the underlying latent variable. That is, some data points from cases and items of a construct are omitted, and the remaining items are used to estimate a PLS model. This PLS model, with the omitted data, is then used to estimate the omitted data points.

The redundancy $\mathrm{Q}^{2}$, on the other hand, tests how well antecedent constructs predict the omitted data. Of the two $\mathrm{Q}^{2}$ measures, the redundancy $\mathrm{Q}^{2}$ is the stronger test of the theoretical model to predict missing data at the item level. The estimation is repeated for all cases yielding an overall $\mathrm{Q}^{2}$ measure of redundancy index, without a loss of degrees of freedom (Fornell \& Bookstein, 1982). In either case an estimate larger than zero (0) indicates the model has predictive relevance, whereas a $Q^{2}$ less than zero $(0)$ implies a lack of predictive relevance in the model (Fornell \& Cha, 1994). As can be seen from Table 5.25 the $\mathrm{Q}^{2}$ results are positive and similar across omission distances, indicating predictive relevance and stable model estimates.

To summarise, the CTA - CR model has been evaluated and validated through a number of processes. First, exploratory and confirmatory factor analysis were conducted to determine the appropriate construct measures. The final measurement item's loadings on the appropriate constructs were assessed based on minimum loading criteria of 0.60 (Hulland, 1999). Convergent validity was demonstrated using both Cronbach's alpha and the composite reliability measure (Fornell \& Larcker, 1981). Discriminant validity was satisfactorily demonstrated using the AVE approach (Fornell \& Larcker, 1981). The theoretical relationships between the constructs were evaluated by examining the weightings and significance of the path coefficients in the structural model using t-tests. The model was respecified, in an attempt to provide an improved and more parsimonious fit to the data. The revised model demonstrated satisfactory fit from the variance explained $\left(\mathrm{R}^{2}\right)$ and predictive relevance $\left(\mathrm{Q}^{2}\right)$ measures. The structural model results, from the revised model, are now discussed further.

\subsubsection{Direct Effects}

In the original model only two of the hypothesised paths, $\mathrm{C}_{-} \mathrm{RS} \rightarrow \mathrm{C}_{-} \mathrm{RP}$ and $\mathrm{MO} \rightarrow$ CTA, are significant at the $99.9 \% \mathrm{CI}$ level, while ITMO $\rightarrow$ CTA is significant only at 
the $90.0 \%$ level. The respecified model (refer to Table 5.24 and Figure 5.6) demonstrates that CRM technology adoption significantly and positively influences customer relationship strength (CTA $\rightarrow$ C_RS). This finding is consistent with the underlying theory and conceptualisation of the original model. The original model hypothesized that CRM technology adoption contributed positively to the relationship between supplier firms and customers. The result of the respecified model provides empirical evidence that CRM technology contributes to customer relationship strength, and, discussed below, indirectly to customer relationship performance. The market orientation of a company positively and significantly influences CRM technology adoption, supporting the concept that a market oriented firm is more likely to adopt CRM technology then non-market oriented firms. The IT management orientation of the firm also provides a significant and positive influence on CRM technology adoption within a firm, suggesting an increasing role for IT within the marketing and customer relationship arenas. In addition there is evidence that customer relationship strength positively and significantly influences customer relationship performance, which is consistent with the extant literature in this area (Z. G. Li \& Dant, 1997).

\subsubsection{Total Effects}

The total effects considers not only the direct relations among the constructs, but also the indirect effects on the dependent (endogenous) variables (Cool et al., 1989). Indirect effects are manifest in the model and relevant in the evaluation, interpretation and understanding of the total impact of one construct on another within the CTA - CR model. For example, from Table 5.26, although CTA does not have a direct effect on relationship performance (C_RP), CTA does have a positive and significant effect on

Table 5.26: Total Effects

\begin{tabular}{lcccc}
\hline & $\begin{array}{c}\text { Path } \\
\text { Coefficient }\end{array}$ & $\begin{array}{c}\text { Standard } \\
\text { Error }\end{array}$ & $\begin{array}{c}\text { t } \\
\text { Statistic }\end{array}$ & $\begin{array}{c}\text { Sig. Level 2- } \\
\text { tailed }\end{array}$ \\
\hline CTA $\rightarrow$ C_RP & 0.148 & 0.064 & 2.325 & $\mathrm{p}<.05$ \\
CTA $\rightarrow$ C_RS & 0.207 & 0.086 & 2.410 & $\mathrm{p}<.05$ \\
C_RS $\rightarrow$ C_RP & 0.714 & 0.064 & 11.153 & $\mathrm{p}<.001$ \\
MO $\rightarrow$ CTA & 0.391 & 0.089 & 4.396 & $\mathrm{p}<.001$ \\
MO $\rightarrow$ C_RP & 0.058 & 0.029 & 2.016 & $\mathrm{p}<.05$ \\
MO $\rightarrow$ C_RS & 0.081 & 0.040 & 2.002 & $\mathrm{p}<.05$ \\
ITMO $\rightarrow$ CTA & 0.166 & 0.084 & 1.989 & $\mathrm{p}<.05$ \\
ITMO $\rightarrow$ C_RP & 0.025 & 0.016 & 1.579 & $\mathrm{ns*}$ \\
ITMO $\rightarrow$ C_RS & 0.034 & 0.021 & 1.620 & $\mathrm{ns*}$ \\
\hline \multicolumn{2}{c}{ ns = not significant } & & &
\end{tabular}


C_RP through relationship strength $\left(\mathrm{C} \_\mathrm{RS}\right),(\mathrm{t}=2.325, \mathrm{p}<.05)$. Similarly market orientation (MO) has a positive and significant effect on C_RP $(t=2.016, p<.05)$, and C_RS $(\mathrm{t}=2.002, \mathrm{p}<.05)$, through CTA, whereas IT management orientation (ITMO) does not directly or indirectly influence C_RP or C_RS $(\mathrm{t}=$ not significant $)$.

The results from the total effects analysis demonstrate that CRM technology adoption does positively and significantly influence customer relationship performance, but only through customer relationship strength (CTA $\rightarrow$ C_RP). The results also show that market orientation positively and significantly influences customer relationship strength and customer relationship performance through CRM technology adoption. That market orientation influences RS and RP through CTA is interesting and may shed some light on the reasons for perceived CRM technology implementation failures. These results also provide empirical support for recent literature arguing that successful CRM technology adoption is more likely with a market oriented firm (Abbott et al., 2001; J.-S. Chen \& Ching, 2004; Goodhue et al., 2002; Ling \& Yen, 2001; Rigby, Reichheld, \& Schefter, 2002b).

\subsubsection{Moderator Effects}

Technology turbulence (STT) and market turbulence (SMT) were originally considered potential moderators of CRM technology adoption; however neither moderator resulted in any significant interactions within the model. Similarly the customer relationship orientation (CRO) and customer CRM expectations (CXP) moderators did not significantly influence customer relationship strength or performance. These results imply that the supplier's perceived level of technology turbulence and market turbulence does not play a significant role in the effect of the model antecedents to adoption of CRM technology. In addition the customer's perceptions of relationship strength and relationship performance are not dependent on the relationship predisposition of the customer, nor their CRM expectations.

\subsection{Hypothesis Testing}

Although hypotheses cannot definitively be proved as true, hypotheses are statistically accepted or rejected based on levels of significance and confidence intervals. Therefore, to 'accept' the hypothesis simply means that there is not sufficient statistical evidence to actually reject the hypotheses. In this study the test results were 
based on a minimum probability level of 0.05 , that is, the same results would occur $95 \%$ of the time.

The hypotheses in this research explicitly relate to the relationship between CRM technology adoption (independent variable) and the customer relationship. There are two dependent variables in the model, customer relationship strength (C_RS) and customer relationship performance (C_RP). It should be emphasised that the independent variables market orientation (MO), IT management orientation (ITMO) and CRM technology adoption (CTA) were measured by the supplier firm responses, while the dependent variables were measured by the customer responses. Each structural path in the model represents a potential relationship between the two variables (constructs) and can be tested for significance. The path coefficient may be considered equivalent to a regression coefficient $(\beta)$ and measures the unidirectional relationship between two constructs, for example the effect of CTA on C_RP, but not the effect of C_RP on CTA (Fornell, 1982; Pedhazur, 1982). Each structural path was tested using the t-statistic, via blindfolding. The critical value for a two-tailed t-test with a 95\% confidence interval

Table 5.27: Summary of Hypotheses Testing

\begin{tabular}{|c|c|}
\hline Hypothesis & Accepted \\
\hline $\begin{array}{l}\mathrm{H}_{1}: \text { The more market oriented the firm the greater the CRM technology } \\
\text { adoption within the firm }\end{array}$ & Yes \\
\hline $\begin{array}{l}\mathrm{H}_{2} \text { : The more market oriented the firm the greater the overall relationship } \\
\text { strength between the firm and the customer. }\end{array}$ & $\begin{array}{l}\text { Yes } \\
\text { (indirectly) }\end{array}$ \\
\hline $\begin{array}{l}\mathrm{H}_{3}: \text { The greater the level of IT management orientation of the firm, the greater } \\
\text { the CRM technology adoption }\end{array}$ & Yes \\
\hline $\begin{array}{l}\mathrm{H}_{4}: \text { The greater the level of CRM technology adoption within a firm the greater } \\
\text { the overall relationship strength with customers. }\end{array}$ & Yes \\
\hline $\begin{array}{l}\mathrm{H}_{5}: \text { The greater the level of CRM technology adoption within a firm the greater } \\
\text { the relationship performance. }\end{array}$ & $\begin{array}{l}\text { Yes } \\
\text { (indirectly) }\end{array}$ \\
\hline $\begin{array}{l}\mathrm{H}_{6}: \text { The greater the relationship strength the greater the relationship } \\
\text { performance. }\end{array}$ & Yes \\
\hline \multicolumn{2}{|l|}{ Secondary hypotheses } \\
\hline $\begin{array}{l}\mathrm{H}_{7} \text { : The greater the level of customer relationship orientation the greater the } \\
\text { CRM technology adoption effect on (a) relationship strength and (b) } \\
\text { relationship performance. }\end{array}$ & No \\
\hline $\begin{array}{l}\mathrm{H}_{8}: \text { The greater the level of customer CRM expectation the greater the CRM } \\
\text { technology adoption effect on (a) relationship strength and (b) } \\
\text { relationship performance. }\end{array}$ & No \\
\hline $\begin{array}{l}\mathrm{H}_{9}: \text { The greater the level of market turbulence the stronger the market } \\
\text { orientation effect on CRM technology adoption. }\end{array}$ & No \\
\hline $\begin{array}{l}\mathrm{H}_{10} \text { : The greater the level of technology turbulence the stronger the (a) market } \\
\text { orientation effect on CRM technology adoption, and (b) the IT } \\
\text { management orientation effect on CRM technology adoption. }\end{array}$ & No \\
\hline
\end{tabular}


(CI) and a sample size of 113 is 1.983 (Lind, Marchal, \& Mason, 2001).

As shown in Table 5.27, Hypotheses 1 and 3 are accepted: both market orientation and IT management orientation positively influences CRM technology adoption. The standardised path coefficients, however, indicate that MO has the greater influence (MO $=0.391, \mathrm{ITMO}=0.166$ ), and a greater level of significance. Hypothesis 4 is also accepted, indicating the positive influence of CRM technology adoption on relationship strength between suppliers and customers. Not unexpectedly, relationship strength has a positive effect on relationship performance, providing evidence for accepting Hypothesis 6 . The effects of the moderator variables customer relationship orientation (CRO) and customer CRM expectations (CXP) stated in hypotheses 7 and 8 were not significant, implying that the customer's predisposition to relationships or CRM is not a significant interacting variable. The level of market turbulence $\left(\mathrm{H}_{9}\right)$ and technology turbulence $\left(\mathrm{H}_{10}\right)$ are not significant moderators of market orientation or IT management orientation. Similar results have been reported in the literature and may simply reflect the types of industries represented in the sample or the minimal impact of these moderating variables on CRM technology adoption (Appiah-Adu, 1997; Jaworski \& Kohli, 1993; Kohli \& Jaworski, 1990; Subramanian \& Gopalakrishna, 2001).

Interestingly, there is no empirical evidence from this data that market orientation directly affects the relationship strength between suppliers and customers, hence Hypothesis 2 is rejected. However, as noted previously, significant indirect effects, through CRM technology adoption, are evident. Hypothesis 5, that CRM technology adoption positively influences relationship performance, is also rejected, although, as Table 5.26 shows, there is evidence of significant indirect effects through relationship strength.

\subsection{Chapter Summary}

This chapter described the survey response data collected, the process of measurement refinement; established measurement validity and reliability, and presented the results from the exploratory factor analysis, PLS analysis and hypotheses testing. A respecified structural model provided a more parsimonious solution to the data. Four of the ten hypotheses were accepted as significant, while six hypotheses were not significant. The key finding is that CRM technology adoption positively and directly influences customer relationship strength. In addition there is empirical support that the 
market orientation of a firm works through CRM technology to positively influence customer relationship strength and relationship performance.

Although the direct effect of the firm's market orientation on relationship strength $\left(\mathrm{H}_{2}\right)$ is not significant, there is a significant indirect effect through CTA. The effect of market orientation on business performance has been difficult to establish directly (Han, Kim, \& Srivastava, 1998; Narver \& Slater, 1990), however one characteristic of market orientation is the collection and dissemination of customer and competitor information (Slater \& Narver, 1995). CRM technology may provide an appropriate medium from which to collect and disseminate such information. The second hypothesis not supported is that CRM technology adoption would positively affect relationship performance $\left(\mathrm{H}_{5}\right)$. Previous studies have shown CRM technology to positively affect customer satisfaction (Srinivasan \& Moorman, 2005) and retention (Jayachandran et al., 2005), both are components of the relationship performance construct used in this study. Notwithstanding the non-significant direct effect, there is evidence of a significant indirect effect of CRM technology adoption on relationship performance through relationship strength. This indirect result provides a level of support for the positive effect of CRM technology adoption on relationship performance, consistent with the extant literature. Chapter 6 will discuss the implications of the results for practitioners and academics, and the contribution to the marketing and IT literatures. 


\section{CHAPTER 6. Discussion and Conclusions}

\subsection{Introduction}

The primary objectives of the study were to determine the effect of CRM technology adoption on business-to-business relationships, and the impact of market orientation and technology orientation on that adoption. To this end the research drew upon the management, IT and marketing literatures from which a preliminary research model was conceptualised. The model was then refined and tested through a two-stage, crosssectional research design, involving an exploratory, qualitative phase to inform the explanatory, quantitative approach. The exploratory phase, involving in-depth interviews with key informants from medium and large New Zealand businesses, helped refine and validate the conceptual model. Insights gained from these interviews were used to confirm and adjust the hypotheses, and informed the scale development for the explanatory phase. A mail survey was conducted using a dyadic approach, matching supplier and customer responses, with medium and large New Zealand businesses across a number and variety of industry sectors. The results of the nationwide survey were analysed using Partial Least Squares.

The purpose of this chapter is to discuss and draw conclusions from the results of the research. The central objective of this research was to develop and test an integrated conceptual model in order to understand the effect of CRM technology adoption on customer relationships. The study sought to extend previous research in the marketing and information technology areas by investigating the impact of market orientation (MO) and IT management orientation (ITMO) factors on CRM technology adoption (CTA), and the subsequent impact of these factors on customer relationship strength (C_RS) and relationship performance (C_RP). Two key findings are evident from the research results. The first is that market orientation works through CTA to influence and predict relationship strength and relationship performance. The second finding is that the extent of CRM technology adoption within a firm can help predict relationship strength.

\subsection{Effect of CRM Antecedents}

The results of this study clearly indicate that between the two antecedents, market orientation and IT management orientation, market orientation is the more important 
factor predicting CRM technology adoption within a firm. The market orientation of a firm positively influences employee adoption of CRM technology within the firm. This finding provides empirical evidence for the CRM literature where market orientation has been conceptualised as a factor contributing to the success of CRM technology implementation (Ling \& Yen, 2001; Lloyd et al., 2001; Wright et al., 2002).

\subsubsection{Market Orientation}

With respect to $H_{1}$ : The greater the level of market orientation of the firm the greater the CRM technology adoption within the firm, the data demonstrate that market orientation significantly and positively impacts CRM technology adoption. That is, the greater the market orientation levels of the firm the greater the adoption of CRM technology. This result supports the view that market oriented firms, and their employees, are more likely to recognise and adopt the inherent market orientation advantages of CRM technology: (a) intelligence generation, (b) intelligence dissemination, and (c) responsiveness within the CRM technology framework (Kohli et al., 1993). The implication is that firms with little market orientation may not realise the full relationship value from the implementation of a CRM system. The finding underscores the importance of market orientation as a key factor in the successful implementation and adoption of CRM technology. In addition it shows that CRM technology adoption by a firm can provide value to customer relationships and that through the correct use of CRM technology customer relationships can be enhanced.

Of particular interest is the finding that market orientation influences and predicts relationship strength and relationship performance through CRM technology adoption (CTA). $\mathrm{H}_{2}$ : The greater the level of market orientation of the firm the greater the overall relationship strength between the firm and the customer hypothesised, based on the extant literature, that the firm's market orientation would directly influence relationship strength with the customer (Farrelly \& Quester, 2003; Helfert et al., 2002; Sanzo et al., 2003; Yau et al., 2000). However, no significant direct relationship was found between market orientation of the supplier firm and customer relationship strength. This result supports studies where market orientation is not considered an accurate predictor of performance (Deshpandé et al., 1993; S. Henderson, 1998). Jayachandran, Sharma, Kaufman and Raman (2005) reported similar results between a firm's customer orientation and their relational information processes. One interpretation is that for the market orientation of a firm to manifest itself the firm 
requires a medium which can satisfy the three key characteristics of market orientation: intelligence generation, intelligence dissemination, and responsiveness as found in CRM technology. These results support Gummesson's (2004) view that CRM is simply the practical application of relationship marketing principles, whereby both the appropriate orientation and the technical capability are required to enjoy success (Day et al., 2004).

The influence of market orientation working through CRM technology may help explain the divergent results from both CRM research and market orientation research. CRM technology implementation has not always demonstrated positive results or successful implementation (Arnold, 2002; Davids, 1999; R. Davis, 2002; Nairn, 2002; O'Brien, 2004; Raman \& Pashupati, 2004; Rigby et al., 2002a) and market orientation is not uniformly viewed as valuable predictor of business performance (Deshpandé et al., 1993; S. Henderson, 1998; Langerak, 2003; Noble et al., 2002). The current results indicate that firms with a strong market orientation are more likely to successfully adopt and use CRM technology to deliver market oriented value to customers (i.e., improved information, response and communication), thereby improving relationship strength and performance (i.e., retention, loyalty and customer satisfaction). On the other hand, firms with weak market orientation are less likely to successfully adopt CRM technology to deliver customer value and improve customer relationship strength. The implication is that neither market orientation nor CRM technology is sufficiently valuable alone. It is the two working in concert that provides the greatest potential value.

From an alternate perspective, a firm with a strong market orientation, but without any medium (i.e., CRM technology) to collect, generate, or disseminate customer and competitor information would have difficulty demonstrating and leveraging the value of that market orientation to customers. As Wright et al (2002, p. 340) state "CRM [is] a concept that adds value to the meaning of customer orientation." The evidence from this study indicates that CRM technology can provide an appropriate medium, as well as offer a response channel to interact with customers, from which market orientation can successfully influence relationship strength and relationship performance.

\subsubsection{IT Management Orientation}

IT management orientation (IT management style and practices) has been demonstrated to influence the success of CRM technology adoption (Karimi et al., 
2001). The results of testing $\mathrm{H}_{3}$ : The greater the level of IT management orientation of the firm, the greater the CRM technology adoption confirms that IT management orientation does play a role, albeit limited, in predicting CRM technology adoption within a firm. The IT management orientation of the firm's managers can provide a positive predisposition towards the adoption of CRM technology within the firm. Emphasising the usefulness and customer knowledge benefits appears to provide the greatest incentive for users to adopt CRM technology. One interpretation is that business management which provides and communicates clear IT direction, organisation, planning and control, aids both the firm's CRM technology decision making and subsequent employee adoption. Clearly positioning and communicating the CRM technology advantage, focusing on improved customer knowledge and CRM usefulness, improves the users' perception and adoption of the CRM technology. Users are more likely to adopt CRM technology provided they can appreciate the advantages (F. D. Davis, 1989; Venkatesh \& Davis, 2000; Venkatesh et al., 2003). These results support and help explain other findings where clear direction and practices from management positively impact the successful adoption of CRM technology (Karimi et al., 2001; Ling \& Yen, 2001).

However the IT management orientation factor is not as important as the market orientation of the firm in adding value to the firm and the customer.

\subsection{Effects of CTA on Relationship Strength and Relationship Performance}

Not only does CRM technology adoption provide a medium for market orientation to influence relationship strength and relationship performance, CTA also predicts relationship strength itself. That is, the two dimensions of CTA, customer knowledge and CRM usefulness provide valuable information and processes to benefit relationship building through trust and communications. Customer relationship orientation (CRO) did not appear to moderate the effect of CTA on relationship strength or relationship performance. Although the exploratory phase indicated that some customers have expectations from CRM implementation (CXP) (see Appendix A2, Q9), the survey results indicate that any such expectations do not play a significant role in the moderation of the CTA effect on relationship strength or relationship performance. 


\subsubsection{Relationship Strength}

Trust is an essential attribute of relationships (Narayandas \& Rangan, 2004; Sirdeshmukh et al., 2002), and is enhanced by two-way communications (E. Anderson $\&$ Weitz, 1989). The positive significant result of testing $H_{4}$ : The greater the level of CRM technology adoption within a firm the greater the overall relationship strength with customers provides further support for the prevailing view that trust and communication are necessary for strong relationships between suppliers and customers (Berry, 1995; Duncan \& Moriarty, 1998; Dwyer et al., 1987; Fontenot \& Wilson, 1997; Geyskens et al., 1998). An interpretation of this result is that, independent of the firm's market orientation, CRM technology provides a platform from which to collect and communicate relevant information between suppliers and customers, thus helping to build trust between the two parties. CRM technology applications collect customer data from multiple sources and can provide a complete view of the customer. The customer knowledge (CKN) and CRM usefulness (USF) dimensions provide a significant conceptual and tangible linkage between CTA and relationship strength. In particular, this aspect of CRM technology provides the capability for supplier - customer interaction consistency, relevancy and appropriateness (Zablah et al., 2004).

Reinartz, Krafft, and Hoyer (2004) recognized that consistency in the CRM process aids the identification and measurement of valuable customers. Consistency in actions and information can build and enhance levels of trust and relationship strength more generally (Pan \& Lee, 2003; Rheault \& Sheridan, 2002). Relevancy is an aspect of communication which is favoured by customers (Ansari \& Mela, 2003; Postma \& Brokke, 2002; Thorbjornsen, Supphellen, Nysveen, \& Pedersen, 2002). The right mix of communications can help develop and maintain trust in a relationship (MacDonald \& Smith, 2004). Contractual, goodwill and competence trust is enhanced by a firm's knowledge, appropriate behaviour and communications; knowing what is required, delivering to the contract, and informing the customer accurately, credibly and completely is a fundamental requirement and basis of trust (Sako, 1992; Tellefsena \& Thomas, 2005).

This means that CRM application developers, CRM system implementers and CRM users need to highlight and make use of the fact that CRM technology can help provide appropriate levels of relevance and consistency to relationships. CRM technology is a powerful medium for collecting, analysing and communicating relevant and useful 
customer information. Through the consistent, relevant and appropriate use of customer knowledge relationships can be developed and improved.

\subsubsection{Relationship Performance}

Performance has multiple definitions, evidences considerable multidimensionality and is itself influenced by a number of external factors (Dess \& Robinson, 1984; Venkatraman \& Ramanujam, 1986). Therefore it is not completely surprising that $H_{5}$ : The greater the level of CRM technology adoption within a firm the greater the relationship performance was not supported and that CTA did not significantly influence relationship performance directly. Reinartz et al. (2004) for example found that the level of CRM technology did not significantly improve economic performance through the CRM process. The results from this study demonstrate however that CTA does work through relationship strength to positively influence relationship performance. This is most likely due to the impact of trust and communication on the relationship satisfaction, loyalty and retention dimensions of relationship performance (Garbarino \& Johnson, 1999; Moorman et al., 1993; Morgan \& Hunt, 1994; Selnes, 1998). CRM technology provides the basis for interaction consistency, relevancy and appropriateness of behaviour and communication. Data from the exploratory interviews, particularly the customer perspective, lend weight to the interpretation that the CRM technology adds value to relationship strength and relationship performance by incorporating and enhancing not only trust building and communications functionality, but more importantly dependability and consistency (see Appendix A2, Q14, Q16, Q17 and Q22). It is the dependability (goodwill trust) dimension which contributes a higher level of relationship satisfaction, hence improved customer retention and loyalty (Bhattacherjee, 2002; Gounaris, 2005; Sako, 1992; Tellefsena \& Thomas, 2005).

That $H_{6}$ : The greater the level of relationship strength the greater the relationship performance was found to be significant is consistent with other studies and provides support for developing trust, commitment and strong communication channels in order to improve business and relationship performance (Z. G. Li \& Dant, 1997).

\subsubsection{Moderator and Control Factors}

Neither of the two moderator variables, customer relationship orientation (CRO) and customer CRM expectation (CXP), included in the research model had a significant influence on CRM technology adoption's impact on relationship trust or relationship 
performance. Contrary to existing studies the non-significance of $H_{7}$ : The greater the level of customer relationship orientation the greater the CRM technology adoption effect on (a) relationship strength and (b) relationship performance indicates that the orientation of the customer towards relationships may not be all that important to maintaining B2B relationships (Ganesan, 1994; Jayachandran et al., 2005; Kapoulas et al., 2004). This implies that a customer's predisposition to a supplier relationship does not materially affect CTA's impact on the supplier - customer relationship. However, the raw data were highly skewed (e.g., $\overline{\mathrm{x}}=6.63, \mathrm{SD}=0.82$ ) indicating that the majority of customers considered themselves relationship oriented and hence this dimension of relationships needs to be examined more thoroughly in future research (see Appendix A9.2 for additional detail).

Similarly, the results from testing hypothesis $\mathrm{H}_{8}$ : The greater the level of customer CRM expectation the greater the CRM technology adoption effect on (a) relationship strength and (b) relationship performance was found to be non-significant. These results indicate that any pre-formed customer expectations, based on either previous experience or supplier promises, does not influence CTA's affect on customer relationship strength or performance.

Although market turbulence (MT) and technological turbulence (TT) have been shown to interact significantly with key variables in marketing studies investigating MO and business performance, this was not the case in this study (e.g., Pelham, 1999; Pulendran et al., 2003). Hypothesis $H_{9}$ : The greater the level of market turbulence the stronger the market orientation effect on CRM technology adoption was found to be non-significant, indicating that MT does not moderate the effect of MO on the adoption of CTA. This is somewhat counter intuitive; one would expect that high customer churn or a more volatile and competitive environment would positively influence the effect of MO on the adoption of business practices aimed at reducing customer churn and dealing with volatility. One interpretation of this result is that firms do not understand the potential application of CRM technology to add value to business relationships in a turbulent market environment. On the other hand firms may simply consider a turbulent market environment as normal.

Neither of the two versions of hypothesis $H_{10}$ : The greater the level of technology turbulence the stronger the (a) market orientation effect on CRM technology adoption, and (b) the IT management orientation effect on CRM technology adoption provided 
significant results. The lack of technology turbulence, across a variety of industries, to moderate MO and ITMO suggests the application of new technology itself does little to influence the general adoption of CRM technology.

\subsection{Research Implications and Contributions}

The results of the research provide a number of contributions to theory, research and practice.

\subsubsection{Contributions to Theory}

The development and empirical testing of the CRM technology adoption - customer relationship (CTA - CR) model, bringing together the IT and marketing research areas, is a key contribution of this study. The CTA - CR model establishes clear links between (a) CRM technology adoption and key relationship marketing components, (b) IT management orientation and CTA, and (c) market orientation and CTA.

In particular, three findings contribute to theory building in the marketing and IT domains. First, CRM technology adoption has been demonstrated to positively affect relationship strength and indirectly affect relationship performance. Jayachandran et al. (2005) demonstrated that relational information processes positively influenced customer relationship performance. The current study expands upon those findings and clearly demonstrates that it is the CRM knowledge management applications and usefulness aspects of the information that are important to the users of CRM technology. In addition the present study also provides empirical support to the Jayachandran et al. qualitative finding that communications (through relationship strength in the current study) plays an important role influencing relationship performance. This study shows that knowledge management plays a key role in CRM technology adoption (Romano \& Fjermestad, 2003). This result supports a growing consensus that $\mathrm{KM}$ is a competitive advantage for companies with the ability and capability to tap into the customer and competitor information, analyse the information, use it and disseminate the knowledge appropriately throughout the organisation (Bose \& Sugumaran, 2003; Bueren, Schierholz, Kolbe, \& Brenner, 2005; H. Lee \& Choi, 2003).

Second, and perhaps more importantly, market orientation influences relationship strength through CRM technology. The results of this study support the view that market orientation requires a mechanism, such as CRM technology, in order to manifest 
itself appropriately (Wright et al., 2002). It may be that one of the underlying reasons for the mixed results and debate surrounding the impact of market orientation is simply the lack of an effective mechanism to deliver specific outcomes from a firm's market orientation (Gray et al., 1998; Langerak, 2003).

Third, IT management orientation positively influences CRM technology adoption, although it does not impact relationship strength and relationship performance directly. Although the results do not completely support Karimi et al. (2001) finding that IT management practices influence CRM technology adoption and customer service (i.e., relationship strength and relationship performance), they do support and extend Karimi et al.'s original study which was focused only on IT managers in financial services. In particular the results of the IT Management Orientation scale, successfully administered to marketing, sales and customer service executives was found to be generalisable, valid and robust across industries and functional areas. These results provide additional empirical evidence that IT management practice is a key component in the initial adoption and success of CRM technology (J. C. Henderson \& Venkatraman, 1999; Ling \& Yen, 2001; Ravichandran \& Rai, 2000).

In addition, while the importance of determining the CRM technology adoption level within a firm has been identified, few studies have focused on understanding and measuring the level of CRM technology adoption by users (Jayachandran et al., 2005; Reinartz et al., 2004). This study introduces a new scale used to determine the level of CRM technology adoption within a firm. This scale measures customer knowledge and CTM usefulness and can be used to predict customer relationship strength and relationship performance. Previous studies attempting to measure CRM practice have not always measured technology adoption, emphasising instead strategic readiness (e.g., Bull, 2003; Payne \& Frow, 2006), organisational preparedness (e.g., Liu, 2007; Sin, Tse, \& Yim, 2005), systems and process (e.g., Bueren et al., 2005; Jayachandran et al., 2005) or performance benefits (e.g., Ang \& Buttle, 2006). However a number of recent studies have focused on the level of IT or CRM investment and resources (e.g., Reinartz et al., 2004; Srinivasan \& Moorman, 2005), IT architecture (e.g., Stefanou et al., 2003), and the extent of system integration (e.g., Ling \& Yen, 2001; M. Meyer \& Kolbe, 2005; Zeng et al., 2003).

The use of the technology adoption model (TAM) is extended into the CRM and marketing research context. TAM has been used extensively to explain and analyse 
information systems usage behaviour (Venkatesh \& Davis, 2000; Venkatesh et al., 2003), but has not been widely used to investigate CRM usage (cf. Robinson, Marshall, \& Stamps, 2005; Wu \& Wu, 2005). In particular the results from this study indicate that CRM usefulness, and not ease of use or attitude provides clear support for the applicability, robustness and generalisability of the TAM scales in the CRM technology context. The underlying TAM theory is that users adopt technology which provides some distinct and valuable advantage (F. D. Davis et al., 1989). The current study provides supports that view that implementing new technology and gaining user acceptance depends first and foremost on the usefulness of the application.

The research adds empirical support for the view that CRM requires a holistic conceptualisation; that both IT and marketing need to be involved and work together in order to be successful, and that the firm's business and market orientation needs to be relationship marketing focused and properly aligned with the CRM technology implementation (Mitussis et al., 2006).

\subsubsection{Contributions to Methodology}

The study reviews methodological issues and obstacles to be considered when conducting dyadic business relationship research. A CRM technology adoption measure was developed and verified. A number of scales have been developed attempting to measure CRM technology from a variety of perspectives. In particular Raman and Pashupati (2004) have attempted to measure the CRM functionality in use, Stefanou et al. (2003) considered the level of CRM technology employed, while Reinartz et al. (2004) developed an instrument to measure the CRM processes utilised within a firm Sin, Tse and Yim (2005) identified and measured the extent of CRM technology support available within firms. The CTA scale developed in this study measures two key value add outcomes of CRM technology adoption. First, from the CRM user's perspective, the extent to which CRM technology helps accumulate and provide customer knowledge (CKN) and second, based on the technology adoption model (TAM), the level of CRM usefulness (USF) to the user (F. D. Davis, 1989).

The use of PLS within a dyadic business-to-business marketing study including moderating variables was demonstrated. The use of PLS to test hypotheses within complex models is still relatively underutilised in marketing. However this multivariate analysis technique "is ideal for the early stages of theory development" and has been 
demonstrated as a useful technique for small samples with non-normal distributions, such as found in dyadic research (Grégoire \& Fisher, 2006, p. 38).

Traditionally the robustness of multivariate analysis techniques using non-normal data distributions have been demonstrated through Monte Carlo simulation (Hau \& Marsh, 2004; Muthén \& Kaplan, 1985; Yanagihara \& Yuan, 2005). The current research provides a case study of the robustness of factor analysis with highly nonnormal (extreme kurtosis and skewness) and transformed data (Rummel, 1970).

The utilisation of the relationship dyad overcomes a key weakness of many previous studies in CRM; specifically taking the research focus and perspective exclusively from the CRM user and not explicitly measuring the potential customer impact (e.g., Jayachandran et al., 2005; Reinartz et al., 2004). In a related sense insights from both the qualitative and quantitative research methods were gained that could only be obtained through the dyadic research model.

\subsection{Managerial Implications}

Given the uneven CRM technology implementation and adoption success rate, many companies and practitioners are concerned about the return on investment from CRM (Brown \& Vessey, 2003; Croteau \& Li, 2003; Gummesson, 2004; J. W. Kim et al., 2004; Lemon et al., 2002; Reinartz et al., 2004). This study provides evidence that the firm's level of market orientation will impact CRM technology adoption and relationship marketing outcomes. Providing clear processes for collecting, analysing, using and communicating customer knowledge is important in building better customer relationships. Managers need to spend time to ensure CRM users understand the usefulness of the CRM applications to add value to their jobs as well as the capability of CRM technology to identify and help meet customer needs. For those firms considering CRM adoption, it would be prudent to address the level of market orientation within the firm first. IT management involvement with CRM business decisions at the senior levels of the organisation benefits the extent of CRM technology adoption within the firm, although it does not appear to add any relationship marketing value in and of itself. IT managers need to provide clear communication of IT strategy, effective IT system integration, and quality IT management based on an understanding of the strategic direction of the business, and technology in order to positively impact CRM technology adoption within the firm. People need to understand how CRM technology 
will be useful to them in their job and how the CRM system can provide improved customer information and knowledge. The key message here is to take time understanding how the CRM technology fits with the organisation's culture and business requirements, and how it will add value (Day, 1994; Karimi et al., 2001). IT management needs to provide and communicate clear and unambiguous implementation plans, focused on CRM usefulness to customers, users and business requirements. On the other hand implementing CRM technology, no matter how expensive or feature laden, will not by itself automatically deliver relationship benefits. CRM technology is not the silver bullet that can eliminate poor customer relationships, processes or business culture.

Companies looking to implement CRM technology need therefore to consider a balanced portfolio of action. This means cultivating and aligning a customer-centric market orientation, preparing and implementing a comprehensive IT implementation plan, identifying and implementing process change requirements, and communicating the expected CRM technology benefits. A balanced approach can provide a synergy where the whole is more than the sum of the individual parts.

\subsubsection{CRM Technology Adoption}

CRM technology provides a number of advantages including providing an interactive and broad-based medium for information collection and dissemination. The results of this study indicate that users consider the most important dimensions of CRM technology to be the organisation and provision of customer knowledge $(\mathrm{CKN})$ and the CRM usefulness (USF) of the technology itself. As indicated from the items found to measure $\mathrm{CKN}$, it is the customer knowledge gathering and information storage and retrieval applications that differentiate successful from less successful CRM technology adoptions. This is consistent with the interview data, which suggests both the suppliers and the customers perceive that CRM systems and technology provides better customer history, improved knowledge transfer, and facilitates data collection and data retrieval (refer to Appendix A2 Q12 and Q13 for additional detail).

The items found to measure USF demonstrate a focus on performance, effectiveness and productivity improvements. Other measures indicate that the attitude toward, and acceptance of, CRM technology is a differentiator for adoption. The perspective is again supported by the interview data, with users indicating that CRM system implementation 
should provide better integration with other systems, improved knowledge management, and increased sales support (refer to Appendix A2, Q12 and Q13 for additional detail).

From both the survey and the interview data it appears that the users are not overly concerned regarding the specific CRM technology implemented. The responses suggest that customer information collection applications (e.g., knowledge management) and perceived data utilisation applications (e.g., information collection and retrieval) provide the most important advantages. These are deemed to be the applications which help build and sustain relationships.

\subsubsection{CRM Application Development}

This research provides some useful additional perspectives for CRM software and systems developers. CRM technology can genuinely be used to enhance relationships. In particular, developing applications that combine customer knowledge collection with trust building and appropriate communication tools benefits both customers and suppliers. CRM technology adoption influences customer relationship performance only through customer relationship strength. This implies that mechanisms to support building customer loyalty, improving relationship satisfaction and retaining customers should be strengthened through CRM applications. It is the communications and trustbuilding features of CRM systems that are most likely to result in performance improvements. CRM technology software and system developers need to look more closely at the features of their systems that can reinforce consistency, relevance, dependability, appropriateness, trust building and communications aspect of CRM.

Enhancements to CRM knowledge management applications can in addition help to smooth the effects of staff turnover and prevent the loss of corporate knowledge (Droege \& Hoobler, 2003). CRM databases can provide a knowledge repository for customer information that can bolster the organisation's ongoing and continuous relationship effort (Bose \& Sugumaran, 2003; Bueren et al., 2005; H. Lee \& Choi, 2003).

\subsection{Limitations of the Research Study}

The present research focused on only a snapshot in time to test the hypothesised model and provide some general principles. CRM is an evolving process where some of the identified variables, such as market orientation, or customer satisfaction, would be 
expected to change over time and vary across firms. That similar traits were exhibited across firms provides justification for the current design and hypothesised model. Since CRM is a dynamic phenomenon a longitudinal design would provide additional benefit; tracking the implementation and adoption of CRM technology over time could further test and refine our insights into the relationship between market orientation, CRM technology adoption and customer relations.

A potential methodological limitation was the small sample size due to the sequential data collection approach required by the dyadic research. The small sample size makes a Type II error more likely, that is, the statistical tests employed may fail to detect significant relationships. The measurement items and relationship constructs are imperfect; there are additional variables which might have been included in the measurement of relationship strength and performance. In addition, factors other than CRM technology are known to affect supplier - customer relationships, such as the strategic fit between organisations (Selnes \& Sallis, 2003), inter-firm power asymmetry (J. C. Anderson \& Narus, 1984; Iacobucci \& Ostrom, 1996; Narayandas \& Rangan, 2004), cooperation (J. C. Anderson \& Narus, 1990) and commitment (Morgan \& Hunt, 1994). Expanding the model to include additional relational factors could uncover additional CRM technology linkages and benefits, as well as provide a better understanding of CRM technology within a broader relationship context.

The CTA operational measures did not differentiate functionality or the integration of the actual CRM technology adopted. The result of the exploratory factor analysis (EFA) indicates that the scales did not adequately measure the functionality and integration constructs. The CRM scales were newly created for this study, and therefore there exists opportunity for further measurement refinement. The scope of the present findings contributes useful insights and the incorporation of additional factors is left for further research.

\subsection{Directions for Further Research}

The combination of marketing and information technology provides many opportunities for research and the results of this study open a number of avenues for further investigation. Although the results indicate customer relationship orientation showed no significant moderating effect on CTA, the customer data were highly skewed towards relationship orientation. Given the positive impact of CRO reported by 
(Jayachandran et al., 2005) there is a need to investigate further and better understand the impact of the customer's perspective on relationships. The exploratory interview data, as well as the survey data, indicate customer expectations development and subsequent consequences is a promising research area, since suppliers adopting CRM technology, but not achieving (or managing) customer expectations may create customer dissatisfaction, to the detriment of their CRM implementation and relationship-building efforts.

The impact of market turbulence and technology turbulence on CRM technology adoption may be influenced by industry. Identifying and investigating CRM technology adoption in industries that are more susceptible to market and technology turbulence (i.e., technology based products and services) would be beneficial in understanding the potential differential effects of CRM technology adoption and impact between industry sectors. A portion of the reported CRM failures may simply stem from specific industries inappropriately implementing CRM technology as a proxy for a customercentric business strategy.

A small number of interview participants indicated that customer expectations may be developed with the awareness that supplier firms have implemented CRM. If so, there is a danger that customer expectations may not be realised by supplier firms causing a relationship backlash. Research into this area, including the impact of CRM implied and explicit promises on relationships, may be a fruitful avenue of study. Similarly, from the dyadic-based interviews, a number of customers stated that the supplier firm was not market oriented, contrary to the supplier's perception. The inability for firms to accurately self-report their market orientation has been reported in the literature (S. Henderson, 1998). Therefore there may be some advantage to use the customer's perception of the supplier's market orientation in the CTA - CR model.

Another research approach is to investigate CRM technology adoption and the link to business performance measures of both the supplier and the customer sides. Is there a flow-on effect to the customer from a supplier firm adopting CRM? The current research attempted to provide generalisable results by aggregating a number of different industries, however, CRM technology adoption and relationship market orientation may have differential effect based on the type of industry (Yau et al., 2000). In addition firm size may impact the adoption, functionality and integration of CRM deployed, since 
larger companies spend more on information technology than smaller firms (Mahmood \& Mann, 1993; Mitra \& Chaya, 1996).

\subsection{Conclusion}

The research brought together a number of domains and areas of marketing and IT, including technology adoption, customer relationship management, and relationship marketing. Market orientation and IT management orientation were considered and found to be antecedents to CRM technology adoption. A CTA measurement instrument was developed in order to provide a measure of CTA technology implemented and adopted by firms. The dependent variables were relationship strength and relationship performance measured from the customer perspective. The independent variables consisted of market orientation, IT management orientation and CTA. Data collection began with ten dyadic (matched supplier - customer) interviews used to inform the model and scale development. A mail survey, using matched pairs of suppliers and customer (supplier - customer dyads) provided the data which were analysed using PLS. The results were interpreted in light of the existing literature and the qualitative data captured in the exploratory phase of the research.

The results showed that greater CRM technology adoption improves relationship strength and consequently relationship performance. As expected, the level of IT management orientation (ITMO) within a firm positively influences CRM technology adoption. This suggests that companies which embrace IT as part of their business strategy more successfully adopt and benefit more from CRM technology.

More interestingly however, are the results which indicate that market orientation works through CTA to positively affect relationship strength, but does not directly influence relationship strength. This finding suggests that the firm's market orientation is leveraged through CRM technology, and that gaining maximum benefits from CRM technology depends on a firm's level of market orientation. The results also demonstrate that CTA can, itself, influence relationship strength and relationship performance through trust-building and communications functionality.

The outcomes of the research met the objectives set out in Chapter 1, which were to:

\section{- Determine whether CRM technology adoption has a positive effect on} business-to-business relationships and the extent of that impact. The results 
of the PLS analysis show that CTA does have a significant and positive effect on $\mathrm{B} 2 \mathrm{~B}$ relationships.

- Determine whether the supplier firm's market orientation and IT management orientation has a positive effect on CRM technology adoption and the extent of that impact. The results demonstrate that market orientation and IT management orientation do significantly and positively influence CRM technology adoption within a firm.

- Contribute to the current marketing and IT literature on CRM technology and relationship marketing. This study adds to the growing CRM literature in the business-to-business context. The results complement a number of recently published studies and extend the research into new areas, methodologically by incorporating dyadic research techniques using PLS, and developing a CRM technology adoption measurement instrument. In addition the data provide support for the CTA - CR conceptualisation, and the link between CRM technology and relationship marketing has been empirically demonstrated.

- Inform CRM practitioners engaged in CRM implementation and software development. The study is of interest to businesses that currently have CRM systems or are considering CRM technology implementation - sixty-three supplier respondents requested a summary of the results. The findings benefit CRM vendors and software developers through an improved understanding how CRM technology adoption, products and applications affect customer relationships. This has the potential for improved CRM applications around B2B relationships.

\subsubsection{Closing Remarks}

In spite of the mixed reviews and variable levels of reported success regarding its effectiveness, companies continue to implement CRM and the associated technology in an attempt to improve business performance (Bohling et al., 2006; Boulding, Staelin, Ehret, \& Johnston, 2005; Reinartz et al., 2004). There is a growing concern that the classical 4Ps of marketing are no longer sufficient for business success and that businesses need to focus more on long-term relationships with customers and partners (Day et al., 2004; Mithas et al., 2005). Companies generally invest in technology to achieve tangible results and CRM technology has been heralded as a vehicle for implementing relationship marketing (Jayachandran et al., 2005). This study provides 
clear evidence that CRM technology adoption by a firm can significantly and positively affects customer relationships, thereby improving customer satisfaction, loyalty and retention. The extent of the effect is dependent on the level of market orientation within the firm. These findings support the view that a sufficient level of market orientation, coupled with CRM technology and supported by appropriate IT management positively affects customer relationship strength and relationship performance. The challenge to both the businesses implementing CRM technology and the CRM vendors themselves is properly developing and implementing all the customer facing, knowledge management and communications components comprehensively in order to gain more than simply what a 'sum of the individual parts' might suggest. This study provides guidance as to what areas of CRM technology need to be emphasised in order to improve customer relationships. It also provides insights to CRM vendors regarding application development areas to assist their customers in implementing successful CRM technology. 


\section{APPENDIXES}

\section{Appendix A1: Interview Protocols and Contact Summary Forms}

\section{Field Interview Protocol - Supplier}

\section{Section 1: Research and interview objectives}

\section{Overall research issues}

The overall objectives of this research are to determine, by interviewing firms and their customers:

- Whether CRM technology adoption has any effect on business-to-business relationship development and the extent of that impact.

- Whether the firm's orientation (market orientation and technology orientation) has any effect on CRM technology adoption and the extent of that impact

\section{Research questions}

1. What is the impact of CRM technology on B2B customer relationships?

2. How does the market orientation of the firm affect the adoption of CRM?

3. How does the technology orientation of the firm affect the adoption of CRM?

4. Do different CRM functionality, adoption and integration affect the relationship strength between the firm and its customers?

5. What constitutes relationship strength within a B2B relationship?

6. How is relationship strength measured?

7. How do firms measure relationship performance? Benefits

8. How does CRM technology adoption influence relationship strength and performance?

\section{Interview objectives}

- Determine whether respondents are familiar with and understand the constructs.

- Ensure that the terminology to be used in the questionnaire is understandable by practitioners and customers.

- Identify any new or obsolete variables.

- Identify problems managers have encountered implementing and adopting CRM technology.

- Identify how managers use CRM to accomplish relationship-building goals.

- Identify performance measures related to CRM adoption and relationship building. 


\section{Section 2: Introduction of project for participant}

Thank you for taking your time to participate in this interview.

\section{Description of project:}

As outlined in the information brief my research concerns understanding the link between customer relationship management (CRM) technology use and customer relationship development and maintenance. Your firm has been identified as a user of CRM technology and therefore I would like to learn what you have experienced during and after your CRM implementation and adoption.

\section{Format of questions and information sought during the interview}

I have developed a set of open-ended questions in order to gain a deeper understanding of the CRM technology as adopted in your company and how you perceive the impact of CRM technology on customer relationships. Please feel free to talk about whatever comes to mind regarding these issues.

It would be appreciated if you could nominate and provide contact details for three of your customers. One or two of the nominated customers will be asked to participate in an interview to examine their perception of the relationship strength and performance between the two companies including the perceived impact of CRM technology.

Do you have any reservations nominating three customers?

Yes

No

\section{Involvement of other companies in this study}

Similar conversations have been or will be held with marketing executives and customers from other companies in a variety of industries. Based on what I learn from these conversations, a questionnaire will be developed and distributed to a large number of companies in 2005. Each participating company will receive a summary report of the study results at the end of the project.

\section{Ethical issues}

My university's ethics committee requires me to inform you that:

- Your answers will remain confidential and anonymous.

- You can refuse to answer questions or discontinue this conversation at any time. 
- With your permission your answers will be taped. The tape will be transcribed for subsequent analysis, and destroyed at the end of the project. Taping the conversation allows me to stay focused on the conversation.

Do you have any reservations about me taping the conversation?

\section{Do you have any questions before we start the interview?}

Company name:

ANZSIC:

Time of Interview:

Date:

Place:

Interviewer:

Participant (Interviewee): \# of employees

Position: Revenues:

\section{Section 3: Interview questions}

\section{CRM - Relationship Model Firm Interview Protocol}

\section{General questions}

1.) Tell me about your role in the company.

2.) How would you characterise your firm's customer relationships?

3.) Tell me about the CRM technology implemented in your company? 
4.) What do you think prompted the company to adopt CRM technology? (Who first brought it up - IT, Marketing, Sales, or Senior Management? What was going on within the company at the time it was first discussed?)

\section{Market and technology orientation characteristics}

Market orientation can be characterised by the firm's gathering of market intelligence to help understand and react to current and future customer needs, taking into consideration competitive capabilities and response.

5.) Do you consider your company to be market oriented? Why or why not?

a. In your opinion does this orientation have a bearing on the type and strength of your B2B customer relationships? How so?

b. In your opinion does this orientation have a bearing on the functionality, integration and acceptance of CRM technology? How so?

Technology orientation can be characterised by the firm's IT management sophistication and leadership. Firms in which IT management and leadership hold senior positions and direct the firm's business tend to benefit more from technology.

6.) Do you consider your company to be technology oriented? Why or why not? 
a. In your opinion does technology orientation have a bearing on the functionality, integration and acceptance of CRM technology within your firm?

\section{CRM adoption characteristics}

7.) Can you tell me what CRM functions you have in place? What does the CRM technology actually do for you? The customer? The business?

8.) What CRM functions would you like to have?

9.) As far as you know what CRM functions are available?

a. What functionality best describes the CRM technology implemented at your firm?

\begin{tabular}{c|c|c|c|c|c|c|}
$\begin{array}{c}\text { Stand-alone } \\
\text { address } \\
\text { book }\end{array}$ & $\begin{array}{c}\text { contact } \\
\text { Management }\end{array}$ & $\begin{array}{c}\text { Sales } \\
\text { support }\end{array}$ & $\begin{array}{c}\text { Integrated with } \\
\text { customer } \\
\text { support }\end{array}$ & $\begin{array}{c}\text { Integrated with } \\
\text { some } \\
\text { departments }\end{array}$ & $\begin{array}{c}\text { Enterprise-wide } \\
\text { integration }\end{array}$ & $\begin{array}{c}\text { Partner } \\
\text { collaboration }\end{array}$ \\
\hline 1 & 2 & 3 & 4 & 5 & 6 & 7 \\
\hline
\end{tabular}

b. What functions does your CRM system provide? Choose that entire match.

\begin{tabular}{|l|l|}
\hline Manual customer surveys & \\
\hline Data collection & \\
\hline Campaign management & \\
\hline Data Mining & \\
\hline Lead distribution & \\
\hline Sales management & \\
\hline Call centre integration & \\
\hline Collaborative communication & \\
\hline Measures customer loyalty & \\
\hline Handles multi-channel & \\
\hline Derives customer value & \\
\hline Provides relevant information & \\
\hline Churn analysis & \\
\hline Other, please describe:
\end{tabular}

\begin{tabular}{|l|l|}
\hline Manual recording & \\
\hline Analytics & \\
\hline Sales automation & \\
\hline Marketing automation & \\
\hline Contact management & \\
\hline Customer self-service & \\
\hline Web-based self-service & \\
\hline Customer retention rates & \\
\hline Calculates customer lifetime value & \\
\hline Synchronises customer interactions & \\
\hline Forecast demand & \\
\hline Ad hoc queries & \\
\hline Propensity scoring & \\
\hline
\end{tabular}


10.) Do you believe CRM technology is widely used within the company? By whom? Why?

11.) Is the CRM technology widely integrated with other IT systems (functional areas or process) within your company? [i.e., Finance, Accounts Receivable, Operations, Customer Service, etc]

12.) What are your expectations of CRM technology? What do the employees think of the CRM technology?

13.) What does CRM technology help you do better?

14.) How does CRM technology help initiate, develop and/or maintain Business-to-Business (B2B) relationships?

\section{Relationship characteristics}

15.) What terms would you use to describe B2B relationships?

16.) What do you consider to be the Key elements of a B2B relationship?

17.) In your opinion what are drivers of a strong B2B relationship? 
18.) How would you prioritise each of the following within a $B 2 B$ relationship?
a. Trust
b. Power
c. Control
d. Commitment
e. Satisfaction
f. Cooperation
g. Performance
h. Conflict \& conflict resolution

19.) What role does trust play in a B2B relationship?

20.) What role does commitment play in a $\mathrm{B} 2 \mathrm{~B}$ relationship?

21.) What role does communications quality play in a B2B relationship? How is communications quality improved?

22.) In your opinion how does CRM technology affect relationship building and relationship strength?

\section{Measuring relationship performance}

23.) From your perspective what is relationship performance? How is relationship performance generally measured?

24.) How would you prioritise these measures?

25.) In your opinion how does CRM technology adoption affect relationship performance? 
26.) Is customer satisfaction important to you? Your firm? How do you measure customer satisfaction?

27.) Is customer loyalty important to you? Your firm? How do you measure customer loyalty?

28.) Is customer retention important to you? Your firm? How do you measure customer retention?

29.) In what ways do you see CRM technology affecting these elements of a relationship?

Thank you for your participation. All your responses are confidential. If requested a copy of the report will be available to you when the research is completed. 


\section{Field Interview Protocol - Customer}

\section{Section 1: Research and interview objectives}

\section{Overall research issues}

The overall objectives of this research are to determine, by interviewing firms and their customers:

- Whether CRM technology adoption has any effect on business-to-business relationship development and the extent of that impact

- Whether the firm's orientation (market orientation and technology orientation) has any effect on CRM technology adoption and the extent of that impact

\section{Research questions}

1. What is the impact of CRM technology on B2B customer relationships?

2. How does the market orientation of the firm affect the adoption of CRM?

3. How does the technology orientation of the firm affect the adoption of CRM?

4. Do different CRM functionality, adoption and integration affect the relationship strength between the firm and its customers?

5. What constitutes relationship strength within a $\mathrm{B} 2 \mathrm{~B}$ relationship?

6. How is relationship strength measured?

7. How do firms measure relationship performance?

\section{Benefits}

8. How does CRM technology adoption influence relationship strength and performance?

\section{Interview objectives}

- Determine whether respondents are familiar with and understand the constructs.

- Ensure that the terminology to be used in the questionnaire is understandable by practitioners and customers.

- Identify any new or obsolete variables.

- Identify problems managers have encountered implementing and adopting CRM technology.

- Identify how managers use CRM to accomplish relationship building goals.

- Identify performance measures related to CRM adoption and relationship building. 


\section{Section 2: Introduction of project for participant}

\section{Thank you for taking your time to participate in this interview.}

\section{Description of project:}

As outlined in the information brief my research concerns understanding the link between customer relationship management (CRM) technology use and customer relationship development and maintenance. Your firm has been nominated by a firm using CRM technology and therefore I would like to learn about your relationship experience with this firm.

\section{Format of questions and information sought during the interview}

I have developed a set of open-ended questions in order to gain a deeper understanding of the CRM technology effect on customer relationships. Please feel free to talk about whatever comes to mind regarding these issues.

\section{Involvement of other companies in this study}

Similar conversations have been or will be held with marketing executives and customers from other companies in a variety of industries. Based on what I learn from these conversations, a questionnaire will be developed and distributed to a large number of companies in 2005 .

\section{Ethical issues}

My university's ethics committee requires me to inform you that:

- Your answers will remain confidential and anonymous.

- You can refuse to answer questions or discontinue this conversation at any time.

- With your permission your answers will be taped. The tape will be transcribed for subsequent analysis, and destroyed at the end of the project. Taping the conversation allows me to stay focused on the conversation.

Do you have any reservations about me taping the conversation?

Do you have any questions before we start the interview? 
Company name: ANZSIC:

Time of Interview:

Date:

Place:

Interviewer:

Participant (Interviewee): \# of employees

Position: Revenues:

\section{Section 3: Interview questions}

\section{CRM - Relationship Model Customer Interview Protocol}

\section{General questions}

1.) Can you tell me a little about your role in your company?

2.) Tell me about your relationship with (company name).

3.) What do you think prompted that company to adopt CRM technology?

4.) What do you consider to be the key elements of a B2B relationship?

\section{Relationship characteristics}

5.) What terms would you use to describe B2B relationships?

6.) How do you measure relationship strength? How do you think relationship strength is generally measured? 
7.) In your opinion what are drivers of a strong B2B relationship?

8.) How would you prioritise each of the following within a B2B relationship?
a. Trust
b. Power
c. Control
d. Commitment
e. Satisfaction
f. Cooperation
g. Performance
h. Conflict and conflict resolution

9.) What role does trust play in a $\mathrm{B} 2 \mathrm{~B}$ relationship?

10.) What role does commitment play in a $\mathrm{B} 2 \mathrm{~B}$ relationship?

11.) What role does communications quality play in a B2B relationship? How is communications quality improved?

12.) In your opinion how does CRM technology affect relationship building and relationship strength?

\section{Measuring relationship performance}

13.) From your perspective what is relationship performance? How is relationship performance generally measured?

14.) How would you prioritise these measures? 
23.) In what ways do you see CRM technology affecting elements of a relationship?

24.) Do you consider yourself to be relationship oriented? Is your firm relationship oriented?

Thank you for your participation. All your responses are confidential. If requested a copy of the report will be available to you when the research is completed 


\section{Appendix A2: Interview Data Display Summaries}

Table A2.1: Interview Questionnaire Summary

\begin{tabular}{|c|c|c|c|c|c|c|c|c|c|}
\hline Firm & Cust & & F1 & C1 & F2 & $\mathrm{C} 2$ & F3 & C3 & F4 \\
\hline Q4 & Q3 & $\begin{array}{l}\text { What do you think prompted the } \\
\text { company to adopt CRM technology? }\end{array}$ & Right product & No idea & Leverage growth & No idea & $\begin{array}{l}\text { multiple contacts } \\
\text { with multiple } \\
\text { customers }\end{array}$ & $\begin{array}{l}\text { Long-term } \\
\text { relationships; Key } \\
\text { Success Factor }\end{array}$ & $\begin{array}{l}\text { Determined a } \\
\text { Need }\end{array}$ \\
\hline \multirow[t]{2}{*}{ Q5 } & & $\begin{array}{l}\text { Do you consider your company to be } \\
\text { market oriented? }\end{array}$ & Yes & & Yes & & Yes & & Yes \\
\hline & Q22 & $\begin{array}{l}\text { Do you perceive the supplier firm to be } \\
\text { market oriented? }\end{array}$ & & Yes & & Yes & & Yes & \\
\hline Q5a & & $\begin{array}{l}\text { In your opinion does this orientation have } \\
\text { a bearing on the type and strength of your } \\
\text { B2B customer relationships? }\end{array}$ & Yes & & Yes & & Yes & & Yes \\
\hline Q5b & & $\begin{array}{l}\text { In your opinion does this orientation have } \\
\text { a bearing on the functionality, integration } \\
\text { and acceptance of CRM technology? }\end{array}$ & Yes & & Yes & & Yes & & No \\
\hline Q6 & & $\begin{array}{l}\text { Do you consider your company to be } \\
\text { technology oriented? }\end{array}$ & Yes & & unknown & & Yes & & No \\
\hline Q6a & & $\begin{array}{l}\text { In your opinion does technology } \\
\text { orientation have a bearing on the } \\
\text { functionality, integration and acceptance } \\
\text { of CRM technology within your firm? }\end{array}$ & Yes & & unknown & & Yes & & Yes \\
\hline Q7 & & $\begin{array}{l}\text { Can you tell me what CRM functions you } \\
\text { have in place? }\end{array}$ & Yes & & Yes & & Yes & & Yes \\
\hline Q8 & & $\begin{array}{l}\text { What CRM functions would you like to } \\
\text { have? }\end{array}$ & known & & unknown & & known & & unkown \\
\hline Q9 & & $\begin{array}{l}\text { As far as you know what CRM functions } \\
\text { are available? }\end{array}$ & some & & known & & unkown & & some \\
\hline Q9a & & $\begin{array}{l}\text { What functionality best describes the } \\
\text { CRM technology implemented at your } \\
\text { firm? }\end{array}$ & $3-4$ & & $6-7$ & & 2 & & 3 \\
\hline
\end{tabular}




\begin{tabular}{|c|c|c|c|c|c|c|c|c|c|}
\hline Firm & Cust & & F1 & C1 & F2 & C2 & F3 & C3 & F4 \\
\hline Q10 & & $\begin{array}{l}\text { Do you believe CRM technology is } \\
\text { widely used within the company? }\end{array}$ & Yes & & Yes & & Yes & & No \\
\hline Q11 & Q21 & $\begin{array}{l}\text { Is the CRM technology widely integrated } \\
\text { with other IT systems (functional areas or } \\
\text { process) within your company? }\end{array}$ & Yes & No & Yes & Don't know & No & No & No \\
\hline Q12 & Q19 & $\begin{array}{l}\text { What are your expectations of CRM } \\
\text { technology? }\end{array}$ & $\begin{array}{l}\text { Better integration } \\
\text { w/ other sys }\end{array}$ & None & KM & None & $\begin{array}{l}\text { Not high; meets } \\
\text { needs }\end{array}$ & $\begin{array}{l}\text { Structured } \\
\text { communications; } \\
\text { consistency; } \\
\text { persistence; } \\
\text { instructional; } \\
\text { change } \\
\text { behaviours }\end{array}$ & $\begin{array}{l}\text { sales support } \\
\text { system; analyse } \\
\text { sales }\end{array}$ \\
\hline Q13 & & $\begin{array}{l}\text { What does CRM technology help you do } \\
\text { better? }\end{array}$ & customer service & & reminders & & $\begin{array}{l}\text { manage } \\
\text { information }\end{array}$ & & $\begin{array}{l}\text { automates; client } \\
\text { history }\end{array}$ \\
\hline Q14 & Q20 & $\begin{array}{l}\text { How does CRM technology help initiate, } \\
\text { develop and/or maintain Business-to- } \\
\text { Business (B2B) relationships? }\end{array}$ & $\begin{array}{l}\text { history; trends; } \\
\text { customer needs }\end{array}$ & $\begin{array}{l}\text { Purpose built } \\
\text { system }\end{array}$ & big picture & $\begin{array}{l}\text { Research ability; } \\
\text { analytics }\end{array}$ & $\begin{array}{l}\text { record; } \\
\text { communications }\end{array}$ & $\begin{array}{l}\text { Only a tool; } \\
\text { combines DBs; } \\
\text { assists, analytics }\end{array}$ & $\begin{array}{l}\text { knowledge } \\
\text { capture }\end{array}$ \\
\hline Q15 & Q5 & $\begin{array}{l}\text { What terms would you use to describe } \\
\text { B2B relationships? }\end{array}$ & $\begin{array}{l}\text { empathy; regular } \\
\text { contact }\end{array}$ & Personal level & $\begin{array}{l}\text { value; } \\
\text { communication; } \\
\text { understanding; } \\
\text { knowledge }\end{array}$ & $\begin{array}{l}\text { Value; } \\
\text { understanding; } \\
\text { communications; } \\
\text { contracts; } \\
\text { personalities }\end{array}$ & $\begin{array}{l}\text { practical; deliver; } \\
\text { needs focused }\end{array}$ & $\begin{array}{l}\text { Performance; } \\
\text { treatment; } \\
\text { understanding; } \\
\text { importance }\end{array}$ & $\begin{array}{l}\text { different for } \\
\text { different people }\end{array}$ \\
\hline Q16 & Q4 & $\begin{array}{l}\text { What do you consider to be the Key } \\
\text { elements of a B2B relationship? }\end{array}$ & $\begin{array}{l}\text { friendliness; } \\
\text { contacts }\end{array}$ & $\begin{array}{l}\text { Reliability; } \\
\text { integrity; honesty }\end{array}$ & $\begin{array}{l}\text { respect; } \\
\text { performance }\end{array}$ & $\begin{array}{l}\text { Value; flexibility; } \\
\text { formal structure; } \\
\text { trust }\end{array}$ & trust; respect & $\begin{array}{l}\text { Competence; } \\
\text { communication; } \\
\text { flexibility; } \\
\text { timeliness; speed; } \\
\text { responsiveness }\end{array}$ & $\begin{array}{l}\text { honesty; } \\
\text { informed; } \\
\text { forewarning }\end{array}$ \\
\hline Q17 & Q7 & $\begin{array}{l}\text { In your opinion what are drivers of a } \\
\text { strong B2B relationship? }\end{array}$ & value & Mutual benefit & performance & $\begin{array}{l}\text { Mutual value; } \\
\text { personality }\end{array}$ & trust; respect & $\begin{array}{l}\text { Personality; } \\
\text { people; } \\
\text { consistency; } \\
\text { levels of } \\
\text { engagement }\end{array}$ & people \\
\hline
\end{tabular}




\begin{tabular}{|c|c|c|c|c|c|c|c|c|c|}
\hline Firm & Cust & & F1 & C1 & F2 & $\mathrm{C} 2$ & F3 & $\mathrm{C} 3$ & F4 \\
\hline$\overline{\text { Q19 }}$ & Q9 & $\begin{array}{l}\text { What role does trust play in a } \mathrm{B} 2 \mathrm{~B} \\
\text { relationship? }\end{array}$ & deliver & Vital & important & $\begin{array}{l}\text { Assumption; } \\
\text { Builds over time }\end{array}$ & essential & Fundamental & huge \\
\hline Q20 & Q10 & $\begin{array}{l}\text { What role does commitment play in a } \\
\text { B2B relationship? }\end{array}$ & important & Vital & important & Low priority & important & $\begin{array}{l}\text { Varies on nature } \\
\text { of the relationship }\end{array}$ & huge \\
\hline Q21 & Q11 & $\begin{array}{l}\text { What role does communications quality } \\
\text { play in a B2B relationship? }\end{array}$ & vital & $\begin{array}{l}\text { Prevents } \\
\text { misunderstanding }\end{array}$ & valuable & $\begin{array}{l}\text { Initially very } \\
\text { important }\end{array}$ & essential & $\begin{array}{l}\text { Extremely } \\
\text { important }\end{array}$ & huge \\
\hline Q22 & Q12 & $\begin{array}{l}\text { In your opinion how does CRM } \\
\text { technology affect relationship building } \\
\text { and relationship strength? }\end{array}$ & support role & $\begin{array}{l}\text { Only a tool; does } \\
\text { not create a } \\
\text { relationship }\end{array}$ & continuity & $\begin{array}{l}\text { Standardised } \\
\text { practices; } \\
\text { overcomes } \\
\text { information \& } \\
\text { cultural } \\
\text { boundaries }\end{array}$ & communications & $\begin{array}{l}\text { Only a tool; } \\
\text { enabler }\end{array}$ & support role \\
\hline Q23 & Q13a & $\begin{array}{l}\text { From your perspective what is } \\
\text { relationship performance? }\end{array}$ & $\begin{array}{l}\text { Customer } \\
\text { satisfaction; } \\
\text { maintain } \\
\text { relationship; not } \\
\text { lose a client }\end{array}$ & $\begin{array}{l}\text { Ranking; helps } \\
\text { you grow the } \\
\text { business; } \\
\text { understand the } \\
\text { customer } \\
\text { business }\end{array}$ & $\begin{array}{l}\text { Commitment; } \\
\text { loyalty }\end{array}$ & $\begin{array}{l}\text { Don't know; } \\
\text { Quality of the } \\
\text { relationship } \\
\text { outside the value } \\
\text { add }\end{array}$ & $\begin{array}{l}\text { Nature of the } \\
\text { relationship; More } \\
\text { business; loyalty }\end{array}$ & $\begin{array}{l}\text { Achieving } \\
\text { outcomes that } \\
\text { both parties want; } \\
\text { task related; } \\
\text { interpersonal }\end{array}$ & $\begin{array}{l}\text { Trust level; share } \\
\text { of mind; loyalty }\end{array}$ \\
\hline Q23a & Q13a & $\begin{array}{l}\text { How is relationship performance } \\
\text { generally measured? }\end{array}$ & Not done & Not done & $\begin{array}{l}\text { Measure } \\
\text { commitment; } \\
\text { winning tenders }\end{array}$ & Not done & $\begin{array}{l}\text { Number of unique } \\
\text { contacts per } \\
\text { month }\end{array}$ & $\begin{array}{l}\text { Volumes; } \\
\text { revenues; costs } \\
\text { incurred; quality } \\
\text { of relationship }\end{array}$ & Not done \\
\hline Q25 & Q15 & $\begin{array}{l}\text { Does CRM technology adoption affect } \\
\text { relationship performance? }\end{array}$ & Yes & Enhances & Yes & $\begin{array}{l}\text { Knowledge } \\
\text { transfer; } \\
\text { benchmarking }\end{array}$ & Yes & $\begin{array}{l}\text { Enabler; tool for } \\
\text { face to face sales }\end{array}$ & $\begin{array}{l}\text { only in support } \\
\text { role }\end{array}$ \\
\hline
\end{tabular}




\begin{tabular}{|c|c|c|c|c|c|c|c|c|c|}
\hline Firm & Cust & & F1 & C1 & F2 & C2 & F3 & C3 & F4 \\
\hline $\bar{Q} 26$ & Q16 & Is customer satisfaction important to & Yes & No & Yes & Yes & Yes & Yes & Yes \\
\hline Q26a & Q16a & Your firm? & Yes & No & Yes & Yes & Yes & Yes & Yes \\
\hline Q27 & & Is customer loyalty important to you? & Yes & & Yes & & Yes & & Yes \\
\hline \multirow[t]{3}{*}{ Q27a } & & Your firm? & Yes & & Yes & & Yes & & Yes \\
\hline & Q17 & $\begin{array}{l}\text { Is being loyal to your supplier important } \\
\text { to you? }\end{array}$ & & Yes & & No & & Yes & \\
\hline & Q17a & Your firm? & & Yes & & No & & Yes & \\
\hline Q28 & & Is customer retention important to you? & Yes & & Yes & & Yes & & Yes \\
\hline \multirow[t]{3}{*}{ Q28a } & & Your firm? & Yes & & Yes & & Yes & & Yes \\
\hline & Q18 & $\begin{array}{l}\text { Is staying with the same supplier } \\
\text { important to you? }\end{array}$ & & Yes & & Yes \& No & & Yes & \\
\hline & Q18a & $\begin{array}{l}\text { Do you think customer retention is } \\
\text { important to your supplier? }\end{array}$ & & Yes & & Yes \& No & & Yes & \\
\hline \multirow[t]{3}{*}{ Q29 } & Q23 & $\begin{array}{l}\text { Do you see CRM technology affecting } \\
\text { these elements of a relationship? }\end{array}$ & somewhat & Yes & Yes & $\begin{array}{l}\text { Standards; } \\
\text { organisational } \\
\text { memory; DB } \\
\text { search } \\
\text { capabilities }\end{array}$ & Yes & Enha & somewhat \\
\hline & Q24 & $\begin{array}{l}\text { Do you consider yourself to be } \\
\text { relationship oriented? }\end{array}$ & & Yes & & No & & Yes & \\
\hline & Q24a & Is your firm relationship oriented? & & Yes & & No & & Yes & \\
\hline
\end{tabular}




\begin{tabular}{|c|c|c|c|c|c|c|c|c|}
\hline Firm & Cust & & C4 & F5 & C5 & $\mathrm{C6}$ & F7 & C7 \\
\hline Q4 & Q3 & $\begin{array}{l}\text { What do you think prompted the } \\
\text { company to adopt CRM technology? }\end{array}$ & Keep up-to-date & $\begin{array}{l}\text { customer } \\
\text { conversions; } \\
\text { paper trail }\end{array}$ & $\begin{array}{l}\text { Data capture; } \\
\text { sales churn }\end{array}$ & $\begin{array}{c}\text { time management Improve business } \\
\text { efficiencies }\end{array}$ & $\begin{array}{l}\text { Competitive } \\
\text { advantage }\end{array}$ & $\begin{array}{l}\text { Automate } \\
\text { relationship } \\
\text { managemnt data }\end{array}$ \\
\hline Q5 & & $\begin{array}{l}\text { Do you consider your company to be } \\
\text { market oriented? }\end{array}$ & & Yes & & Yes & Yes & \\
\hline & Q22 & $\begin{array}{l}\text { Do you perceive the supplier firm to be } \\
\text { market oriented? }\end{array}$ & Yes & & No & Yes \& No & & Yes \\
\hline Q5a & & $\begin{array}{l}\text { In your opinion does this orientation have } \\
\text { a bearing on the type and strength of your } \\
\text { B2B customer relationships? }\end{array}$ & & Yes & & Yes & No & \\
\hline Q5b & & $\begin{array}{l}\text { In your opinion does this orientation have } \\
\text { a bearing on the functionality, integration } \\
\text { and acceptance of CRM technology? }\end{array}$ & & No & & No & Yes & \\
\hline Q6 & & $\begin{array}{l}\text { Do you consider your company to be } \\
\text { technology oriented? }\end{array}$ & & Yes & & No & No & \\
\hline Q6a & & $\begin{array}{l}\text { In your opinion does technology } \\
\text { orientation have a bearing on the } \\
\text { functionality, integration and acceptance } \\
\text { of CRM technology within your firm? }\end{array}$ & & No & & No & Yes & \\
\hline Q7 & & $\begin{array}{l}\text { Can you tell me what CRM functions you } \\
\text { have in place? }\end{array}$ & & Yes & & Yes & Yes & \\
\hline Q8 & & $\begin{array}{l}\text { What CRM functions would you like to } \\
\text { have? }\end{array}$ & & known & & known & don't care & \\
\hline Q9 & & $\begin{array}{l}\text { As far as you know what CRM functions } \\
\text { are available? }\end{array}$ & & unkown & & known & known & \\
\hline Q9a & & $\begin{array}{l}\text { What functionality best describes the } \\
\text { CRM technology implemented at your } \\
\text { firm? }\end{array}$ & & $3-5$ & & 2 & 6 & \\
\hline
\end{tabular}




\begin{tabular}{|c|c|c|c|c|c|c|c|c|c|}
\hline Firm & Cust & & C4 & F5 & C5 & F6 & C6 & F7 & C7 \\
\hline Q10 & & $\begin{array}{l}\text { Do you believe CRM technology is } \\
\text { widely used within the company? }\end{array}$ & & $\begin{array}{l}\text { No; sales yes - } \\
\text { reluctently }\end{array}$ & & Yes & & Yes & \\
\hline Q11 & Q21 & $\begin{array}{l}\text { Is the CRM technology widely integrated } \\
\text { with other IT systems (functional areas or } \\
\text { process) within your company? }\end{array}$ & Don't care & No & No & No & Yes & Yes & Don't know \\
\hline Q12 & Q19 & $\begin{array}{l}\text { What are your expectations of CRM } \\
\text { technology? }\end{array}$ & None & $\begin{array}{l}\text { collect \& retrieve } \\
\text { customer info }\end{array}$ & $\begin{array}{l}\text { Account history; } \\
\text { understand what } \\
\text { is important to me }\end{array}$ & $\begin{array}{l}\text { collect \& retrieve } \\
\text { customer info; } \\
\text { efficiencies }\end{array}$ & None & not high & None \\
\hline Q13 & & $\begin{array}{l}\text { What does CRM technology help you do } \\
\text { better? }\end{array}$ & & $\begin{array}{l}\text { knowledge; } \\
\text { customer service }\end{array}$ & & $\begin{array}{l}\text { collect \& retrieve } \\
\text { customer info; } \\
\text { efficiencies }\end{array}$ & & $\begin{array}{l}\text { customer service } \\
\text { queries }\end{array}$ & \\
\hline Q14 & Q20 & $\begin{array}{l}\text { How does CRM technology help initiate, } \\
\text { develop and/or maintain Business-to- } \\
\text { Business (B2B) relationships? }\end{array}$ & $\begin{array}{l}\text { Formalise, timely } \\
\text { respones; good } \\
\text { info }\end{array}$ & a tool & $\begin{array}{l}\text { KMS; customer } \\
\text { management; } \\
\text { coordiantion of } \\
\text { customer data; } \\
\text { availability of } \\
\text { customer data }\end{array}$ & $\begin{array}{l}\text { information } \\
\text { organising tool }\end{array}$ & $\begin{array}{l}\text { Marketing tool; } \\
\text { good info; } \\
\text { tracking }\end{array}$ & No; leads maybe & $\begin{array}{l}\text { Can not initiate; } \\
\text { reactive; } \\
\text { efficiencies; } \\
\text { automated } \\
\text { reminders }\end{array}$ \\
\hline Q15 & Q5 & $\begin{array}{l}\text { What terms would you use to describe } \\
\text { B2B relationships? }\end{array}$ & $\begin{array}{l}\text { Performance; } \\
\text { ethical; honesty; } \\
\text { operations; } \\
\text { records }\end{array}$ & $\begin{array}{l}\text { open; } \\
\text { honest;proactive; } \\
\text { friendly; fun }\end{array}$ & $\begin{array}{l}\text { Appropriate } \\
\text { contact; reliability; } \\
\text { performance; } \\
\text { commitment }\end{array}$ & culture & - & $\begin{array}{l}\text { honest; give and } \\
\text { take }\end{array}$ & $\begin{array}{l}\text { Partnership; give } \\
\text { \& take; honesty; } \\
\text { marriage }\end{array}$ \\
\hline Q16 & Q4 & $\begin{array}{l}\text { What do you consider to be the Key } \\
\text { elements of a B2B relationship? }\end{array}$ & $\begin{array}{l}\text { Understand } \\
\text { requirements; } \\
\text { honesty }\end{array}$ & $\begin{array}{l}\text { trust; } \\
\text { understanding } \\
\text { customer }\end{array}$ & $\begin{array}{l}\text { Understand } \\
\text { customer's } \\
\text { business; what is } \\
\text { critiacl }\end{array}$ & $\begin{array}{l}\text { trust; } \\
\text { communications; } \\
\text { credibility; } \\
\text { flexibility }\end{array}$ & $\begin{array}{l}\text { Information } \\
\text { sharing }\end{array}$ & $\begin{array}{l}\text { trust; } \\
\text { honesty;goodwill;r } \\
\text { eliable; good } \\
\text { handshake }\end{array}$ & $\begin{array}{l}\text { Honesty; } \\
\text { communications }\end{array}$ \\
\hline Q17 & Q7 & $\begin{array}{l}\text { In your opinion what are drivers of a } \\
\text { strong B2B relationship? }\end{array}$ & $\begin{array}{l}\text { Matching of } \\
\text { product } \\
\text { requirements; } \\
\text { honesty; fiduciary; } \\
\text { ethics }\end{array}$ & $\begin{array}{l}\text { knowing \& buying- } \\
\text { in to customer } \\
\text { strategy }\end{array}$ & $\begin{array}{ll}\text { Trust; confidence; } & \text { r } \\
\text { relaibility; } & \text { i } \\
\text { personal } & \text { i } \\
\text { chemistry } & s\end{array}$ & $\begin{array}{l}\text { regular } \\
\text { interaction; } \\
\text { information; } \\
\text { solutions }\end{array}$ & - & trust; reliability & $\begin{array}{l}\text { People; } \\
\text { reputation; gut } \\
\text { feel }\end{array}$ \\
\hline
\end{tabular}




\begin{tabular}{|c|c|c|c|c|c|c|c|c|c|}
\hline Firm & Cust & & $\mathrm{C} 4$ & F5 & C5 & F6 & C6 & F7 & C7 \\
\hline Q19 & Q9 & $\begin{array}{l}\text { What role does trust play in a } \mathrm{B} 2 \mathrm{~B} \\
\text { relationship? }\end{array}$ & $\begin{array}{l}\text { Industry depends } \\
\text { on trust }\end{array}$ & Huge & Critical & critical & Very important & $\begin{array}{l}\text { ultimate selling } \\
\text { tool }\end{array}$ & Very important \\
\hline Q20 & Q10 & $\begin{array}{l}\text { What role does commitment play in a } \\
\text { B2B relationship? }\end{array}$ & $\begin{array}{l}\text { Industry depends } \\
\text { on commitment }\end{array}$ & follows trust & $\begin{array}{l}\text { Helps build trust; } \\
\text { 2-way }\end{array}$ & stability & Very important & $\begin{array}{l}\text { basis for best } \\
\text { result }\end{array}$ & $\begin{array}{l}\text { Delivery; degree } \\
\text { of trust }\end{array}$ \\
\hline Q21 & Q11 & $\begin{array}{l}\text { What role does communications quality } \\
\text { play in a B2B relationship? }\end{array}$ & Reasonably high & huge & $\begin{array}{l}\text { Big role; } \\
\text { necessary; } \\
\text { nothing will } \\
\text { happen without it }\end{array}$ & critical & Extremely high & $\begin{array}{l}\text { understanding; } \\
\text { same songsheet }\end{array}$ & Easier \\
\hline Q22 & Q12 & $\begin{array}{l}\text { In your opinion how does CRM } \\
\text { technology affect relationship building } \\
\text { and relationship strength? }\end{array}$ & $\begin{array}{l}\text { Risk of } \\
\text { depersonalising } \\
\text { relationship }\end{array}$ & & $\begin{array}{l}\text { Add value; } \\
\text { corporate } \\
\text { memory; internal } \\
\text { communications; } \\
\text { can detract from } \\
1: 1 \text { contact }\end{array}$ & $\begin{array}{l}\text { reliability; context; } \\
\text { credibility }\end{array}$ & $\begin{array}{l}\text { Complete history } \\
\text { at hand }\end{array}$ & None & $\begin{array}{l}\text { Operationally; } \\
\text { NOT face-to-face }\end{array}$ \\
\hline Q23 & Q13a & $\begin{array}{l}\text { From your perspective what is } \\
\text { relationship performance? }\end{array}$ & Commitment & $\begin{array}{l}\text { Customer } \\
\text { satisfaction; trust }\end{array}$ & $\begin{array}{l}\text { Customer } \\
\text { satisfaction; } \\
\text { loyalty }\end{array}$ & $\begin{array}{l}\text { Value the } \\
\text { customer places } \\
\text { on the } \\
\text { relationship; } \\
\text { added value }\end{array}$ & $\begin{array}{l}\text { Timely } \\
\text { information; } \\
\text { timely delivery; } \\
\text { customer } \\
\text { satisfaction }\end{array}$ & $\begin{array}{l}\text { How you feel } \\
\text { about the } \\
\text { relationship }\end{array}$ & $\begin{array}{l}\text { Being } \\
\text { professional; } \\
\text { communication }\end{array}$ \\
\hline Q23a & Q13a & $\begin{array}{l}\text { How is relationship performance } \\
\text { generally measured? }\end{array}$ & $\begin{array}{l}\text { Customer } \\
\text { satisfaction }\end{array}$ & Not done & $\begin{array}{l}\text { Sales growth; } \\
\text { complaints }\end{array}$ & $\begin{array}{l}\text { Sales; } \\
\text { profitability; } \\
\text { mutual } \\
\text { relationship } \\
\text { value; keen ness } \\
\text { to renew contract }\end{array}$ & Not done & $\begin{array}{l}\text { Winning the } \\
\text { business }\end{array}$ & Not done \\
\hline Q25 & Q15 & $\begin{array}{l}\text { Does CRM technology adoption affect } \\
\text { relationship performance? }\end{array}$ & $\begin{array}{l}\text { Potential to } \\
\text { improve }\end{array}$ & No & $\begin{array}{l}\text { Highlights issues; } \\
\text { identifies } \\
\text { problems }\end{array}$ & Yes & Timely info & No & Not sure \\
\hline
\end{tabular}




\begin{tabular}{|c|c|c|c|c|c|c|c|c|c|}
\hline Firm & Cust & & C4 & F5 & C5 & F6 & C6 & F7 & C7 \\
\hline Q26 & Q16 & Is customer satisfaction important to & Yes & Yes & Yes & Yes & Yes & Yes & Yes \\
\hline Q26a & Q16a & Your firm? & Yes & Yes & Yes & Yes & Yes & Yes & Yes \\
\hline Q27 & & Is customer loyalty important to you? & & Yes & & Yes & & Yes & \\
\hline Q27a & & Your firm? & & Yes & & No & & Yes & \\
\hline & Q17 & $\begin{array}{l}\text { Is being loyal to your supplier important } \\
\text { to you? }\end{array}$ & No & & Yes & & Yes & & Yes \\
\hline & Q17a & Your firm? & No & & Yes & & Yes & & Yes \\
\hline Q28 & & Is customer retention important to you? & & Yes & & Yes & & Yes & \\
\hline Q28a & & Your firm? & & Yes & & No & & Yes & \\
\hline & Q18 & $\begin{array}{l}\text { Is staying with the same supplier } \\
\text { important to you? }\end{array}$ & No & & Yes & & Yes \& No & & Yes \\
\hline & Q18a & $\begin{array}{l}\text { Do you think customer retention is } \\
\text { important to your supplier? }\end{array}$ & Yes & & Yes & & Yes & & Yes \\
\hline Q29 & Q23 & $\begin{array}{l}\text { Do you see CRM technology affecting } \\
\text { these elements of a relationship? }\end{array}$ & No & part of the mix & Take surprise out & $\begin{array}{l}\text { quality; } \\
\text { timeliness; } \\
\text { consistency }\end{array}$ & Data tool only & retention only & Operationally \\
\hline & Q24 & $\begin{array}{l}\text { Do you consider yourself to be } \\
\text { relationship oriented? }\end{array}$ & Yes & & Yes & & Yes & & Yes \\
\hline & Q24a & Is your firm relationship oriented? & Yes & & Yes & & Yes & & No \\
\hline
\end{tabular}




\begin{tabular}{|c|c|c|c|c|c|c|c|c|}
\hline Firm & Cust & & F8 & $\mathrm{C8}$ & F9 & $\mathrm{Cg}$ & F10 & C10 \\
\hline Q4 & Q3 & $\begin{array}{l}\text { What do you think prompted the } \\
\text { company to adopt CRM technology? }\end{array}$ & $\begin{array}{l}\text { New people from } \\
\text { IT; needed at } \\
\text { sales level }\end{array}$ & Don't know & $\begin{array}{l}\text { Internal focus; } \\
\text { global reporting } \\
\text { tool }\end{array}$ & Don't know & $\begin{array}{l}\text { Competitive } \\
\text { reasons }\end{array}$ & No idea \\
\hline Q5 & & $\begin{array}{l}\text { Do you consider your company to be } \\
\text { market oriented? }\end{array}$ & Yes & & Yes & & Yes & \\
\hline & Q22 & $\begin{array}{l}\text { Do you perceive the supplier firm to be } \\
\text { market oriented? }\end{array}$ & & Yes & & No & & No \\
\hline Q5a & & $\begin{array}{l}\text { In your opinion does this orientation have } \\
\text { a bearing on the type and strength of your } \\
\text { B2B customer relationships? }\end{array}$ & Yes & & Yes & & Yes & \\
\hline Q5b & & $\begin{array}{l}\text { In your opinion does this orientation have } \\
\text { a bearing on the functionality, integration } \\
\text { and acceptance of CRM technology? }\end{array}$ & $\begin{array}{l}\text { Yes - long-term; } \\
\text { No - now }\end{array}$ & & No & & Yes & \\
\hline Q6 & & $\begin{array}{l}\text { Do you consider your company to be } \\
\text { technology oriented? }\end{array}$ & No & & Yes & & Yes & \\
\hline Q6a & & $\begin{array}{l}\text { In your opinion does technology } \\
\text { orientation have a bearing on the } \\
\text { functionality, integration and acceptance } \\
\text { of CRM technology within your firm? }\end{array}$ & Not sure & & Yes & & Yes & \\
\hline Q7 & & $\begin{array}{l}\text { Can you tell me what CRM functions you } \\
\text { have in place? }\end{array}$ & Yes & & Yes & & Yes & \\
\hline Q8 & & $\begin{array}{l}\text { What CRM functions would you like to } \\
\text { have? }\end{array}$ & known & & known & & known & \\
\hline Q9 & & $\begin{array}{l}\text { As far as you know what CRM functions } \\
\text { are available? }\end{array}$ & known & & known & & unkown & \\
\hline Q9a & & $\begin{array}{l}\text { What functionality best describes the } \\
\text { CRM technology implemented at your } \\
\text { firm? }\end{array}$ & $2-3$ & & 5 & & $2+5$ & \\
\hline
\end{tabular}




\begin{tabular}{|c|c|c|c|c|c|c|c|c|}
\hline Firm & Cust & & F8 & C8 & F9 & C9 & F10 & C10 \\
\hline Q10 & & $\begin{array}{l}\text { Do you believe CRM technology is } \\
\text { widely used within the company? }\end{array}$ & No & & $\begin{array}{l}\text { No - within sales, } \\
\text { marketing \& sr. } \\
\text { management only }\end{array}$ & & No & \\
\hline Q11 & Q21 & $\begin{array}{l}\text { Is the CRM technology widely integrated } \\
\text { with other IT systems (functional areas or } \\
\text { process) within your company? }\end{array}$ & No & Don't know & No & No & No & No idea \\
\hline Q12 & Q19 & $\begin{array}{l}\text { What are your expectations of CRM } \\
\text { technology? }\end{array}$ & $\begin{array}{l}\text { don't see full } \\
\text { value }\end{array}$ & None & $\begin{array}{l}\text { efficiencies; not } \\
\text { be a burden }\end{array}$ & None & $\begin{array}{l}\text { service customer } \\
\text { better }\end{array}$ & No \\
\hline Q13 & & $\begin{array}{l}\text { What does CRM technology help you do } \\
\text { better? }\end{array}$ & $\begin{array}{l}\text { sales } \\
\text { management }\end{array}$ & & $\begin{array}{l}\text { sales } \\
\text { process;planning; } \\
\text { information }\end{array}$ & & $\begin{array}{l}\text { information; } \\
\text { analysis }\end{array}$ & \\
\hline Q14 & Q20 & $\begin{array}{l}\text { How does CRM technology help initiate, } \\
\text { develop and/or maintain Business-to- } \\
\text { Business (B2B) relationships? }\end{array}$ & $\begin{array}{l}\text { not much; helps } \\
\text { drive internal } \\
\text { behaviour }\end{array}$ & $\begin{array}{l}\text { Better customer } \\
\text { info; invitations to } \\
\text { events }\end{array}$ & information & $\begin{array}{l}\text { Capture } \\
\text { stakeholder info \& } \\
\text { record; vehicle to } \\
\text { provide process }\end{array}$ & $\begin{array}{l}\text { understand \& } \\
\text { meet customer } \\
\text { needs \& wants }\end{array}$ & $\begin{array}{l}\text { Knowledge; } \\
\text { customer info }\end{array}$ \\
\hline Q15 & Q5 & $\begin{array}{l}\text { What terms would you use to describe } \\
\text { B2B relationships? }\end{array}$ & $\begin{array}{l}\text { trust; mutual } \\
\text { beneficial; ethical; } \\
\text { professional; long- } \\
\text { term; reputation }\end{array}$ & Trust; confidence & $\begin{array}{l}\text { outcomes; } \\
\text { challenging; } \\
\text { rewarding }\end{array}$ & $\begin{array}{l}\text { Trust; value; } \\
\text { contractual; } \\
\text { meeting of minds; } \\
\text { confidence }\end{array}$ & $\begin{array}{l}\text { important; } \\
\text { personal }\end{array}$ & $\begin{array}{l}\text { Customer - } \\
\text { supplier }\end{array}$ \\
\hline Q16 & Q4 & $\begin{array}{l}\text { What do you consider to be the Key } \\
\text { elements of a B2B relationship? }\end{array}$ & $\begin{array}{l}\text { trust; mutual } \\
\text { beneficial }\end{array}$ & $\begin{array}{l}\text { Understand each } \\
\text { other's processes }\end{array}$ & $\begin{array}{l}\text { trust; value add; } \\
\text { mutually } \\
\text { beneficial; } \\
\text { understand goals }\end{array}$ & Don't know & service; advice & Contact; Value \\
\hline Q17 & Q7 & $\begin{array}{l}\text { In your opinion what are drivers of a } \\
\text { strong B2B relationship? }\end{array}$ & $\begin{array}{l}\text { mutual value add; } \\
\text { rapport }\end{array}$ & Don't know & $\begin{array}{l}\text { Face to face time; } \\
\text { delivery; } \\
\text { performance }\end{array}$ & $\begin{array}{l}\text { Evidence of } \\
\text { value; } \\
\text { understanding; } \\
\text { alignment; } \\
\text { outcomes; } \\
\text { cooperate }\end{array}$ & $\begin{array}{l}\text { partnership; } \\
\text { knowledge of } \\
\text { customer } \\
\text { business and } \\
\text { products }\end{array}$ & Increase revenue \\
\hline
\end{tabular}




\begin{tabular}{|c|c|c|c|c|c|c|c|c|}
\hline Firm & Cust & & F8 & C8 & F9 & C9 & F10 & C10 \\
\hline Q19 & Q9 & $\begin{array}{l}\text { What role does trust play in a B2B } \\
\text { relationship? }\end{array}$ & fundamental & $\begin{array}{l}\text { Performance; will } \\
\text { deliver }\end{array}$ & Significant & $\begin{array}{l}\text { Certainty of } \\
\text { supply; info } \\
\text { sharing; quality; } \\
\text { type of } \\
\text { relationship }\end{array}$ & Vital & Required \\
\hline Q20 & Q10 & $\begin{array}{l}\text { What role does commitment play in a } \\
\text { B2B relationship? }\end{array}$ & $\begin{array}{l}\text { important; long- } \\
\text { term }\end{array}$ & $\begin{array}{l}\text { Takes care of } \\
\text { problems }\end{array}$ & Paramount & $\begin{array}{l}\text { Important; } \\
\text { investment in } \\
\text { relationship }\end{array}$ & strong & One-way only \\
\hline Q21 & Q11 & $\begin{array}{l}\text { What role does communications quality } \\
\text { play in a B2B relationship? }\end{array}$ & helps & $\begin{array}{l}\text { Important; need } \\
\text { to understand } \\
\text { each other }\end{array}$ & Very High & $\begin{array}{l}\text { Important; clear } \\
\text { messages; trust; } \\
\text { governance } \\
\text { framework; info } \\
\text { sharing }\end{array}$ & & $\begin{array}{l}\text { Want limited } \\
\text { contact; too sales } \\
\text { focused }\end{array}$ \\
\hline Q22 & Q12 & $\begin{array}{l}\text { In your opinion how does CRM } \\
\text { technology affect relationship building } \\
\text { and relationship strength? }\end{array}$ & $\begin{array}{l}\text { the more you } \\
\text { know the better } \\
\text { the } \\
\text { communications }\end{array}$ & $\begin{array}{l}\text { It can; pushing } \\
\text { sales }\end{array}$ & None & No evidence & Information tool & Yes \\
\hline Q23 & Q13a & $\begin{array}{l}\text { From your perspective what is } \\
\text { relationship performance? }\end{array}$ & $\begin{array}{l}\text { Help each other } \\
\text { achieve goals; } \\
\text { customer } \\
\text { satisfaction }\end{array}$ & $\begin{array}{l}\text { Acknowledging } \\
\text { and } \\
\text { understanding } \\
\text { their role with the } \\
\text { customer }\end{array}$ & $\begin{array}{l}\text { Score card; Trust, } \\
\text { commitment, } \\
\text { delivery, value, } \\
\text { ongoing } \\
\text { contribution }\end{array}$ & $\begin{array}{l}\text { Realising value } \\
\text { proposition of } \\
\text { both parties; } \\
\text { confidence; trust }\end{array}$ & $\begin{array}{l}\text { Successful } \\
\text { partnering; } \\
\text { provide } \\
\text { solutions/tools to } \\
\text { customer to help } \\
\text { meet their goals }\end{array}$ & Sales \\
\hline Q23a & Q13a & $\begin{array}{l}\text { How is relationship performance } \\
\text { generally measured? }\end{array}$ & Not done & $\begin{array}{l}\text { Service level } \\
\text { agreements }\end{array}$ & Surveys & $\begin{array}{l}\text { Performance; } \\
\text { communications }\end{array}$ & $\begin{array}{l}\text { Subjectively; how } \\
\text { the customer } \\
\text { feels or thinks }\end{array}$ & Sales volume \\
\hline Q25 & Q15 & $\begin{array}{l}\text { Does CRM technology adoption affect } \\
\text { relationship performance? }\end{array}$ & Yes & Yes & Yes & \multicolumn{2}{|c|}{$\begin{array}{l}\text { No evidence; help Yes } \\
\text { measure value }\end{array}$} & Yes \\
\hline
\end{tabular}




\begin{tabular}{|c|c|c|c|c|c|c|c|c|}
\hline Firm & Cust & & F8 & C8 & F9 & C9 & F10 & C10 \\
\hline Q26 & Q16 & Is customer satisfaction important to & Yes & Yes & Yes & Yes & Yes & Yes \\
\hline Q26a & Q16a & Your firm? & Yes & Yes & Yes & Yes & Yes & Yes \\
\hline Q27 & & Is customer loyalty important to you? & Yes & & Yes & & Yes & \\
\hline \multirow[t]{3}{*}{ Q27a } & & Your firm? & Yes & & Yes & & Yes & \\
\hline & Q17 & $\begin{array}{l}\text { Is being loyal to your supplier important } \\
\text { to you? }\end{array}$ & & Yes & & Somewhat & & No \\
\hline & Q17a & Your firm? & & No & & Somewhat & & No \\
\hline Q28 & & Is customer retention important to you? & Yes & & Yes & & Yes & \\
\hline \multirow[t]{3}{*}{ Q28a } & & Your firm? & Yes & & Yes & & Yes & \\
\hline & Q18 & $\begin{array}{l}\text { Is staying with the same supplier } \\
\text { important to you? }\end{array}$ & & No & & No & & $\begin{array}{l}\text { Can't be bothered } \\
\text { to change }\end{array}$ \\
\hline & Q18a & $\begin{array}{l}\text { Do you think customer retention is } \\
\text { important to your supplier? }\end{array}$ & & Yes & & Yes & & No \\
\hline \multirow[t]{3}{*}{ Q29 } & Q23 & $\begin{array}{l}\text { Do you see CRM technology affecting } \\
\text { these elements of a relationship? }\end{array}$ & critical & $\begin{array}{l}\text { Performance; will } \\
\text { deliver }\end{array}$ & not strong & $\begin{array}{l}\text { Tracking common } \\
\text { issues; a tool }\end{array}$ & Strongly & No \\
\hline & Q24 & $\begin{array}{l}\text { Do you consider yourself to be } \\
\text { relationship oriented? }\end{array}$ & & Yes & & Yes & & No \\
\hline & Q24a & Is your firm relationship oriented? & & Yes & & No & & No \\
\hline
\end{tabular}


Table A2.2: Summary of CRM Technical Functionality Provided

\begin{tabular}{|c|c|c|c|c|c|c|c|c|c|c|c|c|c|}
\hline & ষ্ঠু & ষ্ঠ & 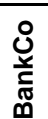 & 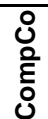 & $\frac{0}{0}$ & $\sum_{u}^{U}$ & $\sum_{m}^{\infty}$ & 巳ั & $\begin{array}{l}\stackrel{O}{\frac{\pi}{\pi}} \\
\sum_{\Sigma}^{\pi}\end{array}$ & 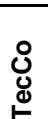 & Total & Rank & $\begin{array}{c}\text { Degree } \\
\text { of CRM } \\
\text { Use }\end{array}$ \\
\hline Provides relevant information & 1 & 1 & 1 & 1 & 1 & 1 & 1 & 1 & 1 & 1 & 10 & 1 & \multirow{5}{*}{$\begin{array}{l}\text { High } \\
\text { use }\end{array}$} \\
\hline Contact management & 1 & 1 & 1 & 1 & 1 & & 1 & 1 & 1 & 1 & 9 & 2 & \\
\hline Data collection & 1 & 1 & 1 & 1 & 1 & 1 & 1 & 1 & & 1 & 9 & 2 & \\
\hline Manual recording & 1 & & 1 & 1 & 1 & 1 & 1 & 1 & 1 & 1 & 9 & 2 & \\
\hline Sales management & 1 & 1 & 1 & 1 & 1 & 1 & & 1 & 1 & 1 & 9 & 2 & \\
\hline Campaign management & 1 & 1 & & 1 & 1 & & 1 & 1 & 1 & & 7 & 6 & \multirow{10}{*}{$\begin{array}{c}\text { Medium } \\
\text { use }\end{array}$} \\
\hline Collaborative communication & 1 & 1 & & 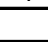 & 1 & 1 & & 1 & 1 & & 6 & 7 & \\
\hline Manual customer surveys & 1 & 1 & 1 & 1 & 1 & & 1 & & & & 6 & 7 & \\
\hline Ad hoc queries & 1 & 1 & 1 & 1 & & 1 & & & & & 5 & 9 & \\
\hline Analytics & 1 & 1 & 1 & 1 & 1 & & & & & & 5 & 9 & \\
\hline Forecast demand & 1 & 1 & 1 & 1 & & & & 1 & & & 5 & 9 & \\
\hline Lead distribution & 1 & 1 & 1 & & 1 & & 1 & & & & 5 & 9 & \\
\hline Data Mining & 1 & 1 & 1 & & & 1 & & & & & 4 & 13 & \\
\hline Derives customer value & 1 & & 1 & 1 & & 1 & & & & & 4 & 13 & \\
\hline Measures customer loyalty & 1 & & 1 & 1 & & 1 & & & & & 4 & 13 & \\
\hline Call centre integration & 1 & & 1 & & & & 1 & & & & 3 & 16 & \multirow{12}{*}{ Low use } \\
\hline Churn analysis & 1 & 1 & 1 & & & & & & & & 3 & 16 & \\
\hline Customer retention rates & 1 & 1 & 1 & & & & & & & & 3 & 16 & \\
\hline Handles multi-channel & 1 & 1 & & 1 & & & & & & & 3 & 16 & \\
\hline Marketing automation & 1 & 1 & 1 & & & & & & & & 3 & 16 & \\
\hline Propensity scoring & 1 & 1 & 1 & & & & & & & & 3 & 16 & \\
\hline Sales automation & 1 & 1 & & 1 & & & & & & & 3 & 16 & \\
\hline Web-based self-service & & 1 & 1 & & & & 1 & & & & 3 & 16 & \\
\hline Customer self-service & 0.5 & 1 & 1 & & & & & & & & 2.5 & 24 & \\
\hline Calculates customer lifetime value & 1 & & 1 & & & & & & & & 2 & 25 & \\
\hline Synchronises customer interactions & 1 & 1 & & & & & & & & & 2 & 25 & \\
\hline Other, please describe: & & & & & & & & & & & 0 & 27 & \\
\hline Total & 24.5 & 21 & 21 & 14 & 10 & 9 & 9 & 8 & 6 & 5 & 128 & & \\
\hline Rank & 1 & 2 & 2 & 4 & 5 & 6 & 6 & 8 & 9 & 10 & & & \\
\hline Degree of CRM funtionality & \multicolumn{3}{|c|}{ High } & \multicolumn{4}{|c|}{ Medium } & \multicolumn{3}{|c|}{ Low } & & & \\
\hline
\end{tabular}

Note: Full functionality $=1$; Partial functionality $=0.5$; No functionality reported $=$ blank

Table A2.3: Summary of CRM Functionality Implemented

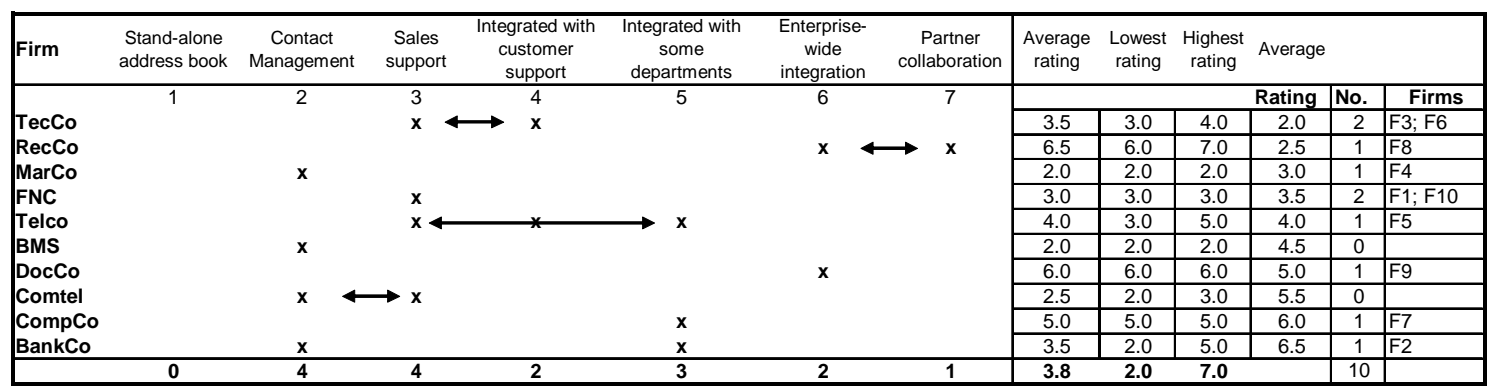

Summary of Question 9a - What functionality best describes the CRM technology implemented at your firm? 
Table A2.4: CRM Integration Rating and Relationship Impact

\begin{tabular}{|l|c|c|c|}
\hline \multicolumn{1}{|c|}{ Firm } & $\begin{array}{c}\text { Integration } \\
\text { rating }\end{array}$ & $\begin{array}{c}\text { Relationship } \\
\text { Strength }\end{array}$ & $\begin{array}{c}\text { Relationship } \\
\text { Performance }\end{array}$ \\
\hline TecCo & 3.5 & Enabler & Positive \\
\hline RecCo & 6.5 & KMS & Positive \\
\hline MarCo & 2.0 & KMS & Positive \\
\hline FNC & 3.0 & Enabler & Enabler \\
\hline Telco & 4.0 & No effect & Enabler \\
\hline BMS & 2.0 & Enabler & Positive \\
\hline DocCo & 6.0 & No effect & No effect \\
\hline Comtel & 2.5 & Enabler & Positive \\
\hline CompCo & 5.0 & No effect & Positive \\
\hline BankCo & 3.5 & KMS & Positive \\
\hline
\end{tabular}

Table A2.5: Market Orientation Influence on CRM Technology Adoption

\begin{tabular}{|c|c|c|c|c|c|c|}
\hline \multicolumn{3}{|c|}{ Supplier perspective } & \multirow{2}{*}{$\begin{array}{c}\text { CRM } \\
\text { adoption }\end{array}$} & \multirow{2}{*}{$\begin{array}{c}\text { CRM } \\
\text { functionality }\end{array}$} & \multirow[b]{2}{*}{ CRM use } & \multirow[b]{2}{*}{ Comment } \\
\hline Firm & Industry & MO & & & & \\
\hline F1 & Computer services & $\mathrm{Y}$ & \begin{tabular}{|l|} 
Positive \\
\end{tabular} & Low & High & Right product MO \& ITMO driven \\
\hline $\mathrm{F} 2$ & Recruitment & $\mathrm{Y}$ & Positive & High & High & Leverage info for sales, MO focused \\
\hline F3 & Marketing analytics & $\bar{Y}$ & Positive & Low & High & KMS use, ITMO focused \\
\hline F6 & Sales Agency & $\bar{Y}$ & Positive & Med & High & Promise fulfilment - MO \\
\hline F7 & Document Services & $\mathrm{Y}$ & Positive & High & Med & Competitive advantage, MO driven \\
\hline F10 & Financial services & $\mathrm{Y}$ & Positive & High & High & Competitive advantage, MO driven \\
\hline F4 & Financial Investment & $\mathrm{Y}$ & Negative & Med & Low & MO driven \\
\hline F5 & Telecommunications & $\mathrm{Y}$ & Negative & Med & Low & Management decision, ITMO driven \\
\hline F9 & Computer consultants & $\mathrm{Y}$ & Negative & Med & Low & Global reporting tool, ITMO driven \\
\hline F8 & Telecommunications & $\mathrm{Y}$ & Both & Low & Low & IT sales people, ITMO driven \\
\hline
\end{tabular}

The following table summarises the customer's view of the supplier market orientation

\begin{tabular}{|c|c|c|c|c|c|}
\hline \multicolumn{2}{|c|}{ Customer perspective } & \multirow{2}{*}{$\begin{array}{l}\text { Customer } \\
\text { MO rating }\end{array}$} & \multirow{2}{*}{$\begin{array}{c}\text { CRM } \\
\text { adoption }\end{array}$} & \multirow{2}{*}{$\begin{array}{c}\text { functiona } \\
\text { lity }\end{array}$} & \multirow[b]{2}{*}{ CRM use } \\
\hline Firm & Industry & & & & \\
\hline F5 & Telecommunications & \begin{tabular}{|c|}
$\mathrm{N}$ \\
\end{tabular} & Negative & Med & Low \\
\hline F9 & Computer consultants & $\mathrm{N}$ & Negative & Med & Low \\
\hline F6 & Sales Agency & $\mathrm{N}$ & Positive & Med & High \\
\hline F10 & Financial services & $\mathrm{N}$ & Positive & High & High \\
\hline F8 & Telecommunications & $\mathrm{Y}$ & Both & Low & Low \\
\hline $\mathrm{F} 4$ & Financial Investment & $\mathrm{Y}$ & Negative & Med & Low \\
\hline F1 & Computer services & $\mathrm{Y}$ & Positive & Low & High \\
\hline $\mathrm{F} 2$ & Recruitment & $\mathrm{Y}$ & Positive & High & High \\
\hline F3 & Marketing analytics & $\mathrm{Y}$ & Positive & Low & High \\
\hline F7 & Document Services & $\mathrm{Y}$ & Positive & High & Med \\
\hline
\end{tabular}

Although suppliers consider themselves MO, they have different views as to its affect on CRM technology adoption. The majority believes MO affects CRM technology adoption positively. Those that believe MO does little to affect CRM technology adoption demonstrate the lowest CRM use, even though the CRM functionality is medium. High, medium or low functionality does not appear affected by 
a perceived positive effect of MO on CRM technology adoption, yet usage appears to be greater.

Table A2.6: IT Management Orientation Influence on CRM Adoption

\begin{tabular}{|c|c|c|c|c|c|c|}
\hline & & & & & & \multirow[b]{2}{*}{ Comment } \\
\hline & $\begin{array}{c}\text { CRM } \\
\text { adoption }\end{array}$ & $\begin{array}{c}\text { CRM } \\
\text { functionality }\end{array}$ & $\begin{array}{l}\text { CRM } \\
\text { use }\end{array}$ & \\
\hline F10 & Financial services & $\mathrm{Y}$ & Positive & High & High & ITMO and MO driven - strategid \\
\hline F9 & Computer consultants & $\bar{Y}$ & Positive & Med & Low & ITMO driven - low usage \\
\hline F1 & Computer services & $\mathrm{Y}$ & Positive & Low & High & More ITMO driven \\
\hline F3 & Marketing analytics & $\mathrm{Y}$ & Positive & Low & High & ITMO focused \\
\hline F5 & Telecommunications & $\mathrm{Y}$ & Negative & Med & Low & ITMO driven - low usage \\
\hline $\mathrm{F} 4$ & Financial Investment & $\mathrm{N}$ & Positive & Med & Low & MO driven \\
\hline F6 & Sales Agency & $\mathrm{N}$ & Negative & Med & High & MO driven \\
\hline F7 & Document Services & $\mathrm{N}$ & Positive & High & Med & MO driven \\
\hline $\mathrm{F} 8$ & Telecommunications & $\mathrm{N}$ & Uncertain & Low & Low & ITMO driven \\
\hline $\mathrm{F} 2$ & Recruitment & Uncertain & Uncertain & High & High & MO focused \\
\hline
\end{tabular}

Five firms view themselves as ITMO, four do not consider their firms ITMO and one is unsure. From this sample there are mixed results as to the potential effect of ITMO on CRM adoption. If we ignore F10 as being a unique hybrid, the remaining four ITMO firms show a distinct variance between CRM usage, whereas the four firms that do not consider themselves ITMO have a distribution of CRM usage. The CRM functionality also denotes a similar pattern. This indicates that ITMO may play a role in the functionality adopted and used. 


\section{Appendix A3: Scale Construction}

\section{Table A3.1: Supplier Questionnaire Construction}

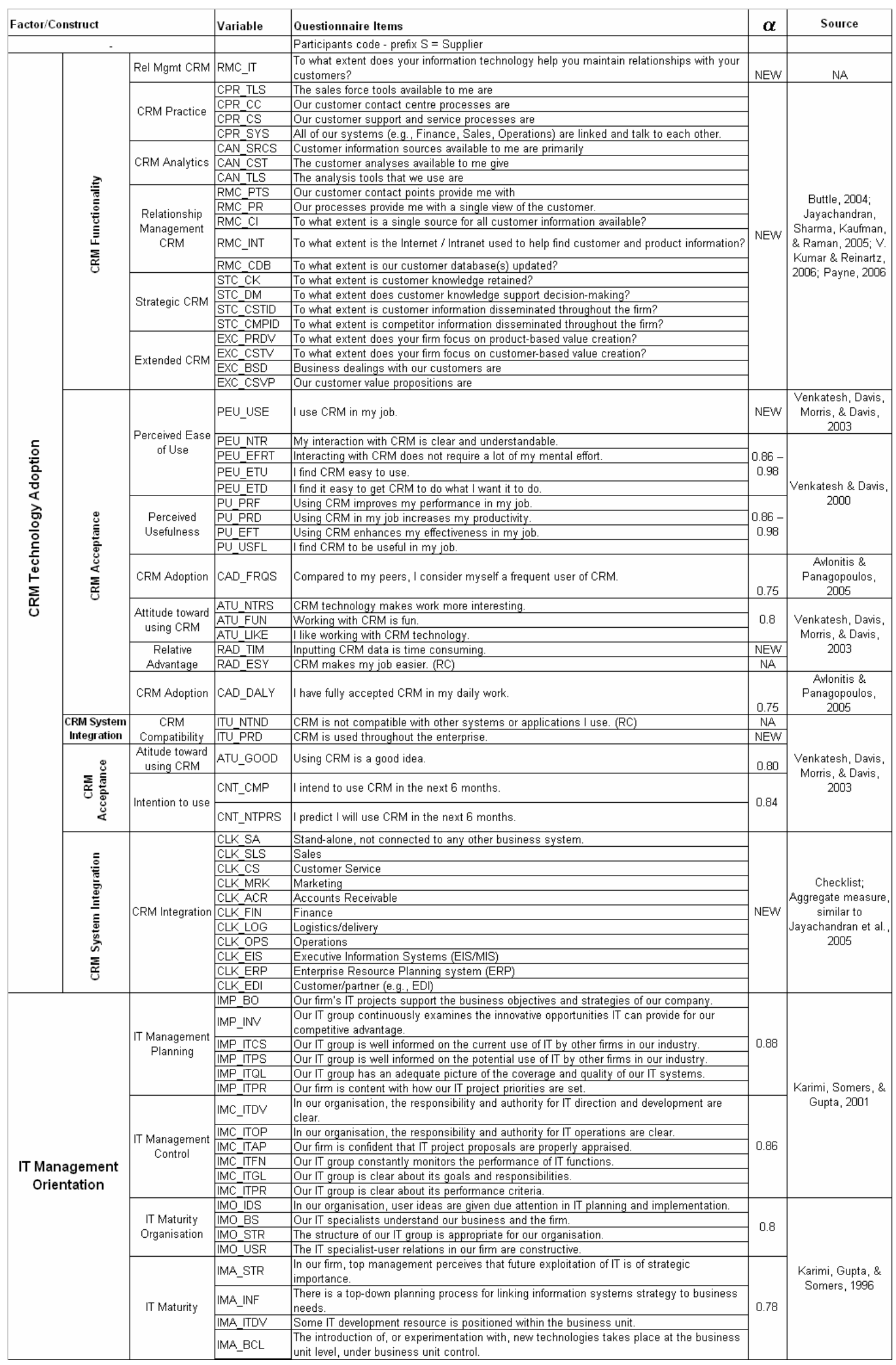


Supplier Questionnaire (cont'd)

\begin{tabular}{|c|c|c|c|c|c|c|}
\hline \multicolumn{3}{|c|}{ Factor/Construct } & Variable & Questionnaire Items & $\alpha$ & Source \\
\hline \multirow{10}{*}{\multicolumn{3}{|c|}{ Market Orientation }} & MO_FN & All our functions (not just marketing and sales) are responsive to serving target markets. & \multirow{10}{*}{0.92} & \multirow{10}{*}{$\begin{array}{l}\text { Pelham \& Wilson, } \\
\qquad 1996\end{array}$} \\
\hline & & & MO_INT & All our functions are integrated in serving target markets. & & \\
\hline & & & MO_CSND & $\begin{array}{l}\text { Our firm's strategy for competitive advantage is based on a thorough understanding of our } \\
\text { customer needs. }\end{array}$ & & \\
\hline & & & MO_CSTV & $\begin{array}{l}\text { All our managers understand how the entire business can contribute to creating customer } \\
\text { value. }\end{array}$ & & \\
\hline & & & MO_CMM & $\begin{array}{l}\text { Information on customers, marketing success, and marketing failures is communicated } \\
\text { across the firm. }\end{array}$ & & \\
\hline & & & MO_RSP & $\begin{array}{l}\text { If a major competitor were to launch an intensive campaign targeted at our customers, we } \\
\text { would implement a response immediately. }\end{array}$ & & \\
\hline & & & MO_CR8VL & $\begin{array}{l}\text { Our firm's market strategies are to a great extent driven by our understanding of } \\
\text { possibilities for creating value for customers. }\end{array}$ & & \\
\hline & & & MO_RSPQ & $\begin{array}{l}\text { Our firm responds quickly to negative customer satisfaction wherever it may occur in the } \\
\text { organisation. }\end{array}$ & & \\
\hline & & & MO_SW & Senior managers frequently discuss competitive strengths and weaknesses. & & \\
\hline & & & MO_CMPW & $\begin{array}{l}\text { We frequently leverage targeted opportunities to take advantage of competitor's } \\
\text { weaknesses. }\end{array}$ & & \\
\hline Rel'n Per & Relations & iip Satisfaction & RS_RL & Our business relationship with this customer is strong. & NEW & \\
\hline \multirow{26}{*}{ 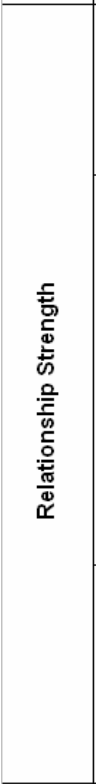 } & \multirow{6}{*}{$\stackrel{\underline{\underline{m}}}{\underline{E}}$} & \multirow{3}{*}{ Goodwill Trust } & GWT_SCR & This customer has made sacrifices for us in the past. & \multirow{3}{*}{0.76} & \multirow{6}{*}{ Ganesan, 1994} \\
\hline & & & GWT WLF & This customer cares for my firm's welfare. & & \\
\hline & & & GWT_PRB & In times of delivery problems, this customer has been very understanding. & & \\
\hline & & Contractual & CNT_FRK & This customer has been frank in dealing with us. & \multirow{3}{*}{0.8} & \\
\hline & & & CNT_PRMS & Promises made by this customer are reliable. & & \\
\hline & & $\begin{array}{l}\text { Competence } \\
\text { Trust }\end{array}$ & CMT_KNW & This customer is knowledgeable about the product. & & \\
\hline & \multirow{11}{*}{ 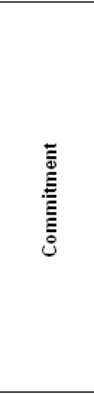 } & & AFC_DRP & $\begin{array}{l}\text { Even if we could, we would not drop this customer because we like being associated with } \\
\text { them. }\end{array}$ & & \\
\hline & & Commitment & AFC_ENJ & We want to keep this customer because we genuinely enjoy our relationship with them. & 0.82 & \\
\hline & & & AFC_FLN & $\begin{array}{l}\text { Our positive feelings towards this customer are a major reason we continue working with } \\
\text { them. }\end{array}$ & & \\
\hline & & Expectation of & EOC_TIM & We expect our relationship with this customer to continue for a long time. & & \\
\hline & & Continuity & \begin{tabular}{|l} 
EOC_AT \\
EOC_BS
\end{tabular} & $\begin{array}{l}\text { The renewal of our relationship with this customer is virtually automatic. } \\
\text { It is unlikely our firm will still be doing business with this customer in two years. (RC) }\end{array}$ & & \& Steenkamp, 1995 \\
\hline & & & WTI_SPRT & $\begin{array}{l}\text { If the customer requested it, we would be willing to make further investment in supporting } \\
\text { this customer. }\end{array}$ & 0.82 & \\
\hline & & $\begin{array}{l}\text { Willingness to } \\
\text { Invest }\end{array}$ & WTI_EFRT & $\begin{array}{l}\text { We are willing to put more effort and investment into building our business with this } \\
\text { customer. }\end{array}$ & & \\
\hline & & & WTL_CSCT & If asked we would go so far as to work with this customer's customer. & & \\
\hline & & & CLC_BRK & It would be difficult to break this relationship. & & \\
\hline & & Commitment & CLC_NLT & There are no worthwhile alternative customers. (RC) & 0.87 & Gounaris, 2005 \\
\hline & & & CLC_CST & There is a high cost to drop this customer. & & \\
\hline & & & CM_EVNT & We keep each other informed about events that affect each other. & & \\
\hline & & Communication & CM_NFML & We often exchange information informally. & 0.83 & 1i \& Dant 1997 \\
\hline & & Corminumication & CM_RQ & We often exchange information beyond what is required by our formal agreements. & 0.05 & 다 \& Dant, 1996 \\
\hline & $\bar{E}$ & & CM_HLP & We provide each other with information that may be of help. & & \\
\hline & 垔 & & CME_TIM & Please indicate the nature of your communication with this customer - Time & & \\
\hline & $\bar{z}$ & & CME_ACC & Please indicate the nature of your communication with this customer - Accurate & & \\
\hline & & Communication & CME_ADQ & Please indicate the nature of your communication with this customer - Adequate & 0.92 & Mohr \& Sohi, 1995 \\
\hline & & & CME_CPLT & Please indicate the nature of your communication with this customer - Complete & & \\
\hline & & & CME_CRD & Please indicate the nature of your communication with this customer - Credible & & \\
\hline & & & PR_PRD & Our relationship with them has been productive. & & \\
\hline & & formance & PR_WRTH & The time and effort invested in the relationship with them has been worthwhile. & 0.90 & Li \& Dant, 1997 \\
\hline$\frac{\mathrm{L}}{\sigma}$ & & & PR_ST & The relationship with them has been satisfactory. & & \\
\hline & & & RS_HPY & The relationship between my company and this customer reflects a happy situation. & & \\
\hline & Relations & hip Satisfaction & RS_PS & The relationship between the two companies is very positive. & 0.95 & Andaleeb, 1996 \\
\hline 盇 & & & RS_ST & My company is very satisfied with this customer. & & \\
\hline 0 & & & LY_SYPS & I say positive things about this customer to others. & & \\
\hline 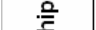 & Custc & mer Lovalty & LY_PR & I encourage others to purchase from this customer. & 0.94 & Zeithaml, Berry, \& \\
\hline$\frac{5}{\omega}$ & Custe & mer Loyanty & LY RCD & I would recommend this customer to someone who seeks my advice. & 0.94 & Parasuraman, 1996 \\
\hline ธ & & & LYXXPT & We expect to do more business with this customer in the next few years. & & \\
\hline 䒕 & & & RN_HIR & In general our customer retention rate is higher than our competitors'. & NA & \\
\hline$\stackrel{\bar{\Phi}}{\widetilde{\alpha}}$ & Custor & ier Retention & RN_NCR & $\begin{array}{l}\text { Since we have implemented CRM our customer retention rate has increased compared to } \\
\text { our major competitor. }\end{array}$ & NEW & \& Chow, 2002 \\
\hline & & & $\pi$ TCHG & The technology in our industry is changing rapidly. & & \\
\hline & & & $\pi$ TIOPP & Technology changes provide big opportunities in our industry. & & Jaworski \& Kohli, \\
\hline Tech & nology $t$ & Jrbulence & TT_BRKT & $\begin{array}{l}\text { Many new product ideas have been made possible through technological breakthroughs in } \\
\text { our industry. }\end{array}$ & 0.84 & $\begin{array}{l}\text { 1993; Moorman \& } \\
\text { Miner, } 1997\end{array}$ \\
\hline & & & $\pi$ TIMINR & Technological developments in our industry are rather minor. (RC) & & \\
\hline & & & MT_CHG & In our kind of business, customers' product preferences change quite a bit over time. & & \\
\hline & & & MT_NPD & Our customers tend to look for new products all the time. & & \\
\hline Mar & keting tu & bulence & MT_CDM & $\begin{array}{l}\text { We are witnessing demand for our products and services from customers who never bought } \\
\text { them before. }\end{array}$ & $0.68-$ & $\begin{array}{l}\text { Jaworski \& Kohli, } \\
\text { 1993; Moorman \& }\end{array}$ \\
\hline & & & MT_NDM & $\begin{array}{l}\text { New customers tend to have product-related needs that are different from those of our } \\
\text { existing customers. }\end{array}$ & & \\
\hline & & & MT_MRKT & The nature of the market has changed significantly over the last few years. & & \\
\hline & & & GENDER & Your gender: 1 = Male; 2 = Female & & \\
\hline & & & INDUSTRY & $\begin{array}{l}\text { Type of industry in which your firm is involved: } 1=\text { Manufacturing; } 2=\text { Wholesale; } 3= \\
\text { Services; } 4=\text { Other }\end{array}$ & & \\
\hline & & & GR_REV & $\begin{array}{l}\text { Your firm's annual gross revenues: } 1=\langle \$ 1 \mathrm{M} ; 2=\$ 1-\$ 10 \mathrm{M} ; 3=\$ 11-50 \mathrm{M} ; 4=\$ 51-\$ 100 \mathrm{M} ; \\
5=>\$ 100 \mathrm{M}\end{array}$ & & \\
\hline & & & EMPLOYEES & Number of employees in your company: $1=<19 ; 2=20-49 ; 3=50-99 ; 4=100+$ & & \\
\hline Demo & graphic & nformation & RELN_LGTH & Length of relationship with the nominated customer: & & NA \\
\hline & & & WORK_EXP & $\begin{array}{l}\text { Your full-time working experience: } 1=<5 y \mathrm{ys} ; 2=5-10 \mathrm{yrs} ; 3=11-15 \mathrm{yrs} ; 4=16-20 \mathrm{yrs} ; 5= \\
>20 \mathrm{yrs}\end{array}$ & & \\
\hline & & & EDUC_LVL & $\begin{array}{l}\text { Your education level: } 1=\text { None; } 2=\text { School cert; } 3=\text { Some tertiary; } 4=\text { Tertiary; } 5=\text { Post } \\
\text { grad; } 6=\text { Other }\end{array}$ & & \\
\hline & & & AGE & Your age: $1=<26 \mathrm{yrs} ; 2=26-35 \mathrm{yrs} ; 3=36-45 \mathrm{yrs} ; 4=46-55 \mathrm{yrs} ; 5=>55 \mathrm{yrs}$ & & \\
\hline & & & TITLE & Your position or title (text) & & \\
\hline & Dummy V: & riable & CRI LINKS & CRM Linkages - aggregate of the CRM Integration scores & & NA \\
\hline
\end{tabular}


Table A3.2: Customer Questionnaire Construction

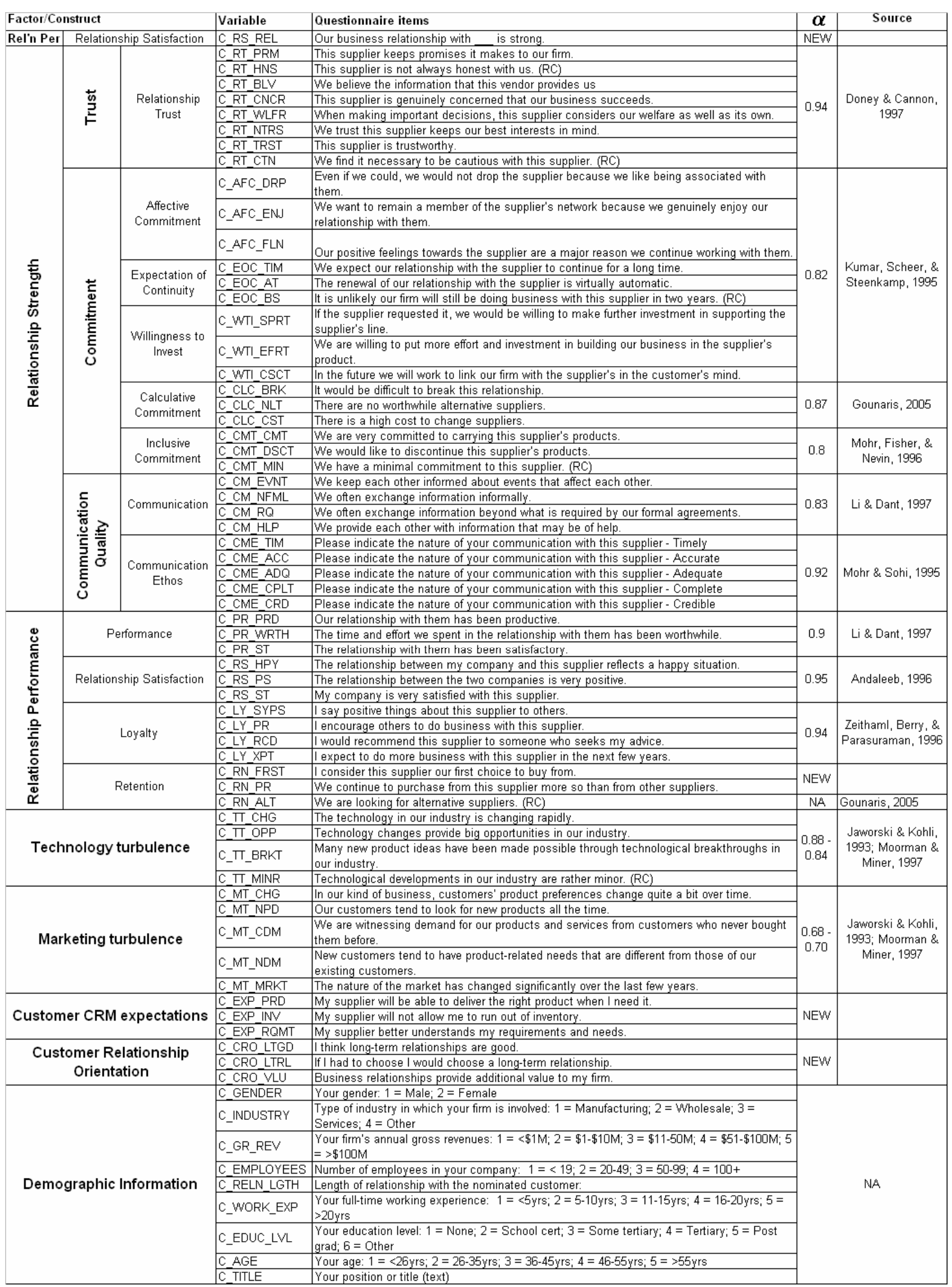




\section{Appendix A4: Copies of Survey Questionnaires}

\section{Supplier Questionnaire}

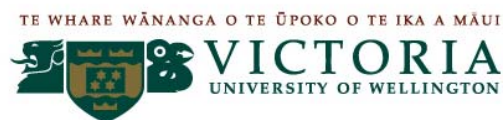

\begin{tabular}{|c|}
\hline Customer Relationship Management (CRM) \\
Technology Impact on Business Relationships \\
A New Zealand industry-wide study \\
Supplier Questionnaire \\
September 2006
\end{tabular}

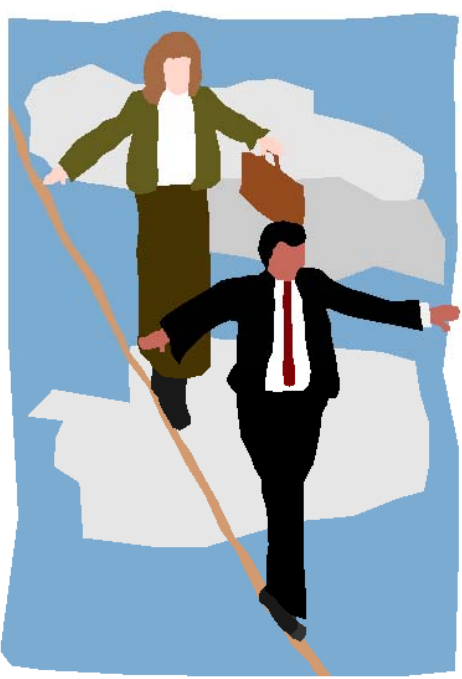

Balancing technology and relationships
This survey is being conducted in order to better understand the link between customer relationship management (CRM) technology use and customer relationships. The results of this study will be used to help businesses better understand the adoption and use of CRM technology in sustaining and maintaining customer relationships.

Please answer all of the questions as accurately as you can. There are no right or wrong answers. It is your opinions and understanding that are important. If you wish to comment on any questions or qualify your answers, please feel free to use the space in the margins. Your comments will be read and taken into account.

For this study, CRM technology is considered to be any manual or automated information tool, process or application that aids in the management of customers, customer relationships or customer information. This could be as simple as a Rolodex card file or as sophisticated as integrated enterprise databases and applications.

Thank you for your help.

James E. Richard

$\mathrm{PhD}$ candidate

School of Marketing and International Business

Victoria University of Wellington

PO Box 600, Wellington, New Zealand

Ph: (04) 4635415

Fax (04) 4635231 


\section{Section A: Customer relationship management in your firm}

For this study CRM technology is considered to be any information tool, process or application that aids in the management of customers, customer relationships or customer information.

It is your opinion that is important to this study. Please circle one number on each line which best represents your view.

To what extent does your information technology help you maintain relationships with your customers?

The sales force tools available to me are

Our customer contact centre processes are

Our customer support and service processes are

All of our systems (e.g., Finance, Sales, Operations) are linked and talk to each other.

Customer information sources available to me are primarily

The customer analyses available to me give

The analysis tools that we use are

Our customer contact points provide me with

Our processes provide me with a single view of the customer.

To what extent is a single source for all customer information available?

To what extent is the Internet / Intranet used to help find customer and product information?

To what extent is our customer database(s) updated?

To what extent is customer knowledge retained?

To what extent does customer knowledge support decisionmaking?

To what extent is customer information disseminated throughout the firm?

To what extent is competitor information disseminated throughout the firm?

To what extent does your firm focus on product-based value creation?

To what extent does your firm focus on customer-based value creation?

Business dealings with our customers are

Our customer value propositions are

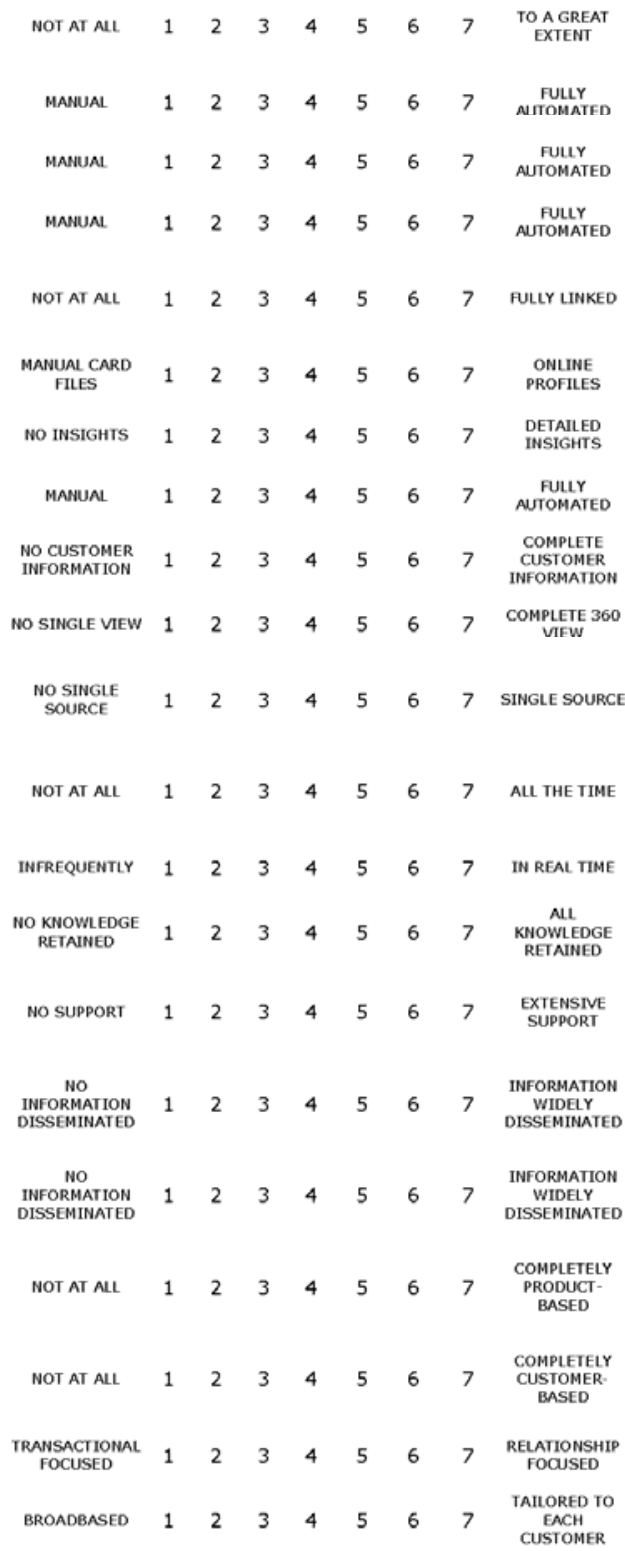


This section explores your use of customer relationship management technology (CRM) in your current position. CRM technology is considered to be any information tool, process or application that aids in the management of customers, customer relationships or customer information.

Please circle the extent you agree with each statement.

I use CRM in my job.

If you answered 'NEVER' to the above statement, follow the RED arrow;

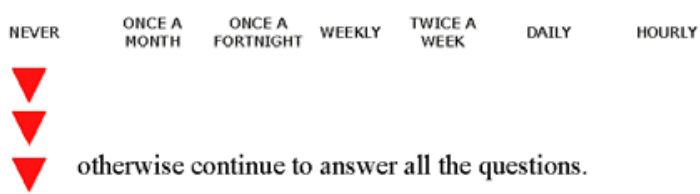

My interaction with CRM is clear and understandable.

Interacting with CRM does not require a lot of my mental effort.

I find CRM easy to use.

I find it easy to get CRM to do what I want it to do.

Using CRM improves my performance in my job.

Using CRM in my job increases my productivity.

Using CRM enhances my effectiveness in my job.

I find CRM to be useful in my job.

Compared to my peers, I consider myself a frequent user of CRM.

CRM technology makes work more interesting.

Working with CRM is fun.

I like working with CRM technology.

Inputting CRM data is time consuming.

CRM makes my job easier.

I have fully accepted CRM in my daily work.

CRM is not compatible with other systems or applications I use.

CRM is used throughout the enterprise.

Using CRM is a good idea.

I intend to use CRM in the next 6 months.

I predict I will use CRM in the next 6 months.

\begin{tabular}{|c|c|c|c|c|c|c|}
\hline $\begin{array}{l}\text { STRONGIY } \\
\text { DISAGREE }\end{array}$ & $\begin{array}{c}\text { MODERATELY } \\
\text { DISAGREE }\end{array}$ & $\begin{array}{l}\text { SUGHTIY } \\
\text { DISAGREEE }\end{array}$ & NEUTRAL & $\begin{array}{l}\text { SUGHTLY } \\
\text { AGREE }\end{array}$ & $\begin{array}{l}\text { MODERATELY } \\
\text { AGREE }\end{array}$ & $\begin{array}{c}\text { STRONGLY } \\
\text { AGREE }\end{array}$ \\
\hline $\begin{array}{l}\text { STRONGIY } \\
\text { DISAGREEE }\end{array}$ & $\begin{array}{c}\text { MODERATELY } \\
\text { DISAGREE }\end{array}$ & $\begin{array}{l}\text { SLIGHTLY } \\
\text { DISAGREE }\end{array}$ & NEUTRAL & $\begin{array}{c}\text { SLIGHTLY } \\
\text { AGREEE }\end{array}$ & $\begin{array}{l}\text { MODERATELY } \\
\text { AGREE }\end{array}$ & $\begin{array}{l}\text { STRONGLY } \\
\text { AGREE }\end{array}$ \\
\hline $\begin{array}{l}\text { STRONGLY } \\
\text { DISAGREE }\end{array}$ & $\begin{array}{l}\text { MODERATELY } \\
\text { DISAGREE }\end{array}$ & $\begin{array}{l}\text { SUGHTLY } \\
\text { DISAGREE }\end{array}$ & NEUTRAL & $\begin{array}{c}\text { SUGHTLY } \\
\text { AGREE }\end{array}$ & $\begin{array}{l}\text { MODERATELY } \\
\text { AGREE }\end{array}$ & $\begin{array}{c}\text { STRONGLY } \\
\text { AGREE }\end{array}$ \\
\hline $\begin{array}{l}\text { STRONGIY } \\
\text { DISAGREEE }\end{array}$ & $\begin{array}{l}\text { MODERATELY } \\
\text { DISAGREE }\end{array}$ & $\begin{array}{l}\text { SULGHTLY } \\
\text { DISAGREE }\end{array}$ & NEUTRAL & $\begin{array}{c}\text { SUGHTLY } \\
\text { AGREE }\end{array}$ & $\begin{array}{l}\text { MODERATELY } \\
\text { AGREE }\end{array}$ & $\begin{array}{c}\text { STRONGLY } \\
\text { AGREE }\end{array}$ \\
\hline $\begin{array}{l}\text { STRONGIY } \\
\text { DISAGREE }\end{array}$ & $\begin{array}{l}\text { MODERATELY } \\
\text { DISAGREE }\end{array}$ & $\begin{array}{l}\text { SLIGHTLY } \\
\text { DISAGREE }\end{array}$ & NEUTRAL & $\begin{array}{l}\text { SLIGHTLY } \\
\text { AGREE }\end{array}$ & $\begin{array}{c}\text { MODERATELY } \\
\text { AGREE }\end{array}$ & $\begin{array}{c}\text { STRONGLY } \\
\text { AGREE }\end{array}$ \\
\hline $\begin{array}{l}\text { STRONGIY } \\
\text { DISAGREEE }\end{array}$ & $\begin{array}{c}\text { MODERATEIY } \\
\text { DISAGREE }\end{array}$ & $\begin{array}{l}\text { SUGGTTLY } \\
\text { DISAGREE }\end{array}$ & NEUTRAL & $\begin{array}{l}\text { SUGHTLY } \\
\text { AGREE }\end{array}$ & $\begin{array}{l}\text { MODERATELY } \\
\text { AGREE }\end{array}$ & $\begin{array}{l}\text { STRONGLY } \\
\text { AGREE }\end{array}$ \\
\hline $\begin{array}{l}\text { STRONGLY } \\
\text { DISAGREE }\end{array}$ & $\begin{array}{l}\text { MODERATELY } \\
\text { DISAGREE }\end{array}$ & $\begin{array}{l}\text { SUGGHTLY } \\
\text { DISAGREE }\end{array}$ & NEUTRAL & $\begin{array}{l}\text { SLGHTLYY } \\
\text { AGREE }\end{array}$ & $\begin{array}{c}\text { MODERATELY } \\
\text { AGREE }\end{array}$ & $\begin{array}{c}\text { STRONGLY } \\
\text { AGREEE }\end{array}$ \\
\hline $\begin{array}{l}\text { STRONGLY } \\
\text { DISAGREEE }\end{array}$ & $\begin{array}{l}\text { MODERATELY } \\
\text { DISAGREE }\end{array}$ & $\begin{array}{l}\text { SUIGHTLY } \\
\text { DISAGREE }\end{array}$ & NEUTRAL & $\begin{array}{l}\text { SUGHTLYY } \\
\text { AGREE }\end{array}$ & $\begin{array}{c}\text { MODERATELY } \\
\text { AGREE }\end{array}$ & $\begin{array}{c}\text { STRONGLY } \\
\text { AGREE }\end{array}$ \\
\hline $\begin{array}{l}\text { STRONGIY } \\
\text { DISAGREE }\end{array}$ & $\begin{array}{l}\text { MODERATELY } \\
\text { DISAGREE }\end{array}$ & $\begin{array}{l}\text { SUGHTLYY } \\
\text { DISAGREE }\end{array}$ & NEUTRAL & $\begin{array}{c}\text { SUGHTLY } \\
\text { AGREE }\end{array}$ & $\begin{array}{l}\text { MODERATELY } \\
\text { AGREE }\end{array}$ & $\begin{array}{c}\text { STRONGLY } \\
\text { AGREE }\end{array}$ \\
\hline $\begin{array}{l}\text { STRONGLY } \\
\text { DISAGREE }\end{array}$ & $\begin{array}{l}\text { MODERATELY } \\
\text { DISAGREE }\end{array}$ & $\begin{array}{l}\text { SLIGHTLY } \\
\text { DISAGREE }\end{array}$ & NEUTRAL & $\begin{array}{l}\text { SLIGHTLY } \\
\text { AGREE }\end{array}$ & $\begin{array}{c}\text { MODERATELY } \\
\text { AGREE }\end{array}$ & $\underset{\text { AGREE }}{\text { STRONGLY }}$ \\
\hline $\begin{array}{l}\text { STRONGLY } \\
\text { DISAGREEE }\end{array}$ & $\begin{array}{l}\text { MODERATELY } \\
\text { DISAGREE }\end{array}$ & $\begin{array}{l}\text { SUIGHTIY } \\
\text { DISAGREE }\end{array}$ & NEUTRAL & $\begin{array}{l}\text { SUGHTLY } \\
\text { AGREE }\end{array}$ & $\begin{array}{c}\text { MODERATELYY } \\
\text { AGREE }\end{array}$ & $\begin{array}{c}\text { STRONGLY } \\
\text { AGREE }\end{array}$ \\
\hline $\begin{array}{l}\text { STRONGLY } \\
\text { DISAGREE }\end{array}$ & $\begin{array}{l}\text { MODERATELY } \\
\text { DISAGREE }\end{array}$ & $\begin{array}{l}\text { SUIGHTLY } \\
\text { DISAGREE }\end{array}$ & NEUTRAL & $\begin{array}{l}\text { SLIGHTLY } \\
\text { AGREE }\end{array}$ & $\begin{array}{c}\text { MODERATELY } \\
\text { AGREE }\end{array}$ & $\begin{array}{l}\text { STRONGLY } \\
\text { AGREE }\end{array}$ \\
\hline $\begin{array}{l}\text { STRONGLY } \\
\text { DISAGREE }\end{array}$ & $\begin{array}{l}\text { MODERATELY } \\
\text { DISAGREE }\end{array}$ & $\begin{array}{l}\text { SUIGHTLY } \\
\text { DISAGREE }\end{array}$ & NEUTRAL & $\begin{array}{l}\text { SUGHTLY } \\
\text { AGREE }\end{array}$ & $\begin{array}{l}\text { MODERATELY } \\
\text { AGREE }\end{array}$ & $\begin{array}{l}\text { STRONGLY } \\
\text { AGREE }\end{array}$ \\
\hline $\begin{array}{l}\text { STRONGIY } \\
\text { DISAGREE }\end{array}$ & $\begin{array}{l}\text { MODERATELY } \\
\text { DISAGREE }\end{array}$ & $\begin{array}{l}\text { SLIGHTLY } \\
\text { DISAGREE }\end{array}$ & NEUTRAL & $\begin{array}{l}\text { SUGHTLY } \\
\text { AGREE }\end{array}$ & $\begin{array}{c}\text { MODERATELY } \\
\text { AGREE }\end{array}$ & $\begin{array}{l}\text { STRONGLY } \\
\text { AGREE }\end{array}$ \\
\hline $\begin{array}{l}\text { STRONGLY } \\
\text { DISAGREE }\end{array}$ & $\begin{array}{c}\text { MODERATELY } \\
\text { DISAGREE }\end{array}$ & $\begin{array}{l}\text { SUGHTLY } \\
\text { DISAGREE }\end{array}$ & NEUTRAL & $\begin{array}{c}\text { SUGHTLY } \\
\text { AGREE }\end{array}$ & $\begin{array}{c}\text { MODERATELY } \\
\text { AGREE }\end{array}$ & $\begin{array}{c}\text { STRONGLY } \\
\text { AGREE }\end{array}$ \\
\hline $\begin{array}{l}\text { STRONGLY } \\
\text { DISAGREEE }\end{array}$ & $\begin{array}{l}\text { MODERATELY } \\
\text { DISAGREE }\end{array}$ & $\begin{array}{l}\text { SUIGHTLY } \\
\text { DISAGREEE }\end{array}$ & NEUTRAL & $\begin{array}{l}\text { SUIGHTLY } \\
\text { AGREEE }\end{array}$ & $\begin{array}{c}\text { MODERATELY } \\
\text { AGREE }\end{array}$ & $\begin{array}{c}\text { STRONGLY } \\
\text { AGREE }\end{array}$ \\
\hline $\begin{array}{l}\text { STRONGLY } \\
\text { DISAGREE }\end{array}$ & $\begin{array}{l}\text { MODERATELY } \\
\text { DISAGREE }\end{array}$ & $\begin{array}{l}\text { SUIGHTLY } \\
\text { DISAGREE }\end{array}$ & NEUTRAL & $\begin{array}{l}\text { SUGHTLY } \\
\text { AGREE }\end{array}$ & $\begin{array}{c}\text { MODERATELY } \\
\text { AGREE }\end{array}$ & $\begin{array}{l}\text { STRONGLY } \\
\text { AGREEE }\end{array}$ \\
\hline $\begin{array}{l}\text { STRONGIY } \\
\text { DISAGREE }\end{array}$ & $\begin{array}{l}\text { MODERATELY } \\
\text { DISAGREE }\end{array}$ & $\begin{array}{l}\text { SUGHTLYY } \\
\text { DISAGREE }\end{array}$ & NEUTRAL & $\begin{array}{l}\text { SLIGHTLY } \\
\text { AGREE }\end{array}$ & $\begin{array}{l}\text { MODERATELY } \\
\text { AGREE }\end{array}$ & $\begin{array}{l}\text { STRONGLY } \\
\text { AGREE }\end{array}$ \\
\hline $\begin{array}{l}\text { STRONGIY } \\
\text { DISAGREE }\end{array}$ & $\begin{array}{l}\text { MODERATELY } \\
\text { DISAGREE }\end{array}$ & $\begin{array}{l}\text { SUIGHTLY } \\
\text { DISAGREE }\end{array}$ & NEUTRAL & $\begin{array}{l}\text { SUGHTLY } \\
\text { AGREE }\end{array}$ & $\begin{array}{c}\text { MODERATELY } \\
\text { AGREE }\end{array}$ & $\begin{array}{c}\text { STRONGLY } \\
\text { AGREE }\end{array}$ \\
\hline $\begin{array}{l}\text { STRONGIY } \\
\text { DISAGREE }\end{array}$ & $\begin{array}{l}\text { MODERATELYY } \\
\text { DISAGREE }\end{array}$ & $\begin{array}{l}\text { SLIGHTLY } \\
\text { DISAGREEE }\end{array}$ & NEUTRAL & $\begin{array}{l}\text { SUGHTLY } \\
\text { AGREE }\end{array}$ & $\begin{array}{l}\text { MODERATELYY } \\
\text { AGREE }\end{array}$ & $\begin{array}{l}\text { STRONGLY } \\
\text { AGREE }\end{array}$ \\
\hline
\end{tabular}

$\begin{array}{ccccc}\text { SLGHTLY } & \text { NeUtral } & \text { SLiGHTLY } & \text { MODERATELY } & \text { Strongly } \\ \text { AGREE } & \text { AGREE }\end{array}$ otherwise continue to answer all the questions. 
Please continue.

What other information systems is your CRM system linked to?

Stand-alone, not connected to any other business system

\section{OR}

Linked to (please tick all that apply):

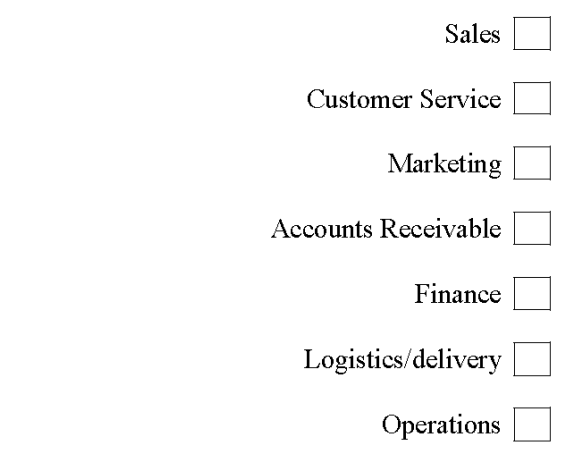

Executive Information Systems (EIS/MIS)

Enterprise Resource Planning system (ERP)

Customer/partner (e.g., F.DI)

\section{Section B: Information technology management practice in your firm}

Another important part of this study is to understand the IT management practices in your firm. Please circle one answer on each line that best represents your viewpoint.

Our firm's IT projects support the business objectives and strategies of our company.

Our IT group continuously examines the innovative opportunities IT can provide for our competitive advantage.

Our IT group is well informed on the current use of IT by other firms in our industry.

Our IT group is well informed on the potential use of IT by other firms in our industry.

Our IT group has an adequate picture of the coverage and quality of our IT systems.

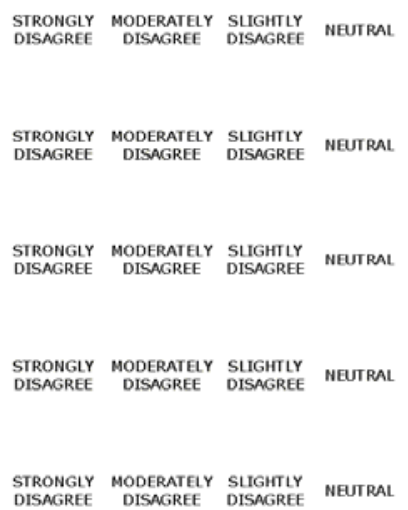
STRONGLY MODERATEIY SLIGHTLY NAUTRAL
DISAGREE DISAGREE DISAGREE

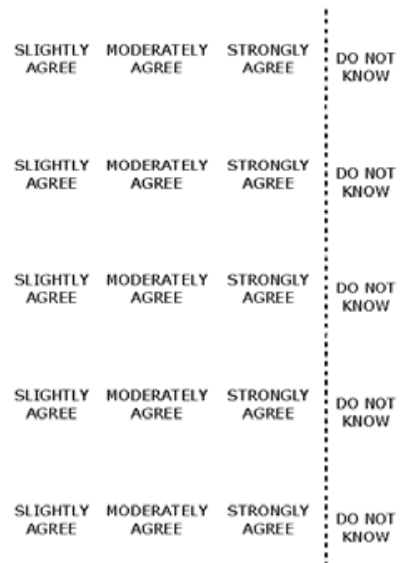


Our firm is content with how our IT project priorities are set.

In our organisation, the responsibility and authority for IT direction and development are clear.

In our organisation, the responsibility and authority for IT operations are clear.

Our firm is confident that IT project proposals are properly appraised.

Our IT group constantly monitors the performance of IT functions.

Our IT group is clear about its goals and responsibilities.

Our IT group is clear about its performance criteria.

In our organisation, user ideas are given due attention in IT planning and implementation.

Our IT specialists understand our business and the firm.

The structure of our IT group is appropriate for our organisation.

The IT specialist-user relations in our firm are constructive.

In our firm, top management perceives that future exploitation of IT is of strategic importance.

There is a top-down planning process for linking information systems strategy to business needs.

Some IT development resource is positioned within the business unit.

The introduction of, or experimentation with, new technologies takes place at the business unit level, under business unit control.

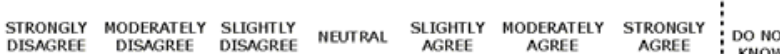

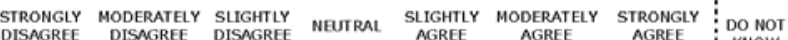

STRONGLY MODERATEY SUGHTIY SUIGHTLY MODERATELY STRONGLY

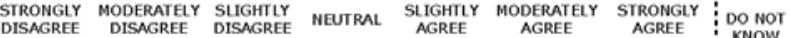

STRONGLY MODERATELY SLIGHTLY MEUTRAL SLIGHTLY MODERATELY STRONGLY kNOW STRONGLY
DISAGREE
DISAGREE STRONGLY MODRATEYY SUGHTLY SUIGHTLY MODERATEYY STRONGYY DIRAGREF DISAGREE DUGAGR NEUTRAL SLIGHILY MODERATE STRONGLY DO NOT STRONGLY MODERATEYY SLIGHTIY MEUTRAL SLIGHTLY MODERATELY SIROMGY DISONGYY MODERATLYY SLIGHLY MEUTRAL SLIGHILY MODERATELY STRONGLY DO NOT KNOW SIRONGLY MODERATEYY SUGHTIY
DISAGREF
DISAGREE $\begin{array}{cccc}\text { SLIGHTLY MODERATELY } & \text { STRONGLY } \\ \text { AGREE } & \text { AGREE } & \text { AGREE } & \text { DO NOT } \\ \text { KNOW }\end{array}$ STRONGLY MODERATELY SUGHTIY NEUTRAL SLIGHTIY MODERATELY STRONGLY

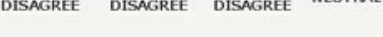
STRONGLY MODERATELY SLIGHTLY
DISAGREF NEUTRAL

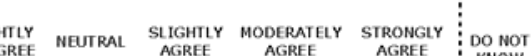
know STRONGLY
DISAGREE
DISAGREE $\begin{array}{ccc}\text { SLIGHTLY MODERATELY } & \text { STRONGLY } \\ \text { AGREE } & \text { AGREE } & \text { AGREE } \\ \end{array}$ KNOW STRONGLY MODERATELY SLIGHTLY NEUTRAL $\begin{array}{cc:c}\text { SLIGHTLY MODERATELY } & \text { STRONGLY } \\ \text { AGREE } & \text { AGREE } & \text { DGREE } \\ \text { KNOW }\end{array}$

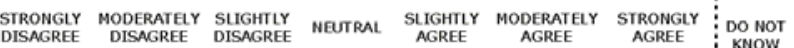

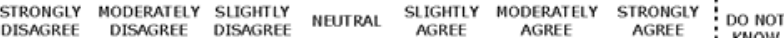

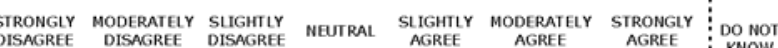
STRONGLY MODERATEYY SUGHTLY
DISAGREE
DISAGREE 


\section{Section C: Market orientation of your firm}

Please circle the extent you agree with each statement.

All our functions (not just marketing and sales) are responsive to serving target markets. DISAGREE

MODERATELY SUGHTiY

All our functions are integrated in

serving target markets.

STRONGLY

DISAGREE

NEUTRAL

AGREE

MODERATELY
AGREE

STRONGLY

DISAGREE

MODERATELY

SLIGHTLY

SUIGITIY

Our firm's strategy for competitive advantage is based on a thorough understanding of our customer needs.

STRONGLY DISAGREE

DISAGREE

AGREE

MODERATELY

STRONGLY

MODERATELY

SLIGHTLY DISAGREE

NEUTRAL

SLIGHTLY

TODEATELY

All our managers understand how the entire business can contribute to creating customer value.

STRONGLY DISAGREE

MODERATELY DISAGREE

SUGHTLY

Information on customers, marketing success, and marketing failures is communicated across the firm.

STRONGLY
DISAGREE MODERATELY

SUGHTIY

GGREE NEUT

Burral SLIGHTIY AGREE

STRONGLY

If a major competitor were to launch an intensive campaign targeted at our customers, we would implement a response immediately.

Our firm's market strategies are to a great extent driven by our understanding of possibilities for creating value for STRONGIY customers.

SUGHTIY DISAGREE DISAGREE

NEUTRAL

SLIGHTIY

MODERATELY

STRONGLY

Our firm responds quickly to negative customer satisfaction wherever it may

occur in the organisation.

STRONGLY

MODERATELY

SLIGH

Senior managers frequently discuss competitive strengths and weaknesses.

STRONGLY
DISAGREE

MODERATE OISAGRE

NEUTRAL

SLIGHTL

AGREE

MODERATEIY

AGREE

STRONGLY AGREE

DISAGREE

SLIGHTIY

MEUTRAL

SLIGHTLY

MODERATE

STRONGLY

We frequently leverage targeted opportunities to take advantage of competitor's weaknesses. 
It is critical to this study that I am able to contact one of your customers in order to understand the effect of CRM technology on the relationship aspects from both the supplier and the customer perspectives.

If you have not already done so, please provide customer contact details for either your third or your fourth most important customer.

Please feel free to contact the customer beforehand, if you prefer. All information will be kept confidential.

Nominated customer

Company name:

\begin{tabular}{lll} 
Contact person: (First Name) $\quad$ (Surname) \\
\hline
\end{tabular}

Phone number, email or address (if known):

Please circle the extent to which you agree with this statement.

Our business relationship with this customer is strong.

$\begin{array}{lccccc}\text { STRONGLY } & \text { MODERATELY } & \text { SOMEWHAT } & \text { NETTHER AGREE NOR } & \text { SOMEWHAT } \\ \text { DISAGREE } & \text { DISAGREE } & \text { DISAGREE } & \text { DISAGREE } & \text { MODERATELY } & \text { STRONGLY } \\ \text { AGREE }\end{array}$




\section{Section E: Relationship strength between your firm and your nominated} customer

This customer has made sacrifices for us in the past.

This customer cares for my firm's welfare.

In times of delivery problems, this customer has been very understanding.

This customer has been frank in dealing with us.

Promises made by this customer are reliable.

This customer is knowledgeable about the product.

This customer has problems understanding our position.

Even if we could, we would not drop this customer because we like being associated with them.

We want to keep this customer because we genuinely enjoy our relationship with them.

Our positive feelings towards this customer are a major reason we continue working with them.

We expect our relationship with this customer to continue for a long time.

The renewal of our relationship with this customer is virtually automatic.

It is unlikely our firm will still be doing business with this customer in two years.

If the customer requested it, we would be willing to make further investment in supporting this customer.

We are willing to put more effort and investment into building our business with this customer.

If asked we would go so far as to work with this customer's customer.

It would be difficult to break this relationship.

There are no worthwhile alternative customers.

There is a high cost to drop this customer.

We keep each other informed about events that affect each other. STRONGIY
DISAGREE

\section{STRONGLY} DISAGREF

STRONGIY

STRONGIY

DISAGRE

STRONGLY

DISAGREE

STRONGLY
DISAGREE

STrongiY

STRONGIY
DISAGREE

STRONGLY
DISAGREE

STRONGLY

DISAGRE

STRONGLY DISAGRE

STRONGLY

DISAGREE

STRONGLY
DISAGREE

STRONGLY
DISAGREE

STRONGLY

STRONGIY STRONGLY
DISAGREE

DISAGREE

STRONGLY DISAGREE

STRONGLY

DISAGREE

STRONGLY

STRONGLY

STRONGLY
DISAGREE

STRONGLY DISAGREE

\section{MODERATELY} DISAGREE

MODERATELY DISAGREE

MODERATELY DISAGREE

MODERATELY

MODERATEIY
DISAGREE

moDrateYY

DODERATELY

MODERATEYY
DISAGREE

MODERATEIY

DISAGREE

MODERATELY

MODERATELY
DISAGREE

MODERATELY
DISAGREE

DISAGRE

MODERATELY

MODERATELY
DISAGREE

MODERATELY

MODERATELY
DISAGREE

MODERATEIY

DISAGREE

moDerater

MODERATELY

Dishone

MODERATELY

MODERATEYY

DISAGREE

MODERATELY

DISAGREE

MODERATELY

DISAGREE

MODERATEYY

MODERATELY

DISAGREE

MODERATEL

DISAGREE
SUIGHTLY
DISAGREE

NEUTRAL SLIGHTLY
AGREE MODERATELY
AGREE STRONGLY
AGREE SUGHTLY NEUTRAL SUGHTLY MODERATELY STRONGLY

SLIGHTLY NEUTRAL SLIGHTLY AGREE

DISAGREE

$$
\text { AGREE }
$$$$
\begin{aligned}
& \text { MODERATELY } \\
& \text { AGREE }
\end{aligned}
$$

STRONGLY

SUIGHTLY
DISAGREE NEUTRAL SLIGHTIY

$\underset{\substack{\text { MODERATELY } \\ \text { AGREE }}}{ }$

$\underset{\text { AGREE }}{\text { STRONGLY }}$

SLIGHTLY NEUTRAL SUGHTLY

DISAGREE NEUTRAL AGREE

MODERATELY

AGREE

STRONGLY

SLIGHTLY MUTRAL SLIGHTLY MODERATELY STRONGLY

DISAGREE NEUTRAL AGREE

MODERATELY
AGREE

STRONGLY
AGREE

SUGHTIY

SLIGHTIY

MODERATELY
AGREE

STRONGLY
AGREE

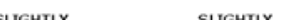

MODERATELY

STRONGLY

DISAGREE NEUTRAL SUGHTLY MODERAIEY

AGREE

SLIGHTIY NEUTRAL SLIGHTIY

MODERATELY

AGREE

STRONGLY
AGREE

AGREE

SLIGHTLY
DISAGREE

MODERATELY
AGREE

STRONGLY

SUGHTYY

SUGHTLY METTAL

AGREE

MODERATELY

STRONGLY

AGREE

SLIGHTLY NEUTRAL

SUGHTLY
AGREE

MODERATELY

STRONGLY

(10)

STRONGLY

AGREE STRONGLY

SUIGHTLY NEUTRAL

SLIGHTLY

(a)

SLIGHTIY

DISAGRE

SughtuY DISAGRE

SLGHTLY
DISAGREE

SUGGTLY

SLIGHTLY
DISAGREE

SLIGHTLY
DISAGREE

SUGHTLY

DISAGREE

NEUTRAL

MODERATELY

STRONGLY
AGREE

RONGLY

STRONGLY 
We often exchange information informally.

We often exchange information beyond what is required by our formal agreements.

We provide each other with information that may be of help.

Please indicate the nature of your communication with this customer.

\begin{tabular}{|c|c|c|c|c|c|c|c|}
\hline $\begin{array}{l}\text { STRONGLY } \\
\text { DISAGREE }\end{array}$ & $\begin{array}{c}\text { MODERATELY } \\
\text { DISAGREE }\end{array}$ & $\begin{array}{l}\text { SLIGHTLY } \\
\text { DISAGREE }\end{array}$ & NEUTRAL & $\begin{array}{l}\text { SLIGHTLY } \\
\text { AGREE }\end{array}$ & & $\begin{array}{l}\text { MODERATELY } \\
\text { AGREE }\end{array}$ & $\begin{array}{c}\text { STRONGLY } \\
\text { AGREE }\end{array}$ \\
\hline $\begin{array}{l}\text { STRONGLY } \\
\text { DISAGREE }\end{array}$ & $\begin{array}{l}\text { MODERATELY } \\
\text { DISAGREE }\end{array}$ & $\begin{array}{l}\text { SUIGHTLY } \\
\text { DISAGREE }\end{array}$ & NEUTRAL & $\begin{array}{l}\text { SLIGHTLY } \\
\text { AGREE }\end{array}$ & & $\begin{array}{l}\text { MODERATELY } \\
\text { AGREE }\end{array}$ & $\begin{array}{c}\text { STRONGLY } \\
\text { AGREE }\end{array}$ \\
\hline $\begin{array}{l}\text { STRONGIY } \\
\text { DISAGREE }\end{array}$ & $\begin{array}{l}\text { MODERATELY } \\
\text { DISAGREE }\end{array}$ & $\begin{array}{l}\text { SUIGHTLY } \\
\text { DISAGREE }\end{array}$ & NEUTRAL & $\begin{array}{l}\text { SLIGHTLY } \\
\text { AGREE }\end{array}$ & & $\begin{array}{l}\text { MODERATELY } \\
\text { AGREE }\end{array}$ & $\begin{array}{l}\text { STRONGLY } \\
\text { AGREE }\end{array}$ \\
\hline UNTIMELY & 1 & 2 & 4 & 5 & 6 & 7 & TIMELY \\
\hline INACCURATE & 1 & 2 & 4 & 5 & 6 & 7 & ACCURATE \\
\hline INADEQUATE & 1 & 2 & 4 & 5 & 6 & 7 & ADEQUATE \\
\hline INCOMPLETE & 1 & 2 & 4 & 5 & 6 & 7 & COMPLETE \\
\hline NOT CREDIBLE & 1 & 2 & 4 & 5 & 6 & 7 & CREDIBLE \\
\hline
\end{tabular}

\section{Section F: Relationship performance between your firm and your nominated} customer

Our relationship with them has been productive.

The time and effort invested in the relationship with them has been worthwhile.

The relationship with them has been satisfactory.

The relationship between my company and this customer reflects a happy situation.

The relationship between the two companies is very positive.

My company is very satisfied with this customer.

I say positive things about this customer to others.

I encourage others to purchase from this customer.

I would recommend this customer to someone who seeks my advice.

We expect to do more business with this customer in the next few years.

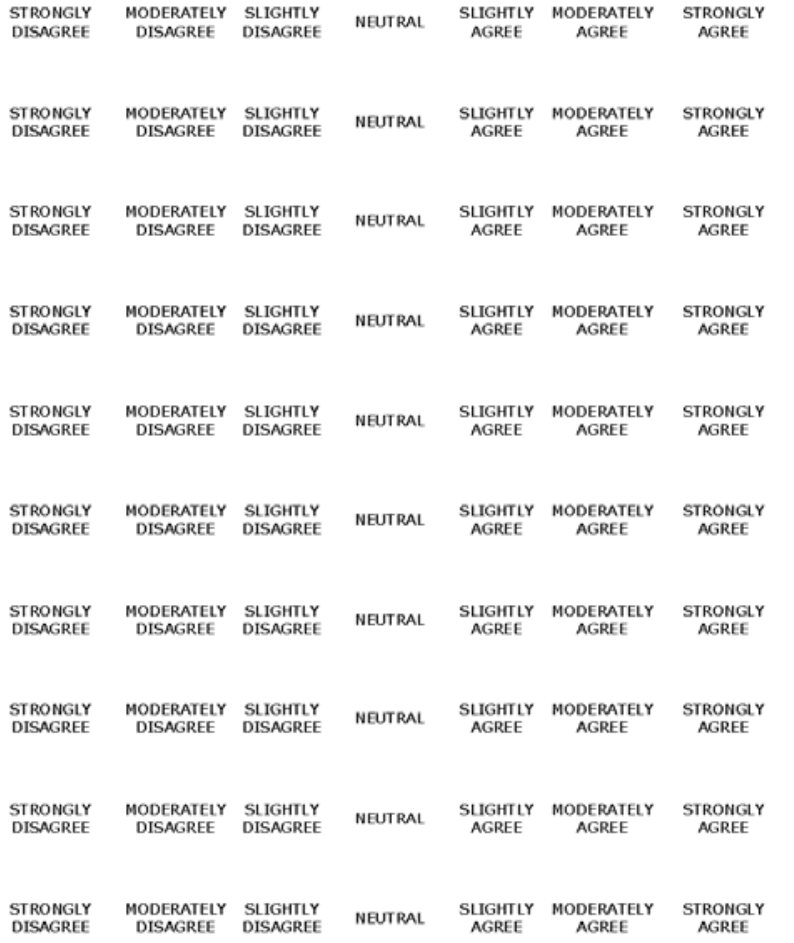




\section{Section G: Your business environment}

In general our customer retention rate is higher than our competitors'.

Since we have implemented CRM our customer retention rate has increased compared to our major competitor.

The technology in our industry is changing rapidly.

Technology changes provide big opportunities in our industry.

Many new product ideas have been made possible through technological breakthroughs in our industry.

Technological developments in our industry are rather minor.

In our kind of business, customers ' product preferences change quite a bit over time.

Our customers tend to look for new products all the time.

We are witnessing demand for our products and services from customers who never bought them before.

New customers tend to have productrelated needs that are different from those of our existing customers.

The nature of the market has changed significantly over the last few years.

\begin{tabular}{|c|c|c|c|c|c|c|}
\hline $\begin{array}{l}\text { STRONGLY } \\
\text { DISAGREE }\end{array}$ & $\begin{array}{c}\text { MODERATEIY } \\
\text { DISAGREE }\end{array}$ & $\begin{array}{l}\text { SLIGHTLY } \\
\text { DISAGREE }\end{array}$ & NEUTRAL & $\begin{array}{c}\text { SLIGHTLY } \\
\text { AGREE }\end{array}$ & $\begin{array}{l}\text { MODERATELY } \\
\text { AGREE }\end{array}$ & $\begin{array}{c}\text { STRONGLY } \\
\text { AGREE }\end{array}$ \\
\hline $\begin{array}{l}\text { STRONGLY } \\
\text { DISAGREE }\end{array}$ & $\begin{array}{l}\text { MODERATELY } \\
\text { DISAGREE }\end{array}$ & $\begin{array}{l}\text { SLIGHTLY } \\
\text { DISAGREE }\end{array}$ & NEUTRAL & $\begin{array}{c}\text { SLIGHTLY } \\
\text { AGREE }\end{array}$ & $\begin{array}{l}\text { MODERATELY } \\
\text { AGREE }\end{array}$ & $\begin{array}{l}\text { STRONGLY } \\
\text { AGREE }\end{array}$ \\
\hline $\begin{array}{l}\text { STRONGLY } \\
\text { DISAGREEE }\end{array}$ & $\begin{array}{c}\text { MODERATEIY } \\
\text { DISAGREE }\end{array}$ & $\begin{array}{l}\text { SLIGHTLY } \\
\text { DISAGREE }\end{array}$ & NEUTRAL & $\begin{array}{c}\text { SLIGHTIY } \\
\text { AGREE }\end{array}$ & $\begin{array}{l}\text { MODERATELY } \\
\text { AGREE }\end{array}$ & $\begin{array}{c}\text { STRONGLY } \\
\text { AGREE }\end{array}$ \\
\hline $\begin{array}{l}\text { STRONGLY } \\
\text { DISAGREE }\end{array}$ & $\begin{array}{l}\text { MODERATELY } \\
\text { DISAGREE }\end{array}$ & $\begin{array}{l}\text { SUGHTLY } \\
\text { DISAGREE }\end{array}$ & NEUTRAL & $\begin{array}{c}\text { SLIGHTLYY } \\
\text { AGREE }\end{array}$ & $\begin{array}{l}\text { MODERATELY } \\
\text { AGREE }\end{array}$ & $\begin{array}{c}\text { STRONGLY } \\
\text { AGREE }\end{array}$ \\
\hline $\begin{array}{l}\text { STRONGLY } \\
\text { DISAGREE }\end{array}$ & $\begin{array}{c}\text { MODERATELY } \\
\text { DISAGREE }\end{array}$ & $\begin{array}{l}\text { SLIGHTLY } \\
\text { DISAGREE }\end{array}$ & NEUTRAL & $\begin{array}{c}\text { SLIGHTLY } \\
\text { AGREE }\end{array}$ & $\begin{array}{l}\text { MODERATELY } \\
\text { AGREE }\end{array}$ & $\begin{array}{c}\text { STRONGLY } \\
\text { AGREE }\end{array}$ \\
\hline $\begin{array}{l}\text { STRONGLY } \\
\text { DISAGREE }\end{array}$ & $\begin{array}{c}\text { MODERATELY } \\
\text { DISAGREE }\end{array}$ & $\begin{array}{l}\text { SUGGTLY } \\
\text { DISAGREE }\end{array}$ & NEUTRAL & $\begin{array}{l}\text { SUGHTLY } \\
\text { AGREE }\end{array}$ & $\begin{array}{l}\text { MODERATEIY } \\
\text { AGREE }\end{array}$ & $\begin{array}{c}\text { STRONGLY } \\
\text { AGREE }\end{array}$ \\
\hline $\begin{array}{l}\text { STRONGLY } \\
\text { DISAGREE }\end{array}$ & $\begin{array}{c}\text { MODERATELY } \\
\text { DISAGREE }\end{array}$ & $\begin{array}{l}\text { SLIGHTLY } \\
\text { DISAGREE }\end{array}$ & NEUTRAL & $\begin{array}{l}\text { SLIGHTLY } \\
\text { AGREE }\end{array}$ & $\begin{array}{l}\text { MODERATELY } \\
\text { AGREE }\end{array}$ & $\begin{array}{c}\text { STRONGLY } \\
\text { AGREE }\end{array}$ \\
\hline $\begin{array}{l}\text { SI RONGLY } \\
\text { DISAGREE }\end{array}$ & $\begin{array}{c}\text { MODERAIELY } \\
\text { DISAGREE }\end{array}$ & $\begin{array}{l}\text { SUGHILY } \\
\text { DISAGREE }\end{array}$ & NEUTRAL & $\begin{array}{c}\text { SUGHILY } \\
\text { AGREE }\end{array}$ & $\begin{array}{c}\text { MODERAIELY } \\
\text { AGREE }\end{array}$ & $\begin{array}{l}\text { SIRONGLY } \\
\text { AGREE }\end{array}$ \\
\hline $\begin{array}{l}\text { STRONGIY } \\
\text { DISAGREE }\end{array}$ & $\begin{array}{l}\text { MODERATELY } \\
\text { DISAGREE }\end{array}$ & $\begin{array}{l}\text { SLIGHTLY } \\
\text { DISAGREE }\end{array}$ & NEUTRAL & $\begin{array}{l}\text { SLIGHTLY } \\
\text { AGREE }\end{array}$ & $\begin{array}{c}\text { MODERATELY } \\
\text { AGREE }\end{array}$ & $\begin{array}{c}\text { STRONGLY } \\
\text { AGREE }\end{array}$ \\
\hline $\begin{array}{l}\text { STRONGLY } \\
\text { DISAGREE }\end{array}$ & $\begin{array}{c}\text { MODERATELY } \\
\text { DISAGREE }\end{array}$ & $\begin{array}{l}\text { SUGGHTLY } \\
\text { DISAGREE }\end{array}$ & NEUTRAL & $\begin{array}{l}\text { SLIGHTLY } \\
\text { AGREE }\end{array}$ & $\begin{array}{l}\text { MODERATELY } \\
\text { AGREE }\end{array}$ & $\begin{array}{l}\text { STRONGLY } \\
\text { AGREE }\end{array}$ \\
\hline $\begin{array}{l}\text { STRONGLY } \\
\text { DISAGREE }\end{array}$ & $\begin{array}{l}\text { MODERATELY } \\
\text { DISAGREE }\end{array}$ & $\begin{array}{l}\text { SLIGHTLY } \\
\text { DISAGREE }\end{array}$ & NEUTRAL & $\begin{array}{c}\text { SLIGHTLY } \\
\text { AGREE }\end{array}$ & $\begin{array}{c}\text { MODERATELY } \\
\text { AGREE }\end{array}$ & $\begin{array}{l}\text { STRONGLY } \\
\text { AGREE }\end{array}$ \\
\hline
\end{tabular}




\section{Section H: General details about you and your company}

Finally, we would like to ask a few questions about yourself and your company, to help us interpret the results. Please tick the appropriate box for each question. Please note: ALL of the information collected is completely confidential.

Your gender:

Male

Female

Type of industry in which your firm is involved:

$\square$ Manufacturing
$\square$ Wholesale
$\square$ Services
$\square$ Other

Your firm's annual gross revenues:

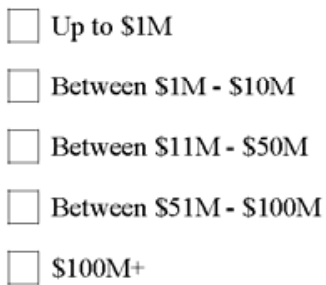

Number of employees in your company:

$$
\begin{aligned}
& \square \text { Less than } 19 \\
& \square \text { Between } 20 \text { and } 49 \\
& \square \text { Between } 50 \text { and } 99 \\
& \square 100+
\end{aligned}
$$

Length of relationship with the nominated customer:

years months
Your full-time working experience:

$$
\begin{aligned}
& \text { Less than } 5 \text { years } \\
& \text { Between } 5 \text { and } 10 \text { years } \\
& \text { Between } 11 \text { and } 15 \text { years } \\
& \text { Between } 16 \text { and } 20 \text { years } \\
& \text { More than } 20 \text { years }
\end{aligned}
$$

Your education level:

$$
\begin{aligned}
& \square \text { No qualification held } \\
& \square \text { School certificate } \\
& \square \text { Some tertiary } \\
& \square \text { Tertiary qualification } \\
& \square \text { Post-graduate degree } \\
& \square \text { Other }
\end{aligned}
$$

Your age:

$$
\begin{aligned}
& \square \text { Under } 26 \text { years } \\
& \square \text { Between } 26 \text { and } 35 \text { years } \\
& \square \text { Between } 36 \text { and } 45 \text { years } \\
& \square \text { Between } 46 \text { and } 55 \text { years } \\
& \square \text { Over } 55 \text { years }
\end{aligned}
$$

Your position or title: 
Is there anything else you would like to tell us about CRM technology and its potential impact on business-to-business relationships? If so please use this space for that purpose.

Also, any comments you wish to make that you think may help us in future efforts to understand what business leaders want from CRM technology will be appreciated, either here or in a separate letter.

your contribution to this effort is greatly appreciated. If you would like access to the summary of results, and a report of the results for your firm, please print your name, address and email on the back of the return envelope (NOT on this questionnaire). We will see that you are notified when the results are available on our web site. 


\section{Customer Questionnaire}
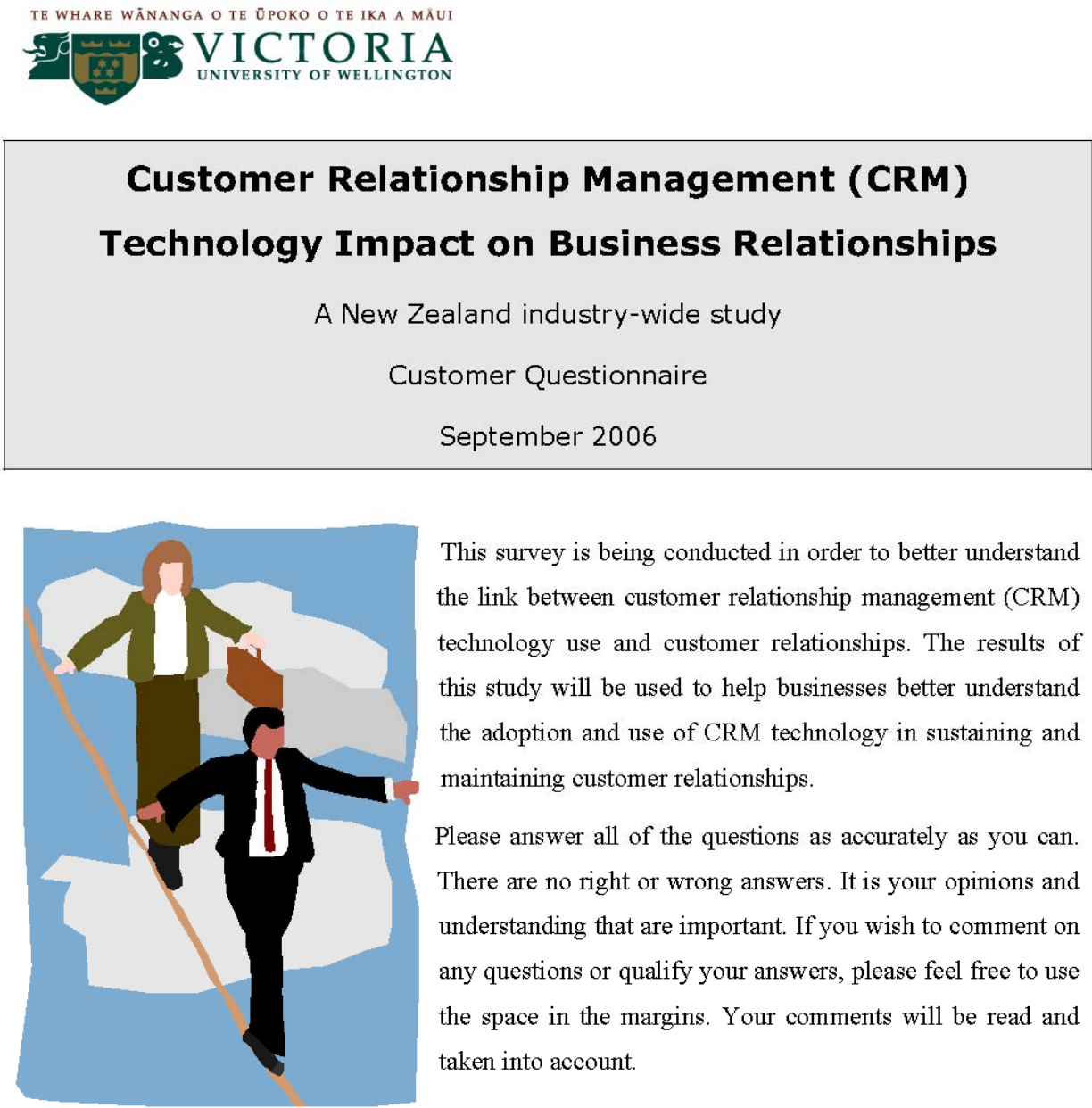

This survey is being conducted in order to better understand the link between customer relationship management (CRM) technology use and customer relationships. The results of this study will be used to help businesses better understand the adoption and use of CRM technology in sustaining and maintaining customer relationships.

Please answer all of the questions as accurately as you can. There are no right or wrong answers. It is your opinions and understanding that are important. If you wish to comment on any questions or qualify your answers, please feel free to use the space in the margins. Your comments will be read and taken into account.

\section{Balancing technology and relationships}

Thank you for your help.

James E. Richard

$\mathrm{PhD}$ candidate

School of Marketing and International Business

Victoria University of Wellington

PO Box 600, Wellington, New Zealand

Ph: (04) 4635415

Fax (04) 4635231 


\section{Section A: Relationship strength between your firm and the nominating supplier}

This section explores the relationship between your company and your nominating supplier. Please circle one answer on each line indicating the extent to which you agree with each statement.

Our business relationship with

STRONGLY MODERATEY
DISAGREE

MODERATELY
DISAGREE

SOMEWHAT
DISAGREE

METHHER AGREE NOR
DISAGREE

SOMEWHAT

MODERATEYY

is strong.

DISAGRE

DISAGREE

This supplier keeps promises it makes to our firm. STRONG

This supplier is not always honest with us.

We believe the information that this vendor provides us

This supplier is genuinely concerned that our business succeeds.

When making important decisions, this supplier considers our welfare as well as its own.

We trust this supplier keeps our best interests in mind.

This supplier is trustworthy.

We find it necessary to be cautious with this supplier.

Even if we could, we would not drop the supplier because we like being associated with them.

We want to remain a member of the supplier's network because we genuinely enjoy our relationship with them.

Our positive feelings towards the supplier are a major reason we continue working with them

We expect our relationship with the supplier to continue for a long time.

The renewal of our relationship with the supplier is virtually automatic.

It is unlikely our firm will still be doing business with this supplier in two years.

If the supplier requested it, we would be willing to make further investment in supporting the supplier's line.

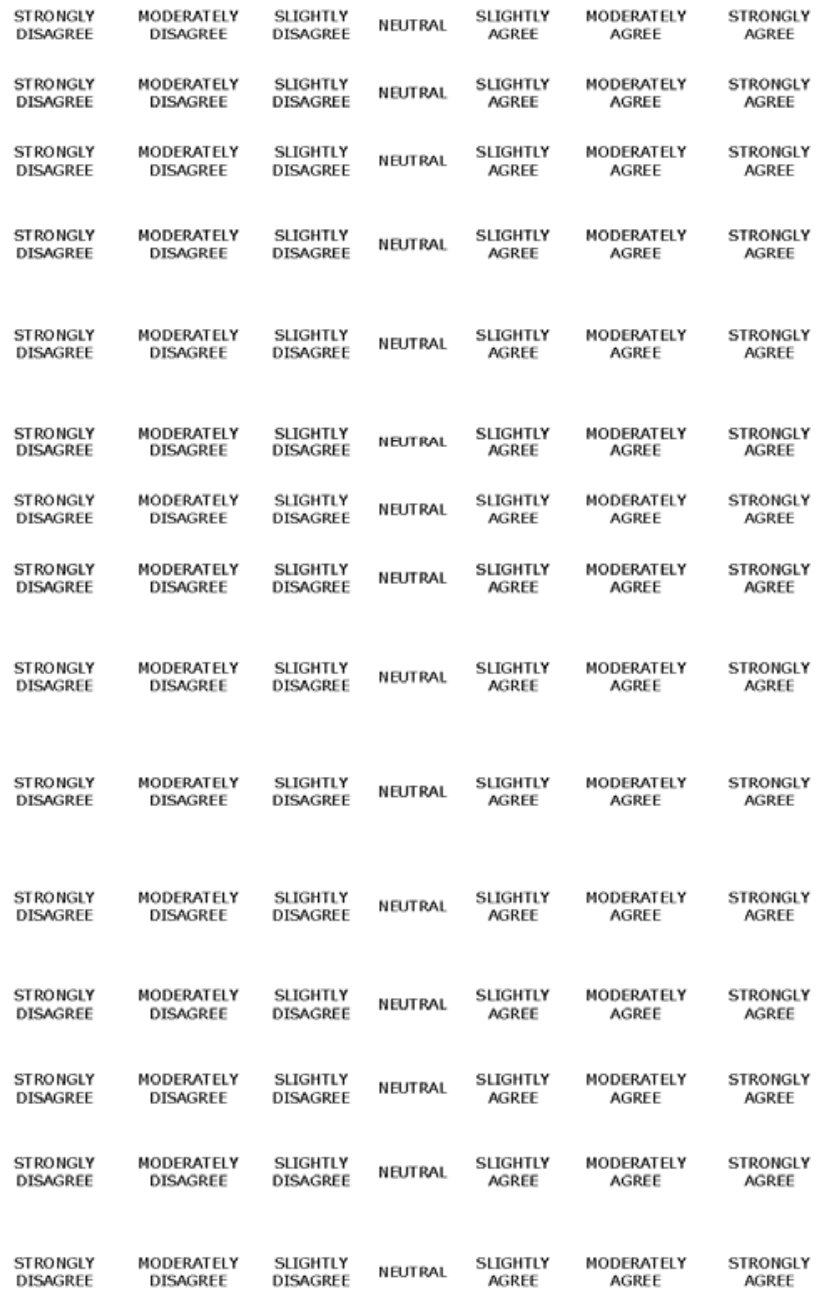


We are willing to put more effort and investment in building our business in the supplier's product.

In the future we will work to link our firm with the supplier's in the customer's mind.

It would be difficult to break this relationship.

There are no worthwhile alternative suppliers.

There is a high cost to change suppliers.

We are very committed to carrying this supplier's products.

We would like to discontinue this supplier's products.

We have a minimal commitment to this supplier.

We keep each other informed about events that affect each other.

We often exchange information informally.

We often exchange information beyond what is required by our formal agreements.

We provide each other with information that may be of help.

Please indicate the nature of your communication with this supplier.
STRONGLY

(1) STRONGLY

STRONG STRONGLY
DISAGREE

STRONGLY STRONGLY

STRONGLY

DISAGREF

STRONGLY

STRONGLY
DISAGREE STRONGLY
DISAGREE

STRONGIY

STRONGLY
DISAGREE

DISAGREE

STRONGLY
DISAGREE

STRONGLY

$$
\text { MODERAT }
$$$$
\text { MODERA }
$$

STRONGLY

\section{MODERATELY}

DISAGREE

SUIGHTLY
DISAGREE

SUIGHTIY$$
\text { DISAGREE }
$$

ODERATELY

SUIGHTLY
DISAGREE

suchiry

\section{(1)}

ERATELY STG

DI sungutr

AGREE MODERATEL

a

SLIGHTLY MODERATELY
AGREE
AGREE

STRONGLY

NEUTRAL

SLIGHTIY
AGREE

MODERATELY

AGREE

STRONGLY
AGREE

SLISTIY NGHTLY

MODERATELY

AGREE

SLIGHTLY NEUTRAL SLGHTI

MODERATELY

MODERATELY

AGREE

(1)

STRONGLY
AGREE

STRONGLY
AGREE

(1)

STRONGLY

AGREE

STRONGLY

AGREE

SUGHTLY NEUTRAL SLIGHTIY

MODERATELY
AGREE

rer

STRONGLY

STRONGLY

AGREE

$\begin{array}{ccccccccc}\text { UNTIMELY } & 1 & 2 & 3 & 4 & 5 & 6 & 7 & \text { TIMELY } \\ \text { INACCURATE } & 1 & 2 & 3 & 4 & 5 & 6 & 7 & \text { ACCURATE } \\ \text { INADEQUATE } & 1 & 2 & 3 & 4 & 5 & 6 & 7 & \text { ADEQUATE } \\ \text { INCOMPLETE } & 1 & 2 & 3 & 4 & 5 & 6 & 7 & \text { COMPLETE } \\ \text { NOT CREDIBLE } & 1 & 2 & 3 & 4 & 5 & 6 & 7 & \text { CREDIBLE }\end{array}$


Section B: Relationship performance between your firm and the nominating supplier

This section explores the relationship performance between your company and the nominating supplier. Please circle one answer on each line that best represents your level of agreement with each statement.

Our relationship with them has been productive.

The time and effort we spent in the relationship with them has been worthwhile.

The relationship with them has been satisfactory.

The relationship between my company and this supplier reflects a happy situation.

The relationship between the two companies is very positive.

My company is very satisfied with this supplier.

I say positive things about this supplier to others.

I encourage others to do business with this supplier.

I would recommend this supplier to someone who seeks my advice.

I expect to do more business with this supplier in the next few years.

I consider this supplier our first choice to buy from.

We continue to purchase from this supplier more so than from other suppliers.

We are looking for alternative suppliers.

\begin{tabular}{|c|c|c|c|c|c|c|}
\hline $\begin{array}{l}\text { STRONGLY } \\
\text { DISAGREE }\end{array}$ & $\begin{array}{l}\text { MODERATELY } \\
\text { DISAGREEE }\end{array}$ & $\begin{array}{l}\text { SLIGHTLY } \\
\text { DISAGREE }\end{array}$ & NEUTRAL & $\begin{array}{c}\text { SLGHTLY } \\
\text { AGREE }\end{array}$ & $\begin{array}{c}\text { MODERATELY } \\
\text { AGREE }\end{array}$ & $\begin{array}{c}\text { STRONGLY } \\
\text { AGREE }\end{array}$ \\
\hline $\begin{array}{l}\text { STRONGLY } \\
\text { DISAGREE }\end{array}$ & $\begin{array}{l}\text { MODERATELY } \\
\text { DISAGREEE }\end{array}$ & $\begin{array}{l}\text { SLIGHTLY } \\
\text { DISAGREEE }\end{array}$ & NEUTRAL & $\begin{array}{c}\text { SLIGHTLY } \\
\text { AGREE }\end{array}$ & $\begin{array}{l}\text { MODERATELY } \\
\text { AGREE }\end{array}$ & $\begin{array}{c}\text { STRONGLY } \\
\text { AGREE }\end{array}$ \\
\hline $\begin{array}{l}\text { STRONGLY } \\
\text { DISAGREE }\end{array}$ & $\begin{array}{l}\text { MODERATELY } \\
\text { DISAGREE }\end{array}$ & $\begin{array}{l}\text { SLIGHTLY } \\
\text { DISAGREEE }\end{array}$ & NEUTRAL & $\begin{array}{c}\text { SLGHTIYY } \\
\text { AGREE }\end{array}$ & $\begin{array}{l}\text { MODERATELY } \\
\text { AGREE }\end{array}$ & $\begin{array}{c}\text { STRONGLY } \\
\text { AGREE }\end{array}$ \\
\hline $\begin{array}{l}\text { STRONGIY } \\
\text { DISAGREE }\end{array}$ & $\begin{array}{l}\text { MODERATELY } \\
\text { DISAGREE }\end{array}$ & $\begin{array}{l}\text { SLIGHTLY } \\
\text { DISAGREE }\end{array}$ & NEUTRAL & $\begin{array}{c}\text { SLIGHTLY } \\
\text { AGREE }\end{array}$ & $\begin{array}{c}\text { MODERATELY } \\
\text { AGREE }\end{array}$ & $\begin{array}{c}\text { STRONGLY } \\
\text { AGREE }\end{array}$ \\
\hline $\begin{array}{l}\text { STRONGLY } \\
\text { DISAGREE }\end{array}$ & $\begin{array}{l}\text { MODERATELY } \\
\text { DISAGREE }\end{array}$ & $\begin{array}{l}\text { SLIGHTLY } \\
\text { DISAGREE }\end{array}$ & NEUTRAL & $\begin{array}{l}\text { SLIGHTLY } \\
\text { AGREE }\end{array}$ & $\begin{array}{l}\text { MODERATELY } \\
\text { AGREE }\end{array}$ & $\begin{array}{l}\text { STRONGLY } \\
\text { AGREE }\end{array}$ \\
\hline $\begin{array}{l}\text { STRONGIY } \\
\text { DISAGREE }\end{array}$ & $\begin{array}{l}\text { MODERATELY } \\
\text { DISAGREE }\end{array}$ & $\begin{array}{l}\text { SLIGHTLY } \\
\text { DISAGREEE }\end{array}$ & NEUTRAL & $\begin{array}{c}\text { SLGHTIIY } \\
\text { AGREE }\end{array}$ & $\begin{array}{c}\text { MODERATELY } \\
\text { AGREE }\end{array}$ & $\begin{array}{c}\text { STRONGLY } \\
\text { AGREE }\end{array}$ \\
\hline $\begin{array}{l}\text { STRONGLY } \\
\text { DISAGREE }\end{array}$ & $\begin{array}{l}\text { MODERATELY } \\
\text { DISAGREE }\end{array}$ & $\begin{array}{l}\text { SLIGHTLY } \\
\text { DISAGREE }\end{array}$ & NEUTRAL. & $\begin{array}{c}\text { SLIGHTLY } \\
\text { AGREE }\end{array}$ & $\begin{array}{l}\text { MODERATELY } \\
\text { AGREE }\end{array}$ & $\begin{array}{c}\text { STRONGLY } \\
\text { AGREE }\end{array}$ \\
\hline $\begin{array}{l}\text { STRONGLY } \\
\text { DISAGREE }\end{array}$ & $\begin{array}{l}\text { MODERATELY } \\
\text { DISAGREEE }\end{array}$ & $\begin{array}{l}\text { SLIGHTLY } \\
\text { DISAGRIEE }\end{array}$ & NEUTRAL & $\begin{array}{c}\text { SLIGHTLY } \\
\text { AGREE }\end{array}$ & $\begin{array}{c}\text { MODERATELY } \\
\text { AGREE }\end{array}$ & $\begin{array}{c}\text { STRONGLY } \\
\text { AGREE }\end{array}$ \\
\hline $\begin{array}{l}\text { STRONGLY } \\
\text { DISAGREE }\end{array}$ & $\begin{array}{l}\text { MODERATELY } \\
\text { DISAGREE }\end{array}$ & $\begin{array}{l}\text { SLIGHTLY } \\
\text { DISAGREEE }\end{array}$ & NEUTRAL & $\begin{array}{c}\text { SLGGHTLY } \\
\text { AGREE }\end{array}$ & $\begin{array}{c}\text { MODERATELY } \\
\text { AGREE }\end{array}$ & $\begin{array}{c}\text { STRONGLY } \\
\text { AGREE }\end{array}$ \\
\hline $\begin{array}{l}\text { STRONGLY } \\
\text { DISAGREE }\end{array}$ & $\begin{array}{l}\text { MODERATELY } \\
\text { DISAGREE }\end{array}$ & $\begin{array}{l}\text { SLIGHTLY } \\
\text { DISAGREEE }\end{array}$ & NEUTRAL & $\begin{array}{c}\text { SLIGHTIYY } \\
\text { AGREE }\end{array}$ & $\begin{array}{c}\text { MODERATELY } \\
\text { AGREE }\end{array}$ & $\begin{array}{c}\text { STRONGLY } \\
\text { AGREE }\end{array}$ \\
\hline $\begin{array}{l}\text { STRONGLY } \\
\text { DISAGREE }\end{array}$ & $\begin{array}{l}\text { MODERATELY } \\
\text { DISAGREE }\end{array}$ & $\begin{array}{l}\text { SLIGHTLY } \\
\text { DISAGREE }\end{array}$ & NEUTRAL & $\begin{array}{l}\text { SLIGHTLY } \\
\text { AGREE }\end{array}$ & $\begin{array}{l}\text { MODERATELY } \\
\text { AGREE }\end{array}$ & $\begin{array}{c}\text { STRONGLY } \\
\text { AGREE }\end{array}$ \\
\hline $\begin{array}{l}\text { STRONGLY } \\
\text { DISAGREE }\end{array}$ & $\begin{array}{l}\text { MODERATELY } \\
\text { DISAGREE }\end{array}$ & $\begin{array}{l}\text { SLIGHTLY } \\
\text { DISAGREE }\end{array}$ & NEUTRAL & $\begin{array}{c}\text { SLIGHTLY } \\
\text { AGREE }\end{array}$ & $\begin{array}{l}\text { MODERATELY } \\
\text { AGREE }\end{array}$ & $\begin{array}{l}\text { STRONGLY } \\
\text { AGREE }\end{array}$ \\
\hline $\begin{array}{l}\text { STRONGLY } \\
\text { DISAGREE }\end{array}$ & $\begin{array}{l}\text { MODERATELY } \\
\text { DISAGREE }\end{array}$ & $\begin{array}{l}\text { SLIGHTLY } \\
\text { DISAGREEE }\end{array}$ & NEUTRAL & $\begin{array}{c}\text { SLIGHTLY } \\
\text { AGREE }\end{array}$ & $\begin{array}{l}\text { MODERATELY } \\
\text { AGREE }\end{array}$ & $\begin{array}{l}\text { STRONGLY } \\
\text { AGREE }\end{array}$ \\
\hline
\end{tabular}




\section{Section C: Your business environment}

This section is interested in understanding your business environment. Please circle one answer on each line that best represents the extent of your agreement with each statement.

The technology in our industry is changing rapidly.

Technology changes provide big opportunities in our industry.

STRONG DISAGREE

STRONGLY

Many new product ideas have been made possible through technological

breakthroughs in our industry.

Technological developments in our industry are rather minor.

In our kind of business, customers' product preferences change quite a bit over time.

Our customers tend to look for new products all the time.

We are witnessing demand for our products and services from customers who never bought them before.

New customers tend to have productrelated needs that are different from those of our existing customers.

The nature of the market has changed significantly over the last few years.

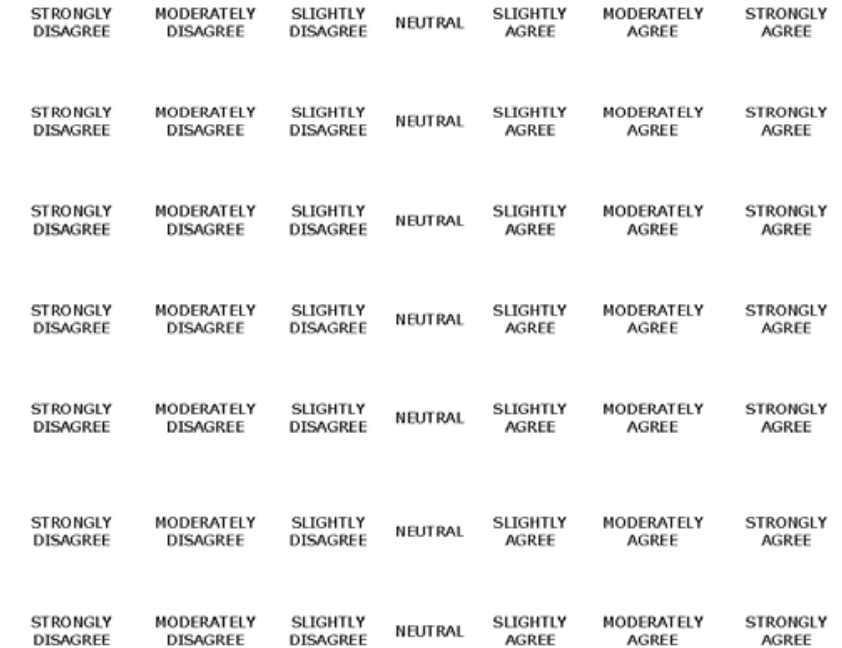

It is important for us to understand your expectations of CRM and your relationship orientation.

My supplier will be able to deliver the right product when I need it.

My supplier will not allow me to run out of inventory.

My supplier better understands my requirements and needs.

I think long-term relationships are good.

If I had to choose I would choose a longterm relationship.

Business relationships provide additional value to my firm.

\begin{tabular}{|c|c|c|c|c|c|c|}
\hline $\begin{array}{l}\text { STRONGLY } \\
\text { DISAGREE }\end{array}$ & $\begin{array}{l}\text { MODERATELY } \\
\text { DISAGREEE }\end{array}$ & $\begin{array}{l}\text { SUGHTIYY } \\
\text { DISAGREE }\end{array}$ & NEUTRAL & $\begin{array}{c}\text { SUIGHTIY } \\
\text { AGREE }\end{array}$ & $\begin{array}{c}\text { MODERATELY } \\
\text { AGREE }\end{array}$ & $\begin{array}{c}\text { STRONGLY } \\
\text { AGREE }\end{array}$ \\
\hline $\begin{array}{l}\text { STRONGLY } \\
\text { DISAGREE }\end{array}$ & $\begin{array}{l}\text { MODERATELY } \\
\text { DISAGREE }\end{array}$ & $\begin{array}{l}\text { SUGHTIYY } \\
\text { DISAGREE }\end{array}$ & NEUTRAL & $\begin{array}{l}\text { SUIGHTIY } \\
\text { AGREE }\end{array}$ & $\begin{array}{l}\text { MODERATELY } \\
\text { AGREE }\end{array}$ & $\begin{array}{c}\text { STRONGLY } \\
\text { AGREE }\end{array}$ \\
\hline $\begin{array}{l}\text { STRONGLY } \\
\text { DISAGREE }\end{array}$ & $\begin{array}{l}\text { MODERATELY } \\
\text { DISAGREEE }\end{array}$ & $\begin{array}{l}\text { SUIGHTLY } \\
\text { DISAGREE }\end{array}$ & MEUTRAL & $\begin{array}{l}\text { SUIGHTLY } \\
\text { AGREE }\end{array}$ & $\begin{array}{l}\text { MODERATELY } \\
\text { AGREE }\end{array}$ & $\begin{array}{c}\text { STRONGLY } \\
\text { AGREE }\end{array}$ \\
\hline $\begin{array}{l}\text { STRONGLY } \\
\text { DISAGREE }\end{array}$ & $\begin{array}{l}\text { MODERATELY } \\
\text { DISAGREE }\end{array}$ & $\begin{array}{l}\text { SUGHTIY } \\
\text { DISAGREE }\end{array}$ & NEUTRAL & $\begin{array}{c}\text { SUIGHTIY } \\
\text { AGREE }\end{array}$ & $\begin{array}{c}\text { MODERATELY } \\
\text { AGREE }\end{array}$ & $\begin{array}{c}\text { STRONGLY } \\
\text { AGREE }\end{array}$ \\
\hline $\begin{array}{l}\text { STRONGLY } \\
\text { DISAGREE }\end{array}$ & $\begin{array}{l}\text { MODERATELY } \\
\text { DISAGREE }\end{array}$ & $\begin{array}{l}\text { SUGHTIYY } \\
\text { DISAGREE }\end{array}$ & NEUTRAL & $\begin{array}{l}\text { SUIGHTIY } \\
\text { AGREE }\end{array}$ & $\begin{array}{l}\text { MODERATELY } \\
\text { AGREE }\end{array}$ & $\begin{array}{l}\text { STRONGLY } \\
\text { AGREE }\end{array}$ \\
\hline $\begin{array}{l}\text { STRONGLY } \\
\text { DISAGREE }\end{array}$ & $\begin{array}{l}\text { MODERATELY } \\
\text { DISAGREEE }\end{array}$ & $\begin{array}{l}\text { SUIGHTLY } \\
\text { DISAGREE }\end{array}$ & NEUTRAL & $\begin{array}{c}\text { SUGGHTIY } \\
\text { AGREE }\end{array}$ & $\begin{array}{c}\text { MODERATELY } \\
\text { AGREE }\end{array}$ & $\begin{array}{c}\text { STRONGLY } \\
\text { AGREE }\end{array}$ \\
\hline
\end{tabular}




\section{Section D: General details about you and your company}

Finally, we would like to ask a few questions about yourself and your company, to help us interpret the results. Please tick the appropriate box for each question. Please note: ALL of the information collected is completely confidential.

Your gender:

$$
\text { Male } \square \text { Female }
$$

Type of industry in which your firm is involved:

$\square$ Manufacturing
$\square$ Wholesale
$\square$ Services
$\square$ Other

Your firm's annual gross revenues:

$$
\begin{aligned}
& \square \text { Up to \$1M } \\
& \square \text { Between \$1M - \$10M } \\
& \square \text { Between \$11M- \$50M } \\
& \square \text { Between \$51M- \$100M } \\
& \square \text { \$100M+ }
\end{aligned}
$$

Number of employees in your company:

Less than 19

Between 20 and 49

Between 50 and 99

$100+$

Length of relationship with this supplier: months

Your full-time working experience:

$$
\begin{aligned}
& \text { Less than } 5 \text { years } \\
& \text { Between } 5 \text { and } 10 \text { years } \\
& \text { Between } 11 \text { and } 15 \text { years } \\
& \text { Between } 16 \text { and } 20 \text { years } \\
& \text { More than } 20 \text { years }
\end{aligned}
$$

Your education level:

$$
\begin{aligned}
& \text { No qualification held } \\
& \text { School certificate } \\
& \text { Some tertiary } \\
& \text { Tertiary qualification } \\
& \text { Post-graduate degree } \\
& \text { Other }
\end{aligned}
$$

Your age:

$$
\begin{aligned}
& \square \text { Under } 26 \text { years } \\
& \text { Between } 26 \text { and } 35 \text { years } \\
& \text { Between } 36 \text { and } 45 \text { years } \\
& \square \text { Between } 46 \text { and } 55 \text { years } \\
& \square \text { Over } 55 \text { years }
\end{aligned}
$$

Your position or title: 
This page intentionally left blank. 
Is there anything else you would like to tell us about CRM technology and its potential impact on business-to-business relationships? If so please use this space for that purpose.

Also, any comments you wish to make that you think may help us in future efforts to understand what business leaders want from CRM technology will be appreciated, either here or in a separate letter.

your contribution to this effort is greatly appreciated. If you would like access to the summary of results, please print your name, address and email on the back of the return envelope ( $\mathcal{N} O \mathcal{T}$ on this questionnaire). We will see that you are notified when the results are available on our web site. 


\section{Appendix A5: Cover Letters}

\section{Personalised Supplier Cover Letter}

This cover letter was sent to the key participant at the supplier firm.

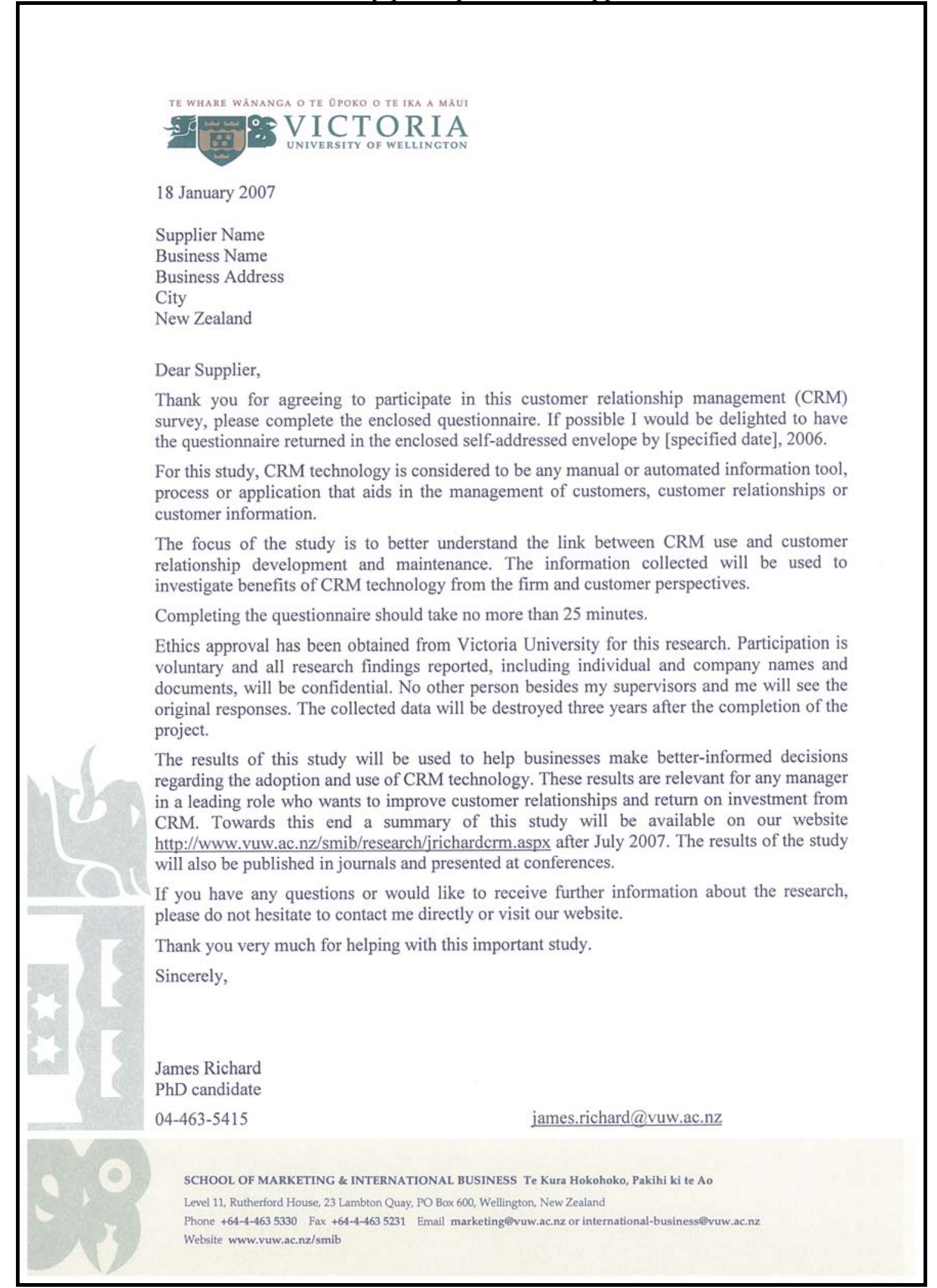




\section{Generic Customer Cover Letter}

This cover letter was used when the customer questionnaire was forwarded on by the supplier.

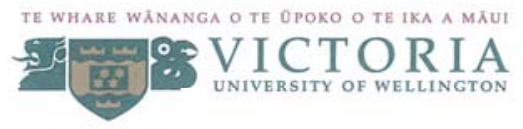

17 January 2007

Thank you for agreeing to participate in this survey.

You have been nominated by your supplier to participate in this customer relationship management (CRM) survey, please complete the enclosed questionnaire. I would be delighted to have the questionnaire returned in the enclosed self-addressed envelope by [specified date], 2006.

One of the unique characteristics of this CRM study is its focus on customer relationship value from the customer perspective, not many studies do this. It is important that the customer's voice be heard and understood in the application of technology. Therefore the information you provide is critical to the study.

The focus of the study is to better understand the link between CRM technology use and customer relationship development and maintenance. The information collected will be used to investigate benefits of CRM technology from the firm and customer perspectives.

Completing the questionnaire should take no more than 15 minutes.

Ethics approval has been obtained from Victoria University for this research. Participation is voluntary and all research findings reported, including individual and company names and documents, will be confidential. No other person besides my supervisors and me will see the original responses. The collected data will be destroyed three years after the completion of the project.

The results of this study will be used to help businesses make better-informed decisions regarding the adoption and use of CRM technology. These results are relevant for any manager in a leading role who wants to improve customer relationships and return on investment from CRM. As a customer completing the survey you will have access to the general survey results, giving you an indication of what to expect in a B2B relationship from suppliers that adopt and use CRM technology. Towards this end a summary of this study will be available on our website http://www.vuw.ac.nz/smib/research/jrichardcrm.aspx after July 2007. The results of the study will also be published in journals and presented at conferences.

If you have any questions or would like to receive further information about the research, please do not hesitate to contact me directly or go to our website.

Thank you very much for helping with this important study.

Sincerely,

James Richard

$\mathrm{PhD}$ candidate

04-463-5415

james.richard@vuw.ac.nz 
This cover letter was used when the customer questionnaire was distributed directly by the researcher.

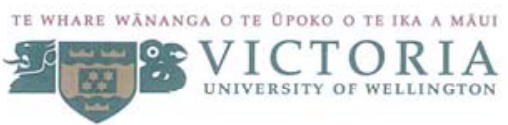

17 January 2007

\author{
Customer Name \\ Business Name \\ Business address \\ City \\ New Zealand
}

\title{
Dear Customer,
}

You have been nominated by Apotex NZ Ltd to participate in this customer relationship management (CRM) survey, please complete the enclosed questionnaire. I would be delighted to have the questionnaire returned in the enclosed self-addressed envelope by [specified date], 2006.

One of the unique characteristics of this CRM study is its focus on customer relationship value from the customer perspective, not many studies do this. It is important that the customer's voice be heard and understood in the application of technology. Therefore the information you provide is critical to the study.

The focus of the study is to better understand the link between CRM technology use and customer relationship development and maintenance. The information collected will be used to investigate benefits of CRM technology from the firm and customer perspectives.

Completing the questionnaire should take no more than 15 minutes.

Ethics approval has been obtained from Victoria University for this research. Participation is voluntary and all research findings reported, including individual and company names and documents, will be confidential. No other person besides my supervisors and me will see the original responses. The collected data will be destroyed three years after the completion of the project.

The results of this study will be used to help businesses make better-informed decisions regarding the adoption and use of CRM technology. These results are relevant for any manager in a leading role who wants to improve customer relationships and return on investment from CRM. As a customer completing the survey you will have access to the general survey results, giving you an indication of what to expect in a B2B relationship from suppliers that adopt and use CRM technology. Towards this end a summary of this study will be available on our website http://www.vuw.ac.nz/smib/research/jrichardcrm.aspx after July 2007. The results of the study will also be published in journals and presented at conferences.

If you have any questions or would like to receive further information about the research, please do not hesitate to contact me directly or go to our website.

Thank you very much for helping with this important study.

Sincerely,

James Richard

$\mathrm{PhD}$ candidate

04-463-5415

james.richard@vuw.ac.nz

SCHOOL OF MARKETING \& INTERNATIONAL BUSINESS Te Kura Hokohoko, Pakihi ki te Ao

Level 11, Rutherford House, 23 Lambton Quay, PO Box 600, Wellington, New Zealand

Phone +64-4-4635330 Fax +64-4-4635231 Email marketing@vuw.ac.nz or international-business@vuw.ac.nz

Website www.vuw.ac.nz/smib 
Appendix A6: Summary of Supplier Respondent Demographic Information

Table A6.1: Respondent's Gender $(n=113)$

\begin{tabular}{lccc}
\hline \multicolumn{3}{c}{ Respondent's Sex } \\
\hline & Male & Female & Total \\
Frequency & 99 & 14 & 113 \\
Percent & 87.6 & 12.4 & \\
\hline
\end{tabular}

Table A6.2: Reported Gross Revenues $(n=113)$

\begin{tabular}{lcccccc}
\hline & \multicolumn{7}{c}{ Gross Revenue } \\
& Less & & & & & \\
& than & $\$ 1 \mathrm{~m}-$ & $\mathbf{\$ 1} \mathbf{m}-$ & $\mathbf{\$ 1 m}-$ & Over & \\
& $\$ 1 \mathrm{~m}$ & $\mathbf{\$ 1 0 \mathrm { m }}$ & $\mathbf{\$ 5 0 m}$ & $\mathbf{\$ 1 0 0 m}$ & $\mathbf{\$ 1 0 0 m}$ & Total \\
Frequency & 2 & 50 & 40 & 8 & 13 & 113 \\
Percent & $1.8 \%$ & $44.2 \%$ & $35.4 \%$ & $7.1 \%$ & $11.5 \%$ & \\
\hline
\end{tabular}

Table A6.3: Reported Work Experience $(n=113)$

\begin{tabular}{lcccccc}
\hline & \multicolumn{7}{c}{ Work Experience } \\
& Less & & & More \\
& than 5 & $\mathbf{5 - 1 0}$ & $\mathbf{1 1 - 1 5}$ & $\mathbf{1 6 - 2 0}$ & than 20 & \\
& years & years & years & years & years & Total \\
Frequency & 2 & 4 & 5 & 14 & 88 & 113 \\
Percent & $1.8 \%$ & $3.5 \%$ & $4.4 \%$ & $12.4 \%$ & $77.9 \%$ & \\
\hline
\end{tabular}

Table A6.4: Reported Education Level $(n=113)$

\begin{tabular}{lcc}
\hline \multicolumn{3}{c}{ Education Level } \\
\hline & Frequency & Percent \\
\hline No qualification & 5 & $4.40 \%$ \\
School certification & 15 & $13.30 \%$ \\
Some tertiary & 24 & $21.20 \%$ \\
Tertiary qualification & 44 & $38.90 \%$ \\
Post-graduate & 18 & $15.90 \%$ \\
Other & 6 & $5.30 \%$ \\
Total & $\mathbf{1 1 2}$ & \\
\hline
\end{tabular}

Table A6.5: Respondent Age $(n=113)$

\begin{tabular}{lcccccc}
\hline & \multicolumn{7}{c}{ Respondent Age } \\
& Under & & & & & \\
& $\mathbf{2 6}$ & $\mathbf{2 6 - 3 5}$ & $\mathbf{3 6 - \mathbf { 4 5 }}$ & $\mathbf{4 6 - 5 5}$ & Over $\mathbf{5 5}$ & \\
& years & years & years & years & years & Total \\
Frequency & 1 & 10 & 42 & 40 & 19 & 112 \\
Percent & $0.9 \%$ & $8.8 \%$ & $37.2 \%$ & $35.4 \%$ & $16.8 \%$ & \\
\hline
\end{tabular}


Table A6.6: Reported Relationship Length $(n=113)$

\begin{tabular}{|c|c|c|}
\hline \multicolumn{3}{|c|}{ Relationship Length } \\
\hline Years & Frequency & Percent \\
\hline 0.5 & 1 & $0.9 \%$ \\
\hline 1.0 & 1 & $0.9 \%$ \\
\hline 1.8 & 1 & $0.9 \%$ \\
\hline 2.0 & 4 & $3.5 \%$ \\
\hline 2.3 & 1 & $0.9 \%$ \\
\hline 2.5 & 1 & $0.9 \%$ \\
\hline 3.0 & 8 & $7.1 \%$ \\
\hline 4.0 & 3 & $2.7 \%$ \\
\hline 4.3 & 2 & $1.8 \%$ \\
\hline 5.0 & 15 & $13.3 \%$ \\
\hline 5.2 & 1 & $0.9 \%$ \\
\hline 5.8 & 1 & $0.9 \%$ \\
\hline 6.0 & 5 & $4.4 \%$ \\
\hline 7.0 & 4 & $3.5 \%$ \\
\hline 8.0 & 6 & $5.3 \%$ \\
\hline 9.0 & 1 & $0.9 \%$ \\
\hline 9.5 & 1 & $0.9 \%$ \\
\hline 10.0 & 16 & $14.2 \%$ \\
\hline 10.1 & 1 & $0.9 \%$ \\
\hline 10.6 & 1 & $0.9 \%$ \\
\hline 10.9 & 1 & $0.9 \%$ \\
\hline 11.0 & 1 & $0.9 \%$ \\
\hline 12.0 & 2 & $1.8 \%$ \\
\hline 13.0 & 1 & $0.9 \%$ \\
\hline 14.0 & 2 & $1.8 \%$ \\
\hline 15.0 & 8 & $7.1 \%$ \\
\hline 16.0 & 3 & $2.7 \%$ \\
\hline 18.0 & 1 & $0.9 \%$ \\
\hline 20.0 & 9 & $8.0 \%$ \\
\hline 25.0 & 3 & $2.7 \%$ \\
\hline 26.0 & 1 & $0.9 \%$ \\
\hline 26.4 & 1 & $0.9 \%$ \\
\hline 32.0 & 1 & $0.9 \%$ \\
\hline 55.0 & 1 & $0.9 \%$ \\
\hline Total & 109 & $96.5 \%$ \\
\hline
\end{tabular}


Table A6.7: Reported Work Activity $(n=113)$

\begin{tabular}{|c|c|c|}
\hline \multicolumn{3}{|c|}{ Work Position/Title } \\
\hline Position & Frequency & Percent \\
\hline$A D$ & 1 & $0.9 \%$ \\
\hline Adm & 1 & $0.9 \%$ \\
\hline AM & 2 & $1.8 \%$ \\
\hline $\mathrm{BD}$ & 1 & $0.9 \%$ \\
\hline BDM & 4 & $3.5 \%$ \\
\hline BM & 5 & $4.4 \%$ \\
\hline BS & 1 & $0.9 \%$ \\
\hline CEO & 3 & $2.7 \%$ \\
\hline CFO & 1 & $0.9 \%$ \\
\hline Con & 3 & $2.7 \%$ \\
\hline CSM & 2 & $1.8 \%$ \\
\hline $\mathrm{D}$ & 18 & $15.9 \%$ \\
\hline FC & 1 & $0.9 \%$ \\
\hline GM & 12 & $10.6 \%$ \\
\hline KAM & 3 & $2.7 \%$ \\
\hline $\mathrm{M}$ & 1 & $0.9 \%$ \\
\hline MD & 13 & $11.5 \%$ \\
\hline Mgr & 3 & $2.7 \%$ \\
\hline MM & 2 & $1.8 \%$ \\
\hline MP & 1 & $0.9 \%$ \\
\hline OM & 2 & $1.8 \%$ \\
\hline Ptr & 1 & $0.9 \%$ \\
\hline RM & 3 & $2.7 \%$ \\
\hline S\&M & 3 & $2.7 \%$ \\
\hline SD & 3 & $2.7 \%$ \\
\hline SE & 1 & $0.9 \%$ \\
\hline SM & 18 & $15.9 \%$ \\
\hline SMM & 1 & $0.9 \%$ \\
\hline SR & 1 & $0.9 \%$ \\
\hline Sv M & 1 & $0.9 \%$ \\
\hline$A D$ & 1 & $0.9 \%$ \\
\hline Adm & 1 & $0.9 \%$ \\
\hline $\mathrm{AM}$ & 2 & $1.8 \%$ \\
\hline $\mathrm{BD}$ & 1 & $0.9 \%$ \\
\hline Total & 112 & \\
\hline
\end{tabular}

Table A6.8: Reported Work Position/Title $(n=113)$

\begin{tabular}{lcc}
\hline \multicolumn{3}{c}{ Work Position/Title } \\
\hline \multicolumn{1}{c}{ Position } & Frequency & Percent \\
Executive & 48 & $42.5 \%$ \\
Sales & 41 & $36.3 \%$ \\
Marketing & 19 & $16.8 \%$ \\
Administration & 4 & $3.5 \%$ \\
$\quad$ Total & 112 & \\
\hline
\end{tabular}




\section{Appendix A7: Test for Non-response Bias}

Table A7.1: Late Supplier Respondent Demographic Statistics $(n=113)$

\begin{tabular}{lllccc}
\hline & & & $\begin{array}{c}\text { Std. } \\
\text { Deviation }\end{array}$ & $\begin{array}{c}\text { Std. Error } \\
\text { Mean }\end{array}$ \\
\hline Industry Segment & Late & 14 & 2.21 & 1.05 & 0.28 \\
& General & 99 & 2.19 & 1.00 & 0.10 \\
Gross Revenues & Late & 14 & 2.86 & 1.03 & 0.27 \\
& General & 99 & 2.83 & 1.00 & 0.10 \\
Number of Employees & Late & 14 & 2.50 & 1.22 & 0.33 \\
& General & 99 & 2.74 & 0.91 & 0.09 \\
Relationship Length & Late & 14 & 14.94 & 7.65 & 2.04 \\
Work Experience & General & 99 & 9.81 & 7.77 & 0.78 \\
& Late & 14 & 5.00 & 0.00 & 0.00 \\
Education Level & General & 99 & 4.54 & 0.92 & 0.09 \\
& Late & 14 & 3.79 & 0.97 & 0.26 \\
Respondent Age & General & 99 & 4.68 & 9.65 & 0.97 \\
& Late & 14 & 4.07 & 0.83 & 0.22 \\
& General & 99 & 4.45 & 9.65 & 0.97 \\
\hline
\end{tabular}

Table A7.2: Late Supplier Respondent CTA Response Statistics $(n=113)$

\begin{tabular}{llcccc}
\hline & N & Mean & $\begin{array}{c}\text { Std. } \\
\text { Deviation }\end{array}$ & $\begin{array}{c}\text { Std. Error } \\
\text { Mean }\end{array}$ \\
\hline CKN & General & 14 & 99 & 4.535 & 1.179 \\
$\begin{array}{l}\text { Customer } \\
\text { Knowledge }\end{array}$ & Late & 99 & 14 & 4.514 & 1.186 \\
\hline USF & General & 14 & 99 & 5.990 & 0.926 \\
CRM & Late & 99 & 14 & 5.653 & 0.929 \\
Usefulness & & & & &
\end{tabular}


Table A7.3: Comparing Late Supplier Respondent Demographics $(n=113)$

\begin{tabular}{|c|c|c|c|c|c|c|c|c|c|c|}
\hline & & \multicolumn{2}{|c|}{$\begin{array}{l}\text { Levene's Test for } \\
\text { Equality of Variances }\end{array}$} & \multicolumn{7}{|c|}{ t-test for Equality of Means } \\
\hline & & \multirow[t]{2}{*}{$\mathrm{F}$} & \multirow{2}{*}{ Sig. } & \multirow[t]{2}{*}{$\mathrm{t}$} & \multirow[t]{2}{*}{ df } & \multirow[t]{2}{*}{$\begin{array}{l}\text { Sig. }(2- \\
\text { tailed })\end{array}$} & \multirow[t]{2}{*}{$\begin{array}{c}\text { Mean } \\
\text { Difference }\end{array}$} & \multirow[t]{2}{*}{$\begin{array}{l}\text { Std. Error } \\
\text { Difference }\end{array}$} & \multicolumn{2}{|c|}{$\begin{array}{l}95 \% \text { Confidence Interval } \\
\text { of the Difference }\end{array}$} \\
\hline & & & & & & & & & Lower & Upper \\
\hline \multirow[t]{2}{*}{ Industry Segment } & \multirow{2}{*}{$\begin{array}{l}\text { Equal variances assumed } \\
\text { Equal variances not } \\
\text { assumed }\end{array}$} & \multirow[t]{2}{*}{0.00} & \multirow[t]{2}{*}{0.99} & 0.08 & 111.00 & 0.94 & 0.02 & 0.29 & -0.55 & 0.59 \\
\hline & & & & 0.08 & 16.48 & 0.94 & 0.02 & 0.30 & -0.61 & 0.65 \\
\hline \multirow[t]{2}{*}{ Gross Revenues } & \multirow{2}{*}{$\begin{array}{l}\text { Equal variances assumed } \\
\text { Equal variances not } \\
\text { assumed }\end{array}$} & \multirow[t]{2}{*}{0.18} & \multirow[t]{2}{*}{0.67} & 0.10 & 111.00 & 0.92 & 0.03 & 0.29 & -0.54 & 0.60 \\
\hline & & & & 0.10 & 16.68 & 0.92 & 0.03 & 0.29 & -0.59 & 0.65 \\
\hline \multirow{2}{*}{$\begin{array}{l}\text { Number of } \\
\text { Employees }\end{array}$} & Equal variances assumed & \multirow[t]{2}{*}{4.72} & \multirow[t]{2}{*}{0.03} & -0.87 & 111.00 & 0.38 & -0.24 & 0.27 & -0.78 & 0.30 \\
\hline & $\begin{array}{l}\text { Equal variances not } \\
\text { assumed }\end{array}$ & & & -0.70 & 15.10 & 0.50 & -0.24 & 0.34 & -0.96 & 0.49 \\
\hline \multirow{2}{*}{$\begin{array}{l}\text { Relationship } \\
\text { Length }\end{array}$} & Equal variances assumed & \multirow[t]{2}{*}{0.25} & \multirow[t]{2}{*}{0.62} & 2.32 & 111.00 & $0.02^{*}$ & 5.13 & 2.21 & 0.74 & 9.52 \\
\hline & $\begin{array}{l}\text { Equal variances not } \\
\text { assumed }\end{array}$ & & & 2.34 & 17.02 & 0.03 & 5.13 & 2.19 & 0.51 & 9.75 \\
\hline \multirow[t]{2}{*}{ Work Experience } & \multirow{2}{*}{$\begin{array}{l}\text { Equal variances assumed } \\
\text { Equal variances not } \\
\text { assumed }\end{array}$} & \multirow[t]{2}{*}{17.69} & \multirow[t]{2}{*}{0.00} & 1.89 & 111.00 & 0.06 & 0.46 & 0.25 & -0.02 & 0.95 \\
\hline & & & & 5.03 & 98.00 & $0.00^{* *}$ & 0.46 & 0.09 & 0.28 & 0.65 \\
\hline \multirow[t]{2}{*}{ Education Level } & \multirow{2}{*}{$\begin{array}{l}\text { Equal variances assumed } \\
\text { Equal variances not } \\
\text { assumed }\end{array}$} & \multirow[t]{2}{*}{0.33} & \multirow[t]{2}{*}{0.57} & -0.34 & 111.00 & 0.73 & -0.89 & 2.59 & -6.02 & 4.24 \\
\hline & & & & -0.89 & 108.40 & 0.38 & -0.89 & 1.00 & -2.88 & 1.10 \\
\hline \multirow[t]{2}{*}{ Respondent Age } & \multirow{2}{*}{$\begin{array}{l}\text { Equal variances assumed } \\
\text { Equal variances not } \\
\text { assumed }\end{array}$} & \multirow[t]{2}{*}{0.31} & 0.58 & -0.15 & 111.00 & 0.88 & -0.38 & 2.59 & -5.51 & 4.75 \\
\hline & & & & -0.39 & 106.32 & 0.70 & -0.38 & 0.99 & -2.35 & 1.59 \\
\hline
\end{tabular}


Table A7.4: Comparing Late Supplier Respondent CTA Responses $(n=113)$

\begin{tabular}{|c|c|c|c|c|c|c|c|c|c|c|}
\hline & & \multicolumn{2}{|c|}{$\begin{array}{l}\text { Levene's Test for } \\
\text { Equality of Variances }\end{array}$} & \multicolumn{7}{|c|}{ t-test for Equality of Means } \\
\hline & & \multirow[t]{2}{*}{$\mathrm{F}$} & \multirow{2}{*}{ Sig. } & \multirow[t]{2}{*}{$\mathrm{t}$} & \multirow[t]{2}{*}{$d f$} & \multirow[t]{2}{*}{$\begin{array}{l}\text { Sig. }(2- \\
\text { tailed) }\end{array}$} & \multirow[t]{2}{*}{$\begin{array}{c}\text { Mean } \\
\text { Difference }\end{array}$} & \multirow[t]{2}{*}{$\begin{array}{l}\text { Std. Error } \\
\text { Difference }\end{array}$} & \multicolumn{2}{|c|}{$\begin{array}{l}95 \% \text { Confidence Interval } \\
\text { of the Difference }\end{array}$} \\
\hline & & & & & & & & & Lower & Upper \\
\hline \multirow{2}{*}{$\begin{array}{l}\text { CKN } \\
\text { Customer } \\
\text { Knowledge }\end{array}$} & \multirow{2}{*}{$\begin{array}{l}\text { Equal variances assumed } \\
\text { Equal variances not } \\
\text { assumed }\end{array}$} & 0.009 & 0.926 & 0.063 & 111.00 & 0.950 & 0.021 & 0.337 & -0.647 & 0.689 \\
\hline & & & & 0.062 & 16.84 & 0.951 & 0.021 & 0.339 & -0.694 & 0.736 \\
\hline \multirow{2}{*}{$\begin{array}{l}\text { USF } \\
\text { CRM } \\
\text { Usefulness }\end{array}$} & \multirow{2}{*}{$\begin{array}{l}\text { Equal variances assumed } \\
\text { Equal variances not } \\
\text { assumed }\end{array}$} & 0.028 & 0.867 & 1.274 & 111.00 & 0.205 & 0.337 & 0.264 & -0.187 & 0.861 \\
\hline & & & & 1.271 & 16.87 & 0.221 & 0.337 & 0.265 & -0.223 & 0.896 \\
\hline
\end{tabular}

No significant differences between late respondents and general respondents 


\section{Appendix A8: Analysis of Supplier "Do Not Know" Answers}

Table A8.1: Supplier “Do Not Know” Response Statistics $(\mathbf{n}=150)$

\begin{tabular}{|c|c|c|c|c|c|c|c|c|c|c|c|c|c|c|c|c|c|c|c|c|c|c|c|}
\hline & $\begin{array}{l}\text { CODE } \\
\text { NAME }\end{array}$ & $\begin{array}{r}\text { IMP } \\
\text { BO }\end{array}$ & $\begin{array}{l}\text { IMP } \\
\text { INV }\end{array}$ & $\begin{array}{l}\text { IMP } \\
\text { ITCS }\end{array}$ & $\begin{array}{l}\text { IMP } \\
\text { ITPS }\end{array}$ & $\begin{array}{l}\text { IMP }_{-} \\
\text {ITQL }\end{array}$ & $\begin{array}{l}\text { IMP } \\
\text { ITPR }\end{array}$ & $\begin{array}{l}\text { IMC } \\
\text { ITDV }\end{array}$ & $\begin{array}{l}\text { IMC } \\
\text { ITOP }\end{array}$ & $\begin{array}{l}\text { IMC } \\
\text { ITAP }\end{array}$ & $\begin{array}{l}\text { IMC } \\
\text { ITFN }\end{array}$ & $\begin{array}{l}\text { IMC } \\
\text { ITGL }\end{array}$ & $\begin{array}{l}\text { IMC } \\
\text { ITPR }\end{array}$ & $\begin{array}{l}\text { IMO_- } \\
\text { IDS }\end{array}$ & $\begin{array}{c}\text { IMO_- } \\
\text { BS }\end{array}$ & $\begin{array}{c}\text { IMO_ } \\
\text { STR }\end{array}$ & $\begin{array}{l}\text { IMO_ } \\
\text { USR }\end{array}$ & $\begin{array}{l}\text { IMA } \\
\text { STR }\end{array}$ & $\begin{array}{c}\text { IMA } \\
\text { INFF }\end{array}$ & $\begin{array}{l}\text { IMA } \\
\text { ITDV }\end{array}$ & $\begin{array}{l}\text { IMA } \\
\text { BCL }\end{array}$ & "DNK" & \% "DNK" \\
\hline 1 & 1006 & 7 & 5 & 5 & 5 & 6 & 1 & 2 & 2 & 1 & 3 & 2 & 5 & 3 & 2 & 1 & 3 & 8 & 3 & 2 & 6 & 1 & $5.0 \%$ \\
\hline 2 & 3113 & 7 & 6 & 6 & 6 & 6 & 4 & 6 & 7 & 5 & 6 & 6 & 4 & 6 & 5 & 3 & 5 & 7 & 6 & 6 & 8 & 1 & $5.0 \%$ \\
\hline 3 & 3278 & 5 & 3 & 2 & 2 & 3 & 8 & 1 & 1 & 1 & 1 & 1 & 1 & 1 & 1 & 5 & 1 & 2 & 2 & 2 & 2 & 1 & $5.0 \%$ \\
\hline 4 & 3322 & 5 & 2 & 2 & 3 & 3 & 8 & 2 & 5 & 4 & 3 & 4 & 4 & 5 & 3 & 2 & 3 & 6 & 3 & 4 & 3 & 1 & $5.0 \%$ \\
\hline 5 & B2120 & 5 & 4 & 6 & 6 & 6 & 6 & 6 & 6 & 8 & 4 & 4 & 4 & 6 & 7 & 6 & 6 & 4 & 3 & 3 & 2 & 1 & $5.0 \%$ \\
\hline 6 & B3153 & 6 & 3 & 4 & 3 & 5 & 3 & 4 & 4 & 3 & 8 & 3 & 5 & 2 & 4 & 4 & 5 & 6 & 6 & 2 & 3 & 1 & $5.0 \%$ \\
\hline 7 & 3189 & 7 & 7 & 6 & 6 & 7 & 6 & 7 & 7 & 5 & 6 & 6 & 6 & 6 & 7 & 7 & 7 & 7 & 8 & 7 & 8 & 2 & $10.0 \%$ \\
\hline 8 & 3035 & 5 & 3 & 4 & 4 & 6 & 6 & 6 & 6 & 5 & 6 & 8 & 8 & 5 & 6 & 7 & 7 & 4 & 4 & 5 & 8 & 3 & $15.0 \%$ \\
\hline 9 & 3121 & 6 & 1 & 5 & 5 & 7 & 8 & 6 & 7 & 8 & 7 & 7 & 7 & 2 & 6 & 2 & 7 & 8 & 7 & 1 & 2 & 3 & $15.0 \%$ \\
\hline 10 & B1232 & 4 & 5 & 7 & 7 & 8 & 6 & 6 & 6 & 5 & 6 & 6 & 5 & 4 & 4 & 4 & 5 & 6 & 6 & 8 & 8 & 3 & $15.0 \%$ \\
\hline 11 & B1064 & 6 & 6 & 7 & 8 & 6 & 8 & 6 & 6 & 7 & 8 & 6 & 6 & 7 & 7 & 7 & 7 & 7 & 8 & 7 & 7 & 4 & $20.0 \%$ \\
\hline 12 & B1205 & 6 & 6 & 6 & 4 & 6 & 3 & 4 & 6 & 6 & 4 & 5 & 6 & 6 & 6 & 8 & 8 & 7 & 8 & 6 & 8 & 4 & $20.0 \%$ \\
\hline 13 & 1043 & 3 & 8 & 8 & 8 & 3 & 4 & 4 & 3 & 8 & 8 & 8 & 8 & 5 & 5 & 5 & 3 & 3 & 8 & 2 & 2 & 8 & $40.0 \%$ \\
\hline 14 & 3147 & 6 & 8 & 8 & 5 & 6 & 3 & 2 & 2 & 2 & 8 & 8 & 8 & 4 & 4 & 8 & 8 & 6 & 8 & 8 & 8 & 10 & $50.0 \%$ \\
\hline 15 & 1111 & 7 & 7 & 8 & 8 & 8 & 8 & 8 & 8 & 8 & 8 & 7 & 7 & 8 & 6 & 6 & 8 & 8 & 8 & 8 & 8 & 14 & $70.0 \%$ \\
\hline 16 & B2022 & 8 & 8 & 8 & 8 & 8 & 8 & 8 & 8 & 8 & 8 & 8 & 8 & 8 & 8 & 8 & 8 & 8 & 8 & 8 & 8 & 20 & $100.0 \%$ \\
\hline
\end{tabular}

Table 5C.1 shows the frequency (16) and occurrence of "Do Not Know" responses from the Supplier survey (10.7\%). Case numbers 1111 and B2022 (1.3\%) were deleted from the final analysis due to the high number of DNK item responses. 
Table A8.2: Comparing Supplier “Do Not Know” Respondent CTA Construct Responses (n = 115)

\begin{tabular}{|c|c|c|c|c|c|c|c|c|c|c|}
\hline & & \multicolumn{2}{|c|}{$\begin{array}{l}\text { Levene's Test for } \\
\text { Equality of Variances }\end{array}$} & \multicolumn{7}{|c|}{ t-test for Equality of Means } \\
\hline & & \multirow[t]{2}{*}{$\mathrm{F}$} & \multirow[t]{2}{*}{ Sig. } & \multirow[t]{2}{*}{$\mathrm{t}$} & \multirow[t]{2}{*}{ df } & \multirow[t]{2}{*}{$\begin{array}{l}\text { Sig. }(2- \\
\text { tailed) }\end{array}$} & \multirow[t]{2}{*}{$\begin{array}{c}\text { Mean } \\
\text { Difference }\end{array}$} & \multirow[t]{2}{*}{$\begin{array}{l}\text { Std. Error } \\
\text { Difference }\end{array}$} & \multicolumn{2}{|c|}{$\begin{array}{c}\text { 95\% Confidence Interval } \\
\text { of the Difference }\end{array}$} \\
\hline & & & & & & & & & Lower & Upper \\
\hline CKN & Equal variances assumed & 0.023 & 0.880 & 1.612 & 113.00 & 0.110 & 0.552 & 0.342 & -0.126 & 1.229 \\
\hline $\begin{array}{l}\text { Customer } \\
\text { Knowledge }\end{array}$ & Equal variances not assumed & & & 1.574 & 15.02 & 0.136 & 0.552 & 0.350 & -0.195 & 1.298 \\
\hline USF & Equal variances assumed & 0.308 & 0.580 & -0.318 & 113.00 & 0.751 & -0.088 & 0.276 & -0.635 & 0.459 \\
\hline $\begin{array}{l}\text { CRM } \\
\text { Usefulness }\end{array}$ & Equal variances not assumed & & & -0.321 & 15.29 & 0.753 & -0.088 & 0.274 & -0.671 & 0.495 \\
\hline
\end{tabular}

No significant differences between "DNK" and non-DNK respondents. 
Appendix A9: Survey Data Distribution

Table A9.1: Supplier Survey Data

\begin{tabular}{|c|c|c|c|c|c|c|}
\hline & Mean & $\begin{array}{c}\text { Std. } \\
\text { Deviation }\end{array}$ & Skewness & $\begin{array}{l}\text { Std. Error } \\
\text { Skewness }\end{array}$ & Kurtosis & $\begin{array}{l}\text { Std. Error } \\
\text { Kurtosis }\end{array}$ \\
\hline RMC_IT & 5.25 & 1.44 & -0.67 & 0.23 & -0.24 & 0.45 \\
\hline CPR_TLS & 4.56 & 1.42 & -0.26 & 0.23 & -0.04 & 0.45 \\
\hline CPR_CC & 4.25 & 1.80 & -0.21 & 0.23 & -0.93 & 0.45 \\
\hline CPR_CS & 4.29 & 1.71 & -0.13 & 0.23 & -0.84 & 0.45 \\
\hline CPR_SYS & 4.63 & 1.96 & -0.40 & 0.23 & -1.08 & 0.45 \\
\hline CAN_SRCS & 5.23 & 1.36 & -0.44 & 0.23 & -0.61 & 0.45 \\
\hline CAN_CST & 4.87 & 1.44 & -0.42 & 0.23 & -0.22 & 0.45 \\
\hline CAN_TLS & 4.76 & 1.55 & -0.59 & 0.23 & -0.16 & 0.45 \\
\hline RMC_PTS & 4.81 & 1.30 & -0.27 & 0.23 & -0.08 & 0.45 \\
\hline RMC_PR & 4.22 & 1.41 & -0.09 & 0.23 & -0.46 & 0.45 \\
\hline RMC_Cl & 4.15 & 1.86 & -0.24 & 0.23 & -0.96 & 0.45 \\
\hline RMC_INT & 4.72 & 1.63 & -0.41 & 0.23 & -0.83 & 0.45 \\
\hline RMC_CDB & 5.02 & 1.47 & -0.40 & 0.23 & -0.37 & 0.45 \\
\hline STC_CK & 5.02 & 1.43 & -0.40 & 0.23 & -0.60 & 0.45 \\
\hline STC_DM & 5.28 & 1.17 & -0.70 & 0.23 & 0.10 & 0.45 \\
\hline STC_CSTID & 4.54 & 1.48 & -0.09 & 0.23 & -0.64 & 0.45 \\
\hline STC_CMPID & 3.90 & 1.69 & 0.13 & 0.23 & -0.69 & 0.45 \\
\hline CEX_PRDV & 4.70 & 1.48 & -0.58 & 0.23 & -0.35 & 0.45 \\
\hline CEX_CSTV & 5.25 & 1.30 & -0.95 & 0.23 & 1.04 & 0.45 \\
\hline CEX BSD & 5.74 & 0.97 & -0.67 & 0.23 & 0.24 & 0.45 \\
\hline CEX_CSVP & 5.17 & 1.28 & -0.67 & 0.23 & 0.36 & 0.45 \\
\hline PEU_USE & 5.17 & 1.61 & -0.93 & 0.23 & -0.40 & 0.45 \\
\hline PEU_NTR & 5.43 & 1.43 & -0.89 & 0.23 & -0.07 & 0.45 \\
\hline PEU EFRT & 4.70 & 1.76 & -0.56 & 0.23 & -0.86 & 0.45 \\
\hline PEU_ETU & 5.16 & 1.59 & -0.89 & 0.23 & -0.20 & 0.45 \\
\hline PEU_ETD & 4.62 & 1.61 & -0.51 & 0.23 & -0.89 & 0.45 \\
\hline PU_PRF & 5.90 & 1.05 & -1.01 & 0.23 & 0.54 & 0.45 \\
\hline PU_PRD & 5.81 & 1.21 & -1.12 & 0.23 & 1.02 & 0.45 \\
\hline PU_EFT & 5.92 & 1.01 & -0.83 & 0.23 & 0.32 & 0.45 \\
\hline PU_USFL & 6.15 & 0.96 & -1.40 & 0.23 & 2.80 & 0.45 \\
\hline CAD_FRQS & 4.83 & 1.42 & -0.49 & 0.23 & -0.04 & 0.45 \\
\hline ATU_NTRS & 4.97 & 1.41 & -0.44 & 0.23 & -0.51 & 0.45 \\
\hline ATU_FUN & 4.50 & 1.40 & -0.26 & 0.23 & 0.26 & 0.45 \\
\hline ATU_LIKE & 5.08 & 1.38 & -0.49 & 0.23 & -0.35 & 0.45 \\
\hline RAD_TIM (RC) & 2.82 & 1.48 & 0.93 & 0.23 & 0.65 & 0.45 \\
\hline RAD_ESY & 5.86 & 1.11 & -1.22 & 0.23 & 1.78 & 0.45 \\
\hline CAD_DALY & 5.60 & 1.60 & -1.08 & 0.23 & 0.15 & 0.45 \\
\hline CNT_CMP (RC) & 4.32 & 1.78 & -0.30 & 0.23 & -0.98 & 0.45 \\
\hline CNT_NTPRS & 4.68 & 2.02 & -0.52 & 0.23 & -1.09 & 0.45 \\
\hline ATU_GOOD & 6.37 & 0.87 & -2.00 & 0.23 & 5.68 & 0.45 \\
\hline ITU_NTND & 6.37 & 1.20 & -2.52 & 0.23 & 6.66 & 0.45 \\
\hline ITU_PRD & 6.34 & 1.20 & -2.27 & 0.23 & 5.40 & 0.45 \\
\hline CLK_SA & 0.22 & 0.41 & 1.39 & 0.23 & -0.07 & 0.45 \\
\hline CLK_SLS & 0.65 & 0.48 & -0.65 & 0.23 & -1.61 & 0.45 \\
\hline CLK_CS & 0.48 & 0.50 & 0.09 & 0.23 & -2.03 & 0.45 \\
\hline CLK_MRK & 0.36 & 0.48 & 0.61 & 0.23 & -1.66 & 0.45 \\
\hline CLK_ACR & 0.57 & 0.50 & -0.30 & 0.23 & -1.94 & 0.45 \\
\hline CLK_FIN & 0.49 & 0.50 & 0.05 & 0.23 & -2.03 & 0.45 \\
\hline CLK_LOG & 0.36 & 0.48 & 0.61 & 0.23 & -1.66 & 0.45 \\
\hline CLK_OPS & 0.43 & 0.50 & 0.27 & 0.23 & -1.96 & 0.45 \\
\hline CLK_EIS & 0.24 & 0.43 & 1.21 & 0.23 & -0.54 & 0.45 \\
\hline CLK_ERP & 0.14 & 0.35 & 2.11 & 0.23 & 2.51 & 0.45 \\
\hline CLK_EDI & 0.16 & 0.36 & 1.92 & 0.23 & 1.70 & 0.45 \\
\hline IMP_BO & 5.82 & 1.24 & -1.30 & 0.23 & 1.87 & 0.45 \\
\hline IMP INV & 5.03 & 1.59 & -0.67 & 0.23 & -0.36 & 0.45 \\
\hline
\end{tabular}




\begin{tabular}{|c|c|c|c|c|c|c|}
\hline & Mean & $\begin{array}{c}\text { Std. } \\
\text { Deviation }\end{array}$ & Skewness & $\begin{array}{l}\text { Std. Error } \\
\text { Skewness }\end{array}$ & Kurtosis & $\begin{array}{c}\text { Std. Error } \\
\text { Kurtosis }\end{array}$ \\
\hline IMP_ITCS & 4.90 & 1.66 & -0.56 & 0.23 & -0.49 & 0.45 \\
\hline IMP ITPS & 4.85 & 1.63 & -0.69 & 0.23 & -0.16 & 0.45 \\
\hline IMP ITQL & 5.50 & 1.43 & -0.98 & 0.23 & 0.38 & 0.45 \\
\hline IMP ITPR & 4.83 & 1.56 & -0.59 & 0.23 & -0.67 & 0.45 \\
\hline IMC_ITDV & 5.05 & 1.67 & -0.61 & 0.23 & -0.82 & 0.45 \\
\hline IMC_ITOP & 5.29 & 1.61 & -0.89 & 0.23 & -0.28 & 0.45 \\
\hline IMC_ITAP & 4.99 & 1.51 & -0.49 & 0.23 & -0.48 & 0.45 \\
\hline IMC_ITFN & 4.99 & 1.52 & -0.71 & 0.23 & -0.09 & 0.45 \\
\hline IMC_ITGL & 5.05 & 1.58 & -0.64 & 0.23 & -0.40 & 0.45 \\
\hline IMC_ITPR & 5.00 & 1.50 & -0.72 & 0.23 & -0.03 & 0.45 \\
\hline IMO_IDS & 4.99 & 1.56 & -0.76 & 0.23 & -0.13 & 0.45 \\
\hline IMO_BS & 5.40 & 1.53 & -0.82 & 0.23 & -0.22 & 0.45 \\
\hline IMO_STR & 5.35 & 1.64 & -1.04 & 0.23 & 0.39 & 0.45 \\
\hline IMO_USR & 5.32 & 1.38 & -0.85 & 0.23 & 0.21 & 0.45 \\
\hline IMA_STR & 5.87 & 1.34 & -1.50 & 0.23 & 1.98 & 0.45 \\
\hline IMA_INF & 5.07 & 1.57 & -0.50 & 0.23 & -0.63 & 0.45 \\
\hline IMA_ITDV & 4.55 & 1.81 & -0.47 & 0.23 & -0.73 & 0.45 \\
\hline IMA_BCL & 4.66 & 1.71 & -0.44 & 0.23 & -0.60 & 0.45 \\
\hline MO_FN & 5.54 & 1.31 & -1.08 & 0.23 & 1.29 & 0.45 \\
\hline MO_INT & 5.07 & 1.43 & -0.71 & 0.23 & 0.16 & 0.45 \\
\hline MO_CSND & 5.77 & 1.26 & -1.24 & 0.23 & 1.60 & 0.45 \\
\hline MO_CSTV & 5.54 & 1.32 & -0.98 & 0.23 & 0.47 & 0.45 \\
\hline MO_CMM & 4.88 & 1.61 & -0.62 & 0.23 & -0.51 & 0.45 \\
\hline MO_RSP & 5.35 & 1.64 & -0.70 & 0.23 & -0.74 & 0.45 \\
\hline MO_CR8VL & 5.74 & 1.19 & -1.15 & 0.23 & 1.07 & 0.45 \\
\hline MO_RSPQ & 5.96 & 1.19 & -1.29 & 0.23 & 1.54 & 0.45 \\
\hline MO SW & 5.68 & 1.38 & -1.19 & 0.23 & 1.14 & 0.45 \\
\hline MO CMPW & 5.15 & 1.65 & -0.94 & 0.23 & 0.31 & 0.45 \\
\hline RS RL & 6.40 & 0.84 & -2.71 & 0.23 & 14.02 & 0.45 \\
\hline GWT SCR & 5.28 & 1.31 & -0.95 & 0.23 & 1.08 & 0.45 \\
\hline GWT_WLF & 5.37 & 1.30 & -0.65 & 0.23 & -0.03 & 0.45 \\
\hline GWT_PRB & 5.95 & 1.12 & -1.22 & 0.23 & 1.63 & 0.45 \\
\hline CNT_FRK & 6.38 & 0.85 & -2.72 & 0.23 & 13.23 & 0.45 \\
\hline CNT_PRMS & 6.23 & 1.01 & -1.82 & 0.23 & 4.08 & 0.45 \\
\hline CMT_KNW & 6.21 & 1.20 & -2.26 & 0.23 & 6.09 & 0.45 \\
\hline CMT_PSTN (RC) & 5.19 & 1.68 & -0.91 & 0.23 & -0.09 & 0.45 \\
\hline AFC_DRP & 6.34 & 1.03 & -2.32 & 0.23 & 7.14 & 0.45 \\
\hline AFC_ENJ & 6.50 & 0.89 & -2.74 & 0.23 & 11.84 & 0.45 \\
\hline AFC_FLN & 5.72 & 1.45 & -1.51 & 0.23 & 2.31 & 0.45 \\
\hline EOC_TIM & 6.42 & 0.97 & -2.84 & 0.23 & 11.12 & 0.45 \\
\hline EOC_AT & 5.26 & 1.61 & -0.85 & 0.23 & -0.22 & 0.45 \\
\hline EOC_BS (RC) & 6.35 & 1.27 & -2.74 & 0.23 & 7.96 & 0.45 \\
\hline WTI_SPRT & 5.80 & 1.19 & -1.46 & 0.23 & 2.66 & 0.45 \\
\hline WTI_EFRT & 6.18 & 1.00 & -1.68 & 0.23 & 4.03 & 0.45 \\
\hline WTI_CSCT & 6.17 & 1.17 & -2.14 & 0.23 & 5.83 & 0.45 \\
\hline CLC_BRK & 5.41 & 1.39 & -0.77 & 0.23 & 0.06 & 0.45 \\
\hline CLC_NLT & 2.71 & 1.66 & 0.81 & 0.23 & -0.29 & 0.45 \\
\hline CLC_CST & 5.14 & 1.89 & -0.88 & 0.23 & -0.42 & 0.45 \\
\hline CM_EVNT & 5.92 & 1.03 & -1.18 & 0.23 & 1.80 & 0.45 \\
\hline CM_NFML & 5.87 & 1.04 & -1.07 & 0.23 & 1.44 & 0.45 \\
\hline CM_RQ & 5.73 & 1.21 & -0.92 & 0.23 & 0.46 & 0.45 \\
\hline CM HLP & 5.83 & 1.10 & -1.20 & 0.23 & 1.78 & 0.45 \\
\hline CME_TIM & 5.79 & 0.93 & -1.49 & 0.23 & 5.47 & 0.45 \\
\hline CME ACC & 6.00 & 1.03 & -2.32 & 0.23 & 8.56 & 0.45 \\
\hline CME ADQ & 5.71 & 1.23 & -1.43 & 0.23 & 2.53 & 0.45 \\
\hline CME_CPLT & 5.83 & 0.98 & -1.21 & 0.23 & 2.38 & 0.45 \\
\hline CME_CRD & 6.25 & 0.91 & -2.03 & 0.23 & 6.89 & 0.45 \\
\hline PR_PRD & 6.49 & 0.61 & -1.00 & 0.23 & 1.18 & 0.45 \\
\hline PR_WRTH & 6.57 & 0.58 & -0.99 & 0.23 & 0.00 & 0.45 \\
\hline PR_ST & 6.37 & 0.98 & -2.88 & 0.23 & 11.28 & 0.45 \\
\hline RS_HPY & 6.40 & 0.76 & -1.56 & 0.23 & 3.50 & 0.45 \\
\hline
\end{tabular}




\begin{tabular}{|l|c|c|c|c|c|c|}
\hline & Mean & $\begin{array}{c}\text { Std. } \\
\text { Deviation }\end{array}$ & Skewness & $\begin{array}{c}\text { Std. Error } \\
\text { Skewness }\end{array}$ & Kurtosis & $\begin{array}{c}\text { Std. Error } \\
\text { Kurtosis }\end{array}$ \\
\hline RS_PS & 6.50 & 0.72 & -1.22 & 0.23 & 0.59 & 0.45 \\
\hline RS_ST & 6.48 & 0.73 & -1.58 & 0.23 & 3.48 & 0.45 \\
\hline LY_SYPS & 6.50 & 0.73 & -1.64 & 0.23 & 2.84 & 0.45 \\
\hline LY_PR & 5.61 & 1.29 & -0.38 & 0.23 & -1.13 & 0.45 \\
\hline LY_RCD & 6.35 & 0.86 & -1.42 & 0.23 & 1.53 & 0.45 \\
\hline LY_XPT & 6.35 & 1.01 & -2.21 & 0.23 & 6.88 & 0.45 \\
\hline RN_HIR & 5.49 & 1.26 & -0.56 & 0.23 & 0.00 & 0.45 \\
\hline RN_NCR & 4.65 & 1.19 & 0.20 & 0.23 & 0.71 & 0.45 \\
\hline TT_CHG & 5.68 & 1.27 & -1.06 & 0.23 & 0.69 & 0.45 \\
\hline TT_OPP & 5.77 & 1.30 & -1.31 & 0.23 & 1.39 & 0.45 \\
\hline TT_BRKT & 5.28 & 1.50 & -0.84 & 0.23 & 0.05 & 0.45 \\
\hline TT_MINR (RC) & 4.58 & 1.82 & -0.27 & 0.23 & -1.13 & 0.45 \\
\hline MT_CHG & 4.79 & 1.43 & -0.78 & 0.23 & -0.05 & 0.45 \\
\hline MT_NPD & 4.79 & 1.44 & -0.66 & 0.23 & 0.09 & 0.45 \\
\hline MT_CDM & 5.03 & 1.34 & -0.78 & 0.23 & 0.64 & 0.45 \\
\hline MT_NDM & 4.16 & 1.54 & -0.16 & 0.23 & -0.69 & 0.45 \\
\hline MT_MRKT & 5.45 & 1.38 & -0.98 & 0.23 & 0.52 & 0.45 \\
\hline
\end{tabular}

$\mathrm{RC}=$ Item reverse coded

Table A9.2: Customer Survey Data

\begin{tabular}{|l|c|c|c|c|c|c|}
\hline & Mean & $\begin{array}{c}\text { Std. } \\
\text { Deviation }\end{array}$ & Skewness & $\begin{array}{c}\text { Std. Error } \\
\text { Skewness }\end{array}$ & Kurtosis & $\begin{array}{c}\text { Std. Error } \\
\text { Kurtosis }\end{array}$ \\
\hline C_RS_REL & 6.50 & 0.89 & -3.07 & 0.23 & 13.71 & 0.45 \\
\hline C_RT_PRM & 6.41 & 0.89 & -3.20 & 0.23 & 15.79 & 0.45 \\
\hline C_RT_HNS (RC) & 6.11 & 1.63 & -1.98 & 0.23 & 2.84 & 0.45 \\
\hline C_RT_BLV & 6.37 & 0.94 & -2.15 & 0.23 & 5.76 & 0.45 \\
\hline C_RT_CNCR & 6.31 & 1.13 & -2.44 & 0.23 & 7.02 & 0.45 \\
\hline C_RT_WLFR & 5.87 & 1.17 & -1.27 & 0.23 & 1.36 & 0.45 \\
\hline C_RT_NTRS & 6.21 & 0.97 & -1.43 & 0.23 & 1.98 & 0.45 \\
\hline C_RT_TRST & 6.57 & 0.83 & -2.90 & 0.23 & 10.78 & 0.45 \\
\hline C_RT_CTN & 6.20 & 1.35 & -2.26 & 0.23 & 4.93 & 0.45 \\
\hline C_AFC_DRP & 5.43 & 1.73 & -1.24 & 0.23 & 0.55 & 0.45 \\
\hline C_AFC_ENJ & 6.09 & 1.23 & -1.86 & 0.23 & 3.75 & 0.45 \\
\hline C_AFC_FLN & 5.89 & 1.28 & -1.75 & 0.23 & 4.00 & 0.45 \\
\hline C_EOC_TIM & 6.34 & 0.84 & -1.26 & 0.23 & 1.08 & 0.45 \\
\hline C_EOC_AT & 5.44 & 1.60 & -1.04 & 0.23 & 0.30 & 0.45 \\
\hline C_EOC_BS (RC) & 6.24 & 1.41 & -2.34 & 0.23 & 4.93 & 0.45 \\
\hline C_WTI_SPRT & 4.53 & 1.60 & -0.30 & 0.23 & -0.51 & 0.45 \\
\hline C_WTI_EFRT & 5.17 & 1.43 & -0.61 & 0.23 & 0.42 & 0.45 \\
\hline C_WTI_CSCT & 4.66 & 1.66 & -0.65 & 0.23 & 0.00 & 0.45 \\
\hline C_CLC_BRK & 4.80 & 1.92 & -0.55 & 0.23 & -0.97 & 0.45 \\
\hline C_CLC_NLT & 2.97 & 1.87 & 0.73 & 0.23 & -0.70 & 0.45 \\
\hline C_CLC_CST & 3.77 & 2.06 & 0.04 & 0.23 & -1.39 & 0.45 \\
\hline C_CMT_CMT & 5.37 & 1.63 & -0.96 & 0.23 & 0.08 & 0.45 \\
\hline C_CMT_DSCT (RC) & 6.50 & 1.06 & -2.80 & 0.23 & 8.83 & 0.45 \\
\hline C_CMT_MIN (RC) & 6.04 & 1.50 & -1.79 & 0.23 & 2.36 & 0.45 \\
\hline C_CM_EVNT & 5.99 & 1.19 & -1.58 & 0.23 & 2.62 & 0.45 \\
\hline C_CM_NFML & 6.00 & 1.12 & -1.47 & 0.23 & 2.69 & 0.45 \\
\hline C_CM_RQ & 5.73 & 1.37 & -1.35 & 0.23 & 1.83 & 0.45 \\
\hline C_CM_HLP & 6.08 & 1.22 & -2.12 & 0.23 & 5.57 & 0.45 \\
\hline C_CME_TIM & 5.87 & 0.98 & -0.88 & 0.23 & 0.60 & 0.45 \\
\hline C_CME_ACC & 6.15 & 0.90 & -1.62 & 0.23 & 4.24 & 0.45 \\
\hline C_CME_ADQ & 6.09 & 0.93 & -1.83 & 0.23 & 6.86 & 0.45 \\
\hline C_CME_CPLT & 6.09 & 0.90 & -1.77 & 0.23 & 5.85 & 0.45 \\
\hline C_CME_CRD & 6.38 & 0.85 & -2.72 & 0.23 & 13.23 & 0.45 \\
\hline C_PR_PRD & 6.50 & 0.82 & -3.19 & 0.23 & 17.07 & 0.45 \\
\hline C_PR_WRTH & 6.47 & 0.80 & -2.32 & 0.23 & 8.50 & 0.45 \\
\hline & & & & & & \\
\hline
\end{tabular}


Appendix A9: Data Distribution

\begin{tabular}{|c|c|c|c|c|c|c|}
\hline & Mean & $\begin{array}{c}\text { Std. } \\
\text { Deviation }\end{array}$ & Skewness & $\begin{array}{l}\text { Std. Error } \\
\text { Skewness }\end{array}$ & Kurtosis & $\begin{array}{l}\text { Std. Error } \\
\text { Kurtosis }\end{array}$ \\
\hline C_PR_ST & 6.21 & 1.28 & -2.49 & 0.23 & 6.76 & 0.45 \\
\hline C_RS_HPY & 6.43 & 0.83 & -1.60 & 0.23 & 2.19 & 0.45 \\
\hline C_RS_PS & 6.50 & 0.88 & -1.96 & 0.23 & 3.39 & 0.45 \\
\hline C_RS_ST & 6.30 & 0.97 & -2.07 & 0.23 & 5.33 & 0.45 \\
\hline C_LY_SYPS & 6.39 & 0.94 & -2.39 & 0.23 & 8.88 & 0.45 \\
\hline C_LY_PR & 6.05 & 1.26 & -1.64 & 0.23 & 2.73 & 0.45 \\
\hline C_LY_RCD & 6.37 & 1.08 & -2.54 & 0.23 & 7.74 & 0.45 \\
\hline C_LY_XPT & 6.43 & 0.93 & -1.89 & 0.23 & 3.32 & 0.45 \\
\hline C_RN_FRST & 6.14 & 1.28 & -1.76 & 0.23 & 2.97 & 0.45 \\
\hline C_RN_PR & 6.14 & 1.39 & -1.87 & 0.23 & 3.17 & 0.45 \\
\hline C_RN_ALT & 2.49 & 1.68 & 0.81 & 0.23 & -0.62 & 0.45 \\
\hline C_TT_CHG & 5.77 & 1.37 & -1.48 & 0.23 & 2.26 & 0.45 \\
\hline C_TT_OPP & 5.75 & 1.31 & -1.14 & 0.23 & 1.23 & 0.45 \\
\hline C_TT_BRKT & 5.49 & 1.40 & -0.59 & 0.23 & -0.57 & 0.45 \\
\hline C_TT_MINR (RC) & 4.91 & 1.93 & -0.44 & 0.23 & -1.29 & 0.45 \\
\hline C_MT_CHG & 4.86 & 1.65 & -0.68 & 0.23 & -0.60 & 0.45 \\
\hline C_MT_NPD & 4.66 & 1.74 & -0.66 & 0.23 & -0.60 & 0.45 \\
\hline C_MT_CDM & 5.02 & 1.37 & -0.97 & 0.23 & 1.03 & 0.45 \\
\hline C_MT_NDM & 4.17 & 1.58 & -0.37 & 0.23 & -0.78 & 0.45 \\
\hline C_MT_MRKT & 5.63 & 1.35 & -1.28 & 0.23 & 1.74 & 0.45 \\
\hline C_EXP_PRD & 6.21 & 1.04 & -1.86 & 0.23 & 3.81 & 0.45 \\
\hline C_EXP_INV & 5.32 & 1.45 & -0.42 & 0.23 & -0.72 & 0.45 \\
\hline C_EXP_RQMT & 5.92 & 1.03 & -1.18 & 0.23 & 1.80 & 0.45 \\
\hline C_CRO_LTGD & 6.63 & 0.82 & -2.68 & 0.23 & 7.50 & 0.45 \\
\hline C_CRO_LTRL & 6.57 & 0.93 & -2.50 & 0.23 & 5.86 & 0.45 \\
\hline C_CRO_VLU & 6.58 & 0.65 & -1.49 & 0.23 & 1.84 & 0.45 \\
\hline
\end{tabular}

$\mathrm{RC}=$ Item reverse coded 
Appendix A10: Measurement Item Loading on Composite Indicator Scales

\begin{tabular}{|c|c|c|c|c|c|c|c|c|c|c|c|c|c|c|c|c|}
\hline & $\begin{array}{c}\mathrm{CKN}_{-} \\
\mathrm{SSC}\end{array}$ & $\begin{array}{c}\text { C_CME } \\
\text { SSC }\end{array}$ & $\begin{array}{c}\mathrm{C}_{\mathrm{S}} \mathrm{CM} \\
\mathrm{SSC}\end{array}$ & $\begin{array}{c}\text { C_LY_ } \\
\text { SSC }\end{array}$ & $\begin{array}{c}\text { C_RN } \\
\text { SSC }\end{array}$ & $\begin{array}{c}\text { C_RSA } \\
\text { SSC }\end{array}$ & $\begin{array}{r}\text { C_RT } \\
\text { SSC }\end{array}$ & $\begin{array}{l}\text { IMC } \\
\text { SSC }\end{array}$ & $\begin{array}{c}\text { IMI_S } \\
\text { SC }\end{array}$ & $\begin{array}{c}\text { IMO_S } \\
\text { SC }\end{array}$ & IMP & $\begin{array}{c}\text { MO1 } \\
\text { SSC }\end{array}$ & $\begin{array}{c}\mathrm{MO2} \\
\mathrm{SSC}\end{array}$ & $\begin{array}{c}\text { MO3 } \\
\text { SSC }\end{array}$ & $\begin{array}{r}\text { USF1 } \\
\text { SSC }\end{array}$ & $\begin{array}{r}\text { USF2 } \\
\text { SSC }\end{array}$ \\
\hline ATU GOOD & & & & & & & & & & & & & & & 0.850 & 0.629 \\
\hline CAD DALY & & & & & & & & & & & & & & & 0.850 & 0.650 \\
\hline CPR TLS & 0.784 & & & & & & & & & & & & & & & \\
\hline C CME ACC & & 0.846 & & & & & & & & & & & & & & \\
\hline C CME CPLT & & 0.892 & 0.503 & & & 0.565 & 0.506 & & & & & & & & & \\
\hline C CME CRD & & 0.894 & & & & 0.634 & 0.606 & & & & & & & & & \\
\hline C CM EVNT & & 0.574 & 0.933 & & & 0.525 & 0.569 & & & & & & & & & \\
\hline C CM HLP & & & 0.902 & & & & & & & & & & & & & \\
\hline C LY PR & & & & 0.866 & & & & & & & & & & & & \\
\hline C LY RCD & & & & 0.881 & & 0.635 & 0.573 & & & & & & & & & \\
\hline C LY XPT & & & & 0.797 & 0.642 & & & & & & & & & & & \\
\hline C RN ALT & & & & & 0.608 & & & & & & & & & & & \\
\hline C RN FRST & & & & 0.620 & 0.919 & & & & & & & & & & & \\
\hline C RN PR & & & & 0.510 & 0.860 & & & & & & & & & & & \\
\hline C RS HPY & & 0.577 & 0.515 & 0.590 & 0.538 & 0.939 & 0.590 & & & & & & & & & \\
\hline C RS ST & & 0.601 & & 0.534 & & 0.927 & 0.633 & & & & & & & & & \\
\hline C RT NTRS & & 0.594 & 0.549 & 0.533 & & 0.617 & 0.911 & & & & & & & & & \\
\hline C RT TRST & & 0.547 & & & & 0.619 & 0.832 & & & & & & & & & \\
\hline C RT WLFR & & & & & & & 0.846 & & & & & & & & & \\
\hline IMA BCL & & & & & & & & & 0.782 & & & & & & & \\
\hline IMA INF & & & & & & & & 0.596 & 0.807 & 0.572 & 0.560 & & & & & \\
\hline IMA ITDV & & & & & & & & & 0.746 & 0.532 & 0.537 & 0.536 & & & & \\
\hline IMA STR & & & & & & & & & 0.741 & & & & & & & \\
\hline IMC ITAP & & & & & & & & 0.821 & 0.581 & 0.736 & 0.568 & & & & & \\
\hline IMC ITDV & & & & & & & & 0.874 & & 0.709 & 0.652 & & & & & \\
\hline IMC ITFN & & & & & & & & 0.832 & 0.575 & 0.646 & 0.622 & & & & & \\
\hline IMC ITGL & & & & & & & & 0.891 & 0.536 & 0.671 & 0.653 & & & & & \\
\hline IMC ITOP & & & & & & & & 0.854 & & 0.657 & 0.572 & & & & & \\
\hline IMC ITPR & & & & & & & & 0.870 & & 0.673 & 0.606 & & & & & \\
\hline IMO BS & & & & & & & & 0.720 & 0.561 & 0.889 & 0.638 & & & & & \\
\hline IMO IDS & & & & & & & & 0.673 & 0.576 & 0.858 & 0.603 & & & & & \\
\hline IMO STR & & & & & & & & 0.651 & 0.522 & 0.884 & 0.678 & & & & & \\
\hline IMO USR & & & & & & & & 0.762 & 0.553 & 0.900 & 0.673 & & & & & \\
\hline IMP BO & & & & & & & & & & 0.508 & 0.671 & & & & & \\
\hline IMP INV & & & & & & & & & 0.626 & 0.587 & 0.804 & & & & & \\
\hline IMP ITCS & & & & & & & & 0.569 & 0.523 & 0.547 & 0.849 & & & & & \\
\hline IMP ITPR & & & & & & & & 0.630 & & 0.599 & 0.620 & & & & & \\
\hline IMP ITPS & & & & & & & & & & & 0.794 & & & & & \\
\hline IMP ITQL & & & & & & & & 0.644 & 0.566 & 0.650 & 0.818 & & & & & \\
\hline MO CMM & & & & & & & & & & & & 0.852 & 0.622 & 0.566 & & \\
\hline MO CR8VL & & & & & & & & & & & & 0.851 & 0.572 & 0.607 & & \\
\hline MO CSND & & & & & & & & & & & & 0.665 & 0.917 & & & \\
\hline MO CSTV & & & & & & & & & & & & 0.622 & 0.919 & 0.534 & & \\
\hline MO FN & & & & & & & & & & & & 0.634 & & 0.874 & & \\
\hline MO INT & & & & & & & & & & & & 0.553 & & 0.859 & & \\
\hline MO RSPQ & & & & & & & & & & & & & & 0.691 & & \\
\hline PU EFT & & & & & & & & & & & & & & & 0.712 & 0.948 \\
\hline PU PRD & & & & & & & & & & & & & & & 0.693 & 0.912 \\
\hline PU PRF & & & & & & & & & & & & & & & 0.699 & 0.918 \\
\hline PU USFL & & & & & & & & & & & & & & & 0.723 & 0.901 \\
\hline RAD ESY & & & & & & & & & & & & & & & 0.882 & 0.702 \\
\hline RMC PR & 0.864 & & & & & & & & & & & & & & & \\
\hline RMC_PTS & 0.833 & & & & & & & & & & & & & & & \\
\hline
\end{tabular}

* only loadings $=>0.50$ are shown 


\section{REFERENCES}

Aaker, D. A., Kumar, V., \& Day, G. S. (2004). Marketing research (8th ed.). New York: John Wiley \& Sons.

Abbott, J., Stone, M., \& Buttle, F. (2001). Customer relationship management in practice - a qualitative study. Journal of Database Marketing, 9(1), 24-34.

ACT! (2004). ACT! Products. Retrieved 25 November, 2004, from http://www.act.com/

Adamson, I., Chan, K.-M., \& Handford, D. (2003). Relationship marketing: Customer commitment and trust as a strategy for the smaller Hong Kong corporate banking sector. The International Journal of Bank Marketing, 21(6/7), 347-358.

Adebanjo, D. (2003). Classifying and selecting e-CRM applications: An analysis-based proposal. Management Decision, 41(5/6), 570-577.

Ahn, J. Y., Kim, S. K., \& Han, K. S. (2003). On the design concepts for CRM system. Industrial Management + Data Systems, 103(5/6), 324-331.

Aijo, T. S. (1996). The theoretical and philosophical underpinnings of relationship marketing: Environmental factors behind the changing marketing paradigm. European Journal of Marketing, 30(2), 8-18.

Alavi, M., \& Leidner, D. E. (2001). Review: Knowledge management and knowledge management systems: Conceptual foundations and research issues. MIS Quarterly, 25(1), 107-136.

Alderson, W., \& Cox, R. (1948). Towards a theory of marketing. Journal of Marketing, 13(2), 137-152.

Almquist, E., Heaton, C., \& Hall, N. (2002). Making CRM make money. Marketing Management, 11(3), 16-21.

Alreck, P., L., \& Settle, R. B. (2004). The survey research handbook (3rd ed.). Boston: McGraw-Hill Irwin.

Álvarez, L. S., Martín, A. M. D., \& Casielles, R. V. (2007). Relationship marketing and information and communication technologies: Analysis of retail travel agencies. Journal of Travel Research, 45(4), 453-463.

Andaleeb, S. S. (1996). An experimental investigation of satisfaction and commitment in marketing channels: The role of trust and dependence. Journal of Retailing, 72(1), 77-93.

Anderson, E., Lodish, L. M., \& Weitz, B. A. (1987). Resource allocation behavior in conventional channels. Journal of Marketing Research, 24(1), 85-97. 
Anderson, E., \& Weitz, B. (1989). Determinants of continuity in conventional industrial channel dyads. Marketing Science, 8(4), 310-323.

Anderson, E., \& Weitz, B. (1992). The use of pledges to build and sustain commitment in distribution channels. Journal of Marketing Research, 29(1), 18-34.

Anderson, E. W., Fornell, C., \& Lehmann, D. R. (1994). Customer satisfaction, market share, and profitability: Findings from Sweden. Journal of Marketing, 58(3), 5366.

Anderson, E. W., Fornell, C., \& Rust, R. T. (1997). Customer satisfaction, productivity, and profitability: Differences between goods and services. Marketing Science, 16(2), 129-145.

Anderson, J. C. (1995). Relationships in business markets: Exchange episodes, value creation, and their empirical assessment. Journal of the Academy of Marketing Science, 23(4), 346-350.

Anderson, J. C., \& Gerbing, D. W. (1988). Structural equation modeling in practice: A review and recommended two-step approach. Psychological Bulletin, 103(3), 411-423.

Anderson, J. C., \& Narus, J. A. (1984). A model of the distributor's perspective of distributor-manufacturer working relationships. Journal of Marketing, 48(4), 6274 .

Anderson, J. C., \& Narus, J. A. (1990). A model of distributor firm and manufacturer firm working partnerships. Journal of Marketing, 54(1), 42-58.

Ang, L., \& Buttle, F. (2002). ROI on CRM: A customer-journey approach. Paper presented at the IMP-conference.

Ang, L., \& Buttle, F. (2006). CRM software applications and business performance. Journal of Database Marketing \& Customer Strategy Management, 14(1), 4-16.

Ansari, A., \& Mela, C. F. (2003). E-customization. Journal of Marketing Research, $40(2), 131-145$.

Appiah-Adu, K. (1997). Market orientation and performance: Do the findings established in large firms hold in the small business sector? Journal of Euro Marketing, 6(3), 1-26.

Appiah-Adu, K., \& Singh, S. (1999). Marketing culture and performance in UK service firms. The Service Industries Journal, 19(1), 152-170.

Applegate, L. M., \& Elam, J. J. (1992). New information systems leaders: A changing role in a changing world. MIS Quarterly, 16(4), 469-490.

Armstrong, J. S., \& Overton, T. S. (1977). Estimating nonresponse bias in mail surveys. Journal of Marketing Research, 14(3), 396-402. 
Arnett, D. B., Laverie, D. A., \& Meiers, A. (2003). Developing parsimonious retailer equity indexes using partial least squares analysis: A method and applications. Journal of Retailing, 79(3), 161-170.

Arnold, C. (2002). So much for CRM. Marketing News, 36(25), 14.

Ashill, N. J., Carruthers, J., \& Krisjanous, J. (2005). Antecedents and outcomes of service recovery performance in a public health-care environment. Journal of Services Marketing, 19(5), 293-308.

Ashill, N. J., Carruthers, J., \& Krisjanous, J. (2006). The effect of management commitment to service quality on frontline employees' affective and performance outcomes: an empirical investigation of the New Zealand public healthcare sector. International Journal of Nonprofit and Voluntary Sector Marketing, 11(4), 271-287.

Aspinall, E., Nancarrow, C., \& Stone, M. (2001). The meaning and measurement of customer retention. Journal of Targeting, Measurement and Analysis for Marketing, 10(1), 79-87.

Assael, H., \& Keon, J. (1982). Nonsampling vs. sampling errors in survey research. Journal of Marketing, 46(2), 114-123.

Aulakh, P. S., Kotabe, M., \& Sahay, A. (1996). Trust and performance in cross-border marketing partnerships: A behavioral approach. Journal of International Business Studies, 27(5), 1005-1032.

Avlonitis, G. J., \& Panagopoulos, N. G. (2005). Antecedents and consequences of CRM technology acceptance in the sales force. Industrial Marketing Management, 34(4), 355-368.

Bagozzi, R. P. (1977). Structural equation models in experimental research. Journal of Marketing Research, 14(2), 209-226.

Bagozzi, R. P. (1994a). Measurement in marketing research: Basic principles of questionnaire design. In R. P. Bagozzi (Ed.), Principles of marketing research (pp. 1-49). Cambridge, MA: Blackwell.

Bagozzi, R. P. (1994b). Structural equation models in marketing research: Basic principles. In R. P. Bagozzi (Ed.), Principles of marketing research (pp. 317385). Cambridge, MA: Blackwell.

Bagozzi, R. P., \& Baumgartner, H. (1994). The evaluation of structural equation models and hypothesis testing. In R. P. Bagozzi (Ed.), Principles of marketing research (pp. 386-422). Cambridge, MA: Blackwell.

Bagozzi, R. P., Gopinath, M., \& Nyer, P. U. (1999). The role of emotions in marketing. Journal of the Academy of Marketing Science, 27(2), 184-206. 
Bagozzi, R. P., \& Heatherton, T. F. (1994). A general approach to representing multifaceted personality constructs: Application to state self-esteem. Structural Equation Modeling, 1(1), 35-67.

Bagozzi, R. P., \& Yi, Y. (1991). Multitrait-multimethod matrices in consumer research. Journal of Consumer Research, 17(4), 426-439.

Baldauf, A., Reisinger, H., \& Moncrief, W. C. (1999). Examining motivations to refuse in industrial mail surveys. Journal of the Market Research Society, 41(3), 345348.

Barclay, D. W. (1991). Interdepartmental conflict in organizational buying: The impact of the organizational context. Journal of Marketing Research, 28(2), 145-159.

Baxter, R., \& Matear, S. (2004). Measuring intangible value in business-to-business buyer-seller relationships: An intellectual capital perspective. Industrial Marketing Management, 33(6), 491-500.

Beath, C. M. (1991). Supporting the information technology champion. MIS Quarterly, 15(3), 355-372.

Beckett-Camarata, E. J., Camarata, M. R., \& Barker, R. T. (1998). Integrating internal and external customer relationships through relationship management: A strategic response to a changing global environment. Journal of Business Research, 41(1), 71-81.

Beckett, A., Hewer, P., \& Howcroft, B. (2000). An exposition of consumer behaviour in the financial services industry. The International Journal of Bank Marketing, 18(1), 15-26.

Bentler, P. M. (2005). EQS 6 structural equations program manual. Encino, CA: Multivariate Software.

Bernieri, F. J., Gillis, J. S., Davis, J. M., \& Grahe, J. E. (1996). Dyad rapport and the accuracy of its judgment across situations: A lens model analysis. Journal of Personality and Social Psychology, 71(1), 110-129.

Berry, L. L. (1983). Relationship marketing. In L. L. Berry, G. L. Shostack \& G. D. Upah (Eds.), Emerging perspectives on services marketing (pp. 25-28). Chicago: American Marketing Association.

Berry, L. L. (1995). Relationship marketing of services - Growing interest, emerging perspectives. Journal of the Academy of Marketing Science, 23(4), 236-245.

Bharadwaj, S. G., Varadarajan, P. R., \& Fahy, J. (1993). Sustainable competitive advantage in service industries: A conceptual model and research propositions. Journal of Marketing, 57(4), 83-99.

Bhattacherjee, A. (2002). Individual trust in online firms: Scale development and initial test. Journal of Management Information Systems, 19(1), 211-241. 
Birkinshaw, J., Morrison, A., \& Hulland, J. (1995). Structural and competitive determinants of a global integration strategy. Strategic Management Journal, 16(8), 637-655.

Bitner, M. J. (1995). Building service relationships: It's all about promises. Journal of the Academy of Marketing Science, 23(4), 246-251.

Blois, K. J. (1999). Trust in business to business relationships: An evaluation of its status. The Journal of Management Studies, 36(2), 197-215.

Bohling, T., Bowman, D., LaValle, S., Mittal, V., Narayandas, D., Ramani, G., et al. (2006). CRM Implementation: Effectiveness issues and insights. Journal of Service Research, 9(2), 184-194.

Bollen, K. A. (1989). Structural equations with latent variables. New York: John Wiley \& Sons.

Bolton, R. N. (1998). A dynamic model of the duration of the customer's relationship with a continuous service provider: The role of satisfaction. Marketing Science, 17(1), 45-65.

Bolton, R. N., \& Lemon, K. N. (1999). A dynamic model of customers' usage of services: Usage as an antecedent and consequence of satisfaction. Journal of Marketing Research, 36(2), 171-186.

Boone, D. S., \& Roehm, M. (2002). Retail segmentation using artificial neural networks. International Journal of Research in Marketing, 19(3), 287-301.

Bordia, P. (1997). Face-to-face versus computer-mediated communication: A synthesis of the experimental literature. The Journal of Business Communication, 34(1), 99-120.

Bos, N., Olson, J., Gergle, D., Olson, G., \& Wright, Z. (2002, 20 - 25 April). Effects of four computer-mediated communications channels on trust development. Paper presented at the SIGCHI Conference on Human Factors in Computing Systems, Minneapolis, Minnesota.

Bose, R. (2002). Customer relationship management: Key components for IT success. Industrial Management \& Data Systems, 102(1-2), 89-97.

Bose, R., \& Sugumaran, V. (2003). Application of knowledge management technology in customer relationship management. Knowledge and Process Management, 10(1), 3-17.

Boulding, W., Staelin, R., Ehret, M., \& Johnston, W. (2005). A customer relationship management roadmap: What is known, potential pitfalls, and where to go. Journal of Marketing, 69(4), 155-166.

Bowen, H. P., \& Wiersema, M. F. (1999). Matching method to paradigm in strategy research: Limitations of cross-sectional analysis and some methodological alternatives. Strategic Management Journal, 20(7), 625-636. 
Brennan, D. R., Turnbull, P. W., \& Wilson, D. T. (2003). Dyadic adaptation in business-to-business markets. European Journal of Marketing, 37(11/12), 16361665.

Brown, C. V., \& Vessey, I. (2003). Managing the next wave of enterprise systems: Leveraging lessons from ERP. MIS Quarterly Executive, 2(1), 65-77.

Bueren, A., Schierholz, R., Kolbe, L. M., \& Brenner, W. (2005). Improving performance of customer-processes with knowledge management. Business Process Management Journal, 11(5), 573-588.

Bull, C. (2003). Strategic issues in customer relationship management (CRM) implementation. Business Process Management Journal, 9(5), 592-602.

Burnett, K. (2001). The handbook of key customer relationship management: The definitive guide to winning, managing and developing key account business. London: Pearson Education.

Bush, A. J., Moore, J. B., \& Rocco, R. (2005). Understanding sales force automation outcomes: A managerial perspective. Industrial Marketing Management, 34(4), 369-377.

Buttle, F. (2004). Customer relationship management: Concepts and tools. Sydney: Elsevier.

Byrne, B. M. (2001). Structural Equation Modeling with AMOS: Basic concepts, applications, and programming. Mahwah, NJ: Lawrence Erlbaum Associates.

Byrne, B. M. (2006). Structural Equation Modeling with EQS: Basic concepts, applications, and programming (2nd ed.). Mahwah, NJ: Lawrence Erlbaum Associates.

Campbell, A. J. (1998). Cooperation in international value chains: Comparing an exporter's supplier versus customer relationships. The Journal of Business \& Industrial Marketing, 13(1), 22-39.

Campbell, D. T. (1955). The informant in quantitative research. The American Journal of Sociology, 60(4), 339-342.

Cannon, J. P., Achrol, R. S., \& Gundlach, G. T. (2000). Contracts, norms, and plural form governance. Journal of the Academy of Marketing Science, 28(2), 180-194.

Cannon, J. P., \& Homburg, C. (2001). Buyers-supplier relationships and customer firm costs. Journal of Marketing, 65(1), 29-43.

Cano, C. R., Carrillat, F. A., \& Jaramillo, F. (2004). A meta-analysis of the relationship between market orientation and business performance: Evidence from five continents. International Journal of Research in Marketing, 21(2), 179-200.

Carver, R. H., \& Nash, J. G. (2005). Doing data analysis with SPSS version 12. Southbank, Victoria, Australia: Thomson Learning. 
Cass, K., \& Lauer, T. (2002, 9-11 August). What is the relationship in customer relationship management? Paper presented at the Eighth Americas Conference on Information Systems (AMCIS), Dallas, Texas.

Casselman, G. (2003). Has the ship sailed for CRM projects? Computing Canada, 29(1), 18-19.

Cassels, J. M. (1936). The significance of early economic thought on marketing. Journal of Marketing, 1(2), 129-133.

Chalmeta, R. (2006). Methodology for customer relationship management. The Journal of Systems and Software, 79(7), 1015-1024.

Chan, Y. E., Huff, S. L., Barclay, D. W., \& Copeland, D. G. (1997). Business strategic orientation, information systems strategic orientation, and strategic alignment. Information Systems Research, 8(2), 125-150.

Chang, J., Yen, D. C., Young, D., \& Ku, C.-Y. (2002). Critical issues in CRM adoption and implementation. International Journal of Services Technology and Management, 3(3), 311-324.

Chau, P. Y. K. (1997). Reexamining a model for evaluating information center success using a structural equation modeling approach. Decision Sciences, 28(2), 309334.

Chen, I. J., \& Popovich, K. (2003). Understanding customer relationship management (CRM): People, process and technology. Business Process Management Journal, 9(5), 672-688.

Chen, J.-S., \& Ching, R. K. H. (2004, 5-8 August). An examination of the effects of information and communication technology on customer relationship management and customer lock-in. Paper presented at the Tenth Americas Conference on Information Systems (AMCIS), New York, NY.

Chin, W. W. (1995). Partial least squares is to Lisrel as principal components analysis is to common factor analysis [Electronic Version], 1-6. Retrieved 16 February 2007 from http://disc-nt.cba.uh.edu/chin/technologystudies.pdf.

Chin, W. W. (1998a). Issues and opinion on structural equation modeling. MIS Quarterly, 22(1), vii-xv.

Chin, W. W. (1998b). The partial least squares approach for structural equation modeling. In G. A. Marcoulides (Ed.), Modern methods for business research (pp. 295-336). Mahwah, NJ: Lawrence Erlbaum Associates.

Chin, W. W. (2000). Partial least squares for researchers: An overview and presentation of recent advances using the PLS approach. Retrieved 24 April, 2007, from http://disc-nt.cba.uh.edu/chin/icis2000plstalk.pdf

Chin, W. W., Marcolin, B. L., \& Newsted, P. R. (1996, 16-18 December). A partial least squares latent variable modeling approach for measuring interaction 
effects: Results from a Monte Carlo simulations study and voice mail emotion/adoption study. Paper presented at the Seventeenth International Conference on Information Systems (ICIS) 1996, Cleveland, OH.

Chong, I. E. M., \& Dick, G. N. (2004, 6 - 8 August). An empirical investigation into the influence of predictable and timely communication on cognition-based trust. Paper presented at the Tenth Americas Conference on Information Systems (AMCIS), New York, NY.

Christiaanse, E., \& Venkatraman, N. (2002). Beyond Sabre: An empirical test of expertise exploitation in electronic channels. MIS Quarterly, 26(1), 15-38.

Chung, E., \& Alagaratnam, S. (2001). "Teach ten thousand stars how not to dance": A survey of alternative ontologies in marketing research. Qualitative Market Research, 4(4), 224-234.

Churchill, G. A., Jr. (1979). A paradigm for developing better measures of marketing constructs. Journal of Marketing Research, 16(1), 64-73.

Churchill, G. A., Jr., \& Brown, T. J. (2004). Basic marketing research (5th ed.). Sydney: South-Western College.

Churchill, G. A., Jr., \& Iacobucci, D. (2005). Marketing research: Methodological foundations (9th ed.). Sydney: South-Western College.

Churchill, G. A., Jr., \& Peter, J. P. (1984). Research design effects on the reliability of rating scales: A meta-analysis. Journal of Marketing Research, 21(4), 360-375.

Cochran, J. (2004, 5-8 August). Increasing customer intimacy through customer relationship management. Paper presented at the Tenth Americas Conference on Information Systems (AMCIS), New York, NY.

Cohen, J. (1988). Statistical power analysis for the behavioral sciences. Hillsdale, HJ: Erlbaum.

Cohen, J. (1992). A power primer. Psychological Bulletin, 112(1), 155-159.

Colgate, M. (1998). Creating sustainable competitive advantage through marketing information system technology: A triangulation methodology within the banking industry. The International Journal of Bank Marketing, 16(2), 80-89.

Compeau, D. R., \& Higgins, C. A. (1995). Computer self-efficacy: Development of a measure and initial test. MIS Quarterly, 19(2), 189-211.

Compeau, D. R., Higgins, C. A., \& Huff, S. (1999). Social cognitive theory and individual reactions to computing technology: A longitudinal study. MIS Quarterly, 23(2), 145-158.

Computerworld. (2004). CRM buyer's guide. Retrieved 25 November, 2004, from http://www.computerworld.com/services/buyersguide/subcat/0,4846,KEY51_S $\underline{\mathrm{UB} 6,00 . \mathrm{html}}$ 
Cool, K., Dierickx, I., \& Jemison, D. (1989). Business strategy, market structure and risk-return relationships: A structural approach. Strategic Management Journal, 10(6), 507-522.

Cooper, B. L., Watson, H. J., Wixom, B. H., \& Goodhue, D. L. (2000). Data warehousing supports corporate strategy at First American Corporation. MIS Quarterly, 24(4), 547-567.

Corner, B. A. (2002). Measuring customer relationships. Marketing Management, 11(3), $10-11$.

Corner, I., \& Hinton, M. (2002). Customer relationship management systems: implementation risks and relationship dynamics. Qualitative Market Research, 5(4), 239-251.

Couper, M. P., Kapteya, A., Schonlau, M., \& Winter, J. (2007). Noncoverage and nonresponse in an Internet survey. Social Science Research, 36(1), 131-148.

Coupey, E. (2005). Digital business: Concepts and strategy (2nd ed.). Upper Saddle River, NJ: Pearson-Prentice Hall.

Coviello, N. E., \& Brodie, R. J. (2001). Contemporary marketing practices of consumer and business-to-business firms: How different are they? The Journal of Business \& Industrial Marketing, 16(5), 382-400.

Coviello, N. E., Brodie, R. J., Danaher, P. J., \& Johnston, W. J. (2002). How firms relate to their markets: An empirical examination of contemporary marketing practices. Journal of Marketing, 66(3), 33-46.

Cox, E. P., III. (1980). The optimal number of response alternatives for a scale: A review. Journal of Marketing Research, 17(4), 407-422.

Creswell, J. W. (1998). Qualitative inquiry and research design: Choosing among five traditions. Thousand Oaks: Sage.

Creswell, J. W. (2003). Research design: Qualitative, quantitative, and mixed methods approaches (2nd ed.). Thousand Oaks: Sage.

Crosby, L. A., Evans, K. R., \& Cowles, D. (1990). Relationship quality in services selling: An interpersonal influence perspective. Journal of Marketing, 54(3), 6881 .

Crosby, L. A., \& Johnson, S. L. (2001). High performance marketing in the CRM era. Marketing Management, 10(3), 10-11.

Crosby, L. A., \& Stephens, N. (1987). Effects of relationship marketing on satisfaction, retention, and prices in the life insurance industry. Journal of Marketing Research, 24(4), 404-411.

Croteau, A.-M., \& Li, P. (2003). Critical success factors of CRM technological initiatives. Canadian Journal of Administrative Sciences, 20(1), 21-34. 
Davenport, T. H., \& Klahr, P. (1998). Managing customer support knowledge. California Management Review, 40(3), 195-208.

Davids, M. (1999). How to avoid the 10 biggest mistakes in CRM. The Journal of Business Strategy, 20(6), 22-26.

Davis, F. D. (1989). Perceived usefulness, perceived ease of use, and user acceptance of information technology. MIS Quarterly, 13(3), 318-339.

Davis, F. D., Bagozzi, R. P., \& Warshaw, P. R. (1989). User acceptance of computer technology: A comparison of two theoretical models. Management Science, 35(8), 982-1003.

Davis, R. (2002). The Wizard of Oz in CRMland: CRM's need for business process management. Information Systems Management, 19(4), 43-48.

Day, G. S. (1994). The capabilities of market-driven organizations. Journal of Marketing, 58(4), 37-52.

Day, G. S. (2000). Managing market relationships. Journal of the Academy of Marketing Science, 28(1), 24-30.

Day, G. S. (2003). Creating a superior customer-relating capability. Sloan Management Review, 44(3), 77-82.

Day, G. S., Deighton, J., Narayandas, D., Gummesson, E., Hunt, S. D., Prahalad, C. K., et al. (2004). Invited commentaries on "Evolving to a new dominant logic for marketing". Journal of Marketing, 68(1), 18-27.

Day, G. S., \& Montgomery, D. B. (1999). Charting new directions for marketing. Journal of Marketing, 63(Special Issue), 3-13.

De Wulf, K., Odekerken-Schroder, G., \& Iacobucci, D. (2001). Investments in consumer relationships: A cross-country and cross-industry exploration. Journal of Marketing, 65(4), 33-50.

DeJarnett, L., Laskey, R., \& Trainor, H. E. (2004). From the CIO point of view: The "IT Doesn't Matter" debate. Communications of the Association for Information Systems, 13, 443-455.

Delios, A., \& Beamish, P., W. (1999). Geographic scope, product diversification, and the corporate performance of Japanese firms. Strategic Management Journal, 20(8), 711-727.

DeLone, W. H., \& McLean, E. R. (1992). Information systems success: The quest for the dependent variable. Information Systems Journal, 3(1), 60-95.

DeLone, W. H., \& McLean, E. R. (2003). The DeLone and McLean model of information systems success: A ten-year update. Journal of Management Information Systems, 19(4), 9-30. 
Demirdjian, Z. S. (2003). Marketing research and information systems: The unholy separation of the Siamese twins. Journal of American Academy of Business, Cambridge, 3(1/2), 218-223.

Deng, S., \& Dart, J. (1994). Measuring market orientation: A multi-factor, multi-item approach. Journal of Marketing Management, 10(8), 725-742.

Denzin, N. K., \& Lincoln, Y. S. (2000). Introduction: The discipline and practice of qualitative research. In N. K. Denzin \& Y. S. Lincoln (Eds.), Handbook of qualitative research (2nd ed., pp. 1-28). Thousand Oaks: Sage.

Deshpandé, R. (1983). "Paradigms Lost": On theory and method in research in marketing. Journal of Marketing, 47(4), 101-110.

Deshpandé, R., Farley, J. U., \& Webster Jr., F. E. (1993). Corporate culture, customer orientation, and innovativeness in Japanese firms: A quadrad analysis. Journal of Marketing, 57(1), 23-27.

Dess, G. G., \& Robinson, R. B., Jr. (1984). Measuring organizational performance in the absence of objective measures: The case of the privately-held firm and conglomerate business unit. Strategic Management Journal, 5(3), 265-273.

destinationCRM. (2002, 21 February). What is CRM? Retrieved 1 September, 2004, from http://www.destinationcrm.com/articles/default.asp?articleid=1747

DeVellis, R. F. (2003). Scale development: Theory and applications (2 ed. Vol. 26). Thousand Oaks, CA: Sage Publications.

DeWitt, T., \& Brady, M. K. (2003). Rethinking service recovery strategies. Journal of Service Research, 6(2), 193-207.

Diamantopoulos, A., Reynolds, N., \& Schlegelmilch, B. (1994). Pretesting in questionnaire design: The impact of respondent characteristics on error detection. Journal of the Market Research Society, 36(4), 295-311.

Dibb, S. (2001). Banks, customer relationship management and barriers to the segment of one. Journal of Financial Services Marketing, 6(1), 10-23.

Dillman, D. A. (1978). Mail and telephone surveys: The total design method. New York: John Wiley \& Sons.

Dillman, D. A. (1998). Mail and other self-administered surveys in the 21st century: The beginning of a new era (pp. 24). Pullman, WA: Washington State University.

Dillman, D. A. (2000). Mail and Internet surveys: The tailored design method (2nd ed.). New York: John Wiley \& Sons.

Dillman, D. A., Sinclair, M. D., \& Clark, J. R. (1993). Effects of questionnaire length, respondent-friendly design, and a difficult question on response rates for occupant-addressed census mail surveys. Public Opinion Quarterly, 57(3), 289304. 
Dishaw, M. T., \& Strong, D. M. (1999). Extending the technology acceptance model with task-technology fit constructs. Information \& Management, 36(1), 9-21.

Doherty, N. F., \& Lockett, N. J. (2007). Closing the gap between the expectations of relationship marketing and the reality of e-CRM. International Journal of EBusiness Research, 3(2), i-vi.

Doney, P. M., \& Cannon, J. P. (1997). An examination of the nature of trust in buyerseller relationships. Journal of Marketing, 61(2), 35-51.

Dorsch, M. J., Swanson, S. R., \& Kelley, S. W. (1998). The role of relationship quality in the stratification of vendors as perceived by customers. Journal of the Academy of Marketing Science, 26(2), 128-142.

Droege, S. B., \& Hoobler, J. M. (2003). Employee turnover and tacit knowledge diffusion: A network perspective. Journal of Managerial Issues, 15(1), 50-64.

Duncan, T., \& Moriarty, S. E. (1998). A communication-based marketing model for managing relationships. Journal of Marketing, 62(2), 1-13.

Durand, R. M., \& Lambert, Z. V. (1988). Don't know responses in surveys: Analyses and interpretational consequences. Journal of Business Research, 16(2), 169188.

Dwyer, F. R., Schurr, P. H., \& Oh, S. (1987). Developing buyer-seller relationships. Journal of Marketing, 51(2), 11-27.

Dyché, J. (2002). The CRM handbook: A business guide to customer relationship management. Boston: Addison-Wesley.

Easton, G., Easton, A., \& Belch, M. (2003). An experimental investigation of electronic focus groups. Information \& Management, 40(8), 717-727.

Efron, B., \& Gong, G. (1983). A leisurely look at the bootstrap, the jackknife, and cross-validation. The American Statistician, 37(1), 36-48.

Eisenhardt, K. M. (1989). Building theories from case study research. Academy of Management Review, 14(4), 532-550.

Enns, H. G., Huff, S. L., \& Higgins, C. A. (2003). CIO lateral influence behaviors: Gaining peers' commitment to strategic information systems. MIS Quarterly, 27(1), 155-176.

Epiphany. (2004). Epiphany products. Retrieved 25 November, 2004, from http://www.epiphany.com/products/

Eunson, B. (2005). Communicating in the 21st Century. Singapore: John Wiley \& Sons.

Falk, R. F., \& Miller, N. B. (1992). A primer for soft modeling. Akron, OH, USA: The University of Akron Press. 
Farrell, M. A., \& Oczkowski, E. (2002). Are market orientation and learning orientation necessary for superior organizational performance? Journal of Market - Focused Management, 5(3), 197-217.

Farrelly, F., \& Quester, P. (2003). The effects of market orientation on trust and commitment: The case of the sponsorship business-to-business relationship. European Journal of Marketing, 37(3/4), 530-553.

Feeny, D. F., Edwards, B. R., \& Simpson, K. M. (1992). Understanding the CEO/CIO relationship. MIS Quarterly, 16(4), 435-448.

Fink, A. (1995). The survey handbook (Vol. 1). Thousand Oaks, CA: Sage Publications.

Firth, D. R. (2001, 2-5 August). The organizing vision for customer relationship management. Paper presented at the Seventh Americas Conference on Information Systems (AMCIS), Boston, MA.

Fish, K. E., \& Segall, R. S. (2004). A visual analysis of learning rule effects and variable importance for neural networks in data mining operations. Kybernetes, 33(7/8), 1127-1142.

Fjermestad, J., \& Hiltz, S. R. (2000). Group support systems: A descriptive evaluation of case and field studies. Journal of Management Information Systems, 17(3), 115-159.

Fjermestad, J., \& Romano, N. C., Jr. (2003). Electronic customer relationship management: Revisiting the general principles of usability and resistance--an integrative implementation framework. Business Process Management Journal, $9(5), 572-591$.

Fleischer, J. (2002). The scope of CRM. Call Center Magazine, 15(12), 10.

Fontana, A., \& Frey, J. H. (1994). Interviewing: The art of science. In N. K. Denzin \& Y. S. Lincoln (Eds.), Handbook of qualitative research (pp. 361-376). Thousand Oaks: Sage.

Fontenot, R. J., \& Wilson, E. J. (1997). Relational exchange: A review of selected models for a prediction matrix of relationship activities. Journal of Business Research, 39(1), 5-12.

Fornell, C. (1982). A second generation of multivariate analysis - An overview. In C. Fornell (Ed.), A second generation of multivariate analysis: Methods (Vol. 1, pp. 1-21). New York: Praeger.

Fornell, C., \& Bookstein, F. L. (1982). Two structural equation models: LISREL and PLS applied to consumer exit-voice theory. Journal of Marketing Research, 19(4), 440-452.

Fornell, C., \& Cha, J. (1994). Partial least squares. In R. P. Bagozzi (Ed.), Advanced methods in marketing research (pp. 52-78). Malden, MA: Blackwell Publishers. 
Fornell, C., \& Larcker, D. F. (1981). Evaluating structural equation models with unobservable variables and measurement error. Journal of Marketing Research, 18(1), 39-50.

Fornell, C., Lorange, P., \& Roos, J. (1990). The cooperative venture formation process: A latent variable structural modeling approach. Management Science, 36(10), 1246-1255.

Fornell, C., \& Yi, Y. (1992). Assumptions of the two-step approach to latent variable modeling. Sociological Methods and Research, 20(3), 291-320.

Fournier, S., Dobscha, S., \& Mick, D. G. (1998). Preventing the premature death of relationship marketing. Harvard Business Review, 76(1), 42-49.

Frambach, R. T. (1993). An integrated model of organizational adoption and diffusion of innovations. European Journal of Marketing, 27(5), 22-41.

Freeland, J. G. (Ed.). (2003). The ultimate CRM handbook: Strategies and concepts for building enduring customer loyalty and profitability. New York: McGraw-Hill.

French, M. (2001). CRM fails to deliver. Marketing \& eBusiness, August, 42-43.

Frey, J. H. (1983). Survey research by telephone (Vol. 150). Beverly Hills: Sage Publications.

Friedman, B., Khan, P. H., Jr., \& Howe, D. C. (2000). Trust online. Communications of the ACM, 43(12), 34-40.

Friman, M., Garling, T., Millett, B., Mattsson, J., \& Johnston, R. (2002). An analysis of international business-to-business relationships based on the commitment-trust theory. Industrial Marketing Management, 31(5), 403-409.

Gallivan, M. J. (2001). Organizational adoption and assimilation of complex technological innovations: Development and application of a new framework. Database for Advances in Information Systems, 32(3), 51-81.

Ganesan, S. (1994). Determinants of long-term orientation in buyer-seller relationships. Journal of Marketing, 58(2), 1-19.

Garbarino, E., \& Johnson, M. S. (1999). The different roles of satisfaction, trust, and commitment in customer relationships. Journal of Marketing, 63(2), 70-87.

Gefen, D., Karahanna, E., \& Straub, D. W. (2003). Trust and TAM in online shopping: An integrated model. MIS Quarterly, 27(1), 51-90.

Gefen, D., \& Ridings, C. M. (2002). Implementation team responsiveness and user evaluation of customer relationship management: A quasi-experimental design study of social exchange theory. Journal of Management Information Systems, 19(1), 47-69. 
Gefen, D., Straub, D. W., \& Boudreau, M.-C. (2000). Structural equation modeling and regression: Guidelines for research practice. Communications of the Association for Information Systems, 4, 1-76.

Geisser, S. (1975). The predictive sample reuse method with applications. Journal of the American Statistical Association, 70(350), 320-328.

Geissler, G. L. (2001). Building customer relationships online: The Web site designers' perspective. Journal of Consumer Marketing, 18(6), 488-502.

Gendall, P., Hoek, J., \& Esslemont, D. (1995). The effect of appeal, complexity and tone in a mail survey covering letter. Journal of the Market Research Society, 37(3), 251-268.

Gerbing, D. W., \& Anderson, J. C. (1988). An updated paradigm for scale development incorporating unidimensionality and its assessment. Journal of Marketing Research, 25(2), 186-192.

Geyskens, I., \& Steenkamp, J.-B. E. M. (2000). Economic and social satisfaction: Measurement and relevance to marketing channel relationships. Journal of Retailing, 76(1), 11-32.

Geyskens, I., Steenkamp, J.-B. E. M., \& Kumar, N. (1998). Generalizations about trust in marketing channel relationships using meta-analysis. International Journal of Research in Marketing, 15(3), 223-248.

Geyskens, I., Steenkamp, J.-B. E. M., \& Kumar, N. (1999). A meta-analysis of satisfaction in marketing channel relationships. Journal of Marketing Research, 36(2), 223-238.

Geyskens, I., Steenkamp, J.-B. E. M., Scheer, L. K., \& Kumar, N. (1996). The effects of trust and interdependence on relationship commitment: A trans-Atlantic study. International Journal of Research in Marketing, 13(4), 303-317.

Gfeller, J. D., Lynn, S. J., \& Pribble, W. E. (1987). Enhancing hypnotic susceptibility: Interpersonal and rapport factors. Journal of Personality and Social Psychology, 52(3), 586-595.

Goodhue, D. L. (1995). Understanding user evaluations of information systems. Management Science, 41(12), 1827-1844.

Goodhue, D. L., \& Thompson, R. L. (1995). Task-technology fit and individual performance. MIS Quarterly, 19(2), 213-236.

Goodhue, D. L., Wixom, B. H., \& Watson, H. J. (2002). Realizing business benefits through CRM: Hitting the right target in the right way. MIS Quarterly Executive, 1(2), 79-94.

Gopal, A., Bostrom, R. P., \& Chin, W. W. (1992). Applying adaptive structuration theory to investigate the process of group support systems use. Journal of Management Information Systems, 9(3), 45-69. 
Gounaris, S. P. (2005). Trust and commitment influences on customer retention: Insights from business-to-business services. Journal of Business Research, 58(2), 126-140.

Gray, B. J., Matear, S., Boshoff, C., \& Matheson, P. (1998). Developing a better measure of market orientation. European Journal of Marketing, 32(9/10), 884903.

Gray, B. J., Matear, S., \& Matheson, P. K. (2002). Improving service firm performance. Journal of Services Marketing, 16(2/3), 186-200.

Grayson, K., \& Ambler, T. (1999). The dark side of long-term relationships in marketing services. Journal of Marketing Research, 36(1), 132-141.

Green, P. E., \& Rao, V. R. (1970). Rating scales and information recovery. How many scales and response categories to use? Journal of Marketing, 34(3), 33-39.

Greenberg, P. (2002). CRM at the speed of light: Capturing and keeping customers in Internet real time (2nd ed.). Sydney: McGraw-Hill.

Grégoire, Y., \& Fisher, R. J. (2006). The effects of relationship quality on customer retaliation. Marketing Letters, 17(1), 31-46.

Gremler, D. D., \& Gwinner, K. P. (1998). Connecting with customers: An examination of rapport in service industries. American Marketing Association. Conference Proceedings, 9, 161-162.

Gremler, D. D., \& Gwinner, K. P. (2000). Customer-employee rapport in service relationships. Journal of Service Research, 3(1), 82-104.

Grönroos, C. (1989). Defining marketing: A market-oriented approach. European Journal of Marketing, 23(1), 52-60.

Grönroos, C. (1990). Relationship approach to marketing in service contexts: The marketing and organizational behavior interface. Journal of Business Research, 20(1), 3-11.

Grönroos, C. (1991). The marketing strategy continuum: Towards a marketing concept for the 1990s. Management Decision, 29(1), 7-13.

Grönroos, C. (1994a). From marketing mix to relationship marketing: Towards a paradigm shift in marketing. Australasian Marketing Journal, 2(1), 9-29.

Grönroos, C. (1994b). Quo vadis, marketing? - Toward a relationship marketing paradigm. Journal of Marketing Management, 10(5), 347-360.

Grönroos, C. (1995). Relationship marketing: The strategy continuum. Journal of the Academy of Marketing Science, 23(4), 252-254.

Grönroos, C. (1996). Relationship marketing: Strategic and tactical implications. Management Decision, 34(3), 5-14. 
Grönroos, C. (2000). Service management and marketing: A customer relationship management approach (2nd ed.). Chichester, England: John Wiley \& Sons.

Groves, R. M., \& Lyberg, L. E. (1988). An overview of nonresponse issues in telephone surveys. In R. M. Groves, P. P. Biemer, L. E. Lyberg, J. T. Massey, W. L. Nicholls II \& J. Waksberg (Eds.), Telephone survey methodology (pp. 191-211). New York: John Wiley \& Sons.

Gruen, T. W., Summers, J. O., \& Acito, F. (2000). Relationship marketing activities, commitment, and membership behaviors in professional associations. Journal of Marketing, 64(3), 34-49.

Gummesson, E. (1994a). Broadening and specifying relationship marketing. Australasian Marketing Journal, 2(1), 31-43.

Gummesson, E. (1994b). Making relationship marketing operational. International Journal of Service Industry Management, 5(5), 5-20.

Gummesson, E. (2002). Relationship marketing and a new economy: It's time for deprogramming. Journal of Services Marketing, 16(7), 585-589.

Gummesson, E. (2003). All research is interpretive! The Journal of Business \& Industrial Marketing, 18(6/7), 482-492.

Gummesson, E. (2004). Return on relationships (ROR): The value of relationship marketing and CRM in business-to-business contexts. The Journal of Business and Industrial Marketing, 19(2), 136-148.

Gundlach, G. T., Achrol, R. S., \& Mentzer, J. T. (1995). The structure of commitment in exchange. Journal of Marketing, 59(1), 78-92.

Guo, C. (2002). Market orientation and business performance: A framework for service organizations. European Journal of Marketing, 36(9/10), 1154-1163.

Hair, J. F., Jr., Black, W. C., Babin, B. J., Andersen, R. E., \& Tatham, R. L. (2006). Mutilvariate data analysis (6th ed.). Upper Saddle River, NJ: Pearson Prentice Hall.

Hair, J. F., Jr., Bush, R. P., \& Ortinau, D. J. (2003). Marketing research: Within a changing information environment. Boston: McGraw-Hill Irwin.

Han, J. K., Kim, N., \& Srivastava, R. K. (1998). Market orientation and organizational performance: Is innovation a missing link? Journal of Marketing, 62(4), 30-45.

Hansotia, B. (2002). Gearing up for CRM: Antecedents to successful implementation. Journal of Database Marketing, 10(2), 121-132.

Harker, M. J. (1999). Relationship marketing defined? An examination of current relationship marketing definitions. Marketing Intelligence \& Planning, 17(1), 13-20. 
Hau, K.-T., \& Marsh, H. W. (2004). The use of item parcels in structural equation modelling: Non-normal data and small sample sizes. British Journal of Mathematical \& Statistical Psychology, 57, 327-351.

Häubl, G. (1996). A cross-national investigation of the effects of country of origin and brand name on the evaluation of a new car. International Marketing Review, 13(5), 76-97.

Hausman, A. (2001). Variations in relationship strength and its impact on performance and satisfaction in business relationships. The Journal of Business \& Industrial Marketing, 16(6/7), 600-616.

Heck, R. H. (1998). Factor analysis: Exploratory and confirmatory approaches. In G. A. Marcoulides (Ed.), Modern methods for business research (pp. 177-215). Mahwah, NJ: Lawrence Erlbaum Associates.

Heckmann, P., Shorten, D., \& Engel, H. (2003). Capturing the value of supply chain management. Retrieved 18 November, 2004, from http://www.strategybusiness.com/press/enewsarticle/22165?pg $=0$

Heide, J. B., \& John, G. (1992). Do norms matter in marketing relationships? Journal of Marketing, 56(2), 32-44.

Helfert, G., Ritter, T., \& Walter, A. (2002). Redefining market orientation from a relationship perspective: Theoretical considerations and empirical results. European Journal of Marketing, 36(9/10), 1119-1139.

Henderson, J. C., \& Venkatraman, H. (1999). Strategic alignment: Leveraging information technology for transforming organizations. IBM Systems Journal, $38(2 / 3), 472-484$.

Henderson, S. (1998). No such thing as market orientation - a call for no more papers. Management Decision, 36(9), 598-609.

Hess, R. L., Rubin, R. S., \& West, L. A., Jr. (2004). Geographic information systems as a marketing information system technology. Decision Support Systems, 38(2), 197-212.

Hirschman, E. C. (1986). Humanistic inquiry in marketing research: Philosophy, method, and criteria. Journal of Marketing Research, 23(3), 237-249.

Hirschowitz, A. (2001). Closing the CRM loop: The 21st century marketer's challenge: Transforming customer insight into customer value. Journal of Targeting, Measurement and Analysis for Marketing, 10(2), 168-178.

Hoffman, D. L., Novak, T. P., \& Peralta, M. (1999). Building consumer trust online. Association for Computing Machinery. Communications of the ACM, 42(4), 8085. 
Howell, J. M., \& Higgins, C. A. (1990). Champions of change: Identifying, understanding, and supporting champions of technological innovations. Organizational Dynamics, 19(1), 40-55.

Hoyle, R. H. (1995). The structural equation modeling approach: Basic concepts and fundamental issues. In R. H. Hoyle (Ed.), Structural equation modeling: Concepts, issues, and applications (pp. 1-15). Thousand Oaks, CA: Sage Publications.

Hu, L.-T., \& Bentler, P. M. (1995). Evaluating model fit. In R. H. Hoyle (Ed.), Structural equation modeling: Concepts, issues, and applications (pp. 76-99). Thousand Oaks, CA: Sage Publications.

Huber, G. P., \& Power, D. J. (1985). Retrospective reports of strategic-level managers: Guidelines for increasing their accuracy. Strategic Management Journal, 6(2), 171-180.

Hughes, A. M. (2002). Editorial: The mirage of CRM. Journal of Database Marketing, 9(2), 102-104.

Hulland, J. (1999). Use of partial least squares (PLS) in strategic management research: A review of four recent studies. Strategic Management Journal, 20(2), 195-204.

Hulland, J., Chow, Y. H., \& Lam, S. (1996). Use of causal models in marketing research: A review. International Journal of Research in Marketing, 13(2), 181197.

Hunt, S. D. (1990). Truth in marketing theory and research. Journal of Marketing, 54(3), 1-15.

Hunt, S. D., \& Morgan, R. M. (1995). The comparative advantage theory of competition. Journal of Marketing, 59(2), 1-14.

Hwang, Y. (2005). Investigating enterprise systems adoption: Uncertainty avoidance, intrinsic motivation, and the technology acceptance model. European Journal of Information Systems, 14(2), 150-161.

Iacobucci, D., \& Ostrom, A. (1996). Commercial and interpersonal relationships; Using the structure of interpersonal relationships to understand individual-toindividual, individual-to-firm, and firm-to-firm relationships in commerce. International Journal of Research in Marketing, 13(1), 53-72.

Iacovou, C. L., Benbasat, I., \& Dexter, A. S. (1995). Electronic data interchange and small organizations: Adoption and impact of technology. MIS Quarterly, 19(4), 465-485.

IDC. (2002, March). Moving beyond the traditional front office: CRM as a strategic enabler. An IDC Executive Brief Retrieved 10 October, 2003, from http://www.idc.com/getdoc.jhtml?containerId=CA015CRH 
IDC. (2004). Worldwide customer relationship management applications market expected to surpass $\$ 11$ billion by 2008 , according to IDC. Retrieved 3 August, 2004, from http://www.idcresearch.com/getdoc.jsp? containerId=pr2004_07_26_122025

Jaworski, B. J., \& Kohli, A. K. (1993). Market orientation: Antecedents and consequences. Journal of Marketing, 57(3), 53-70.

Jayachandran, S., Sharma, S., Kaufman, P., \& Raman, P. (2005). The role of relational information processes and technology use in customer relationship management. Journal of Marketing, 69(4), 177-192.

Jobber, D. (1986). Improving response rates in industrial mail surveys. Industrial Marketing Management, 15(3), 183-195.

Jobber, D. (1989). An examination of the effects of questionnaire factors on response to an industrial mail survey. International Journal of Research in Marketing, 6(2), 129-140.

Jobber, D., Allen, N., \& Oakland, J. (1985). The impact of telephone notification strategies on response to an industrial mail survey. International Journal of Research in Marketing, 2(4), 291-296.

Jobber, D., Mirza, H., \& Wee, K. H. (1991). Incentives and response rates to crossnational business surveys: A logit model analysis. Journal of International Business Studies, 22(4), 711-721.

Jobber, D., \& O'Reilly, D. (1996). Industrial mail surveys: techniques for inducing response. Marketing Intelligence \& Planning, 14(1), 29-34.

Jobber, D., \& O'Reilly, D. (1998). Industrial mail surveys: A methodological update. Industrial Marketing Management, 27, 95-107.

Jobber, D., \& Saunders, J. (1993). A note on the applicability of the Bruvold-Comer model of mail survey response rates to commercial populations. Journal of Business Research, 26(3), 223-236.

Jobber, D., Saunders, J., \& Mitchell, V.-W. (2004). Prepaid monetary incentive effects on mail survey response. Journal of Business Research, 57(4), 347-350.

Joereskog, K. G., \& Soerbom, D. (1982). Recent developments in structural equation modeling. Journal of Marketing Research, 19(4), 404-416.

Johansson, J. K., \& Yip, G. S. (1994). Exploiting globalization potential: U.S. and Japanese strategies. Strategic Management Journal, 15(8), 579-601.

John, G., \& Reve, T. (1982). The reliability and validity of key informant data from dyadic relationships in marketing channels. Journal of Marketing Research, 19(4), 517-524.

Johnston, H. R., \& Carrico, S. R. (1988). Developing capabilities to use information strategically. MIS Quarterly, 12(1), 37-47. 
Jöreskog, K. G. (1993). Testing structural equation models. In K. A. Bollen \& J. S. Long (Eds.), Testing structural equation models (pp. 294-316). Newbury Park, CA: Sage Publications.

Jutla, D., Craig, J., \& Bodorik, P. (2001, 3 - 6 January). Enabling and measuring electronic customer relationship management readiness. Paper presented at the 34th Hawaii International Conference on System Sciences (HICSS), Maui, Hawaii.

Kale, S. H. (2004). CRM failure and the seven deadly sins. Marketing Management, 13(5), 42-46.

Kamakura, W. A., Mela, C. F., Ansari, A., Bodapati, A., Fader, P., Iyengar, R., et al. (2005). Choice models and customer relationship management. Marketing Letters, 16(3-4), 279-291.

Kamakura, W. A., Mittal, V., Rosa, F. d., \& Mazzon, J. A. (2002). Assessing the service-profit chain. Marketing Science, 21(3), 294-317.

Kamakura, W. A., Ramaswami, S. N., \& Srivastava, R. K. (1991). Applying latent trait analysis in the evaluation of prospects for cross-selling of financial services. International Journal of Research in Marketing, 8(4), 329-349.

Kamakura, W. A., Wedel, M., de Rosa, F., \& Mazzon, J. A. (2003). Cross-selling through database marketing: A mixed data factor analyzer for data augmentation and prediction. International Journal of Research in Marketing, 20(1), 45-65.

Kapoulas, A., Ellis, N., \& Murphy, W. (2004). The voice of the customer in e-banking relationships. Journal of Customer Behaviour, 3(1), 27-51.

Karimi, J., Bhattacherjee, A., Gupta, Y. P., \& Somers, T. M. (2000). The effects of MIS steering committees on information technology management sophistication. Journal of Management Information Systems, 17(2), 207-230.

Karimi, J., Gupta, Y. P., \& Somers, T. M. (1996a). The congruence between a firm's competitive strategy and information technology leader's rank and role. Journal of Management Information Systems, 13(1), 63-88.

Karimi, J., Gupta, Y. P., \& Somers, T. M. (1996b). Impact of competitive strategy and information technology maturity on firms' strategic response to globalization. Journal of Management Information Systems, 12(4), 55-88.

Karimi, J., Somers, T. M., \& Gupta, Y. P. (2001). Impact of information technology management practices on customer service. Journal of Management Information Systems, 17(4), 125-158.

Karimi, J., Somers, T. M., \& Gupta, Y. P. (2004). Impact of environmental uncertainty and task characteristics on user satisfaction with data. Information Systems Research, 15(2), 175-193. 
Kaufmann, P. J., \& Dant, R. P. (1992). The dimensions of commercial exchange. Marketing Letters, 3(2), 171-185.

Kelloway, E. K. (1998). Using LISREL for structural equation modeling : A researcher's guide. Thousand Oaks: Sage.

Kennedy, A., Kelleher, C., \& Quigley, M. (2006). CRM best practice: Getting it right first time at ESB International (ESBI). Irish Journal of Management, 27(1), 255272.

Kerin, R. A., Berkowitz, E. N., Hartley, S. W., \& Rudelius, W. (2003). Marketing (7th ed.). Boston: McGraw-Hill Irwin.

Kim, E., \& Tadisina, S. (2003, 4-6 August). Customers' initial trust in e-business: How to measure customers' initial trust. Paper presented at the Ninth Americas Conference on Information Systems (AMCIS), Tampa, Florida.

Kim, H.-W., Lee, G.-H., \& Pan, S.-L. (2002, 15-18 December). Exploring the critical success factors for customer relationship management and electronic customer relationship management systems. Paper presented at the Twenty-Third International Conference on Information Systems (ICIS), Barcelona, Spain.

Kim, J., Suh, E., \& Hwang, H. (2003). A model for evaluating the effectiveness of CRM using the balanced scorecard. Journal of Interactive Marketing, 17(2), 519.

Kim, J. W., Choi, J., Qualls, W., \& Park, J. (2004). The impact of CRM on firm - and relationship - level performance in distribution networks. Communications of the Association for Information Systems, 14, 632-652.

Kim, K. (2000). On interfirm power, channel climate, and solidarity in industrial distributor-supplier dyads. Journal of the Academy of Marketing Science, 28(3), 388-405.

Kim, K., \& Frazier, G. L. (1997). On distributor commitment in industrial channels of distribution: A multicomponent approach. Psychology \& Marketing, 14(8), 847877.

Kincaid, J. W. (2003). Customer relationship management: Getting it right! Upper Saddle River, NJ: Prentice Hall.

King, M. P. (2001). Cross-sectional and longitudinal research designs issues in the studies of human development [Electronic Version]. Graduate research in Nursing, 3, 1-4. Retrieved 13 January 2007 from http://www.graduateresearch.com/King.htm.

Kingshott, R. P. J. (2004). The impact of psychological contracts upon trust and commitment within supplier-buyer relationships: A social exchange view. Paper presented at the 20th IMP-conference. 
Kirca, A. H., Jayachandran, S., \& Bearden, W. O. (2005). Market orientation: A metaanalytic review and assessment of its antecedents and impact on performance. Journal of Marketing, 69(2), 24-41.

Kirk-Smith, M. (1998). Psychological issues in questionaire-based research. Journal of the Market Research Society, 40(3), 223-236.

Klemz, B. R., Boshoff, C., \& Mazibuko, N.-E. (2006). Emerging markets in black South African townships. European Journal of Marketing, 40(5/6), 590-610.

Kline, R. B. (2005). Principles and practice of structural equation modeling (2nd ed.). New York: The Guilford Press.

Klopping, I. M., \& McKinney, E. (2004). Extending the technology acceptance model and the task-technology fir model to consumer e-commerce. Information Technology, Learning, and Performance Journal, 22(1), 35-48.

Kohli, A. K., \& Jaworski, B. J. (1990). Market orientation: The construct, research propositions, and managerial implications. Journal of Marketing, 54(2), 1-18.

Kohli, A. K., Jaworski, B. J., \& Kumar, A. (1993). MARKOR: A measure of market orientation. Journal of Marketing Research, 30(4), 467-478.

Kompass New Zealand. (2007). Kompass NZ Portal. Retrieved 3 September, 2007

Kong, R., \& Mayo, M. C. (1993). Measuring service quality in the business-to-business context. The Journal of Business \& Industrial Marketing, 8(2), 5-15.

Kotler, P. (1966). A design for the firm's marketing nerve center. Business Horizons, 9(3), 63-74.

Kotler, P. (1970). The future of the computer in marketing. Journal of Marketing, 34(1), 11-14.

Kotler, P. (1989). From mass marketing to mass customization. Planning Review, 17(5), $10-47$.

Kotler, P. (1992). Marketing's new paradigm: What's really happening out there. Planning Review, 20(5), 50-52.

Kotler, P. (2003). Marketing management (11th ed.). Upper Saddle River, NJ: Pearson Education.

Krapfel, R. E., Jr., Salmond, D., \& Spekman, R. (1991). A strategic approach to managing buyer-seller relationships. European Journal of Marketing, 25(9), 2237.

Kreiner, K. (2002). Tacit knowledge management: The role of artifacts. Journal of Knowledge Management, 6(2), 112-123.

Kuhn, T. S. (1996). The structure of scientific revolutions (3rd ed.). Chicago: University of Chicago Press. 
Kumar, N., Scheer, L. K., \& Steenkamp, J.-B. E. M. (1995). The effects of perceived interdependence on dealer attitudes. Journal of Marketing Research, 32(3), 348356.

Kumar, V., \& Reinartz, W. J. (2006). Customer relationship management: A databased approach. Hoboken, NJ: John Wiley \& Sons.

Lages, C., Lages, C. R., \& Lages, L. F. (2005). The RELQUAL scale: A measure of relationship quality in export market ventures. Journal of Business Research, 58, 1040-1048.

Lang, B., \& Colgate, M. (2003). Relationship quality, on-line banking and the information technology gap. The International Journal of Bank Marketing, 21(1), 29-37.

Langerak, F. (2003). An appraisal of research on the predictive power of market orientation. European Management Journal, 21(4), 447-464.

Lastovicka, J. L., \& Thamodaran, K. (1991). Common factor score estimates in multiple regression problems. Journal of Marketing Research, 28(1), 105-112.

Le Pla, R. (2002, October). Seven breakthrough CRM strategies. NZ Marketing Magazine, 8-17.

Lee, C.-S. (2001). An analytical framework for evaluating e-commerce business models and strategies. Internet Research: Electronic Networking Applications and Policy, 11(4), 349-359.

Lee, E., Hu, M. Y., \& Toh, R. S. (2004). Respondent non-cooperation in surveys and diaries: an analysis of item non-response and panel attrition. International Journal of Market Research, 46, 311-326.

Lee, H., \& Choi, B. (2003). Knowledge management enablers, processes, and organizational performance: An integrative view and empirical examination. Journal of Management Information Systems, 20(1), 179-228.

Lee, J. (2004). Discriminant anaysis of technology adoption behavior: A case of Internet technologies in small business. The Journal of Computer Information Systems, 44(4), 57-66.

Lee, J., \& Runge, J. (2001). Adoption of information technology in small business: Testing drivers of adoption for entrepreneurs. The Journal of Computer Information Systems, 42(1), 44-57.

Lee, T. W. (1999). Using qualitative methods in organizational research. Thousand Oaks: Sage.

Leek, S., Turnbull, P. W., \& Naude, P. (2003). How is information technology affecting business relationships? Results from a UK survey. Industrial Marketing Management, 32(2), 119-126. 
Leigh, J. H., \& Martin, C. R., Jr. (1987). 'Don't know' item nonresponse in a telephone survey: Effects of question form and respondent characteristics. Journal of Marketing Research, 24(4), 418-424.

Lemon, K. N., White, T. B., \& Winer, R. S. (2002). Dynamic customer relationship management: Incorporating future considerations into the service retention decision. Journal of Marketing, 66(1), 1-14.

Lendrum, T. (2003). The strategic partnering handbook: The practitioners' guide to partnerships and alliances (4th ed.). Sydney: McGraw-Hill.

Leuthesser, L., \& Kohli, A. K. (1995). Rational behavior in business markets: Implications for relationship management. Journal of Business Research, 34(3), 221-233.

Levasseur, R. E. (2002). People skills: Change management tools--ideal state analysis. Interfaces, 32(4), 84-85.

Levitt, T. (1983). After the sale is over ... Harvard Business Review, 61(5), 87-93.

Lewin, J. E., \& Johnston, W. J. (1997). Relationship marketing theory in practice: A case study. Journal of Business Research, 39(1), 23-31.

Li, E. Y., McLeod, R., Jr., \& Rogers, J. C. (2001). Marketing information systems in Fortune 500 companies: A longitudinal analysis of 1980, 1990, and 2000. Information \& Management, 38(5), 307-322.

Li, S., Davies, B., Edwards, J., Kinman, R., \& Duan, Y. (2002). Integrating group Delphi, fuzzy logic and expert systems for marketing strategy development: The hybridisation and its effectiveness. Marketing Intelligence \& Planning, 20(4/5), 273-284.

Li, Z. G., \& Dant, R. P. (1997). An exploratory study of exclusive dealing in channel relationships. Journal of the Academy of Marketing Science, 25(3), 201-213.

Lincoln, Y. S., \& Guba, E. G. (2000). Paradigmatic controversies, contradictions, and emerging confluences. In N. K. Denzin \& Y. S. Lincoln (Eds.), Handbook of qualitative research (2nd ed., pp. 163-188). Thousand Oaks: Sage.

Lind, D. A., Marchal, W. G., \& Mason, R. D. (2001). Statistical techniques in business \& economics (11th ed.). Boston, MA: McGraw-Hill.

Ling, R., \& Yen, D. C. (2001). Customer relationship management: An analysis framework and implementation strategies. The Journal of Computer Information Systems, 41(3), 82-97.

Lissitz, R. W., \& Green, S. B. (1975). Effect of the number of scale points on reliability: A Monte Carlo approach. Journal of Applied Psychology, 60(1), 10-13.

Liu, H.-Y. (2007). Development of a framework for customer relationship management (CRM) in the banking industry. International Journal of Management, 24(1), 15. 
Lloyd, G. O., Scullin, S., Allora, J., \& Fjermestad, J. (2001, 2-5 August). Electronic customer relationship management: Benefits and pre-implementation considerations. Paper presented at the Seventh Americas Conference on Information Systems (AMCIS), Boston, MA.

Locander, W. B., Hamilton, F., Ladik, D., \& Stuart, J. (2002). Developing a leadershiprich culture: The missing link to creating a market-focused organization. Journal of Market - Focused Management, 5(2), 149-163.

Locke, S. (2004). ICT adoption and SME growth in New Zealand. Journal of American Academy of Business, Cambridge, 4(1/2), 93-102.

Low, B. K. H. (1996). Long-term relationship in industrial marketing: Reality or rhetoric? Industrial Marketing Management, 25(1), 23-35.

MacCallum, R. C., \& Austin, J. T. (2000). Applications of structural equation modeling in psychological research. Annual Review of Psychology, 51(1), 201-226.

MacDonald, J. B., \& Smith, K. (2004). The effects of technology-mediated communication on industrial buyer behavior. Industrial Marketing Management, 33(2), 107-116.

MacKenzie, S. B., Podsakoff, P. M., \& Ahearne, M. (1998). Some possible antecedents and consequences of in-role and extra-role salesperson performance. Journal of Marketing, 62(3), 87-98.

Mahmood, M. A., \& Mann, G. J. (1993). Measuring the organizational impact of information technology investment: An exploratory study. Journal of Management Information Systems, 10(1), 97-122.

Malhotra, N. K. (1999). Marketing research: An applied orientation (3rd ed.). Upper Saddle River, NJ: Prentice Hall.

Malhotra, N. K. (2007). Marketing research: An applied orientation (5th ed.). Upper Saddle River, NJ: Pearson Prentice Hall.

Malhotra, N. K., Hall, J., Shaw, M., \& Oppenheim, P. (2006). Marketing research: An applied orientation (3rd ed.). Frenchs Forest: Prentice Hall.

Markowitz, E. (2002, June 01). Craig Conway: Up close. Retrieved 14 April, 2003, from http://www.destinationcrm.com/articles/default.asp?ArticleID=2321

Markus, M. L. (1983). Power, politics, and MIS implementation. Communications of the ACM, 26(6), 430-444.

Marsden, D., \& Littler, D. (1996). Evaluating alternative research paradigms: A marketoriented framework. Journal of Marketing Management, 12(7), 645-655.

Maruyama, G. M. (1998). Basics of structural equation modeling. Thousand Oaks: Sage. 
Massey, A. P., Montoya-Weiss, M. M., \& Holcom, K. (2001). Re-engineering the customer relationship: Leveraging knowledge assets at IBM. Decision Support Systems, 32(2), 155-170.

Matear, S., Osborne, P., Garrett, T., \& Gray, B. J. (2002). How does market orientation contribute to service firm performance? An examination of alternative mechanisms. European Journal of Marketing, 36(9/10), 1058-1075.

Mayer, C. S., \& Piper, C. (1982). A note on the importance of layout in selfadministered questionnaires. Journal of Marketing Research, 19(3), 390-391.

McDaniel, C., Jr., \& Gates, R. (2005). Marketing research (6th ed.). Hoboken, NJ: John Wiley \& Sons.

McKnight, D. H., \& Chervany, N. L. (1996). The meanings of trust. Retrieved 15 September, 2004, from http://misrc.umn.edu/wpaper/WorkingPapers/9604.pdf

McKnight, D. H., \& Chervany, N. L. (2000, 10-13 August). What is Trust? A conceptual analysis and an interdisciplinary model. Paper presented at the Sixth Americas Conference on Information Systems (AMCIS), Long Beach, CA.

McNamara, C. P. (1972). The present status of the marketing concept. Journal of Marketing, 36(1-7), 50-57.

McQuillen, J. S. (2003). The influence of technology on the initiation of interpersonal relationships. Education, 123(3), 616-623.

Medlin, C. J. (2003). Relationship performance: A relationship level construct. Paper presented at the 19th IMP-conference.

Medlin, C. J., Aurifeille, J.-M., \& Quester, P. G. (2005). A collaborative interest model of relational coordination and empirical results. Journal of Business Research, 58(2), 214-222.

Meehl, P. E. (1990). Why summaries of research on psychological theories are often uninterpretable. Psychological Reports, 66(1), 195-244.

Menon, A., Bharadwaj, S. G., Adidam, P. T., \& Edison, S. W. (1999). Antecedents and consequences of marketing strategy making: A model and a test. Journal of Marketing, 63(2), 18-40.

Meyer, J. P., Allen, N. J., \& Topolnytsky, L. (1998). Commitment in a changing world of work. Canadian Psychology, 39(1/2), 83-93.

Meyer, M., \& Kolbe, L. M. (2005). Integration of customer relationship management: Status quo and implications for research and practice. Journal of Strategic Marketing, 13(3), 175-198.

Michaelidou, N., \& Dibb, S. (2006). Using email questionnaires for research: Good practice in tackling non-response. Journal of Targeting, Measurement and Analysis for Marketing, 14(4), 289-296. 
Microsoft. (2004). Microsoft Business Solutions CRM. Retrieved 25 November, 2004, from http://www.microsoft.com/businesssolutions/crm/crm productoverview.aspx

Miles, M. B., \& Huberman, A. M. (1994). Qualitative data analysis: An expanded sourcebook (2nd ed.). Thousand Oaks: Sage.

Miller, G. A. (1956). The magical number seven, plus or minus two: some limits on our capacity for processing information. Psychological Review, 63(2), 81-97.

Mirchandani, D. A., \& Motwani, J. (2001). Understanding small business electronic commerce adoption: An empirical analysis. The Journal of Computer Information Systems, 41(3), 70-73.

Mithas, S., Krishnan, M. S., \& Fornell, C. (2005). Why do customer relationship management applications affect customer satisfaction? Journal of Marketing, 69(4), 201-209.

Mitra, S., \& Chaya, A. K. (1996). Analyzing cost-effectiveness of organizations: The impact of information technology spending. Journal of Management Information Systems, 13(2), 29-57.

Mitussis, D., O'Malley, L., \& Patterson, M. (2006). Mapping the re-engagement of CRM with relationship marketing. European Journal of Marketing, 40(5/6), 572-589.

Moghrabi, C., \& Eid, M. S. (1998). Modeling users through an expert system and a neural network. Computers \& Industrial Engineering, 35(3,4), 583-586.

Mohr, J. J., Fisher, R. J., \& Nevin, J. R. (1996). Collaborative communication in interfirm relationships: Moderating effects of integration and control. Journal of Marketing, 60(3), 103-115.

Mohr, J. J., \& Nevin, J. R. (1990). Communication strategies in marketing channels: A theoretical perspective. Journal of Marketing, 54(4), 36-51.

Mohr, J. J., \& Sohi, R. S. (1995). Communication flows in distribution channels: Impact on assessments of communication quality and satisfaction. Journal of Retailing, 71(4), 393-416.

Mohr, J. J., \& Spekman, R. (1994). Characteristics of partnership success: Partnership attributes, communication behavior, and conflict resolution techniques. Strategic Management Journal, 15(2), 135-152.

Mohrman, S. A., Gibson, C. B., \& Mohrman Jr., A. M. (2001). Doing research that is useful to practice: A model and empirical exploration. Academy of Management Journal, 44(2), 357-375.

Moore, G. C., \& Benbasat, I. (1991). Development of an Instrument to Measure the Perceptions of Adopting an Information Technology Innovation. Information Systems Research, 2(3), 192-222. 
Moorman, C., Deshpandé, R., \& Zaltman, G. (1993). Factors affecting trust in market research relationships. Journal of Marketing, 57(1), 81-101.

Moorman, C., \& Miner, A. S. (1997). The impact of organizational memory on new product performance and creativity. Journal of Marketing Research, 34(1), 91106.

Moorman, C., \& Rust, R. T. (1999). The role of marketing. Journal of Marketing, 63(Special Issue), 180-197.

Moorman, C., Zaltman, G., \& Deshpandé, R. (1992). Relationships between providers and users of market research: The dynamics of trust within and between organizations. Journal of Marketing Research, 29(3), 314-328.

Morgan, R. M., \& Hunt, S. D. (1994). The commitment-trust theory of relationship marketing. Journal of Marketing, 58(3), 20-38.

Muthén, B., \& Kaplan, D. (1985). A comparison of some methodologies for the factor analysis of non-normal Likert variables: a note on the size of the model. British Journal of Mathematical and Statistical Psychology, 38, 171-189.

Nairn, A. (2002). CRM: Helpful or full of hype? Journal of Database Marketing, 9(4), 376-382.

Nakata, C., \& Zhu, Z. (2006). Information technology and customer orientation: A study of direct, mediated, and interactive linkages. Journal of Marketing Management, 22(3/4), 319-354.

Narayandas, D., \& Rangan, V. K. (2004). Building and sustaining buyer-seller relationships in mature industrial markets. Journal of Marketing, 68(3), 63-77.

Narver, J. C., \& Slater, S. F. (1990). The effect of a market orientation on business profitability. Journal of Marketing, 54(4), 20-35.

Natovich, J. (2002, 9-11 August). IT project failure and vendor related risks: Is outsourcing an solution or a problem? Paper presented at the Eighth Americas Conference on Information Systems (AMCIS), Dallas, Texas.

Netemeyer, R. G., Bearden, W. O., \& Sharma, S. (2003). Scaling procedures: Issues and applications. Thousand Oaks: Sage.

Ngai, E. W. T. (2005). Customer relationship management research (1992-2002): An academic literature review and classification. Marketing Intelligence \& Planning, 23(6/7), 582-605.

Nguyen, T. H., Sherif, J. S., \& Newby, M. (2007). Strategies for successful CRM implementation. Information Management \& Computer Security, 15(2), 102115.

Nielson, C. C. (1998). An empirical examination of the role of "closeness" in industrial buyer-seller relationships. European Journal of Marketing, 32(5/6), 441-463. 
Niraj, R., Gupta, M., \& Narasimhan, C. (2001). Customer profitability in a supply chain. Journal of Marketing, 65(3), 1-16.

Noble, C. H., Sinha, R. K., \& Kumar, A. (2002). Market orientation and alternative strategic orientations: A longitudinal assessment of performance implications. Journal of Marketing, 66(4), 25-39.

Nunnally, J. C. (1959). Tests and Measurements: Assessment and prediction. New York: McGraw-Hill Book Co.

Nunnally, J. C., \& Bernstein, I. H. (1994). Psychometric theory (3rd ed.). New York: McGraw-Hill.

O'Brien, J. A. (2004). Management information systems: Managing information technology in the business enterprise (6th ed.). Boston: McGraw-Hill/Irwin.

O'Cass, A. (2002). Political advertising believability and information source value during elections. Journal of Advertising, 31(1), 63-74.

O'Loughlin, C., \& Coenders, G. (2004). Estimation of the European Customer Satisfaction Index: Maximum likelihood versus partial least squares. Application to postal services. Total Quality Management \& Business Excellence, 15 $(9,10)$, 1231-1255.

O'Malley, L., \& Tynan, C. (1997). A reappraisal of the relationship marketing constructs of commitment and trust. Paper presented at the American Marketing Association: Special Conferences: New and Evolving Paradigms: The emerging future of marketing, Dublin, Ireland.

O'Malley, L., \& Tynan, C. (2000). Relationship marketing in consumer markets Rhetoric or reality? European Journal of Marketing, 34(7), 797-815.

Odekerken-Schroder, G., De Wulf, K., \& Schumacher, P. (2003). Strengthening outcomes of retailer-consumer relationships: The dual impact of relationship marketing tactics and consumer personality. Journal of Business Research, 56(3), 177-190.

Oliver, R. L. (1993). Cognitive, affective, and attribute bases of the satisfaction response. Journal of Consumer Research, 20(3), 418-430.

Oliver, R. L. (1999). Whence consumer loyalty? Journal of Marketing, 63, 33-44.

Oracle. (2004). Oracle Customer Relationship Management. Retrieved 27 April, 2004, from http://www.oracle.com/applications/customermgmt/Oracle_CRM.pdf

Oracle. (2005, August 2005). Oracle Marketing 11i - Data Sheet. Retrieved 7 April, 2006, from http://www.oracle.com/applications/marketing/11i10 mktg_ds.pdf

Palmatier, R. W., Dant, R. P., \& Grewal, D. (2007). A comparative longitudinal analysis of theoretical perspectives of interorganizational relationship performance.

Journal of Marketing, 71(4), 172-194. 
Palmatier, R. W., Gopalakrishna, S., \& Houston, M. B. (2006). Returns on business-tobusiness relationship marketing investments: Strategies for leveraging profits. Marketing Science, 25(5), 477-493.

Palmatier, R. W., Scheer, L. K., Houston, M. B., Evans, K. R., \& Gopalakrishna, S. (2007). Use of relationship marketing programs in building customersalesperson and customer-firm relationships: Differential influences on financial outcomes. International Journal of Research in Marketing, 24(3), 210-223.

Palmer, R. (2007). The transaction-relational continuum: Conceptually elegant but empirically denied. The Journal of Business \& Industrial Marketing, 22(7), 439451.

Palvia, S. C., \& Chervany, N. L. (1995). An experimental investigation of factors influencing predicted success in DSS implementation. Information \& Management, 29(1), 43-53.

Pan, S. L., \& Lee, J.-N. (2003). Using e-CRM for a unified view of the customer. Association for Computing Machinery. Communications of the ACM, 46(4), 9599.

Parasuraman, A., Grewal, D., \& Krishnan, R. (2004). Marketing Research. Boston: Houghton Mifflin.

Park, C.-H., \& Kim, Y.-G. (2003). A framework of dynamic CRM: Linking marketing with information strategy. Business Process Management Journal, 9(5), 652671.

Parvatiyar, A., \& Sheth, J. N. (2000). The domain and conceptual foundations of relationship marketing. In J. N. Sheth \& A. Parvatiyar (Eds.), Handbook of relationship marketing (pp. 3-37). Thousand Oaks: Sage.

Payne, A. (2006). Handbook of CRM: Achieving excellence in customer management. Amsterdam: Butterworth-Heinemann.

Payne, A., \& Frow, P. (2004). The role of multichannel integration in customer relationship management. Industrial Marketing Management, 33(6), 527-538.

Payne, A., \& Frow, P. (2005). A strategic framework for customer relationship management. Journal of Marketing, 69(4), 167-176.

Payne, A., \& Frow, P. (2006). Customer relationship management: From strategy to implementation. Journal of Marketing Management, 22(1,2), 135-168.

Payton, F. C., \& Zahay, D. (2005). Why doesn't marketing use the corporate data warehouse? The role of trust and quality in adoption of data-warehousing technology for CRM applications. The Journal of Business \& Industrial Marketing, 20(4/5), 237-244.

Pearson, S. (1994). Relationship management: Generating business in the diverse markets of Europe. European Business Journal, 6(4), 28-38. 
Pedhazur, E. J. (1982). Multiple regression in behavioral research: Explanation and prediction (2nd ed.). New York: Holt, Rinehart and Winston.

Pelham, A. M. (1997). Mediating influences on the relationship between market orientation and profitability in small industrial firms. Journal of Marketing Theory and Practice, 5(3), 55-76.

Pelham, A. M. (1999). Influence of environment, strategy, and market orientation on performance in small manufacturing firms. Journal of Business Research, 45(1), $33-46$.

Pelham, A. M., \& Wilson, D. T. (1996). A longitudinal study of the impact of market structure, firm structure, strategy, and market orientation culture on dimensions of small-firm performance. Journal of the Academy of Marketing Science, 24(1), $27-43$.

Pels, J., Coviello, N. E., \& Brodie, R. J. (2000). Integrating transactional and relational marketing exchange: A pluralistic perspective. Journal of Marketing Theory and Practice, 8(3), 11-20.

Pennington, R., Wilcox, H. D., \& Grover, V. (2004). The role of system trust in business-to-consumer transactions. Journal of Management Information Systems, 20(3), 197-226.

PeopleSoft. (2003, June 2003). PeopleSoft Customer Relationship Management. Retrieved 27 April, 2004, from http://www.peoplesoft.com/corp/en/doc_archive/brochure/ent_crm.jsp

Peppard, J. (2000). Customer relationship management (CRM) in financial services. European Management Journal, 18(3), 312-327.

Peppers, D., \& Rogers, M. (1993). The one to one future: Building relationships one customer at a time. New York: Doubleday.

Peppers, D., Rogers, M., \& Dorf, B. (1999). Is your company ready for one-to-one marketing? Harvard Business Review, 77(1), 151-160.

Periatt, J. A., LeMay, S. A., \& Chakrabarty, S. (2004). The selling orientation-customer orientation (SOCO) scale: Cross-validation of the revised version. Journal of Personal Selling \& Sales Management, 24(1), 49-54.

Perry, C. (1998). Processes of a case study methodology for postgraduate research in marketing. European Journal of Marketing, 32(9/10), 785-802.

Perry, C., Riege, A., \& Brown, L. (1999). Realism's role among scientific paradigms in marketing research. Irish Marketing Review, 12(2), 16-23.

Peter, J. P. (1979). Reliability: A review of psychometric basics and recent marketing practices. Journal of Marketing Research, 16(1), 6-17.

Peters, L. D., \& Fletcher, K. P. (2004a). Communication strategies and marketing performance: An application of the Mohr and Nevin framework to intra- 
organisational cross-functional teams. Journal of Marketing Management, 20(7,8), 741-770.

Peters, L. D., \& Fletcher, K. P. (2004b). They love me, they love me not: Consumer relationship orientation and CRM. Journal of Customer Behaviour, 3(1), 53-80.

Peterson, R. A. (1995). Relationship marketing and the consumer. Journal of the Academy of Marketing Science, 23(4), 278-281.

Pinsonneault, A., \& Kraemer, K. L. (1993). Survey research methodology in management information systems: An assessment. Journal of Management Information Systems, 10(2), 75-105.

Plakoyiannaki, E., \& Tzokas, N. (2002). Customer relationship management: A capabilities portfolio perspective. Journal of Database Marketing, 9(3), 228237.

Podasakoff, P. M., MacKenzie, S. B., Lee, J.-Y., \& Podsakoff, N. P. (2003). Common method biases in behavioral research: A critical review of the literature and recommended remedies. Journal of Applied Psychology, 88(5), 879-903.

Poe, G. S., Seeman, I., McLaughlin, J., Mehl, E., \& Dietz, M. (1988). 'Don't Know' boxes in factual questions in a mail questionnaire. Public Opinion Quarterly, 52(2), 212-222.

Postma, O. J., \& Brokke, M. (2002). Personalisation in practice: The proven effects of personalisation. Journal of Database Marketing, 9(2), 137-142.

Pressey, A. D., \& Mathews, B. P. (2004). Patterns of trust in buyer-seller relationships: Motives for formation, drivers, outcomes and temporal relationships. Journal of Customer Behaviour, 3(1), 81-100.

Preston, C. C., \& Colman, A. M. (2000). Optimal number of response categories in rating scales: Reliability, validity, discriminating power, and respondent preferences. Acta Psychologica 104, 1-15.

Proctor, T. (2005). Essentials of marketing research (4th ed.). Harlow, England: Prentice Hall.

Puccinelli, N. M., Tickle-Degnen, L., \& Rosenthal, R. (2003). Effect of dyadic context on judgments of rapport: Dyad task and partner presence. Journal of Nonverbal Behavior, 27(4), 211-236.

Pulendran, S., Speed, R., \& Widing, R. E., II. (2003). Marketing planning, market orientation and business performance. European Journal of Marketing, 37(3/4), 476-497.

Ragowsky, A., \& Somers, T. M. (2002). Special section: Enterprise resource planning. Journal of Management Information Systems, 19(1), 11-15. 
Raman, P., \& Pashupati, K. (2004). Is CRM really doomed to fail? An exploratory study of the barriers to CRM implementation. Journal of Customer Behaviour, $3(1), 5-26$.

Raman, P., Wittmann, C. M., \& Rauseo, N. A. (2006). Leveraging CRM for sales: The role of organizational capabilities in successful CRM implementation. Journal of Personal Selling \& Sales Management, 26(1), 39-53.

Ranchhod, A., \& Zhou, F. (2001). Comparing respondents of e-mail and mail surveys: Understanding the implications of technology. Marketing Intelligence \& Planning, 19(4), 254-262.

Ravald, A., \& Grönroos, C. (1996). The value concept and relationship marketing. European Journal of Marketing, 30(2), 19-30.

Ravichandran, T., \& Rai, A. (2000). Quality management in systems development: An organizational system perspective. MIS Quarterly, 24(3), 381-415.

Reichheld, F. F. (1996). The loyalty effect: The hidden force behind growth, profits, and lasting value. Cambridge, MA: Harvard Business School Press.

Reichheld, F. F., \& Sasser, W. E., Jr. (1990). Zero defections: Quality comes to services. Harvard Business Review, 68(5), 105-111.

Reinartz, W. J., Krafft, M., \& Hoyer, W. D. (2004). The customer relationship management process: Its measurement and impact on performance. Journal of Marketing Research, 41(3), 293-305.

Reinartz, W. J., \& Kumar, V. (2000). On the profitability of long-life customers in a noncontractual setting: An empirical investigation and implications for marketing. Journal of Marketing, 64(4), 17-35.

Reinartz, W. J., \& Kumar, V. (2002). The mismanagement of customer loyalty. Harvard Business Review, 80(7), 86-94.

Reinartz, W. J., \& Kumar, V. (2003). The impact of customer relationship characteristics on profitable lifetime duration. Journal of Marketing, 67(1), 7799.

Reynolds, K. E., \& Beatty, S. E. (1999). Customer benefits and company consequences of customer-salesperson relationships in retailing. Journal of Retailing, 75(1), $11-32$.

Rheault, D., \& Sheridan, S. (2002). Reconstruct your business around customers. The Journal of Business Strategy, 23(2), 38-42.

Richard, J. E. (2003). Customer relationship management (CRM) implementation: An exploratory study. Unpublished Honours thesis, Victoria University of Wellington, New Zealand.

Richard, J. E., Thirkell, P. C., \& Huff, S. L. (2007). An examination of customer relationship management (CRM) technology adoption and its impact on 
business-to-business customer relationships. Total Quality Management \& Business Excellence, 18(8), 927-945.

Rigby, D. K., \& Ledingham, D. (2004). CRM done right. Harvard Business Review, 82(11), 118-133.

Rigby, D. K., Reichheld, F. F., \& Schefter, P. (2002a). Avoid the four perils of CRM. Harvard Business Review, 80(2), 101-109.

Rigby, D. K., Reichheld, F. F., \& Schefter, P. (2002b). Start with customer strategy. Harvard Business Review, 80(2), 103.

Rindfleisch, A., \& Heide, J. B. (1997). Transaction cost analysis: Past, present, and future applications. Journal of Marketing, 61(4), 30-54.

Ringle, C. M., Wende, S., \& Will, A. (2005). SmartPLS (Version 2.0 beta). Hamburg, Germany: University of Hamburg.

Rivard, S., \& Huff, S. L. (1988). Factors of success for end-user computing. Communications of the ACM, 31(5), 552-561.

Rix, P., Buss, J., \& Herford, G. (2001). Selling: A consultative approach (2nd ed.). Sydney: McGraw-Hill.

Roberts, F. S. (1994). Limitations on conclusions using scales of measurement. In S. M. Pollock, M. H. Rothkopf \& A. Barnett (Eds.), Operations research and the public sector (Vol. 6, pp. 621-671). Amsterdam: North-Holland.

Roberts, K., Varki, S., \& Brodie, R. (2003). Measuring the quality of relationships in consumer services: An empirical study. European Journal of Marketing, 37(1/2), 169-196.

Roberts, M. L. (2003). Internet marketing: Integrating online and offline strategies. Boston: McGraw-Hill Irwin.

Roberts, M. L., Liu, R. R., \& Hazard, K. (2005). Strategy, technology and organisational alignment: Key components of CRM success. Journal of Database Marketing \& Customer Strategy Management, 12(4), 315-326.

Robinson, L., Jr., Marshall, G. W., \& Stamps, M. B. (2005). An empirical investigation of technology acceptance in a field sales force setting. Industrial Marketing Management, 34(4), 407-415.

Rogers, E. M., \& Albritton, M. M. (1995). Interactive communication technologies in business organizations. The Journal of Business Communication, 32(2), 177195.

Rokkan, A. I., Heide, J. B., \& Wathne, K. H. (2003). Specific investments in marketing relationships: Expropriation and bonding effects. Journal of Marketing Research, 60(2), 210-224. 
Romano, N. C., Jr. (2000, 10-13 August). Customer relations management in information systems research. Paper presented at the Sixth America's Conference on Information Systems (AMCIS), Long Beach, CA.

Romano, N. C., Jr., \& Fjermestad, J. (2001, 2-5 August). An agenda for electronic commerce customer relationship management research. Paper presented at the Seventh America's Conference on Information Systems (AMCIS), Boston, MA.

Romano, N. C., Jr., \& Fjermestad, J. (2003). Electronic commerce customer relationship management: A research agenda. Information Technology and Management, 4(2-3), 233-258.

Rosenbaum, H., \& Huang, B.-Y. (2002, 9-11 August). A framework for web-based ecommerce customer relationship management. Paper presented at the Eighth Americas Conference on Information Systems (AMCIS), Dallas, Texas.

Rossiter, J. R. (2002). The C-OAR-SE procedure for scale development in marketing. International Journal of Research in Marketing, 19(4), 305-335.

Rowley, J. E. (2002). Reflections on customer knowledge management in e-business. Qualitative Market Research, 5(4), 268-280.

Rummel, R. J. (1970). Applied factor analysis. Evanston: Northwestern University Press.

Rust, R. T., \& Chung, T. S. (2006). Marketing models of service and relationships. Marketing Science, 25(6), 560-580.

Rust, R. T., \& Espinoza, F. (2006). How technology advances influence business research and marketing strategy. Journal of Business Research, 59(10-11), 10721078.

Ryals, L. (2005). Making customer relationship management work: The measurement and profitable management of customer relationships. Journal of Marketing, 69(4), 252-261.

Ryals, L., \& Knox, S. (2001). Cross-functional issues in the implementation of relationship marketing through customer relationship management. European Management Journal, 19(5), 534-542.

Ryan, G. W., \& Bernard, H. R. (2000). Data management and analysis methods. In N. K. Denzin \& Y. S. Lincoln (Eds.), Handbook of qualitative research (2nd ed., pp. 769-802). Thousand Oaks: Sage.

Sabherwal, R., \& Kirs, P. (1994). The alignment between organizational critical success factors and information technology capability in academic institutions. Decision Sciences, 25(2), 301-330.

Sako, M. (1992). Prices, quality and trust: Inter-firm relations in Britain and Japan. Cambridge: Cambridge University Press. 
Sambamurthy, V., \& Chin, W. W. (1994). The effects of group attitudes toward alternative GDSS designs on the decision-making performance of computersupported groups. Decision Sciences, 25(2), 215-241.

Sanchez, M. E. (1992). Effects of questionnaire design on the quality of survey data. Public Opinion Quarterly, 56(2), 206-217.

Sanzo, M. J., Santos, M. L., Vázquez, R., \& Álvarez, L. I. (2003). The effect of market orientation on buyer-seller relationship satisfaction. Industrial Marketing Management, 32(4), 327-345.

SAP. (2004). mySAP Customer Relationship Management: Features \& functions. Retrieved 25 November, 2004, from http://www.sap.com/solutions/businesssuite/crm/featuresfunctions/index.aspx

SAP. (2006). mySAP Customer Relationship Management: Features \& Functions. Retrieved 7 April, 2006, from http://www.sap.com/solutions/businesssuite/crm/featuresfunctions/index.epx

SAS. (2004). SAS customer intelligence. Retrieved 25 November, 2004, from http://www.sas.com/solutions/crm/index.html

Sathish, S., Pan, S. L., \& Raman, K. S. (2002, 9-11 August). Customer relationship management (CRM) network: A new approach to studying CRM. Paper presented at the Eighth Americas Conference on Information Systems (AMCIS), Dallas, TX.

Saxe, R., \& Weitz, B. A. (1982). The SOCO scale: A measure of the customer orientation of salespeople. Journal of Marketing Research, 19(3), 343-351.

Scandura, T. A., \& Williams, E. A. (2000). Research methodology in management: Current practices, trends, and implications for future research. Academy of Management Journal, 43(6), 1248-1264.

Schlegelmilch, B. B., \& Diamantopoulos, A. (1991). Prenotification and mail survey response rates: A quantitative integration of the literature. Journal of the Market Research Society, 33(3), 243-255.

Schumacker, R. E., \& Lomax, R. G. (2004). A beginner's guide to structural equation modeling (2nd ed.). Mahwah, NJ: Lawrence Erlbaum Associates.

Sekaran, U. (2003). Research methods for business: A skill building approach (4th ed.). New York: John Wiley \& Sons.

Seligman, M. (2002). Avoid money down the drain: Shift from CRM to CMR. New Zealand Management, 49(4), 59-64.

Selnes, F. (1998). Antecedents and consequences of trust and satisfaction in buyer-seller relationships. European Journal of Marketing, 32(3/4), 305-322.

Selnes, F., \& Sallis, J. (2003). Promoting relationship learning. Journal of Marketing, 67(3), 80-95. 
Seybold, P. B. (2001). Get inside the lives of your customers. Harvard Business Review, 79(5), 80-89.

Shani, D., \& Chalasani, S. (1992). Exploiting niches using relationship marketing. Journal of Services Marketing, 6(4), 43-52.

Shapiro, B. P. (1974). Manage the customer, not just the sales-force. Harvard Business Review, 52(5), 127-134.

Sharma, N., \& Patterson, P. G. (1999). The impact of communication effectiveness and service quality on relationship commitment in consumer, professional services. Journal of Services Marketing, 13(2), 151-170.

Sharma, S., Durvasula, S., \& Dillon, W. R. (1989). Some results on the behavior of alternate covariance structure estimation procedures in the presence of nonnormal data. Journal of Marketing Research, 26(2), 214-221.

Shelby, A. N. (1998). Communication quality revisited: Exploring the link with persuasive effects. The Journal of Business Communication, 35(3), 387-404.

Sheng, Y. P. (2002, 9-11 August). A business model and framework for electronic customer relationship management. Paper presented at the Eighth Americas Conference on Information Systems (AMCIS), Dallas, TX.

Sheppard, B. H., Hartwick, J., \& Warshaw, P. R. (1988). The theory of reasoned action: A meta-analysis of past research with recommendations for modifications and future research. Journal of Consumer Research, 15(3), 325-343.

Sheth, J. N. (2002). The future of relationship marketing. Journal of Services Marketing, 16(7), 590-592.

Sheth, J. N., \& Parvatiyar, A. (2000). The evolution of relationship marketing. In J. N. Sheth \& A. Parvatiyar (Eds.), Handbook of relationship marketing (pp. 119145). Thousand Oaks: Sage.

Shoemaker, M. E. (2001). A framework for examining IT-enabled market relationships. Journal of Personal Selling \& Sales Management, 21(2), 177-185.

Shook, C. L., Ketchen, D. J., Jr., Hult, G. T. M., \& Kacmar, K. M. (2004). An assessment of the use of structural equation modeling in strategic management research. Strategic Management Journal, 25(4), 397-404.

Shrivastava, S., \& Kale, S. H. (2003). Philosophising on the elusiveness of relationship marketing theory in consumer markets: A case for reassessing ontological and epistemological assumptions. Australasian Marketing Journal, 11(3), 61-71.

Siebel. (2004). What is CRM? Retrieved 25 November, 2004, from http://www.siebel.com/what-is-crm/software-solutions.shtm

Siguaw, J. A., Simpson, P., M., \& Baker, T., L. (1998). Effects of supplier market orientation on distributor market orientation and the channel relationship: The distributor perspective. Journal of Marketing, 62(3), 99-111. 
Simsek, Z., \& Veiga, J. F. (2001). A primer on Internet organizational surveys. Organizational Research Methods, 4(3), 218-235.

Sin, L. Y. M., Tse, A. C. B., Yau, O. H. M., Lee, J. S. Y., \& Chow, R. P. M. (2002). The effect of relationship marketing orientation on business performance in a service-oriented economy. Journal of Services Marketing, 16(7), 656-676.

Sin, L. Y. M., Tse, A. C. B., \& Yim, F. H. K. (2005). CRM: Conceptualization and scale development. European Journal of Marketing, 39(11/12), 1264-1290.

Singh, S., \& Ranchod, A. (2004). Market orientation and customer satisfaction: Evidence from British machine tool industry. Industrial Marketing Management, 33(2), 135-144.

Sirdeshmukh, D., Singh, J., \& Sabol, B. (2002). Consumer trust, value, and loyalty in relational exchanges. Journal of Marketing, 66(1), 15-37.

Slater, S. F., \& Narver, J. C. (1995). Market orientation and the learning organization. Journal of Marketing, 59(3), 63-74.

Smith, A. E. (2005). Leximancer Manual, version 2.2. Retrieved 18 July, 2006, from http://www.leximancer.com/cms//index.php?option=com content\&task=view\&i $\underline{\mathrm{d}=53 \& \text { Itemid }=85}$

Smith, A. E., \& Humphreys, M., S. (2006). Evaluation of unsupervised semantic mapping of natural language with Leximancer concept mapping. Behavior Research Methods, 38(2), 262-279.

Smith, J. B., \& Barclay, D. W. (1997). The effects of organizational differences and trust on the effectiveness of selling partner relationships. Journal of Marketing, 61(1), 3-21.

Songini, M. L. (2002). Siebel, SAP push CRM upgrades. Computerworld, 36(37), 1.

Spector, P. E. (1992). Summated rating scale construction: An introduction (Vol. 07082). Newbury Park, CA: Sage.

Speier, C., \& Venkatesh, V. (2002). The hidden minefields in the adoption of sales force automation technologies. Journal of Marketing, 66(3), 98-111.

Srinivasan, R., \& Moorman, C. (2005). Strategic firm commitments and rewards for customer relationship management in online retailing. Journal of Marketing, 69(4), 193-200.

Srivastava, R. K., Shervani, T. A., \& Fahey, L. (1999). Marketing, business processes, and shareholder value: An organizationally embedded view of marketing activities and the discipline of marketing. Journal of Marketing, 63(Special Issue), 168-179.

Stake, R. E. (1994). Case studies. In N. K. Denzin \& Y. S. Lincoln (Eds.), Handbook of qualitative research (pp. 236-247). Thousand Oaks: Sage. 
Stake, R. E. (1995). The art of case study research. Thousand Oaks: Sage.

Stake, R. E. (2000). Case studies. In N. K. Denzin \& Y. S. Lincoln (Eds.), Handbook of qualitative research (2nd ed., pp. 435-454). Thousand Oaks: Sage.

Statistics New Zealand. (2005, February 2004). New Zealand Business Demographic Statistics. Retrieved 13 January, 2005, from http://www2.stats.govt.nz/domino/external/pasfull/pasfull.nsf/7cf46ae26dcb680 0cc256a62000a2248/4c2567ef00247c6acc256f6b000db788?OpenDocument

Stefanou, C. J., Sarmaniotis, C., \& Stafyla, A. (2003). CRM and customer-centric knowledge management: An empirical research. Business Process Management Journal, 9(5), 617-634.

Stephens, C. S., Ledbetter, W. N., Mitra, A., \& Ford, F. N. (1992). Executive or functional manager? The nature of the CIO's job. MIS Quarterly, 16(4), 449467.

Stern, B. B. (1997). Advertising intimacy: Relationship marketing and the services consumer. Journal of Advertising, 26(4), 7-19.

Stone, M. (1974). Cross-validatory choice and assessment of statistical predictions. Journal of the Royal Statistical Society. Series B (Methodological), 36(2), 111147.

Stone, R. W., \& Good, D. J. (1995). Expert systems in the marketing organization. Industrial Management + Data Systems, 95(4), 3-7.

Storbacka, K., Strandvik, T., \& Grönroos, C. (1994). Managing customer relationships for profit: The dynamics of relationship quality. International Journal of Service Industry Management, 5(5), 21-38.

Subramanian, R., \& Gopalakrishna, P. (2001). The market orientation-performance relationship in the context of a developing economy: An empirical analysis. Journal of Business Research, 53(1), 1-13.

Sudman, S., \& Bradburn, N. M. (1982). Asking questions. San Francisco: Jossey-Bass Publishers.

Suppes, P., \& Zinnes, J. L. (1963). Basic measurement theory. In D. R. Luce, R. R. Bush \& E. Galanter (Eds.), Handbook of mathematical psychology (Vol. 1, pp. 1-76). New York: John Wiley and Sons.

Sweat, J., \& Hibbard, J. (1999, June 21). Customer disservice. InformationWeek, 65-78.

Tallon, P. P., Kraemer, K. L., \& Gurbaxani, V. (2000). Executives' perceptions of the business value of information technology: A process-oriented approach. Journal of Management Information Systems, 16(4), 145-173.

Talvinen, J. M. (1995). Information systems in marketing: Identifying opportunities. European Journal of Marketing, 29(1), 8-26. 
Tapp, A. (2005). Principles of direct and database marketing (3rd ed.). Harlow, England: Prentice Hall.

Tellefsena, T., \& Thomas, G. P. (2005). The antecedents and consequences of organizational and personal commitment in business service relationships. Industrial Marketing Management, 34(1 ), 23- 37.

The Data Warehousing Institute. (2000). TDWI industry study 2000 executive summary: Harnessing customer information for strategic advantage: Technical challenges and business solutions (www.dw-institute.com). Seattle, WA: The Data Warehousing Institute.

Thomas, J. S., Blattberg, R. C., \& Fox, E. J. (2004). Recapturing lost customers. Journal of Marketing Research, 41(1), 31-45.

Thomas, R. W., Soutar, G. N., \& Ryan, M. M. (2001). The selling orientation-customer orientation (S.O.C.O.) scale: A proposed short form. Journal of Personal Selling \& Sales Management, 21(1), 63-69.

Thorbjornsen, H., Supphellen, M., Nysveen, H., \& Pedersen, P. E. (2002). Building brand relationships online: A comparison of two interactive applications. Journal of Interactive Marketing, 16(3), 17-34.

Tobias, R. D. (1995). An introduction to partial least squares regression [Electronic Version]. SUGI 20: Proceedings, 1-8. Retrieved 16 February 2007 from http://www.ats.ucla.edu/STAT/SAS/library/pls.pdf.

Too, L. H. Y., Souchon, A. L., \& Thirkell, P. C. (2001). Relationship marketing and customer loyalty in a retail setting: A dyadic exploration. Journal of Marketing Management, 17(3/4), 287-319.

Tourangeau, R., Rips, L. J., \& Rasinski, K. (2000). The psychology of survey response. Cambridge: Cambridge University Press.

Traylor, M. (1983). Ordinal and interval scaling. Journal of the Market Research Society, 25(4), 297-303.

Tuominen, M., Rajala, A., \& Möller, K. (2004). Market-driving versus market-driven: Divergent roles of market orientation in business relationships. Industrial Marketing Management, 33(3), 207-217.

Turban, E., McLean, E., \& Wetherbe, J. (2003). Information technology for management: Transforming organizations in the digital economy (4th ed.). Hoboken, NJ: John Wiley \& Sons.

Turban, E., Rainer, R. K., Jr., \& Potter, R. E. (2003). Introduction to information technology (2nd ed.). New York: John Wiley \& Sons.

Ullman, J. B. (2006). Structural equation modeling: Reviewing the basics and moving forward. Journal of Personality Assessment, 87(1), 35-50. 
van Bentum, R., \& Stone, M. (2005). Customer relationship management and the impact of corporate culture - A European study. Journal of Database Marketing \& Customer Strategy Management, 13(1), 28-54.

Varela, J. A., \& del Río, M. (2003). Market orientation behavior: An empirical investigation using MARKOR. Marketing Intelligence \& Planning, 21(1), 6-15.

Vargo, S. L., \& Lusch, R. (2004). Evolving to a new dominant logic for marketing. Journal of Marketing, 68(1), 1-17.

Venkatesan, R., \& Kumar, V. (2004). A customer lifetime value framework for customer selection and resource allocation strategy. Journal of Marketing, 68(4), 106-125.

Venkatesh, V., \& Davis, F. D. (1996). A model of the antecedents of perceived ease of use: Development and test. Decision Sciences, 27(3), 451-481.

Venkatesh, V., \& Davis, F. D. (2000). A theoretical extension of the technology acceptance model: Four longitudinal field studies. Management Science, 46(2), 186-204.

Venkatesh, V., Davis, F. D., Morris, M. G., \& Davis, G. B. (2003). User acceptance of information technology: Toward a unified view. MIS Quarterly, 27(3), 425-477.

Venkatraman, N., \& Ramanujam, V. (1986). Measurement of business performance in strategy research: A comparison of approaches. Academy of Management. The Academy of Management Review, 11(4), 801-814.

Venugopal, V., \& Baets, W. (1994). Neural networks \& their applications in marketing management. Journal of Systems Management, 45(9), 16-21.

Verhoef, P. C. (2003). Understanding the effect of customer relationship management efforts on customer retention and customer share development. Journal of Marketing, 67(4), 30-45.

Verhoef, P. C., Franses, P. H., \& Hoekstra, J. C. (2001). The impact of satisfaction and payment equity on cross-buying: A dynamic model for a multi-service provider. Journal of Retailing, 77(3), 359-378.

Viswanathan, M. (2005). Measurement error and research design. Thousand Oaks, CA: Sage Publications.

Webb, D., Webster, C., \& Krepapa, A. (2000). An exploration of the meaning and outcomes of a customer-defined market orientation. Journal of Business Research, 48(2), 101-112.

Webster, F. E., Jr. (1992). The changing role of marketing in the corporation. Journal of Marketing, 56(4), 1-17.

Webster, F. E., Jr. (2000). Understanding the relationships among brands, consumers, and resellers. Journal of the Academy of Marketing Science, 28(1), 17-23. 
Wells, J. D., \& Hess, T. J. (2002). Understanding decision-making in data warehousing and related decision support systems: An explanatory study of a customer relationship management application. Information Resources Management Journal, 15(4), 16-32.

Wilcox, R. R. (1998). How many discoveries have been lost by ignoring modern statistical methods? The American Psychologist, 53(3), 300-314.

Wilkinson, I., \& Wiley, J. (2000, 28 Nov - 1 Dec). The impact of connected relations on relationship performance: A comparison of European and Chinese results using the IMP Data Base. Paper presented at the ANZMAC 2000, Gold Coast, Queensland, Australia.

Wilson, D. T. (1995). An integrated model of buyer-seller relationships. Journal of the Academy of Marketing Science, 23(4), 335-345.

Wilson, D. T., \& Vlosky, R. P. (1998). Interorganizational information system technology and buyer-seller relationships. The Journal of Business \& Industrial Marketing, 13(3), 215-234.

Winer, R. S. (2001). A framework for customer relationship management. California Management Review, 43(4), 89-105.

Wixom, B. H., \& Watson, H. J. (2001). An empirical investigation of the factors affecting data warehousing success. MIS Quarterly, 25(1), 17-41.

Wold, H. (1982). Systems under indirect observation using PLS. In C. Fornell (Ed.), A second generation of multivariate analysis: Methods (Vol. 1, pp. 325-347). New York: Praeger.

Wold, H. (1985). Systems analysis by partial least squares. In P. Nijkamp, H. Leitner \& N. Wrigley (Eds.), Measuring the unmeasurable (pp. 221-251). Dordrecht, The Netherlands: Martinus Nijhoff Publishers.

Wong, A., \& Sohal, A. (2002). An examination of the relationship between trust, commitment and relationship quality. International Journal of Retail \& Distribution Management, 30(1), 34-50.

Woodcock, N., \& Starkey, M. (2001). 'I wouldn't start from here': Finding a way in CRM projects. Journal of Database Marketing, 9(1), 61-74.

Wright, L. T., Stone, M., \& Abbott, J. (2002). The CRM imperative - Practice vs theory in the telecommunications industry. Journal of Database Marketing, 9(4), 339349.

Wu, I.-L., \& Wu, K.-W. (2005). A hybrid technology acceptance approach for exploring e-CRM adoption in organizations. Behaviour \& Information Technology, 24(4), $303-316$.

Wyner, G. A. (1999). Customer relationship measurement. Marketing Research, 11(2), 39-41. 
Yanagihara, H., \& Yuan, K.-H. (2005). Four improved statistics for contrasting means by correcting skewness and kurtosis. British Journal of Mathematical \& Statistical Psychology, 58, 209-237.

Yau, O. H. M., McFetridge, P. R., Chow, R. P. M., Lee, J. S. Y., Sin, L. Y. M., \& Tse, A. C. B. (2000). Is relationship marketing for everyone? European Journal of Marketing, 34(9/10), 1111-1127.

Yeung, M. C. H., Ging, L. C., \& Ennew, C. T. (2002). Customer satisfaction and profitability: A reappraisal of the nature of the relationship. Journal of Targeting, Measurement and Analysis for Marketing, 11(1), 24-33.

Yin, R. K. (2003). Case study research: Design and methods (3rd ed. Vol. 5). Thousand Oaks: Sage.

Young, L. C., \& Wilkinson, I. F. (1989). The role of trust and co-operation in marketing channels: A preliminary study. European Journal of Marketing, 23(2), 109-122.

Yu, L. (2001). Successful customer-relationship management. Sloan Management Review, 42(4), 18-19.

Zablah, A. R., Bellenger, D. N., \& Johnston, W. J. (2004). An evaluation of divergent perspectives on customer relationship management: Towards a common understanding of an emerging phenomenon. Industrial Marketing Management, 33(6), 475-489.

Zahra, S. A., \& Covin, J. G. (1993). Business strategy, technology policy and firm performance. Strategic Management Journal, 14(6), 451-478.

Zeithaml, V. A., Berry, L. L., \& Parasuraman, A. (1993). The nature and determinants of customer expectations of service. Journal of the Academy of Marketing Science, 21(1), 1-12.

Zeithaml, V. A., Berry, L. L., \& Parasuraman, A. (1996). The behavioral consequences of service quality. Journal of Marketing, 60(2), 31-46.

Zeithaml, V. A., Rust, R. T., \& Lemon, K. N. (2001). The customer pyramid: Creating and serving profitable customers. California Management Review, 43(4), 118 142 .

Zeng, Y. E., Wen, H. J., \& Yen, D. C. (2003). Customer relationship management (CRM) in business-to-business (B2B) e-commerce. Information Management \& Computer Security, 11(1), 39-44.

Zikmund, W. G., McLeod, R. J., \& Gilbert, F. W. (2003). Customer relationship management: Integrating marketing strategy and information technology. Hoboken, NJ: John Wiley \& Sons.

Zinkhan, G. M., Joachimsthaler, E. A., \& Kinnear, T. C. (1987). Individual differences and marketing decision support system usage and satisfaction. Journal of Marketing Research, 24(2), 208-214. 